\title{
Investigation of Nonlinear Dynamic Soil Property at the Savannah River Site
}

by

R. C. Lee

Westinghouse Savannah River Company

Savannah River Site

Aiken, South Carolina 29808

This paper was prepared in connection with work done under the above contract number with the U.S. Department of Energy. By acceptance of this paper, the publisher and/or recipient acknowledges the U.S. Government's right to retain a nonexclusive, royalty-free license in and to any copyright covering this paper, along with the right to reproduce and to authorize others to reproduce all or part of the copyrighted paper. 


\section{DISCLAIMER}

This report was prepared as an account of work sponsored by an agency of the United States Government. Neither. the United States Government nor any agency thereof, nor any of their employees, make any warranty, express or implied, or assumes any legal liability or responsibility for the accuracy, completeness, or usefulness of any information, apparatus, product, or process disclosed, or represents that its use would not infringe privately owned rights. Reference herein to any specific commercial product, process, or service by trade name, trademark, manufacturer, or otherwise does not necessarily constitute or imply its endorsement, recommendation, or favoring by the United States Government or any agency thereof. The views and opinions of authors expressed herein do not necessarily state or reflect those of the United States Government or any agency thereof. 


\section{DISCLAIMER}

Portions of this document may be illegible in electronic image products. Images are produced from the best available original document. 
WSRC-TR-96-0062

Rev. 0

March 22. 1996

RECORDS ADMINISTRATION

\|\|$\|$

ADEY

\section{Investigations of Nonlinear Dynamic Soil Properties at the Savannah River Site (U)}

Westinghouse Savannah River Company

Savannah River Site

Aiken, SC 29808

Prepared for the U.S. Department of Energy under contract no. DE-AC09-89SR18035 
ECSD-SGS-96-0107

March 28, 1996

Brent J. Gutierrez, P.E.

U.S. Department of Energy

Savannah River Operations Office

Post Office Box A

Aiken, SC 29802

Dear Mr. Gutierrez:

\section{ITEM 1- SIGNIFICANT ACCOMPLISHMENT FOR PERIOD 14 - CORRELATION STUDY OF NONLINEAR DYNAMIC SOIL PROPERTIES (U)}

The University of Texas, Austin (UTA) final report, "Correlation Study of Nonlinear Dynamic Soil Properties", is enclosed. The purpose of the report is to summarize measurements of SRS soil dynamic properties (including those measured by the UTA) and to make specific recommendations on soil dynamic properties to be used in ground motion predictions. The UTA analysis and recommendations represent a significant advancement in the measurement and application of soil dynamic properties in soils.

A summary document, entitled "Investigations of Nonlinear Dynamic Soil Properties at the Savannah River Site", has been prepared with the assistance and concurrence of a Peer Review Panel, which is documented by their signatures. This summary document reflects and extends the major conclusions of the UTA report.

If you should have any questions, please contact M. E. Maryak (2-6846) or R. C. Lee (2-6938) of my staff.

Very truly yours,

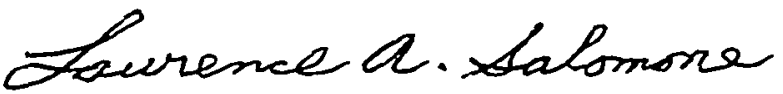

Lawrence A. Salomone

SRS Chief Geotechnical Engineer

LAS:kbk

Att.

CC: J. Kimball, DOE-Germantown, w/o Att. $\quad$ M. R. Lewis, 730-2B, w/o Att.

E. P, Rahe, Jr., 730-B, w/o Att.

F. Loceff, 730-B, w/o Att.

S. K. Formby, 730-B, w/o Att.

R. C. Lee, 730-2B, w/o Att. 
WSRC-TR-96-0062

Rev. 0

March 22, 1996

\section{Investigations of Nonlinear Dynamic Soil Properties at the Savannah River Site (U)}

Westinghouse Savannah River Company

Savannah River Site

Aiken, SC 29808

Prepared for the U.S. Department of Energy under contract no. DE-AC09-89SR18035 


\section{DISCLAIMER}

This report was prepared as an account of work sponsored by an agency of the United States Government. Neither the United States Government nor any agency thereof, nor any of their employees, makes any warranty, express or implied, or assumes any legal liability or responsibility for the accuracy, completeness, or usefulness of any information, apparatus, product or process disclosed, or represents that its use would not infringe privately owned rights. Reference herein to any specific commercial product, process or service by trade name, trademark, manufacturer, or otherwise does not necessarily constitute or imply its endorsement, recommendation, or favoring by the United States Government or any agency thereof. The views and opinions of authors expressed herein do not necessarily state or reflect those of the United States Government or any agency thereof.

This report has been reproduced directly from the best available copy.

Available for sale to the public, in paper, from: U.S. Department of Commerce, National Technical Information Service, 5285 Port Royal Road, Springfield, VA 22161, phone: (800) 553-6847

fax: (703) 605-6900

email: orders@ntis.fedworld.gov

online ordering: http://www.ntis.gov/ordering.htm

Available electronically at http://www.doe.gov/bridge

Available for a processing fee to U.S. Department of Energy and its contractors, in paper, from: U.S. Department of Energy, Office of Scientific and Technical Information, P.O. Box 62, Oak Ridge, TN 37831-0062, phone: (865) 576-8401

fax: (865) 576-5728

email: reports@adonis.osti.gov 


\title{
WSRC-TR-96-0062
}

Rev. 0

\section{Investigations of Nonlinear Dynamic Soil Properties at the Savannah River Site}

\author{
R.C. Lee
}

Approved by: Reurence Q.talomore

Prepared for the U.S. Department of Energy under contract no. DE-AC09-89SR18035 


\section{Introduction}

This document summarizes laboratory dynamic soil testing investigations conducted by the University of Texas at Austin (UTA) for the Savannah River Site (SRS) (Stokoe et al., 1995a, Stokoe et al., 1995b, Sponseller and Stokoe, 1995). The purpose of the investigations is to provide an evaluation of past testing results in the context of new test data and the development of consistent site wide models of material strain dependencies based upon geologic formation, depth, and relevant index properties. The resulting sets of modulus reduction and damping curves and their uncertainties (Figures 3 through 9; Tables 1 through 3) are intended to provide valuable baseline data for guidance in future analyses of site effects as well as the evaluation of previous site response studies. For future applications, the recommended dynamic properties and their uncertainties are specifically intended for SRS site evaluations and should be appropriately updated when site specific data are collected.

The UTA results and recommendations incorporated in this summary have been reviewed by consultants employed by Westinghouse Savannah River Company (WSRC) or the Department of Energy (DOE), namely, Prof. Carl Costantino, Dr. Robert Pyke, and Dr. Walter Silva. Together with Prof. Kenneth Stokoe, II of the UTA, their signatures at the end of this summary constitute concurrence with the results and recommendations.

The UTA (Stokoe et al., 1995a) summarized various studies conducted for the SRS together with results of new dynamic measurements made from samples taken during the Pen Branch Confirmatory Drilling Program. The particular properties of interest are the non-linear behavior in shear modulus $(G)$ (or normalized shear modulus $G / G_{\max }$ ) and hysteretic damping ratio (D) as functions of induced maximum shear strain $(\gamma)$. The data used to assess these relationships were obtained from cyclic triaxial, torsional resonant column and cyclic torsional shear tests conducted on "undisturbed" samples taken at various SRS sites. The data were taken from 29 reports for 17 different site areas at the SRS together with the results from the investigations conducted by UTA for the Pen Branch Fault Confirmatory Drilling Program. The objectives of the program were: (1) to review existing SRS dynamic soil properties test data for the purpose of incorporating the data in a database; (2) to test Pen Branch Fault Confirmatory Drilling Program samples using the latest dynamic testing technology; (3) to construct a dynamic soil properties database with the purpose of deriving possible formation or soil specific correlations of nonlinear dynamic soil properties with parameters of the SRS Coastal Plain sediments; and (4) to provide recommendations for dynamic soil properties associated with the SRS soil column. 


\section{SRS Dynamic Soil Testing Data Review and Database}

A dynamic soil properties database was compiled from available SRS reports on dynamic soil properties (Stokoe et al., 1995b). The SRS areas from which data were obtained are: (1) area of the Pen Branch Fault Confirmatory Drilling Program; (2) H-Area In-Tank Precipitation Facility; (3) H-Area Replacement Tritium Facility; (4) H-Area, Building 221-H (5) Proposed New Production Reactor; (6) Par Pond Dam; (7) K-Reactor Area; (8) Burial Ground Expansion; (9) L-Reactor Area; (10) L-Area Cooling Pond Dam; and (11) F-Area, Sand Filter Structure. These 11 areas represent 8 general locations at the SRS and are shown in Figure 1.

Test Data Limitations

Based on review of the test data presented in these reports, the following conclusions were reached regarding test procedures or methodology in the evaluations of soil properties.

1. All cyclic triaxial test data, previously measured, were excluded based upon a review of the hysteretic data presented in these reports. Equipment related complications are apparent in the hysteretic loops presented in some reports which indicate that piston friction and/or top-cap lifting may have influenced the resultant data generated. These results require a more extensive investigation of the raw data before they could be incorporated into the database.

2. Some resonant column test data, previously measured, were excluded. Three tests which were performed on samples of reconstituted materials were excluded, and 10 tests were excluded which had data presented in graphical form only, making it difficult to evaluate the non-linear behavior.

3. All resonant column damping data were excluded because of strong frequency dependencies observed in the data:-Because there were not sufficient data to model the frequency dependence of $\mathrm{D}(\log \gamma)$, the higher frequency $\mathrm{RC}$ damping measurements made by all organizations (other than UTA) compiled in the database, could not be corrected to the desired lower frequencies typical of TS measurements. Therefore, the recommended $D(\log \gamma)$ functions were estimated from TS measurements only which were performed by UTA at $\mathrm{f}<1 \mathrm{~Hz}$.

\section{Dynamic Property Database}

Based upon a review of the site descriptions at the SRS facility areas, a general stratigraphic description of the site has been formulated in which the order of the soil layers through the overburden is considered reasonably consistent across the SRS (Figure 2). The specific depths and thickness of the various units, however, are expected to vary somewhat depending upon the particular location at the site. A total of 72 resonant 
column (RC) and 15 cyclic torsional shear (TS) tests on "undisturbed" samples were obtained for the various locations at the SRS. Of the 72 samples evaluated, 51 are sand samples taken from the Tobacco Road, Dry Branch, Santee and Snapp formations as shown in Figure 2. The remaining 21 samples were relatively uniformly distributed throughout the other soil layers or are clay samples within these formations.

\section{Dynamic Soil Testing}

The UTA measured strain dependency of the soil shear modulus $(\mathrm{G}(\log \gamma))$ and material damping $(D(\log \gamma))$ by two independent methods (Resonant Column and Torsional Shear) on the same sample and in the same apparatus. Because the RC technique excites the sample at resonance, the frequency $(f)$ of the measurement is inherently higher than the TS frequency. In general, it has been found that both the TS and RC testing lead to similar evaluation of strain dependent shear modulus degradation properties or the strain dependent $\mathrm{G} / \mathrm{G}_{\max }$ ratios. However, significant frequency dependent effects can distort the corresponding hysteretic damping evaluation. These parallel measurements have identified clear first-order dependence of hysteretic damping on excitation frequency. For either the low frequency $\mathrm{TS}(\mathrm{f}<1 \mathrm{~Hz})$ or corresponding higher frequency $\mathrm{RC}$ testing, machine losses and/or frequency dependent effects associated with the cyclic testing must be quantified to ensure that the measured cyclic loss data are appropriate for application for site response analyses. Therefore, to confidently use the results from RC testing, these frequency dependent effects, if any, must be established and quantified. This can be done by performing complementary TS testing on the same samples.

These experimental results, as well as those from other studies, indicate that for either sands or clays, the cyclic properties are sensitive to the applied loading cycle $(N)$ selected, particularly at the higher level of shear strain. This effect is a result of volume and porepressure changes with loading cycle. It is therefore recommended that the values of $\mathrm{G} / \mathrm{G}_{\max }(\log \gamma)$ and $\mathrm{D}(\log \gamma)$ be computed from the tenth load cycle $(\mathrm{N}=10)$ for use in site seismic response analyses. The tenth load cycle was judged to be most appropriate for application to magnitude 6-7 earthquakes. In addition, it is recommended that the highest value of hysteretic damping ratio (D) used in these analyses be limited to $15 \%$ since laboratory measurements at higher strain levels are complicated by degeneration of the shape of the stress-strain loops and the applicability of the damping ratio as used in equivalent linear analysis becomes questionable.

\section{Dynamic Soil Property Correlation and Modeling Results}

The effects of geologic and geotechnical variables on $\mathrm{G} / \mathrm{G}_{\mathrm{max}}(\log \gamma)$ and $\mathrm{D}(\log \gamma)$ were considered in this evaluation. Considerations were made on the dependencies by soil type, plasticity index, fines content, small-strain stiffness, state of stress, specimen depth, boring location, geologic age, and geologic formation. From the review of these experimental results, it is observed that the $\mathrm{G} / \mathrm{G}_{\max }(\log \gamma)$ and $\mathrm{D}(\log \gamma)$ relationships are primarily dependent on the particular soil type and geologic formation from which the sample was obtained. The Unified Soil Classification system was used to establish soil type for sands 
and clays. Effects of plasticity index, fines content, and state of stress are implicitly included in the formation dependency. Confining pressure has only minor effects on. $\mathrm{G} / \mathrm{G}_{\max }(\log \gamma)$ and $\mathrm{D}(\log \gamma)$. The "sands" and "clays" databases were additionally subdivided into shallow (<150 $\mathrm{m}(500 \mathrm{ft})$ ) and deep (>150 $\mathrm{m}(500 \mathrm{ft})$ sample depth) categories. Sufficient data were available to establish statistical confidence bands for analysis of correlated data subsets of shallow sands: (1) Tobacco Road; (2) Dry Branch; (3) Santee; and (4) Snapp. There are however, several formations missing from the sands and clays databases. Statistical summaries for $G / G_{\max }(\log \gamma)$ and $D(\log \gamma)$ were also compiled for deep sands, shallow clays, and deep clays. Application of specific nonlinear strain dependence is based solely on the soil type and stratigraphy as described in Figure 2.

The experimentally determined cyclic data has been found to be reasonably approximated by the hyperbolic stress-strain model (Hardin and Drnevich, 1972, and Pyke, 1993). Pyke (1993) extended this model to provide a unique and consistent relationship between $\mathrm{G}$ (log $\gamma$ ) and $\mathrm{D}(\log \gamma)$, given the specific values of the three parameters $\mathrm{G}_{\max }$ (low strain shear modulus), $D_{\min }$ (low-strain hysteretic damping ratio) and $\gamma_{\mathrm{r}}$ (the reference strain defined as the maximum shear stress divided by $\mathrm{G}_{\max }$ ) for a particular soil. In general, it has been

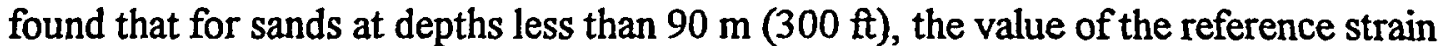
increases with depth or mean effective confining pressure. This is similar to the results and recommendations of other studies (e.g., EPRI, 1993). The results for the deeper sands and clays of SRS, however, did not follow this trend. This discrepancy may be due to sample disturbance effects inherent in the procedures used to retrieve samples at these deeper depths, the limitations of the testing procedures for the deep samples or both.

All data (sands and clays) from the deep soil specimens were discarded, and dynamic properties for deeper portions of the soil column were extrapolated from the shallow correlations. To account for the effects of increased confining pressure at the deeper portions of the column, a normalized power law relationship was derived between $\gamma_{\mathrm{r}}$ and the mean effective stress $\left(\sigma_{o}{ }^{\prime}\right)$ and $D_{\min }$ and $\sigma_{o}{ }^{\prime}$ using test data:

$$
\gamma_{\mathrm{r}} \gamma_{\mathrm{r}, \mathrm{m}}=\left(\sigma_{\mathrm{o}}{ }^{\prime} / \sigma_{\mathrm{m}}{ }^{3}\right)^{0.28}
$$

and

$$
\begin{array}{ll}
D_{\min }=3.2\left(\sigma_{o}^{\prime}\right)^{-0.16} & \text { for clays } \\
D_{\min }=1.6\left(\sigma_{o}^{\prime}\right)^{-0.16} & \text { for sands }
\end{array}
$$

where $\sigma_{m}$ ' is the in situ mean effective stress and $\gamma_{r, m}$ is the reference strain corresponding to the in situ mean effective stress. The dynamic properties $\left(\mathrm{G} / \mathrm{G}_{\max }(\log \gamma)\right.$ and $\left.\mathrm{D}(\log \gamma)\right)$ from these samples have been correlated with the site stratigraphy and are presented in terms of best-estimate values together with their variability. Figures 3 through 6 illustrate 
the recommended dynamic properties for the following shallow sands:

1. Stiff Upland ( $\left.\mathrm{G}_{\max }>200 \mathrm{MPa}\right)$

2. Tobacco Road and Snapp

3. Dry Branch, Santee, Warley Hill, and Congaree Sands (and soft Upland)

4. Unrepresented Shallow Sands (average depth of specimens $35 \mathrm{~m}(116 \mathrm{ft})$ )

The figures show fits to the mean and $+-\sigma$ of the data using the hyperbolic model. In addition, recommendations are presented in Figure 7 for the shallow clays (average depth of $48 \mathrm{~m}(156 \mathrm{ft})$ ), the deep sands (extrapolated from the shallow sands) and the deep clays (extrapolated from the shallow clays) (Figures $8 \& 9$ respectively). Figures $10 \& 11$ illustrate best estimate $G / G_{\max }$ and damping curves for the same general site stratigraphy. Comparison of the recommended SRS G/G $G_{\max }$ curves with those from EPRI (1993) are shown in Figures 12 and 13. Comparisons with EPRI (1993) damping are shown in Figures 14 and 15.

Estimates of the statistical variability in $G / G_{\max }$ data are included in Table 1 for the formations described in the general site stratigraphy recommended for the SRS. These estimates are based upon the analysis of data from both RC and TS tests conducted on these formations. Estimates of variability of hysteretic damping ratio are less robust since so few torsional shear test data are available for inclusion in the database. However, based upon the analysis of damping data from seven TS sand samples taken from several formations of the soil column, it is recommended that the standard deviation (natural log) of $D$ (in percent) be set to about 0.3 for strain levels in the range of $1 \times 10^{-4}$ to $1 \times 10^{-2}$ percent. It is recommended that this value be used for all formations in site response calculations until further test data become available or further statistical analysis is pursued (Table 2).

Finally, it has been noted that a rough inverse correlation exists between shear stiffness and hysteretic damping ratio from the TS test data. Based upon this result as well as the subjective judgment of its appropriateness, these correlations may be accommodated in selection of percentiles for $G / G_{\max }$ and $D$ in any site response calculations.

\section{Comparison To Prior SRS Dynamic Soil Models}

Comparisons of these recommendations to a previously developed degradation model for the SRS, known as the GEI (1991) model with its depth dependent factor, are shown in Figures $16 \& 17$. The GEI model has been used in a number of site response evaluations. The experimental results described above indicate that the degradation properties are related to stratigraphy rather than to a single parameter such as depth. The GEI results compare favorably with the recommended values except that degradation data for the shallow Upland unit and for the shallow and deep clay samples do not correlate well with the GEI model used previously, as can be seen from Figure 16. 
Prior ground motion investigations for the SRS that use the GEI recommendations are not expected to differ significantly as a result of this recommendation. Anticipated earthquakeinduced strains in the shallow Upland unit are low, further, the GEI shallow dynamic property recommendations were more linear so that ground motion predictions for the Upland formation are conservative. The shallow and deep clay modulus and damping relationship are more linear than GEI (Figures $16 \& 17$ ). However, there are no known SRS facility soil column's that have thick clay deposits (that could tend to under-predict larger-strain ground motions using GEI recommended soil properties).

\section{Conclusions}

For application of dynamic soil properties to critical facilities at the SRS, formation dependent degradation models reported herein (Figures 3 through 9; Tables 1 through 3) are considered appropriate for soils or structural analysis. If, for higher hazard facilities, additional site specific sampling and testing is performed, then data correlations described herein should be validated by the new data. If testing is done, additional validation should be done for the recommended variability in $D(\log \gamma)$ and coupling between $G / G_{m a x}(\log$ $\gamma)$ and $D(\log \gamma)$.

For future site characterization or confirmatory analysis, selection of depths for fixedpiston samples should be made on the basis of geologic formation and observed fluctuations in low-strain shear modulus or the occurrence of clay layers with significant thickness (for seismic response purposes, a layer having thickness of one-half of the seismic wavelength or greater at the frequencies of interest). Fixed piston or other samples taken for dynamic testing should not be attempted for depths greater than about $90 \mathrm{~m}$ $(300 \mathrm{ft})$ without additional justification or modification of procedures that may insure that disturbance is minimized.

If cyclic triaxial tests are to be used in the future, deformation measurements must be performed on the soil specimen (not platen-to-platen) and the load cell must be placed inside the confining chamber. The resultant loops should be carefully scrutinized to ensure that (a) the loops are reasonably stable for the initial 10 to 15 load cycles, and (b) no particular machine dependent anomalies are apparent in the data generated in the individual loops. It is recommended that the values of $\mathrm{G} / \mathrm{G}_{\max }(\log \gamma)$ and $\mathrm{D}(\log \gamma)$ be computed from the tenth load cycle $(\mathrm{N}=10)$ and measured at $\mathrm{f}<1 \mathrm{~Hz}$ for use in seismic site response analyses. In addition, it is recommended that the highest value of hysteretic damping ratio (D) used in these analyses be limited to $15 \%$. The low-strain damping $\left(D_{\min }\right)$ and $\mathrm{D}(\log \gamma)$ for all specimens were found to be strongly dependent on frequency of the cyclic test. All future dynamic soil testing should account for this dependency by measuring properties at a suite of frequencies (including the site response analysis frequencies) and in-situ stress levels. The frequency effects can be accounted for by a combination of TS and RC tests on all samples. 
WSRC-TR-96-0062, Rev.0

March 22, 1996
Site Geotechnical Services

Nonlinear Soil Properties
Kenneth H. Stoke, II

Department of Civil Engineering

University of Texas at Austin

Austin, TX 78712

Carl Costantino

Department of Civil Engineering

City College of New York

New York, NY 10031

Robert Pye

Consulting Engineer

1076 Carol Lane \#136

Lafayette, CA 94549

Walter Silva

Pacific Engineering and Analysis

311 Pamona Ave.

El Cerrito, CA 94530
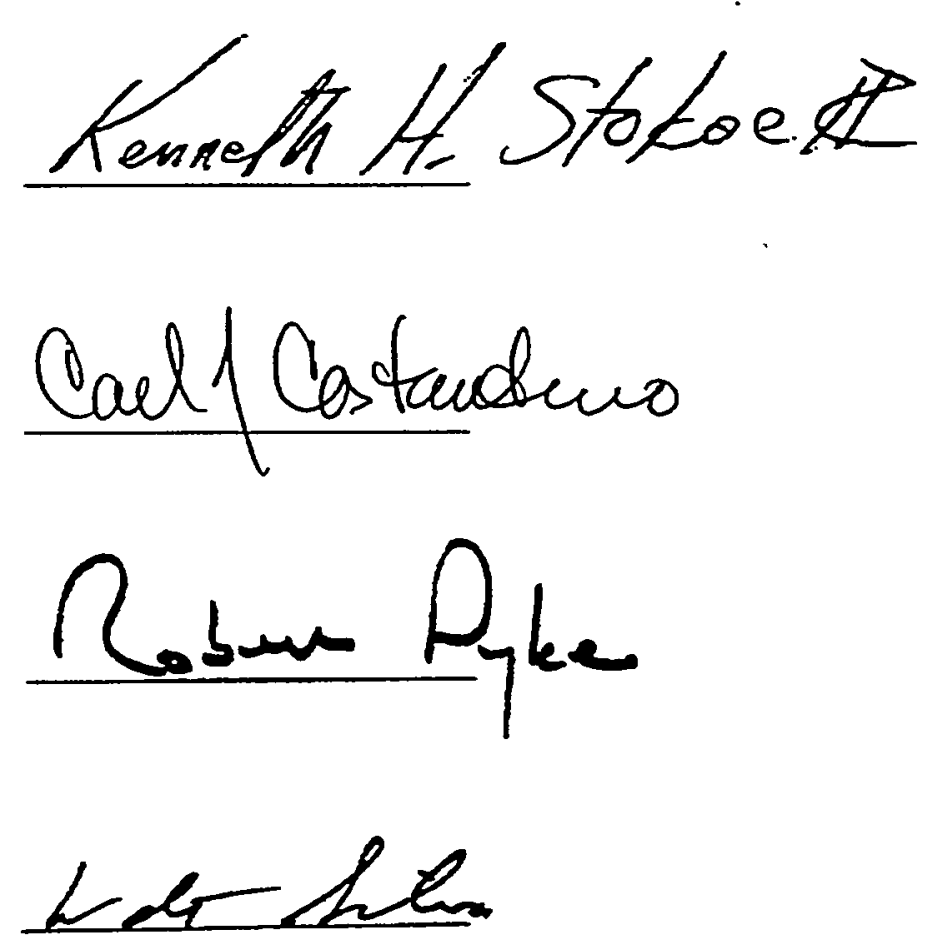

7 


\section{References}

Electric Power Research Institute (1993).Guidelines for determining design basis ground motions, EPRI TR-102293, Nov. 1993.

GEI (1991). K-Reactor Area, Geotechnical Investigation for Seismic Issues-Technical Evaluation, Savannah River Site," Project 90375, March. In Volume 1, Part II, Appendix A of K Reactor Area, Geotechnical Investigation for Seismic Issues, Savannah River Site by WSRC, Report WSRC-TR-91-47, March 1991.

Pyke, R.M. (1993). Modeling of Dynamic Soil Properties, Appendix 7.A in Guidelines for Determining Design Basis Ground Motions, Electric Power Research Institute, J.F. Schneider EPRI Project Manager, pp. 7.A-1 - 7.A-90.

Sponseller, T.E. and K.H. Stokoe II (1995). Evaluation of Transportation Vibrations and Laboratory Handling Activities On the Shear Modulus and Material Damping Ratio of Uncemented and Lightly Cemented Loose Sand, University of Texas at Austin report for WSRC.

Stokoe, K.H., S.K. Hwang, M. Darendeli, and N.J. Lee (1995). Correlation Study of Nonlinear Dynamic Soil Properties, University of Texas at Austin Final Report for WSRC, October, 1995.

Stokoe, K.H., I, N.-K. J. Lee, and R.D. Andrus (1995). Review of Dynamic Soil Properties Determined in Previous Studies, University of Texas at Austin report for WSRC. 
Table 1. Statistics Associated with the $G / G_{\text {mar }}$; Relationships Determined by $R C$ Testing

Formation Reference $\operatorname{Strain}^{(1)} \gamma_{r}(\%)$

Description

Stiff Upland Sands

$3 \quad 0.021$

$(0.031)^{(2)}$

(0.014)

Tobacco Road and Snapp Sands

0.044

0.059

0.033

Dry Branch, Santee, Warley Hill and Congaree Sands

0.077

0.109

0.051

Four Mile Sands and any other Unrepresented Shallow Sands 46

0.066

Shallow Clays

4

0.148

0.246

0.103

Deep Sands

$-\quad 0.111$

0.221

0.068

Deep Clays

0.230

0.493

0.143

Notes: (1) Computation of $G / G_{\max }$ mean and $+-\sigma$ for selected value of shear strain is:

$$
\mathrm{G} / \mathrm{G}_{\max }=1 /\left(1+\gamma / \gamma_{\mathrm{s}}\right)
$$

where $\gamma$ is the desired value of shear strain in percent and $\gamma_{s}$ is the reference strain tabulated. Fit to the mean and $t-\sigma$ of the data was made using hyperbolic model (Pyke, 1993).

(2) Reference strains in parenthesis's were derived on the basis of small sample data sets. 
Table 2. Statistics Associated with the D (log- $\gamma)$; Relationships Determined by TS Testing

\begin{tabular}{llll}
$\begin{array}{l}\text { Formation } \\
\text { Description }\end{array}$ & $\begin{array}{l}\text { Ref. } \\
\text { Strain } \\
\gamma_{\mathrm{r}} \\
(\%)\end{array}$ & $\begin{array}{l}\text { Mean } \\
\mathrm{D}_{\min } \\
(\%)\end{array}$ & $\sigma^{(1)}$ \\
\hline $\begin{array}{l}\text { Stiff Upland Sands } \\
\text { Tobacco Road and Snapp Sands }\end{array}$ & 0.021 & 1.03 & 0.3 \\
$\begin{array}{l}\text { Dry Branch, Santee, Warley Hill } \\
\text { and Congaree Sands }\end{array}$ & 0.077 & 0.61 & 0.3 \\
$\begin{array}{l}\text { Four Mile Sands and any other } \\
\text { Unrepresented Shallow Sands }\end{array}$ & 0.066 & 0.88 & 0.3 \\
$\begin{array}{l}\text { Shallow Clays } \\
\text { Deep Sands }\end{array}$ & 0.148 & 1.36 & \\
Deep Clays & 0.111 & 0.53 & 0.3 \\
\hline & 0.230 & 1.06 & 0.3 \\
\hline
\end{tabular}

Notes: (1) $\sigma$ is ln-normal value that can be applied throughout the strain-range. 
Table 3. Recommended ${ }^{(1)}$ Damping Ratio vs Shear-Strain

Formation Description

$\begin{array}{llccc}\text { Strain (\%) } & \text { Upland } & \text { Tobacco Rd/Snapp } & \text { Dry Branch/Santee } & \text { Shallow Sand } \\ 0.00001 & 1.059 & 0.625 & 0.825 & 0.674 \\ 0.0001 & 1.059 & 0.625 & 0.825 & 0.674 \\ 0.0002 & 1.103 & 0.647 & 0.835 & 0.687 \\ 0.0003 & 1.151 & 0.67 & 0.846 & 0.702 \\ 0.0005 & 1.248 & 0.717 & 0.871 & 0.733 \\ 0.001 & 1.493 & 0.835 & 0.936 & 0.811 \\ 0.002 & 1.973 & 1.07 & 1.07 & 0.97 \\ 0.003 & 2.434 & 1.3 & 1.205 & 1.127 \\ 0.005 & 3.302 & 1.747 & 1.47 & 1.435 \\ 0.01 & 5.201 & 2.79 & 2.108 & 2.171 \\ 0.02 & 8.165 & 4.605 & 3.281 & 3.505 \\ 0.03 & 10.407 & 6.139 & 4.336 & 4.686 \\ 0.05 & 13.639 & 8.614 & 6.162 & 6.692 \\ 0.1 & 18.317 & 12.799 & 9.605 & 10.363 \\ 0.2 & & 17.425 & 13.951 & 14.825 \\ 0.3 & & & 16.683 & \end{array}$

Formation Description

$\begin{array}{llll}\text { Strain (\%) } & \text { Shallow Clay } & \text { Deep Sand } & \text { Deep Clay } \\ 0.00001 & 1.296 & 0.489 & 0.992 \\ 0.0001 & 1.296 & 0.489 & 0.992 \\ 0.0002 & 1.292 & 0.497 & 0.99 \\ 0.0003 & 1.293 & 0.505 & 0.991 \\ 0.0005 & 1.3 & 0.524 & 0.995 \\ 0.001 & 1.326 & 0.57 & 1.013 \\ 0.002 & 1.389 & 0.665 & 1.054 \\ 0.003 & 1.456 & 0.759 & 1.097 \\ 0.005 & 1.594 & 0.945 & 1.186 \\ 0.01 & 1.938 & 1.398 & 1.410 \\ 0.02 & 2.603 & 2.251 & 1.851 \\ 0.03 & 3.233 & 3.039 & 2.276 \\ 0.05 & 4.392 & 4.453 & 3.08 \\ 0.1 & 6.82 & 7.289 & 4.856 \\ 0.2 & 10.356 & 11.179 & 7.671 \\ 0.3 & 12.884 & 13.799 & 9.833 \\ 0.5 & 16.317 & 17.21 & 12.995\end{array}$

Notes: (1) Recommended curves derived using hyperbolic model (Pyke, 1993). 


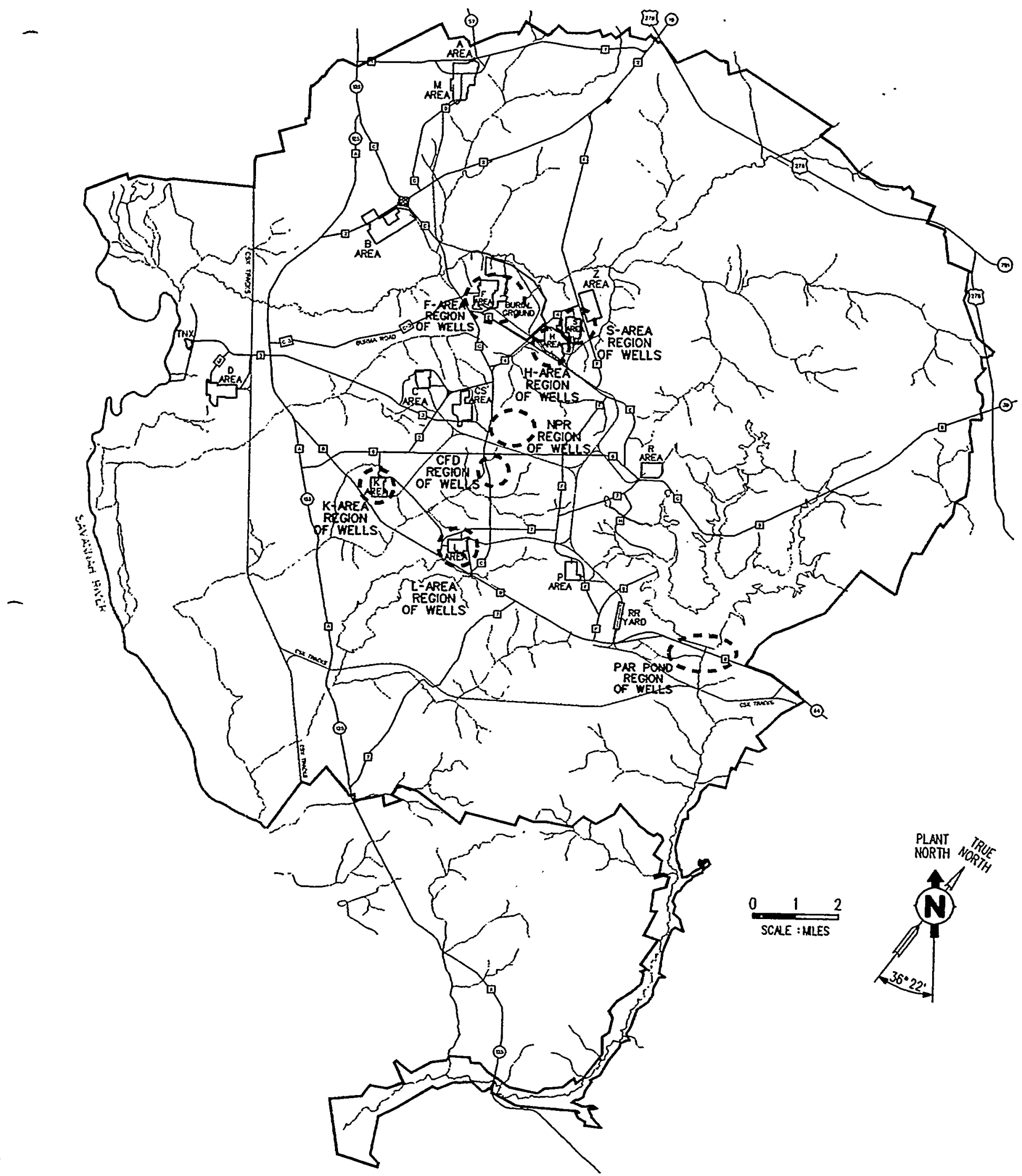

Fig. 1 Map of Savannah River Site Showing the General Boring (Well) Locations of All Specimens Used in the Correlation Database. 


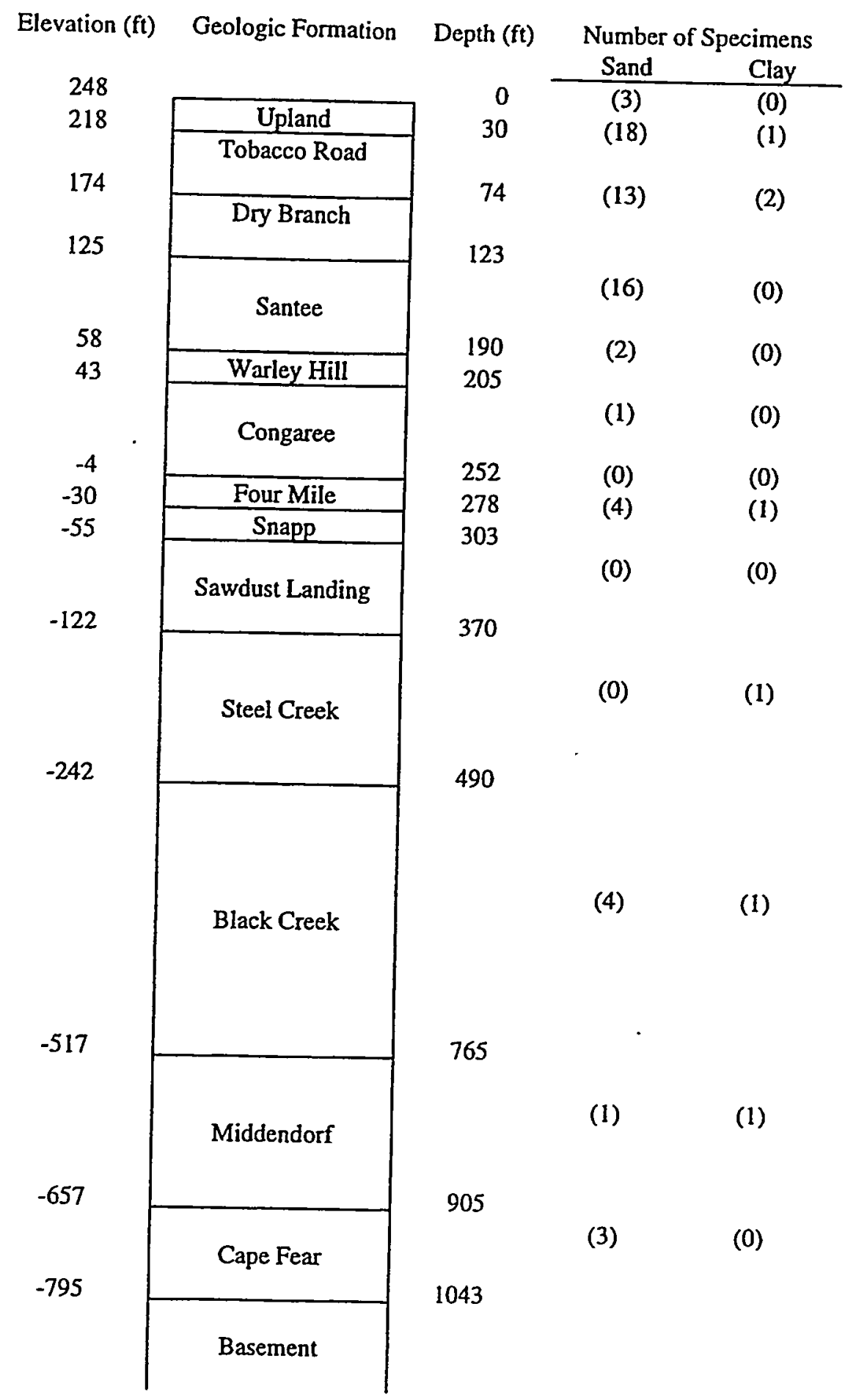

Note: Stratigraphic profile taken from boring CFD 18.

Fig. 2 General Stratigraphic Profile of the Savannah River Site. 

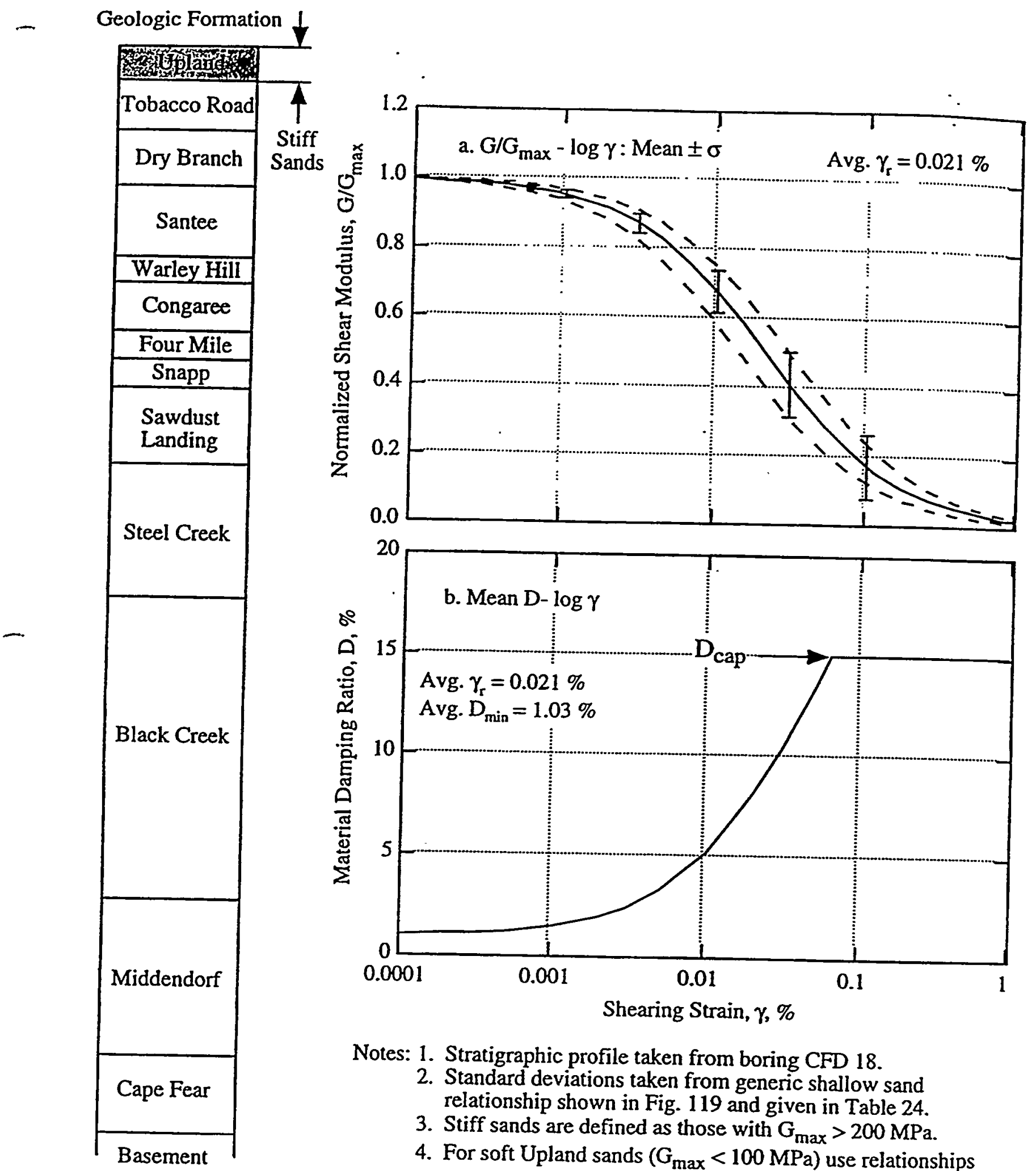

\begin{tabular}{|l|}
\hline Steel Creek \\
\hline
\end{tabular}

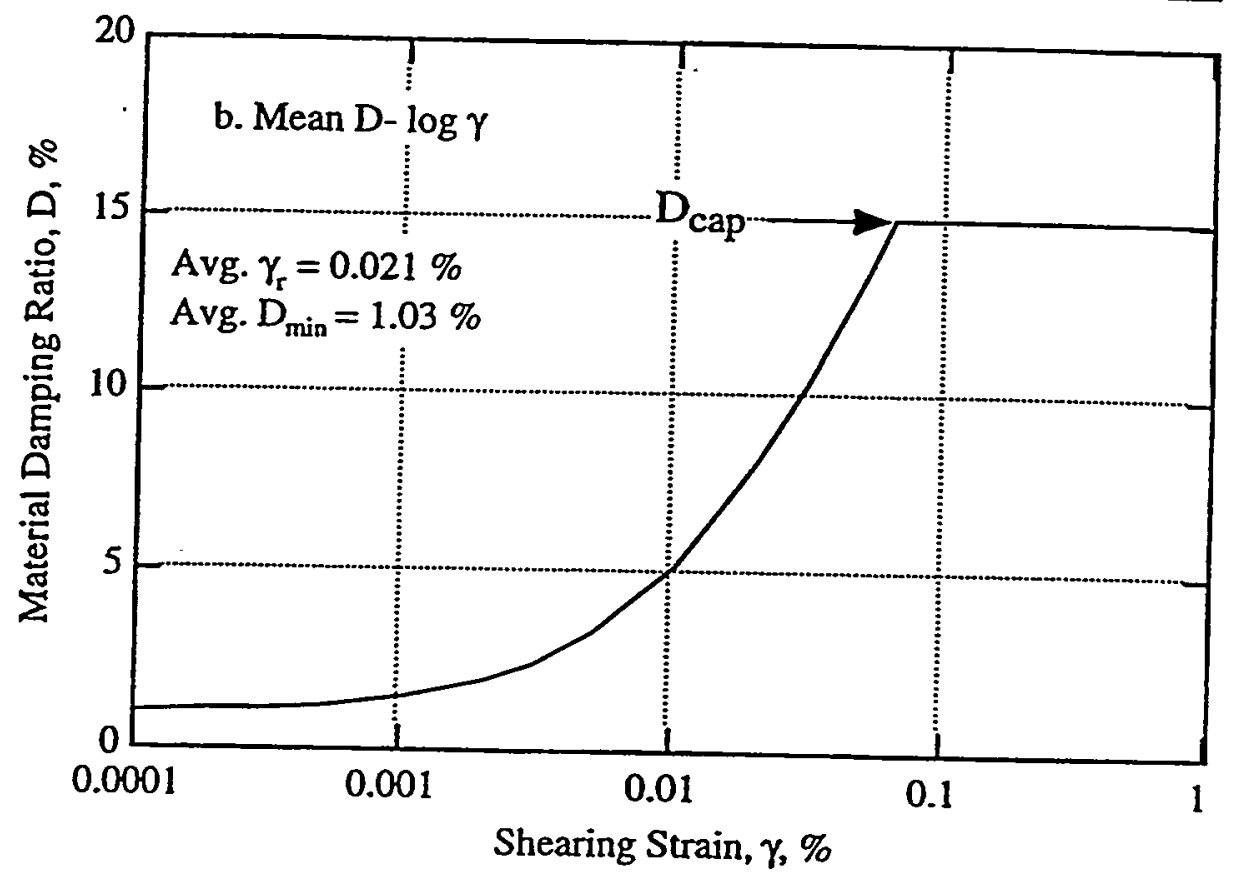

Notes: 1. Stratigraphic profile taken from boring CFD 18.

2. Standard deviations taken from generic shallow sand relationship shown in Fig. 119 and given in Table 24.

3. Stiff sands are defined as those with $G_{\max }>200 \mathrm{MPa}$.

4. For soft Upland sands $\left(\mathrm{G}_{\max }<100 \mathrm{MPa}\right.$ ) use relationships shown in Fig. 123.

5. Values of $D$ evaluated at $f \leq 1 \mathrm{~Hz}$.

Fig. 3 Recommended G/G $G_{\max }(\log -\gamma)$ and D $(\log -\gamma)$ relationships for Stiff Upland Sands at SRS (taken from Stokoe et al., 1995). Numerical values for best estimates and uncertainties for $G / G_{\max }$ (log$\gamma)$ and $D(\log -\gamma)$ can be determined from Tables 1,2 , and 3. 
Geologic Formation
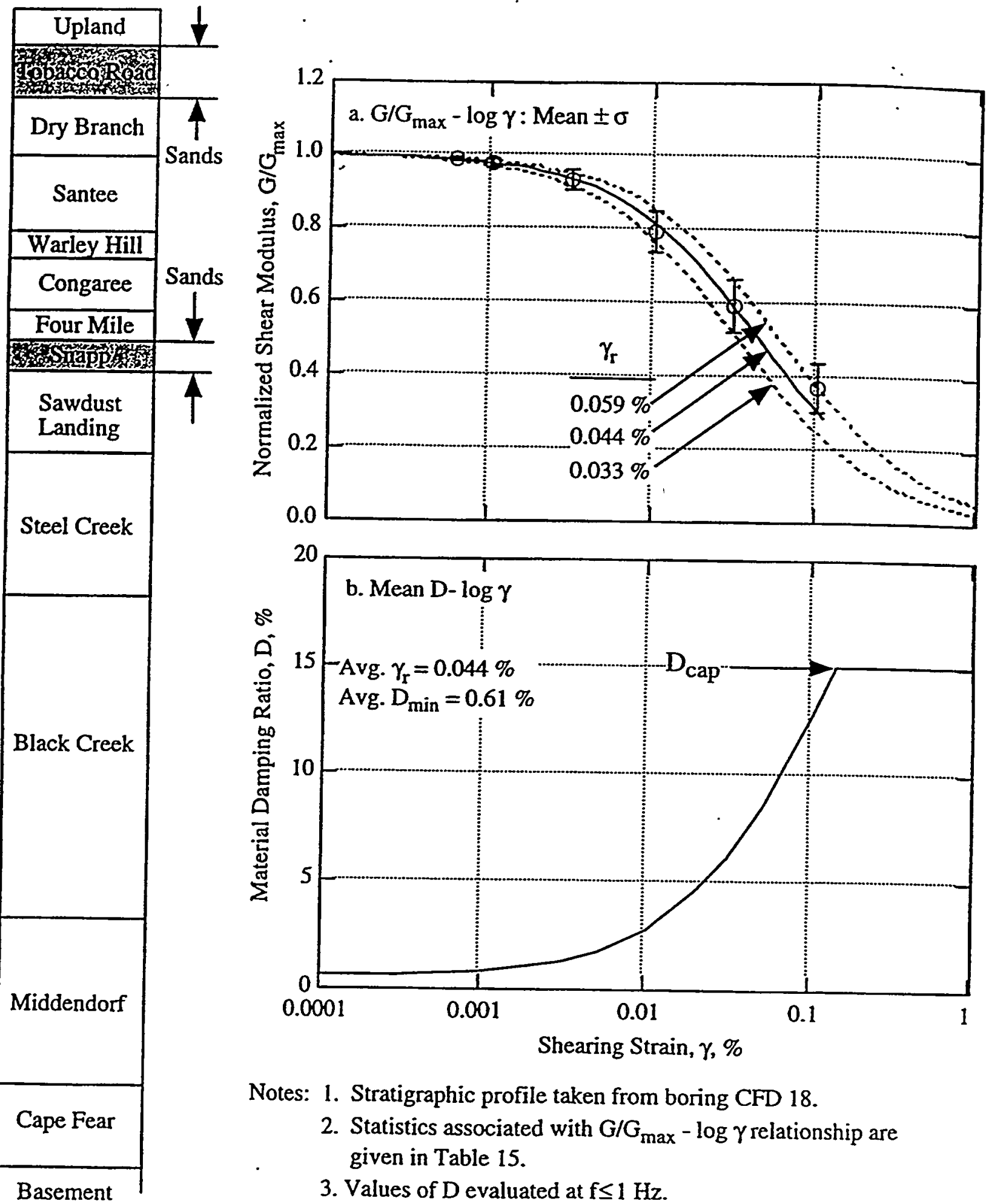

Notes: 1. Stratigraphic profile taken from boring CFD 18.

2. Statistics associated with $\mathrm{G} / \mathrm{G}_{\max }-\log \gamma$ relationship are given in Table 15.

3. Values of $D$ evaluated at $f \leq 1 \mathrm{~Hz}$.

Fig. 4 Recommended $G / G_{\max }(\log -\gamma)$ and $D(\log -\gamma)$ relationships for Tobacco Road and Snapp Sands at SRS (taken from Stokoe et al., 1995). Numerical values for best estimates and uncertainties for $\mathrm{G} / \mathrm{G}_{\max }(\log -\gamma)$ and $\mathrm{D}(\log -\gamma)$ can be determined from Tables 1,2 , and 3 . 
Geologic Formation

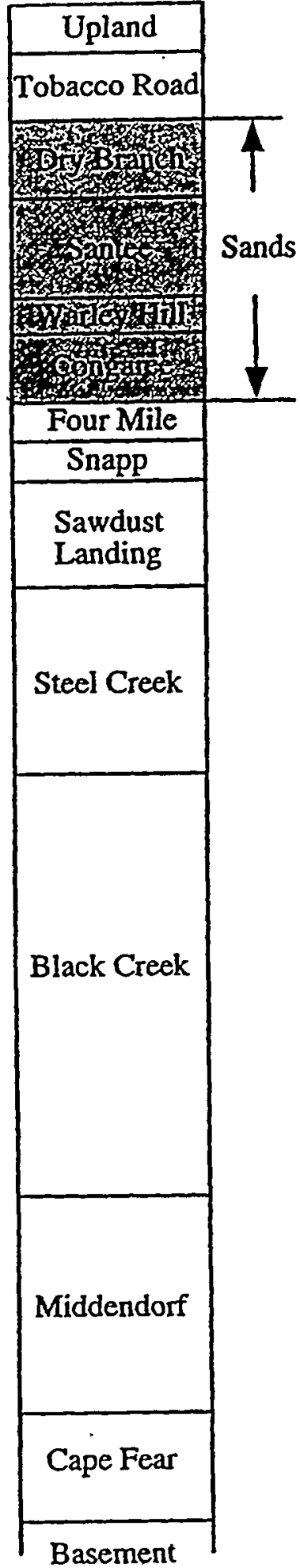
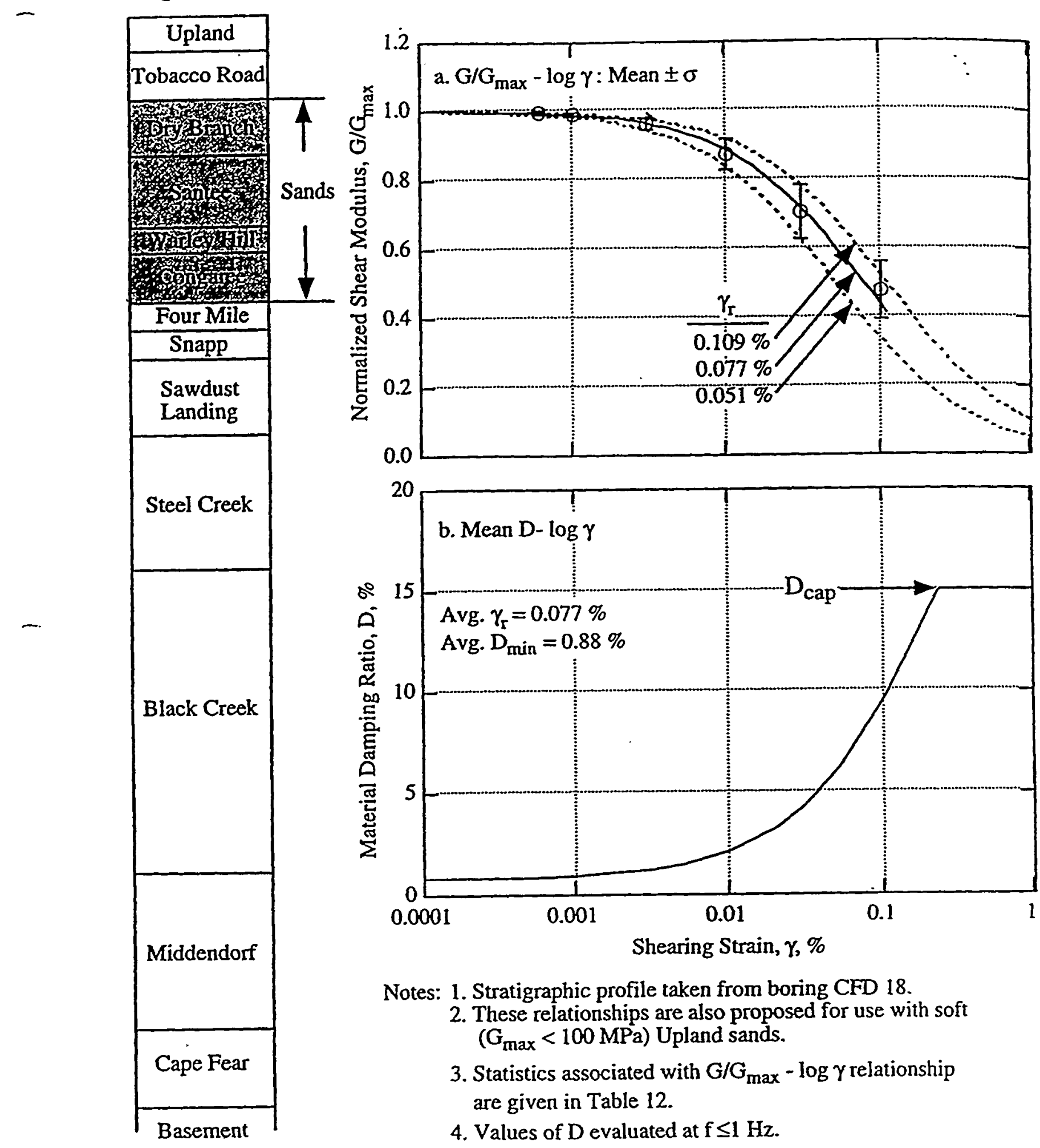

Notes: 1. Stratigraphic profile taken from boring CFD 18.

2. These relationships are also proposed for use with soft $\left(\mathrm{G}_{\max }<100 \mathrm{MPa}\right.$ ) Upland sands.

3. Statistics associated with $\mathrm{G} / \mathrm{G}_{\max }-\log \gamma$ relationship are given in Table 12.

4. Values of $D$ evaluated at $f \leq 1 \mathrm{~Hz}$.

Fig. 5 Recommended $G / G_{\max }(\log -\gamma)$ and $D(\log -\gamma)$ relationships for Dry Branch, Santee, Warley Hill and Congaree Sands at SRS (taken from Stokoe et al., 1995). Numerical values for best estimates and uncertainties for $G / G_{\max }(\log -\gamma)$ and $D(\log -\gamma)$ can be determined from Tables 1,2 , and 3 . 
- Geologic Formation

\begin{tabular}{|c|}
\hline Upland \\
\hline Tobacco Road \\
\hline Dry Branch \\
\hline Santee \\
\hline Warley Hill \\
\hline Congaree \\
\hline Sands \\
\hline Sawdust \\
\hline Steel Creek \\
\hline Banding \\
\hline Black Creek \\
\hline \\
\hline Middendorf \\
\hline
\end{tabular}
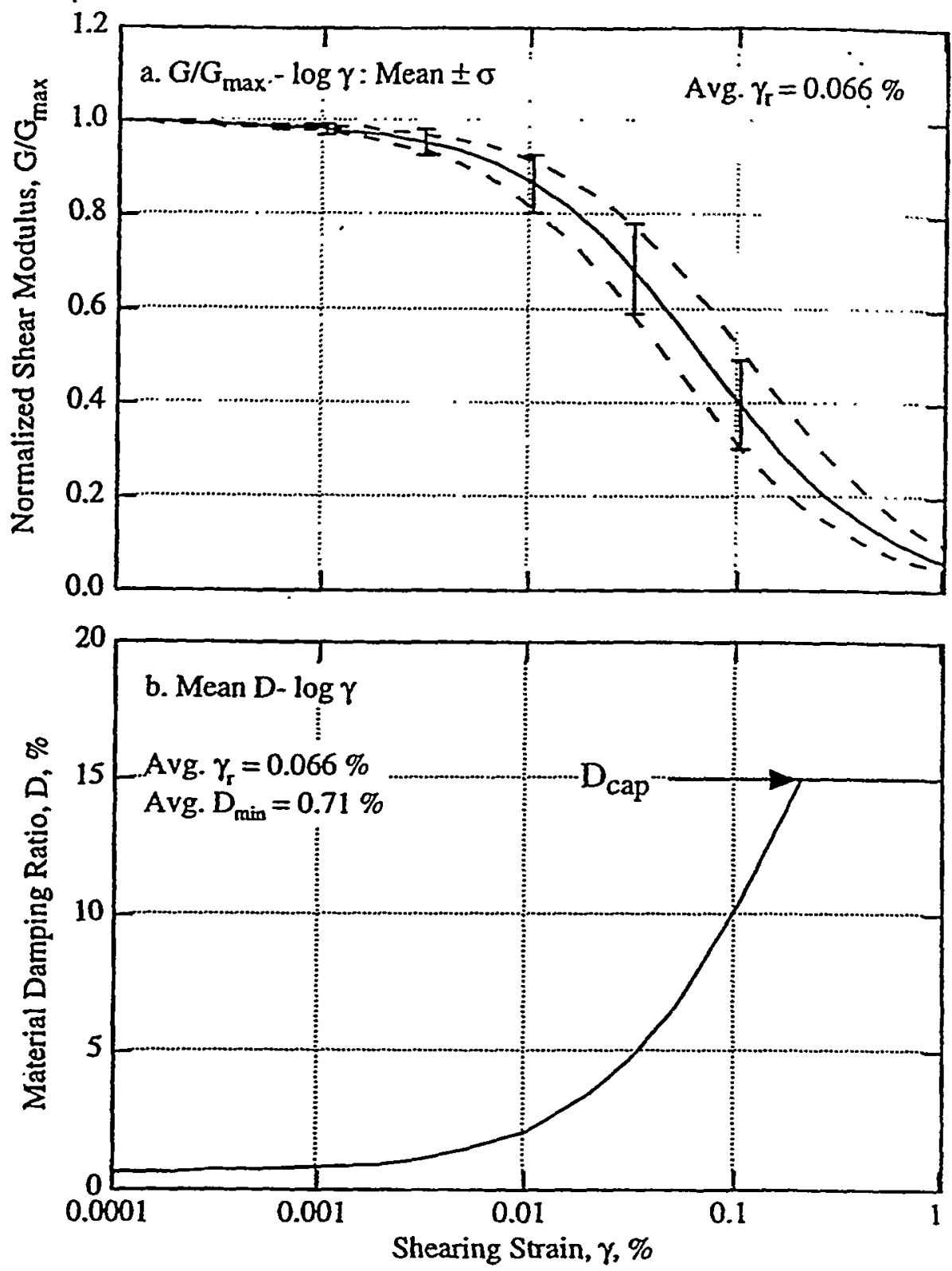

Notes: 1. Stratigraphic profile taken from boring CFD 18.

2. Average depth of "shallow" sand specimens is $116 \mathrm{ft}(35.4 \mathrm{~m})$.

3. Upland sands were not used in calculating these relationships.

4. Statistics associated with $G / G_{\max }-\log \gamma$ relationship are given in Table 24.

5. Relationships should not be used for sands with a significant amount of cementation.

6. Values of $D$ evaluated at $f \leq 1 \mathrm{~Hz}$.

Fig. 6 Recommended $G / G_{\max }(\log -\gamma)$ and $D(\log -\gamma)$ relationships for Four Mile Sands and any other unrepresented shallow sand formation at SRS (taken from Stokoe et al., 1995). Numerical values for best estimates and uncertainties for $G / G_{\operatorname{mix}}(\log -\gamma)$ and $D(\log -\gamma)$ can be determined from Tables 1,2 , and 3 . 


\section{Geologic Formation}
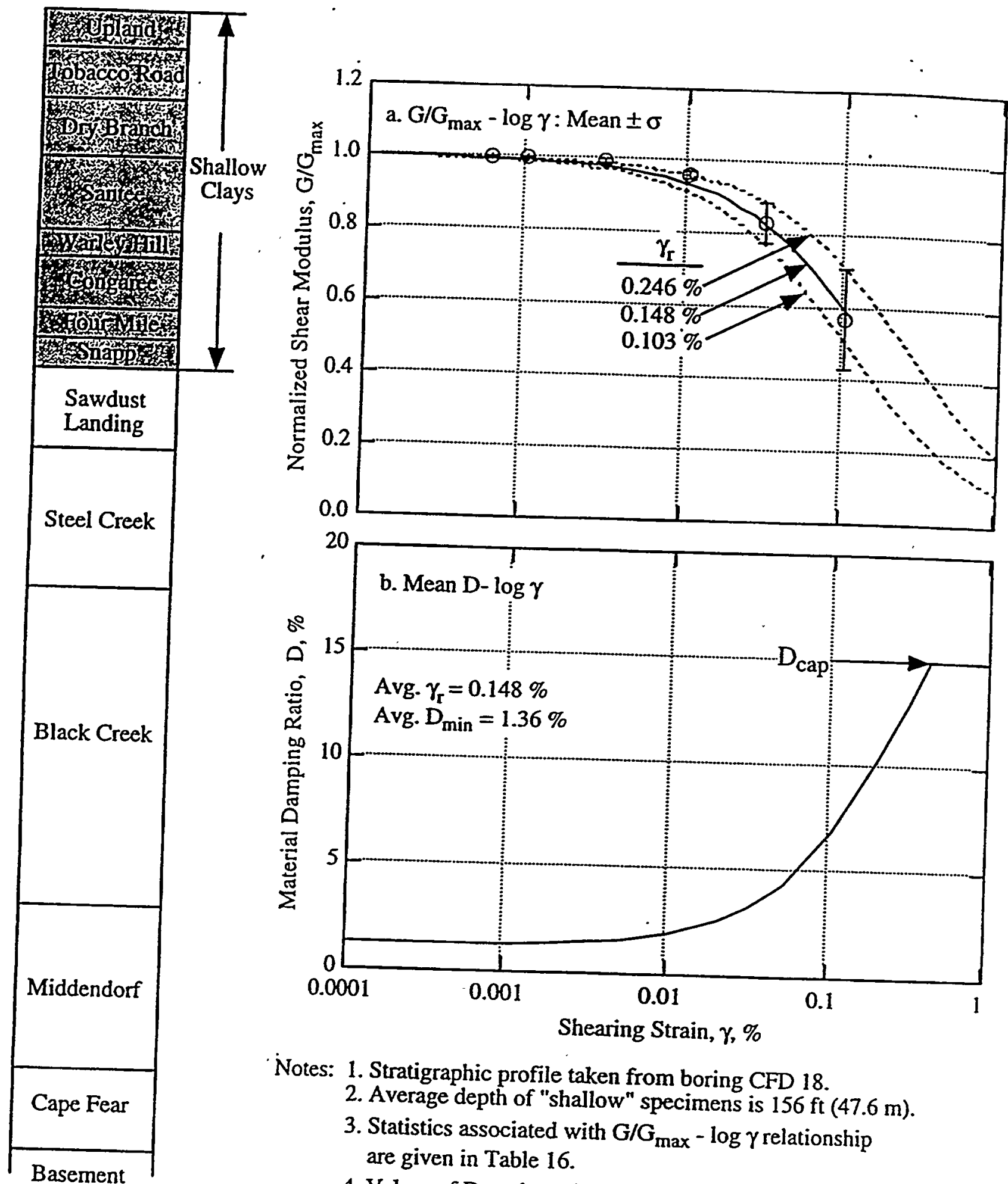

Notes: 1. Stratigraphic profile taken from boring CFD 18.

2. Average depth of "shallow" specimens is $156 \mathrm{ft}(47.6 \mathrm{~m})$.

3. Statistics associated with $G / G_{\max }-\log \gamma$ relationship are given in Table 16.

4. Values of $D$ evaluated at $f \leq 1 \mathrm{~Hz}$.

Fig. 7 Recommended $G / G_{\max }(\log -\gamma)$ and $D(\log -\gamma)$ relationships for Shallow Clays at SRS (taken from Stokoe et al., 1995). Numerical values for best estimates and uncertainties for $G / G_{\max }(\log -\gamma)$ and
$D(\log -\gamma)$ can be determined from Tables 1,2 , and 3 . 
Geologic Formation
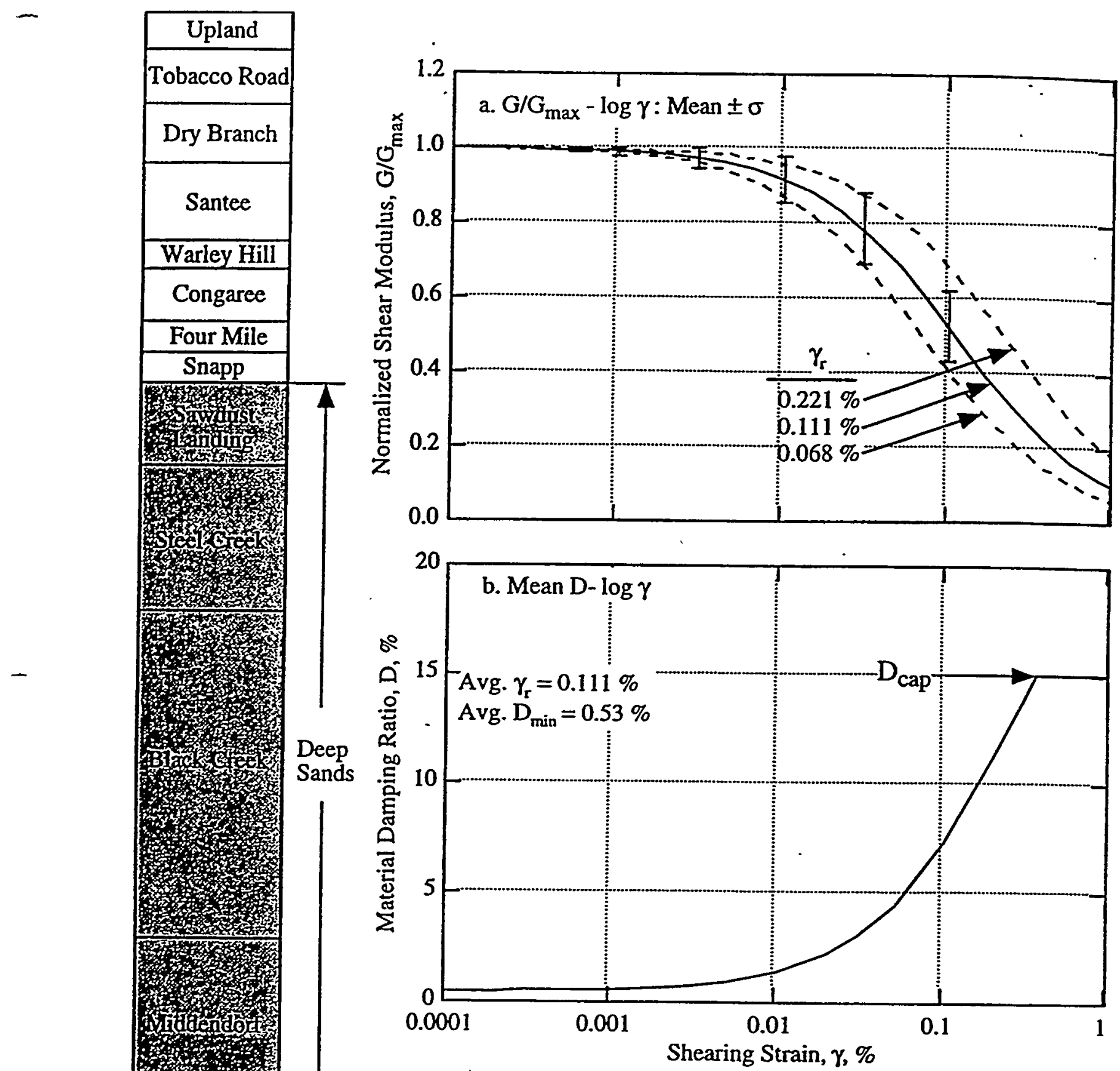

Notes: 1. Stratigraphic profile taken from boring CFD 18.

2. "Deep" sand relationships determined by extrapolating the "shallow" sand relationships shown in Fig. 124 from an average depth of $116 \mathrm{ft}(345.4 \mathrm{~m})$ to a depth of $750 \mathrm{ft}(228.6 \mathrm{~m})$.

3. Statistics associated with $\mathrm{G} / \mathrm{G}_{\max }-\log \gamma$ relationship are given in Table 24.

4. Values of $D$ evaluated at $f \leq 1 \mathrm{~Hz}$.

Fig. 8 Recommended $G / G_{\max }(\log -\gamma)$ and $D(\log -\gamma)$ relationships for Deep Sands at SRS (taken from Stokoe et al., 1995). Numerical values for best estimates and uncertainties for $G / G_{\max }(\log : \gamma)$ and D $(\log -\gamma)$ can be determined from Tables 1,2 , and 3 . 
Geologic Formation
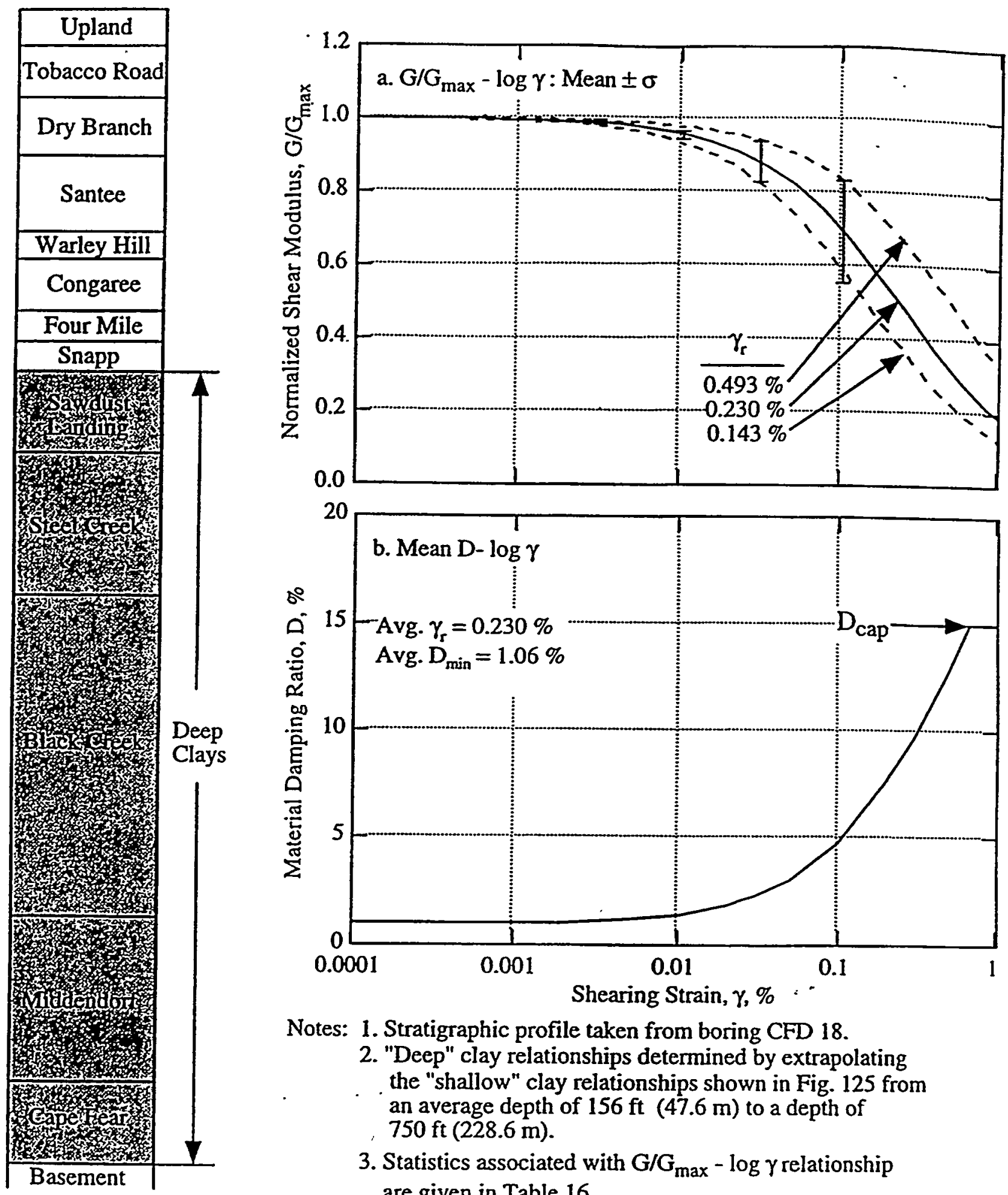

Notes: 1. Stratigraphic profile taken from boring CFD 18.

2. "Deep" clay relationships determined by extrapolating the "shallow" clay relationships shown in Fig. 125 from an average depth of $156 \mathrm{ft}(47.6 \mathrm{~m})$ to a depth of $750 \mathrm{ft}(228.6 \mathrm{~m})$.

3. Statistics associated with $\mathrm{G} / \mathrm{G}_{\max }-\log \gamma$ relationship are given in Table 16.

4. Values of $\mathrm{D}$ evaluated at $\mathrm{f} \leq 1 \mathrm{~Hz}$.

Fig. 9 Recommended $G / G_{\max }(\log -\gamma)$ and $D(\log -\gamma)$ relationships for Deep Clays at SRS (taken from Stokoe et al., 1995). Numerical values for best estimates and uncertainties for $G / G_{\max }(\log -\gamma)$ and $\mathrm{D}(\log -\gamma)$ can be determined from Tables 1,2 , and 3 . . 


\section{SRS Recommended G/Gmax}

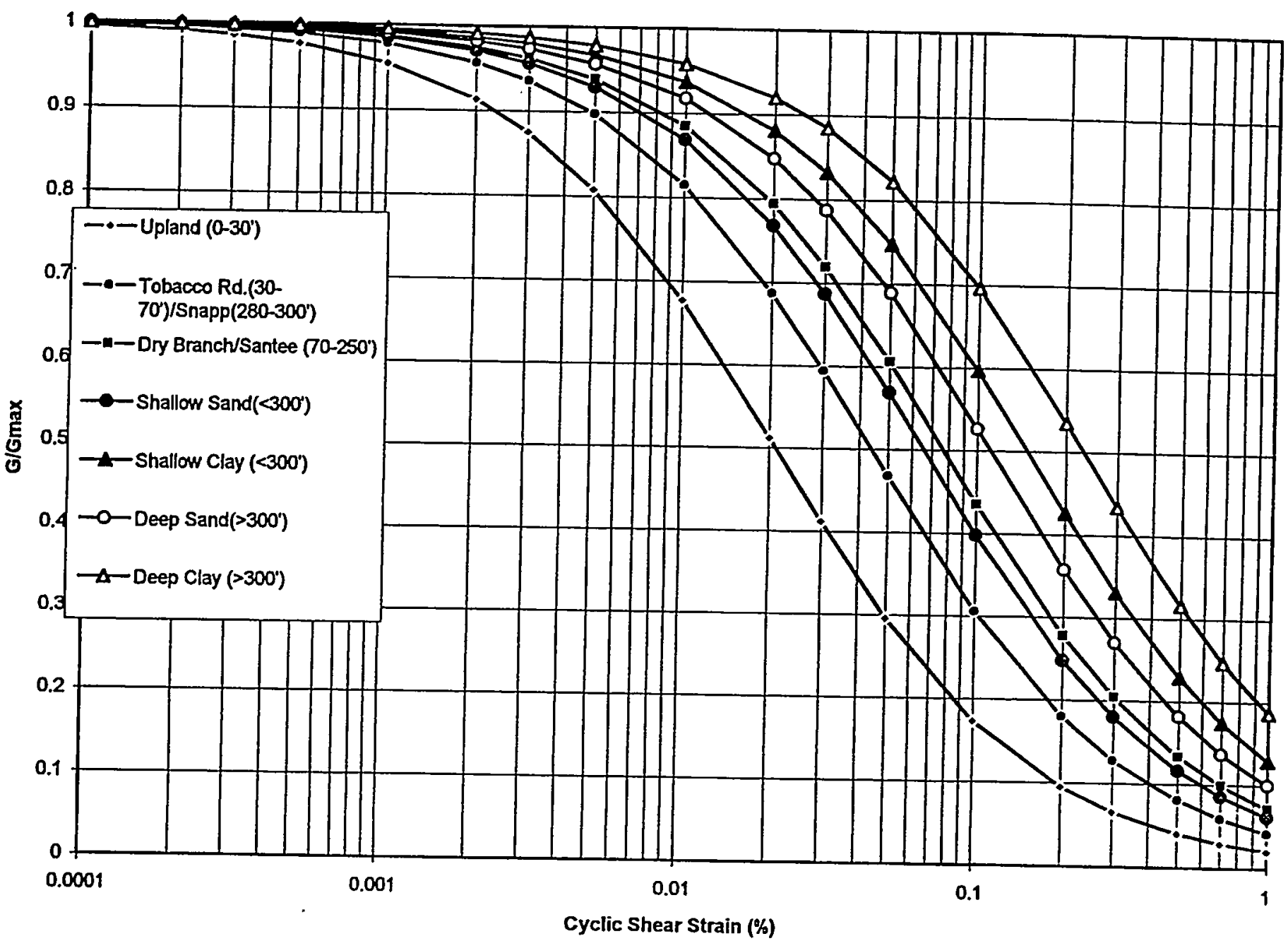

Fig. 10 SRS best estimate normalized shear-modulus curves, by formation. 
SRS Recommended Damping

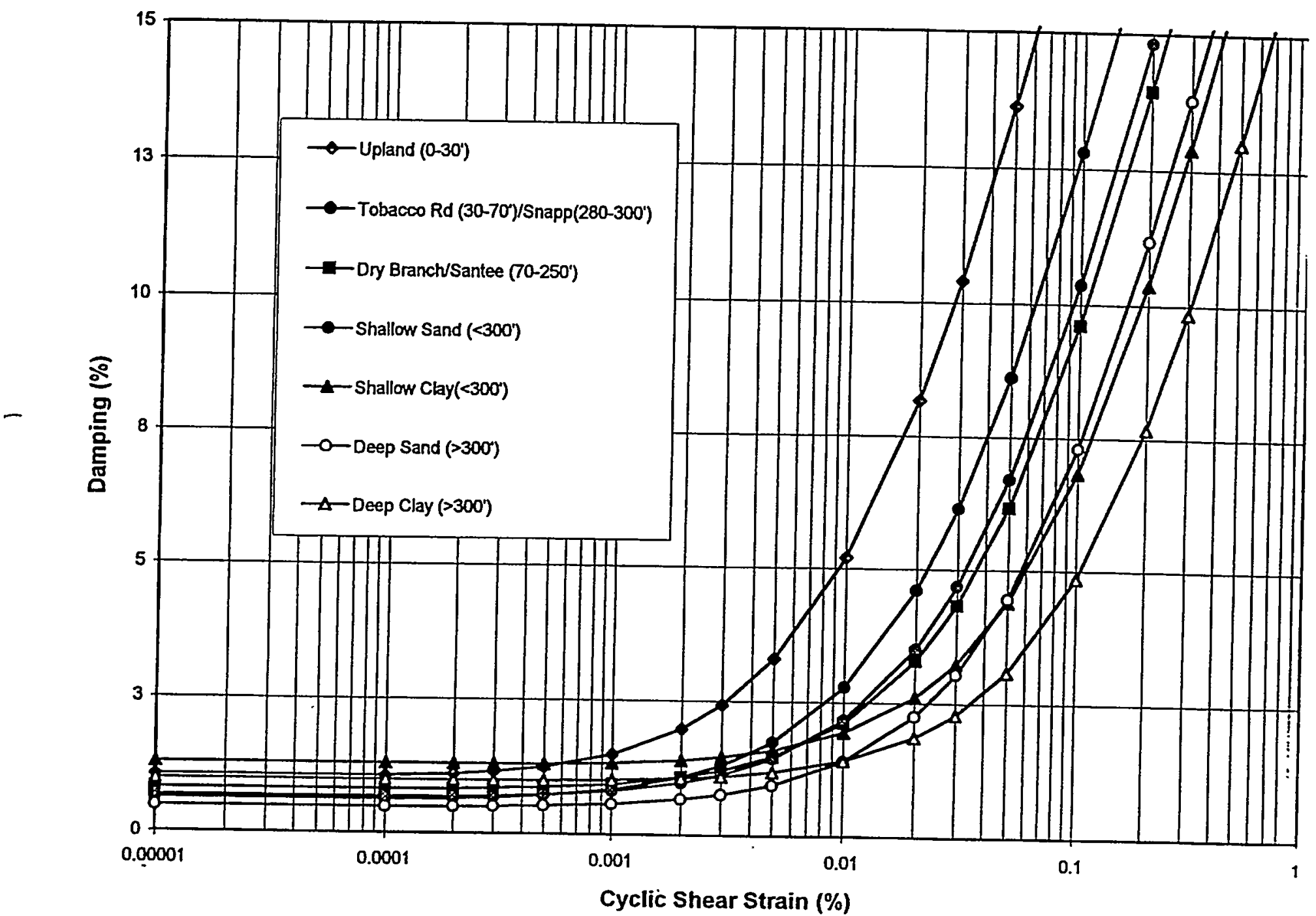

Fig. 11 SRS best estimate damping curves, by formation. 


\section{Comparison of SRS and EPRI G/Gmax}

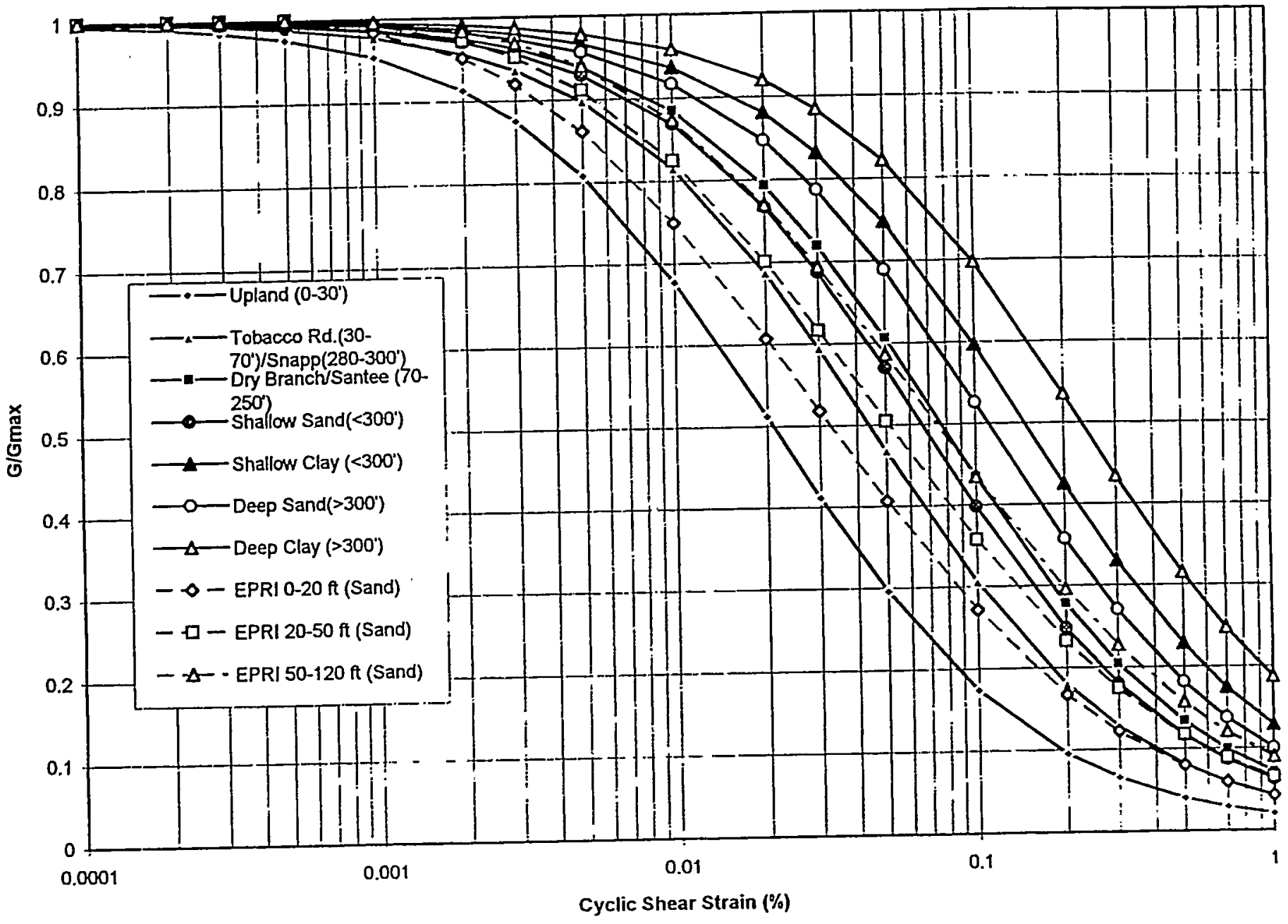

Fig. 12 Comparison of SRS best estimatc G/Gmax (Solid Curves) with shallow EPRJ (1993) (dashed). 
WSRC-TR-96-0062, Rev.0

March 22, 1996
Site Geotechnical Services Nonlinear Soil Properties

\section{Comparison of SRS and EPRI G/Gmax}

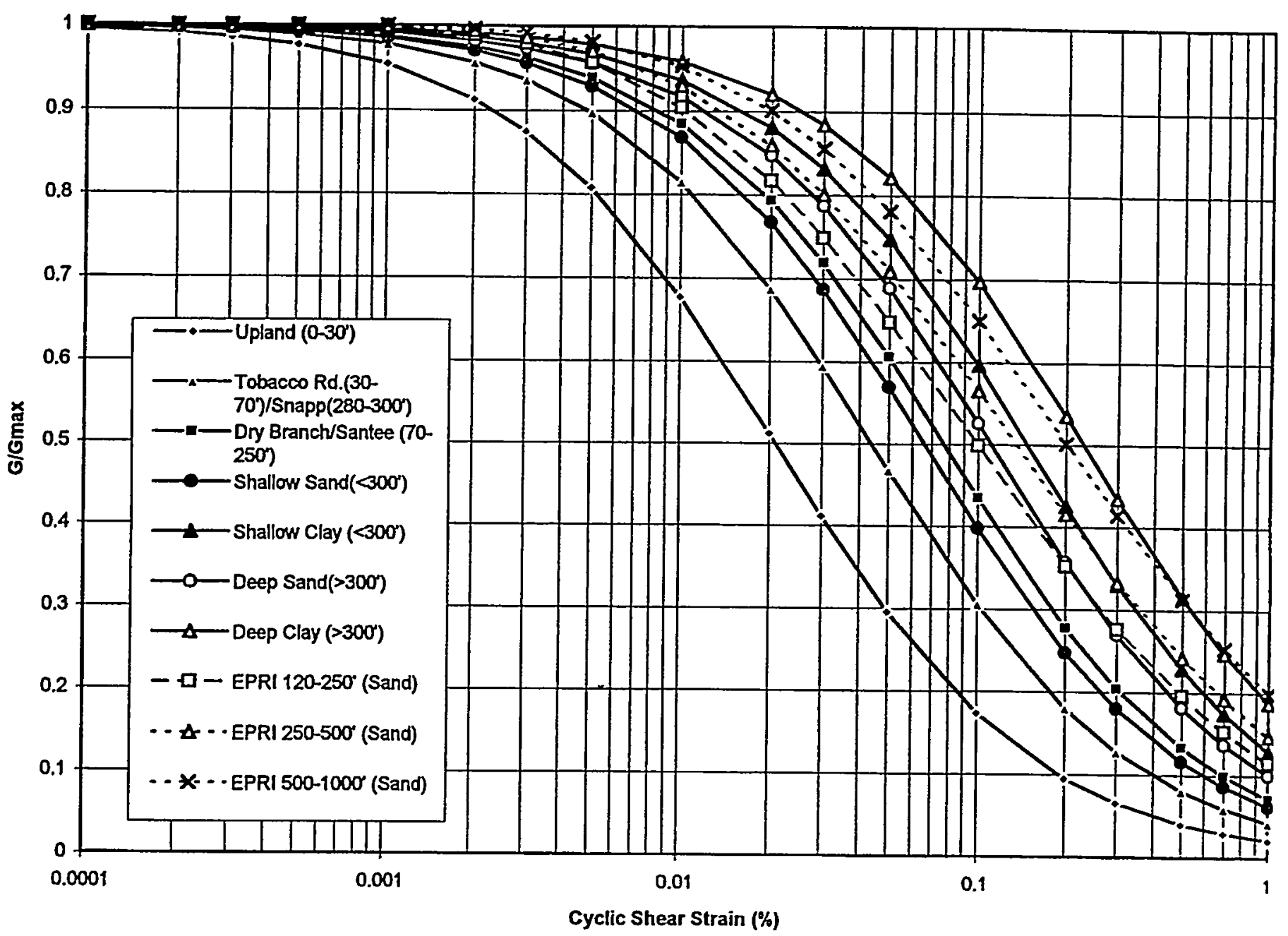

Fig. 13 Comparison of SRS best estimate G/Gmax (Solid Curves) with deep EPRI (1993) (dashed). 
WSRC-TR-96-0062, Rev.0

March 22, 1996
Site Geotechnical Services Nonlinear Soil Properties

\section{Comparison of SRS and EPRI Damping}

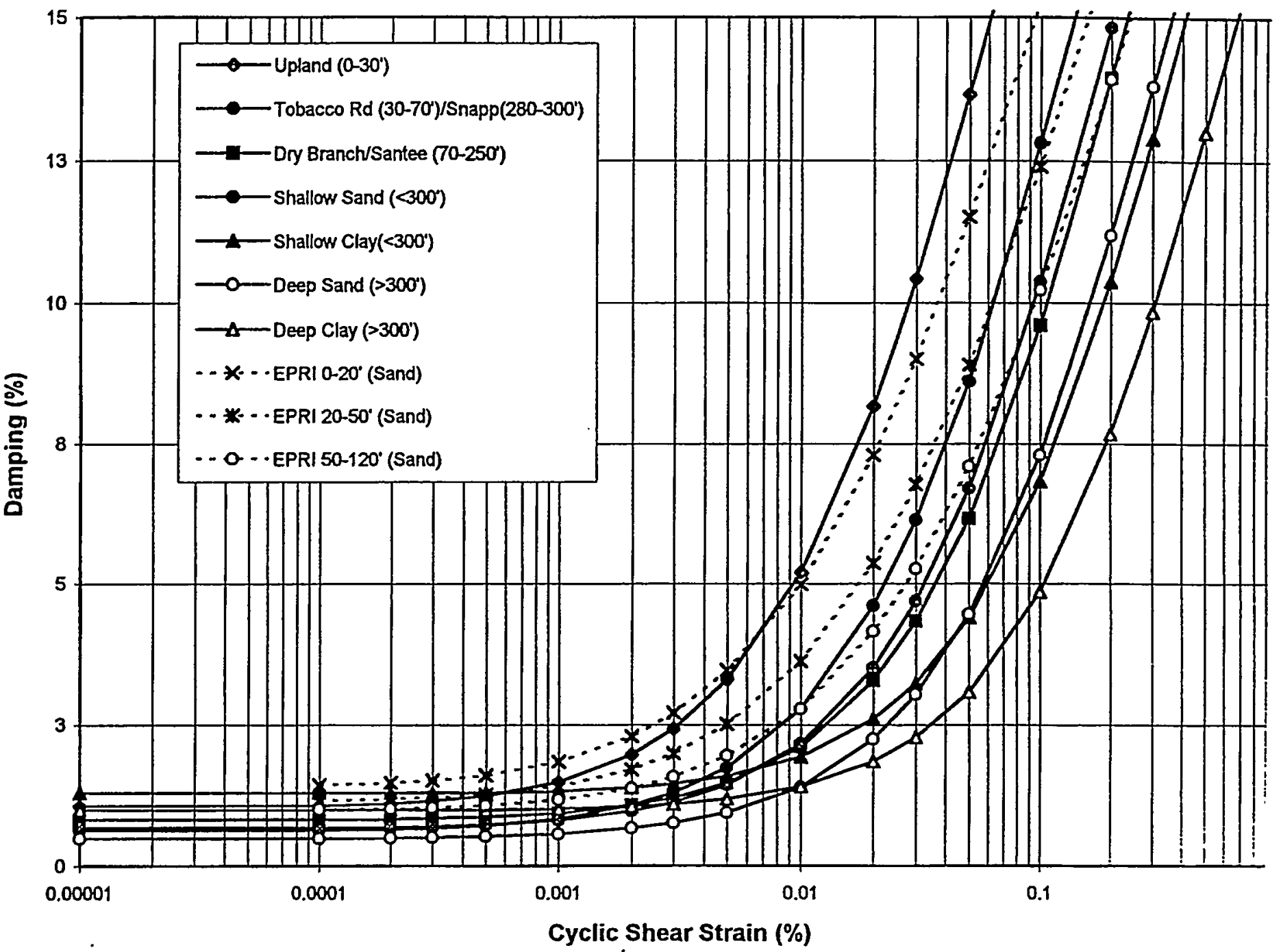

Fig. 14 Comparison of SRS best estimate damping (Solid Curves) with shallow EPRI (1993) (dashed). 


\section{Comparison of SRS and EPRI Damping}

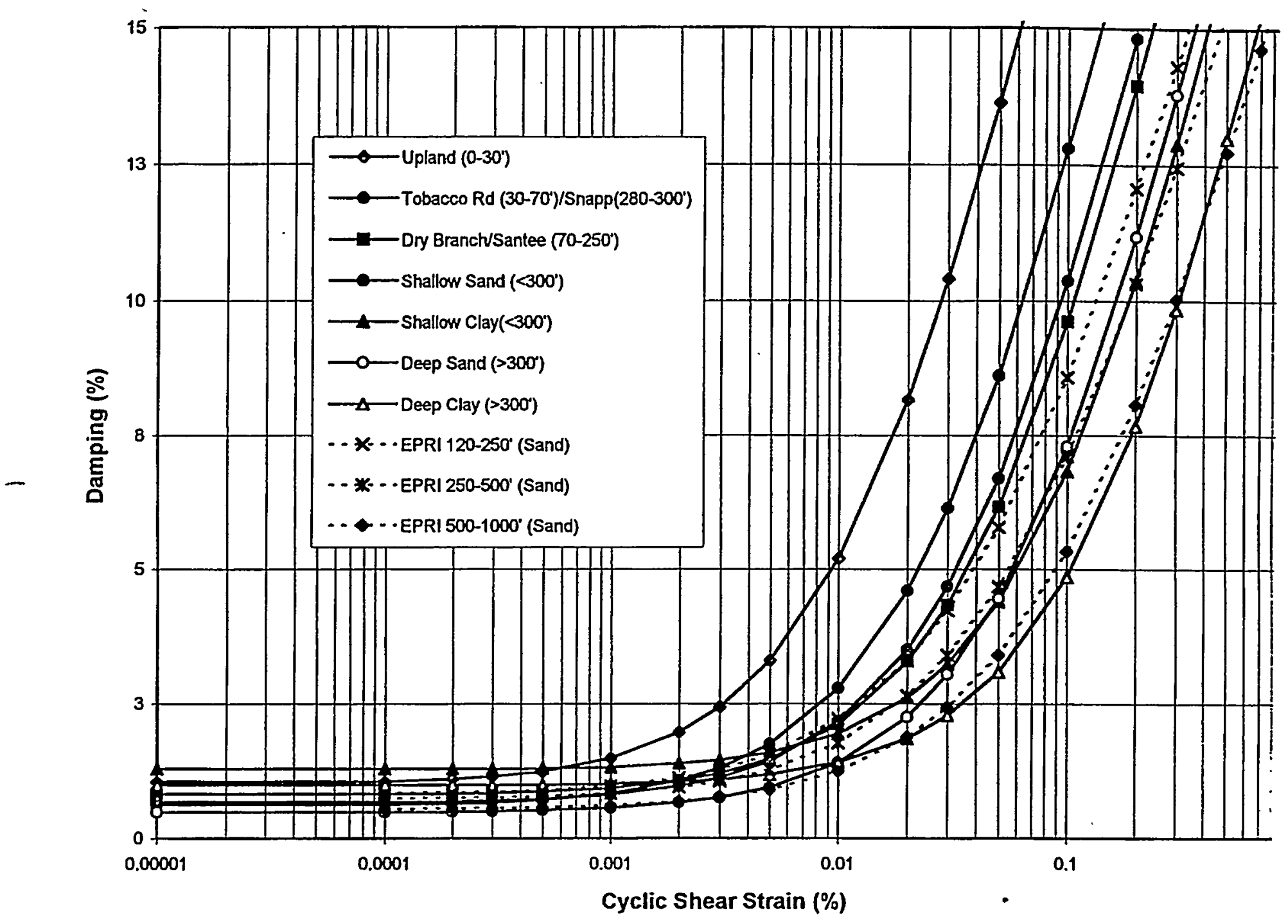

Fig. 15 Comparison of SRS best estimate damping (Solid Curves) with deep EPRI (1993) (dashed). 


\section{Comparison of SRS and GEI G/Gmax}

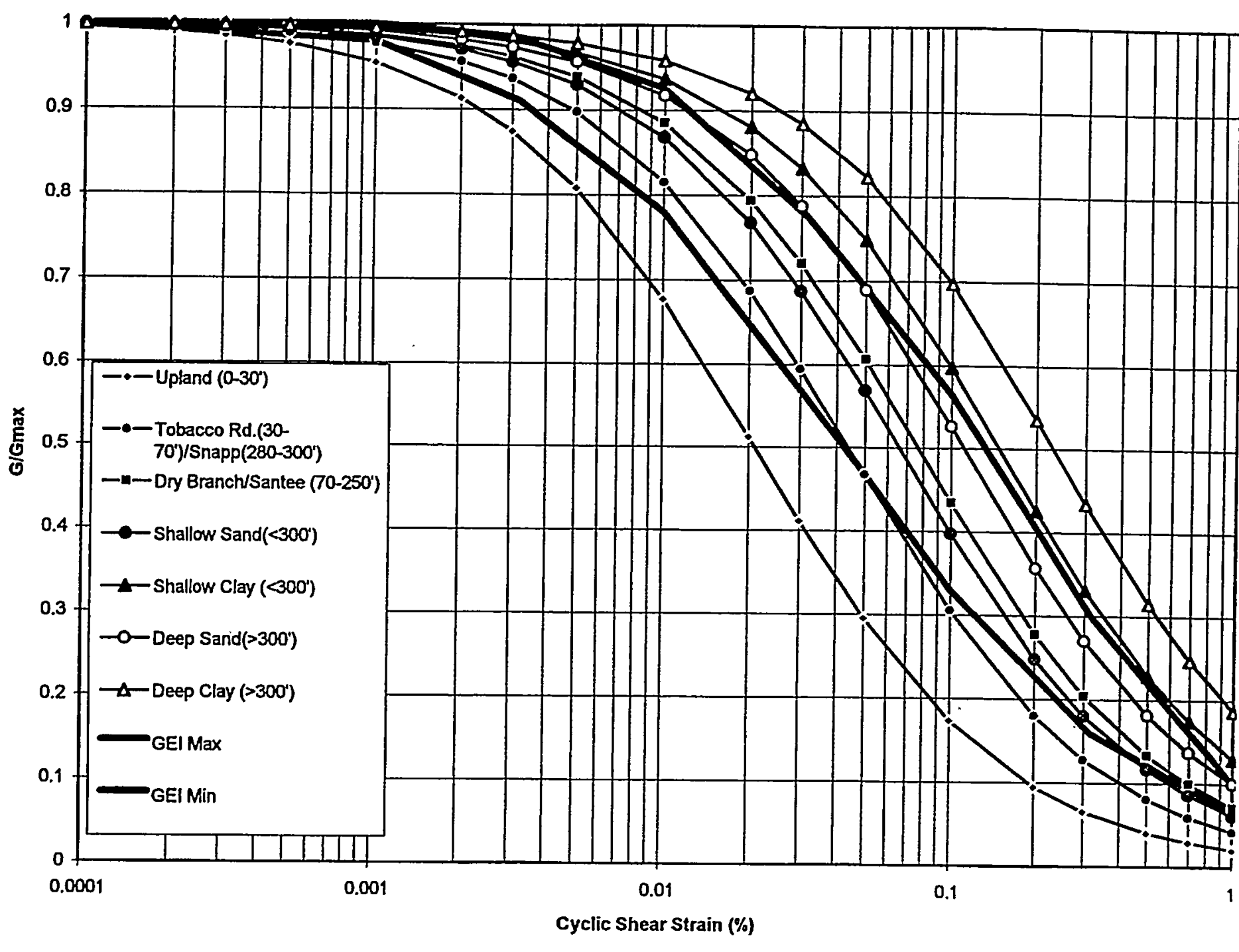

Fig. 16 Comparison of SRS best estimate G/Gmax (Solid Curves) with minimum and maximum GEI (1991) (bold). 


\section{Comparison of SRS and GEI Damping}

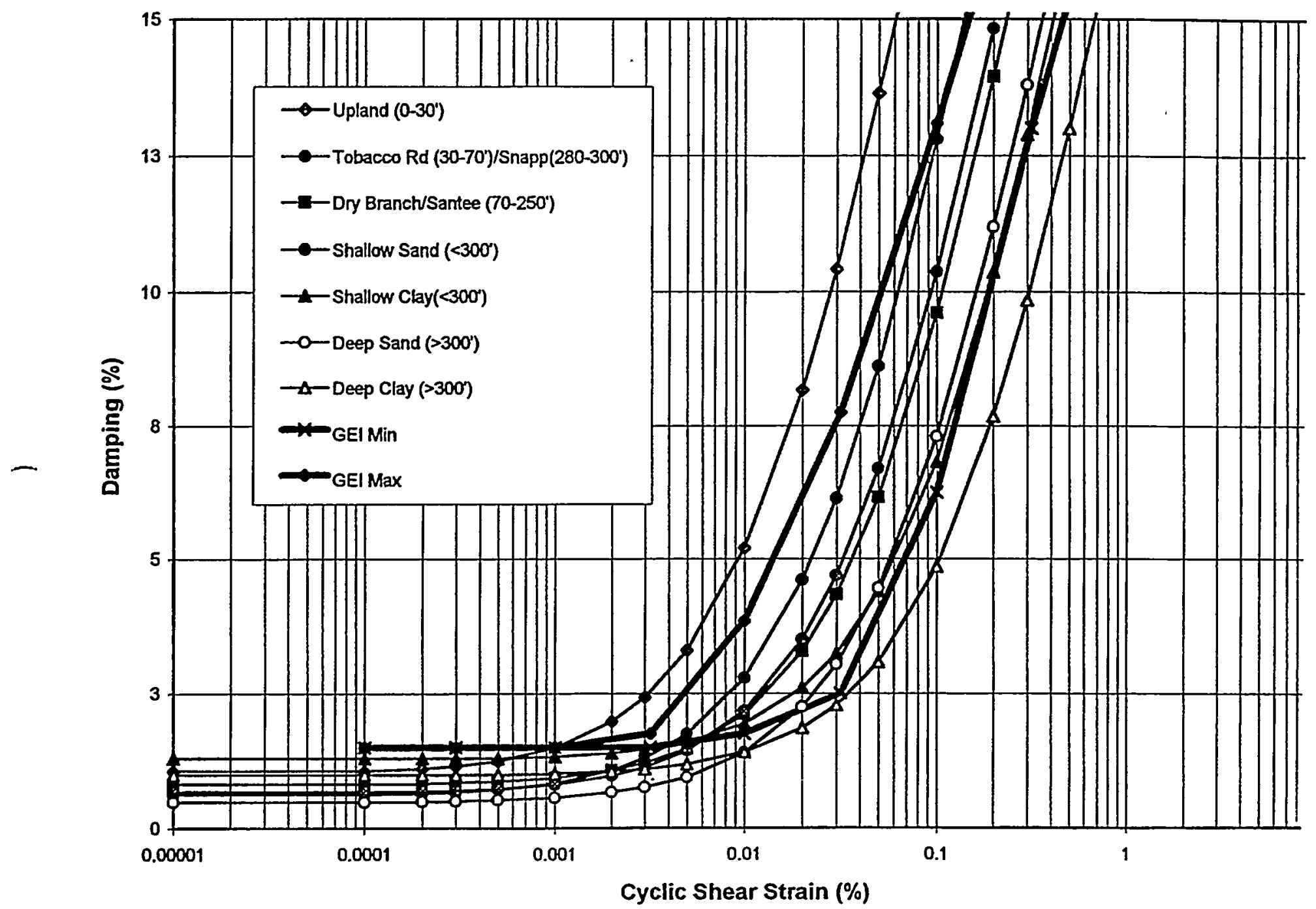

Fig. 17 Comparison of SRS best estimate damping (Solid Curves) with minimum and maximum GEI (1991) (bold). 


\section{CORRELATION STUDY OF NONLINEAR DYNAMIC SOIL PROPERTIES \\ Savannah River Site Aiken, South Carolina}

Revision No. 0

September 13, 1995

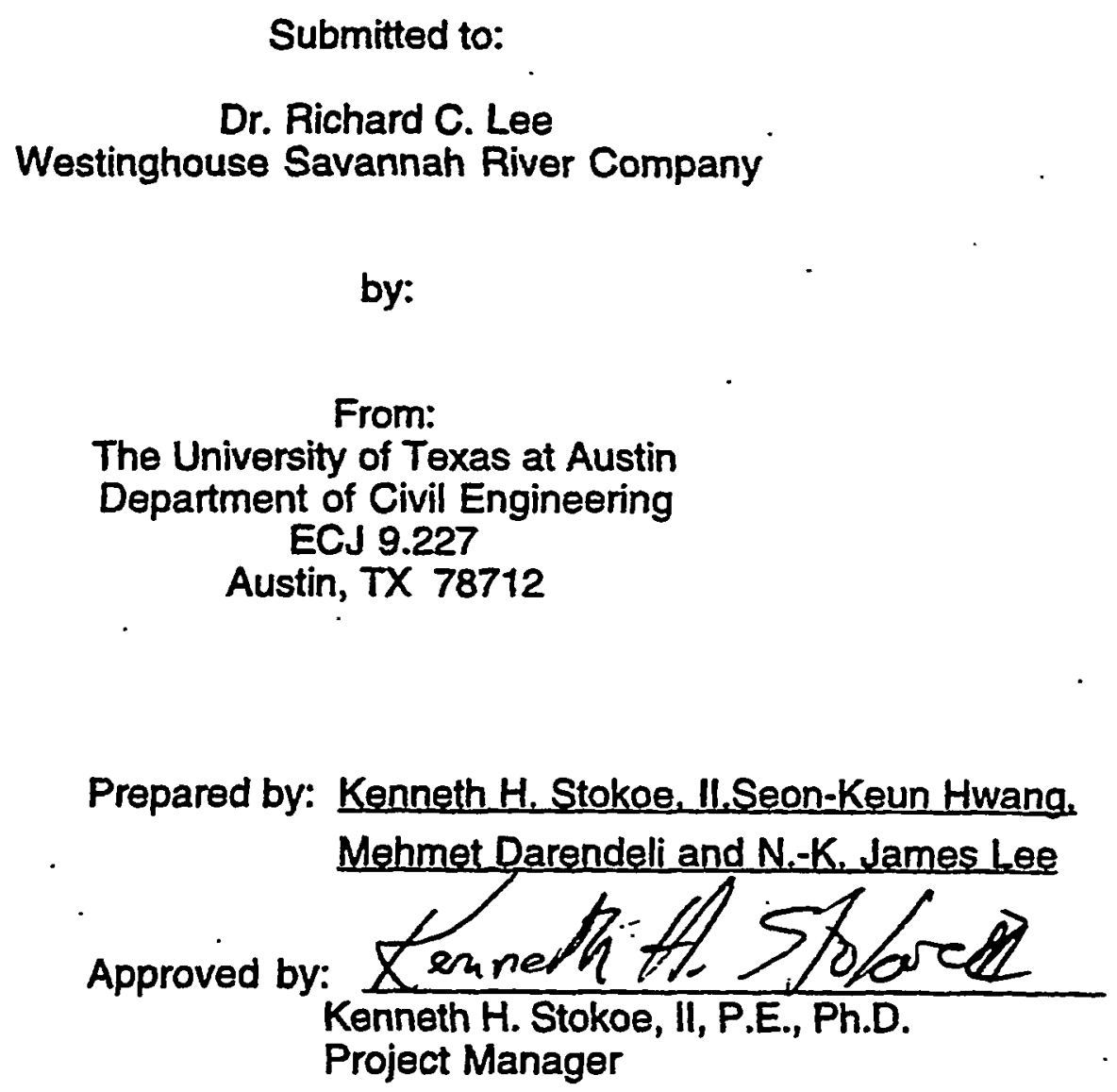

File No: SRS-FR-CDP-95 


\section{TABLE OF CONTENTS}

page

Table of Contents ….............................................................................................. i

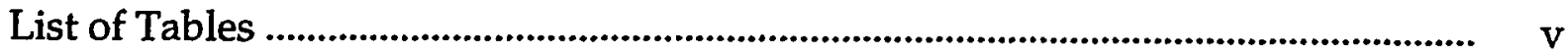

List of Figures ........................................................................................................ vii

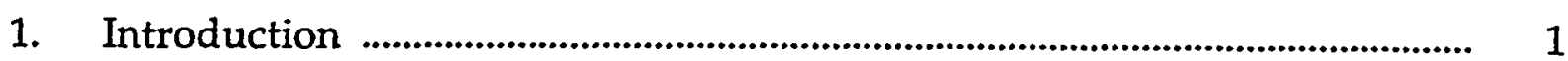

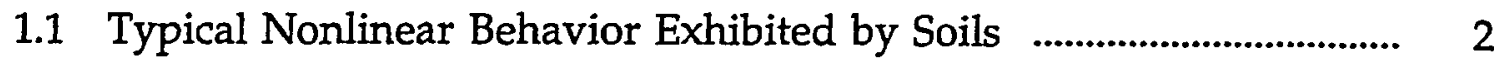

2. Laboratory Results Included in the Correlation Database ............................. 5

2.1 Summary Listings of All Specimens _.................................................. 5

2.2 Summary Plots of All Dynamic Measurements …............................... 6

3. Variables Considered in Developing Correlations ......................................... 6

3.1 Geotechnical and Geologic Variables ................................................... 6

3.2 Laboratory Test Variables ……............................................................. 8

4. Hyperbolic Curve Fitting of Laboratory Data ...................................................... 9

5. General Results of Correlation Study .............................................................. 6

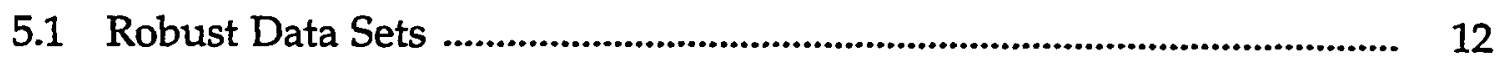

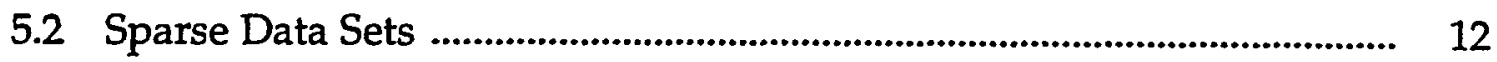

5.3 Unrepresented Soils at SRS ................................................................ 13

6. Correlations Using Shallow Sand Specimens ............................................. 13

6.1 Dry Branch and Santee Sands ................................................................. 13

$\mathrm{G} / \mathrm{G}_{\max }-\log \gamma:$ Complete Data Set .................................................. 14

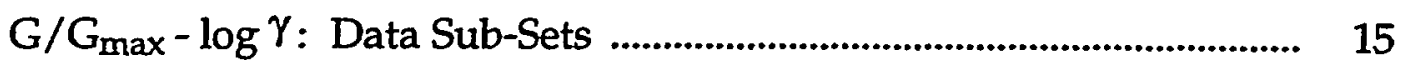

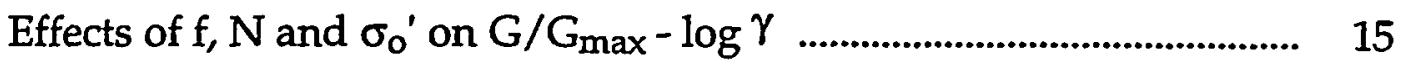

$\mathrm{D}-\log \gamma:$ Complete Data Set ................................................................ 16

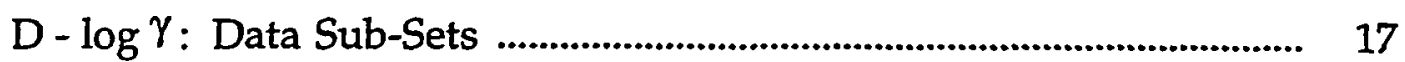

SRS-FR-CDP-95, rev. 0, 13 September 95 i of $x \times x$

Project No. AA891070 


\section{TABLE OF CONTENTS (continued)}

page

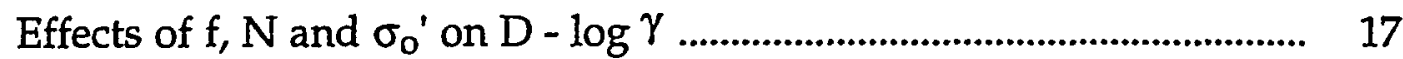

Recommended D - $\log \gamma:$ Relationship .............................................. 17

- $\quad 6.2$ Tobacco Road and Snapp Sands ................................................................... 19

$\mathrm{G} / \mathrm{G}_{\max }-\log \gamma:$ Complete Data Set ...................................................... 20

$\mathrm{G} / \mathrm{G}_{\max }-\log \gamma:$ Data Sub-Sets ................................................................ 21

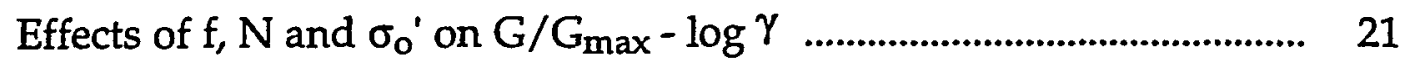

$\mathrm{D}-\log \gamma:$ Complete Data Set ........................................................... 22

D - $\log \gamma:$ Data Sub-Sets .................................................................................. 22

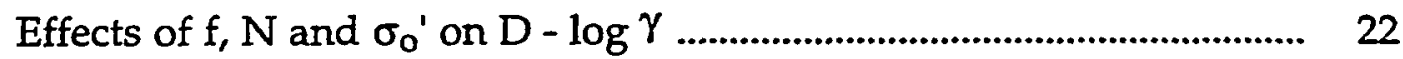

Recommended D - $\log \gamma$ Relationship ...................................................... 23

7. Correlations Using Shallow Clay Specimens ................................................... 24

$G / G_{\max }-\log \gamma:$ Complete Data Set .......................................................... 24

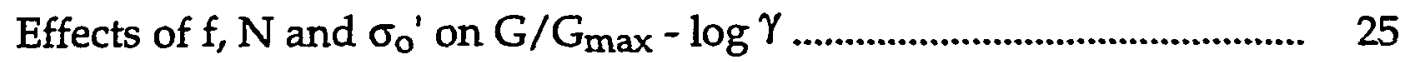

D - $\log \gamma:$ Complete Data Set .................................................................. $\quad 25$

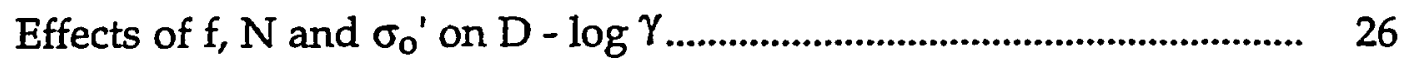

Recommended D - $\log \gamma$ Relationship ...................................................... $\quad 26$

8. Statistical Analyses of Shallow Sand and Clay Correlations ......................... 27

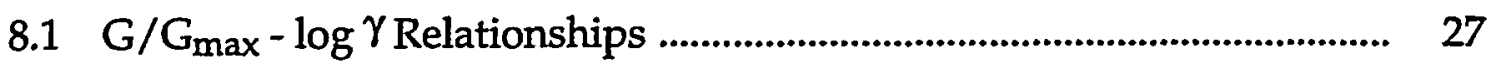

8.2 Testing the Hypotheses of Combining and/or

Separating Data Sets ......................................................................................... 28

9. Comparisons of Sparse and Robust Shallow Sand Data Sets ...................... 30

Effects of $f, N$ and $\sigma_{o}{ }^{\prime}$ on $G$ and $D$........................................................... 30

SRS-FR-CDP-95, rev. 0, 13 September $95 \quad$ ii of $\mathrm{xxx}$

Project No. AA891070 


\section{TABLE OF CONTENTS (continued)}

page

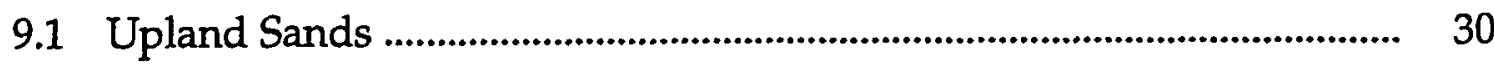

Shear Modulus ....................................................................................... $\quad 30$

Material Damping ....................................................................................... 31

9.2 Warley Hill Sands .......................................................................................... 31

9.3 Congaree Sands ..................................................................................... 32

10. Investigation of the Dynamic Measurements of Deep Specimens ............ 32

10.1 Deep Sand Specimens ................................................................................. 32

Shear Modulus .................................................................................... 33

Material Damping ............................................................................................ 33

10.2 Deep Clays Specimens.................................................................................... 33

Shear Modulus ....................................................................................................... 33

Material Damping ............................................................................................. 34

10.3 Overall Summary of Dynamic Properties of Deep Soils....................... 34

11. Predicting Nonlinear Dynamic Properties of Deep Soils

by Extrapolating the Robust Correlations Determined

for the Shallow Soils

12. Recommended Generic G/G $\max -\log \gamma$ and $D-\log \gamma$ Relationships

for SRS Soils

13. Summary and Conclusions _............................................................................ 38

14. References ........................................................................................................... 41

Tables ...................................................................................................................... 43

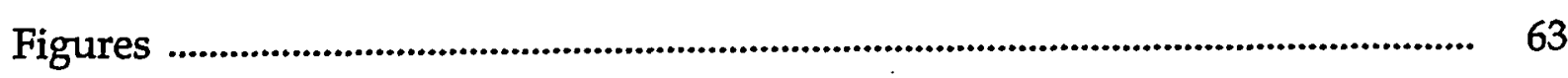

SRS-FR-CDP-95, rev. 0, 13 September $95 \quad$ iii of $x x x$ 


\section{TABLE OF CONTENTS (continued)}

page

Appendix A- Data That Were Deleted From The Correlation Study ............... 190

Appendix B- Nonlinear Dynamic Properties of Similar Soils

Evaluated With The RCTS Equipment at UTA.

Appendix C- Effects of Excitation Frequency, Number of Loading Cycles and Confining Pressure on the Dynamic Properties of Dry Branch and Santee Sands (Specimens CFD-4a, CFD-5a, and CFD-7a)

Appendix D- Effects of Excitation Frequency, Number of Loading Cycles and Confining Pressure on the Dynamic Properties of Tobacco Road and Snapp Sands (Specimens CFD-3b, CFD-12a, and CFD-13a).

Appendix E- Effects of Excitation Frequency, Number of Loading Cycles and Confining Pressure on the Dynamic Properties of Shallow Clays (Specimens CFD-6a and CFD-T1a).

Appendix F- Effects of Excitation Frequency, Number of Loading Cycles and Confining Pressure on the Dynamic Properties of Upland Sands (Specimens CFD-1a and CFD-2a)

Appendix G- Effects of Excitation Frequency and Number of Loading Cycles and Confining Pressure on the Dynamic Properties of Warley Hill Sands (Specimen CFD-8a)

Appendix H- Effects of Excitation Frequency and Number of Loading Cycles on the Dynamic Properties of Congaree Sands (Specimen CFD-11a)

Appendix I- Effects of Excitation Frequency and Number of Loading Cycles on the Dynamic Properties of Deep Sands (Specimens CFD-T6c)

Appendix J- Effects of Excitation Frequency and Number of Loading Cycles on the Dynamic Properties of Deep Clays (Specimens CFD-T4a and CFD-T5b) 305 


\section{LIST OF TABLES}

No.

Title

page

1 Field and Laboratory Dynamic Geotechnical Reports

Received from the Westinghouse Savannah River

Corporation Which Cover Testing at SRS.................................................. 43

$2 \quad$ Nonplastic Specimens Used in Correlation Study ...................................... 45

3 Specimens Used in Correlation Study with a

Plasticity Index Ranging Between 0 and $20 \%$.

4 Specimens Used in Correlation Study with a

Plasticity Index More than $20 \%$

5 Specimens Used in Correlation Study for which

no Plasticity Index was Measured..................................................................... 48

6 Boring Logs Used for Identification of Geologic

Formations of Soil Specimens Dynamically

Tested at SRS

$7 \quad$ Listing of All Specimens Considered in Developing

the Correlation for the Dry Branch and Santee Sands.

8 Listing of All Specimens Considered in Developing

the Correlation for the Tobacco Road and Snapp Sands

9 Listing of All Specimens Considered in Developing

the Correlation for Shallow Clays

10 Statistic Associated with the $G / G_{\max }-\log \gamma$

Relationships Determined by RC Testing of the

Dry Branch Sands.

11 Statistic Associated with the $G / G_{\max }-\log \gamma$

Relationships Determined by RC Testing of

the Santee Sands

12 Statistic Associated with the $G / G_{\max }-\log \gamma$

Relationships Determined by RC Testing of the

Dry Branch and Santee Sands.

13 Statistic Associated with the G/G $\max -\log \gamma$

Relationships Determined by RC Testing of the

Tobacco Road Sands 


\section{LIST OF TABLES (continued)}

No.

Title

page

14 Statistic Associated with the G/G $\mathrm{max}-\log \gamma$

Relationships Determined by RC Testing of the

Snapp Sands.

15 Statistic Associated with the $G / G_{\max }-\log \gamma$

Relationships Determined by RC Testing of the

Tobacco and Snapp Sands.

16 Statistic Associated with the $G / G_{\max }-\log \gamma$

Relationships Determined by RC Testing of the

Shallow Clays Sands.

17 Comparison Between the $\mathrm{G} / \mathrm{G}_{\max }-\log \gamma$ Relationships

for the Dry Branch Sands and Santee Sands

18 Comparison Between the $G / G_{\max }-\log \gamma$ Relationships

for the Tobacco Road Sands and Snapp Sands

19 Comparison Between the G/G $\max -\log \gamma$ Relationships

for the Dry Branch and Santee Sands and the Tobacco

Road and Snapp Sands

20 Comparison Between the $G / G_{\max }-\log \gamma$ Relationships

for the Dry Branch and Santee Sands and the Shallow Clays................. 58

21 Influence of Effective Confining Pressure on the G-log $\gamma(a)$,

$\mathrm{G} / \mathrm{G}_{\max }-\log \gamma(\mathrm{b})$ and $\mathrm{D}-\log \gamma$ (c) Relationships Determined

by Resonant Column Testing of a Clay Specimen

from Dry Branch Formation at the Savannah River Site

22 Listing of All Specimens Considered in Developing the

Correlation for Deep Sands

23 Listing of All Specimens Considered in Developing the

Correlation for Deep Clays

24 Statistics Associated with the $G / G_{\max }-\log \gamma$ Relationships

Determined by RC Testing of the Shallow Sands

25 Average Values of $D_{\min }$ and $\gamma_{r}$ from RCTS Testing of the Shallow at SRS

B.1 Initial Properties of Specimens Presented in Appendix B 201 


\section{LIST OF FIGURES}

No.

Title

page

1 Map of the Savannah River Site Showing the General Boring (Well) Locations of All Specimens Used in the Correlation Database

2 Determination of Shear Modulus, G and Material Damping Ratio, D, in Cyclic Loading Tests.

3 Comparison of Typical G $-\log \gamma(\mathrm{a}), \mathrm{G} / \mathrm{G}_{\max }-\log \gamma(\mathrm{b})$ and $\mathrm{D}-\log \gamma$ (c) Curves Determined from the First Cycle of Torsional Testing for Undisturbed Sand and Clay Specimens Confined Similarly

4 Typical Effects on G $-\log \gamma(a), G / G_{\max }-\log \gamma(b)$ and D - $\log \gamma(\mathrm{c})$ Curves of Excitation Frequency and Number of Loading Cycles for an Undisturbed Sand Specimen

$5 \quad$ Typical Effects on G $-\log \gamma(a), G / G_{\max }-\log \gamma(b)$ and D $-\log \gamma(c)$ Curves of Excitation Frequency and Number of Loading Cycles for an Undisturbed Clay Specimen

6 Summary Plot of All G - $\log \gamma$ Relationships

Determined by Resonant Column Testing with the Specimen Confined At or Near the In-Situ Mean Effective Stress

$7 \quad$ Expanded Summary Plot of All G - $\log \gamma$ Relationships

Determined by Resonant Column Testing With the Specimen

Confined At or Near the In-Situ Mean Effective Stress

8 Summary Plot of All G/G $G_{\max }-\log \gamma$ Relationships

Determined by Resonant Column Testing With the

Specimen Confined At or Near the In-Situ Mean

Effective Stress

9 Summary Plot of All D - $\log \gamma$ Relationships Determined

by Resonant Column Testing With the Specimen Confined

At or Near In-Situ Mean Effective Stress

10 General Stratigraphic Profile of the Savannah River Site

72

11 Comparison of the $G-\log \gamma(a), G / G_{\max }-\log \gamma$

(b) and D $-\log \gamma(c)$ Relationships Determined by

Resonant Column Testing of Sand and Clay Specimens

from the Tobacco Road Formation at the Savannah River Site 


\section{LIST OF FIGURES}

No.

Title

page

12 Comparison of the $G-\log \gamma(a), G / G_{\max }-\log \gamma(b)$ and $D-\log \gamma$ (c) Relationships Determined by Resonant Column Testing of Sand and Clay Specimens from the Dry Branch Formation at the Savannah River Site

13 Influence of Effective Confining Pressure on the $G-\log \gamma$

(a), G/G $\max -\log \gamma(b)$ and $D-\log \gamma(c)$ Relationships Determined by Resonant Column Testing of a Sand Specimen from the Tobacco Road Formation at the Savannah River Site

14 Influence of Effective Confining Pressure on the $G-\log \gamma$

(a), G/G $\max -\log \gamma$ (b) and D - $\log \gamma$ (c) Relationships

Determined by Resonant Column Testing of a Clay

Specimen from the Dry Branch Formation at the

Savannah River Site

15 Effects of Excitation Frequency and Number of Loading

Cycles on the G $-\log \gamma(a), G / G_{\max }-\log \gamma(b)$, and D $-\log \gamma$

(c) Relationships Determined by RCTS Testing of a Sand

Specimen from the Tobacco Road Formation at the

Savannah River Site

16 Effects of Excitation Frequency and Number of Loading

Cycles on the $G-\log \gamma(a), G / G_{\max }-\log \gamma(b)$, and $D-\log \gamma$

(c) Relationships Determined by RCTS Testing of a Clay

Specimen from the Dry Branch Formation at the

Savannah River Site

17 Hyperbolic Modeling of Nonlinear Soil Behavior.

79

18 Typical G/G $\max -\log \gamma$ and D - $\log \gamma$ Relationships Determined from a Hyperbolic Model Combined with $D_{\min }$ and $D_{\text {cap }}$ Values

19 Summary Plot of All G/ $\mathrm{G}_{\max }-\log \gamma$ Relationships

Determined by Resonant Column Testing with the Specimens Confined At or Near the In-Situ Mean Effective Stress for the Dry Branch Sands 


\section{LIST OF FIGURES}

No.

Title

page

20 Summary Plot of All G/G $G_{\max }-\log \gamma$ Relationships Determined by Resonant Column Testing with the Specimens Confined At or Near the In-Situ Mean Effective Stress for the Santee Sands

21 Summary Plot of All G/Gmax - $\log \gamma$ Relationships Determined by Resonant Column Testing with the Specimens Confined At or Near the In-Situ Mean Effective Stress for the Dry Branch and Santee Sands

22 Summary Plot of All G - $\log \gamma$ Relationships

Determined by Resonant Column Testing with the Specimens Confined At or Near the In-Situ Mean Effective Stress for the Dry Branch Sands

23 Summary Plot of All G - $\log \gamma$ Relationships

Determined by Resonant Column Testing with the Specimens Confined At or Near the In-Situ Mean Effective Stress for the Santee Sands

24 Summary Plot of All G - $\log \gamma$ Relationships

Determined by Resonant Column Testing with the Specimens Confined At or Near the In-Situ Mean Effective Stress for the Dry Branch and Santee Sands

25 Comparison of the $G / G_{\max }-\log \gamma$ Relationships

Determined by Resonant Column Testing of Sands from the Dry Branch and Santee Formations with the Relationship Recommended by Seed et al. (1986) for Sands

26 Dry Branch and Santee Sands: $G / G_{\max }-\log \gamma$

Relationships Determined by Resonant Column Testing of the CFD Specimens

27 Dry Branch and Santee Sands: G - $\log \gamma$ Relationships

Determined by Resonant Column Testing of the CFD Specimens

28 Dry Branch and Santee Sands: G/G $\max -\log \gamma$ Relationships Determined by Resonant Column Testing of the CFD and ITP Specimens 


\section{LIST OF FIGURES (continued)}

No. Title

29 Dry Branch and Santee Sands: G - $\log \gamma$ Relationships

Determined by Resonant Column Testing of the CFD and ITP Specimens

30 Dry Branch and Santee Sands: $G / G_{\max }-\log \gamma$ Relationships Determined by Resonant Column Testing of the CFD and

NPR Specimens

31 Dry Branch and Santee Sands: $G-\log \gamma$ Relationships

Determined by Resonant Column Testing of the CFD

and NPR Specimens

32 Dry Branch and Santee Sands: $G / G_{\max }-\log \gamma$ Relationships

Determined by Resonant Column Testing of the CFD,

RTF and KRA Specimens

33 Dry Branch and Santee Sands: $G-\log \gamma$ Relationships

Determined by Resonant Column Testing of the CFD,

RTF and KRA Specimens

34 Dry Branch and Santee Sands: $G / G_{\max }-\log \gamma$ Relationships Determined by Resonant Column Testing of the CFD, BGE,

SFS and BNH Specimens.

35 Dry Branch and Santee Sands: G - $\log \gamma$ Relationships

Determined by Resonant Column Testing of the CFD,

$B G E, S F S$ and BNH Specimens

36 Dry Branch and Santee Sands: $G / G_{\max }-\log \gamma$ Relationships

Determined by Resonant Column Testing of the CFD,

PPD and LRA Specimens

37 Dry Branch and Santee Sands: G - $\log \gamma$ Relationships

Determined by Resonant Column Testing of the CFD,

PPD and LRA Specimens

38 Summary Plot of All D - $\log \gamma$ Relationships Determined by Resonant Column Testing with the Specimens Confined At or Near the In-Situ Mean Effective Stress for the Dry Branch and Santee Sands 


\section{LIST OF FIGURES (continued)}

No. Title

39 Dry Branch and Santee Sands: D - $\log \gamma$ Relationships for the CFD Specimens Determined by Resonant Column Testing

$40 \quad$ Dry Branch and Santee Sands: D - $\log \gamma$ Relationships for the CFD and ITP Specimens Determined by Resonant Column Testing 102

41 Dry Branch and Santee Sands: D - $\log \gamma$ Relationships for the CFD and NPR Specimens Determined by Resonant Column Testing 103

42 Dry Branch and Santee Sands: D - $\log \gamma$ Relationships for the CFD, RTF and KRA Specimens Determined by Resonant Column Testing

43 Dry Branch and Santee Sands: D - $\log \gamma$ Relationships for the CFD, BGE, SFS and BNH Specimens Determined by Resonant Column Testing

44 Dry Branch and Santee Sands: D - $\log \gamma$ Relationships for the CFD, PPD and LRA Specimens Determined by Resonant Column Testing 106

45 Comparison of Material Damping Values Determined for the CFD Specimens Using RC and TS Tests;

Dry Branch and Santee Sands

46 Influence of Number of Loading Cycles on Material Damping Values Determined for the CFD Specimens Using TS Tests; Dry Branch and Santee Sands

47 Comparison of the D - $\log \gamma$ Relationships Measured in the Tenth Cycle of TS Testing with an Average Hyperbolic Relationship and Material Damping Cap for the Dry Branch and Santee Sands

48 General Relationship Between $D_{\min }$ and $\gamma_{\mathrm{r}}$ from TS Testing of All Shallow Sand Specimens at SRS

49 Recommended Average Hyperbolic Relationship and Material Damping Cap for the D - $\log \gamma$ Relationship Determined from RCTS Testing of the Dry Branch and Santee Sands 


\section{LIST OF FIGURES (continued)}

No. Title

50 Comparison of the Recommended Average Hyperbolic D - $\log \gamma$ Relationship for the Dry Branch and Santee Sands with the D-log $\gamma$ Relationship Recommended by Seed et al. (1986) for Sands

51 Comparison of the Recommended Average Hyperbolic D - $\log \gamma$ Relationship Determined from RCTS Testing with the Resonant Column Results for the Dry Branch and Santee Sands

52 Summary Plot of All G/G $G_{\max }-\log \gamma$ Relationships Determined by Resonant Column Testing with the Specimens Confined At or Near the In-Situ Mean Effective Stress for the Tobacco Road Sands

53 Summary Plot of All G/ $\mathrm{G}_{\max }-\log \gamma$ Relationships Determined by Resonant Column Testing with the Specimens Confined At or Near the In-Situ Mean Effective Stress for the Snapp Sands

54 Summary Plot of All $G / G_{\max }-\log \gamma$ Relationships Determined by Resonant Column Testing with the Specimens Confined At or Near the In-Situ Mean Effective Stress for the Tobacco Road and Snapp Sands

55 Summary Plot of All G - $\log \gamma$ Relationships Determined by Resonant Column Testing with the Specimens Confined At or Near the In-Situ Mean Effective Stress for the Tobacco Road Sands

56 Summary Plot of All G - $\log \gamma$ Relationships Determined by Resonant Column Testing with the Specimens Confined At or Near the In-Situ Mean Effective Stress for the Snapp Sands

57 Summary Plot of All G - $\log \gamma$ Relationships Determined by Resonant Column Testing with the Specimens Confined At or Near the In-Situ Mean Effective Stress for the Tobacco Road and Snapp Sands 


\section{LIST OF FIGURES (continued)}

No. Title

page

58 Comparison of the $\mathrm{G} / \mathrm{G}_{\max }-\log \gamma$ Relationships Determined

by Resonant Column Testing of Sands from the Tobacco

Road and Snapp Formations with the Relationship Recommended by Seed et al. (1986) for Sands

59 Tobacco Road and Snapp Sands: $G / G_{\max }-\log \gamma$

Relationships Determined by Resonant Column

Testing of the CFD Specimens

60 Tobacco Road and Snapp Sands: G - $\log \gamma$ Relationships

Determined by Resonant Column Testing of the

CFD Specimens

61 Tobacco Road and Snapp Sands: $G / G_{\max }-\log \gamma$

Relationships Determined by Resonant Column Testing

of the CFD, ITP and BNH Specimens

62 Tobacco Road and Snapp Sands: G $-\log \gamma$ Relationships

Determined by Resonant Column Testing of the CFD,

ITP and BNH Specimens

63 Tobacco Road and Snapp Sands: $G / G_{\max }-\log \gamma$

Relationships Determined by Resonant Column

Testing of the CFD and NPR Specimens

64 Tobacco Road and Snapp Sands: G - $\log \gamma$ Relationships

Determined by Resonant Column Testing of the CFD

and NPR Specimens

65 Tobacco Road and Snapp Sands: $G / G_{\max }-\log \gamma$

Relationships Determined by Resonant Column

Testing of the CFD and RTF Specimens

66 Tobacco Road and Snapp Sands: G - $\log \gamma$ Relationships

Determined by Resonant Column Testing of the CFD

and RTF Specimens

67 Tobacco Road and Snapp Sands: $G / G_{\max }-\log \gamma$

Relationships Determined by Resonant Column

Testing of the CFD, SFS, LRA and LPD Specimens 


\section{LIST OF FIGURES (continued)}

No. Title

68 Tobacco Road and Snapp Sands: G - $\log \gamma$ Relationships

Determined by Resonant Column Testing of the CFD,

SFS, LRA and LPD Specimens

69 Summary Plot of All D - $\log \gamma$ Relationships

Determined by Resonant Column Testing with the Specimens Confined At or Near the In-Situ Mean Effective Stress for the Tobacco Road and Snapp Sands

70 Tobacco Road and Snapp: D - $\log \gamma$ Relationships

- for the CFD Specimens Determined by Resonant

Column Testing

71 Tobacco Road and Snapp: D - $\log \gamma$ Relationships for the

CFD, ITP and BNH Specimens Determined by Resonant

Column Testing

72 Tobacco Road and Snapp: D - $\log \gamma$ Relationships for

the CFD and NPR Specimens Determined by Resonant

Column Testing

73 Tobacco Road and Snapp: D - $\log \gamma$ Relationships for the CFD and RTF Specimens Determined by Resonant Column Testing

74 Tobacco Road and Snapp: D - $\log \gamma$ Relationships for the CFD, SFS, LRA and LPD Specimens Determined by Resonant

Column Testing 136

75 Comparison of Material Damping Values Determined for the CFD Specimens Using RC and TS Tests;

Tobacco Road and Snapp Sands

76 Influence of Number of Cycles on Material Damping

Values Determined for the CFD Specimens Using TS

Tests; Tobacco Road and Snapp Sands

77 Comparison of the $\mathrm{D}-\log \gamma$ Relationships Measured in the Tenth Cycle of TS Testing with an Average Hyperbolic Relationship and Material Damping Cap for the Tobacco Road and Snapp Sands 


\section{LIST OF FIGURES (continued)}

No. Title

page

78 Recommended Average Hyperbolic Relationship and Material

Damping Cap for the D - $\log \gamma$ Relationship Determined

from RCTS Testing of the Tobacco Road and Snapp Sands

79 Comparison of the Recommended Average Hyperbolic D - $\log \gamma$

Relationship for the Tobacco Road and Snapp Sands

with The D - $\log \gamma$ Relationship Recommended by Seed et al. (1986)

for Sands

80 Comparison of the Recommended Average Hyperbolic D - $\log \gamma$

Relationship Determined from RCTS Testing with the

Resonant Column Results for the Tobacco Road and

Snapp Sands

81 Summary Plot of All G/Gmax - $\log \gamma$ Relationships

Determined by Resonant Column Testing with the

Specimens Confined At or Near the In-Situ Mean

Effective Stress for the Shallow Clays

82 Summary Plot of All G - $\log \gamma$ Relationships Determined

by Resonant Column Testing with the Specimens

Confined At or Near the In-Situ Mean Effective Stress

for the Shallow Clays

83 Comparison of the $G / G_{\max }-\log \gamma$ Relationships

Determined by Resonant Column Testing of the

Shallow Clays with the Relationship Recommended by

Seed et al. (1986) for Sands

84 Summary Plot of All D - $\log \gamma$ Relationships

Determined by Resonant Column Testing with the

Specimens Confined At or Near the In-Situ Mean

Effective Stress for the Shallow Clays

85 Comparison of the $\mathrm{D}-\log \gamma$ Relationships Measured

in the Tenth Cycle of TS Testing with the Recommended

Average Hyperbolic Relationship and Material

Damping Cap for the Shallow Clays

86 Comparison of the Recommended Average Hyperbolic

D - $\log \gamma$ Relationship for the Shallow Clays with the

Relationship Recommended by Seed et al. (1986) for Sands 


\section{LIST OF FIGURES (continued)}

No. Title

87 Comparison of the Recommended Average Hyperbolic

D - $\log \gamma$ Relationship Determined from RCTS Testing

with the Resonant Column Results for the Shallow Clays

88 Evaluation of the Distribution of $G / G_{\max }$ Values at

$\gamma=0.03 \%$ for the Dry Branch and Santee Sands

89 Evaluation of the Distribution of $G / G_{\max }$ Values at

$\gamma=0.03 \%$ for the Tobacco Road and Snapp Sands

90 Statistical Evaluation of the $G / G_{\max }$ Values for the

Dry Branch Sands

91 Statistical Evaluation of the $G / G_{\max }$ Values for the Santee Sands

92 Statistical Evaluation of the $G / G_{\max }$ Values for the Combined Dry Branch and Santee Sands

93 Statistical Evaluation of the $G / G_{\max }$ Values of the

Tobacco Road Sands

94 Statistical Evaluation of the $G / G_{\max }$ Values of the Snapp Sands

95 Statistical Evaluation of the $G / G_{\max }$ Values for the Combined Tobacco Road and Snapp Sands

96 Statistical Evaluation of the $G / G_{\max }$ Values for the Shallow Clays

97 Summary Plot of All G/G $G_{\max }-\log \gamma_{\text {Relationships }}$

Determined by Resonant Column Testing with the Specimens Confined At or Near the In-Situ Mean

Effective Stress for the Upland Sands

98 Summary Plot of All G - $\log \gamma$ Relationships

Determined by Resonant Column Testing with the

Specimens Confined At or Near the In-Situ Mean

Effective Stress for the Upland Sands 158

SRS-FR-CDP-95, rev. 0, 13 September 95

Project No. AA891070

$x v i$ of $x x x$ 


\section{LIST OF FIGURES (continued)}

No. Title

99 Comparison of the $G / G_{\max }-\log \gamma$ Relationship

Determined by Resonant Column Testing of the Softer Upland Sand Specimen with the Average Recommended Hyperbolic Relationship for Dry Branch and Santee Sands

100 Summary Plot of All D - $\log \gamma$ Relationships

Determined by Resonant Column Testing with

the Specimens Confined At or Near the In-Situ Mean

Effective Stress for the Upland Sands

101 Comparison of the $D-\log \gamma$ Relationships Measured in the Tenth Cycle of TS Testing with the Recommended Average Hyperbolic Relationship for Stiff Upland Sands

102 Summary Plot of All G/G $/ G_{\max }-\log \gamma$ Relationships Determined by Resonant Column Testing with the Specimens Confined At or Near the In-Situ Mean Effective Stress for the Warley Hill Sands

103 Summary Plot of All G - $\log \gamma$ Relationships

Determined by Resonant Column Testing with the Specimens Confined At or Near the In-Situ Mean Effective Stress for the Warley Hill Sands

104 Summary Plot of All D - $\log \gamma$ Relationships

Determined by Resonant Column Testing with the Specimens Confined At or Near the In-Situ Mean Effective Stress for the Warley Hill Sands

105 Comparison of the D - $\log \gamma$ Relationship Measured in the Tenth Cycle of TS Testing for the Warley Hill Specimen with an Average Hyperbolic Relationship Warley Hill Sands and the Recommended Average Hyperbolic Relationship for the Dry Branch 165

106 Comparison of an Average Hyperbolic G/G $G_{\max }-\log \gamma$

Relationship for the Warley Hill Sands with the

Recommended Average Hyperbolic Relationship for the Dry Branch and Santee Sands 


\section{LIST OF FIGURES (continued)}

No. Title

page

107 Plot of the $G / G_{\max }-\log \gamma$ Relationship Determined by Resonant Column Testing with a Specimen Confined At or Near the In-Situ Mean Effective Stress for the Congaree Sand

108 Comparison of the $D-\log \gamma$ Relationship Measured in the Tenth Cycle of TS Testing for the Congaree Specimen with an Average Hyperbolic Relationship for Congaree Sands and with the Recommended Average Hyperbolic Relationship for the Dry Branch and Santee Sands

109 Summary Plot of All G/G $G_{\max }-\log \gamma$ Relationships Determined by RCTS Testing with the Specimens Confined At or Near the In-Situ Mean Effective Stress for the Deep Sands

110 Summary Plot of All G - $\log \gamma$ Relationships Determined by RCTS Testing with the Specimens Confined At or Near the In-Situ Mean Effective Stress for the Deep Sands

111 Summary Plot of All D - $\log \gamma$ Relationships Determined by RCTS Testing with the Specimens Confined At or Near the In-Situ Mean Effective Stress for the Deep Sands

112 Comparison of the $\mathrm{D}-\log \gamma$ Relationship Measured in the Tenth Cycle of TS Testing with an Average Hyperbolic Curve for the Deep Sands 172

113 Summary Plot of All G/Gmax - $\log \gamma$ Relationships Determined by RCTS Testing with the Specimens Confined At or Near the In-Situ Mean Effective Stress for the Deep Clays 173

114 Summary Plot of All G - $\log \gamma$ Relationships Determined by RCTS Testing with the Specimens Confined At or Near the In-Situ Mean Effective Stress for the Deep Clays 174

115 Summary Plot of All D - $\log \gamma$ Relationships Determined by RCTS Testing with the Specimens Confined At or Near the In-Situ Mean Effective Stress for the Deep Clays 


\section{LIST OF FIGURES (continued)}

No. Title

page

116 Comparison of the D - $\log \gamma$ Relationships Measured in the Tenth Cycle of TS Testing with an Average Hyperbolic Curve for the Deep Clays

117 Variation of Reference Strain with Mean Effective Stress Determined from Shallow Sands and Clays

118 Variation of $D_{\min }$ Measured in the Torsional Shear Test with the Estimated In-Situ Mean Effective Stress

119 Predicted G/G $G_{\max }-\log \gamma$ and D - $\log \gamma$ Relationships for Deep Sands at a Depth of $750 \mathrm{ft}(228.6 \mathrm{~m})$ by Extrapolating the Shallow Sands Correction.

120 Predicted G/G $G_{\max }-\log \gamma_{\text {and }} \mathrm{D}-\log \gamma$ Relationships for Deep Clays at a Depth of $750 \mathrm{ft}(228.6 \mathrm{~m})$ by Extrapolating the Shallow Clays Correction

121 Recommended Generic G/G $\max -\log \gamma$ and D - $\log \gamma$

Relationships for Stiff Upland Sands at SRS

122 Recommended Generic G/G $\max -\log \gamma$ and D - $\log \gamma$

Relationships for Tobacco Road and Snapp Sands at SRS

123 Recommended Generic G/G $\max -\log \gamma$ and D - $\log \gamma$

Relationships for Dry Branch, Santee, Warley Hill and Congaree Sands at SRS

124 Recommended Generic G/G max $-\log \gamma$ and D - $\log \gamma$

Relationships for Four Mile Sands and Any Other

Unrepresented Shallow Sand Formation at SRS

125 Recommended Generic G/G $\max -\log \gamma$ and D - $\log \gamma$

Relationships for Shallow Clays at SRS

126 Recommended Generic G/G $\max -\log \gamma$ and D - $\log \gamma$

Relationships for the Deep Sands at SRS

127 Recommended Generic G/G $\max -\log \gamma$ and D $-\log \gamma$

Relationships for the Deep Clays at SRS

SRS-FR-CDP-95, rev. 0, 13 September 95

$x i x$ of $x x x$

Project No. AA891070 


\section{LIST OF FIGURES (continued)}

No. Title

page

128 Summary Plot of the Average Recommended D - $\log \gamma$

Relationships for Soils at the Savannah River Site.

188

129 Summary Plot of the Average Recommended $G / G_{\max }-\log \gamma$

Relationships for Soils at the Savannah River Site.

A.1 Dry Branch and Santee Sands: $G / G_{\max }-\log \gamma$ Relationships

Deleted from the Correlation

A.2 Dry Branch and Santee Sands: G-log $\gamma$ Relationships

Deleted from the Correlation

A.3 Dry Branch and Santee Sands: D- $\log \gamma$ Relationships

Deleted from the Correlation

A.4 Tobacco Road and Snapp Sands: $G / G_{\max }-\log \gamma$

Relationships Deleted From the Correlation 04

A.5 Tobacco Road and Snapp Sands: G-log $\gamma$ Relationships

Deleted From the Correlation

A.6 Tobacco Road and Snapp Sands: D-log $\gamma$ Relationships

Deleted From the Correlation

A.7 Deep Sands: G/Gmax-log $\gamma$ Relationships Deleted From the Correlation

A.8 Deep Sands: G-log $\gamma$ Relationships Deleted From the Correlation ..... 198

A.9 Deep Sands: D-log $\gamma$ Relationships Deleted From the Correlation...... 199

B.1 Variation in Shear Modulus with Shearing Strain at an Effective Confining Pressure of 6 psi $(=864 \mathrm{psf}=41 \mathrm{kPa})$ from RCTS Tests of Sample T1 202

B.2 Variation in Normalized Shear Modulus with Shearing Strain at an Effective Confining Pressure of

$6 \mathrm{psi}(=864 \mathrm{psf}=41 \mathrm{kPa})$ from RCTS Tests of Sample T1 203

B.3 Variation in Material Damping Ratio with Shearing Strain at an Effective Confining Pressure of $6 \mathrm{psi}(=864 \mathrm{psf}=41 \mathrm{kPa})$ from RCTS Tests of Sample T1 


\section{LIST OF FIGURES (continued)}

No. Title

page

B.4 Variation in Shear Modulus with Shearing Strain and Effective Confining Pressure from Resonant Column Tests of Sample T1

B.5 Comparison of the Variation in Normalized Shear Modulus with Shearing Strain and Effective Confining Pressure from Resonant Column Tests of Sample T1

B.6 Variation in Material Damping Ratio with Shearing Strain and Effective Confining Pressure from Resonant Column Tests of Sample T1

B.7 Variation in Shear Modulus with Shearing Strain at an Effective Confining Pressure of $10 \mathrm{psi}(=1.44 \mathrm{ksf}=69 \mathrm{kPa})$ from RCTS Tests of Sample T2

B.8 Variation in Normalized Shear Modulus with Shearing Strain at an Effective Confining Pressure of 10 psi $(=1.44 \mathrm{ksf}=69 \mathrm{kPa})$ from RCTS Tests of Sample T2

B.9 Variation in Material Damping Ratio with Shearing Strain at an Effective Confining Pressure of 10 psi $(=1.44 \mathrm{ksf}=69 \mathrm{kPa})$ from RCTS Tests of Sample T2

B.10 Variation in Shear Modulus with Shearing Strain and Effective Confining Pressure from Resonant Column Tests of Sample T2

B.11 Comparison of the Variation in Normalized Shear Modulus with Shearing Strain and Effective Confining Pressure from Resonant Column Tests of Sample T2

B.12 Variation in Material Damping Ratio with Shearing Strain and Effective Confining Pressure from Resonant Column Tests of Sample T2

B.13 Variation in Shear Modulus with Shearing Strain at an Effective Confining Pressure of $18 \mathrm{psi}(=2.59 \mathrm{ksf}=124 \mathrm{kPa})$ from RCTS Tests of Sample T3 


\section{LIST OF FIGURES (continued)}

No. Title

page

B.14 Variation in Normalized Shear Modulus with

Shearing Strain at an Effective Confining Pressure of

$18 \mathrm{psi}(=2.59 \mathrm{ksf}=124 \mathrm{kPa})$ from RCTS Tests of Sample T3

B.15 Variation in Material Damping Ratio with Shearing

Strain at an Effective Confining Pressure of

$18 \mathrm{psi}(=2.59 \mathrm{ksf}=124 \mathrm{kPa})$ from RCTS Tests of Sample T3

B.16 Variation in Shear Modulus with Shearing Strain and Effective Confining Pressure from Resonant

Column Tests of Sample T3

B.17 Comparison of the Variation in Normalized Shear Modulus with Shearing Strain and Effective Confining

Pressure from Resonant Column Tests of Sample T3

B.18 Variation in Material Damping Ratio with Shearing Strain and Effective Confining Pressure from Resonant Column Tests of Sample T3

B.19 Variation in Shear Modulus with Shearing Strain at an Effective Confining Pressure of $12 \mathrm{psi}(=1.73 \mathrm{ksf}=83 \mathrm{kPa})$ from RCTS Tests of Sample G2-1

B.20 Variation in Normalized Shear Modulus with Shearing

Strain at an Effective Confining Pressure of $12 \mathrm{psi}(=1.73 \mathrm{ksf}=83 \mathrm{kPa})$ from RCTS Tests of Sample G2-1

B.21 Variation in Material Damping Ratio with Shearing Strain at an Effective Confining Pressure of 12 psi $(=1.73 \mathrm{ksf}=83 \mathrm{kPa})$ from RCTS Tests of Sample G2-1 222

B.22 Variation in Shear Modulus with Shearing Strain and Effective Confining Pressure from Resonant Column Tests of Sample G2-1

B.23 Comparison of the Variation in Normalized Shear Modulus with Shearing Strain and Effective Confining Pressure from Resonant Column Tests of Sample G2-1 224

B.24 Variation in Material Damping Ratio with Shearing Strain and Effective Confining Pressure from Resonant Column Tests of Sample G2-1 225 


\section{LIST OF FIGURES (continued)}

No. Title

B.25 Variation in Shear Modulus with Shearing Strain at an Effective Confining Pressure of $48 \mathrm{psi}(=6.91 \mathrm{ksf}=331 \mathrm{kPa})$ from RCTS Tests of Sample G5-1

B.26 Variation in Normalized Shear Modulus with Shearing Strain at an Effective Confining Pressure of $48 \mathrm{psi}(=6.91 \mathrm{ksf}=331 \mathrm{kPa})$ from RCTS Tests of Sample G5-1

B.27 Variation in Material Damping Ratio with Shearing Strain at an Effective Confining Pressure of $48 \mathrm{psi}(=6.91 \mathrm{ksf}=331 \mathrm{kPa})$ from RCTS Tests of Sample G5-1

B.28 Variation in Shear Modulus with Shearing Strain and Effective Confining Pressure from Resonant Column Tests of Sample G5-1

B.29 Comparison of the Variation in Normalized Shear Modulus with Shearing Strain and Effective Confining Pressure from Resonant Column Tests of Sample G5-1

B.30 Variation in Material Damping Ratio with Shearing Strain and Effective Confining Pressure from Resonant Column Tests of Sample G5-1

B.31 Variation in Shear Modulus with Shearing Strain at an Effective Confining Pressure of $400 \mathrm{psi}(=57.6 \mathrm{ksf}=2.76 \mathrm{MPa})$ from RCTS Tests of Sample HQ-146 232

B.32 Variation in Normalized Shear Modulus with Shearing Strain at an Effective Confining Pressure of $400 \mathrm{psi}(=57.6 \mathrm{ksf}=2.76 \mathrm{MPa})$ from RCTS Tests of Sample HQ-146 233

B.33 Variation in Material Damping Ratio with Shearing Strain at an Effective Confining Pressure of $400 \mathrm{psi}(=57.6 \mathrm{ksf}=2.76 \mathrm{MPa})$ from RCTS Tests of Sample HQ-146

C.1 Variation in Shear Modulus with Shearing Strain at an Effective Confining Pressure of $31 \mathrm{psi}$ $(=4.46 \mathrm{ksf}=214 \mathrm{kPa})$ from RCTS Tests of Specimen CFD-4a 236 


\section{LIST OF FIGURES (continued)}

No. Title

page

C.2 Variation in Normalized Shear Modulus with Shearing Strain at an Effective Confining Pressure of 31 psi $(=4.46 \mathrm{ksf}=214 \mathrm{kPa})$ from RCTS Tests of Specimen CFD-4a

C.3 Variation in Material Damping Ratio with Shearing Strain at an Effective Confining Pressure of 31 psi $(=4.46 \mathrm{ksf}=214 \mathrm{kPa})$ from RCTS Tests of Specimen CFD-4a

C.4 Variation in Shear Modulus with Shearing Strain and Effective Confining Pressure from Resonant Column Tests of Specimen CFD-4a

C.5 Comparison of the Variation in Normalized Shear Modulus with Shearing Strain and Effective Confining Pressure from Resonant Column Tests of Specimen CFD-4a

C.6 Variation in Material Damping Ratio with Shearing Strain and Effective Confining Pressure from Resonant Column Tests of Specimen CFD-4a

C.7 Variation in Shear Modulus with Shearing Strain at an Effective Confining Pressure of $35 \mathrm{psi}(=5.04 \mathrm{ksf}=241 \mathrm{kPa})$ from RCTS Tests of Specimen CFD-5a

C.8 Variation in Normalized Shear Modulus with Shearing Strain at an Effective Confining Pressure of 35 psi $(=5.04 \mathrm{ksf}=241 \mathrm{kPa})$ from RCTS Tests of Specimen CFD-5a 243

C.9 Variation in Material Damping Ratio with Shearing Strain at an Effective Confining Pressure of 35 psi $(=5.04 \mathrm{ksf}=241 \mathrm{kPa})$ from RCTS Tests of Specimen CFD-5a

C.10 Variation in Shear Modulus with Shearing Strain at an Effective Confining Pressure of $46 \mathrm{psi}(=6.62 \mathrm{ksf}=317 \mathrm{kPa})$ from RCTS Tests of Specimen CFD-7a

C.11 Variation in Normalized Shear Modulus with Shearing Strain at an Effective Confining Pressure of 46 psi $(=6.62 \mathrm{ksf}=317 \mathrm{kPa})$ from RCTS Tests of Specimen CFD-7a 


\section{LIST OF FIGURES (continued)}

No. Title

C.12 Variation in Material Damping Ratio with Shearing Strain at an Effective Confining Pressure of 46 psi $(=6.62 \mathrm{ksf}=317 \mathrm{kPa}$ ) from RCTS Tests of Specimen CFD-7a

D.1 Variation in Shear Modulus with Shearing Strain at an Effective Confining Pressure of 23 psi $(=3.31 \mathrm{ksf}=159 \mathrm{kPa})$ from RCTS Tests of Specimen CFD-3b

D.2 Variation in Normalized Shear Modulus with Shearing Strain at an Effective Confining Pressure of 23 psi $(=3.31 \mathrm{ksf}=159 \mathrm{kPa})$ from RCTS Tests of Specimen CFD-3b

D.3 Variation in Material Damping Ratio with Shearing Strain at an Effective Confining Pressure of 23 psi ( $=3.31 \mathrm{ksf}=159 \mathrm{kPa})$ from RCTS Tests of Specimen CFD-3b

D.4 Variation in Shear Modulus with Shearing Strain and Effective Confining Pressure from Resonant Column Tests of Specimen CFD-3b

D.5 Comparison of the Variation in Normalized Shear Modulus with Shearing Strain and Effective Confining Pressure from Resonant Column Tests of Specimen CFD-3b

D.6 Variation in Material Damping Ratio with Shearing Strain and Effective Confining Pressure from Resonant Column Tests of Specimen CFD-3b

D.7 Variation in Shear Modulus with Shearing Strain at an Effective Confining Pressure of $87 \mathrm{psi}(=12.52 \mathrm{ksf}=600 \mathrm{kPa}) 241$ from RCTS Tests of Specimen CFD-12a

D.8 Variation in Normalized Shear Modulus with Shearing Strain at an Effective Confining Pressure of $87 \mathrm{psi}$ $(=12.52 \mathrm{ksf}=600 \mathrm{kPa})$ from RCTS Tests of Specimen CFD-12a

D.9 Variation in Material Damping Ratio with Shearing Strain at an Effective Confining Pressure of $87 \mathrm{psi}$ $(=12.52 \mathrm{ksf}=600 \mathrm{kPa})$ from RCTS Tests of Specimen CFD-12a 


\section{LIST OF FIGURES (continued)}

No. Title page

D.10 Variation in Shear Modulus with Shearing Strain and Effective Confining Pressure from Resonant Column Tests of Specimen CFD-12a

D.11 Comparison of the Variation in Normalized Shear Modulus with Shearing Strain and Effective Confining Pressure from Resonant Column Tests of Specimen CFD-12a

D.12 Variation in Material Damping Ratio with Shearing Strain and Effective Confining Pressure from Resonant Column Tests of Specimen CFD-12a

D.13 Variation in Shear Modulus with Shearing Strain at an Effective Confining Pressure of $93 \mathrm{psi}(=13.39 \mathrm{ksf}=641 \mathrm{kPa})$ from RCTS Tests of Specimen CFD-13a

D.14 Variation in Normalized Shear Modulus with Shearing Strain at an Effective Confining Pressure of 93 psi $(=13.39 \mathrm{ksf}=641 \mathrm{kPa})$ from RCTS Tests of Specimen CFD-13a

D.15 Variation in Material Damping Ratio with Shearing Strain at an Effective Confining Pressure of 93 psi $(=13.39 \mathrm{ksf}=641 \mathrm{kPa})$ from RCTS Tests of Specimen CFD-13a

E.1 Variation in Shear Modulus with Shearing Strain at an Effective Confining Pressure of $41 \mathrm{psi}(=5.90 \mathrm{ksf}=283 \mathrm{kPa})$ from RCTS Tests of Specimen CFD-6a

E.2 Variation in Normalized Shear Modulus with Shearing Strain at an Effective Confining Pressure of $41 \mathrm{psi}$ $(=5.90 \mathrm{ksf}=283 \mathrm{kPa})$ from RCTS Tests of Specimen CFD-6a

E.3 Variation in Material Damping Ratio with Shearing Strain at an Effective Confining Pressure of $41 \mathrm{psi}$ $(=5.90 \mathrm{ksf}=283 \mathrm{kPa})$ from RCTS Tests of Specimen CFD-6a

E.4 Variation in Shear Modulus with Shearing Strain and Effective Confining Pressure from Resonant Column Tests of Specimen CFD-6a 


\section{LIST OF FIGURES (continued)}

No. Title

page

E.5 Comparison of the Variation in Normalized Shear Modulus with Shearing Strain and Effective Confining Pressure from Resonant Column Tests of Specimen CFD-6a

E.6 Variation in Material Damping Ratio with Shearing Strain and Effective Confining Pressure from Resonant Column Tests of Specimen CFD-6a

E.7 Variation in Shear Modulus with Shearing Strain at an Effective Confining Pressure of 111 psi $(=15.98 \mathrm{ksf}$ $=765 \mathrm{kPa}$ ) from RCTS Tests of Specimen CFD-T1a

E.8 Variation in Normalized Shear Modulus with Shearing Strain at an Effective Confining Pressure of $111 \mathrm{psi}$ $(=15.98 \mathrm{ksf}=765 \mathrm{kPa})$ from RCTS Tests of Specimen CFD-T1a

E.9 Variation in Material Damping Ratio with Shearing Strain at an Effective Confining Pressure of 111 psi $(=15.98 \mathrm{ksf}=765 \mathrm{kPa})$ from RCTS Tests of Specimen CFD-T1a

E.10 Variation in Shear Modulus with Shearing Strain and Effective Confining Pressure from Resonant Column Tests of Specimen CFD-T1a

E.11 Comparison of the Variation in Normalized Shear Modulus with Shearing Strain and Effective Confining Pressure from Resonant Column Tests of Specimen CFD-T1a 275

E.12 Variation in Material Damping Ratio with Shearing Strain and Effective Confining Pressure from Resonant Column Tests of Specimen CFD-T1a

F.1 Variation in Shear Modulus with Shearing Strain at an Effective Confining Pressure of $6 \mathrm{psi}(=864 \mathrm{psf}=41 \mathrm{kPa})$ from RCTS Tests of Specimen CFD-1a

F.2 Variation in Normalized Shear Modulus with Shearing Strain at an Effective Confining Pressure of 6 psi $(=864 \mathrm{psf}=41 \mathrm{kPa})$ from RCTS Tests of Specimen CFD-1a 279 


\section{LIST OF FIGURES (continued)}

No. Title

page

F.3 Variation in Material Damping Ratio with Shearing Strain at an Effective Confining Pressure of 6 psi $(=864 \mathrm{psf}=41 \mathrm{kPa})$ from RCTS Tests of Specimen CFD-1a

F.4 Variation in Shear Modulus with Shearing Strain and Effective Confining Pressure from Resonant Column Tests of Specimen CFD-1a

F.5 Comparison of the Variation in Normalized Shear Modulus with Shearing Strain and Effective Confining Pressure from Resonant Column Tests of Specimen CFD-1a

F.6 Variation in Material Damping Ratio with Shearing Strain and Effective Confining Pressure from Resonant Column Tests of Specimen CFD-1a

F.7 Variation in Shear Modulus with Shearing Strain at an Effective Confining Pressure of $13 \mathrm{psi}(=1.87 \mathrm{ksf}=90 \mathrm{kPa})$ from RCTS Tests of Specimen CFD-2a

F.8 Variation in Normalized Shear Modulus with Shearing Strain at an Effective Confining Pressure of 13 psi $(=1.87 \mathrm{ksf}=90 \mathrm{kPa})$ from RCTS Tests of Specimen CFD-2a 285

F.9 Variation in Material Damping Ratio with Shearing Strain at an Effective Confining Pressure of 13 psi $(=1.87 \mathrm{ksf}=90 \mathrm{kPa})$ from RCTS Tests of Specimen CFD-2a

F.10 Variation in Shear Modulus with Shearing Strain and Effective Confining Pressure from Resonant Column Tests of Specimen CFD-2a

F.11 Comparison of the Variation in Normalized Shear Modulus with Shearing Strain and Effective Confining Pressure from Resonant Column Tests of Specimen CFD-2a

F.12 Variation in Material Damping Ratio with Shearing Strain and Effective Confining Pressure from Resonant Column Tests of Specimen CFD-2a 


\section{LIST OF FIGURES (continued)}

No. Title

page

G.1 Variation in Shear Modulus with Shearing Strain at an Effective Confining Pressure of $59 \mathrm{psi}(=8.49 \mathrm{ksf}=407 \mathrm{kPa})$ from RCTS Tests of Specimen CFD-8a

G.2 Variation in Normalized Shear Modulus with Shearing Strain at an Effective Confining Pressure of 59 psi $(=8.49 \mathrm{ksf}=407 \mathrm{kPa})$ from RCTS Tests of Specimen CFD-8a

G.3 Variation in Material Damping Ratio with Shearing Strain at an Effective Confining Pressure of 59 psi $(=8.49 \mathrm{ksf}=407 \mathrm{kPa})$ from RCTS Tests of Specimen CFD-8a

G.4 Variation in Shear Modulus with Shearing Strain and Effective Confining Pressure from Resonant Column Tests of Specimen CFD-8a

G.5 Comparison of the Variation in Normalized Shear Modulus with Shearing Strain and Effective Confining Pressure from Resonant Column Tests of Specimen CFD-8a

G.6 Variation in Material Damping Ratio with Shearing Strain and Effective Confining Pressure from Resonant Column Tests of Specimen CFD-8a

H.1 Variation in Shear Modulus with Shearing Strain at an Effective Confining Pressure of $68 \mathrm{psi}(=9.79 \mathrm{ksf}=469 \mathrm{kPa})$ from RCTS Tests of Specimen CFD-11a

H.2 Variation in Normalized Shear Modulus with Shearing Strain at an Effective Confining Pressure of 68 psi $(=9.79 \mathrm{ksf}=469 \mathrm{kPa})$ from RCTS Tests of Specimen CFD-11a

H.3 Variation in Material Damping Ratio with Shearing Strain at an Effective Confining Pressure of $68 \mathrm{psi}$ $(=9.79 \mathrm{ksf}=469 \mathrm{kPa})$ from RCTS Tests of Specimen CFD-11a 300

I.1 Variation in Shear Modulus with Shearing Strain at an Effective Confining Pressure of $247 \mathrm{psi}(=35.56 \mathrm{ksf}=1.70 \mathrm{MPa})$ from RCTS Tests of Specimen CFD-T6c 302 


\section{LIST OF FIGURES (continued)}

No. Title

I.2 Variation in Normalized Shear Modulus with Shearing Strain at an Effective Confining Pressure of $247 \mathrm{psi}$ ( $=35.56 \mathrm{ksf}=1.70 \mathrm{MPa}$ ) from RCTS Tests of Specimen CFD-T6c

I.3 Variation in Material Damping Ratio with Shearing Strain at an Effective Confining Pressure of 247 psi ( $=35.56 \mathrm{ksf}=1.70 \mathrm{MPa}$ ) from RCTS Tests of Specimen CFD-T6c

J.1 Variation in Shear Modulus with Shearing Strain at an Effective Confining Pressure of 191 psi ( $=27.50 \mathrm{ksf}=1.32 \mathrm{MPa})$ from RCTS Tests of Specimen CFD-T4a

J.2 Variation in Normalized Shear Modulus with Shearing Strain at an Effective Confining Pressure of $191 \mathrm{psi}$ (=27.50 ksf $=1.32 \mathrm{MPa})$ from RCTS Tests of Specimen CFD-T4a

J.3 Variation in Material Damping Ratio with Shearing Strain at an Effective Confining Pressure of 191 psi $(=27.50 \mathrm{ksf}=1.32 \mathrm{MPa}$ ) from RCTS Tests of Specimen CFD-T4a

J.4 Variation in Shear Modulus with Shearing Strain at an Effective Confining Pressure of $215 \mathrm{psi}(=30.95 \mathrm{ksf}=1.48 \mathrm{MPa})$ from RCTS Tests of Specimen CFD-T5b

J.5 Variation in Normalized Shear Modulus with Shearing Strain at an Effective Confining Pressure of 215 psi ( $=30.95 \mathrm{ksf}=1.48 \mathrm{MPa}$ ) from RCTS Tests of Specimen CFD-T5b

J.6 Variation in Material Damping Ratio with Shearing Strain at an Effective Confining Pressure of 215 psi $(=30.95 \mathrm{ksf}=1.48 \mathrm{MPa})$ from RCTS Tests of Specimen CFD-T5b 


\section{CORRELATION STUDY OF NONLINEAR DYNAMIC SOIL PROPERTIES AT THE SAVANNAH RIVER SITE}

\section{Introduction}

This report documents studies conducted by the University of Texas at Austin (UTA) to investigate possible correlations between coastal plain soils and nonlinear dynamic properties of intact natural soils at the Savannah River Site (SRS). The study incorporates nonlinear dynamic soil properties measured in an on-going laboratory investigation conducted by 'UTA (Hwang et al. (1995)) for the Westinghouse Savannah River Corporation (WSRC) with similar results from prior dynamic and cyclic laboratory soil tests performed by other organizations with intact samples obtained from SRS (Stokoe et al., 1995). The UTA correlation study involved reviewing a total of 29 reports from 17 different areas at SRS. These reports are listed in Table 1. The areas (and associated three-letter acronyms) from which data were obtained are:

1: Pen Branch Fault Confirmatory Drilling (CFD),

2. H-Area, In-Tank Precipitation Facility (ITP),

3. H-Area, Replacement Tritium Facility (RTF),

4. New Production Reactor (NPR),

5. Par Pond Dam (PPD),

6. K-Reactor Area (KRA),

7. Burial Ground Expansion (BGE),

8. L-Reactor Area (LRA),

9. L-Area Cooling Pond Dam (LPD),

10. F-Area, Sand Filter Structure (SFS) and

11. H-Area, Building 221-H (B221H).

These 11 areas can be divided into 8 general locations around SRS as shown in Fig. 1. The remaining areas which are discussed in the reports, but from which no data were obtained, are:

1. Replacement High Level Waste Evaporator (RWE),

2. New Waste Transfer Facility (NWT),

3. Gravity Drain Lines In Areas 100-C, 100-K, and 100-P (GDL), 

4. 200-S Area, Defense Waste Processing Facility (DWP),
5. 200-B Area, Away From Reactor Spent Fuel Storage Facility (AFR) and
6. 200-H and 200-F Areas, Radioactive Waste Storage Tanks (RWS).

No data were obtained from these areas because the test results were either limited to field seismic measurements and/or the laboratory results required additional analyses to validate and interpret which were beyond the scope of this study as discussed in Section 2.

Critical assessments were made to establish allowable subsets of the nonlinear dynamic soil properties from the 11 areas considered in the correlation study. The purpose of this report is to provide the key information necessary to select "best estimates" and "ranges" of strain-dependent shear modulus and material damping relationships for intact natural soils at SRS. In the final analysis, the straindependent relationships are correlated with a two-descriptor soil type that is stratigraphically defined by geologic formation and geotechnically defined by soil description.

\subsection{Typical Nonlinear Behavior Exhibited by Soils}

Since the thrust of this correlation study deals with nonlinear dynamic soil . properties, a brief overview of typical nonlinear behavior is initially presented. The terms and parameters used to express nonlinear soil behavior and a framework of expected trends from previous laboratory studies are presented. The emphasis in the overview is placed on the response of intact natural soils to earthquake excitation. In this case, the dynamic properties are generally expressed as shear modulus, $G$, and material damping ratio, $D$. These properties are defined as illustrated in Fig. 2 with a hysteresis loop that is generated by loading the soil specimen with complete stress reversals, commonly referred to as two-way cyclic loading.

In this overview and in the correlation study, it is assumed that intact soil specimens are being tested at representative values of void ratio, e, effective state of stress, $\sigma^{\prime}$, and degree of saturation, $S_{\boldsymbol{t}}$ under undrained loading conditions. The key variables are then soil type (including gradational, plasticity and geological characteristics), strain amplitude, $\gamma$, number of cycles of loading, $N$, and excitation frequency, f. Soil type is discussed more extensively in the correlation study, but for 
now, soil type is simply divided into "sands" and "clays." Sands are assumed to be coarse-grained soils with no plasticity, and clays are assumed to be fine-grained soils with plasticity.

Typical nonlinear behavior exhibited by sands and clays is presented in Fig. 3 in terms of $G-\log \gamma, G / G_{\max }-\log \gamma$ and $D-\log \gamma$ relationships. In this case, testing was performed with $f=0.5 \mathrm{~Hz}$ and $N=1$ in a torsional shear test (Hwang et al., 1995) so that $f$ and $N$ can be eliminated as variables. The results show that both $G$ and $D$ remain essentially constant below some threshold strain. The threshold strain is denoted as the elastic threshold, $\gamma_{t}^{e}$, and the constant values of $G$ and $D$ below $\gamma_{t}^{e}$ are denoted as $G_{\max }$ and $D_{\min }$, respectively. The constant value of $G$ below $\gamma_{t}^{e}$ is easy to see in the normalized modulus, $G / G_{\max }$, versus $\log \gamma$ curve. Once the strain amplitude exceeds $\gamma_{t}^{e}, G$ and $G / G_{\max }$ decrease and $D$ increases as $\gamma$ increases. In these comparisons, the relative value of $G$ between sands and clays is very site dependent and is not considered herein. Therefore, the key nonlinear curves are $G / G_{\max }-\log \gamma$ and $D-\log \gamma$. As shown in Figs. $3 b$ and $3 c$, the dynamic response of sands relative to clays for $N=1$ and $f \leq 1$ can be summarized as:

1. sands exhibit a lower $\gamma_{t}^{e}$ than clays with $\gamma_{t}^{e}$ for sands is often around $0.001 \%$,

2. Sands exhibit a lower value of $G / G_{\max }$ at $\gamma>\gamma_{t}^{e}$ than clays for measurements performed at the samie $\gamma$,

3. sands exhibit a lower value of $D_{\min }$ than clays, with $D_{\min }$ for sands often in the range of 0.5 to $1.5 \%$,

4. sands exhibit a more rapid increase in $D$ than clays at $\gamma>\gamma_{t}^{e}$, and

5. sands generally exhibit a larger value of $D$ than clays at strains above several $0.01 \%$ 's.

The effects of excitation frequency, $f$, and number of cycles of loading, $N$, are important parameters in the evaluation of nonlinear-dynamic soil properties as soon as $\mathrm{N}>1$ and $\mathrm{f}>1 \mathrm{~Hz}$. The effects of these parameters can be especially important when comparing modulus and damping values measured in slow cyclic tests ( $\leq 1 \mathrm{~Hz}$ ) and dynamic tests ( $f$ typically $\geq 10 \mathrm{~Hz}$ ) as done on this project. The effects of $f$ and $N$ on $G$ and $D$ is shown in Figs. 4 and 5 for sands and clays, respectively. 
The effects on natural sands of $f$ and $N$ can be summarized as follows:

1. the effect of increasing $f$ is to increase $G_{\max }$ and increase $D_{\min }$ with this effect being more significant on $D_{\min }$ than $G_{\max }$,

2. the values of $G_{\max }$ and $D_{\min }$ are not affected by $N$ for cyclic loading below $\gamma_{t}^{e}$.

3. another strain threshold exists, termed the cyclic threshold and denoted as $\gamma_{t}^{c}$ above which $\mathrm{N}$ has a significant effect on the values of $G$ and $D$ because of volume changes caused by $N$ in unsaturated sand and pore.pressure generation caused by $\mathrm{N}$ in saturated sands,

4. $\gamma_{t}^{c}>\gamma_{t}^{e}$ and $\gamma_{t}^{c}$ may be different for $G$ than $D$, with values of $G$ greater than or equal to $\gamma_{t}^{c}$ for $D$,

5. the effect of $N$ on unsaturated sands is to increase $G$ and decrease $\mathrm{D}$ at $\gamma>\gamma_{t}^{\mathrm{c}}$, and

6. the effect of $\mathrm{N}$ in saturated sands is directly related to pore pressure generation and effective confinement, with $G$ decreasing and $D$ increasing as the effective stress decreases.

The effects of $f$ and $N$ on the nonlinear dynamic properties of natural clays can be summarized as follows:

1. the effect of increasing $f$ above $1 \mathrm{~Hz}$ on $G_{\max }$ and $D_{\min }$ is to increase their values in a similar, but more significant manner, than sands,

2. as with sands, the values of $G_{\max }$ and $D_{\min }$ are not affected by $N$ for cyclic loading below $\gamma_{t}^{e}$,

3. as with sands, a cyclic strain threshold, $\gamma_{t}^{c}$, exists above which the values of $G$ and $D$ increase with increasing numbers of loading cycles, and

4. the value of $\mathrm{D}$ determined in the first cycle of loading at all strain amplitudes (with most testing performed at $\gamma \leq 0.3 \%$ ) being less than the value of $D$ determined at the same $\gamma$ in the resonant column $(\mathrm{RC})$ test. 


\section{Laboratory Results Included in the Correlation Database}

The review by UTA of the dynamic and cyclic laboratory data presented in the reports listed in Table 1 is given in Stokoe et al., 1995. Based on this review, it was found that most of the $G / G_{\max }-\log \gamma$ relationships determined by resonant column (RC) and torsional shear (TS) testing could be taken directly from the reports for use in the correlation study. However, the $\mathrm{D}-\log \gamma$ relationships determined by RC testing had to be modified using TS results to account, primarily, for the effects of excitation frequency at small strains and for the combined effects of excitation frequency and number of loading cycles at larger strains $\left(\gamma>10^{-2} \%\right)$ as discussed in Section 1.1. In terms of cyclic triaxial data, these results required more extensive investigation of the raw data (hysteresis loops) before they could be incorporated into the database due to equipment-related complications (piston friction and topcap lifting) in some of the hysteresis loops as discussed in Stokoe et al., 1995. The effort required to review the hysteresis loops and re-evaluate some of the data to establish the validity of the results was beyond the scope of this work. Therefore, the database used to investigate correlations is comprised of the results from RC tests with 72 specimens and companion TS tests with 15 of these 72 specimens.

\subsection{Summary Listings of All Specimens}

All specimens considered in the study are listed in Tables 2 through 5 . The specimens can be subdivided into the following categories: 24 nonplastic specimens . (Table 2), 14 specimens with a plasticity index (PI) greater than zero but less than 20 $\%$ (Table 3), 12 specimens with a PI equal to or greater than $20 \%$ (Table 4), and 22 specimens for which the PI was not determined (Table 5). In addition to the index properties, information in Tables 2 through 5 includes geologic formation, soil type (according to the Unified Soil Classification System), and the estimated in-situ values of the total vertical stress, pore water pressure, coefficient of effective horizontal earth pressure at rest and estimated mean effective stress. Information on the complete profile of geologic formations in the soil column determined from five deep borings is presented in Table 6.

It should be noted that, for the purpose of completeness, resonant column tests were performed on 87 specimens as listed in Table 1. However, only 72 specimens were incorporated into the database. The results from 15 specimens were 
not added in the database for the following reasons. Specimens ITP-HBOR29-2B and ITP-HBOR29-4A were fill materials, and specimen BGE-B45-BS1 was a reconstituted specimen. Therefore, these three specimens are not representative of intact natural soils. The results from the 10 specimens presented in D'Appolonia (1982) were only presented in graphical form, and conversion of these data to digital form was not within the scope of the project. Finally, the results from two specimens in Hwang et al. (1995) were incomplete because testing had to be prematurely stopped due to the rupturing of the membrane on sharp particles on the sides of the specimens.

\subsection{Summary Plots of All Dynamic Measurements}

Summary plots of all dynamic measurements for the 72 specimens are presented in Figs. 6 through 9 for the $G-\log \gamma$, expanded $G-\log \gamma, G / G_{\max }-\log \gamma$ and $D-\log \gamma$ relationships, respectively. In some studies, stage testing at multiple confining pressures was conducted. Only measurements that were performed at the confining pressure closest to the estimated in-situ mean effective stress are presented in Figs. 6 through 9. As seen in the figures, the data cover a wide range in each figure and clearly need to be subdivided if possible correlations are to be identified.

\section{Variables Considered in Developing Correlations}

Variables incorporating geotechnical characteristics, geologic considerations, and testing conditions were considered in the correlation study. To allow the geologic setting at SRS to be considered, WSRC personnel identified stratigraphic profiles at each boring from which samples were recovered. A general profile, taken for boring CFD18, is presented in Fig. 10. This profile is presented to show the geologic formations that exist at the site and their relative stratigraphic position. The number of test specimens in the correlation database which are associated with each geologic formation is also shown in Fig. 10. Finally, since the relative location of the specimens across the site was considered in the correlation study, a map of SRS is presented in Fig. 1 showing the locations of all borings (wells) used to recover specimens that form the database.

\subsection{Geotechnical and Geologic Variables}

The following variables, which are based on the geotechnical characteristics of the specimens and the geologic setting at SRS, were considered: 
1. soil type,

2. plasticity index (PI),

3. fines content,

4. small-strain stiffness $\left(G_{\max }\right)$,

5. state of stress,

6. specimen depth,

7. boring (site) location,

8. geologic age, and

9. geologic formation.

To illustrate the general effects of variables associated with the geotechnical characteristics and geologic setting, consider Figs. 11 through 14 . Only specimens in the UTA database are utilized in these figures. In Fig. 11, the dynamic response of two different soil types, a sand (SM) and a clay $(\mathrm{CH})$, are shown. The soils have different fines contents, plasticity indices, and small-strain stiffnesses. However, it can be assumed that the state of stress and geologic age are nearly the same because the specimens come from similar depths in the same geologic formation. Also, the site location within SRS has a minor effect on the dynamic properties as noted in Section 6. Therefore, the main variables are soil type, plasticity index, fines content and small-strain stiffness. It is not possible to say which variables are controlling from this comparison, but it is shown in Sections 6 through 8 that soil type combined with geologic formation are the controlling variables.

A similar comparison to the one shown in Fig. 11 is presented in Fig. 12, except that the sand (SP-SM) and clay $(\mathrm{CH})$ are from a different geologic formation. The same conclusion that soil type combined with geologic formation are the key correlators is found as discussed in Sections 6 through 8 .

The importance of confining pressure on the dynamic response of these soils is illustrated in Figs. 13 and 14 for a sand specimen and a clay specimen, respectively. In this case, confining pressure is assumed to represent the state of stress in the geologic setting. It is important to note that specimen depth is equated to confining pressure so that items 5 and 6 listed above are essentially the same as long as the effective coefficient of earth pressure at rest does not vary by more than about $50 \%$. As seen in Figs. 13 and 14, confining pressure most directly affects the $G-\log \gamma$ relationships. Confining pressure has only a minor effect on the $G / G_{\max }-\log \gamma$ and $D-\log \gamma$ relationships in these comparisons, where the effective pressure was 
changed by a factor of about four. It is best, of course, to perform dynamic laboratory measurements as close as possible to the in-situ state of stress. However, since the purpose of this work is to recommend $G / G_{\max }-\log \gamma$ and $D-\log \gamma$ curves, measurements performed at confining pressures within a factor of about two of the estimated in-situ state of stress can be used in the database without introducing much variability.

\subsection{Laboratory Test Variables}

In terms of variables which could enter the laboratory tests and effect the correlations, the following variables were considered:

1. effective confining pressure $\left(\sigma_{\circ}{ }^{\prime}\right)$,

2. confining time,

3. excitation frequency $(f)$,

4. number of loading cycles $(\mathrm{N})$,

5. degree of saturation $\left(\mathrm{S}_{\mathrm{r}}\right)$, and

6. drainage conditions.

The only variable associated with the resonant column (RC) test which could be carefully evaluated is confining pressure (Stokoe et al., 1995). The importance of this variable is shown in Figs. 13 and 14, and it was carefully considered by only using data from testing at or near the estimate in-situ mean effective stress, $\sigma_{m}$ '. The value of $\sigma_{m}$ ' was evaluated for each specimen in the database from:

$$
\sigma_{\mathrm{m}}{ }^{\prime}=\frac{1}{3}\left(\sigma_{\mathrm{v}}{ }^{\prime}+2 \mathrm{~K}_{\mathrm{o}}{ }^{\prime} \sigma_{\mathrm{v}}{ }^{\prime}\right)
$$

where $\sigma_{\mathrm{v}}{ }^{\prime}=$ effective vertical stress at the specimen depth, and

$K_{0}{ }^{\prime}=$ coefficient of effective horizontal earth pressure at rest.

The value of $\sigma_{\mathrm{v}}{ }^{\prime}$ was determined from:

$$
\sigma_{v}{ }^{\prime}=\sigma_{v}-u
$$

where $\sigma_{\mathrm{v}}=$ total vertical stress at the specimen depth, and

$u=$ pore water pressure at the specimen depth.

The values of $\sigma_{\mathrm{v}}, \mathrm{u}, \mathrm{K}_{\mathrm{o}}$ ' and $\sigma_{\mathrm{m}}$ ' are given in Tables 2 through 5 for all specimens in the database. 
Since combined resonant column and torsional shear (TS) tests were performed on 15 of the 17 confirmatory drilling (CFD) specimens in the database (Hwang et al. (1995)), excitation frequency and number of loading cycles could also be investigated in these tests. The general effects of these variables in the dynamic laboratory measurements are illustrated in Figs. 3 through 5. For measurements performed on the CFD specimens, most torsional shear testing was performed at 0.5 $\mathrm{Hz}$ over 10 cycles of loading (Stokoe and Hwang, 1993) so that this frequency and number of loading cycles are the test variables which most closely fall in the general ranges associated with earthquake shaking. In the $\mathrm{RC}$ test, most measurement frequencies were in the range of 25 to $250 \mathrm{~Hz}$, typically above $50 \mathrm{~Hz}$, and the number of cycles of loading typically ranged from 500 to 1000 . These values exceed the general frequency range and number of loading cycles associated with earthquake shaking.

The impact of testing over different ranges in frequencies and loading cycles is shown in Figs. 15 and 16 on the CFD specimens with RC and TS tests. The most important effect is clearly on the $D-\log \gamma$ relationships for these soils over the strain range investigated $(\gamma<0.1 \%$ ). This behavior is consistent with the behavior evaluated in previous work as shown in Figs. 3 through 5, and modification of the $\mathrm{D}-\log \gamma$ relationships determined by RC testing by using $\mathrm{D}-\log \gamma$ relationships from TS testing forms one of the major efforts of this study and one of the most important conclusions.

\section{Hyperbolic Curve Fitting of Laboratory Data}

Before the correlations for the SRS data are presented, it is helpful to briefly discuss hyperbolic modeling of nonlinear soil behavior. A hyperbolic model has been shown to be a very useful model in representing nonlinear dynamic soil properties and in differentiating trends between various data sets (Hardin and Drnevich, 1972 and Pyke, 1993). The basis for using a hyperbolic model is that a hyperbola can be used to represent the shape of the stress-strain curve in simple shear loading as illustrated in Fig. 17a. With this model and two-way cyclic loading without permanent deformations, the $G / G_{\max }-\log \gamma$ relationship can be written as:

$$
\mathrm{G} / \mathrm{G}_{\max }=1 /\left(1+\gamma / \gamma_{\mathrm{r}}\right)
$$

where $G_{\max }=$ small-strain shear modulus, 


$$
\begin{aligned}
& G=\text { secant shear modulus at } \gamma, \\
& \gamma=\text { peak cyclic shearing strain, and } \\
& \gamma_{I}=\text { reference (shearing) strain. }
\end{aligned}
$$

The relationship of $G_{\max }, G, \gamma$ and $\gamma_{r}$ to the hyperbolic stress-strain illustrated in Fig. 17a. Hardin and Drnevich (1972) defined reference strain, $\gamma_{r}$, as:

$$
\begin{aligned}
& \gamma_{\mathrm{r}}=\tau_{\max } / \mathrm{G}_{\max } \\
& \text { where } \tau_{\max }=\text { shear strength. }
\end{aligned}
$$

The shear strength in Eq. 4 is actually an asymptote to the stress-strain relationship as shown in Fig. 17a which is a curve fitting parameter and is not the shear strength measured in the laboratory because of deviations from a hyperbolic shape caused by real soil behavior at large shearing strains (Pyke, 1993).

The $G-\log \gamma$ relationship determined from the hyperbolic stress-strain curve in Fig. 17a is shown in Fig. 17b. The resulting $G / G_{\max }-\log \gamma$ relationship is shown in Fig. 18a. As seen in Figs. $17 \mathrm{~b}$ and 18a, the hyperbolic model exhibits strainindependent behavior at small strains $\left(\gamma \leq \gamma_{t}^{e}\right)$ and strain-dependent behavior at larger strains $\left(\gamma<\gamma_{t}^{e}\right)$. This behavior closely mimics the behavior exhibited by real soils as presented in Figs. 3 through 16. The effects of cyclic loadings, excitation frequency and number of loading cycles can also be added to the model (Pyke, 1993). However, as used herein, the model is fit at a selected frequency (around $1 \mathrm{~Hz}$ ) and at a given number of loading cycles (10 cycles) so that these two variables are implicitly incorporated into the data set.

The hyperbolic model described by Eq. 3 is well-suited to represent the $G / G_{\max }$ $-\log \gamma$ relationship. However, without modification, it can not be used to represent the $D-\log \gamma$ relationship. Therefore, Pyke (1993) combined the hyperbolic model with $D_{\min }$ measured in RCTS testing to generate a D - $\log \gamma$ curve compatible with the $G / G_{\max }-\log \gamma$ curve described by Eq. 3. At the request of the SRS Dynamic Property Advisory Panel (1995), a computer program was supplied by Pyke (1995) to UTA which was used to fit all D - $\log \gamma$ relationships shown in this report. Compatibility between the hyperbolic curve representing the $G / G_{\max }-\log \gamma$ relationship and the resulting $D-\log \gamma$ relationship is maintained by using $\gamma_{r}$ determined from fitting the laboratory modulus measurements and using this value in the construction of the D - $\log \gamma$ relationship. All values of $\gamma_{\mathrm{r}}$ reported 
herein were determined by fitting the hyperbolic model (Eq. 3) to each laboratory curve of $G / G_{\max }-\log \gamma$ using a least-squares approach.

An example of the $D-\log \gamma$ relationship determined with Pyke's program is shown in Fig. 18b. the relationship was determined for the hyperbolic curve shown in Fig. $17\left(\gamma_{\mathrm{r}}=0.1 \%\right)$ combined with an assumed value for $D_{\min }$ of $1 \%$. (The value of $D_{\min }$ had to be assumed simply because no laboratory measurements were performed in this case.) As shown in Sections 6 through 8, the nonlinear D - $\log \gamma$ relationship follows the measured data quite closely. However, one additional parameter was added in the damping curve fit. This parameter is $D_{\text {cap }}$, and it represents a maximum value of material damping for use in analytical studies. The SRS Dynamic Property Advisory Panel (1995) recommended a value of $15 \%$ for $D_{\text {cap. }}$ Therefore, in the $D-\log \gamma$ relationship in Fig. $18 \mathrm{~b}$, a constant value of $D$ equal to $15 \%$ is shown once the value of $D$ determined with Pyke's program reaches $15 \%$.

\section{General Results of Correlation Study}

Based on initial correlation studies conducted during the general review of prior work (Stokoe, et al., 1995), the main variables associated with the geologic setting and geotechnical characteristics which incorporate most of the other variables are geologic formation and soil type. Soil type (based on the Uniform Soil Classification System) was used to form subsets within the geologic formation category because of the wide range in soil types found in various formations at SRS. Therefore, in the correlations, resonant column results measured at or near the estimated in-situ mean effective stress for a given geologic formation and soil type ("sands" or "clays") were used as the starting point because these results form the vast majority of data in the database. In addition, the $G / G_{\max }-\log \gamma$ curves from $R C$ and TS testing of the CFD specimen are essentially the same (as shown in Figs. 15 and 16 and in some of the appendices) for most of the CFD specimens. Therefore, the effects of excitation frequency and number of loadings can be neglected in this part of the correlation study.

As the study progressed, it became apparent that specimen depth should also be used to divide the results into two general sets of data. These data sets are called "shallow" and "deep" herein. Shallow specimens are those specimens obtained from depths less than $500 \mathrm{ft}(153 \mathrm{~m})$. Deep specimens, on the other hand, were obtained from depths equal to or greater than $500 \mathrm{ft}(153 \mathrm{~m})$. There is no theoretical 
- basis for this dividing line, and it probably resulted, to some extent, from the lack of a significant number of deep samples. However, the nonlinear behavior exhibited by the deep soils does appreciably differ from that exhibited by the shallow soils.

\subsection{Robust Data Sets}

Sufficient data to develop meaningful correlations exist in only five sets of data. Four of the data sets are composed of shallow sands and the fifth data set is composed of shallow clays. The shallow sands can be subdivided according to geologic formations as follows: 1) Tobacco Road sand (a total of 18 specimens from which data from 16 specimens were used), 2) Dry Branch sand (a total of 13 specimens from which data from 11 specimens were used), 3) Santee sand (a total of 16 specimens which were all used) and 4) Snapp sand (a total of 4 specimens which were all used). Data from two specimens were deleted from two of the sand correlation sets, because (assumed) testing difficulties resulted in the data not fitting data trends formed by the other specimens. All deleted data are presented in Appendix A (by the solid symbols) and are shown relative to the data trends (shown by the open symbols) determined in the correlations for comparison purposes.

The data set for the shallow clays is composed of 5 specimens from 4 geologic formations (Tobacco Road, Dry Branch, Snapp and Steel Creek). Therefore, there were not enough data to subdivide this data set according to geologic formations so all shallow clay data were combined.

\subsection{Sparse Data Sets}

The remaining data sets which are divided according to soil type and geologic formation for the shallow specimens are composed of the following three sets: Upland sand ( 3 specimens), Warley Hill sand (2 specimens), and Congaree sand (1 specimen). The remaining data sets for the deep specimens have simply been divided into two sets: clay ( 2 specimens) and sand ( 8 specimens). Although the number of deep sand specimens would seem to allow this category to be subdivided by geologic formation, significant variability in the results and obvious difficulty in testing precluded any subdivisions.

Correlations for the under-populated data sets (three "shallow" sand sets, one "deep" sand set and one "deep" clay set) are estimated from comparisons with the 
five robust data sets and/or from comparisons with data in the literature or other research reports from UTA. Example data from UTA reports are presented in Appendix B. The data in Appendix B form important supporting data for estimating nonlinear behavior at shearing strains around and above $0.1 \%$.

\subsection{Unrepresented Soils at SRS}

It is important to note at this point that both shallow and deep specimens of sands and clays from many formations at SRS do not exist in the database. In terms of shallow sands and clays, no specimens are in the database from the following geologic formations:

1. Sands-
a. Four Mile,
b. Sawdust Landing,
c. Steel Creek,

2. Clays-
a. Upland,
d. Congaree,
b. Santee,
e. Four Mile, and
c. Warley Hill,

In terms of deep sands and clays, only a deep clay from the Cape Fear formation has not been tested. However, as discussed in Sections 10 and 11, the test results from all deep specimens (sands and clays) seem to be determined with specimens which were altered by the sampling and test-preparation processes and/or were of such a stiffness and uniformity that the laboratory results were comprised. This conclusion is based on the fact that the trends with depth of the $G / G_{\max }-\log \gamma$ and $D-\log \gamma$ relationships are contrary to those that would be predicted with the robust data sets from the shallow specimens. Therefore, the important conclusion is reached that there is essentially no test data in the database for deep specimens at SRS.

\section{Correlations Using Shallow Sand Specimens}

As noted earlier, shallow specimens are designated as those specimens obtained from depths less than $500 \mathrm{ft}(153 \mathrm{~m})$. In fact, all but two of the 54 shallow sand specimens were recovered from depths less than $300 \mathrm{ft}(92 \mathrm{~m})$.

\subsection{Dry Branch and Santee Sands}

The most consistent trend and best correlation was found by combining "sands" from the Dry Branch and Santee formations. The word "sands" is used because these specimens contain more than $50 \%$ sand particles by weight but exhibit 
a wide range in plasticity so that the specimen classifications range from SP-SM to SM to SP-SC to SC as shown in Table 7. It is interesting to note that the Dry Branch and Santee formations are adjacent to each other (Fig. 10), with the Dry Branch overlying the Santee. The 29 specimens which comprise this data set were recovered over the depth range of 37.5 to $232.5 \mathrm{ft}$ (11.4 to $70.9 \mathrm{~m}$ ).

$G / G_{\max }-\log \gamma:$ Complete Data Set - All resonant column measurements of the $\mathrm{G} / \mathrm{G}_{\max }-\log \gamma$ relationships are plotted in Figs 19 through 21 for the Dry Branch specimens (11 specimens), the Santee specimens (16 specimens) and the combination of Dry Branch and Santee specimens, respectively. The companion figures for the $G-\log \gamma$ relationships are plotted in Figs. 22 through 24 , respectively. (The data from Dry Branch specimens ITP-10b and BNH-29c have been deleted because they do not follow the trend of data from the remaining 27 specimens. The data from these two specimens are presented in Appendix A (by the solid symbols in Figs. A.1 through A.3 for comparison and documentation purposes.) The $G-\log \gamma$ relationships are included to show the general range in stiffness over which these measurements exist. The very wide range in the $G-\log \gamma$ relationships clearly shows that these relationships are not correlated without further manipulations. However, the $G / G_{\max }-\log \gamma$ relationships exhibit a good correlation, although the data band is rather wide in each figure. The general correlation shown in Fig. 21 is a significant improvement over the wide band in the $G / G_{\max }-\log \gamma$ relationships exhibited by all SRS data presented in Fig. 8 . The statistical significance of the data sets and justification for combining the data sets as presented in Fig. 8 are discussed in Section 8.

Average $G / G_{\max }-\log \gamma$ curves were fit to the data in Figs. 19 through 21. Only the results from specimens which exhibited a reasonable amount of nonlinearity were used in curve fitting. A reasonable amount of nonlinearity is defined in this study to be represented by measurements at strains large enough so that $G / G_{\max } \leq 0.80$. (This criterion resulted in the exclusion of specimens LRA-9 and SFS- $8 \mathrm{c}$ from the remaining 25 specimens used in the curve-fitting data set.) The average curve was fit using the hyperbolic model discussed in Section 4 . The average hyperbolic curve is shown by the solid line for $\gamma \leq 0.1 \%$ and by the dashed line for $\gamma>0.1 \%$ where little, if any, data exist. The average reference strain, $\gamma_{r}$, used to define the hyperbolic curve is given in the insert in the figure. 
The empirical $G / G_{\max }-\log \gamma$ relationship recommended for sands by Seed et al. (1986) is compared in Fig. 25 with the data from the Dry Branch and Santee sands. This comparison is presented simply as a frame of reference because the Seed et al. (1986) relationship has been widely cited in the past. The upper bound of this relationship is the closest predictor of the nonlinear behavior exhibited by the Dry Branch and Santee sands, although the upper bound curve still falls somewhat below the average hyperbolic curve used to represent the complete data set.

$G / G_{\max }-\log \gamma:$ Data Sub-Sets - The range exhibited in the $G / G_{\max }-\log \gamma$ curves in Fig. 21 can be significantly reduced by subdividing the data according to site location. This subdivision is presented in Figs. 26 through 37. This group of figures is divided into six sets of two figures, with the first figure showing the $G / G_{\max }-\log \gamma$ relationships and the second figure showing the $G-\log \gamma$ relationships. In all figures, data determined from the three specimens at the CFD site act as the reference, and these data are shown by themselves in the first set of figures, Figs. 26 and 27.

There is a general order in the $G / G_{\max }-\log \gamma$ curves according to site location

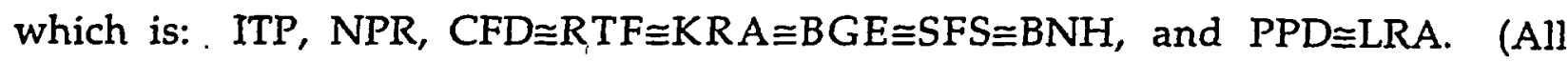
acronyms are defined in Table 1.) This order represents a slight shifting to the right (shifting to slightly higher strains) of the set of $G / G_{\max }-\log \gamma$ relationships from one figure to the next. It is interesting to note that this general order follows a slight trending to the south at SRS as shown in Fig. 1. It is also interesting to note that the stiffest specimens were recovered from the NPR site while the softest specimens were recovered from the $B N H$ site. Hence, no consistent trend in the $G / G_{\max }-\log \gamma$ relationships occurs with stiffness.

Effects of $f, N$ and $\sigma_{Q^{\prime}}$ on $G / G_{\max }-\log \gamma$ - All data presented in Figs. 19 through 37 (as well as Figs. 6 through 8) were determined using RC testing at or near the estimated in-situ mean effective stress. The good comparisons between results determined by different laboratories over a period of about 15 years demonstrates the robustness of the RC test. However, the RC test involves 100's of cycles of loading around the resonant frequency before a measurement is obtained (Stokoe and Hwang, 1993). Therefore, the effects of excitation frequency, $f$, and number of loading cycles, $\mathrm{N}$, can not be evaluated in the RC test. On the other hand, TS testing can be used to evaluate the effects of $f$ and $N$ on the $G-\log \gamma$ and $G / G_{\max }-\log \gamma$ relationships.

SRS-FR-CDP-95, rev. 0, 13 September 95

Project No. AA891070 
Typical results for the effects of excitation frequency and number of loading cycles on natural sands and clays are illustrated in Figs. 4 and 5 (Stokoe et al., 1994). The effects of $f$ and $N$ on the CFD specimens are briefly discussed in Section 3 (Figs. 15 and 16) and are presented in detail in Appendix C. In terms of the $G / G_{\max }-\log \gamma$ relationships for the Dry Branch and Santee sands, these two effects can be considered very small at shearing strains less than $0.1 \%$, with generally only a slight stiffening of the relationship as number of cycles of loading increases at strains around $0.1 \%$. At strains above $0.1 \%$, the effects have not been determined in this correlation study.

Effective confining pressure, $\sigma_{0}{ }^{\prime}$, is another parameter which can affect the $\mathrm{G} / \mathrm{G}_{\max }-\log \gamma$ relationships presented in Figs. 19 through 37. The importance of $\sigma_{\mathrm{o}}{ }^{\circ}$ on these relationships is discussed in Section 3 (Figs. 13 and 14), and results for the CFD specimens are shown in Appendix C. Basically, if the $G / G_{\max }-\log \gamma$ relationship is determined at a confining pressure within about $\pm 30 \%$ of the in-situ value, this effect is small and can be ignored in these tests.

In summary, the effects of $f, N$ and $\sigma_{o}^{\prime}$ on the $G / G_{\max }-\log \gamma$ relationships presented in Figs. 19 through 37 are small. Therefore, it is recommended that the data be used as shown, keeping in mind that these effects will have a slight tendency to increase the value of $G / G_{\max }$ under most earthquake shaking relative to the values shown.

D- $\log \gamma:$ Complete Data Set - All resonant column measurements of D - $\log \gamma$ are plotted in Fig. 38 (except for specimens ITP-10b and BNH-29c as in the correlations with shear modulus). The data in this correlation cover a wide band, with $D_{\text {min }}$ values ranging from 0.52 to $3.75 \%$. However, this band width is narrower than the one seen for all SRS data presented in Fig. 9 in which the value of $D_{\min }$ ranges from 0.50 to $5.80 \%$. It is interesting to note that the data from the different investigations generally fall within the same band, lending credibility to the data and to the RC test. However, the width of the band of data presented in Fig. 38 is too large to develop a meaningful correlation.

D- $\log \gamma:$ Data Sub-Sets - When the D $-\log \gamma$ relationships are subdivided according to site location, as done with the $G / G_{\max }-\log \gamma$ relationships, the data band is not reduced, and no significant trend is observed as seen by reviewing Figs. 39 through 44 . The main reasons for the wide range in damping values at a given 
strain level are excitation frequency and number of loading cycles as discussed below.

Effects of $f, N$ and $\sigma_{0}$ on $D-\log \gamma$ - When excitation frequency is taken into account by using the torsional shear tests on the CFD specimens, the range in material damping data at small strains, strains less than about $10^{-3} \%$, is dramatically reduced as shown in Fig. 45 for the CFD sand specimens from the Dry Branch and Santee formations. In this case, the range in values of small-strain material damping, $D_{\min }$, from the RC tests is 0.77 to $3.54 \%$ while the range in $D_{\min }$ from the TS tests is 0.44 to $1.13 \%$. In addition, the average value of small-strain material damping for the three CFD specimens is reduced by slightly more than a factor of two when the TS results are compared with the average value determined from the $R C$ tests. (Average $D_{\min }$ from the TS tests is about $0.88 \%$, while it is about $2 \%$ from the RC tests.) It is recommended that the CFD results be used to form the data band at small strains for all sands from the Dry Branch and Santee formations.

Besides the impact on $D_{\min }$ of using $T S$ test results, the use of the torsional shear results for the CFD specimens at strains above $0.02 \%$ leads to two more differences in the correlation data set when compared with values determined from $\mathrm{RC}$ testing. First, the torsional shear results show that material damping values at strains above about $0.02 \%$ depend on number of loading cycles as shown in Figs. 45 and 46 and Appendix $C$. Therefore, all material damping data determined by resonant column testing need to be adjusted upward at strains above $0.02 \%$ to account for number of loading cycles. In addition, the second difference between TS and $\mathrm{RC}$ results at larger strains is the more rapid increase in D with increasing $\gamma$ in the TS test results. This effect is most easily seen in Fig. 45.

Recommended D - $\log \gamma$ Relationship - Based on the discussion above, it is recommended that the $D-\log \gamma$ relationship be based on TS test results. Furthermore, these relationships should be those determined for the tenth loading cycle because this number of cycles is a reasonable first approximation of potential earthquake shaking at SRS. Also, from a conservative point of view, the maximum value of material damping should be capped at $15 \%$. The general idea of a cap on material damping is supported by the absence of measured values of $\mathrm{D}$ above $15 \%$, including all RC measurements as shown in Fig. 9, and was suggested by the SRS Dynamic Property Advisory Panel (1995). 
With these criteria, a hyperbolic model which accounts for $D_{\min }$ (Pyke, 1993) was fit to the damping values determined in the tenth cycle of TS testing. Comparison of the average hyperbolic curve and cap (denoted as $D_{\text {cap }}$ ) with the CFD data is shown in Fig. 47 . The average reference strain $(0.0778 \%)$ is the arithmetic average value determined from the $G / G_{\max }-\log \gamma$ curves measured in the TS tests of the three CFD specimens. The average $D_{\min }(0.88 \%)$ is the arithmetic average determined from TS testing of the three CFD specimens. The average hyperbolic curve fits the TS data quite closely, with the possible underprediction of $D$ at strains above $0.04 \%$ as shown in Fig. 47. Unfortunately no measurements at strains around $0.1 \%$ were performed because of the inability of the TS equipment to generate sufficient torque to reach such strains with the specimen stiffnesses and sizes involved.

Unfortunately, only material damping data from TS testing of the CFD specimens exist. As such, this set of damping data and the average hyperbolic curve with $D_{\text {cap }}$ presented in Fig. 47 are recommended for use as the guide to estimating material damping values of all sands from the Dry Branch and Santee formations. The average value of $\gamma_{\mathrm{r}}$ determined from all resonant column tests presented in Fig. 21 is $0.0771 \%$. This value of $\gamma_{r}$ can be considered equal to the average value of $\gamma_{\mathrm{r}}$ from the same population of TS tests based on the finding that $f$ and $N$ have little effect on the $G / G_{\max }-\log \gamma$ relationships of the Dry Branch and Santee sands as noted earlier. A representative average value of $D_{\min }$ still needs to be obtained for the same population of test results from which $\gamma_{\mathrm{r}}=0.0771 \%$ was determined. This value of $D_{\min }$ is estimated from a general relationship between $D_{\min }$ and $\gamma_{r}$ for all shallow sands at SRS that were tested in the TS device. The $D_{\min }-\gamma_{\mathrm{r}}$ relationship is shown in Fig. 48 . The general relationship shows $D_{\min }$ decreasing as $\gamma_{I}$ increases. This trend is also seen in stage testing with a given specimen, where $\gamma_{\mathrm{r}}$ increases with increasing $\sigma_{0}{ }^{\prime}$ and $D_{\min }$ decreases with increasing $\sigma_{0}^{\prime}$.

By using the general trend shown in Fig. 48 with the average $D_{\min }(0.88 \%)$ from the TS tests, the estimated $D_{\min }$ going from $\gamma_{r}=0.0778 \%$ ( 3 TS tests) to $\gamma_{r}=$ $0.0771 \%$ (25 RC tests) is still $0.88 \%$. Therefore, the value of $D_{\min }$ of $0.88 \%$ is combined with $\gamma_{\mathrm{r}}$ of $0.0771 \%$ to generate the recommended average hyperbolic D -

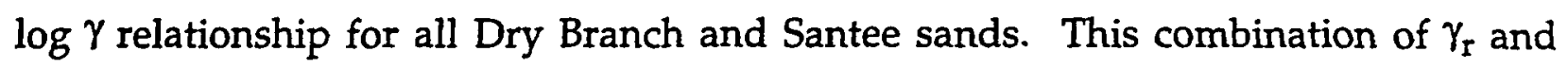
$D_{\min }$ was selected to have internal compatibility for cyclic loading between the recommended average $G / G_{\max }-\log \gamma$ relationship and the $D-\log \gamma$ relationship. 
The resulting recommended average curve is shown in Fig. 49. The curve is essentially the same as the one shown in Fig. 47 because the overall average $\gamma_{\mathrm{r}}$ from the RC tests (Fig. 21) is very close to the average $\gamma_{\mathrm{r}}$ from the three TS tests.

Comparison of the recommended average $\mathrm{D}-\log \gamma$ relationship with the Seed et al. (1986) relationship for sands is shown in Fig. 50. As with the $G / G_{\max }-\log$ $\gamma$ results, this comparison is shown mainly for reference purposes. The comparison shows that the empirical relationship underpredicts the average value of $D_{\min }$ and the extent of the linear range, the range over which $D_{\min }$ is a reasonable approximation. However, the lower bound curve predicts very well the recommended average hyperbolic curve and the measured TS data in the shearing strain range of about $0.002 \%$ to about $0.25 \%$ as seen by comparing Figs. 47 and 49 .

Comparison of the recommended average $D-\log \gamma$ relationship with all resonant column results determined for the Dry Branch and Santee sands is shown in Fig. 51 for reference purposes. This comparison shows the significant impact that the TS test results have had on evaluation of the $D-\log \gamma$ relationship, with one important difference being the general lowering of all values of $D$ at strains less than about $0.03 \%$.

\subsection{Tobacco Road and Snapp Sands}

The second set of data which exhibit a consistent trend and a strong correlation is the "sands" from the Tobacco Road and Snapp formations. As with the Dry Branch and Santee sands, the word "sands" is used because these specimens contain more than $50 \%$ sand particles by weight but exhibit a wide range in plasticity so that the specimen classifications range from SP-SM to SM to SP-SC to SC as shown in Table 8. Contrary to the Dry Branch and Santee formations which formed one data set, these two geologic formations are not next to each other but are separated by five other geologic formations as shown in Fig. 10. As a result, the recovery depths of the 22 specimens which comprise this data set fall into two groups; the first one associated with the Tobacco Road formation ( 21 to $102.6 \mathrm{ft}$ (6.4 to $31.3 \mathrm{~m}$ )) and the second one associated with the Snapp formation (262.8 to $492 \mathrm{ft}$ (80.1 to $150 \mathrm{~m})$ ).

It is important to note that two of the four Snapp specimens used in this data set were taken from sample tubes which were designated as "disturbed" by the 
driller. The specimens, CFD-12a and CFD-13a, were tested at UTA and were hand carved from intact portions of extruded samples. Visual inspection of the specimens during trimming uncovered no manifestations of disturbance. Each trimmed specimen was whole and was composed of competent material which visually appeared to be representative of intact soil. An earlier study by Sponseller and Stokoe (1995) working with artificially cemented loose sand showed that the $G / G_{\max }-\log \gamma$ and $D-\log \gamma$ curves were only slightly affected by various amounts of disturbance caused by transportation and laboratory handling activities. Additional studies presented by Stokoe et al. (1994) showed that disturbance had little effect on the $G / G_{\max }-\log \gamma$ curves for a naturally cemented sandy soil. (Unfortunately, Stokoe et al. (1994) did not study the D - $\log \gamma$ relationships of the naturally cemented soil.) Based on these previous studies, it was decided to test specimens CFD-12a and CFD-13a. After testing was completed, it was found that the results from these specimens were consistent with the trends determined by the other Dry Branch and Santee sands, and the specimens were incorporated into the database.

$G / G_{\max }=\log \gamma:$ Complete Data Set - All resonant column measurements of the $\mathrm{G} / \mathrm{G}_{\max }-\log \gamma$ relationships are plotted in Figs. 52 through 54 for the Tobacco Road specimens (16 specimens), the Snapp specimens (4 specimens) and the combination of Tobacco Road and Snapp specimens, respectively. The companion figures for the $G-\log \gamma$ relationships are plotted in Figs. 55 through 57, respectively. (The data from Tobacco Road specimens ITP- $8 \mathrm{C}$ and $\mathrm{BNH}-1 \mathrm{c}$ have been deleted because they do not follow the trend of data from the remaining 16 Tobacco Road specimens. The data from these specimens are contained in Appendix $A$ for comparison and documentation purposes.) The $\dot{G}-\log \gamma$ relationships are included to show the general range in stiffness over which these measurements exist and clearly show that these relationships are not correlated without further manipulations. On the other hand, the $G / G_{\max }-\log \gamma$ relationships exhibit a general correlation, although the band is becoming rather wide as shearing strains increase above $0.03 \%$. The general correlation shown in Fig. 54 is a significant improvement over the wide band in the $G / G_{\max }-\log \gamma$ relationships exhibited by all SRS data presented in Fig. 8 . The statistical significance of the data sets and justification for combining the data sets as done in Fig. 54 are discussed in Section 8.

Average $G / G_{\max }-\log \gamma$ curves were fit to the data in Figs. 52 through 54 . Only the results from specimens which exhibited a reasonable amount of 
nonlinearity were used in curve fitting; that is, only those measurements in which $\mathrm{G} / \mathrm{G}_{\max } \leq 0.80$. This criterion resulted in the exclusion of specimens LPD-8c and LPD-10c from the remaining 18 specimens used in the curve-fitting data set. The average curve was fit using the hyperbolic model discussed in Section 4. The average reference strain, $\gamma_{r}$, used to define the hyperbolic curve is given in the inserts in Figs. 52 through 54.

The empirical $G / G_{\max }-\log \gamma$ relationship recommended for sands by Seed et al. (1986) is compared in Fig. 58 with the data from the Tobacco Road and Snapp sands. As with the Dry Branch and Santee sands, this comparison is presented simply as a frame of reference. The upper bound of this relationship is the closest predictor of the nonlinear behavior exhibited by the Tobacco Road and Snapp sands at strains less than $0.03 \%$. At larger strains, the average hyperbolic curve dips more rapidly than the Seed et al. relationship until it coincides with the lower bound at strains above $0.5 \%$.

G/G $/ G_{\max }-\log \gamma$ : Data Sub-Sets - As with the Dry Branch and Santee sands, the band width in the $G / G_{\max }-\log \gamma$ curves for the Tobacco Road and Snapp sands can be significantly reduced by subdividing the data according to site location. This subdivision is presented in Figs. 59 through 68. This group of figures is divided into five sets of two figures, with the first figure showing the $G / G_{\max }-\log \gamma$ relationships and the second figure showing the $G-\log \gamma$ relationships. In all figures, data determined from specimens at the CFD site act as the reference, and these data are shown by themselves in the first set of figures, Figs. 59 and 60.

There is a general order in the $G / G_{\max }-\log \gamma$ curves according to site location

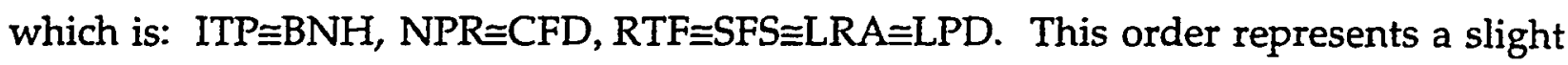
shifting to the right (shifting to slightly higher strains) of the set of $G / G_{\max }-\log \gamma$ relationships from one figure to the next. It is interesting to note that this order closely (but not exactly) follows the order determined for the Dry Branch and Santee sands. This order represents a slight trending to the south at SRS. The good general agreement between the order in the Dry Branch and Santee sands and the Tobacco Road and Snapp sands strengthens the appropriateness of these correlations.

Effects of $f, N$ and $\sigma_{0}{ }^{\prime}$ on $G / G_{\max }=\log \gamma$ - As with the Dry Branch and Santee sands, combined torsional shear and resonant column testing of the CFD specimens was used to evaluate the effects of $f$ and $N$ on the $G / G_{\max }-\log \gamma$ relationships. In 
addition, stage testing at several confining pressures was used to evaluate the effect of $\sigma_{o}$ ' on the $G / G_{\max }-\log \gamma$ relationships determined by $R C$ testing. These results are briefly discussed in Section 3 and all data are presented in Appendix D. Basically, the test results show that the effects of $f, N$ and $\sigma_{0}{ }^{\prime}$ on the $G / G_{\max }-\log \gamma$ relationships presented in Figs. 52 through 54 are small. Therefore, it is recommended that the data be used as shown in summary Fig. 54 for all Tobacco Road and Snapp sands.

D- $\log \gamma$ : Complete Data Set - All resonant column measurements of the D - log $\gamma$ relationships are plotted in Fig. 69 (except for specimens ITP-8c and BNH-1c as in the correlations with shear modulus). The data in this correlation cover a wide band, although the band is narrower than the one seen for all SRS data presented in Fig. 9. However, the width of the data band is too large to develop a meaningful correlation.

D $-\log \gamma:$ Data Sub-Sets - When the D $-\log \gamma$ relationships are subdivided according to site location, as done with the $G / G_{\max }-\log \gamma$ relationships, the data band is not appreciably reduced when three or more specimens are considered, and no significant trend is observed as seen by reviewing Figs. 70 through 74 .

Effects of $f, N$ and $\sigma_{0}{ }^{\prime}$ on $D-\log \gamma-A s$ in the case of the Dry Branch and Santee sands, when excitation frequency is taken into account by using the TS tests on the CFD specimens, the range in material damping values at small strains is significantly reduced as shown in Fig. 75 for the CFD sands specimens from the Tobacco Road and Snapp formations. In this case, the range in values of smallstrain material damping, $D_{\min }$, from the $R C$ tests is 0.68 to $1.55 \%$ while the range in $D_{\min }$ from the TS tests is 0.49 to $0.94 \%$. In addition, the average value of smallstrain material damping for the three CFD specimens is reduced by about $50 \%$ when the TS results are compared with the average value determined from the resonant column tests (average $D_{\min }$ from the TS tests is about $0.60 \%$ and it is about $1.10 \%$ from the RC tests). It should be noted that, no SC materials from the CFD site were tested in this data set, and it is expected that such sands would increase the $D_{\min }$ values somewhat. It is recommended, however, that the TS results from the CFD specimens be used to form the data band at small strains for all sands from the Tobacco Road and Snapp formations, realizing that this value may tend towards a lower bound. 
Use of the torsional shear results for the CFD specimens at strains above 0.02 $\%$ leads to the same additional differences found in the Dry Branch and Santee correlation data set based on the RC tests. First, the torsional shear results show that material damping at strains above $0.02 \%$ depends on number of loading cycles as shown in Fig. 76. Therefore, all higher-amplitude material damping data determined by resonant column testing need to be adjusted upwards for number of loading cycles. In addition, the second difference between the TS and RC results at larger strains is the more rapid increase in D with increasing $\gamma$ in the TS test results. This effect is seen in Fig. 75 and also results in an increase in values of $D$ at larger strains.

Recommended D - $\log \gamma$ Relationship - As with the Dry Branch and Santee sands, only material damping data from TS testing of the CFD specimens exist. As such, it is recommended that this set of TS damping data be used with the hyperbolic model combined with $D_{\min }$ (Pyke, 1993) and $D_{\text {cap }}$ to estimate an average $D-\log \gamma$ relationship for the Tobacco Road and Snapp sands based on the tenth cycle of loading.

Comparison of the TS tenth-cycle results with the average hyperbolic curve determined from the average $\gamma_{r}$ measured in the TS tests combined with $D_{\text {cap }}$ is shown in Fig. 77. The tendency for the average curve is to begin to underestimate $D$ in the range around $0.01 \%$ and to more substantially underestimate $D$ in the range around $0.1 \%$. However, additional TS measurements around strains of $0.1 \%$ are needed to better quantify this comparison.

As with the Dry Branch and Santee sands, the recommended average hyperbolic curve for the Tobacco Road and Snapp sands comes from combining the average value of $\gamma_{\mathrm{r}}$ determined from all $G / G_{\max }-\log \gamma$ curves measured in RC testing (shown in Fig. 54) with the average $D_{\min }$ determined from the average $D_{\min }$ $\gamma_{\mathrm{I}}$ relationship shown in Fig. 48. This combination is done to have internal compatibility for cyclic loading between the recommended average $G / G_{\max }-\log \gamma$ relationship and the $D-\log \gamma$ relationship. Therefore, the $D_{\min }$ of $0.61 \%$ and $\gamma_{\mathrm{r}}$ of $0.056 \%$ from the average of three TS tests combined with a $\gamma_{r}$ of $0.0441 \%$ from the average of $18 \mathrm{RC}$ tests give a $D_{\min }$ of $0.066 \%$. The resulting recommended average hyperbolic D - $\log \gamma$ relationship for use with all Tobacco Road and Snapp sands is given in Fig. 78.

SRS-FR-CDP-95, rev. 0, 13 September 95

Project No. AA891070 
Comparison of the average recommended curve in Fig. 78 with the D $-\log \gamma$ relationship recommended by Seed et al. (1986) for sands shows a somewhat different comparison than found for the Dry Branch and Santee sands. In the case of the Tobacco Road and Snapp sands, the lower bound empirical curve falls slightly below the average hyperbolic curve for the TS results based on the tenth loading cycle around a strain of $0.001 \%$ as shown in Fig. 79. At strains above $0.01 \%$, the lower bound curve underpredicts values of $D$ estimated from the hyperbolic curve.

Comparison of the average recommended curve with all resonant column results is presented in Fig. 80 for reference purposes. Just as found for the Dry Branch and Santee sands, the recommended curve is near the lower bound of all RC results at strains below $0.003 \%$. As strains increase above $0.003 \%$, the recommended D - $\log \gamma$ relationship generally increases more rapidly than the RC results.

\section{Correlations Using Shallow Clay Specimens}

The last of the five robust data sets discussed in Section 5.1 is the data set composed of shallow clays. Shallow clays are designated as those clay specimens which were recovered from depths less than $500 \mathrm{ft}(153 \mathrm{~m})$. A listing of these specimens is presented in Table 9. Five specimens exist in the database. The specimens were recovered over a large depth range, depths ranging from 36 to $424 \mathrm{ft}$ $(11.0$ to $129.2 \mathrm{~m})$. The specimens were obtained from four sites and from four geologic formations. Therefore, insufficient data exist to develop a meaningful correlation based on both geologic formation and soil type, as done with the shallow sands. Hence only soil type could be used in developing this correlation. The trends exhibited by the shallow clays are easily differentiated from the trends of the shallow sands, as expected (see Figs. 3 through 5), indicating the necessity for this correlation.

$G / G_{\max }=\log \gamma:$ Complete Data Set - All resonant column measurements of the $\mathrm{G} / \mathrm{G}_{\max }-\log \gamma$ relationships are plotted in Fig. 81. The companion $\mathrm{G}-\log \gamma$ relationships are plotted in Fig. 82. There is a tendency for the $G / G_{\max }-\log \gamma$ relationships to divide into two groups at strains above about $0.03 \%$. This division occurs from differences in stiffnesses of the two groups of specimens as shown in Fig. 82, with the softer specimens ( $G_{\max }<100 \mathrm{MPa}$ ) exhibiting slightly more linearity to larger strains and a somewhat less rapid decrease in modulus in the nonlinear range than the stiffer specimens. However, the limited number of test specimens in 
the database precludes the development of any meaningful correlation for any data set other than the complete data set.

An average hyperbolic curve was fit to four of the five $G / G_{\max }-\log \gamma$ curves shown in Fig. 81. The data from specimen NPR-96x were not used because measurements were not performed to. sufficiently high strains. The average hyperbolic curve exhibits a slightly different nonlinear shape than the results from the four specimens, with the hyperbolic curve slightly beneath the data at strains around $0.01 \%$ and generally exhibiting a slightly flatter slope than the trend in the measurements at strains above $0.03 \%$. This comparison between measured data and the hyperbolic curve is shown individually for each of the CFD specimens in Appendix E.

The shallow clay specimens exhibit considerably more linearity to larger strains than any of the shallow sands discussed in Section 6. This data trend is typical of that predicted in the literature, with linearity increasing as PI increases (Vucetic and Dobry, 1991). This trend is also clearly demonstrated by comparison with the empirical Seed et al. (1986) curve for sands in Fig. 83. This comparison is done simply to illustrate the increased linearity of the shallow clays with respect to the shallow sands.

Effects of $f, N$ and $\sigma_{0}^{\prime}$ on $G / G_{\max }=\log \gamma$ - The effects of excitation frequency and number of loading cycles on the CFD specimens are presented in Appendix E. Unfortunately, no strains above $10^{-2} \%$ were generated in these tests. The data show that $f$ and $\mathrm{N}$ had little effect on the normalized modulus over the strain range tested. It is assumed that a similar behavior would be exhibited at higher strains, strains around $0.1 \%$ as shown in Appendix B for clays. It is recommended, therefore, to ignore the effects of $f$ and $N$ on the tenth cycle of loading in the shallow clays and to use the average hyperbolic curve shown in Fig. 81.

The effect of $\sigma_{0}{ }^{\prime}$ on the $G / G_{\max }-\log \gamma$ relationship is shown in Appendix $E$ for both CFD specimens. The effect of increasing the effective confining pressure is to increase the strain range over which $G_{\max }$ exists. This effect is demonstrated by the increasing value of $\gamma_{\mathrm{r}}$ with increasing $\sigma_{\mathrm{o}}$ ' for the hyperbolic curve fit at different pressures as noted in Appendix E. As with the shallow sand specimens discussed in Section 6 , this effect does not enter the correlations in the shallow clays because all tests were performed at or near the estimated in-situ mean effective stress, $\sigma_{m}$ '. 
However, this effect needs to be taken into account when comparing with the deep clays in Sections 10 and 11.

D- $\log \gamma$ : Complete Data Set - The RC measurements of the D - $\log \gamma$ relationships are plotted in Fig. 84. The data form a reasonably narrow band at strains below 0.01 $\%$, but they form two somewhat divergent nonlinear patterns at strains above 0.01 $\%$. These two higher-strain patterns follow the tends expected from the $G / G_{\max }-\log$ $\gamma$ relationships; that is, clays exhibiting the more rapid decrease in $G / G_{\max }$ with increasing $\gamma$ also exhibited the more rapid increase in D with increasing $\gamma$.

Effects of $f, N$ and $\sigma_{0}{ }^{\prime}$ on $D-\log \gamma$ - The TS results for the CFD specimens are shown in Fig. 85. When the TS and RC results are compared for the CFD specimens (by comparing Figs. 84 and 85 and reviewing Appendix D), it is apparent that the effect of frequency on material damping is quite important, and the RC results overestimate the values of small-strain material damping, $D_{\min }$, for earthquake analyses.

Unfortunately, the TS results shown in Fig. 85 do not extend to strains around $0.1 \%$. Therefore, results from other shallow clays tested on other projects at UTA are included in Appendix B. The intent of presenting these results is to show typical trends between TS and RC results at higher strains for sands and clays. Basically, the $\mathrm{D}-\log \gamma$ relationships from the RC and TS tests parallel each other for clays, and the number of cycles of loading has a rather small effect. It is recommended, therefore, that this trend be followed in constructing the $D-\log \gamma$ relationship for the shallow clays. This process can be done by using the fitting procedure recommended by Pyke (1993) which incorporates $D_{\min }$ estimated from the TS results and the average $\gamma_{r}$ determined from the $G / G_{\max }-\log \gamma$ relationships measured in RC testing (Fig. 81) as described below.

The effect of $\sigma_{0}{ }^{\prime}$ on the $D-\log \gamma$ relationship is shown in Appendix $E$ for both CFD specimens. This effect was only determined using the RC test and, therefore, can not be used to adjust any of the TS results because of the significant impact of excitation frequency on the RC results. However, no adjustment for $\sigma_{0}{ }^{\prime}$. is required for the shallow clays because all measurements were performed at or near $\sigma_{\mathrm{m}}$ '.

Recommended D - $\log \gamma$ Relationship - The recommended average D - $\log \gamma$ curve using $D_{\min }$ from the TS tests combined with the hyperbolic model (Pyke, 1993) and 
the $R C$ results for $G / G_{\max }-\log \gamma$ is presented in Fig. 85. This curve is recommended for use with all shallow clays. The curve is compared with the Seed et al. (1986) relationship for sands in Fig. 86. (The comparison with the Seed et al. sand curve is done because use of the Seed and Idriss (1970) clay curve was discontinued more than a decade ago.) As expected (Stokoe et al., 1994), the shallow clays exhibit considerably more material damping at strains around $10^{-4} \%$, a much larger linear region over which $D_{\min }$ acts, and significantly less material damping at strains above $0.01 \%$ than the recommended curve for sands. Resonant column testing has had a significant impact on the values of $D$ at $\gamma \leq 0.1 \%$ which were selected in the past. Comparison of material damping values of the shallow clays measured by $\mathrm{RC}$ tests with the (new) recommended D - $\log \gamma$ relationship is presented in Fig. 87. This comparison clearly shows the decrease in material damping values which has occurred over strains ranging from very small to rather large as a result of improved testing techniques.

\section{Statistical Analyses of Shallow Sand and Clay Correlations}

Statistical analyses of the $G / G_{\max }-\log \gamma$ relationships for the shallow sand and clay correlations presented in Sections 6 and 7 were studied. The purpose of these analyses were: 1 . to determine values of the mean, standard deviation and standard error of the mean associated with the various data sets, 2 . to evaluate the applicability of using a normal distribution or log normal distribution to represent the relationships, and 3 to test the hypothesis of combining and/or separating the data sets. These statistical analyses were only performed with the RC results for $G / G_{\max }$. No analyses were performed on the $\dot{D}-\log \gamma$ relationships from TS testing because of the scarcity of these data.

\section{1 $G / G_{\max }-\log \gamma$ Relationships}

The mean, standard deviation $(\sigma)$ and standard error of the mean $(\sigma / \sqrt{\mathrm{n}})$ were determined for the individual and combined $G / G_{\max }-\log \gamma$ data sets. The results of these calculations are presented in the following tables: Dry Branch sands - Table 10; Santee sands - Table 11; Dry Branch and Santee sands - Table 12; Tobacco Road sand - Table 13; Snapp sands-Table 14; Tobacco and Snapp sands - Table 15; and shallow clays - Table 16 . The statistics were calculated assuming a normal distribution and a log normal distribution as shown in the tables.

SRS-FR-CDP-95, rev. 0, 13 September 95

27 of 311

Project No. AA891070 
The values of $\mathrm{G} / \mathrm{G}_{\max }$ which are presented in Table 10 through 16 at selected strain amplitudes were determined from a Ramberg-Osgood ( $R-O)$ relationship which was fit to each individual RC test result. All R-O fitting parameters are presented in Hwang et al. (1995). (The R-O curve-fitting procedure was used because a two-parameter model is used which more closely fits all $G / G_{\max }-\log \gamma$ relationships up to strains of about $0.1 \%$ than the hyperbolic model. The hyperbolic model is, however, much easier to incorporate in nonlinear dynamic analyses of earthquake site response such as at SRS.) Once the curves were fit, $G / G_{\max }$ values were then determined at selected strain amplitudes over the strain range of concern for the total population in the data set. Representation from the total population in each data set was not possible without a curve-fitting approach because some of the soil specimens in the each data set were not tested at the highest strain amplitudes $(0.06$ and $0.1 \%)$ considered in the statistical study.

To evaluate if a normal or log normal distribution is a reasonable representation of the population for $\mathrm{G} / \mathrm{G}_{\max }$ at a given strain amplitude, the values of $G / G_{\max }$ at $\gamma=0.03 \%$ were evaluated as suggested by the SRS Dynamic Property Advisory Panel (1995). Figures 88 and 89 show the $G / G_{\max }$ values plotted on probability graphs for the Dry Branch and Santee sands and for the Tobacco Road and Snapp sands, respectively. If the assumed distribution (normal or log normal) is a reasonable representation, the data should plot as straight lines in these figures. As can be seen, either assumption can be applied about equally well to the data. Therefore, a normal distribution is used hereafter.

Values of the mean and the mean $\pm \sigma$ for the $G / G_{\max }-\log \gamma$ relationships representing the individual and combined data sets are presented in Figs. 90 through 96. The results presented are those based on the assumption of a normal distribution. Average hyperbolic curves from the average reference strains presented in Sections 6 and 7 are also included in the figures for comparison purposes. The average hyperbolic curves fit the mean values of $G / G_{\max }$ quite well, with the main variation occurring at $\gamma=0.1 \%$ for the Tobacco Road and Snapp sands where the hyperbolic curve underpredicts the mean value of $G / G_{\max }$ by approximately $\sigma$.

Also included in Figs. 90 through 96 are hyperbolic curves fit at $\gamma=0.03 \%$ to the values of the mean $G / G_{\max } \pm \sigma$. These curves were fit at the suggestion of the 
SRS Dynamic Property Advisory Panel (1995) and are used in Section 13 to illustrate the variability expected in the curves.

\subsection{Testing the Hypotheses of Combining and/or Separating Data Sets}

The following hypotheses have been made in Sections 6 and 7 with regard to the similarities or differences in the $G / G_{\max }-\log \gamma$ data sets:

1. the Santee and Dry Branch sands are statistically similar populations,

2. the Tobacco Road and Snapp sands are statistically similar populations,

3. the Santee and Dry Branch sands are statistically different populations than the Tobacco Road and Snapp sands, and

4. the shallow clays are statistically different populations than either the Dry Branch and Santee sands or the Tobacco Road and Snapp sands.

The Student $t$ test (suitable for small sample sizes) was used for this purpose. Student $t$ confidence intervals were calculated for the difference in the $G / G_{\max }$ means for the four hypotheses outlined above. A confidence interval for the difference in the population mean value was estimated assuming independent random samples from two normal populations with differing means and common variances. Following Bhattacharyya and Johnson (1977), the $100(1-\alpha) \%$ confidence interval (C.I.) for the difference in the means of the two populations is given by:

$$
100(1-\alpha) \% \text { C.I. }=X 1-X 2 \pm t_{\alpha / 2} s_{\text {pooled }} \sqrt{\frac{1}{n_{1}}+\frac{1}{n_{2}}}
$$

where $X 1$ and $X 2$ are the two sample means containing $n_{1}$ and $n_{2}$ samples, $t_{a} / 2$ is the upper $\alpha / 2$ point of the $t$ distribution with $\left(n_{1}+n_{2}-2\right)$ degrees of freedom, and the pooled variance is given by:

$$
s_{\text {pooled }}^{2}=\frac{\left(\mathrm{n}_{1}-1\right) \sigma_{1}^{2}+\left(\mathrm{n}_{2}-1\right) \sigma_{2}^{2}}{\mathrm{n}_{1}+\mathrm{n}_{2}-2}
$$

where $\sigma_{1}$ and $\sigma_{2}$ are the sample standard deviations. When the confidence interval does not contain zero, the hypothesis that the population means are equal is rejected at the $95 \%$ confidence level. The procedure was to test the relationship between any two formations by computing confidence intervals for the sample difference at each strain range. Tables 17 through 20 contain the estimated confidence intervals for the difference in the means at the $95 \%$ confidence level. 
Table 17 shows the t-test for the Dry Branch and Santee sands. At all selected strains, the $95 \%$ confidence intervals indicate that the samples come from the same population, and that pooling the two formations is justified. The Tobacco Road and Snapp t-test is given in Table 18 and indicates that the sample populations are indistinguishable at all strains except the lowest strains $(0.0006$ and $0.001 \%)$ where independent populations should not be indicated at low strains because of the normalization of $G$.

Table 19 shows the t-test for the Dry Branch and Santee sands and the Tobacco Road and Snapp sands. The $95 \%$ confidence intervals indicate that the sample come from different populations at all strain levels and that separating the two populations is justified. The same result holds true for separating the shallow clays from the shallow sands as shown in Table 20.

In summary, the t-tests support the pooling and separating of data sets as done in Sections 6 and 7.

\section{Comparisons of Sparse and Robust Shallow Sand Data Sets}

There are three sparse sets of data which are composed of shallow sands. These data sets can be divided by geologic formation as follows: Upland ( 3 specimens), Warley Hill (2 specimens) and Congaree (1 specimen). Since, there are no more than three specimens in any data set, the data sets are considered sparse and are too small to develop independent meaningful correlations. Therefore, the $G / G_{\max }-\log \gamma$ and $D-\log \gamma$ relationships are studied by comparison with the correlations presented in Section 6 for the robust data sets of shallow sands and by comparison with trends predicted by previous studies in the literature.

Effects of $f, N$ and $\sigma_{Q}^{\prime}$ on $G$ and $D$ - As done with the Dry Branch and Santee sands and the Tobacco Road and Snapp sands, the effects of $f$ and $N$ on the $G / G_{\max }-\log \gamma$ relationship are small as shown in Appendices $F, G$ and $H$ for CFD specimens from the Upland, Warley Hill and Congaree formations, respectively. Because the effects are small, they are ignored (along with the effect of $\sigma_{0}{ }^{\prime}$ ) for all tests performed at or near the estimated in-situ mean effective stress, $\sigma_{\mathrm{m}}$. The effects of $f$ and $N$ on the $D$ $-\log \gamma$ relationships are taken into account by using the tenth cycle of loading in the TS test for measurements at or near $\sigma_{\mathrm{m}}$ ' just as done in Sections 6 and 7. 


\subsection{Upland Sands}

The correlation database consists of three "sand" specimens from the Upland formation. Two of these specimens were recovered from the CFD site, and the third was recovered from the LPD site. The specimen classifications range from SP-SC to $\mathrm{SC}$ as shown in Table 21. The specimens divide into two groups as discussed below. However, there are insufficient data for correlation purposes. On the other hand, the trends in nonlinear behavior exhibited by the limited data are quite important and consistent with the trends exhibited by the robust data sets of the shallow sands as shown below.

Shear Modulus - The $G / G_{\max }-\log \gamma$ and $G-\log \gamma$ relationships determined by RC tests are shown in Figs. 97 and 98, respectively. As seen in Fig. 98, the specimen from the LPD site is quite soft compared with the two specimens from the CFD site. Also, the CFD specimens are very stiff considering the shallow depths from which the specimens were recovered. The CFD specimens are, therefore, likely cemented.

An average hyperbolic curve was fit to the RC test results for the two CFD specimens as shown in Fig. 97. This curve is recommended as an average curve for stiff $\left(G_{\max } \geq 100 \mathrm{MPa}\right)$ sand specimens from the Upland formation. The $G / G_{\max }-$ $\log \gamma$ relationship of the softer specimen correlates quite well with sand specimens from the Dry Branch and Santee formations as shown in Fig. 99, and this relationship is suggested for softer sand specimens from the Upland formation.

Material Damping - The RC measurements of the $D-\log \gamma$ relationships are plotted in Fig. 100. A wide band of data exists. The data for the CFD specimens agree quite closely when the TS results are compared as shown in Fig. 101. It is suggested that material damping of stiff Upland sands be patterned after the results in Fig. 101 using the hyperbolic model combined with $D_{\min }$ from the TS tests. Based on the $\mathrm{G} / \mathrm{G}_{\max }-\log \gamma$ comparisons, material damping of softer specimens, like LPD $-2 b$, should be patterned after the $D-\log \gamma$ relationship suggested for the Dry Branch and Santee sands as shown in Fig. 44.

\subsection{Warley Hill Sands}

Only two sand specimens from the Warley Hill formation (CFD-8a and NPR$52 x$, Table 2) exist in the correlation database. The $G / G_{\max }-\log \gamma$ and $G-\log \gamma$ 
relationships determined from the RC tests are shown in Figs. 102 and 103, respectively. The $\mathrm{D}-\log \gamma$ relationship determined by $\mathrm{RC}$ testing is shown in Fig. 104. The $\mathrm{D}-\log \gamma$ relationship determined by TS testing is shown in Fig. 105.

Upon comparison with the correlations determined for the Dry Branch and Santee sands, an average hyperbolic $G / G_{\max }-\log \gamma$ relationship fit through the Warley Hill data falls slightly above the average relationship recommended for the Dry Branch and Santee sands as shown in Fig. 106. Similarly, an average hyperbolic D - $\log \gamma$ relationship from TS testing falls slightly below the relationship recommended for the Dry Branch and Santee sands as shown in Fig. 105. The difference in these curves follows the trends based on confining pressure; that is, increasing the confining pressure results in increasing $\gamma_{r}$ and decreasing $D_{\min }$. However, the average $\gamma_{r}$ for the Warley Hill sands is essentially equal to the value of $\gamma_{\mathrm{r}}$ representing the relationship at the mean $+\sigma$ distribution for the Dry Branch and Santee sands (see Fig. 92), indicating a reasonable match. In addition, the $D_{\min }$ .of $0.44 \%$ for the Warley Hill specimen is close to the value of $D_{\min }$ of $51 \%$ which was measured for specimen CFD- $4 a$ of the Dry Branch and Santee sands.

\subsection{Congaree Sands}

Only one sand specimen from the Congaree formation (CFD-11a, Table 2) exists in the correlation database. The $G / G_{\max }-\log \gamma$ and $G-\log \gamma$ results determined from the RC tests are presented in Fig. 107. The D $-\log \gamma$ results determined by TS testing are presented in Fig. 108. (Additional results are shown in Appendix $\mathrm{H}_{\text {.) }}$ Upon comparison with the correlations determined for the Dry Branch and Santee sands, the $G / G_{\max }-\log \gamma$ and $D-\log \gamma$ relationships are closely approximated by the recommended correlations and are suggested for use with all Congaree sands.

It should be noted that this Congaree specimen was hand carved from intact soil from a tube that was marked "disturbed" by the driller. The trimmed specimen was competent and exhibited no visual manifestations of disturbance, just as in the case of the two CFD Snapp specimens discussed in Section 6.2. Therefore, the specimen was dynamically tested, and the results were added to the database because they fit the expected trends. 


\section{Investigation of the Dynamic Measurements of Deep Specimens -}

Very few deep soil specimens (depth $\geq 500 \mathrm{ft}(153 \mathrm{~m})$ ) from SRS have been dynamically tested. The data set in the correlation database is composed of eight sand specimens from three geologic formations and two clay specimens from one geologic formation as noted in Fig. 10. The results from these specimens are discussed below. Insufficient data exist to develop any meaningful correlations, and only trends in the data are examined below.

\subsection{Deep Sand Specimens}

The eight specimens from the three geologic formations in this data set are listed in Table 22. Unfortunately, three specimens (NPR-143x, NPR-158x and NPR247) were deleted from the database because the results from these specimens do not follow the trends from the other specimens and were, therefore, judged to be suspect. The data from these three specimens are contained in Appendix A so that comparisons can easily be made.

Shear Modulus - The $G / G_{\max }-\log \gamma$ and $G-\log \gamma$ relationships determined by $R C$ and/or TS testing are presented in Figs. 109 and 110. Only TS testing data from specimen CFD-T6c are shown because resonance testing was unsuccessful due to : overlapping multiple peaks in the resonance curve. It seems that significant difficulties occurred in testing deep sands by all organizations involved simply by reviewing the data that were deleted. The deleted data show missing parts in the $G / G_{\max }-\log \gamma$ and $D-\log \gamma$ relationships as well as distinctly different trends in the nonlinear behavior and significant variations in $\gamma_{t}^{e}$ for similar specimens.

The $G / G_{\max }-\log \gamma$ results shown in Fig. 109 exhibit nonlinear behavior as expected. However, when compared with the correlations from the Dry Branch and Santee sands and from the Tobacco Road and Snapp sands, nonlinear behavior begins to occur at strains which are much smaller than expected. This onset of nonlinear behavior is also inconsistent with backcalculations of site response at SRS from micro-tremors (Silva, 1995). This trend is discussed further in Section 10.3.

Material Damping - The material damping measurements from the $\mathrm{RC}$ tests are shown in Fig. 111. The same measurements from the TS tests are presented in Fig. 112. The nonlinear material damping behavior is consistent with behavior which would be associated with the nonlinear modulus behavior. However, as with SRS-FR-CDP-95, rev. 0, 13 September 95

Project No. AA891070

33 of 311 
modulus, the exhibited nonlinear damping behavior is inconsistent with trends that are predicted from the shallow sand correlations or with observations from backcalculations of micro-tremors at SRS (Silva, 1995).

\subsection{Deep Clay Specimens}

The two deep clay specimens in the data set are listed in Table 23 and both come from the Black Creek formation. Both of these specimens were tested at UTA.

Shear Modulus - The G/G $\max -\log \gamma$ and G - $\log \gamma$ relationships determined by RC and/or TS testing are presented in Figs. 113 and 114, respectively. Only TS results for specimen CFD-T5b are shown because multiple peaks in the RC data resulted in unsuccessful resonant column testing, the same problem that occurred with deep sand specimen CFD-T6c. Clearly, the two deep clays exhibit much less linearity than the shallow clays. However, the extent of the linear region decreases with increasing stiffness, a trend also exhibited by the shallow clays at SRS and by cemented soils presented by Stokoe et al. (1994). One possible reason for this trend would be an increased amount of cementation in the deeper, stiffer specimens, although observations from micro-tremors indicate more linearity in the deep clays than exhibited in Fig. 113 (Silva, 1995).

Material Damping - The same set of RC and TS measurements presented for modulus are presented for the $D-\log \gamma$ relationships in Figs. 115 and 116, respectively. As with the deep sands, the nonlinear material damping behavior of the deep clays is consistent with behavior which would be associated with the nonlinear modulus behavior. However, this behavior is consistent with trends that are predicted from the shallow clay correlations; that is, increasing $\sigma_{\mathrm{o}}$ should result in increasing $\gamma_{\mathrm{r}}$ and decreasing $D_{\min }$ as discussed in Section 11 .

\subsection{Overall Summary of Dynamic Properties of Deep Soils}

Both the deep sands and deep clays exhibited the onset of nonlinear behavior at shearing strains much less expected for such deep soils. This observation is based on the wealth of test results from shallow specimens which exists in the literature. The observation is also supported by the SRS test data which show the Tobacco Road and Snapp sands exhibiting the least linearity in the shallow soils database, with an average $\gamma_{r}$ of $0.0327 \%$ compared to $0.0309 \%$ and $0.0275 \%$ for the deep sands and clays, respectively.(The strain at which nonlinearity begins to occur increases as $\gamma_{\mathrm{r}}$ 
increases.) Only the cemented Upland sand specimens exhibit less linearity than the deep specimens, and this behavior can be attributed to the significant degree of cementation (Stokoe et al., 1994).

The SRS Dynamic Property Advisor Panel (1995) recommended that all data from the deep specimens be discarded and that the correlations from the shallow specimens be extrapolated to depths associated with the deep soils. The reason or reasons for this unexpected nonlinear behavior could not be determined but was assumed to result, at least in part, from changes created by difficulties associated with sampling at such large depths and from the significant stress relief which occurred upon sample removal. Further evidence that the deep soils exhibit more linear behavior than shown in the laboratory tests was given by Silva(1995), where backcalculations from micro-tremors at SRS indicate linear soil response at larger strains than shown in Figs. 109 and 113 for the deep sands and clays, respectively.

\section{Predicting Nonlinear Dynamic Properties of Deep Soils by Extrapolating the Robust Correlations Determined for the Shallow Soils}

To extrapolate the correlations determined for the shallow specimens to depths associated with the deep specimens, it is necessary to account for the influence of effective confining pressure on $\gamma_{I}$ and $D_{\min }$. The influence of $\sigma_{0}{ }^{\prime}$ on $\gamma_{r}$ and $D_{\min }$ was evaluated with stage testing results from the shallow specimens (shown in Appendices $C$ through $G$ ) combined with the results presented in Appendix B and Stokoe et al. (1994).

The first relationship between $\gamma_{I}$ and $\sigma_{0}^{\prime}$ is shown in Fig. 117. This relationship is presented in a normalized form using the estimated in-situ mean effective stress, $\sigma_{m}$, to normalize the mean effective stress and the reference strain at the estimated in-situ mean effective stress, $\gamma_{r, m}$, to normalize the reference strain. The results from both the shallow sand and clay specimens at SRS are presented together. Also included are sand and clay specimens from other recent work (Stokoe et al., 1994). The data define a general relationship which can be expressed in the form:

$$
\gamma_{r} / \gamma_{r, m}=\left(\sigma_{0}{ }^{\prime} / \sigma_{m}\right)^{0.28}
$$

The general trend in the relationship determined by the shallow SRS soils is consistent with the results determined from other similarly shallow soils. It is also interesting to note that sands and clays give similar results in this normalized plot. 
The second relationship is the one relating $D_{\min }$ and $\sigma_{0}{ }^{\prime}$. This relationship is presented in Fig. 118. The values of $D_{\min }$ are only those values measured at $0.5 \mathrm{~Hz}$ in the TS test. The general trend clearly shows a difference in the values of $D_{\min }$ for the shallow sands and clays, with the average value for the clays twice that for the sands at the same $\sigma_{o}{ }^{\prime}$. The values of $D_{\min }$ can be expressed as:

$$
\begin{array}{ll}
\text { clay: } & D_{\min }=3.2\left(\sigma_{o}{ }^{\prime}\right)^{-0.16} \\
\text { sand: } & D_{\min }=1.6\left(\sigma_{o}^{\prime}\right)^{-0.16}
\end{array}
$$

These two equations are simply straight - line approximations constructed "by-eye", but they reasonably represent the general trend in the data.

With the relationships shown in Figs. 117 and 118 and the results presented in Section 8, the shallow sand and clay correlations were extrapolated to depths representative of deep sands and deep clays as follows. For the deep sands, the results from all shallow sands (except the Upland sands due to the cemented nature of these sands) were incorporated into one data set. Statistical analyses were then performed on this data set following the procedure described in the Section 8.1. The results of these calculations are presented in Table 24. The depth selected to represent the deep sands is $750 \mathrm{ft}(228.6 \mathrm{~m})$. The average $\gamma_{\mathrm{r}}$ for the RC tests is $0.066 \%$ as shown in Table 25. This value increases to $0.111 \%$ for the deep sands using Fig. 117. The average $D_{\min }$ from TS testing of 8 shallow sand specimens is $0.68 \%$ and is associated with an average $\gamma_{\mathrm{r}}$ of $0.076 \%$. With Fig. 48 and the average values of $\gamma_{\mathrm{r}}$ from the TS and RC tests, the representative value of $D_{\min }$ for the specimen population associated with the RC tests is $0.71 \%$. This value is extrapolated to a depth of $750 \mathrm{ft}(228.6 \mathrm{~m})$ using Fig. 118. The resulting value of $D_{\min }$ is $0.53 \%$. In both cases involving Figs. 117 and 118, the assumption that $\sigma_{0}{ }^{\prime}$ is proportional to depth is made so that the ratio of effective stresses can be equated to the ratio of depths. Also, the value of $\sigma$ (standard deviation) in Table 24 is assumed to be independent of depth. With the values of $\gamma_{r}, \sigma$, and $D_{\min }$ for the deep sands, the relationships presented in Fig. 119 are recommended.

The same procedure is followed in the prediction of the relationships for the deep clays. The depth selected to represent the deep clays is also $750 \mathrm{ft}(228.6 \mathrm{~m})$. The average $\gamma_{\text {I }}$ of $0.148 \%$ for the shallow clays increases to $0.230 \%$ for the deep clays using Fig. 117. The value of $\sigma$ for the shallow clays in Table 16 is assumed to be independent of depth. The average $D_{\min }$ from TS testing of two shallow clay 
specimens is $1.36 \%$ and is associated with an average $\gamma_{I}$ of $0.148 \%$ determined from $\mathrm{RC}$ testing. The average value of $\gamma_{\mathrm{r}}$ for the shallow clays in the TS tests had to be assumed equal to the value determined in the RC tests because insufficient data were generated at high enough strains in the TS tests to give an independent determination of $\gamma_{\mathrm{r}}$. Therefore, Fig. 48 could not be used to adjust for different specimen populations in the TS and RC tests. The value of $D_{\min }$ of $1.36 \%$ from the TS tests is extrapolated to a depth of $750 \mathrm{ft}(228.6 \mathrm{~m})$ using Fig. 118. The resulting value of $D_{\min }$ is $1.06 \%$. In both cases involving Figs. 117 and 118, the assumption that $\sigma_{o}{ }^{\prime}$ is proportional to depth is made so that the ratio of effective stresses can be equated to the ratio of depths. With the values of $\gamma_{r}, \sigma$, and $D_{\min }$ for the deep clays, the relationships presented in Fig. 120 are recommended.

It is important to note that the procedure outlined above for extrapolating the shallow correlations to a depth of $750 \mathrm{ft}(228.6 \mathrm{~m})$ is a general procedure which can be used to extrapolate the shallow correlations to any desired depth.

\section{Recommended Generic $G / G_{\max }-\log \gamma$ and $D-\log \gamma$ Relationships for SRS Soils}

Based on the results presented in Sections 6 through 11, generic $G / G_{\max }-\log$ $\gamma$ and $D-\log \gamma$ relationships are presented in Figs. 121 through 122 . The term "generic" is used because data from many locations around SRS were used to develop the $G / G_{\max }-\log \gamma$ relationships, not data from one location such as the CFD site. The figures summarize the findings, beginning with the shallowest formation and ending with the recommended relationships for deep sands and deep clays, Figs. 126 and 127, respectively.

The presentation in Figs. 121 through 127 is the same in each figure. The general stratigraphic profile is shown along the left side, with the formation or formations to which the figure applies being shaded. The $G / G_{\max }-\log \gamma$ relationship is presented in the upper graph, with the mean and the mean $\pm \sigma$ curves shown and the associated values of $\gamma_{\mathrm{r}}$ listed next to the curves. The statistics associated with the curves are those given in Section 8 for all figures except the unrepresented shallow sands (Fig. 124) which are discussed in Section 11. The D $\log \gamma$ relationship is shown in the lower graph. Only a mean relationship is shown because insufficient data exist to evaluate any statistics since all curves represent the tenth cycle of loading measured in the TS test using specimens which were

SRS-FR-CDP-95, rev. 0, 13 September 95

Project No. AA891070

37 of 311 
- recovered from the CFD site (discussed in Sections 6 through 10). The mean value of $D_{\min }$ is given in the figure insert. General notes are presented below the $D-\log \gamma$ graph describing any special considerations or important details associated with the figure.

The recommended relationships are presented as follows:

1. Stiff Upland Sands - Fig. 121,

2. Tobacco Road and Snapp Sands - Fig. 122,

3. Dry Branch, Santee, Warley Hill and Congaree Sands - Fig. 123,

4. Unrepresented Shallow Sands - Fig. 124,

5. Shallow Clays - Fig. 125,

6. Deep Sands - Fig. 126, and

7. Deep Clays - Fig. 127.

Points that have not already be emphasized and which should be noted follow.

1. The average depth of all "shallow" sand specimens used to develop the relationship is $116 \mathrm{ft}(35.4 \mathrm{~m})$. Therefore, care must be exercised if these results are required at specific sites with significantly different depths.

2. The same point as No. 1 holds true for the "shallow" clays which have an average depth of $156 \mathrm{ft}(47.6 \mathrm{~m})$.

3. The soft Upland sands $\left(G_{\max }<100 \mathrm{MPa}\right.$ ) should be approximated by the Dry Branch and Santee sands (Fig. 123).

4. All relationships for the deep sands and deep clays were determined by extrapolating the shallow sand and shallow clay results, respectively.

Finally, the question arises of recommending the G- $\log \gamma$ and D $-\log \gamma$ curves for use in evaluating earthquake ground shaking. The $D-\log \gamma$ curves presented in Figs. 121 through 127 should be used directly in the analyses, with some judgment required about the statistics associated with the range in material damping values. The $G-\log \gamma$ curves come from the $G / G_{\max }-\log \gamma$ curves presented in Figs. 121 through 127 after they have been multiplied by representative values of $G_{\max }$, in-situ as follows:

$$
G_{\text {in-situ, } \gamma}=\left(G / G_{\max }\right)_{\text {lab, } \gamma}{ }^{*} G_{\max , \text { in-situ }}
$$

SRS-FR-CDP-95, rev. 0, 13 September 95

Project No. AA891070 
where $G_{\text {in-situ, } \gamma}=$ the in-situ value of $G$ at a strain of $\gamma$, and

$\left(G / G_{\max }\right)_{\text {lab, } \gamma}=$ the value of $G / G_{\max }$ from Figs. 121 through 127 at a strain of $\gamma$.

The in-situ values of $G_{\max }$ in-situ are typically determined by some type of in-situ seismic test involving shear wave measurements such as the crosshole, downhole and/or suspension logger.

\section{Summary and Conclusions}

An extensive study was conducted by the University of Texas at Austin to investigate possible correlations between nonlinear dynamic soil properties and the soils at the Savannah River Site. Results were incorporated into a database of dynamic measurements performed on 72 specimens by resonant column testing and on 15 (of the 72) specimens by torsional shear testing. The dynamic measurements in the database include the $G-\log \gamma, G / G_{\max }-\log \gamma$ and $D-\log \gamma$ relationships. The following variables involving the geotechnical characteristics of the specimens, the geologic setting at SRS, and the testing state in the laboratory were considered:

Geotechnical and Geologic Variables -

1. soil type,

2. plasticity index (PI),

3. fines content,

4. small-strain stiffness $\left(G_{\max }\right)$,

5. stress state (including overconsolidation),
6. specimen depth,

7. boring (site) location,

8. geologic age, and

9. geologic formation.

Laboratory Test Variables -

1. effective confining pressure $\left(\sigma_{0}{ }^{\prime}\right)$,

4. number of loading cycles $(\mathrm{N})$,

2. confining time at a given $\sigma_{0}{ }^{\circ}$,

5. degree of saturation $\left(\mathrm{S}_{\mathrm{r}}\right)$, and

3. excitation frequency (f),

6. drainage conditions.

It was found that meaningful correlations could be developed for the $G / G_{\max }$ $-\log \gamma$ and $D-\log \gamma$ relationships of soils at SRS. (The $G-\log \gamma$ relationships are developed from in-situ seismic measurements using Eq. 10 and the laboratory

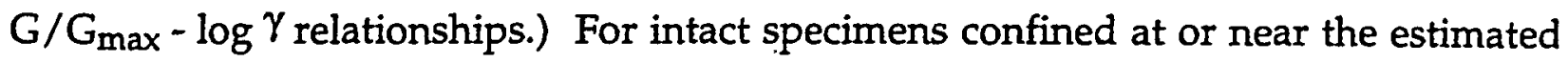
in-situ mean effective stress, soil type combined with geologic formation were the 
key variables in these correlations. These two variables, soil type and geologic formation, implicitly account for plasticity index, fines content, degree of saturation and geologic age. The small-strain stiffness and boring location were found to have little effect on the correlations. Confining pressure in the laboratory test accounts for state of stress and specimen depth. Confining time was not taken into account in the $G / G_{\max }-\log \gamma$ and $D-\log \gamma$ relationships other than to perform tests at anywhere from one to three days after confinement at a given $\sigma_{0}$. Drainage conditions during nonlinear testing were undrained as generally assumed during earthquake loading. Finally, the effects of excitation frequency and number of cycles of loading were evaluated in the laboratory, and the recommended $G / G_{\max }-\log \gamma$ and $D-\log \gamma$ relationships are for $f \leq 1 \mathrm{~Hz}$ and $N=10$ cycles.

Robust data sets with meaningful correlations for the $G / G_{\max }-\log \gamma$ and D $\log \gamma$ relationships were found for the following three sets of shallow soils: 1 . Dry Branch and Santee sands, 2. Tobacco Road and Snapp sands, and 3. shallow clays. The term "shallow" is used to denote sands and clays from depths less than $500 \mathrm{ft}$ $(153 \mathrm{~m})$, although the average depth of the sand specimens is $116 \mathrm{ft}(35.4 \mathrm{~m})$ and the average depth of the clay specimens is $156 \mathrm{ft}(47.6 \mathrm{~m})$. Also, shallow clays could not be subdivided according to geologic formation due to the lack of laboratory data.

All other correlations suggested in this study were determined by comparisons of three robust data sets with limited laboratory data or by assumption because of the nonexistence of laboratory data.

Recommended generic $G / G_{\max }-\log \gamma$ and $D-\log \gamma$ relationships for the soils at SRS are presented in Figs. 121 through 127. Statistical analyses could only be conducted with the $G / G_{\max }-\log \gamma$ relationships and not with the $D-\log \gamma$ relationships. This happened because of the relatively small importance of excitation frequency on the $G / G_{\max }-\log \gamma$ relationship and the significant importance of excitation frequency on the $D-\log \gamma$ relationship measured at frequencies above $f \equiv 5 \mathrm{~Hz}$. Therefore, $72 \mathrm{RC}$ tests were available for the $G / G_{\max }$ $\log \gamma$ correlations while only 15 TS tests, which were performed at a frequency of 0.5 $\mathrm{Hz}$, were available for use in the $\mathrm{D}-\log \gamma$ correlations. The damping measurements show very low values of $D_{\min }$ (generally between 0.5 and $1.3 \%$ ), a relatively large strain range over which $D_{\min }$ is constant (often up to strains on the order of $0.005 \%$ ) and a significant increase in D with $\gamma$ above this strain amplitude. Further, the 
value of $\mathrm{N}$ was important in the measurement of $\mathrm{D}$ of sands at $\gamma>0.03 \%$, with $\mathrm{N}=$ 10 cycles used in these relationships.

Summary plots showing comparisons of the average recommended $G / G_{\max }$ $\log \gamma$ and $\dot{D}-\log \gamma$ relationships are presented in Figs. 128 and 129 , respectively. As seen in Fig. 128, the normalized modulus measurements cover a wide range, with the general trend of clays being more linear than sands clearly exhibited and generally (but not always) deeper soils exhibiting more linearity than shallower ones. In terms of the $\mathrm{D}-\log \gamma$ relationships, there is a remarkably narrow range in $D_{\min }$ values $(0.5$ to $1.4 \%)$ and a significantly widening range in values of $D$ above $\gamma$ $\cong 0.005 \%$. As with normalized modulus, the general trends seen in Fig. 129 show clays having higher values of $D_{\min }$ than sands and lower values of $D$ at $\gamma>0.01 \%$ than sands. Also, $\mathrm{N}$ was important in the measurement of $\mathrm{D}$ of sands at $\gamma>0.03 \%$, with the recommended relationships for $N=10$ cycles.

\section{References}

Bhattacharyya, G. and Johnson, R. A. (1977), Statistical Concepts and Methods, John Wiley and Sons, $639 \mathrm{pp}$.

Hardin, B. O. and Drnevich, V.P. (1972), "Shear Modulus and Damping in Soils: Measurement and Parameter Effects," Lournal of Soil Mechanics and Foundation Engineering Div., ASCE, Vol. 98 No. SM6, June, pp. 603-624.

Hwang, S.-K., Stokoe, K.H., II and Darendeli, M (1995), “Dynamic Properties of Soils from Resonant Column and Torsional Shear Testing: Samples Obtained from the Confirmatory Drilling Program at the Savannah River Site," Geotechnical Engineering Report GD95-1, University of Texas at Austin, (in progress).

Ni, S.-H. (1987), "Dynamic Properties of Sand Under True Triaxial Stress States from Resonant/Column Torsional Shear Tests," Ph.D. Dissertation, University of Texas at Austin.

Pyke, R. M. (1993), "Modeling of Dynamic Soil Properties," Appendix 7.A in Guidelines for Determining Design Bases Ground Motions, Electric Power Research Institute, J. F. Schneider EPRI Project Manager, pp. 7.A-1 - 7.A-90.

Pyke, R. M. (1995), Computer program to Evaluate D - $\log \gamma$ Relationships from $D_{\min }$ and $\gamma_{\mathrm{r}}$. 
Seed, H.B. and Idriss, I.M. (1970), "Soil Moduli and Damping Factors for Dynamic Response Analysis," Report No. EERC 70-10, Earthquake Engineering Research Center, University of California at Berkeley, September, pp. 37.

Seed, H.B., Wong, R.T., Idriss, I.M., and Tokimatsu, K. (1986), "Moduli and Damping Factors for Dynamic Analyses of Cohesionless Soils," Iournal of the Soil Mechanics and Foundations Division, ASCE, Vol. 112, No. SM11, pp. 1016-1032.

Silva, W. (1995), personal communications during meeting at SRS on July 25.

Sponseller, T.E. and Stokoe, K.H., II (1995), "Evaluation Of Transportation Vibrations And Laboratory Handling Activities On The Shear Modulus And Material Damping Ratio Of Uncemented And Lightly Cemented Loose Sand," Geotechnical Engineering Report GT95-2, University of Texas at Austin.

SRS Dynamic Property Advisory Panel (1995), personal communications during meeting at SRS on July 25.

Stokoe, K.H., II and Hwang, S.-K. (1993), "Technical Procedures for Resonant Column and Torsional Shear (RCTS) Testing of Intact Soil Samples," Geotechnical Engineering Center, Procedures PBFRCTS-1, rev. 0.

Stokoe, K.H., II, Hwang, S.-K. Lee, N.-K. J. and Andrus, R.D. (1994), "Effects of Various Parameters on the Stiffness and Damping of Soils at Small to Medium Strains," International Symposium on Prefailure Deformation Characteristics of Geomaterials, Keynote Lecture, Sapporo, Japan.

Stokoe, K.H., II, Lee, N.-K. J. and Andrus, R.D. (1995), "Review of Dynamic Soil Properties Determined in Previous Studies," Final Report (Unfinished Draft), prepared for Dr. Richard C. Lee of Westinghouse Savannah River Company, Rev. No. 0.

Vucetic, M. and Dobry, R. (1991), "Effect of Soil Plasticity on Cyclic Response," Lournal of the Geotechnical Engineering Division, ASCE, Vol. 177, No. 1, January, pp. 89-107. 
Table 1 - Field and Laboratory Dynamic Geotechnical Reports Received from the Westinghouse Savannah River Corporation Which Cover Testing at SRS (from Stokoe et al., 1995).

\begin{tabular}{|c|c|c|c|c|}
\hline \multirow[t]{2}{*}{ Report } & \multirow{2}{*}{$\begin{array}{c}\text { No. of } \\
\text { RC [a] } \\
\text { Specimens }\end{array}$} & \multirow{2}{*}{$\begin{array}{c}\text { No. of } \\
\text { CT [b] } \\
\text { Specimens }\end{array}$} & \multicolumn{2}{|c|}{$\begin{array}{l}\text { In Situ Seismic } \\
\text { Test Arrays }\end{array}$} \\
\hline & & & No. & Type \\
\hline \multicolumn{5}{|c|}{ Pen Branch Fault Confirmatory Drilling (CFD) } \\
\hline $\begin{array}{l}\text { UTA (1995) } \\
\text { Agbabian Assoc. (1992) }\end{array}$ & $\begin{array}{c}17[c, d] \\
\text { none }\end{array}$ & $\begin{array}{l}\text { none } \\
\text { none }\end{array}$ & $\begin{array}{c}\text { none } \\
2\end{array}$ & OYO logger \\
\hline \multicolumn{5}{|c|}{ H-Area, In-Tank Precipitation Facility (ITP) } \\
\hline $\begin{array}{l}\text { Law (1994) } \\
\text { Ebasco (1994) } \\
\text { ARA (1993a) }\end{array}$ & $\begin{array}{c}9 \\
\text { none } \\
\text { none }\end{array}$ & $\begin{array}{c}9 \\
\text { none } \\
\text { none }\end{array}$ & $\begin{array}{c}\text { none } \\
3 \\
23\end{array}$ & $\begin{array}{c}\text { Crosshole } \\
\text { CPT downhole }\end{array}$ \\
\hline
\end{tabular}

Replacement High Level Waste Evaporator (RWE)

\begin{tabular}{|c|c|c|c|c|}
\hline ARA (1993c) & none & none & 4 & CPT downhole \\
\hline \multicolumn{5}{|c|}{ New Waste Transfer Facility (NWT) } \\
\hline ARA (1993d) & none & none & 5 & CPT downhole \\
\hline \multicolumn{5}{|c|}{ H-Area, Replacement Tritium Facility (RTF) } \\
\hline $\begin{array}{l}\text { Law (1992a) } \\
\text { UT (1992) } \\
\text { ARA (1993b) }\end{array}$ & $\begin{array}{c}9 \\
\text { none } \\
\text { none }\end{array}$ & $\begin{array}{c}8 \\
\text { none } \\
\text { none }\end{array}$ & $\begin{array}{c}\text { none } \\
2 \\
5\end{array}$ & $\begin{array}{c}\text { - } \\
\text { crosshole } \\
\text { CPT downhole }\end{array}$ \\
\hline \multicolumn{5}{|c|}{ New Production Reactor (NPR) } \\
\hline $\begin{array}{l}\text { Purdue (1992a) } \\
\text { Purdue (1992b,c) } \\
\text { Law (1992b) } \\
\text { ARA (1991) }\end{array}$ & $\begin{array}{c}5[d] \\
12[d] \\
\text { none } \\
\text { none }\end{array}$ & $\begin{array}{c}\text { none } \\
\text { none } \\
20 \\
\text { none }\end{array}$ & $\begin{array}{c}\text { none } \\
\text { none } \\
\text { none } \\
12\end{array}$ & $\frac{\bar{z}}{\text { CPT downhole }}$ \\
\hline \multicolumn{5}{|c|}{ Par Pond Dam (PPD) } \\
\hline $\begin{array}{l}\text { GEI (1992c,d) } \\
\text { ARA (1992) }\end{array}$ & $\begin{array}{c}3 \\
\text { none }\end{array}$ & $\begin{array}{c}3 \\
\text { none }\end{array}$ & $\begin{array}{l}1 \\
9\end{array}$ & $\begin{array}{l}\text { crosshole } \\
\text { CPT downhole }\end{array}$ \\
\hline \multicolumn{5}{|c|}{ K-Reactor Area (KRA) } \\
\hline $\begin{array}{l}\text { GEI (1991) } \\
\text { Camp (1991) } \\
\text { ARA (1990) }\end{array}$ & $\begin{array}{c}3 \\
\text { none } \\
\text { none }\end{array}$ & $\begin{array}{c}3 \\
\text { none } \\
\text { none }\end{array}$ & $\begin{array}{c}\text { none } \\
3 \\
17\end{array}$ & $\begin{array}{c}\text { - } \\
\text { crosshole } \\
\text { CPT downhole }\end{array}$ \\
\hline
\end{tabular}

[a] RC = Resonant Rolumn

[b] CT = Cyclic Triaxial (strain-controlled)

[c] Both resonant column and cyclic torsional shear tests were performed. Additional low-amplitude resonant column and cyclic torsional shear data are available.

[d] Specimens tested at multiple confining pressures. 
Table 1 (continued) - Field and Laboratory Dynamic Geotechnical Reports Received from the Westinghouse Savannah River Corporation Which Cover Testing at SRS (from Stokoe et al., 1995).

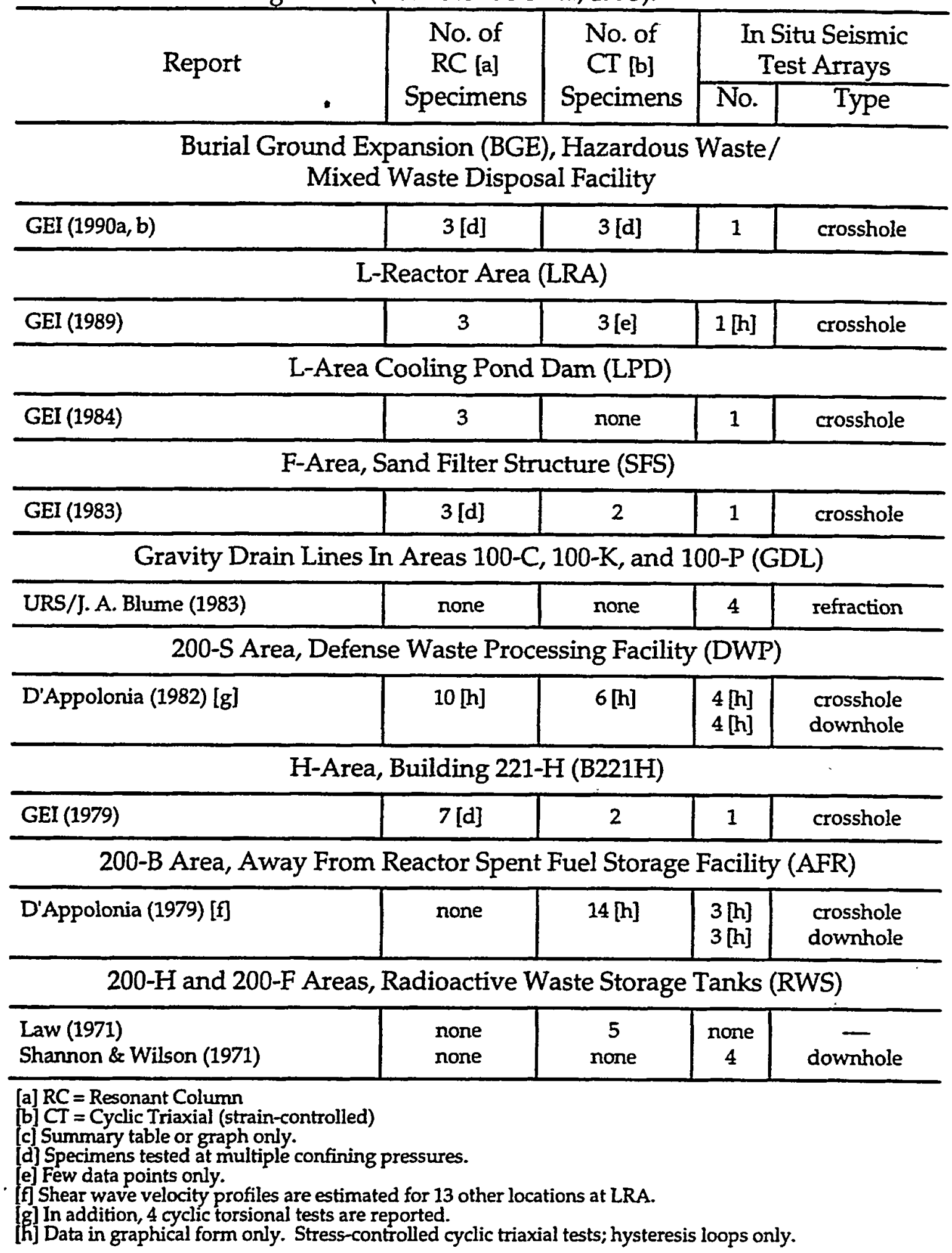


Table 2 Nonplastic Specimens Used in Correlation Study

\begin{tabular}{|c|c|c|c|c|c|c|c|c|c|c|}
\hline $\begin{array}{c}\text { Borehole } \\
\text { Ident. } \\
\text { Number }\end{array}$ & $\begin{array}{c}\text { Sample } \\
\text { Tube } \\
\text { Number }\end{array}$ & $\begin{array}{c}\text { Approx. } \\
\text { Depth to } \\
\text { Center of } \\
\text { Specimen } \\
\text { m } \\
\text { (ft) } \\
\end{array}$ & $\begin{array}{c}\text { Liquid } \\
\text { Limit } \\
\text { Using } \\
\# 40 \text { Sieve } \\
(\# 100 \text { or } \\
\# 200) \\
\% \\
\end{array}$ & $\begin{array}{c}\text { Plasticity } \\
\text { Index } \\
\text { Using } \\
\# 40 \text { Sieve } \\
(\# 100 \text { or } \\
\# 200) \\
\% \\
\end{array}$ & $\begin{array}{c}\text { Soil Type } \\
\text { According } \\
\text { to Unified } \\
\text { Soil } \\
\text { Classfi. } \\
\text { System }\end{array}$ & $\begin{array}{l}\text { Geologic } \\
\text { Formation }\end{array}$ & $\begin{array}{c}\text { Total } \\
\text { Vertical } \\
\text { Stress* } \\
\\
\mathrm{MPa} \\
\end{array}$ & $\begin{array}{c}\text { Pore } \\
\text { Water } \\
\text { Pressure } \\
\mathrm{MPa} \\
\end{array}$ & $\begin{array}{c}\text { Coeff. of } \\
\text { Effectuve } \\
\text { Horizontal } \\
\text { Earth } \\
\text { Pressure } \\
\text { at Rest** } \\
\text { Ko } \\
\end{array}$ & $\begin{array}{c}\text { Estimated } \\
\text { In Situ } \\
\text { Mean } \\
\text { Effective } \\
\text { Stress } \\
\mathrm{MPa} \\
\end{array}$ \\
\hline $\begin{array}{l}\text { PBF } \\
\text { CFD1 }\end{array}$ & PS3B & \begin{tabular}{|c|}
12.6 \\
$(41.5)$ \\
\end{tabular} & \begin{tabular}{c|}
$\mathrm{NP}$ \\
$(82)$ \\
\end{tabular} & \begin{tabular}{c|}
$\mathrm{NP}$ \\
$(30)$ \\
\end{tabular} & SM & $\begin{array}{c}\text { Tobacco } \\
\text { Road }\end{array}$ & 0.24 & 0.12 & 1.00 & 0.12 \\
\hline $\begin{array}{c}\text { PBF } \\
\text { CFDI }\end{array}$ & PS4A & $\begin{array}{c}16.8 \\
(55.0) \\
\end{array}$ & $\begin{array}{c}\mathrm{NP} \\
(128) \\
\end{array}$ & $\begin{array}{l}\text { NP } \\
(86) \\
\end{array}$ & $\mathbf{S M}$ & $\begin{array}{c}\text { Dry } \\
\text { Branch }\end{array}$ & 0.32 & 0.16 & 1.00 & 0.16 \\
\hline $\begin{array}{c}\text { PBF } \\
\text { CFDI }\end{array}$ & PS7A & $\begin{array}{c}32.2 \\
(105.5) \\
\end{array}$ & $\begin{array}{c}\mathrm{NP} \\
(103)\end{array}$ & $\begin{array}{l}N P \\
(50)\end{array}$ & $S M$ & Santee & 0.61 & 0.31 & 1.00 & 0.30 \\
\hline $\begin{array}{l}\text { PBF } \\
\text { CFDI } \\
\end{array}$ & PS8A & $\begin{array}{c}47.2 \\
(155.0) \\
\end{array}$ & $\begin{array}{c}N P \\
(N P)\end{array}$ & $\begin{array}{c}\mathrm{NP} \\
(\mathrm{NP}) \\
\end{array}$ & SP-SM & Santec & 0.89 & 0.46 & 1.00 & 0.43 \\
\hline $\begin{array}{l}\text { PBF } \\
\text { CFDI }\end{array}$ & PS11A & $\begin{array}{c}57.2 \\
(187.8) \\
\end{array}$ & $\begin{array}{l}\text { NP } \\
(37) \\
\end{array}$ & $\begin{array}{l}\mathrm{NP} \\
\text { (11) }\end{array}$ & SP-SM & Congaree & 1.08 & 0.55 & 1.00 & 0.53 \\
\hline $\begin{array}{c}\text { PBF } \\
\text { CFD 1 } \\
\end{array}$ & PS12A & $\begin{array}{c}80.1 \\
(262.8) \\
\end{array}$ & $\begin{array}{l}\mathrm{NP} \\
(55) \\
\end{array}$ & $\begin{array}{l}\text { NP } \\
\text { (13) }\end{array}$ & SM & Snapp & 1.51 & 0.77 & 1.00 & 0.73 \\
\hline $\begin{array}{c}\text { PBF } \\
\text { CFD1 } \\
\end{array}$ & PS13A & $\begin{array}{c}86.4 \\
(283.5) \\
\end{array}$ & $\begin{array}{l}\text { NP } \\
(35) \\
\end{array}$ & $\begin{array}{l}\mathrm{NP} \\
(9) \\
\end{array}$ & $S M$ & Snapp & 1.63 & 0.61 & 1.00 & 1.02 \\
\hline $\begin{array}{c}\text { IIP } \\
\text { HBOR29 } \\
\end{array}$ & ST24-B & $\begin{array}{c}60.0 \\
(197) \\
\end{array}$ & $\begin{array}{c}\text { NP[d] } \\
(89) \\
\end{array}$ & $\begin{array}{c}\text { NP[d] } \\
(64) \\
\end{array}$ & SM & Sawdust & 1.13 & 0.33 & 1.00 & 0.80 \\
\hline RTFB2 & PS-1 & $\begin{array}{r}16.1 \\
(52.9) \\
\end{array}$ & $\begin{array}{l}\mathrm{NP} \\
(-) \\
\end{array}$ & $\begin{array}{l}\mathbf{N P} \\
(-) \\
\end{array}$ & SM & $\begin{array}{c}\text { Tobacco } \\
\text { Road }\end{array}$ & 0.30 & 0.09 & 1.00 & 0.21 \\
\hline RTFB2 & PB-3 & $\begin{array}{c}32.3 \\
(106.0) \\
\end{array}$ & $\begin{array}{l}\text { NP } \\
(-)\end{array}$ & $\begin{array}{l}\text { NP } \\
(-) \\
\end{array}$ & SP & Santee & 0.61 & 0.21 & 1.00 & 0.40 \\
\hline RTFB2 & ST-2 & $\begin{array}{c}24.3 \\
(79.8) \\
\end{array}$ & $\begin{array}{l}\mathrm{NP} \\
(-) \\
\end{array}$ & $\begin{array}{l}\text { NP } \\
(-) \\
\end{array}$ & SP-SM & $\begin{array}{c}\text { Dry } \\
\text { Branch }\end{array}$ & 0.46 & 0.17 & 1.00 & 0.29 \\
\hline RTFB3 & PB-5 & $\begin{array}{c}47.4 \\
(155.4) \\
\end{array}$ & $\begin{array}{l}\text { NP } \\
(-) \\
\end{array}$ & $\begin{array}{l}\text { NP } \\
(-) \\
\end{array}$ & $S M$ & Santee & 0.89 & 0.33 & 1.00 & 0.56 \\
\hline RTFB4 & $\mathrm{PB}-3$ & $\begin{array}{c}19.8 \\
(65.0) \\
\end{array}$ & $\begin{array}{l}\mathbf{N P} \\
(-) \\
\end{array}$ & $\begin{array}{l}\text { NP } \\
(-)\end{array}$ & $S M$ & $\begin{array}{c}\text { Tobacco } \\
\text { Road }\end{array}$ & 0.37 & 0.12 & 1.00 & 0.25 \\
\hline $\begin{array}{l}\text { NPR } \\
\text { DHI }\end{array}$ & $52 X$ & $\begin{array}{c}75.6 \\
(248.1) \\
\end{array}$ & $\begin{array}{l}\text { NP } \\
(-) \\
\end{array}$ & $\begin{array}{l}\text { NP } \\
(-) \\
\end{array}$ & SM & $\begin{array}{c}\text { Warley } \\
\text { Hill }\end{array}$ & 3.42 & 0.57 & 1.00 & 0.85 \\
\hline $\begin{array}{l}\text { NPR } \\
\text { DHI } \\
\end{array}$ & $73 x$ & $\begin{array}{c}103.0 \\
(337.9) \\
\end{array}$ & $\begin{array}{l}\text { NP } \\
(-) \\
\end{array}$ & $\begin{array}{l}\text { NP } \\
(-)\end{array}$ & SM & Snapp & 1.94 & 0.61 & 1.00 & 1.33 \\
\hline $\begin{array}{l}\text { NPR } \\
\text { DHI } \\
\end{array}$ & $130 \mathrm{X}$ & $\begin{array}{r}169.2 \\
(555.1) \\
\end{array}$ & $\begin{array}{l}\text { NP } \\
(-) \\
\end{array}$ & $\begin{array}{l}\text { NP } \\
(-)\end{array}$ & $S M$ & $\begin{array}{l}\text { Black } \\
\text { Creek }\end{array}$ & 3.19 & 1.24 & 1.00 & 1.95 \\
\hline $\begin{array}{l}\text { NPR } \\
\text { DH1 } \\
\end{array}$ & $143 X$ & $\begin{array}{r}182.3 \\
(598.0) \\
\end{array}$ & $\begin{array}{l}\mathbf{N P} \\
(-)\end{array}$ & $\begin{array}{l}\text { NP } \\
(-)\end{array}$ & SM & $\begin{array}{l}\text { Black } \\
\text { Creek } \\
\end{array}$ & 3.43 & 1.36 & 1.00 & 2.07 \\
\hline $\begin{array}{l}\text { NPR } \\
\text { DH1 } \\
\end{array}$ & 247 & $\begin{array}{c}310.9 \\
(1020.0) \\
\end{array}$ & $\begin{array}{l}\text { NP } \\
(-)\end{array}$ & $\begin{array}{l}\text { NP } \\
(-) \\
\end{array}$ & Sand & $\begin{array}{l}\text { Cape } \\
\text { Fear }\end{array}$ & 5.86 & 2.63 & 1.00 & 3.23 \\
\hline $\begin{array}{l}\text { NPR } \\
\text { DH1 } \\
\end{array}$ & $260 \mathrm{X}$ & $\begin{array}{c}325.9 \\
(1069.2)\end{array}$ & $\begin{array}{l}\text { NP } \\
(-)\end{array}$ & $\begin{array}{l}\text { NP } \\
(-)\end{array}$ & SM & $\begin{array}{l}\text { Cape } \\
\text { Fear }\end{array}$ & 6.14 & 2.77 & 1.00 & 3.37 \\
\hline $\begin{array}{l}\text { NPR } \\
\text { B-6 }\end{array}$ & - & $\begin{array}{c}66.3 \\
(217.5) \\
\end{array}$ & $\begin{array}{l}\text { NP } \\
(-)\end{array}$ & $\begin{array}{l}\mathrm{NP} \\
(-)\end{array}$ & SM & Santee & 1.25 & 0.46 & 1.00 & 0.78 \\
\hline $\begin{array}{c}\text { NPR } \\
\text { B-6 } \\
\end{array}$ & - & $\begin{array}{c}70.9 \\
(232.5) \\
\end{array}$ & $\begin{array}{l}\text { NP } \\
(-) \\
\end{array}$ & $\begin{array}{l}\text { NP } \\
(-) \\
\end{array}$ & SM & Santec & 1.34 & 0.51 & 1.00 & 0.83 \\
\hline $\begin{array}{c}\text { NPR } \\
\text { B-8 } \\
\end{array}$ & $\overline{-}$ & $\begin{array}{c}54.1 \\
(177.6) \\
\end{array}$ & $\begin{array}{l}\text { NP } \\
(-) \\
\end{array}$ & $\begin{array}{l}\text { NP } \\
(-) \\
\end{array}$ & SM & Santee & 1.02 & 0.37 & 1.00 & 0.65 \\
\hline $\begin{array}{l}\text { NPR } \\
\text { B-8 } \\
\end{array}$ & - & $\begin{array}{c}57.2 \\
(187.8)\end{array}$ & $\begin{array}{l}\mathrm{NP} \\
(-)\end{array}$ & $\begin{array}{l}\mathrm{NP} \\
(-)\end{array}$ & SM & Santec & 1.08 & 0.40 & 1.00 & 0.68 \\
\hline
\end{tabular}

* Based on an average total unit weight of 120 pef.

* Based on advice from Mr. James Cameron of WSRC. 
Table 3 Specimens Used in Correlation Study with a Plasticity Index Ranging between 0 and $20 \%$

\begin{tabular}{|c|c|c|c|c|c|c|c|c|c|c|}
\hline $\begin{array}{c}\text { Borchole } \\
\text { Ident. } \\
\text { Number }\end{array}$ & $\begin{array}{l}\text { Sample } \\
\text { Tube } \\
\text { Number }\end{array}$ & $\begin{array}{l}\text { Approx. } \\
\text { Depth to } \\
\text { Center of } \\
\text { Specimen } \\
m \\
\text { (fi) }\end{array}$ & $\begin{array}{c}\text { Liquid } \\
\text { Limit } \\
\text { Using } \\
\text { \#40 Sieve } \\
\text { (\#100 or } \\
\# 200) \\
\%\end{array}$ & \begin{tabular}{|c|} 
Plasticity \\
Index \\
Using \\
$\# 40$ Sieve \\
(\#100 or \\
$\# 200$ ) \\
$\mathscr{F}_{c}$
\end{tabular} & \begin{tabular}{|c|} 
Soil Type \\
According \\
to Unified \\
Soil \\
Classfi. \\
System
\end{tabular} & $\begin{array}{l}\text { Geologic } \\
\text { Formation }\end{array}$ & $\begin{array}{c}\text { Total } \\
\text { Vertical } \\
\text { Stress* } \\
\text { MPa }\end{array}$ & $\begin{array}{c}\text { Pore } \\
\text { Water } \\
\text { Pressure } \\
\text { MPa }\end{array}$ & \begin{tabular}{|c|} 
Coeff. of \\
Effectuve \\
Horizontal \\
Earth \\
Pressure \\
at Rest** \\
Ko
\end{tabular} & $\begin{array}{l}\text { Estimated } \\
\text { In Situ } \\
\text { Mean } \\
\text { Effective } \\
\text { Stress } \\
\\
\text { MPa }\end{array}$ \\
\hline $\begin{array}{l}\text { PBF } \\
\text { CFD1 }\end{array}$ & PS2A & $\begin{array}{c}7.0 \\
(23.0) \\
\end{array}$ & $\begin{array}{c}46 \\
(63) \\
\end{array}$ & \begin{tabular}{|c|}
19 \\
$(22)$ \\
\end{tabular} & SC & Upland & 0.13 & 0.06 & 1.50 & 0.09 \\
\hline $\begin{array}{c}\text { PBF } \\
\text { CFDlB }\end{array}$ & T4A & $\begin{array}{c}198.8 \\
(652.2)\end{array}$ & $\begin{array}{l}39 \\
(39)\end{array}$ & $\begin{array}{l}14 \\
(14)\end{array}$ & $\mathrm{Cl}$ & $\begin{array}{l}\text { Black } \\
\text { Creek }\end{array}$ & 3.74 & 1.68 & 1.00 & 2.06 \\
\hline $\begin{array}{c}\text { PBF } \\
\text { CFD1B }\end{array}$ & T5B & $\begin{array}{l}226.2 \\
(742.0)\end{array}$ & $\begin{array}{l}30 \\
(31)\end{array}$ & $\begin{array}{l}12 \\
\text { (12) }\end{array}$ & CI & $\begin{array}{l}\text { Black } \\
\text { Creek }\end{array}$ & 4.26 & 1.95 & 1.00 & 2.31 \\
\hline $\begin{array}{c}\text { PBF } \\
\text { CFDIB }\end{array}$ & TEC & $\begin{array}{l}262.5 \\
(861.2)\end{array}$ & $\begin{array}{c}34 \\
(60)\end{array}$ & $\begin{array}{l}16 \\
(32)\end{array}$ & SC & Middendorf & $\overline{4.94}$ & 2.31 & 1.00 & 2.64 \\
\hline $\begin{array}{c}\text { IIP } \\
\text { HBOR23 }\end{array}$ & ST4-B & $\begin{array}{l}16.8 \\
(55)\end{array}$ & $\begin{array}{c}27 \\
(127)\end{array}$ & $\begin{array}{c}8 \\
(86)\end{array}$ & SP-SC & $\begin{array}{c}\text { Dry } \\
\text { Branch }\end{array}$ & 0.32 & 0.07 & 1.00 & 0.24 \\
\hline $\begin{array}{c}\text { ITP } \\
\text { HBOR 12 }\end{array}$ & STB-C & $\begin{array}{l}24.4 \\
(80)\end{array}$ & $\begin{array}{c}34 \\
(167)\end{array}$ & $\begin{array}{c}11 \\
(122)\end{array}$ & SC & $\begin{array}{c}\text { Tobacco } \\
\text { Road }\end{array}$ & 0.46 & 0.14 & 1.00 & 0.32 \\
\hline RTFB1 & PS-2 & $\begin{array}{r}12.2 \\
(40.0)\end{array}$ & 40 & 17 & SC & $\begin{array}{c}\text { Tobacco } \\
\text { Road }\end{array}$ & 0.23 & 0.04 & 1.50 & 0.25 \\
\hline RTFB3 & $\overline{\mathrm{PB}-3}$ & $\begin{array}{c}28.8 \\
(94.4)\end{array}$ & 39 & 19 & SC & UNIDENTIFIED & 0.54 & 0.22 & 1.00 & 0.33 \\
\hline RTFB6A & $\overline{\text { STA }}$ & $\begin{array}{r}21.9 \\
(72.0) \\
\end{array}$ & 28 & 5 & SM & $\begin{array}{l}\text { Tobacco } \\
\text { Road }\end{array}$ & 0.41 & 0.13 & 1.00 & 0.28 \\
\hline RTFB7 & PS-2 & $\begin{array}{c}17.6 \\
(57.8)\end{array}$ & 32 & 3 & SM & $\begin{array}{c}\text { Tobacco } \\
\text { Road }\end{array}$ & 0.33 & 0.10 & 1.00 & 0.23 \\
\hline $\begin{array}{l}\text { NPR } \\
\text { DHI }\end{array}$ & $96 x$ & $\begin{array}{c}129.2 \\
(424.0)\end{array}$ & 46 & 19 & $\mathrm{Cl}$ & Srapp & 2.43 & 0.85 & 1.00 & 1.58 \\
\hline $\begin{array}{l}\text { NPR } \\
\text { DHI }\end{array}$ & $192 X$ & $\begin{array}{c}247.4 \\
(811.8)\end{array}$ & 27 & 6 & SC-SM & $\begin{array}{l}\text { Black } \\
\text { Creek }\end{array}$ & 4.66 & 2.00 & 1.00 & 2.66 \\
\hline $\begin{array}{c}\text { NPR } \\
\text { B-5 }\end{array}$ & & $\begin{array}{c}31.3 \\
(102.6)\end{array}$ & $\overline{42}$ & 19 & SC & $\begin{array}{c}\text { Tobacco } \\
\text { Road }\end{array}$ & 0.59 & 0.12 & 1.00 & 0.47 \\
\hline $\begin{array}{c}\mathrm{KRA} \\
\mathrm{K} 1003 \mathrm{~A}\end{array}$ & FP10B & $\begin{array}{c}40.9 \\
(134.1)\end{array}$ & 38 & 17 & SC/SM & Santee & 0.77 & 0.19 & 0.50 & 0.38 \\
\hline
\end{tabular}

- Based on an average total unit weight of 120 pcf.

* Based on advice from Mr. James Cameron of WSRC. 


\begin{tabular}{|c|c|c|c|c|c|c|c|c|c|c|c|c|c|}
\hline 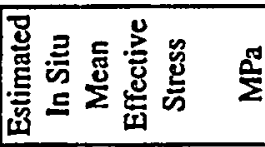 & $\because$ & స్ํ & స్త్ & ֻั & $\frac{ \pm}{0}$ & 竎 & ָָּ & $\bar{D}$ & 辑 & $\dddot{0}$ & $\stackrel{3}{8}$ & t? & జֶ̃ \\
\hline 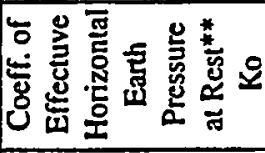 & ?ำ & 8 & $\stackrel{8}{=}$ & $\stackrel{8}{-}$ & i্ & $\int_{i}$ & ?ִ & 8 & $\stackrel{8}{\mathscr{C}}$ & $\stackrel{8}{=}$ & $\frac{\pi}{0}$ & $\stackrel{2}{0}$ & भิ \\
\hline 总密 & חֶ: & તું & $\mid \begin{array}{l}\infty \\
\infty \\
0 \\
0\end{array}$ & జ్ & 量 & 8 & 8 & శ్తి & 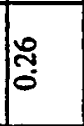 & $\stackrel{n}{0}$ & $\frac{\pi}{0}$ & $\frac{0}{0}$ & 8 \\
\hline 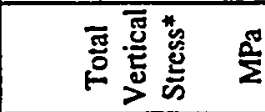 & 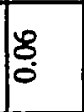 & If & $\underset{\text { స̃ }}{\tilde{N}}$ & দ্ & : & $\frac{\partial}{0}$ & $\frac{5}{0}$ & $\underset{\substack{\infty \\
\hdashline \\
\hdashline}}{\infty}$ & 战 & 疋 & 我 & స్ & $\bar{্}$ \\
\hline 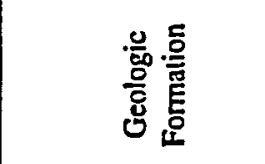 & 㝕 & 店 & 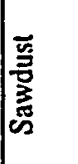 & 居 & E & 需 & 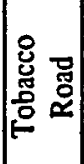 & ट्ञ & $\frac{\mathscr{E}}{5}$ & 居总 & 逆 & 㸃 & 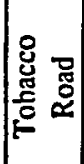 \\
\hline 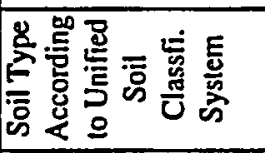 & $y$ & u & $E$ & I & U & U & $y$ & U & $\mid \begin{array}{l}0 \\
2 \\
0 \\
\vdots \\
5\end{array}$ & u & 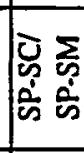 & 倠 & I \\
\hline 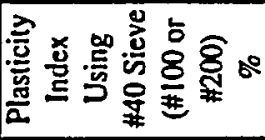 & $\bar{m} \widehat{\sigma}$ & $\bar{N}$ & $\approx \widetilde{\Xi}$ & in 8 & $\stackrel{E}{\infty}$ & $\approx \widetilde{్}$ & 果 & $\approx$ & $\approx \underset{\Xi}{\Xi}$ & $\nabla_{1}$ & |ন & $\bar{\sigma}$ & 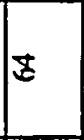 \\
\hline 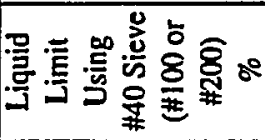 & กิ \& & $\sigma \widehat{\Xi}$ & $\overline{\bar{s}}$ & $\infty \frac{\bar{m}}{=}$ & 8 & $n$ 을 & $\bar{\nabla}$ & t웅 & $\infty \frac{8}{3}$ & 8 & $n$ & in & स \\
\hline 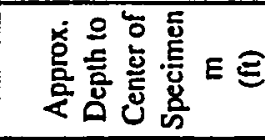 & mo & 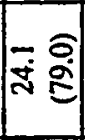 & : & : & $\underset{*}{0} \cong$ & $\div \sqrt{2}$ & 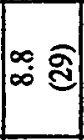 & $\widehat{\vec{v}} \stackrel{\widehat{\theta}}{=}$ & $\frac{\sigma}{\%}$ & $\frac{\sigma}{\dot{m}}$ & 家 & -。․․ & 至 \\
\hline 言最占 & $\frac{5}{2}$ & 路 & 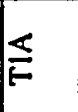 & 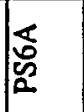 & 岕 & $\frac{5}{\frac{5}{5}}$ & $\frac{1}{5}$ & 焦 & 帒 & 希 & 傍 & $\leqslant$ & 袋 \\
\hline 党 & 畄 & 造 & 这 & 遌富 & 墕 & E 产 & 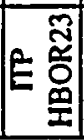 & E & E & $\frac{\alpha}{2} \bar{z}$ & 解 & $\frac{\varangle}{\tilde{c}}$ & II \\
\hline
\end{tabular}


Table 5 Specimens Used in Correlation Study for which no Plasticity Index were Measured

\begin{tabular}{|c|c|c|c|c|c|c|c|c|c|c|}
\hline $\begin{array}{c}\text { Borehole } \\
\text { Ident. } \\
\text { Number }\end{array}$ & $\begin{array}{c}\text { Sample } \\
\text { Tube } \\
\text { Number }\end{array}$ & $\begin{array}{c}\text { Approx. } \\
\text { Depth to } \\
\text { Center of } \\
\text { Specimen } \\
\mathbf{m} \\
\text { (ft) }\end{array}$ & \begin{tabular}{|c|} 
Liquid \\
Limit \\
Using \\
$\# 40$ Sieve \\
$(\# 100$ or \\
$\# 200)$ \\
$\%$ \\
\end{tabular} & $\begin{array}{c}\text { Plasticity } \\
\text { Index } \\
\text { Using } \\
\# 40 \text { Sieve } \\
(\# 100 \text { or } \\
\$ 200) \\
\% \\
\end{array}$ & \begin{tabular}{|c|} 
Soil Type \\
According \\
to Unified \\
Soil \\
Classfi. \\
System
\end{tabular} & $\begin{array}{l}\text { Geologic } \\
\text { Formation }\end{array}$ & $\begin{array}{c}\text { Total } \\
\text { Vertical } \\
\text { Stress* } \\
\text { MPa } \\
\end{array}$ & $\begin{array}{c}\text { Pore } \\
\text { Water } \\
\text { Pressure } \\
\mathrm{MPa}\end{array}$ & \begin{tabular}{|c|} 
Coeff. of \\
Effectuve \\
Horizontal \\
Earth \\
Pressure \\
at Rest** \\
Ko \\
\end{tabular} & $\begin{array}{c}\text { Estimated } \\
\text { In Sin } \\
\text { Mean } \\
\text { Effective } \\
\text { Stress } \\
\text { MPa }\end{array}$ \\
\hline $\begin{array}{c}\text { ITP } \\
\text { HBOR29 } \\
\end{array}$ & PS12-B & \begin{tabular}{|c|}
45.7 \\
$(150)$ \\
\end{tabular} & (205) & (172) & Cl & UNIDENTIFIED & 0.86 & 0.23 & 1.00 & 0.64 \\
\hline $\begin{array}{l}\text { NPR } \\
\text { DHI }\end{array}$ & 113 & $\begin{array}{c}150.0 \\
(492.0)\end{array}$ & & & SM-SC & Srapp & 2.83 & 3.05 & 1.00 & 1.78 \\
\hline $\begin{array}{l}\text { NPR } \\
\text { DHI }\end{array}$ & $158 \mathrm{X}$ & $\begin{array}{l}201.5 \\
(661.0) \\
\end{array}$ & & & $\begin{array}{l}\text { Loose } \\
\text { Sand }\end{array}$ & $\begin{array}{l}\text { Black } \\
\text { Creek }\end{array}$ & 3.80 & 1.55 & 1.00 & 2.24 \\
\hline $\begin{array}{l}\text { NPR } \\
\text { DHI }\end{array}$ & $204 X$ & $\begin{array}{c}260.1 \\
(853.3)\end{array}$ & & & $\begin{array}{l}\text { Coarse } \\
\text { Sand }\end{array}$ & Middendorf & 4.90 & 2.12 & 1.00 & 2.78 \\
\hline $\begin{array}{l}\text { PPD } \\
\text { B308 }\end{array}$ & UF $2 B$ & $\begin{array}{c}20.7 \\
(67.8) \\
\end{array}$ & & & SP-SC & Santee & 0.39 & 0.20 & 1.00 & 0.19 \\
\hline $\begin{array}{l}\text { PPD } \\
\text { B304 }\end{array}$ & UF4B & $\begin{array}{c}33.8 \\
(110.8) \\
\end{array}$ & & & SC & Santee & 0.64 & 0.21 & 1.00 & 0.42 \\
\hline $\begin{array}{l}\text { PPD } \\
\text { B307 }\end{array}$ & UF5B & $\begin{array}{c}49.2 \\
(161.4)\end{array}$ & & & SC & Santee & 0.93 & 0.31 & 1.00 & 0.62 \\
\hline$\overline{B G E 2}$ & UF7C & $\begin{array}{c}11.4 \\
(37.5) \\
\end{array}$ & & & SP-SC & $\begin{array}{c}\text { Dry } \\
\text { Branch }\end{array}$ & 0.21 & 0.00 & 1.50 & $\overline{0.29}$ \\
\hline BGE2 & UFIOC & $\begin{array}{c}20.2 \\
(66.2) \\
\end{array}$ & & & SP-SC & $\begin{array}{c}\text { Dry } \\
\text { Branch }\end{array}$ & 0.38 & 0.00 & 1.00 & 0.38 \\
\hline BGEB45 & BS1 & $\begin{array}{l}3.7 \\
(12) \\
\end{array}$ & & & $\overline{S C}$ & $\begin{array}{c}\text { Tobacco } \\
\text { Road }\end{array}$ & 0.07 & 0.00 & 1.50 & 0.09 \\
\hline $\begin{array}{l}\text { LRA } \\
\text { L202 }\end{array}$ & UFI & $\begin{array}{c}9.0 \\
(29.5) \\
\end{array}$ & & & SC & $\begin{array}{c}\text { Tobacco } \\
\text { Road }\end{array}$ & 0.17 & 0.04 & 0.75 & 0.11 \\
\hline $\begin{array}{l}\text { LRA } \\
\text { L205 }\end{array}$ & UF5 & $\begin{array}{c}25.4 \\
(83.4) \\
\end{array}$ & & & $\overline{S P}$ & $\begin{array}{c}\text { Dry } \\
\text { Branch }\end{array}$ & 0.48 & 0.16 & 0.75 & 0.27 \\
\hline $\begin{array}{l}\text { LRA } \\
\text { L205 }\end{array}$ & UP9 & $\begin{array}{c}39.0 \\
(128.0) \\
\end{array}$ & & & $S C$ & Santee & 0.73 & 0.29 & 0.50 & 0.30 \\
\hline $\begin{array}{l}\text { LPD } \\
\text { S-103 }\end{array}$ & UD-2B & $\begin{array}{c}5.9 \\
(19.4) \\
\end{array}$ & & & SP-SC & Upland & 0.11 & 0.00 & 1.00 & 0.11 \\
\hline $\begin{array}{l}\text { LPD } \\
\text { S-103 }\end{array}$ & UD-10C & $\begin{array}{c}11.3 \\
(37.2)\end{array}$ & & & SP-SC & $\begin{array}{c}\text { Tobacco } \\
\text { Road }\end{array}$ & 0.21 & 0.05 & 0.75 & 0.13 \\
\hline $\begin{array}{l}\text { LPD } \\
S-102\end{array}$ & UD-8C & $\begin{array}{l}7.3 \\
(24)\end{array}$ & & & SP-SC & $\begin{array}{c}\text { Tobacco } \\
\text { Road }\end{array}$ & 0.14 & 0.02 & 0.75 & 0.10 \\
\hline$\overline{\text { SFSBR2 }}$ & UD.2A & $\begin{array}{l}7.6 \\
(25) \\
\end{array}$ & & & 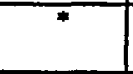 & $\begin{array}{c}\text { Tobacco } \\
\text { Road }\end{array}$ & 0.14 & 0.00 & 1.50 & 0.19 \\
\hline SFSBR2 & UD-AA & $\begin{array}{l}13.7 \\
(45) \\
\end{array}$ & & & * & $\begin{array}{c}\text { Tobacco } \\
\text { Road }\end{array}$ & 0.26 & 0.00 & 1.50 & 0.34 \\
\hline SFSBR2 & UD-8C & $\begin{array}{l}25.9 \\
(85)\end{array}$ & & & * & $\begin{array}{c}\text { Dry } \\
\text { Branch }\end{array}$ & 0.49 & 0.00 & 1.00 & 0.49 \\
\hline $\begin{array}{c}\mathrm{B} 221 \mathrm{H} \\
6 \mathrm{UB}\end{array}$ & $29 \mathrm{U}-\mathrm{C}$ & $\begin{array}{c}26.3 \\
(86.2)\end{array}$ & & & SP-SM & $\begin{array}{c}\text { Dry } \\
\text { Branch }\end{array}$ & 0.50 & 0.13 & 1.00 & 0.36 \\
\hline $\begin{array}{l}\text { B221H } \\
\text { GUC }\end{array}$ & $30-C$ & $\begin{array}{r}7.9 \\
(26) \\
\end{array}$ & & & SC-SM & $\begin{array}{c}\text { Tobacco } \\
\text { Road }\end{array}$ & 0.15 & 0.00 & 150 & 0.20 \\
\hline $\begin{array}{c}\text { B22IH } \\
12 \mathrm{U}\end{array}$ & 17U-B & $\begin{array}{l}15.5 \\
(51) \\
\end{array}$ & & & $\overline{S M}$ & $\begin{array}{c}\text { Dry } \\
\text { Branch }\end{array}$ & 0.29 & 0.03 & 1.00 & 0.26 \\
\hline $\begin{array}{c}\text { B221H } \\
13 U\end{array}$ & IU-C & $\begin{array}{l}6.4 \\
(21)\end{array}$ & & & SC & $\begin{array}{c}\text { Tobacco } \\
\text { Road }\end{array}$ & 0.12 & 0.00 & 1.50 & 0.16 \\
\hline $\begin{array}{c}\text { B221H } \\
\text { 6UC }\end{array}$ & $7 U \cdot B$ & $\begin{array}{l}11.0 \\
(36)\end{array}$ & & & SM-SC & $\begin{array}{c}\text { Tobacco } \\
\text { Road }\end{array}$ & 0.21 & 0.00 & 1.50 & 0.28 \\
\hline $\begin{array}{c}\mathrm{B} 221 \mathrm{H} \\
12 \mathrm{U} \\
\end{array}$ & 29U-B & $\begin{array}{c}25.1 \\
(82.5)\end{array}$ & & & SM & $\begin{array}{c}\text { Dry } \\
\text { Branch }\end{array}$ & 0.47 & 0.13 & 1.00 & 0.34 \\
\hline
\end{tabular}

- Based on an average total unit weight of 120 pcf.

** Based on advice from Mr. James Cameron of WSRC.

SRS-FR-CDP-95, rev. 0, 13 September 95 
Table 6 Boring Logs Used for Identification of Geologic Formations of Soil Specimens Dynamically Tested at SRS

\begin{tabular}{|c|c|c|c|c|c|c|c|c|c|c|c|}
\hline \multirow[b]{3}{*}{$\begin{array}{l}\text { GEOLOGIC } \\
\text { FORMATION }\end{array}$} & \multicolumn{10}{|c|}{ BORING LOGS USED TO IDENTIFY GEOLOGIC FORMATIONS } & \multirow{3}{*}{$\begin{array}{c}\text { NUMBER } \\
\text { OF } \\
\text { SPECIMENS }\end{array}$} \\
\hline & \multicolumn{2}{|c|}{ CFDI } & \multicolumn{2}{|c|}{ CFD18 } & \multicolumn{2}{|c|}{ MMP-2SB . } & \multicolumn{2}{|c|}{\begin{tabular}{|l|} 
MMP-3SB \\
\end{tabular}} & \multicolumn{2}{|c|}{ MMP-4SB } & \\
\hline & $\begin{array}{c}\text { TOP OF } \\
\text { LAYER * } \\
\text { (ft) }\end{array}$ & $\begin{array}{c}\text { LAYER } \\
\text { THICK- } \\
\text { NESS } \\
(\mathrm{ft}) \\
\end{array}$ & $\begin{array}{c}\text { TOP OF } \\
\text { LAYER * } \\
\text { (ft) }\end{array}$ & \begin{tabular}{|c|} 
LAYER \\
THICK- \\
NESS \\
(fi) \\
\end{tabular} & $\begin{array}{c}\text { TOP OF } \\
\text { LAYER * } \\
\text { (ft) }\end{array}$ & \begin{tabular}{|c|} 
LAYER \\
THICK- \\
NESS \\
(fi) \\
\end{tabular} & $\begin{array}{c}\text { TOP OF } \\
\text { LAYER * } \\
\text { (ft) }\end{array}$ & \begin{tabular}{|c|} 
LAYER \\
THICK- \\
NESS \\
(fi) \\
\end{tabular} & $\begin{array}{c}\text { TOP OF } \\
\text { LAYER * } \\
\text { (ft) }\end{array}$ & \begin{tabular}{|c|} 
LAYER \\
THICK- \\
NESS \\
(fi)
\end{tabular} & \\
\hline UPLAND & 269 & 28 & 248 & 34 & 287 & 50 & 265 & 30 & 354 & 24 & 3 \\
\hline TOBACCO ROAD & 241 & 25 & 214 & 22 & 237 & 22 & 235 & 17 & 330 & 23 & 19 \\
\hline DRY BRANCH & 216 & 37 & 192 & 42 & 215 & 40 & 218 & 76 & 307 & 29 & 14 \\
\hline SANTEE & 179 & 62 & 150 & 95 & 175 & 65 & 142 & 39 & 278 & 46 & 16 \\
\hline WARLEY HILL & 117 & 13 & 55 & 5 & $* *$ & 0 & 103 & 5 & 232 & 27 & 1 \\
\hline CONGAREE & 104 & 52 & 50 & 25 & 110 & 60 & 98 & 53 & 205 & 37 & 1 \\
\hline $\begin{array}{c}\text { FOUR MILE } \\
\text { (FISHBURNE)*** }\end{array}$ & 52 & 30 & 25 & 28 & 50 & 13 & 45 & 28 & 168 & 28 & 0 \\
\hline $\begin{array}{c}\text { SNAPP } \\
\text { (WILLIAMSBURG) }^{* * *}\end{array}$ & 22 & 27 & -3 & 12 & 37 & 4 & 17 & 41 & $* *$ & 0 & 5 \\
\hline $\begin{array}{c}\text { LANG SYNE } \\
\text { SAWDUST LANDING } \\
\text { (ELLENTON)**** }\end{array}$ & -5 & 182 & -15 & 40 & 33 & 53 & -24 & 78 & 140 & 56 & 2 \\
\hline $\begin{array}{c}\text { STEEL CREEK } \\
\text { (PEEDEE)*** }\end{array}$ & ** & 0 & -55 & 75 & -20 & 118 & -102 & 75 & 84 & 146 & 0 \\
\hline BLACK CREEK & .187 & 261 & -130 & 270 & -138 & 300 & -177 & 298 & -62 & 191 & 6 \\
\hline MIDDENDORF & -448 & 138 & -400 & 255 & -438 & 162 & -475 & 135 & -253 & 132 & 2 \\
\hline CAPE FEAR & -586 & & -655 & 140 & -600 & 70 & -610 & 153 & -385 & 9 & 2 \\
\hline BASEMENT & $* * * *$ & $* * * *$ & -795 & $* * * *$ & -670 & $* * * *$ & -763 & $* * * *$ & -394 & $* * * *$ & 0 \\
\hline
\end{tabular}

* Elevation of top of layer from horing log.

을 $\quad$ Formation not encountered in boring.

$\stackrel{\omega}{\omega} \quad * * *$ Older name sometimes associated with geologic formation.

**** Boring terminated before encountering top and/or bottom of formation.

Note: Out of the 75 specimens used in the correlation study, two of them still have not been identified. Also two other specimens, which were recovered from a fill, are not presented in this table. 
Table 7 Listing of All Specimens Considered in Developing the Correlation for the Dry Branch and Santee Sands

\begin{tabular}{|c|c|c|c|c|c|c|c|c|c|c|c|}
\hline $\begin{array}{l}\text { Barebole } \\
\text { Ident. } \\
\text { Number }\end{array}$ & $\begin{array}{c}\text { Sample } \\
\text { Tube } \\
\text { Number }\end{array}$ & $\begin{array}{c}\text { Approx. } \\
\text { Depth to } \\
\text { Center of } \\
\text { Specimen } \\
m \\
\text { (fi) }\end{array}$ & $\begin{array}{c}\text { Liquid } \\
\text { Limit } \\
\text { Using } \\
40 \text { Sicve } \\
\text { (1100 or } \\
100) \\
5 \\
\end{array}$ & $\begin{array}{c}\text { Plasticity } \\
\text { Index } \\
\text { Using } \\
40 \text { Sicve } \\
(* 100 \text { or } \\
* 20) \\
g \\
\end{array}$ & $\begin{array}{l}\text { Soil Type } \\
\text { Aocoming } \\
\text { to Unified } \\
\text { Soil } \\
\text { Ctassifi. } \\
\text { System }\end{array}$ & $\begin{array}{l}\text { Goologic } \\
\text { Formation }\end{array}$ & $\begin{array}{l}\text { Tolal } \\
\text { Vertical } \\
\text { Stress* } \\
\text { MPa }\end{array}$ & $\begin{array}{c}\text { Pare } \\
\text { Waler } \\
\text { Pressure"* } \\
\text { MP2 }\end{array}$ & $\begin{array}{l}\text { Coeff. of } \\
\text { Effective } \\
\text { Horizontal } \\
\text { Earh } \\
\text { Pressure } \\
\text { a Rest"* }\end{array}$ & $\begin{array}{l}\text { Esimaled } \\
\text { lo Situ } \\
\text { Mean } \\
\text { Effective } \\
\text { Stress } \\
\text { LPa }\end{array}$ & $\begin{array}{l}\text { Isolropic } \\
\text { Tesl } \\
\text { Pressure } \\
\text { kP3 }\end{array}$ \\
\hline $\begin{array}{l}\text { PBF } \\
\text { CFDI }\end{array}$ & $\overline{\text { PS4A }}$ & $\begin{array}{l}16.80 \\
(55.0) \\
\end{array}$ & $\begin{array}{c}\mathrm{NP} \\
(128) \\
\end{array}$ & $\begin{array}{c}\mathrm{NP} \\
\text { (86) }\end{array}$ & $S M$ & Dry Brach & 0.32 & 0.16 & 1.00 & 156 & 214 \\
\hline $\begin{array}{l}\text { PBF } \\
\text { CFDI }\end{array}$ & PSSA & $\begin{array}{l}24.10 \\
(79.0) \\
\end{array}$ & $\begin{array}{c}61 \\
(127)\end{array}$ & $\begin{array}{c}34 \\
(76) \\
\end{array}$ & SC & Dry Braxcb & 0.45 & 0.23 & 1.00 & 224 & 241 \\
\hline $\begin{array}{l}\text { PBF } \\
\text { CFDI }\end{array}$ & PS7A & $\begin{array}{c}32.20 \\
(1055) \\
\end{array}$ & $\begin{array}{c}\mathrm{NP} \\
(103)\end{array}$ & $\begin{array}{l}N P \\
(50)\end{array}$ & SM & Saniee & 0.61 & 0.31 & 1.00 & 296 & 317 \\
\hline $\begin{array}{c}\text { IIP } \\
\text { HEOR23 }\end{array}$ & ST4B & $\begin{array}{l}16.80 \\
(55)\end{array}$ & $\begin{array}{c}27 \\
\text { (127) }\end{array}$ & $\begin{array}{c}8 \\
(86)\end{array}$ & SP-SC & Dry Branch & 0.32 & 0.07 & 1.00 & $\overline{246}$ & 204 \\
\hline $\begin{array}{c}\text { ITP } \\
\text { HBOR29 }\end{array}$ & PSIO-B & $\begin{array}{l}42.70 \\
(140)\end{array}$ & $\begin{array}{c}46 \\
- \\
\end{array}$ & $\begin{array}{c}25 \\
-\end{array}$ & $\overline{S C}$ & Dry Branch & 0.80 & 0.20 & 1.00 & 604 & 450 \\
\hline $\begin{array}{c}\operatorname{IIP}_{\text {HBOR12 }} \\
\text { HBind }\end{array}$ & STIS-C & $\begin{array}{l}43.60 \\
(143)\end{array}$ & $\begin{array}{c}87 \\
(166) \\
\end{array}$ & $\begin{array}{c}72 \\
(127) \\
\end{array}$ & SP-SC & Sanloe & 0.82 & 0.26 & 1.00 & 561 & 470 \\
\hline $\min _{\text {HBOR29 }}$ & ST24B & $\begin{array}{l}60.00 \\
(197) \\
\end{array}$ & $\begin{array}{c}N P \\
(89)\end{array}$ & $\begin{array}{l}N P \\
(64) \\
\end{array}$ & SM & Santee & 1.13 & 0.33 & 1.00 & 800 & 824 \\
\hline RTFB2 & ST-2 & $\begin{array}{l}24.30 \\
(79.8) \\
\end{array}$ & $\begin{array}{c}\mathrm{NP} \\
- \\
\end{array}$ & NP & SP-SM & Dry Braxh & 0.46 & 0.17 & 1.00 & 288 & 331 \\
\hline RTFB3 & $\overline{\mathrm{PB}-3}$ & $\begin{array}{l}28.80 \\
(94.4) \\
\end{array}$ & $\begin{array}{l}39 \\
- \\
\end{array}$ & $\begin{array}{c}19 \\
- \\
\end{array}$ & $\bar{x}$ & Dry Braxch & 0.54 & 0.22 & 1.00 & 322 & 359 \\
\hline RTFB2 & PB-3 & $\begin{array}{c}32.30 \\
(106.0)\end{array}$ & $\begin{array}{c}\mathbf{N P} \\
-\end{array}$ & $\begin{array}{c}\text { NP } \\
-\end{array}$ & $\mathbf{S P}$ & Sалье & 0.61 & 0.21 & 1.00 & 398 & 405 \\
\hline RTFB3 & PB-S & $\begin{array}{r}47.40 \\
(155.4) \\
\end{array}$ & $\begin{array}{c}\mathrm{NP} \\
- \\
\end{array}$ & $\begin{array}{c}\mathrm{NP} \\
- \\
\end{array}$ & SM & Santece & 0.89 & 0.33 & 1.00 & 563 & 476 \\
\hline $\begin{array}{l}\text { NPR } \\
\text { DHI }\end{array}$ & $26 x$ & $\begin{array}{c}31.90 \\
(104.6) \\
\end{array}$ & $\begin{array}{l}60 \\
- \\
\end{array}$ & $\begin{array}{l}34 \\
- \\
\end{array}$ & $\overline{S C}$ & Dry Braxch & 0.60 & 0.15 & 1.00 & $45 !$ & 843 \\
\hline $\begin{array}{c}\text { NPR } \\
\text { B-6 }\end{array}$ & $6 A^{M}$ & $\begin{array}{l}66.30 \\
(2175)\end{array}$ & $\begin{array}{c}\mathrm{NP} \\
- \\
\end{array}$ & $\begin{array}{c}\mathrm{NP} \\
-\end{array}$ & SM & Santec & 1.25 & 0.46 & 1.00 & 789 & 765 \\
\hline $\begin{array}{l}\text { NPR } \\
\text { B-6 }\end{array}$ & $6 B^{M}$ & $\begin{array}{c}70.90 \\
(2325)\end{array}$ & $\begin{array}{c}\mathbf{N P} \\
-\end{array}$ & $\begin{array}{c}\text { NP } \\
- \\
\end{array}$ & SM & Santec & 1.34 & 0.51 & 1.00 & 825 & 798 \\
\hline $\begin{array}{l}\mathrm{NPR} \\
\mathrm{B}-8\end{array}$ & $8 \AA^{m}$ & $\begin{array}{c}54.10 \\
(177.6)\end{array}$ & $\begin{array}{c}\mathbf{N P} \\
- \\
\end{array}$ & $\begin{array}{c}\mathbf{N P} \\
-\end{array}$ & $5 M$ & Santec & 1.02 & 0.37 & 1.00 & 649 & 640 \\
\hline $\begin{array}{l}\text { NPR } \\
\text { B-8 }\end{array}$ & $88^{m}$ & $\begin{array}{c}57.20 \\
(187.8) \\
\end{array}$ & $\begin{array}{c}\mathbf{N P} \\
- \\
\end{array}$ & $\begin{array}{c}\mathbf{N P} \\
- \\
\end{array}$ & SMI & Sanice & 1.08 & 0.40 & 1.00 & 677 & 671 \\
\hline $\begin{array}{l}\text { PPD } \\
\text { B308 }\end{array}$ & UF2B & $\begin{array}{l}20.70 \\
(67.8) \\
\end{array}$ & 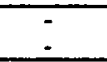 & $\because$ & SP-SC & S2ntec & 0.39 & 0.20 & 1.00 & 190 & 157 \\
\hline $\begin{array}{l}\text { PPD } \\
\text { B304 }\end{array}$ & UFAB & $\begin{array}{c}33.80 \\
(110.8) \\
\end{array}$ & - & - & $\overline{S C}$ & Saniex & 0.64 & $0.2 \mathrm{~J}$ & 1.00 & 427 & 196 \\
\hline $\begin{array}{l}\text { PPD } \\
\text { B307 }\end{array}$ & UFSB & $\begin{array}{c}49.20 \\
(161.4)\end{array}$ & 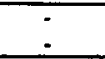 & - & $\mathbf{S C}$ & Santex & 0.93 & 0.31 & 1.00 & 617 & 412 \\
\hline $\begin{array}{l}\text { LRA } \\
\text { L2OS }\end{array}$ & UF5 & $\begin{array}{l}25.40 \\
(83,4) \\
\end{array}$ & $\therefore$ & - & $\overline{5 P}$ & Dry Branch & 0.48 & 0.16 & 0.75 & 265 & 245 \\
\hline $\begin{array}{l}\text { LRA } \\
\text { L20S }\end{array}$ & UF9 & $\begin{array}{c}39.00 \\
(128.0) \\
\end{array}$ & $\therefore$ & $\because$ & $\overline{S C}$ & Santec & 0.73 & 0.29 & 0.50 & 296 & 245 \\
\hline $\begin{array}{c}\text { KRA } \\
\text { K1006 }\end{array}$ & FPAD & $\begin{array}{c}36.00 \\
(118.1) \\
\end{array}$ & $\begin{array}{c}57 \\
- \\
\end{array}$ & $\begin{array}{l}24 \\
- \\
\end{array}$ & $\begin{array}{l}\text { SP-SCI } \\
\text { SP-SM }\end{array}$ & Santer & 0.68 & 0.14 & 0.75 & 448 & 392 \\
\hline $\begin{array}{c}\text { KRA } \\
\text { K100s }\end{array}$ & FP7A & $\begin{array}{c}38.10 \\
(125.0) \\
\end{array}$ & .75 & $\begin{array}{l}41 \\
- \\
\end{array}$ & SW-SC & Sanuec & 0.72 & 0.16 & 0.75 & 465 & 392 \\
\hline $\begin{array}{c}\text { KRA } \\
\text { K1003A }\end{array}$ & FP10B & $\begin{array}{c}40.90 \\
(134.1)\end{array}$ & $\begin{array}{l}38 \\
-\end{array}$ & 17 & SC/SM & Sandec & 0.77 & 0.19 & 0.50 & 387 & 392 \\
\hline BGE2 & UF⿱C & $\begin{array}{l}11.40 \\
(37.5)\end{array}$ & $\begin{array}{l}- \\
-\end{array}$ & - & SP-SC & Dry Braxcb & 021 & 0.00 & 1.00 & 215 & 196 \\
\hline BGE2 & UFIOC & $\begin{array}{l}20.20 \\
(66.2) \\
\end{array}$ & 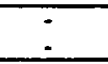 & - & SP.SC & Dry Brach & 0.38 & 0.00 & 1.00 & 380 & 491 \\
\hline SFSBR2 & UD-8C & $\begin{array}{l}25.90 \\
(85)\end{array}$ & - & 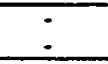 & S2nds & Dry Branch & 0.49 & 0.00 & 1.00 & 488 & 353 \\
\hline $\begin{array}{l}\text { B221H } \\
\text { GUB }\end{array}$ & $290 \mathrm{C}$ & $\begin{array}{l}26.30 \\
(86.2)\end{array}$ &. & . & SP-SM & Dry Braxch & 0.50 & 0.13 & 1.00 & 365 & 245 \\
\hline $\begin{array}{c}\text { B221H } \\
12 \mathrm{U}\end{array}$ & $290-8$ & $\begin{array}{l}25.10 \\
(82.5) \\
\end{array}$ & : & $\dot{-}$ & $S M$ & Dry Brzoch & 0.47 & 0.13 & 1.00 & 343 & 235 \\
\hline
\end{tabular}

- Breed on as average toul unit weigbt of 120 per.

- Based on advice from of WSRC persosinl.
A Specinens classified visuslly but not according to USCS.

$M$ Designation used by University of Texas 


\begin{tabular}{|c|c|c|c|c|c|c|c|c|c|c|c|c|c|c|c|c|c|c|c|c|c|c|}
\hline 总总点 & $z$ & $\overline{\bar{z}}$ & $\bar{z}$ & $\bar{\Sigma}$ & $\equiv$ & $\frac{n}{n-1}$ & I & $\underline{\underline{z}}$ & $\mathbf{E}$ & $\frac{x}{2}$ & $\underline{\underline{n}}$ & 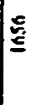 & 7 & $\underline{\underline{\Xi}}$ & $\approx$ & $\neq$ & $\underline{\underline{z}}$ & 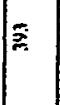 & $\equiv$ & $\vec{r}$ & $\approx$ & $E$ \\
\hline 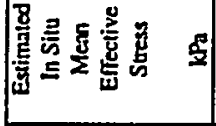 & $=$ & Z & $\overline{\underline{\Xi}}$ & $\underline{\underline{z}}$ & $\bar{\beth}$ & $\bar{x}$ & $\overline{\bar{N}}$ & $\overline{\bar{N}}$ & $\bar{j}$ & $\tilde{\Xi}$ & $\underline{E}$ & $\underline{\Xi}$ & $\bar{\xi}$ & $\underline{\underline{\underline{E}}}$ & 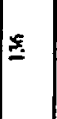 & 5 & 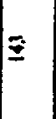 & 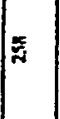 & $\underline{\underline{z}}$ & $\bar{\Xi}$ & $\frac{\bar{x}}{\bar{x}}$ & $\tilde{\approx}$ \\
\hline 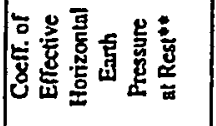 & $\underline{\underline{z}}$ & $\underline{\underline{z}}$ & $\underline{\xi}$ & $\overline{\underline{z}}$ & $\underline{\underline{z}}$ & $\Xi$ & $\Xi$ & $\Xi$ & $\overline{\underline{z}}$ & $\underline{\mathbf{E}}$ & $\underline{\underline{z}}$ & $\underline{\Xi}$ & $\overline{\underline{z}}$ & $\stackrel{\cong}{=}$ & $\stackrel{\curvearrowright}{=}$ & $\stackrel{2}{=}$ & $\underline{\underline{z}}$ & $\underline{\underline{z}}$ & $\underline{\Xi}$ & $\underline{E}$ & $\underline{\underline{z}}$ & $\overline{\mathbf{z}}$ \\
\hline 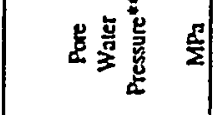 & $\stackrel{2}{=}$ & $\stackrel{5}{=}$ & $\stackrel{\bar{\Sigma}}{\Xi}$ & $\Xi$ & 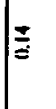 & $\stackrel{Z}{\Xi}$ & 全 & $\equiv$ & $\stackrel{2}{=}$ & $\equiv$ & $\underline{\underline{E}}$ & $\underline{\underline{\Sigma}}$ & 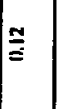 & İ & 苞 & $\cong$ & $\underline{\Xi}$ & $\overline{\mathrm{E}}$ & $\underline{\bar{E}}$ & $\underline{\Xi}$ & $\underline{\underline{\underline{E}}}$ & $\equiv$ \\
\hline 要要噌 & $\ddot{z}$ & $\bar{E}$ & $\bar{E}$ & 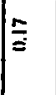 & $\stackrel{5}{\xi}$ & 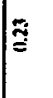 & 榇 & $\bar{E}$ & $\bar{E}$ & $\bar{\Sigma}$ & $\sum_{i}$ & 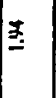 & $\underline{\underline{y}}$ & 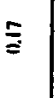 & $\bar{ঙ}$ & $\stackrel{\Sigma}{\Sigma}$ & 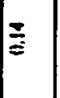 & $\stackrel{\Xi}{\cong}$ & 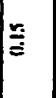 & $\equiv$ & $\bar{\Xi}$ & $\stackrel{\mathbb{Z}}{=}$ \\
\hline 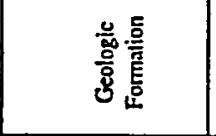 & $\mid$ & E & 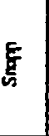 & 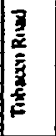 & 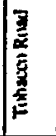 & 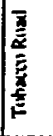 & 竞 & 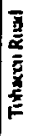 & 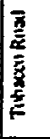 & 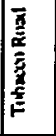 & 点 & $\xi$ & $\mid$ & 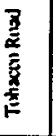 & 墨 & 重 & 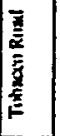 & 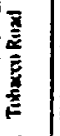 & 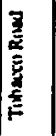 & 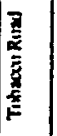 & 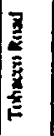 & $\mid$ \\
\hline 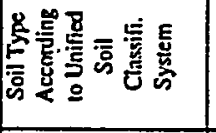 & $\sqrt{3}$ & $\bar{b}$ & $\sqrt{5}$ & $\%$ & $y$ & 4 & $\sqrt{5}$ & כે & $\tilde{z}$ & $E$ & 崖管 & $\bar{z}$ & $\Varangle$ & $y$ & 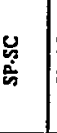 & 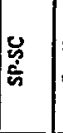 & 旁 & 言 & 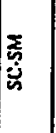 & $\psi$ & 㟧 & 浔 \\
\hline 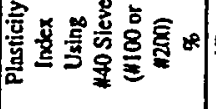 & & & & $\approx$ & & $=$ & 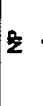 & $=$ & 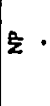 & n. & . & $\underline{z}$ & $\underline{\underline{z}}$ & & & & & & & . & & \\
\hline 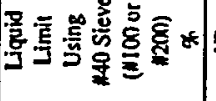 & & & & $\bar{\nabla}$ & $\Rightarrow$ 每 & 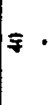 & $\varepsilon$ & $\approx$ & $\Sigma$ & $\approx$ & & E & $\mp$ & & & & & & & - & - & \\
\hline 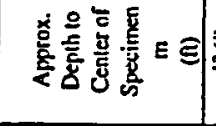 & & & & & & & & & & $\therefore$ & 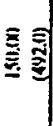 & 桑图 & 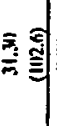 & & & & & & & & $\underline{\Xi}$ & $\underline{0}$ \\
\hline 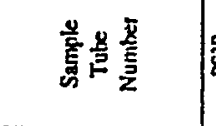 & 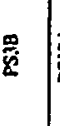 & $\underset{\leftarrow}{\overleftarrow{K}}$ & 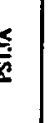 & $\frac{\underline{s}}{\dot{\varphi}}$ & 容 & $\tilde{\varepsilon}$ & $\overline{\mathbf{\varepsilon}}$ & $\tilde{\varepsilon}$ & $\overline{\dot{\varepsilon}}$ & $\vec{t}$ & $\underline{\underline{E}}$ & $\underset{\sim}{x}$ & 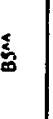 & $\overline{5}$ & 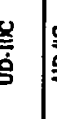 & 㟥 & ডิ & 主 & Sִ & $\underline{\underline{y}}$ & ż & 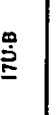 \\
\hline 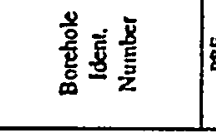 & & 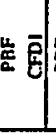 & & $E$ : & $E=$ & & $\tilde{E}$ & 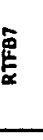 & 覀 & E & 愛言 & $\frac{2}{2} \bar{a}$ & $\frac{x}{2}$ & § & $\xi$ & $\S \bar{\square}$ & 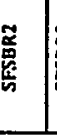 & 蓲 & & & $\bar{\Sigma}$ & $\overline{\bar{z}} \equiv$ \\
\hline
\end{tabular}




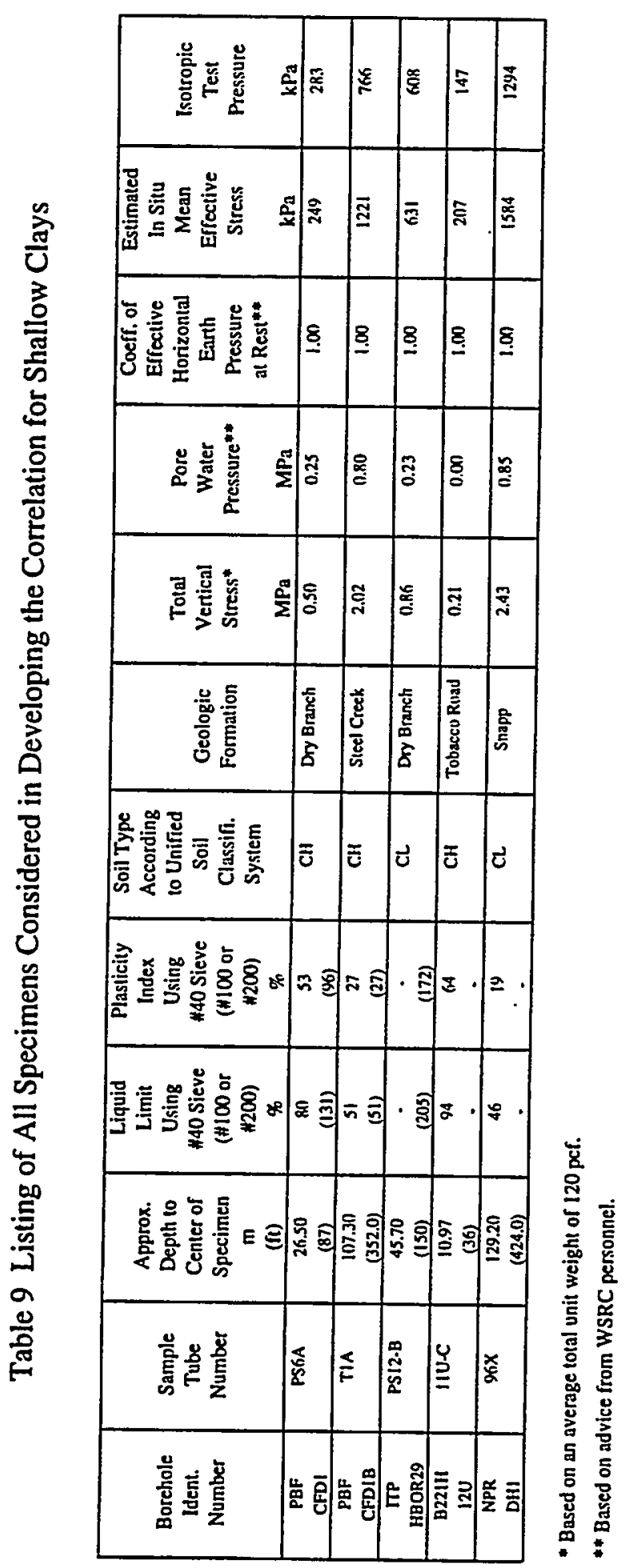


Table 10 Statistics Associated with the $\mathrm{G} / \mathrm{G}_{\max }-\log \gamma$ Relationships Determined by RC Testing of the Dry Branch Sands

\begin{tabular}{|c|c|c|c|c|c|c|c|}
\cline { 3 - 8 } \multicolumn{2}{c|}{} & \multicolumn{3}{c|}{ Based on Normal Distribution } & \multicolumn{2}{c|}{ Based on Log Normal Distribution } \\
\hline $\begin{array}{c}\text { Shearing } \\
\text { Strain }\end{array}$ & $\begin{array}{c}\text { Number } \\
\text { of } \\
\text { Samples } \\
\mathrm{n}\end{array}$ & $\begin{array}{c}\text { Mean } \\
\mathrm{G} / \mathrm{G}_{\max }\end{array}$ & $\begin{array}{c}\text { Standard } \\
\text { Deviation } \\
\sigma\end{array}$ & $\begin{array}{c}\text { Standard } \\
\text { Error of } \\
\text { the Mean } \\
\sigma / \sqrt{\mathrm{n}}\end{array}$ & $\begin{array}{c}\text { Mean } \\
\mathrm{G} / \mathrm{G}_{\max }\end{array}$ & $\begin{array}{c}\text { Standard } \\
\text { Deviation } \\
\sigma *\end{array}$ & $\begin{array}{c}\text { Standard } \\
\text { Error of } \\
\text { the Mean } \\
\sigma * / \sqrt{\mathrm{n}}\end{array}$ \\
\hline 0.0006 & 10 & 0.9934 & 0.0035 & 0.0011 & 0.9933 & 0.0015 & 0.0005 \\
\hline 0.001 & 10 & 0.9880 & 0.0054 & 0.0017 & 0.9879 & 0.0024 & 0.0008 \\
\hline 0.003 & 10 & 0.9577 & 0.0150 & 0.0047 & 0.9575 & 0.0068 & 0.0021 \\
\hline 0.006 & 10 & 0.9120 & 0.0278 & 0.0088 & 0.9116 & 0.0132 & 0.0042 \\
\hline 0.01 & 10 & 0.8572 & 0.0410 & 0.0130 & 0.8563 & 0.0207 & 0.0066 \\
\hline 0.03 & 10 & 0.6789 & 0.0673 & 0.0213 & 0.6758 & 0.0432 & 0.0137 \\
\hline 0.06 & 10 & 0.5454 & 0.0742 & 0.0235 & 0.5409 & 0.0591 & 0.0187 \\
\hline 0.1 & 10 & 0.4503 & 0.0737 & 0.0233 & 0.4449 & 0.0705 & 0.0223 \\
\hline
\end{tabular}

- Table 11 Statistics Associated with the $G / G_{\max }-\log \gamma$ Relationships Determined by RC Testing of the Santee Sands

\begin{tabular}{|c|c|c|c|c|c|c|c|}
\cline { 3 - 8 } \multicolumn{2}{c|}{} & \multicolumn{3}{c|}{ Based on Normal Distribution } & \multicolumn{2}{c|}{ Based on Log Normal Distribution } \\
\hline $\begin{array}{c}\text { Strain } \\
\%\end{array}$ & $\begin{array}{c}\text { Number } \\
\text { of } \\
\text { Samples } \\
\mathrm{n}\end{array}$ & $\begin{array}{c}\text { Mean } \\
\mathrm{G} / \mathrm{G}_{\max }\end{array}$ & $\begin{array}{c}\text { Standard } \\
\text { Deviation } \\
\sigma\end{array}$ & $\begin{array}{c}\text { Standard } \\
\text { Error of } \\
\text { the Mean } \\
\sigma / \sqrt{n}\end{array}$ & $\begin{array}{c}\text { Mean } \\
\text { G/G }\end{array}$ & $\begin{array}{c}\text { Standard } \\
\text { Deviation } \\
\sigma *\end{array}$ & $\begin{array}{c}\text { Standard } \\
\text { Error of } \\
\text { the Mean } \\
\sigma * / \sqrt{n}\end{array}$ \\
\hline 0.0006 & 15 & 0.9943 & 0.0040 & 0.0010 & 0.9943 & 0.0017 & 0.0005 \\
\hline 0.001 & 15 & 0.9898 & 0.0063 & 0.0016 & 0.9897 & 0.0028 & 0.0007 \\
\hline 0.003 & 15 & 0.9655 & 0.0171 & 0.0044 & 0.9654 & 0.0077 & 0.0020 \\
\hline 0.006 & 15 & 0.9288 & 0.0314 & 0.0081 & 0.9283 & 0.0146 & 0.0038 \\
\hline 0.01 & 15 & 0.8836 & 0.0467 & 0.0121 & 0.8825 & 0.0228 & 0.0059 \\
\hline 0.03 & 15 & 0.7245 & 0.0809 & 0.0209 & 0.7202 & 0.0487 & 0.0126 \\
\hline 0.06 & 15 & 0.5945 & 0.0905 & 0.0234 & 0.5880 & 0.0672 & 0.0174 \\
\hline 0.1 & 15 & 0.4977 & 0.0903 & 0.0233 & 0.4899 & 0.0804 & 0.0208 \\
\hline
\end{tabular}

*Used with the log of the mean $G / G_{\max }$ to calculate the mean $\pm \sigma$ 
Table 12 Statistics Associated with the $\mathrm{G} / \mathrm{G}_{\mathrm{ma}}-\log \gamma$ Relationships Determined by RC Testing of the Dry Branch and Santee Sands

\begin{tabular}{|c|c|c|c|c|c|c|c|}
\cline { 3 - 8 } \multicolumn{2}{c|}{} & \multicolumn{3}{c|}{ Based on Normal Distribution } & \multicolumn{3}{|c|}{ Based on Log Normal Distribution } \\
\hline $\begin{array}{c}\text { Strain } \\
\%\end{array}$ & $\begin{array}{c}\text { Number } \\
\text { of } \\
\text { Samples } \\
\mathrm{n}\end{array}$ & $\begin{array}{c}\text { Mean } \\
\mathrm{G} / \mathrm{G}_{\max }\end{array}$ & $\begin{array}{c}\text { Standard } \\
\text { Deviation } \\
\sigma\end{array}$ & $\begin{array}{c}\text { Standard } \\
\text { Error of } \\
\text { the Mean } \\
\sigma / \sqrt{\mathrm{n}}\end{array}$ & $\begin{array}{c}\text { Standard } \\
\text { Mean } \\
\mathrm{G}^{\prime} \mathrm{G}_{\max }\end{array}$ & $\begin{array}{c}\text { Deviation } \\
\sigma *\end{array}$ & $\begin{array}{c}\text { Standard } \\
\text { Error of } \\
\text { the Mean } \\
\sigma * / \sqrt{n}\end{array}$ \\
\hline 0.0006 & 25 & 0.9939 & 0.0037 & 0.0007 & 0.9939 & 0.0016 & 0.0003 \\
\hline 0.001 & 25 & 0.9890 & 0.0059 & 0.0012 & 0.9890 & 0.0026 & 0.0005 \\
\hline 0.003 & 25 & 0.9624 & 0.0164 & 0.0033 & 0.9622 & 0.0074 & 0.0015 \\
\hline 0.006 & 25 & 0.9221 & 0.0306 & 0.0061 & 0.9216 & 0.0144 & 0.0029 \\
\hline 0.01 & 25 & 0.8730 & 0.0456 & 0.0091 & 0.8719 & 0.0225 & 0.0045 \\
\hline 0.03 & 25 & 0.7062 & 0.0777 & 0.0155 & 0.7021 & 0.0477 & 0.0095 \\
\hline 0.06 & 25 & 0.5749 & 0.0863 & 0.0173 & 0.5687 & 0.0654 & 0.0131 \\
\hline 0.1 & 25 & 0.4787 & 0.0858 & 0.0172 & 0.4714 & 0.0779 & 0.0156 \\
\hline
\end{tabular}

Table 13 Statistics Associated with the $\mathrm{G} / \mathrm{G}_{\max }-\log \gamma$ Relationships Determined by RC Testing of the Tobacco Road Sands

\begin{tabular}{|c|c|c|c|c|c|c|c|}
\cline { 3 - 8 } \multicolumn{2}{c|}{} & \multicolumn{3}{c|}{ Based on Normal Distribution } & \multicolumn{2}{c|}{ Based on Log Normal Distribution } \\
$\begin{array}{c}\text { Strain } \\
\%\end{array}$ & $\begin{array}{c}\text { Number } \\
\text { of } \\
\text { Samples } \\
\mathrm{n}\end{array}$ & $\begin{array}{c}\text { Mean } \\
\text { G/G }\end{array}$ & $\begin{array}{c}\text { Standard } \\
\text { Deviation } \\
\sigma\end{array}$ & $\begin{array}{c}\text { Standard } \\
\text { Error of } \\
\text { the Mean } \\
\sigma / \sqrt{n}\end{array}$ & $\begin{array}{c}\text { Mean } \\
\text { G/G }\end{array}$ & $\begin{array}{c}\text { Standard } \\
\text { Deviation } \\
\sigma *\end{array}$ & $\begin{array}{c}\text { Standard } \\
\text { Error of } \\
\text { the Mean } \\
\sigma * / \sqrt{n}\end{array}$ \\
\hline 0.0006 & 14 & 0.9907 & 0.0058 & 0.0016 & 0.9907 & 0.0026 & 0.0007 \\
\hline 0.001 & 14 & 0.9825 & 0.0103 & 0.0028 & 0.9824 & 0.0046 & 0.0012 \\
\hline 0.003 & 14 & 0.9373 & 0.0309 & 0.0083 & 0.9368 & 0.0146 & 0.0039 \\
\hline 0.006 & 14 & 0.8720 & 0.0506 & 0.0135 & 0.8706 & 0.0261 & 0.0070 \\
\hline 0.01 & 14 & 0.7992 & 0.0636 & 0.0170 & 0.7967 & 0.0362 & 0.0097 \\
\hline 0.03 & 14 & 0.5901 & 0.0746 & 0.0199 & 0.5854 & 0.0582 & 0.0156 \\
\hline 0.06 & 14 & 0.4534 & 0.0707 & 0.0189 & 0.4480 & 0.0712 & 0.0190 \\
\hline 0.1 & 14 & 0.3635 & 0.0645 & 0.0172 & 0.3580 & 0.0801 & 0.0214 \\
\hline
\end{tabular}

*Used with the $\log$ of the mean $G / G_{\max }$ to calculate the mean $\pm \sigma$ 
Table 14 Statistics Associated with the $\mathrm{G} / \mathrm{G}_{\max }-\log \gamma$ Relationships Determined by RC Testing of the Snapp Sands

\begin{tabular}{|c|c|c|c|c|c|c|c|}
\cline { 3 - 8 } \multicolumn{2}{c|}{} & \multicolumn{3}{c|}{ Based on Normal Distribution } & \multicolumn{2}{|c|}{ Based on Log Normal Distribution } \\
\hline $\begin{array}{c}\text { Shearing } \\
\text { Strain }\end{array}$ & $\begin{array}{c}\text { Number } \\
\text { of } \\
\text { Samples } \\
\mathrm{n}\end{array}$ & $\begin{array}{c}\text { Mean } \\
\mathrm{G} / \mathrm{G}_{\max }\end{array}$ & $\begin{array}{c}\text { Standard } \\
\text { Deviation } \\
\sigma\end{array}$ & $\begin{array}{c}\text { Standard } \\
\text { Error of } \\
\text { the Mean } \\
\sigma / \sqrt{\mathrm{n}}\end{array}$ & $\begin{array}{c}\text { Mean } \\
\mathrm{G} / \mathrm{G}_{\max }\end{array}$ & $\begin{array}{c}\text { Standard } \\
\text { Deviation } \\
\sigma *\end{array}$ & $\begin{array}{c}\text { Standard } \\
\text { Error of } \\
\text { the Mean } \\
\sigma * / \sqrt{\mathrm{n}}\end{array}$ \\
\hline 0.0006 & 4 & 0.9795 & 0.0097 & 0.0048 & 0.9795 & 0.0043 & 0.0021 \\
\hline 0.001 & 4 & 0.9674 & 0.0127 & 0.0063 & 0.9673 & 0.0057 & 0.0028 \\
\hline 0.003 & 4 & 0.9131 & 0.0169 & 0.0085 & 0.9130 & 0.0081 & 0.0040 \\
\hline 0.006 & 4 & 0.8474 & 0.0217 & 0.0109 & 0.8472 & 0.0110 & 0.0055 \\
\hline 0.01 & 4 & 0.7811 & 0.0332 & 0.0166 & 0.7806 & 0.0184 & 0.0092 \\
\hline 0.03 & 4 & 0.6029 & 0.0656 & 0.0328 & 0.6001 & 0.0488 & 0.0244 \\
\hline 0.06 & 4 & 0.4863 & 0.0769 & 0.0384 & 0.4813 & 0.0731 & 0.0366 \\
\hline 0.1 & 4 & 0.4061 & 0.0782 & 0.0391 & 0.3999 & 0.0909 & 0.0455 \\
\hline
\end{tabular}

Table 15 Statistics Associated with the $G / G_{\max }-\log \gamma$ Relationships Determined by RC Testing of the Tobacco Road and Snapp Sands

\begin{tabular}{|c|c|c|c|c|c|c|c|}
\cline { 3 - 8 } \multicolumn{2}{c|}{} & \multicolumn{3}{c|}{ Based on Normal Distribution } & \multicolumn{3}{|c|}{ Based on Log Normal Distribution } \\
\hline $\begin{array}{c}\text { Strain } \\
\%\end{array}$ & $\begin{array}{c}\text { Number } \\
\text { of } \\
\text { Samples } \\
\mathrm{n}\end{array}$ & $\begin{array}{c}\text { Mean } \\
\mathrm{G} / \mathrm{G}_{\max }\end{array}$ & $\begin{array}{c}\text { Standard } \\
\text { Deviation } \\
\sigma\end{array}$ & $\begin{array}{c}\text { Standard } \\
\text { Error of } \\
\text { the Mean } \\
\sigma / \sqrt{n}\end{array}$ & $\begin{array}{c}\text { Mean } \\
\text { G/G }\end{array}$ & $\begin{array}{c}\text { Deviation } \\
\sigma *\end{array}$ & $\begin{array}{c}\text { Standard } \\
\text { Error of } \\
\text { the Mean } \\
\sigma * / \sqrt{n}\end{array}$ \\
\hline 0.0006 & 18 & 0.9882 & 0.0081 & 0.0019 & 0.9882 & 0.0036 & 0.0008 \\
\hline 0.001 & 18 & 0.9791 & 0.0123 & 0.0029 & 0.9790 & 0.0055 & 0.0013 \\
\hline 0.003 & 18 & 0.9319 & 0.0298 & 0.0070 & 0.9314 & 0.0140 & 0.0033 \\
\hline 0.006 & 18 & 0.8665 & 0.0464 & 0.0109 & 0.8653 & 0.0238 & 0.0056 \\
\hline 0.01 & 18 & 0.7952 & 0.0578 & 0.0136 & 0.7931 & 0.0328 & 0.0077 \\
\hline 0.03 & 18 & 0.5929 & 0.0710 & 0.0167 & 0.5886 & 0.0551 & 0.0130 \\
\hline 0.06 & 18 & 0.4607 & 0.0712 & 0.0168 & 0.4552 & 0.0707 & 0.0167 \\
\hline 0.1 & 18 & 0.3730 & 0.0678 & 0.0160 & 0.3669 & 0.0824 & 0.0194 \\
\hline
\end{tabular}

*Used with the log of the mean $G / G_{\max }$ to calculate the mean $\pm \sigma$ 

Table 16 Statistics Associated with the $\mathrm{G} / \mathrm{G}_{\max }-\log \gamma$ Relationships Determined by
RC Testing of the Shallow Clays

\begin{tabular}{|c|c|c|c|c|c|c|c|}
\cline { 3 - 8 } & \multicolumn{3}{c|}{ Based on Normal Distribution } & \multicolumn{3}{c|}{ Based on Log Normal Distribution } \\
Strain & $\begin{array}{c}\text { Number } \\
\text { of } \\
\text { Samples } \\
\mathrm{n}\end{array}$ & $\begin{array}{c}\text { Mean } \\
\mathrm{G} / \mathrm{G}_{\max }\end{array}$ & $\begin{array}{c}\text { Standard } \\
\text { Deviation } \\
\sigma\end{array}$ & $\begin{array}{c}\text { Standard } \\
\text { Error of } \\
\text { the Mean } \\
\sigma / \sqrt{n}\end{array}$ & $\begin{array}{c}\text { Mean } \\
\text { G/G }\end{array}$ & $\begin{array}{c}\text { Standard } \\
\text { Deviation } \\
\sigma *\end{array}$ & $\begin{array}{c}\text { Standard } \\
\text { Error of } \\
\text { the Mean } \\
\sigma * / \sqrt{n}\end{array}$ \\
\hline 0.0006 & 4 & 0.9990 & 0.0017 & 0.0008 & 0.9990 & 0.0007 & 0.0004 \\
\hline 0.001 & 4 & 0.9981 & 0.0024 & 0.0012 & 0.9981 & 0.0011 & 0.0005 \\
\hline 0.003 & 4 & 0.9933 & 0.0067 & 0.0034 & 0.9932 & 0.0030 & 0.0015 \\
\hline 0.006 & 4 & 0.9828 & 0.0105 & 0.0052 & 0.9827 & 0.0046 & 0.0023 \\
\hline 0.01 & 4 & 0.9638 & 0.0108 & 0.0054 & 0.9637 & 0.0049 & 0.0025 \\
\hline 0.03 & 4 & 0.8331 & 0.0582 & 0.0291 & 0.8315 & 0.0312 & 0.0156 \\
\hline 0.06 & 4 & 0.6881 & 0.1149 & 0.0574 & 0.6803 & 0.0775 & 0.0388 \\
\hline 0.1 & 4 & 0.5740 & 0.1390 & 0.0695 & 0.5600 & 0.1149 & 0.0575 \\
\hline
\end{tabular}

*Used with the $\log$ of the mean $G / G_{\max }$ to calculate the mean $\pm \sigma$ 
Table 17 Comparison Between the $G / G_{\max }-\log \gamma$ Relationships for the Dry Branch Sands and Santee Sands

\begin{tabular}{|c|c|c|c|c|c|c|c|c|c|c|}
\hline \multirow{2}{*}{$\begin{array}{c}\text { Shearing } \\
\text { Strain }\end{array}$} & $\begin{array}{c}\text { Number } \\
\text { of } \\
\%\end{array}$ & $\begin{array}{c}\text { Samples } \\
\mathrm{n}\end{array}$ & $\begin{array}{c}\text { Mean } \\
\mathrm{G} / \mathrm{G}_{\max }\end{array}$ & $\begin{array}{c}\text { Variance } \\
\sigma^{2}\end{array}$ & $\begin{array}{c}\text { Number } \\
\text { of } \\
\text { Samples } \\
\mathrm{n}\end{array}$ & $\begin{array}{c}\text { Mean } \\
\mathrm{G} / \mathrm{G}_{\max }\end{array}$ & $\begin{array}{c}\text { Variance } \\
\sigma^{2}\end{array}$ & $\begin{array}{c}\text { Pooled } \\
\text { Variance } \\
\sigma_{\text {pooled }}^{2}\end{array}$ & $\begin{array}{c}\text { Degrees } \\
\text { of } \\
\text { Freedom }\end{array}$ & $\begin{array}{c}\text { teritical }_{\text {cral }} \\
\text { Confidence } \\
\text { Interval }\end{array}$ \\
\hline 0.0006 & 10 & 0.9934 & 0.0000 & 15 & 0.9943 & 0.0000 & 0.0000 & 23 & 2.07 & {$[0.0023,-0.0041]$} \\
\hline 0.001 & 10 & 0.9880 & 0.0000 & 15 & 0.9898 & 0.0000 & 0.0000 & 23 & 2.07 & {$[0.0032,-0.0069]$} \\
\hline 0.003 & 10 & 0.9577 & 0.0002 & 15 & 0.9655 & 0.0003 & 0.0003 & 23 & 2.07 & {$[0.0059,-0.0216]$} \\
\hline 0.006 & 10 & 0.9120 & 0.0008 & 15 & 0.9288 & 0.0010 & 0.0009 & 23 & 2.07 & {$[0.0085,-0.0423]$} \\
\hline 0.01 & 10 & 0.8572 & 0.0017 & 15 & 0.8836 & 0.0022 & 0.0020 & 23 & 2.07 & {$[0.0113,-0.0641]$} \\
\hline 0.03 & 10 & 0.6789 & 0.0045 & 15 & 0.7245 & 0.0065 & 0.0058 & 23 & 2.07 & {$[0.0185,-0.1097]$} \\
\hline 0.06 & 10 & 0.5454 & 0.0055 & 15 & 0.5945 & 0.0082 & 0.0071 & 23 & 2.07 & {$[0.0223,-0.1206]$} \\
\hline 0.1 & 10 & 0.4503 & 0.0054 & 15 & 0.4977 & 0.0082 & 0.0071 & 23 & 2.07 & {$[0.0238,-0.1186]$} \\
\hline
\end{tabular}

Table 18. Comparison Between the $\mathrm{G} / \mathrm{G}_{\max }-\log \gamma$ Relationships for the Tobacco Road Sands and Snapp Sands

\begin{tabular}{|c|c|c|c|c|c|c|c|c|c|c|}
\hline \multirow[b]{2}{*}{$\begin{array}{c}\text { Shearing } \\
\text { Strain } \\
\%\end{array}$} & \multicolumn{3}{|c|}{ Tobacco Road Sands } & \multicolumn{3}{|c|}{ Snapp Sands } & \multirow[b]{2}{*}{$\begin{array}{c}\text { Pooled } \\
\text { Variance } \\
\sigma^{2} \text { pooled }\end{array}$} & \multirow[b]{2}{*}{$\begin{array}{l}\text { Degrees } \\
\text { of } \\
\text { Freedom }\end{array}$} & \multirow[b]{2}{*}{$t_{\text {critical }}$} & \multirow[b]{2}{*}{$\begin{array}{c}95 \% \\
\text { Confidence } \\
\text { Interval }\end{array}$} \\
\hline & $\begin{array}{c}\text { Number } \\
\text { of } \\
\text { Samples } \\
n\end{array}$ & $\begin{array}{c}\text { Mean } \\
\text { G/G } \max \end{array}$ & $\begin{array}{c}\text { Variance } \\
\sigma^{2}\end{array}$ & $\begin{array}{c}\text { Number } \\
\text { of } \\
\text { Samples } \\
n \\
\end{array}$ & $\underset{\mathrm{G} / \mathrm{G}_{\max }}{\text { Mean }}$ & $\begin{array}{c}\text { Variance } \\
\sigma^{2}\end{array}$ & & & & \\
\hline 0.0006 & 14 & 0.9907 & 0.0000 & 4 & 0.9795 & 0.0001 & 0.0000 & 16 & 2.12 & {$[0.0193,0.0031]$} \\
\hline $\begin{array}{l}0.001 \\
0.003\end{array}$ & 14 & 0.9825 & 0.0001 & 4 & 0.9674 & 0.0002 & 0.0001 & 16 & 2.12 & {$[0.0281,0.0021]$} \\
\hline$\frac{0.003}{0.006}$ & 14 & 0.9373 & 0.0010 & 4 & 0.9131 & 0.0003 & 0.0008 & 16 & 2.12 & {$[0.0588,-0.0105]$} \\
\hline$\frac{0.006}{0.01}$ & $\frac{14}{14}$ & 0.8720 & 0.0026 & 4 & 0.8474 & 0.0005 & 0.0022 & 16 & 2.12 & {$[0.0806,-0.0313]$} \\
\hline 0.03 & $\frac{14}{14}$ & 0.7992 & 0.0040 & 4 & 0.7811 & 0.0011 & 0.0035 & 16 & 2.12 & {$[0.0891,-0.0530]$} \\
\hline 0.06 & $\frac{14}{14}$ & 0.5901 & 0.0056 & 4 & 0.6029 & 0.0043 & 0.0053 & 16 & 2.12 & {$[0.0749,-0.1005]$} \\
\hline 0.1 & $\frac{14}{14}$ & $\frac{0.4534}{0.3635}$ & 0.0050 & 4 & 0.4863 & 0.0059 & 0.0052 & 16 & 2.12 & {$[0.0536,-0.1193]$} \\
\hline & & 0.3635 & 0.0042 & 4 & 0.4061 & 0.0061 & 0.0045 & 16 & 2.12 & {$[0.0382,-0.1235]$} \\
\hline
\end{tabular}


Table 19. Comparison Between the $\mathrm{G} / \mathrm{G}_{\max }-\log \gamma$ Relationships for the Dry Branch and Santee Sands and the Tobacco Road and Snapp Sands

\begin{tabular}{|c|c|c|c|c|c|c|c|c|c|c|}
\hline \multirow[b]{2}{*}{$\begin{array}{c}\text { Shearing } \\
\text { Strain } \\
\%\end{array}$} & \multicolumn{3}{|c|}{ Dry Branch and Santee Sands } & \multicolumn{3}{|c|}{ Tobacco Road and Snapp Sands } & \multirow[b]{2}{*}{$\begin{array}{c}\text { Pooled } \\
\text { Variance } \\
\sigma^{2} \text { pooled }\end{array}$} & \multirow[b]{2}{*}{$\begin{array}{c}\text { Degrees } \\
\text { of } \\
\text { Freedom }\end{array}$} & \multirow[b]{2}{*}{$\begin{array}{c}t_{c r i t i c a} \\
1\end{array}$} & \multirow[b]{2}{*}{$\begin{array}{c}95 \% \\
\text { Confidence } \\
\text { Interval }\end{array}$} \\
\hline & $\begin{array}{c}\text { Number } \\
\text { of } \\
\text { Samples } \\
n\end{array}$ & $\begin{array}{c}\text { Mean } \\
G / G_{\max }\end{array}$ & $\begin{array}{c}\text { Variance } \\
\sigma^{2}\end{array}$ & $\begin{array}{c}\text { Number } \\
\text { of } \\
\text { Samples } \\
n\end{array}$ & $\begin{array}{c}\text { Mean } \\
G / G_{\max }\end{array}$ & $\begin{array}{c}\text { Variance } \\
\sigma^{2}\end{array}$ & & & & \\
\hline 0.0006 & 25 & 0.9939 & 0.0000 & 18 & 0.9882 & 0.0001 & 0.0000 & 41 & 2.02 & {$[0.0094,0.0020]$} \\
\hline 0.001 & 25 & 0.9890 & 0.0000 & 18 & 0.9791 & 0.0002 & 0.0001 & 41 & 2.02 & {$[0.0156,0.0042]$} \\
\hline 0.003 & 25 & 0.9624 & 0.0003 & 18 & 0.9319 & 0.0009 & 0.0005 & 41 & 2.02 & {$[0.0448,0.0161]$} \\
\hline 0.006 & 25 & 0.9221 & 0.0009 & 18 & 0.8665 & 0.0022 & 0.0014 & 41 & 2.02 & {$[0.0793,0.0318]$} \\
\hline 0.01 & 25 & 0.8730 & 0.0021 & 18 & 0.7952 & 0.0033 & 0.0026 & 41 & 2.02 & {$[0.1097,0.0460]$} \\
\hline 0.03 & 25 & 0.7062 & 0.0060 & 18 & 0.5929 & 0.0050 & 0.0056 & 41 & 2.02 & {$[0.1601,0.0665]$} \\
\hline 0.06 & 25 & 0.5749 & 0.0075 & 18 & 0.4607 & 0.0051 & 0.0065 & 41 & 2.02 & {$[0.1644,0.0640]$} \\
\hline 0.1 & 25 & 0.4787 & 0.0074 & 18 & 0.3730 & 0.0046 & 0.0062 & 41 & 2.02 & {$[0.1549,0.0565]$} \\
\hline
\end{tabular}

Table 20. Comparison Between the $\mathrm{G} / \mathrm{G}_{\max }-\log \gamma$ Relationships for the Dry Branch and Santee Sands and the Shallow Clays

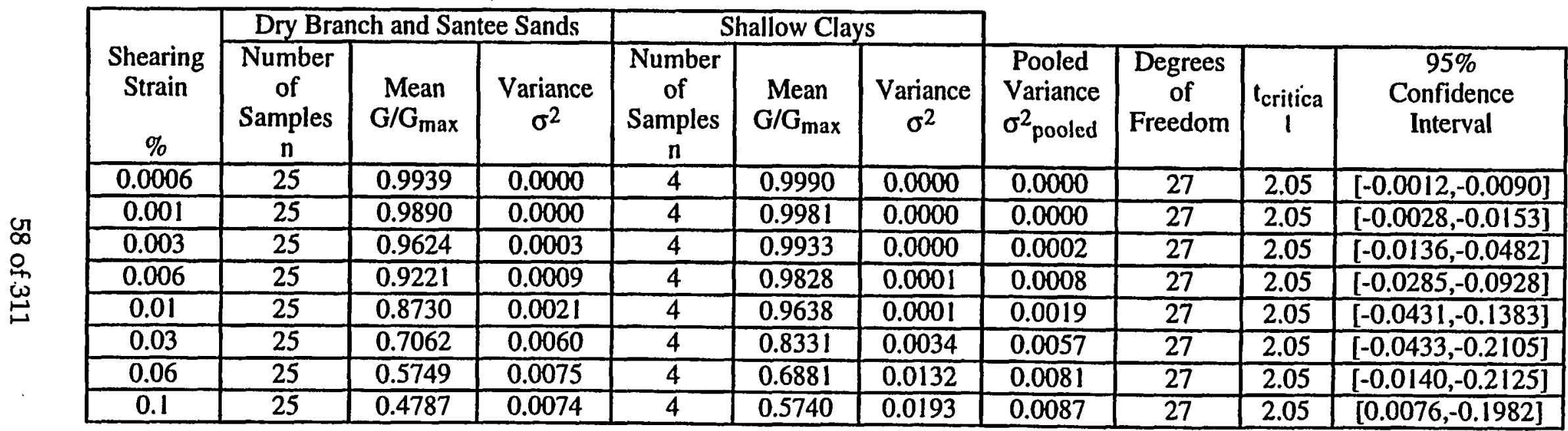


Table 21 Listing of All Specimens Considered in Developing the Correlation for the Upland Sands

రొ

\begin{tabular}{|c|c|c|c|c|c|c|c|c|c|c|c|}
\hline $\begin{array}{l}\text { Borchole } \\
\text { Ident. } \\
\text { Number }\end{array}$ & $\begin{array}{c}\text { Sample } \\
\text { Tube } \\
\text { Number }\end{array}$ & $\begin{array}{l}\text { Approx. } \\
\text { Depth to } \\
\text { Center of } \\
\text { Specimen } \\
\text { m } \\
\text { (fi) }\end{array}$ & $\begin{array}{c}\text { Liquid } \\
\text { Limil } \\
\text { Using } \\
\# 40 \text { Sieve } \\
(\# 100 \text { or } \\
\text { \#200) } \\
\%\end{array}$ & $\begin{array}{c}\text { Plasticity } \\
\text { Index } \\
\text { Using } \\
\# 40 \text { Sieve } \\
(\# 100 \text { or } \\
\# 200) \\
\%\end{array}$ & $\begin{array}{l}\text { Soil Type } \\
\text { According } \\
\text { in Unified } \\
\text { Soil } \\
\text { Classifi. } \\
\text { System }\end{array}$ & $\begin{array}{l}\text { Geologic } \\
\text { Formation }\end{array}$ & $\begin{array}{l}\text { Total } \\
\text { Vertical } \\
\text { Stress* } \\
\text { MPa }\end{array}$ & $\begin{array}{c}\begin{array}{c}\text { Pore } \\
\text { Water } \\
\text { Pressure** }\end{array} \\
\mathrm{MPa}\end{array}$ & $\begin{array}{c}\text { Coeff. of } \\
\text { Effective } \\
\text { Horizontal } \\
\text { Earth } \\
\text { Pressure } \\
\text { at Rest** }\end{array}$ & $\begin{array}{c}\text { Estimated } \\
\text { In Situ } \\
\text { Mean } \\
\text { Effective } \\
\text { Stress } \\
\mathrm{kPa}\end{array}$ & $\begin{array}{c}\text { Isotropic } \\
\text { Test } \\
\text { Pressure } \\
\quad \mathbf{k P a}\end{array}$ \\
\hline $\begin{array}{c}\text { PBF } \\
\text { CFDI }\end{array}$ & PSIA & $\begin{array}{c}3.30 \\
(10.8)\end{array}$ & $\begin{array}{c}52 \\
(90) \\
\end{array}$ & $\begin{array}{c}31 \\
(5.5)\end{array}$ & SC & Upland & 0.06 & 0.03 & 1.00 & 32 & 41 \\
\hline $\begin{array}{c}\mathrm{PBF} \\
\text { CFDI }\end{array}$ & PS2A & $\begin{array}{c}7.00 \\
(23.0)\end{array}$ & $\begin{array}{c}46 \\
(6.3)\end{array}$ & $\begin{array}{c}19 \\
\text { (22) }\end{array}$ & SC & Upland & 0.13 & 0.06 & 1.00 & 72 & 9) \\
\hline $\begin{array}{l}\text { LPD } \\
\text { S. } 10.3\end{array}$ & UD-2B & $\begin{array}{l}5.90 \\
(19.4)\end{array}$ & 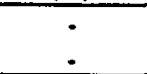 & - & SP-SC & Upland & 0.11 & 0.00 & 1.00 & III & 98 \\
\hline
\end{tabular}

* Based on an average total unit weight of 120 per.

** Based on advice from WSRC personnel. 


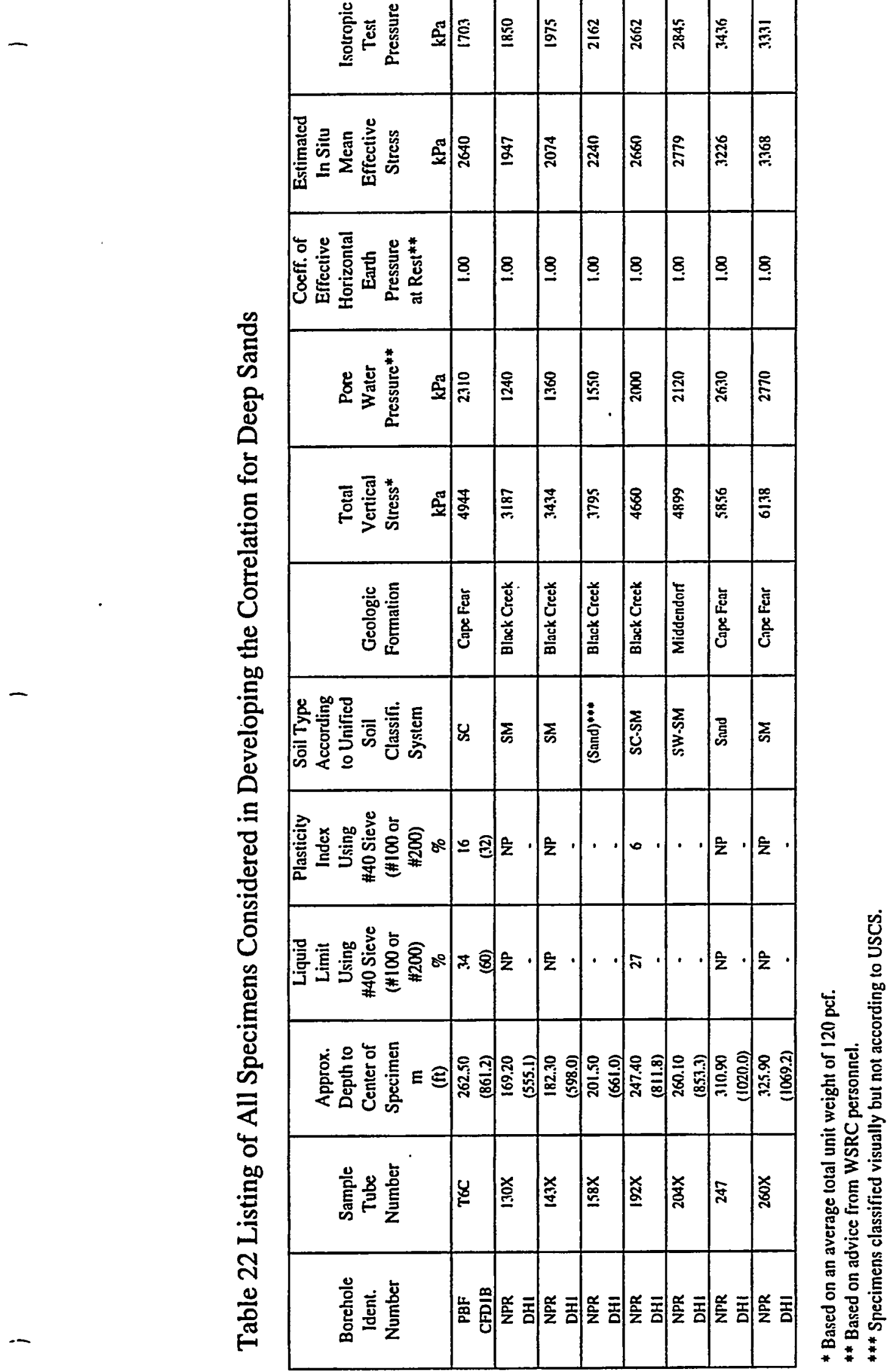

SRS-FR-CDP-95, rev. 0, 13 September 95 


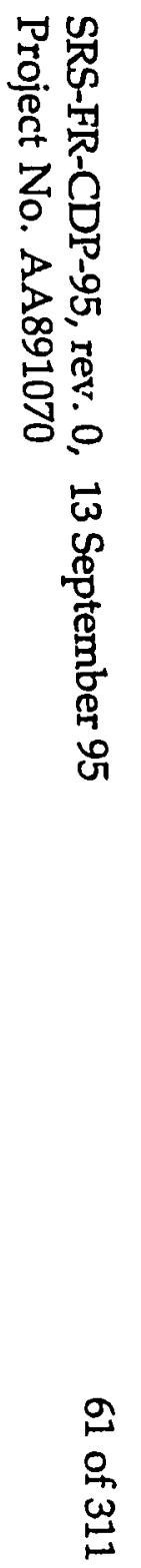

Table 23 Listing of All Specimens Considered in Developing the Correlation for Deep Clays

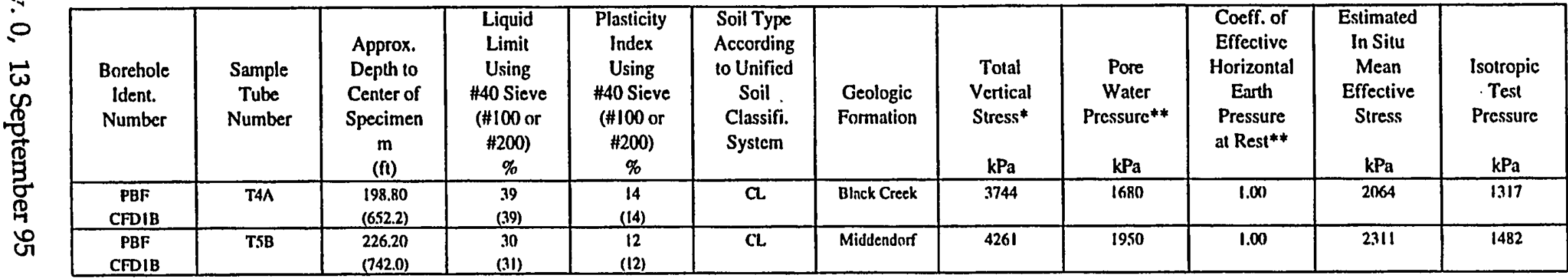

* Based on an average total unit weight of 120 pcf.

** Based on advice from WSRC personnel. 
Table 24 Statistics Associated with the $G / G_{\max }-\log \gamma$ relationships determined by RC Testing of the Shallow Sands

\begin{tabular}{|c|c|c|c|c|c|c|c|}
\cline { 3 - 8 } \multicolumn{2}{c|}{} & \multicolumn{3}{c|}{$\begin{array}{c}\text { Based on Normal } \\
\text { Distribution }\end{array}$} & \multicolumn{3}{c|}{$\begin{array}{c}\text { Based on Log Normal } \\
\text { Distribution }\end{array}$} \\
\hline $\begin{array}{c}\text { Shearing } \\
\text { Strain } \\
\%\end{array}$ & $\begin{array}{c}\text { Number } \\
\text { of } \\
\text { Samples } \\
\mathrm{n}\end{array}$ & $\begin{array}{c}\text { Mean } \\
\mathrm{G} / \mathrm{G}_{\max }\end{array}$ & $\begin{array}{c}\text { Standard } \\
\text { Deviation } \\
\sigma\end{array}$ & $\begin{array}{c}\text { Standard } \\
\text { Error of } \\
\text { the Mean } \\
\sigma / \sqrt{n}\end{array}$ & $\begin{array}{c}\text { Mean } \\
\text { G/G }\end{array}$ & $\begin{array}{c}\text { Standard } \\
\text { Deviation } \\
\sigma^{*}\end{array}$ & $\begin{array}{c}\text { Standard } \\
\text { Error. of } \\
\text { the Mean } \\
\sigma^{*} / \sqrt{n}\end{array}$ \\
\hline 0.0006 & 46 & 0.9916 & 0.0066 & 0.0010 & 0.9916 & 0.0029 & 0.0004 \\
\hline 0.001 & 46 & 0.9851 & 0.0103 & 0.0015 & 0.9850 & 0.0046 & 0.0007 \\
\hline 0.003 & 46 & 0.9505 & 0.0270 & 0.0040 & 0.9501 & 0.0125 & 0.0018 \\
\hline 0.006 & 46 & 0.9003 & 0.0458 & 0.0068 & 0.8991 & 0.0227 & 0.0033 \\
\hline 0.01 & 46 & 0.8423 & 0.0628 & 0.0093 & 0.8400 & 0.0334 & 0.0049 \\
\hline 0.03 & 46 & 0.6613 & 0.0948 & 0.0140 & 0.6545 & 0.0640 & 0.0094 \\
\hline 0.06 & 46 & 0.5302 & 0.1013 & 0.0149 & 0.5205 & 0.0851 & 0.0125 \\
\hline 0.1 & 46 & 0.4378 & 0.0986 & 0.0145 & 0.4268 & 0.1001 & 0.0148 \\
\hline
\end{tabular}

Table 25 Average Values of $D_{\min }$ and $\gamma_{\mathrm{I}}$ from RCTS Testing of the Shallow Sands at SRS.

\begin{tabular}{|c|c|c|c|c|c|c|}
\hline \multirow{2}{*}{$\begin{array}{l}\text { Geologic } \\
\text { Formation }\end{array}$} & \multicolumn{3}{|c|}{ TS Testing } & \multicolumn{3}{|c|}{ RC Testing } \\
\hline & $\begin{array}{c}\text { No. of } \\
\text { Specimens }\end{array}$ & $\begin{array}{l}\text { Avg. } D_{\min } \\
(\%)\end{array}$ & $\begin{array}{l}\operatorname{Avg} \gamma_{I} \\
(\%)\end{array}$ & $\begin{array}{c}\text { No. of } \\
\text { Specimens }\end{array}$ & $\begin{array}{l}\text { Avg. } D_{\min } \\
(\%)\end{array}$ & $\begin{array}{c}\text { Avg } \gamma_{\mathrm{r}} \\
(\%)\end{array}$ \\
\hline Upland & 2 & 1.03 & 0.0241 & 2 & 2.69 & 0.0210 \\
\hline $\begin{array}{c}\text { Tobacco } \\
\text { Road and } \\
\text { Snapp }\end{array}$ & 3 & 0.61 & 0.0558 & $18^{\circ}$ & 1.70 & 0.0441 \\
\hline $\begin{array}{l}\text { Dry Branch } \\
\text { and Santee }\end{array}$ & 3 & 0.88 & 0.0778 & 25 & 2.34 & 0.0771 \\
\hline Warley Hill & 1 & 0.44 & 0.1253 & 2 & 0.80 & 0.1100 \\
\hline Congaree & 1 & $\cdot 0.51$ & 0.0810 & 1 & 1.00 & 0.0810 \\
\hline $\begin{array}{c}\text { Overall } \\
\text { Average }\end{array}$ & 10 & $0.75^{*}$ & $0.066^{*}$ & 48 & $2.02 *$ & $0.064 *$ \\
\hline $\begin{array}{c}\text { Average } \\
\text { Used in } \\
\text { Predicting } \\
\text { Deep Sands }\end{array}$ & 8 & $0.68^{* * *}$ & $0.076^{* *}$ & 46 & $1.99 * *$ & $0.066^{* *}$ \\
\hline
\end{tabular}

* Overall averages are weighted averages.

**Overall averages represents weighted averages without the Upland Sands.

SRS-FR-CDP-95, rev. 0, 13 September 95

62 of 311

Project No. AA891070 


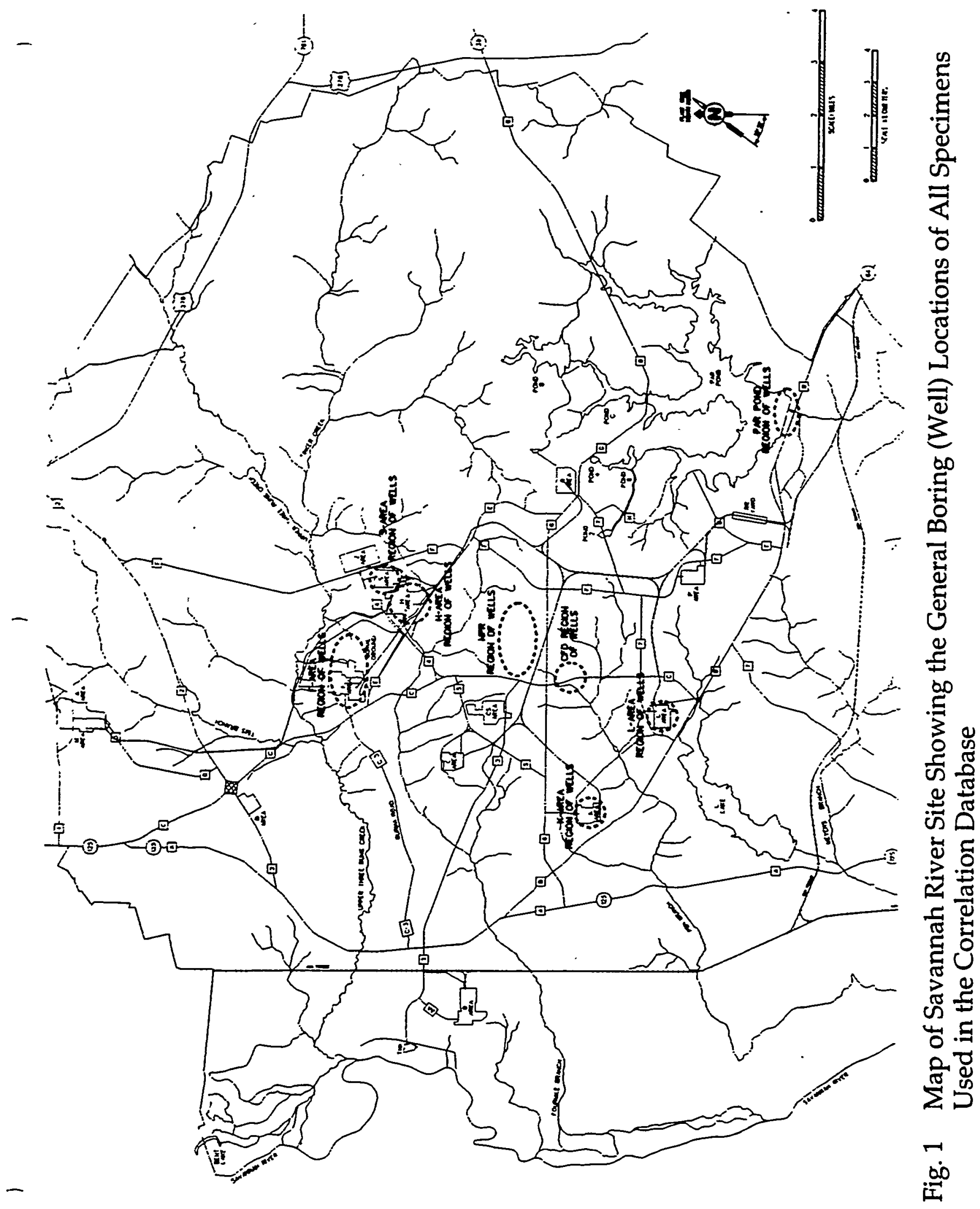

SRS-FR-CDP-95, rev. 0, 13 September 95

Project No. AA891070 


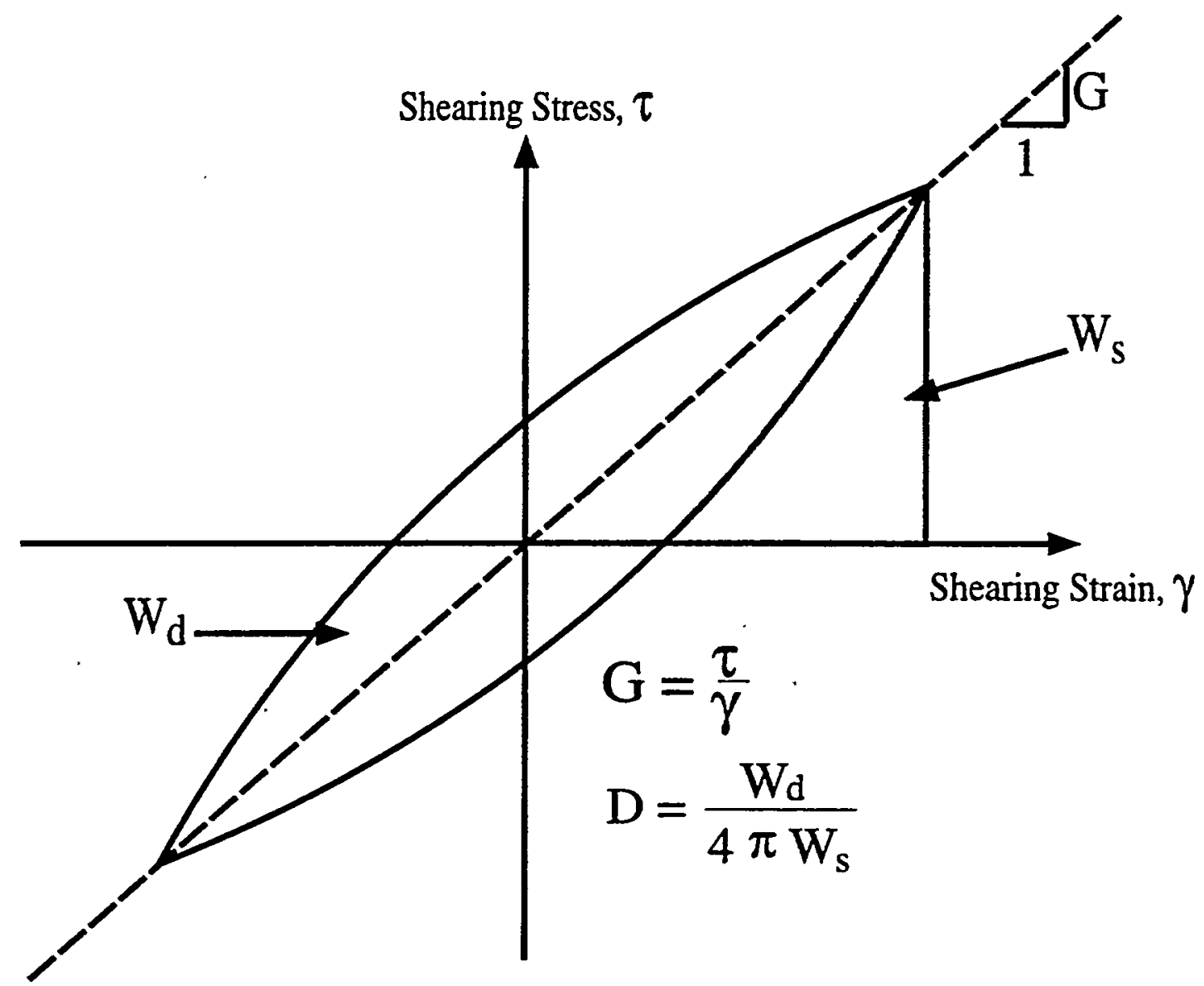

Fig. 2 Determination of Shear Modulus, G and Material Damping Ratio, $\mathrm{D}$, in Cyclic Loading Tests 

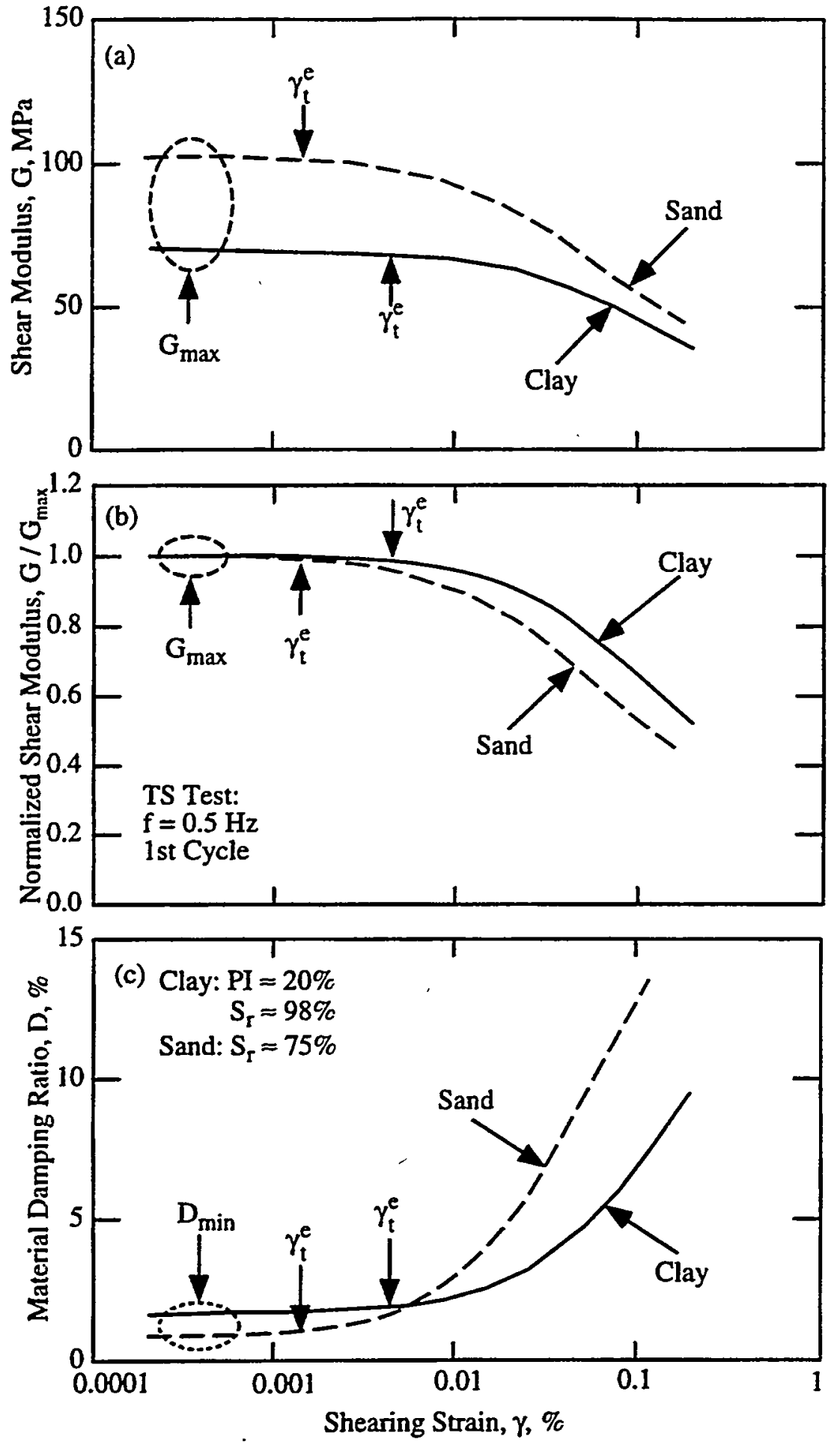

Fig. 3 Comparison of Typical G $-\log \gamma(a), G / G_{\max }-\log \gamma($ b) and D $-\log \gamma$ (c) Curves Determined from the First Cycle of Torsional Testing for Undisturbed Sand and Clay Specimens Confined Similarly 

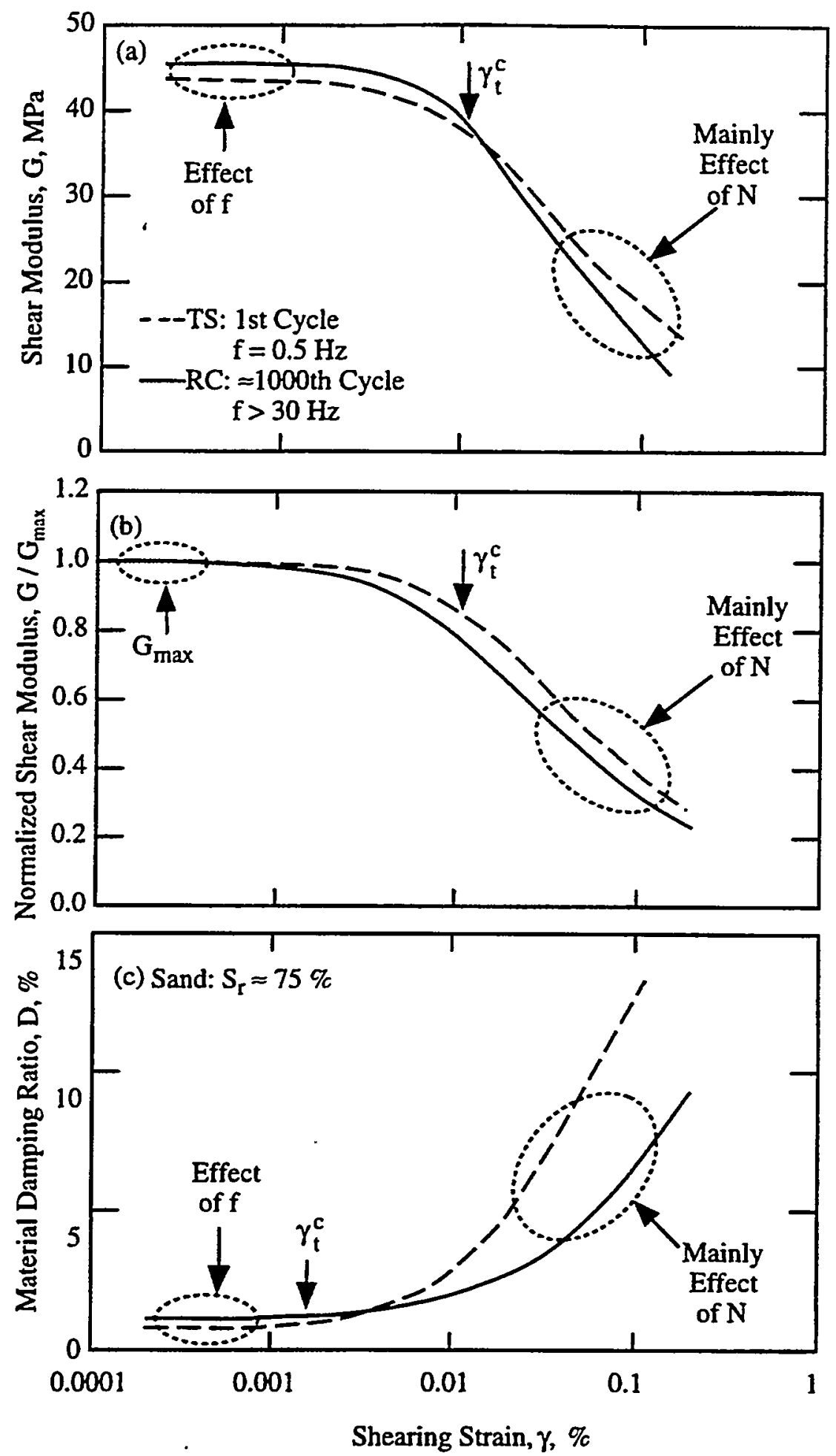

Fig. 4 Typical Effects on G $-\log \gamma(a), G / G_{\max }-\log \gamma$ (b) and D $-\log \gamma$ (c) Curves of Excitation Frequency and Number of Loading Cycles for an Undisturbed Sand Specimen 

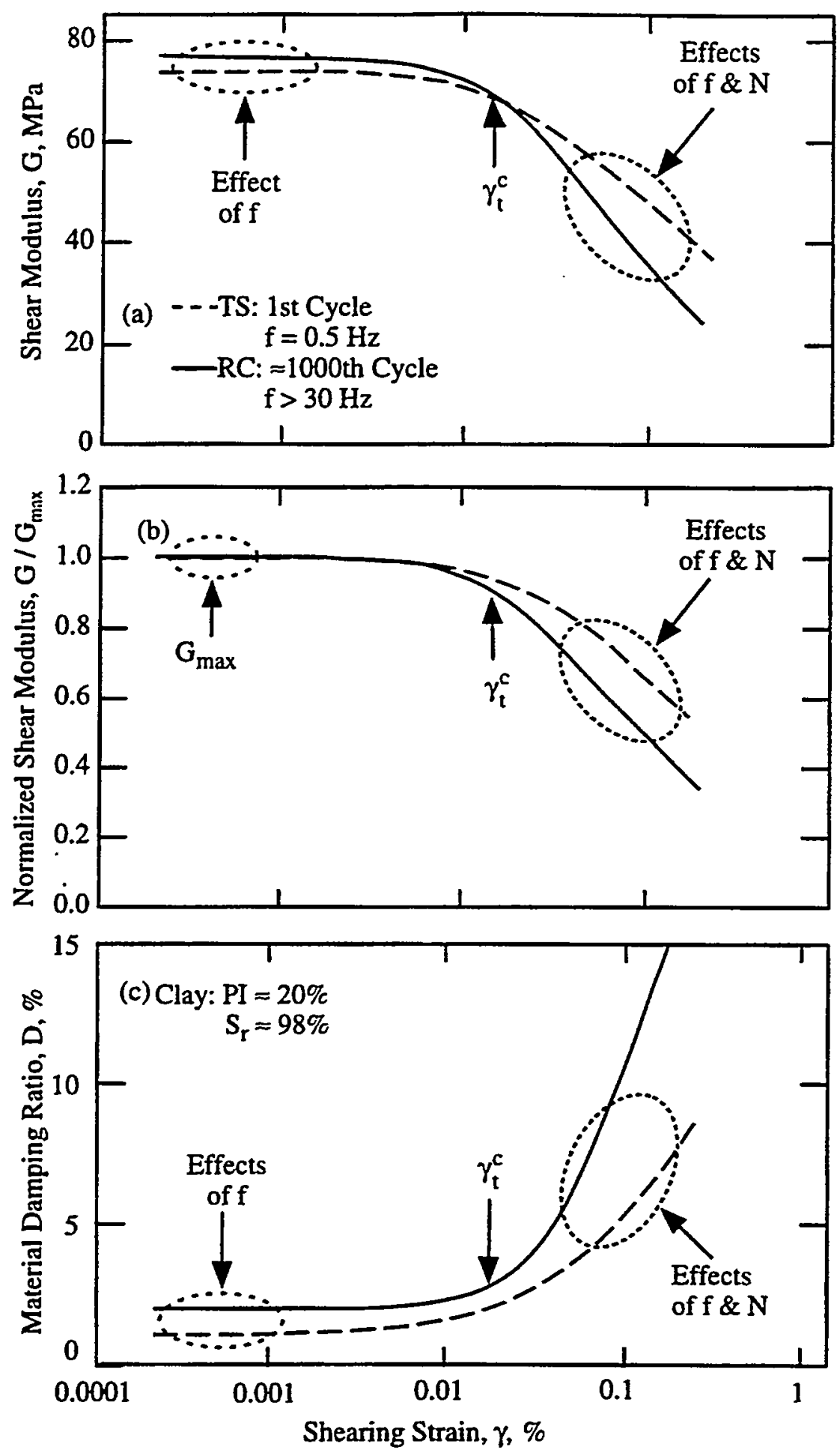

Fig. 5 Typical Effects on $G-\log \gamma(a), G / G_{\max }-\log \gamma$ (b) and D $-\log \gamma$ (c) Curves of Excitation Frequency and Number of Loading Cycles for an Undisturbed Clay Specimen 


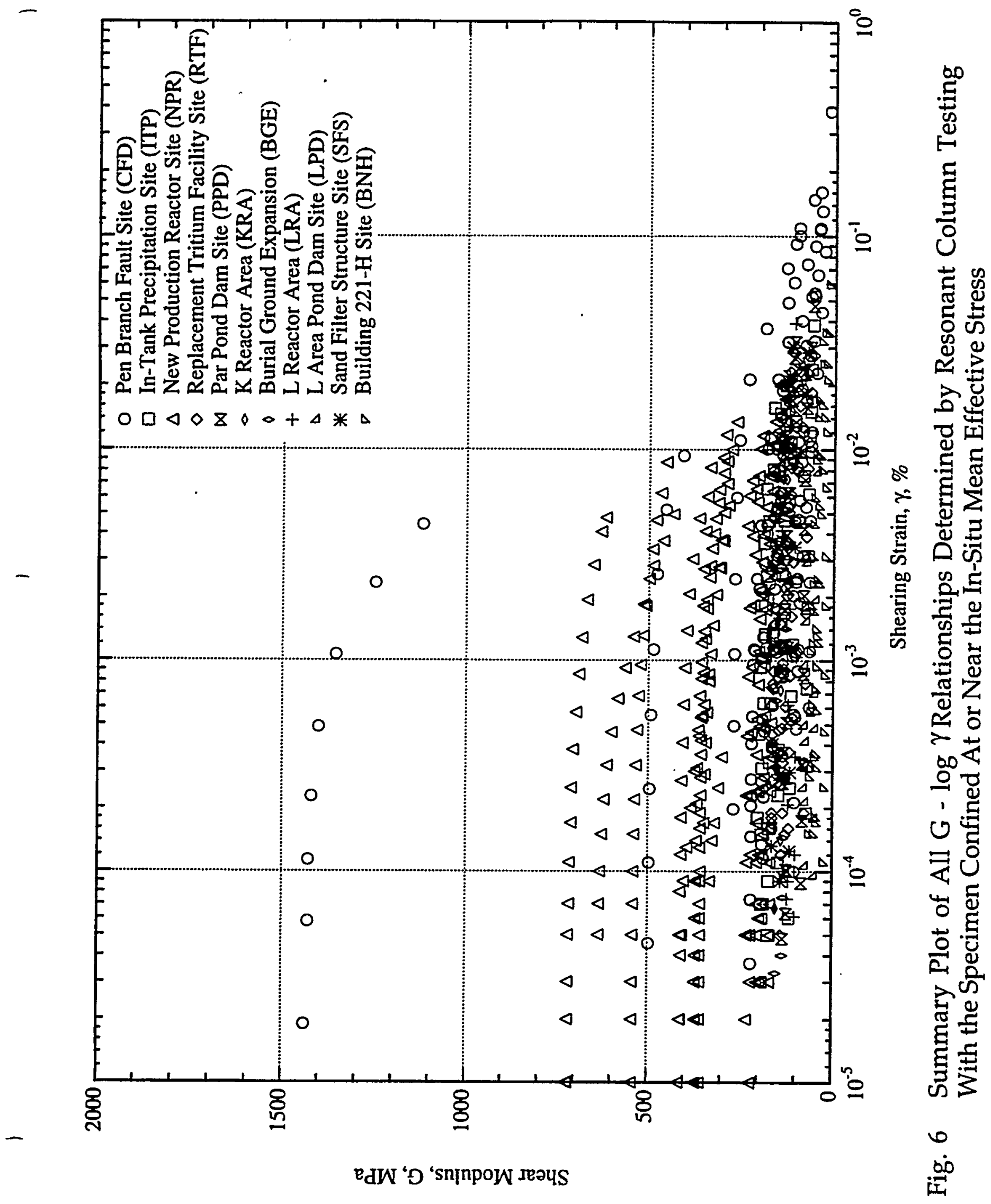

SRS-FR-CDP-95, rev. 0, 13 September 95

68 of 311

Project No. AA891070 


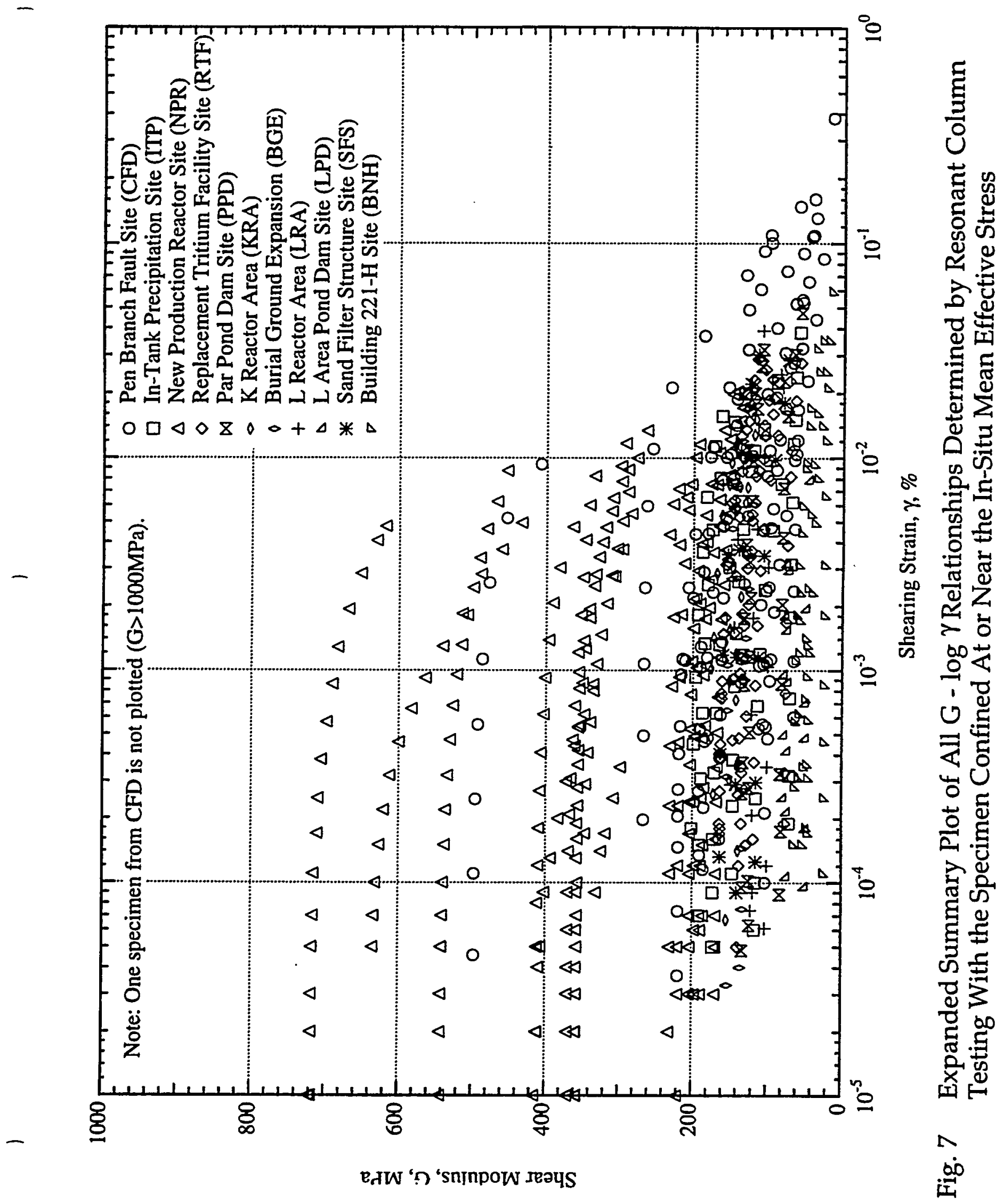

SRS-FR-CDP-95, rev. 0, 13 September 95 


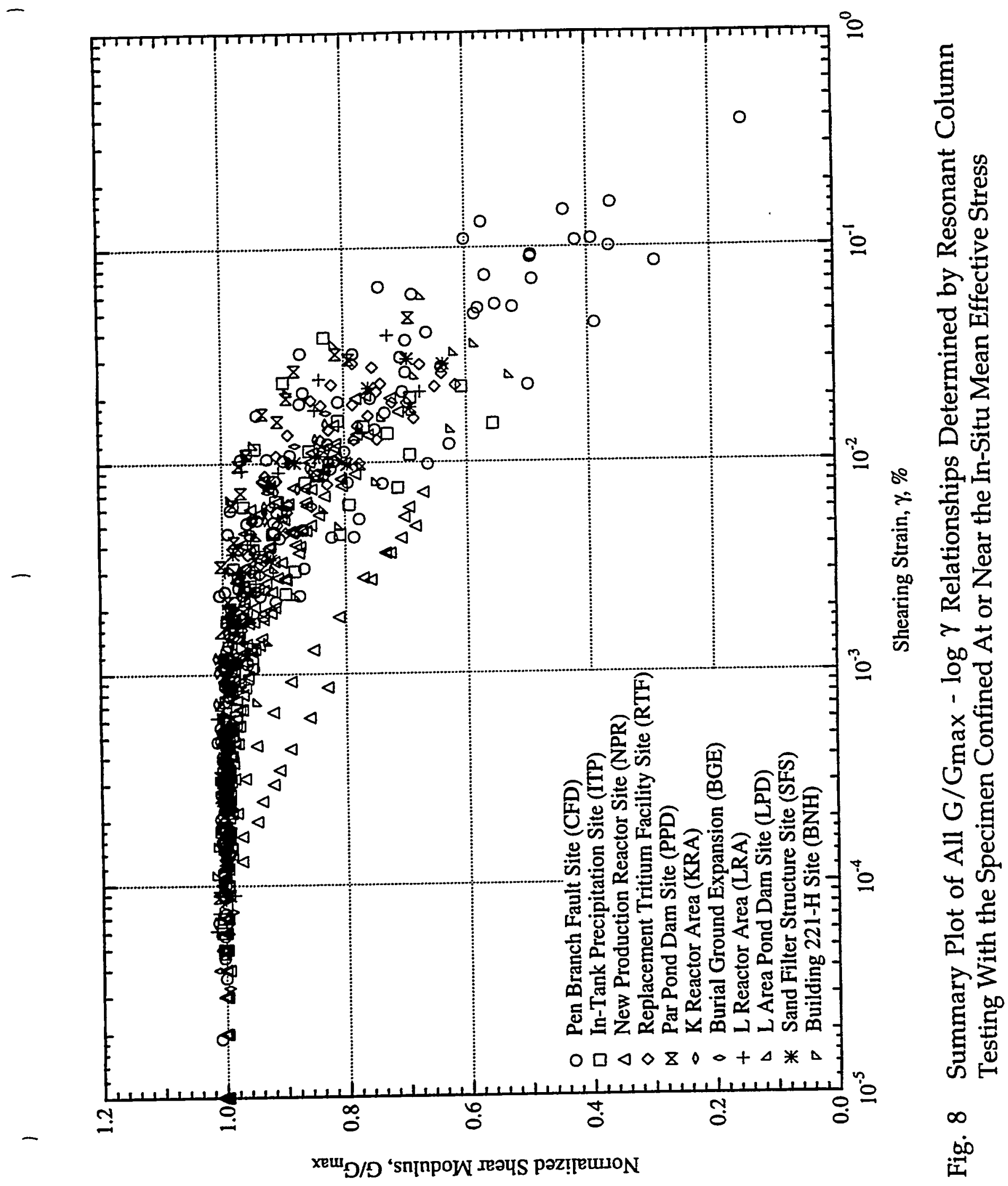

SRS-FR-CDP-95, rev. 0, 13 September 95 


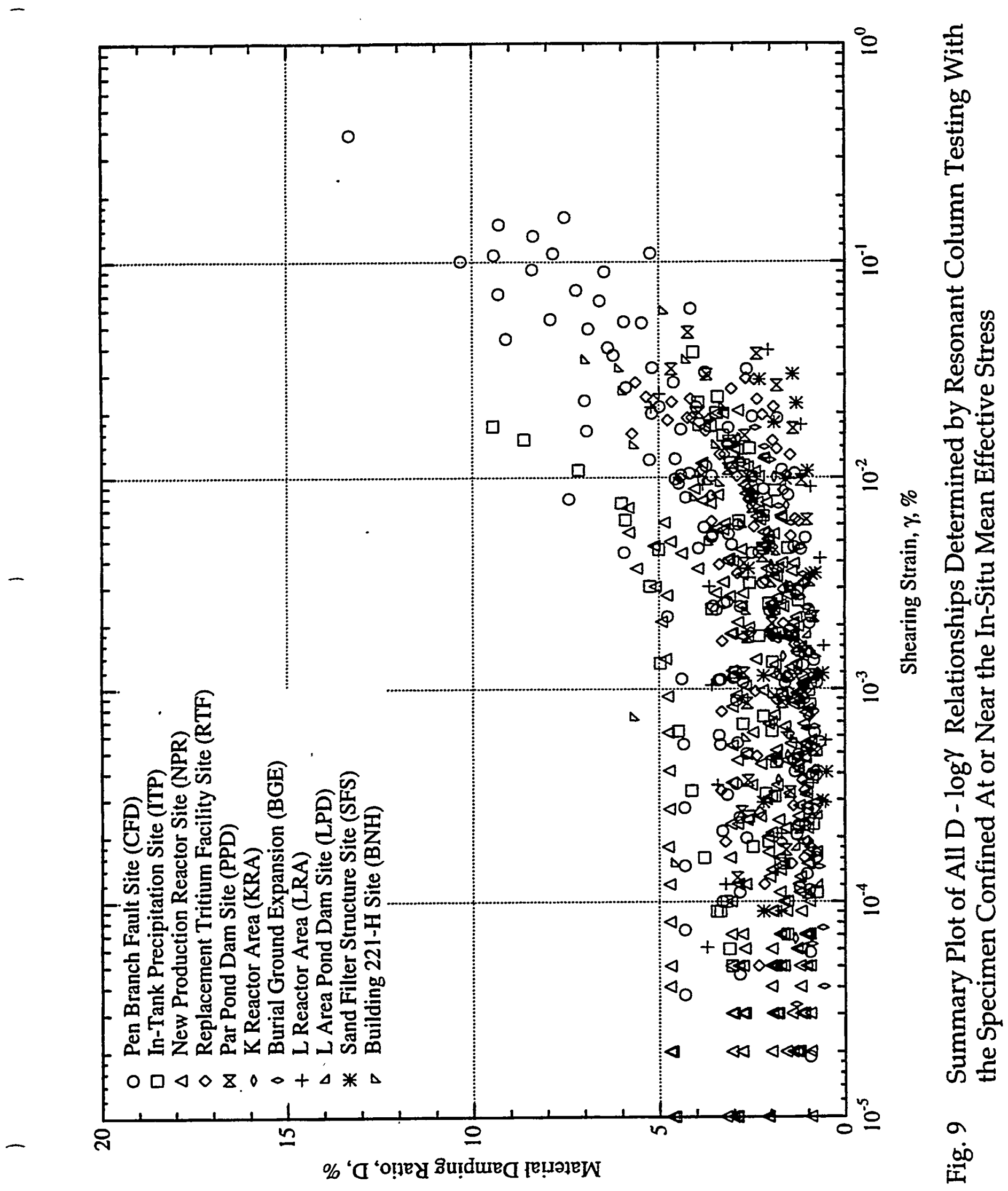

SRS-FR-CDP-95, rev. 0, 13 September 95

71 of 311

Project No. AA891070 


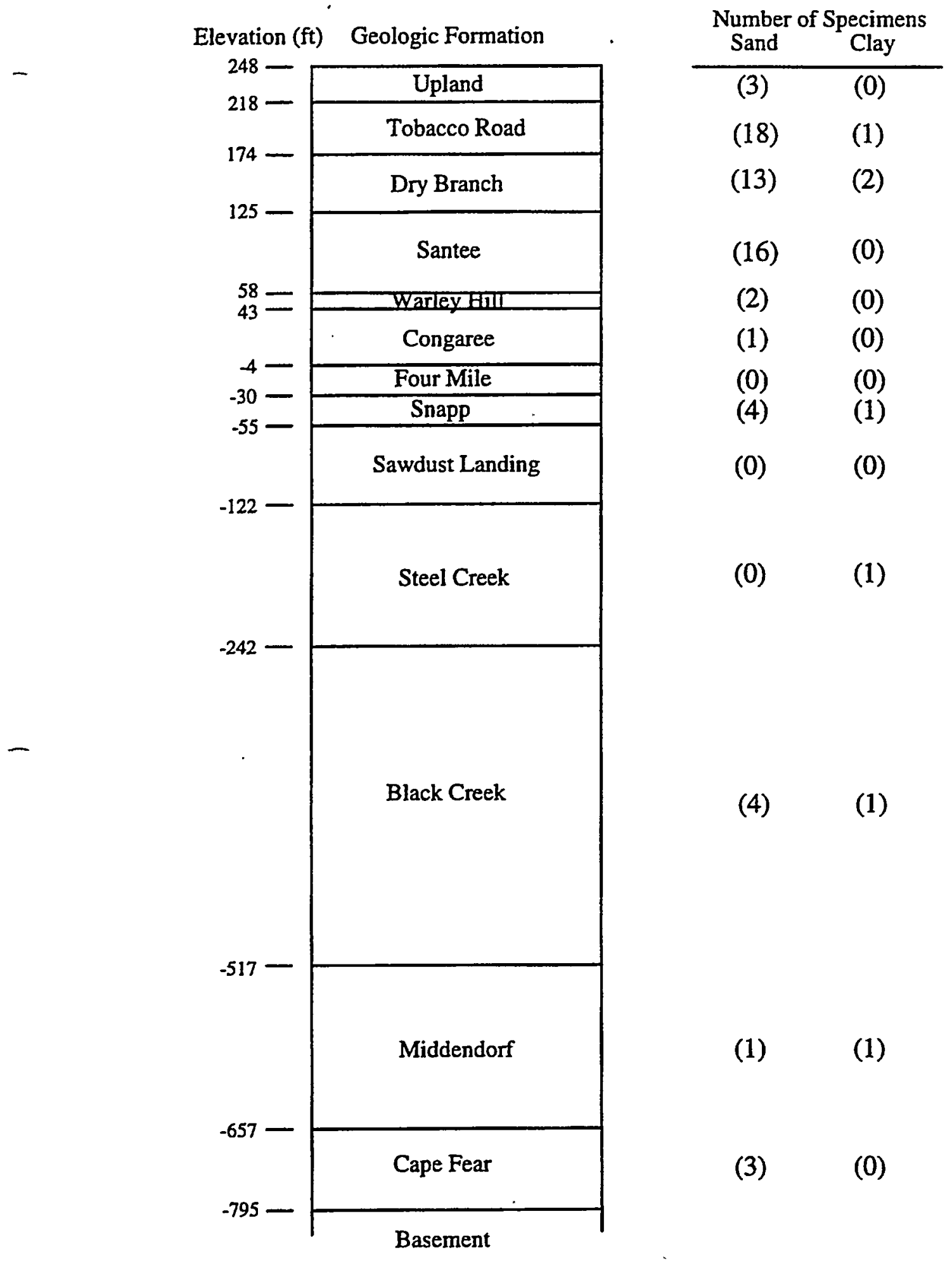

Note: Stratigraphic profile taken from boring CFD 18.

Fig. 10 General Stratigraphic Profile of the Savannah River Site 

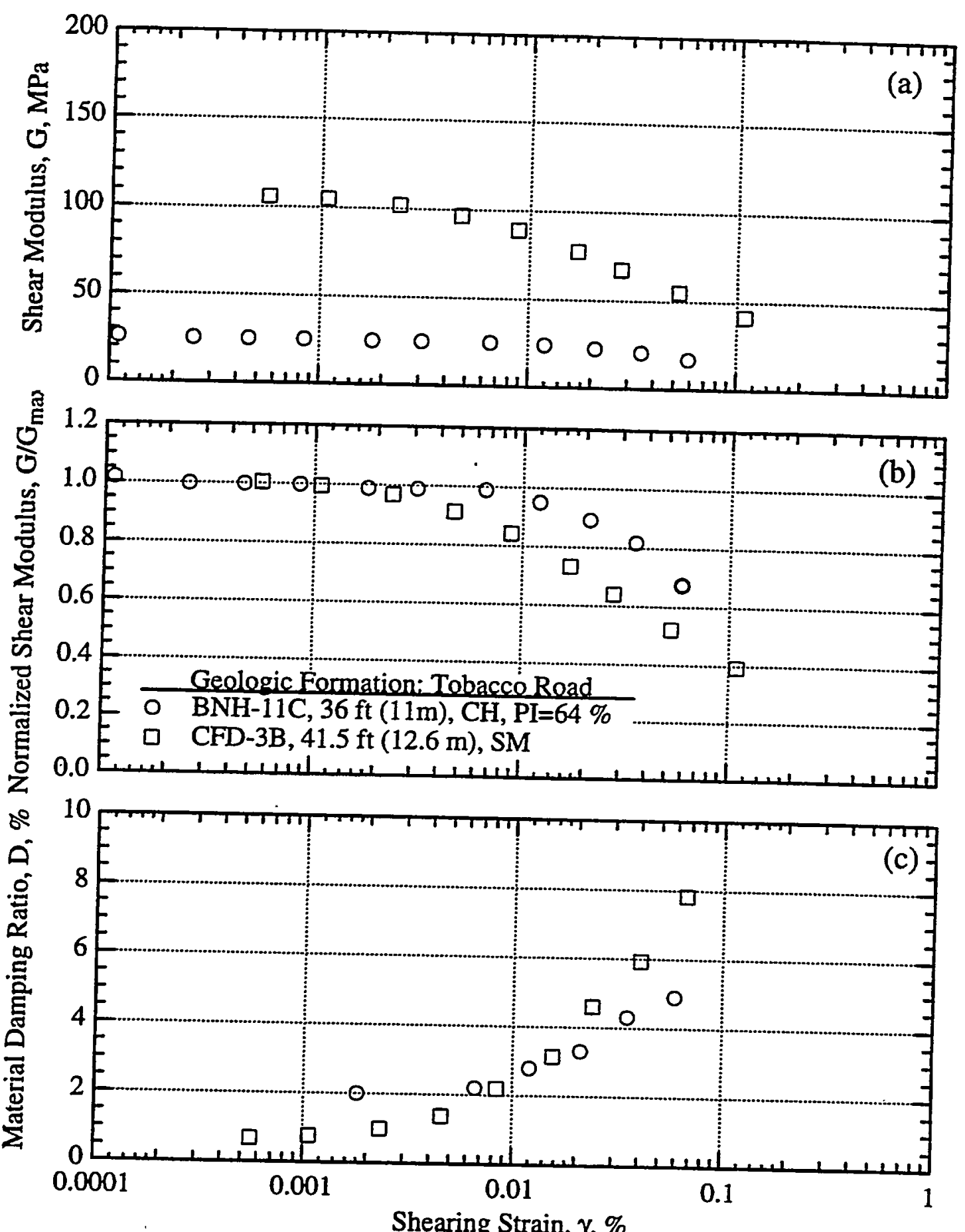

Fig. 11 Comparison of the $G-\log \gamma(a), G / G_{\max }-\log \gamma(b)$ and $D-\log \gamma$ (c) Relationships Determined by Resonant Column Testing of Sand and Clay Specimens from the Tobacco Road Formation at the Savannah River Site 


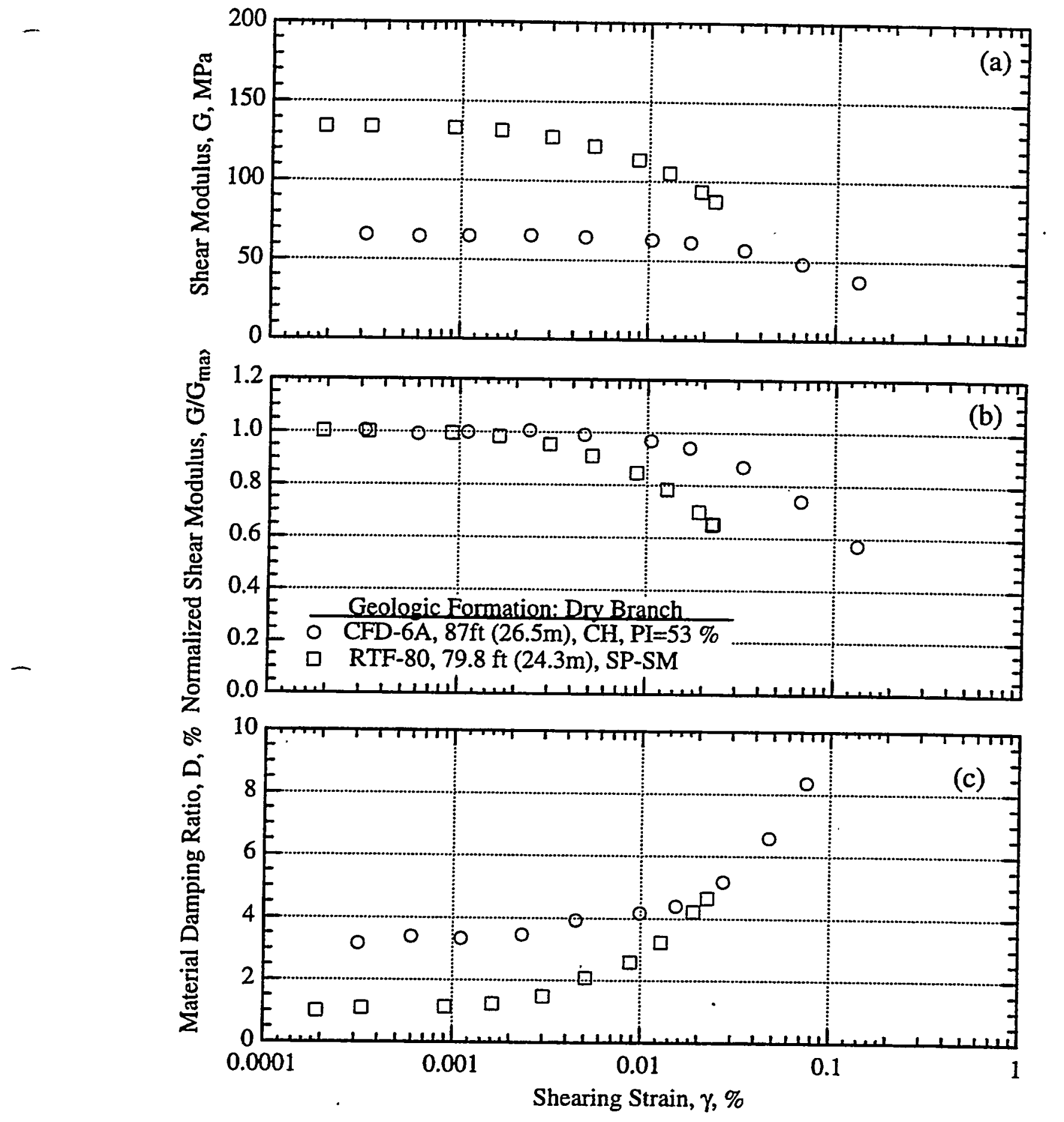

Fig. 12 Comparison of the $G-\log \gamma(a), G / G_{\max }-\log \gamma(b)$ and $D-\log \gamma$ (c) Relationships Determined by Resonant Column Testing of Sand and Clay Specimens from the Dry Branch Formation at the Savannah River Site 

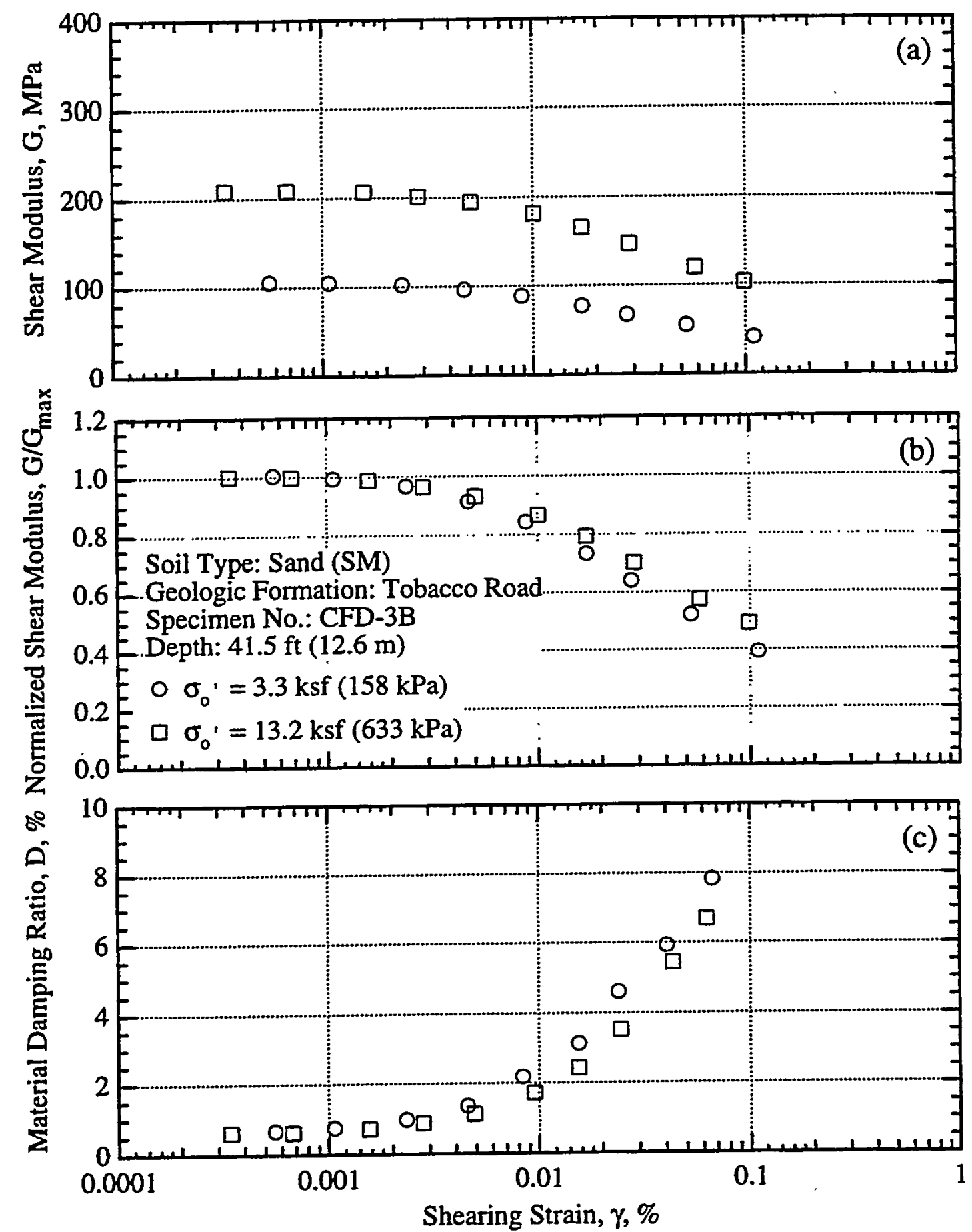

Fig. 13 Influence of Effective Confining Pressure on the $G-\log \gamma(a)$, $\mathrm{G} / \mathrm{G}_{\max }-\log \gamma(\mathrm{b})$ and $\mathrm{D}-\log \gamma(\mathrm{c})$ Relationships Determined by Resonant Column Testing of a Sand Specimen from the Tobacco Road Formation at the Savannah River Site 

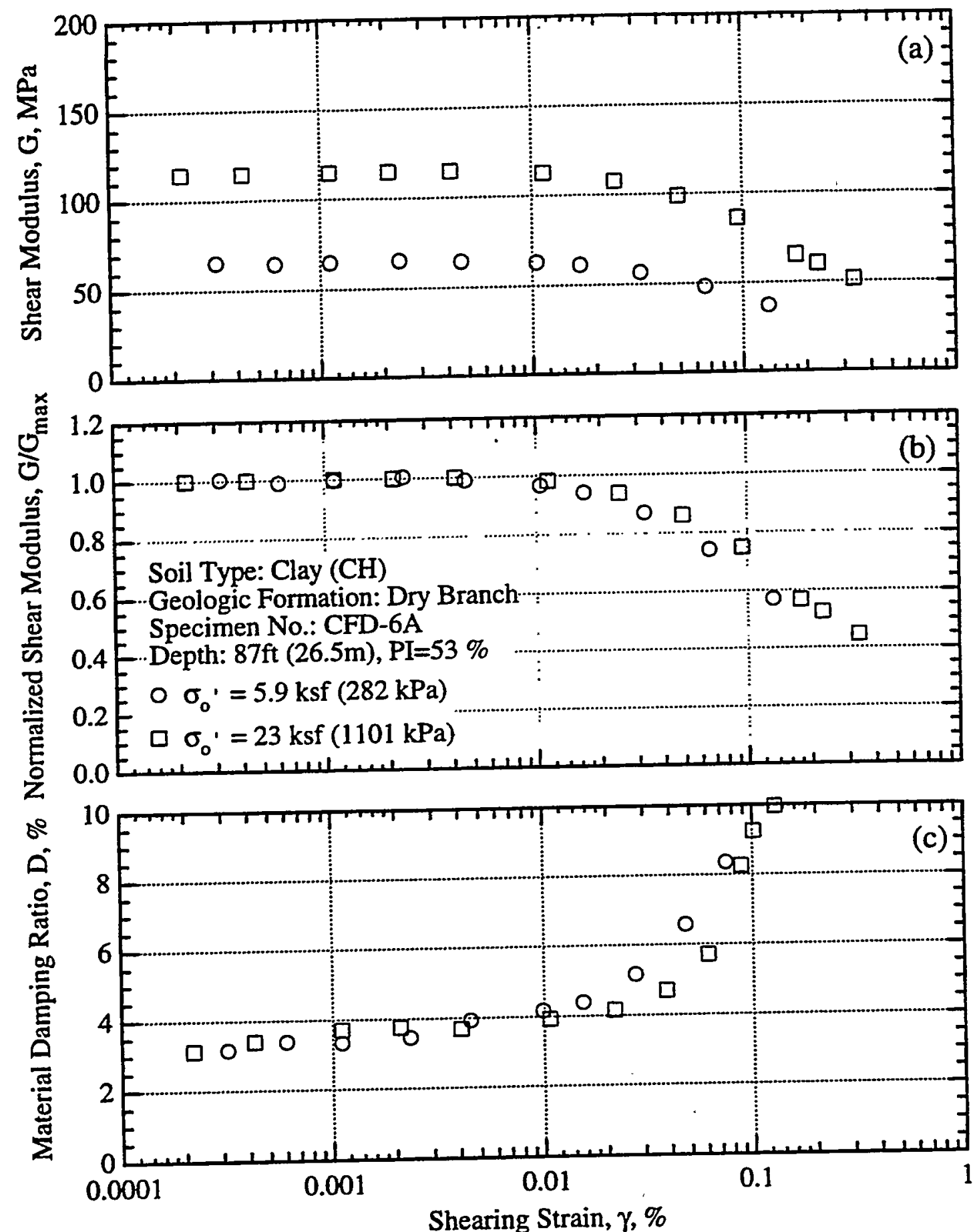

Fig. 14 Influence of Effective Confining Pressure on the $G-\log \gamma(a)$, G/G $\max -\log \gamma(b)$ and D - log $\gamma$ (c) Relationships Determined by Resonant Column Testing of a Clay Specimen from the Dry Branch Formation at the Savannah River Site 

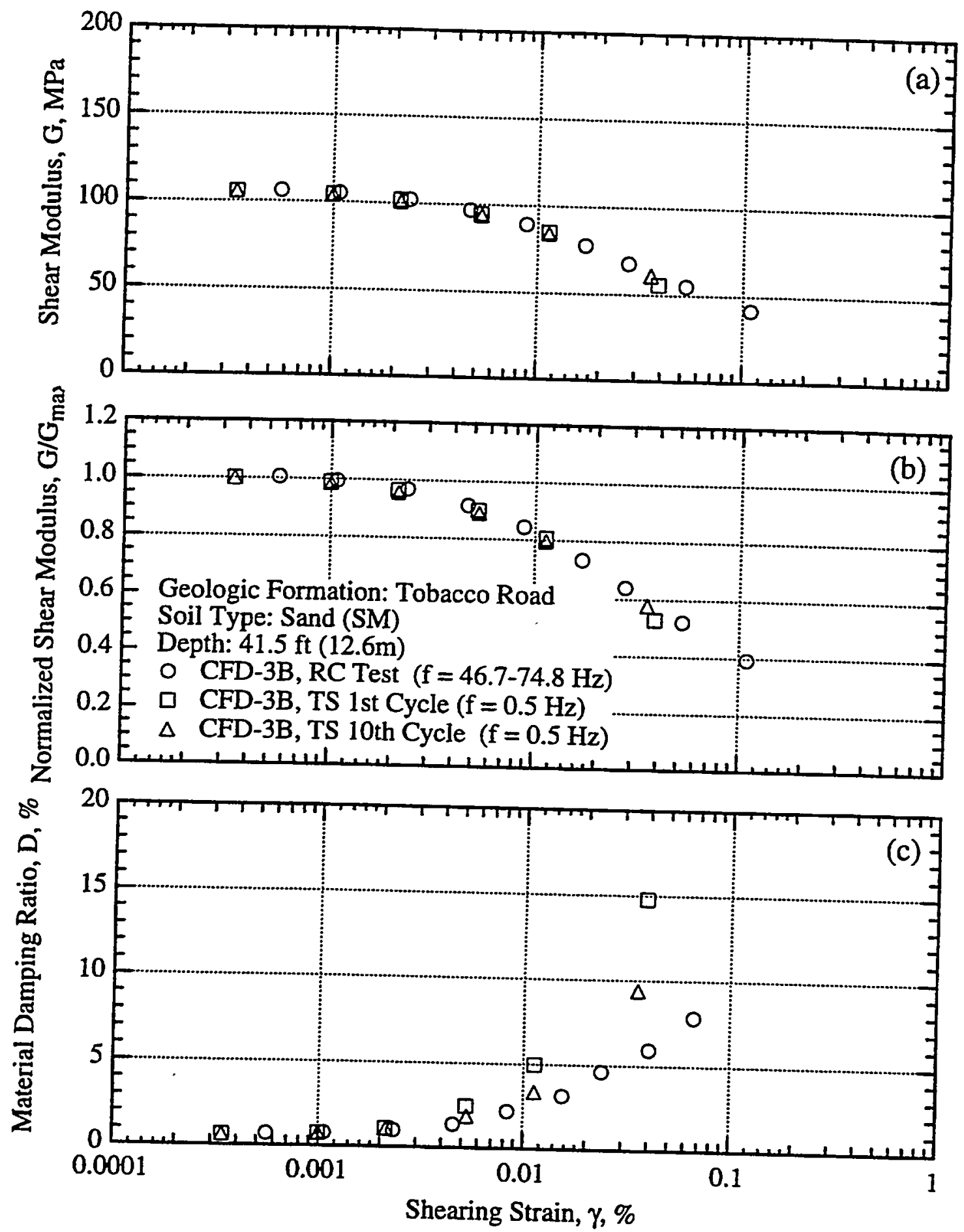

Fig. 15 Effects of Excitation Frequency and Number of Loading Cycles on the $G-\log \gamma(a), G / G \max -\log \gamma(b)$, and D - $\log \gamma$ (c) Relationships Determined by RCTS Testing of a Sand Specimen from the Tobacco Road Formation at the Savannah River Site 

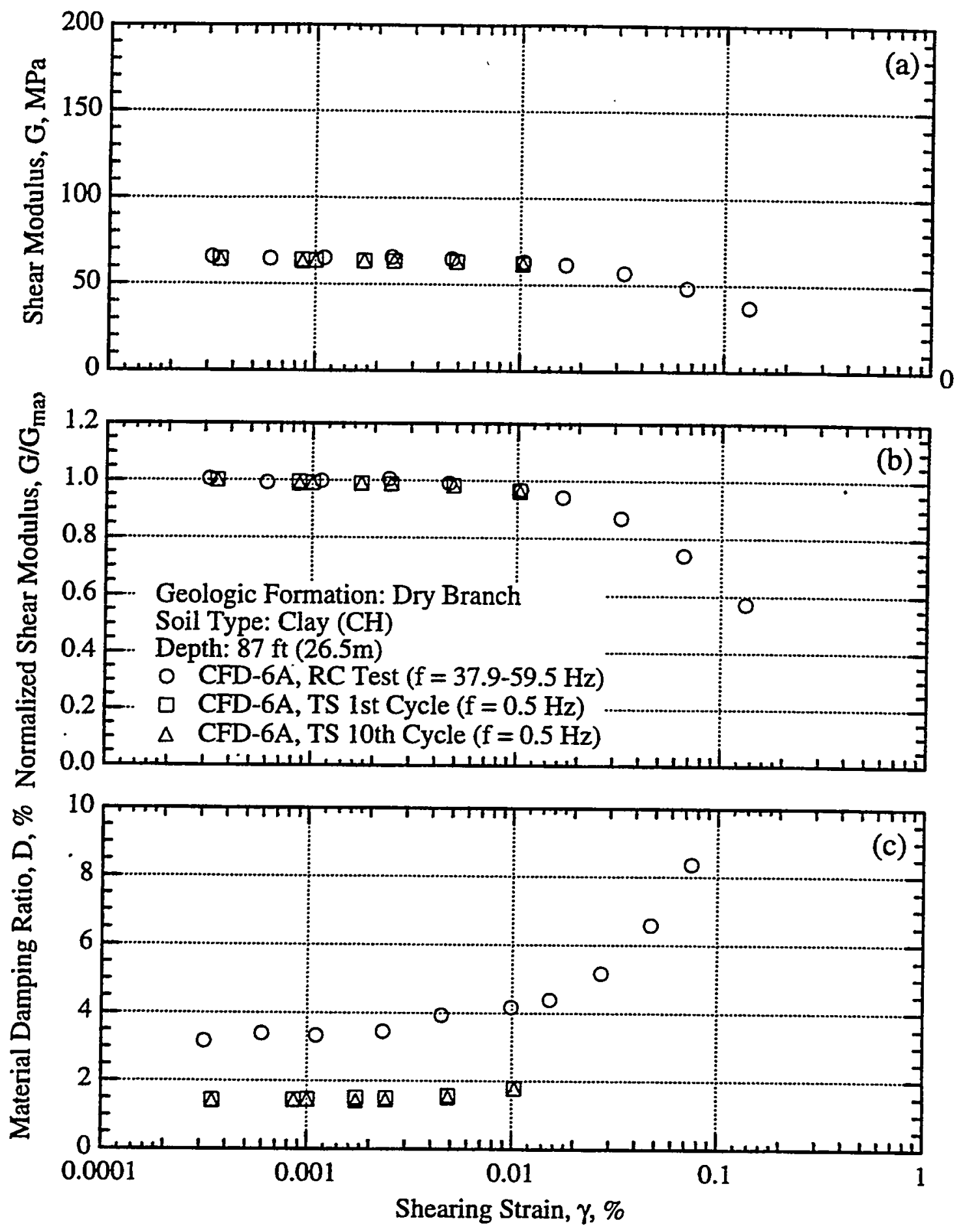

Fig. 16 Effects of Excitation Frequency and Number of Loading Cycles on the $G-\log \gamma(a), G / G_{\max }-\log \gamma(b)$, and D - $\log \gamma(c)$ Relationships Determined by RCTS Testing of a Clay Specimen from the Dry Branch Formation at the Savannah River Site 


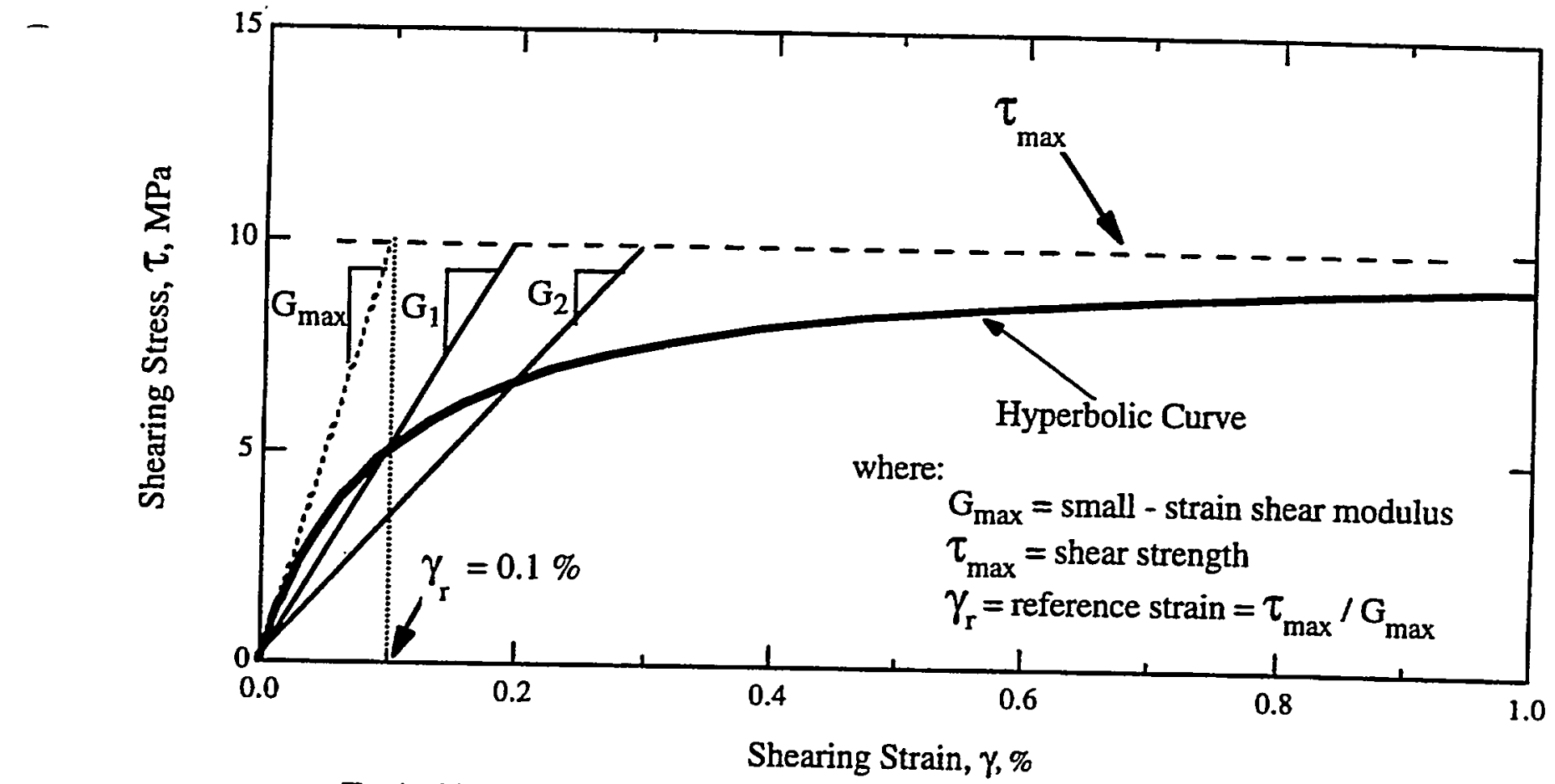

a. Typical Hyperbolic Stress - Strain Curve Used to Represent Nonlinear Soil Behavior

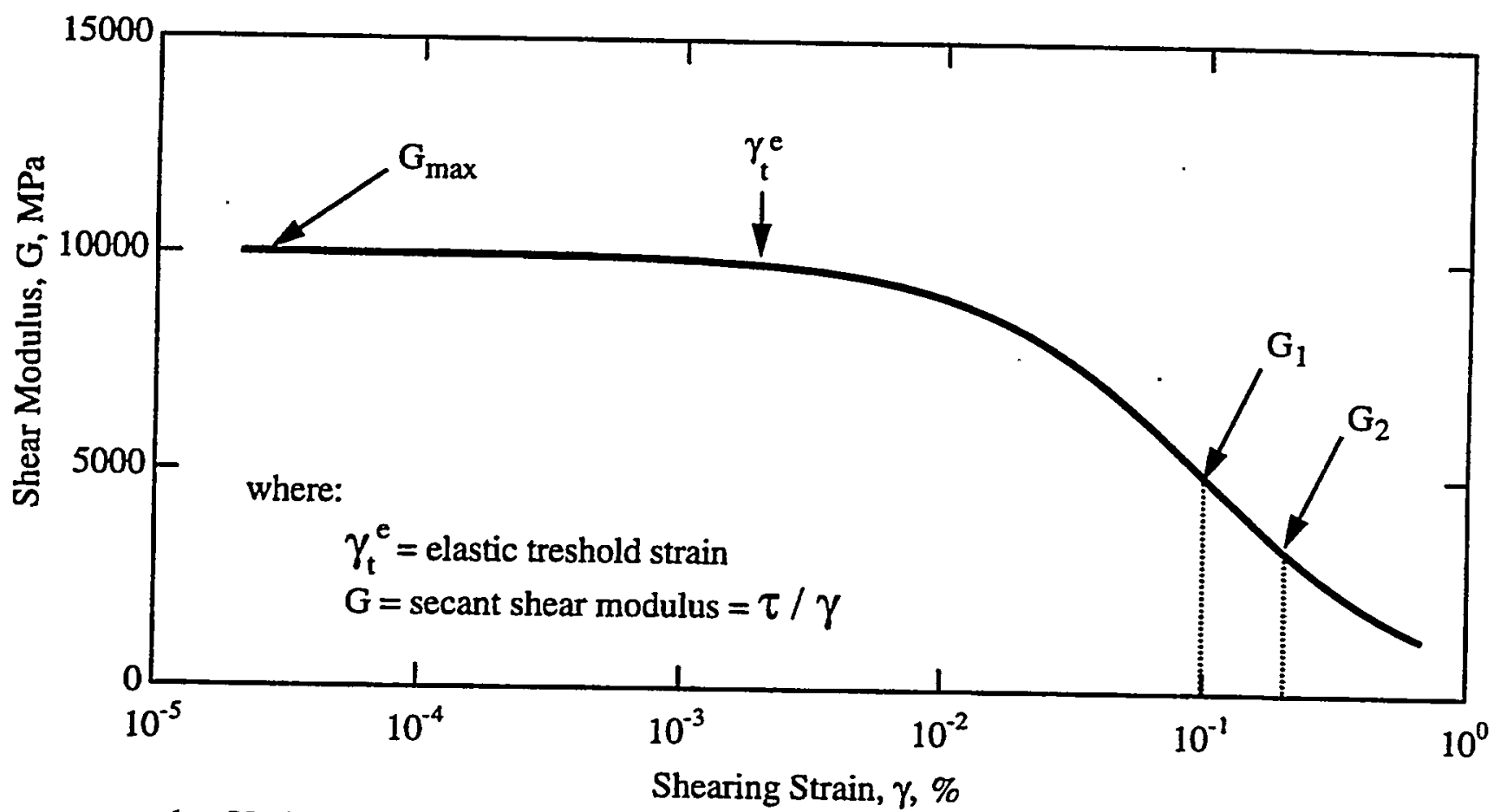

b. Variation in Shear Modulus with Shearing Strain Determined from a Hyperbolic Stress - Strain Curve

Fig. 17 Hyperbolic Modeling of Nonlinear Soil Behavior 


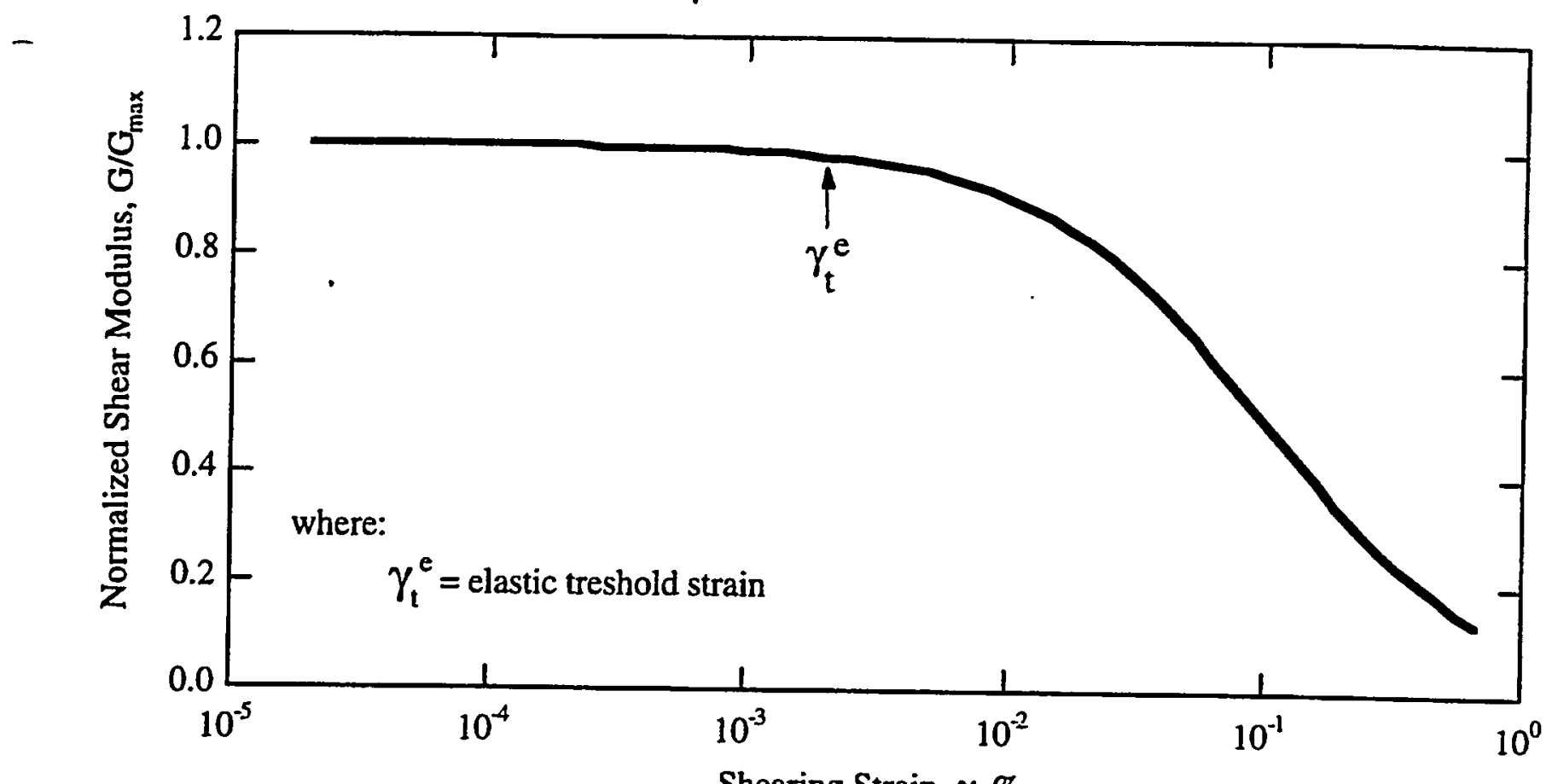

Shearing Strain, $\gamma, \%$

a. Typical $G / G_{\max }-\log \gamma$ Relationship Determined from a Hyperbolic Stress - Strain Curve

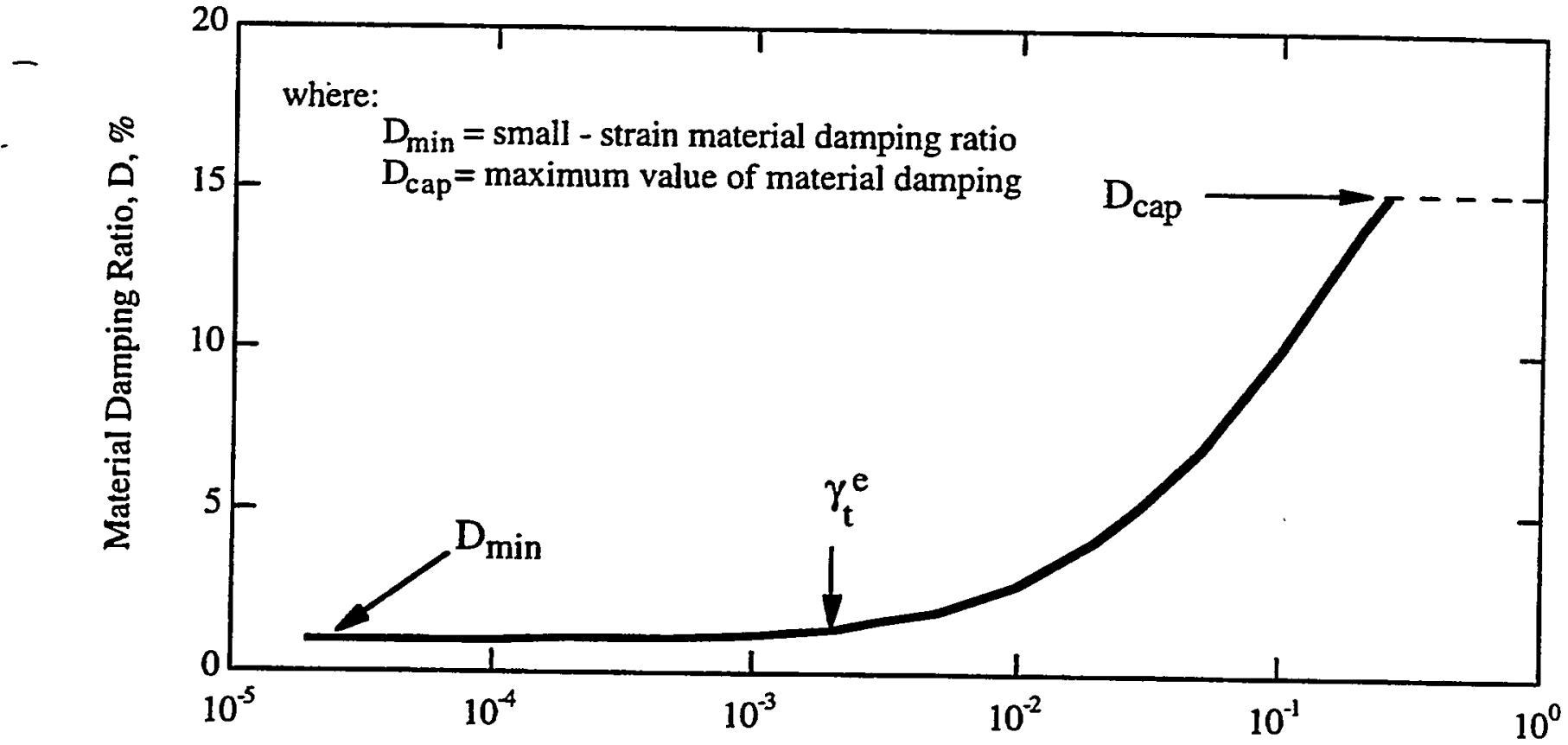

Shearing Strain, $\gamma, \%$ b. Typical $D-\log \gamma$ Relationship Which is Compatible with the $G / G_{\max }-\log \gamma_{\text {Relationship }}$
(Fig. 18a) Combined with $D_{\min }$ and $D_{\text {cap }}$

Fig. 18 Typical G/G $G_{\max }-\log \gamma_{\text {and }} \mathrm{D}-\log \gamma$ Relationships Determined from a Hyperbolic Model Combined with $D_{\min }$ and $D_{\text {cap }}$ Values

SRS-FR-CDP-95, rev. 0, 13 September 95

Project No. AA891070 


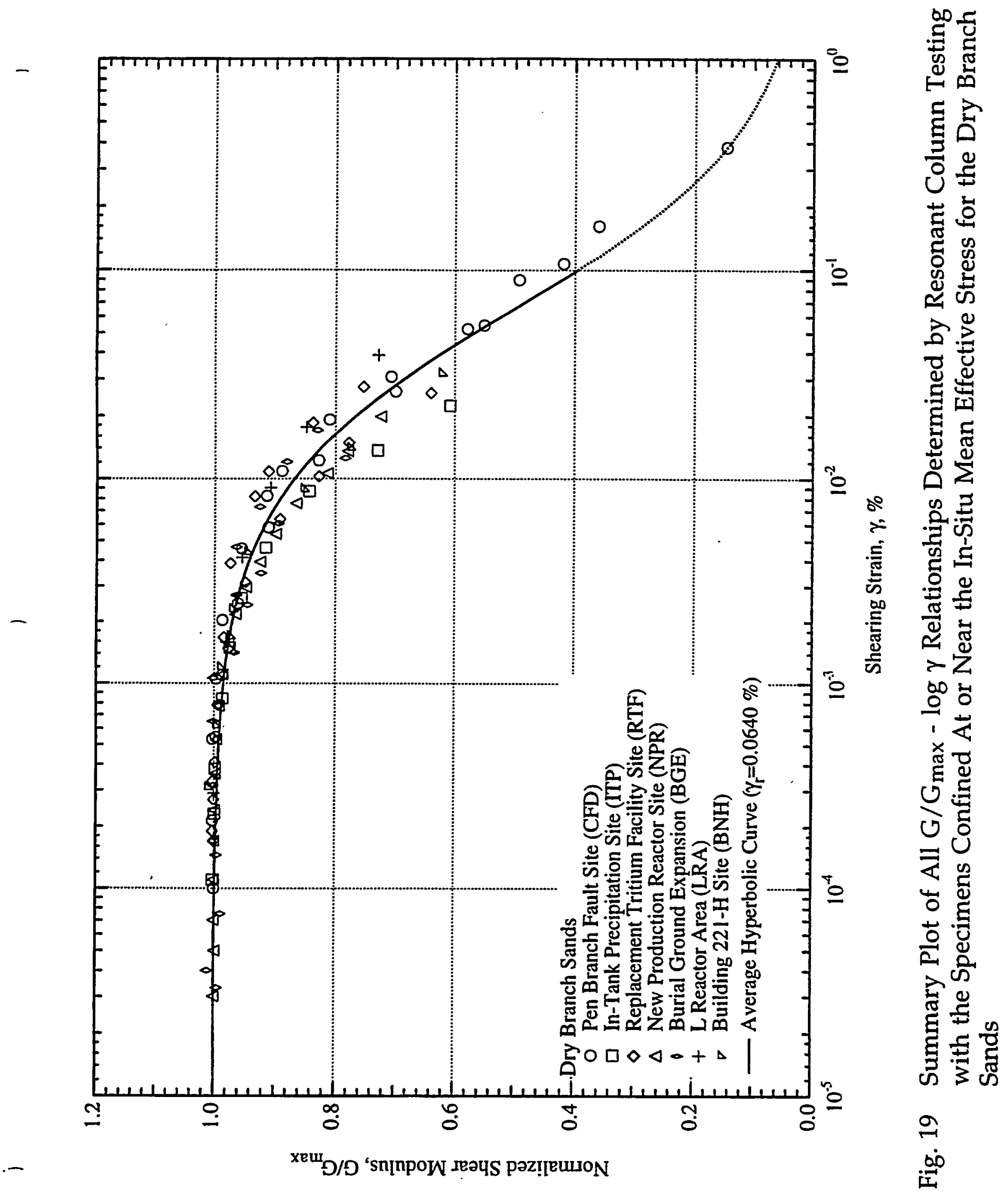

SRS-FR-CDP-95, rev. 0, 13 September 95 


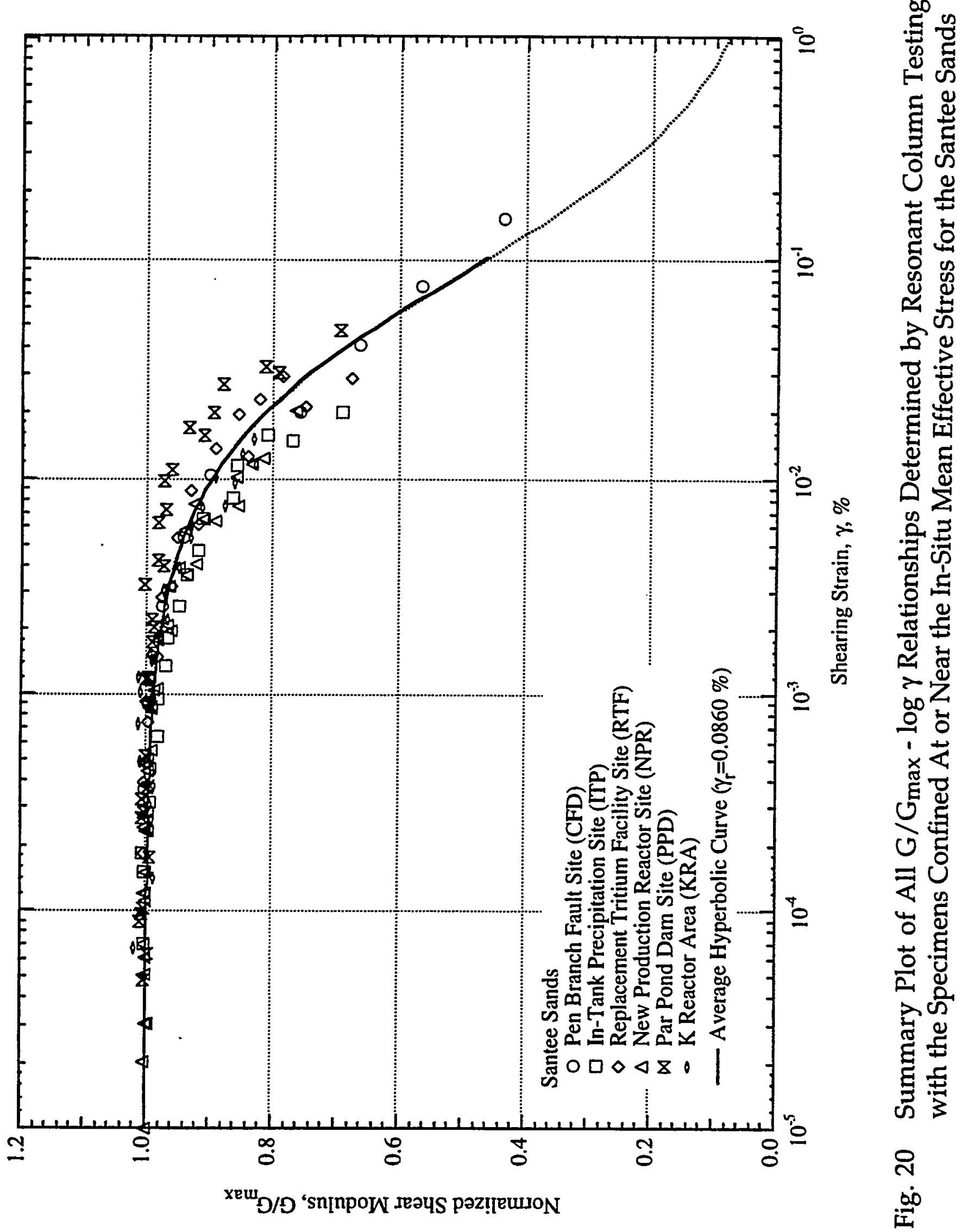

SRS-FR-CDP-95, rev. 0, 13 September 95 


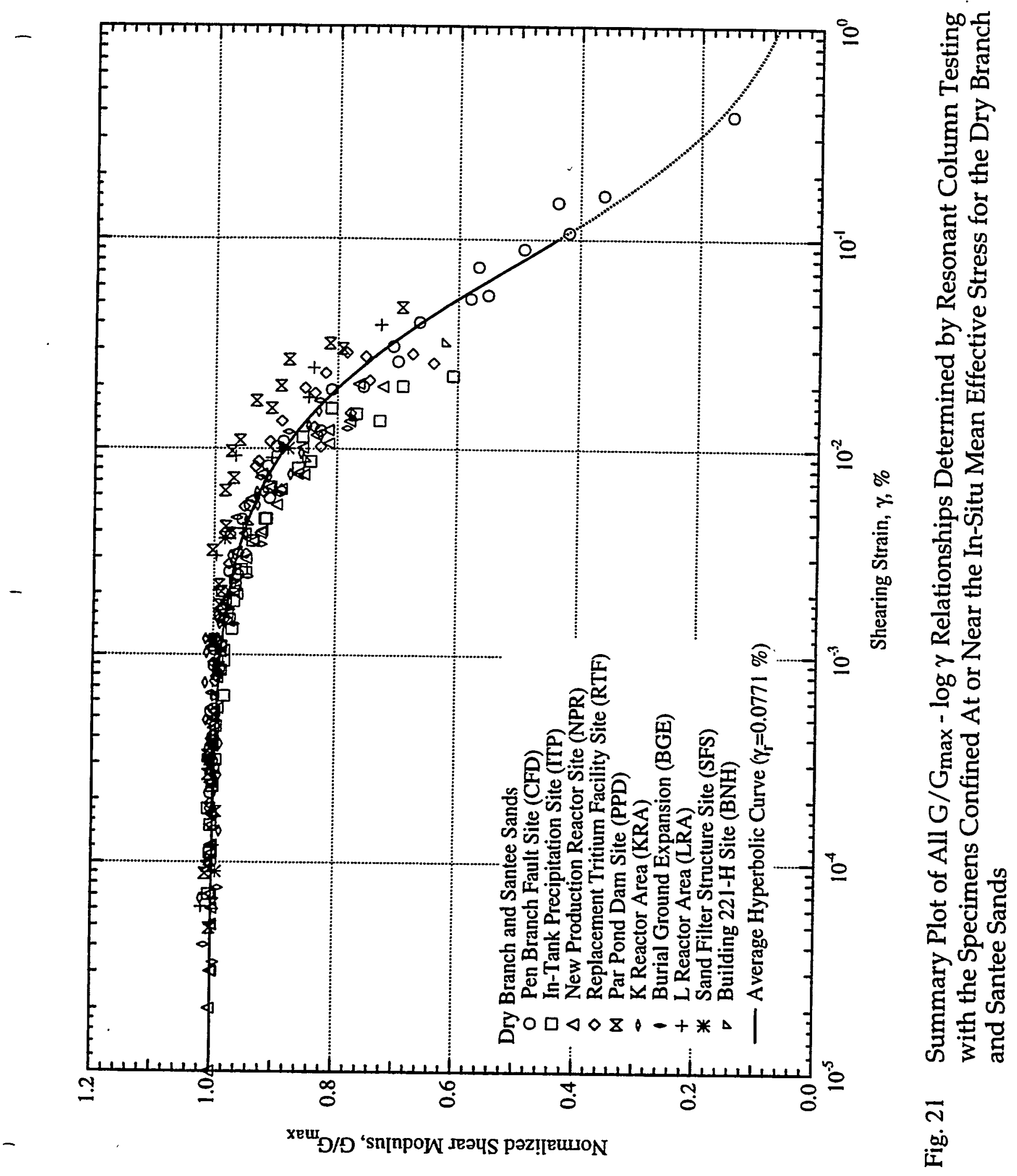

SRS-FR-CDP-95, rev. 0, 13 September 95

Project No. AA891070 


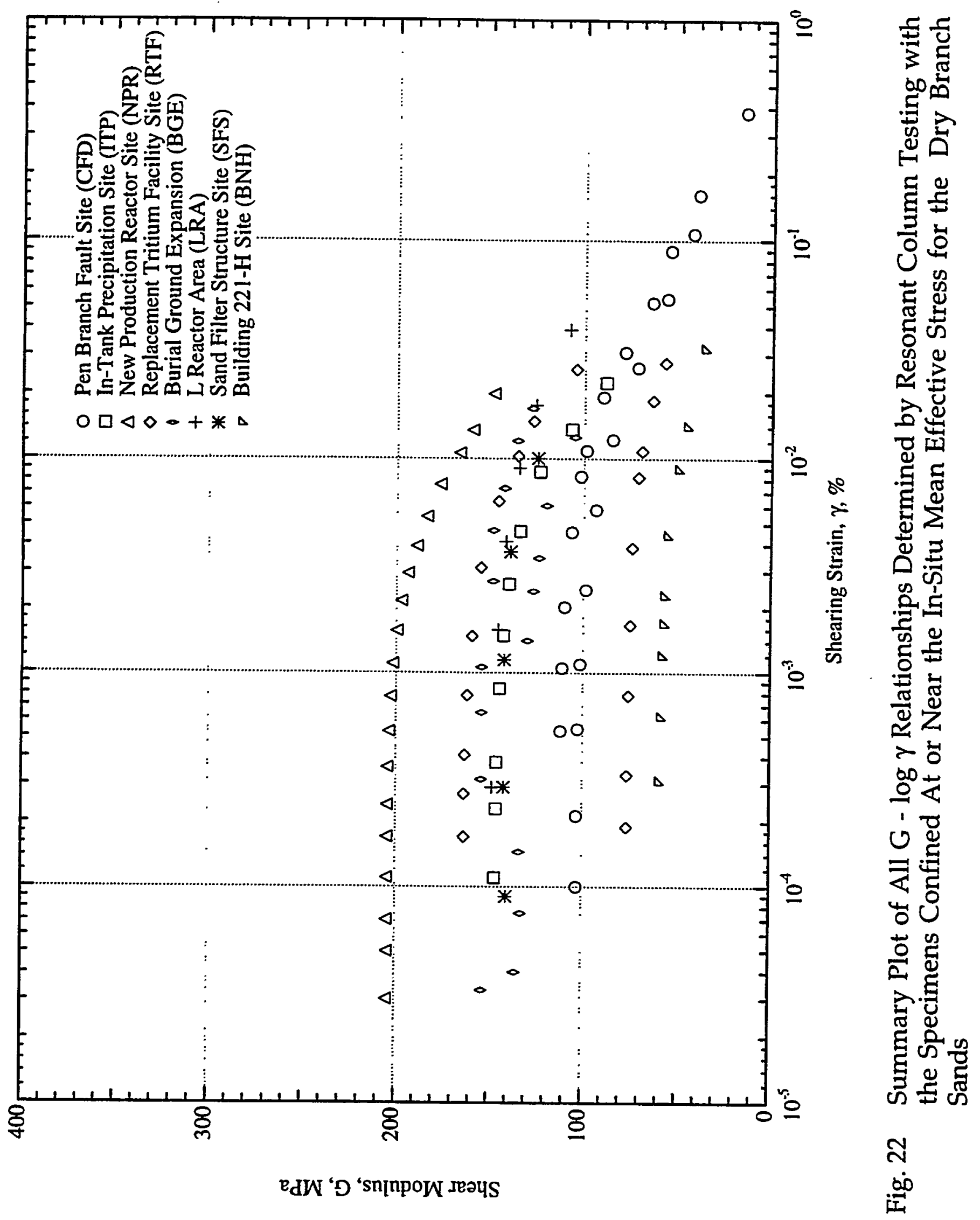

SRS-FR-CDP-95, rev. 0, 13 September 95

Project No. AA891070 


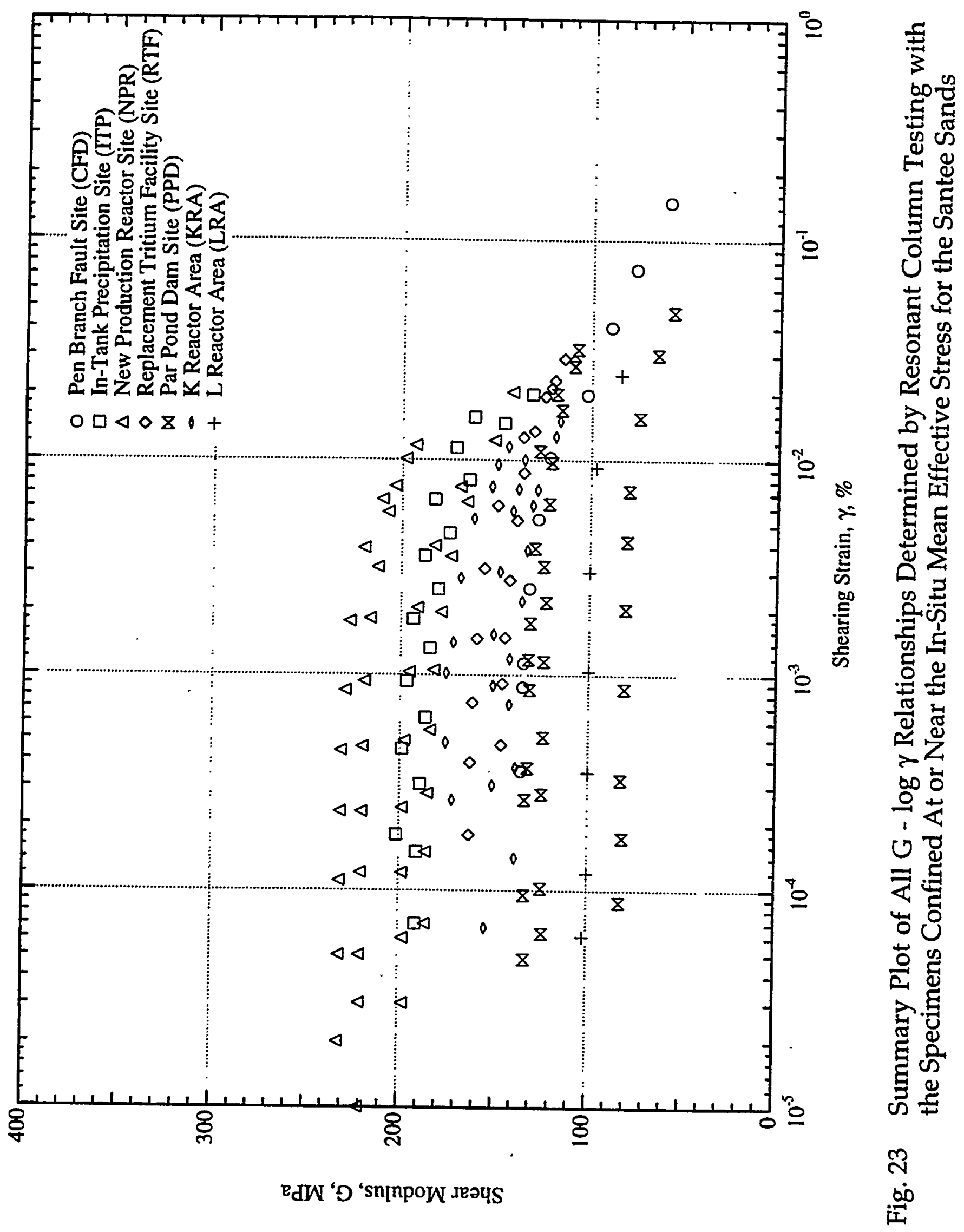

SRS-FR-CDP-95, rev. 0, 13 September 95

Project No. AA891070 


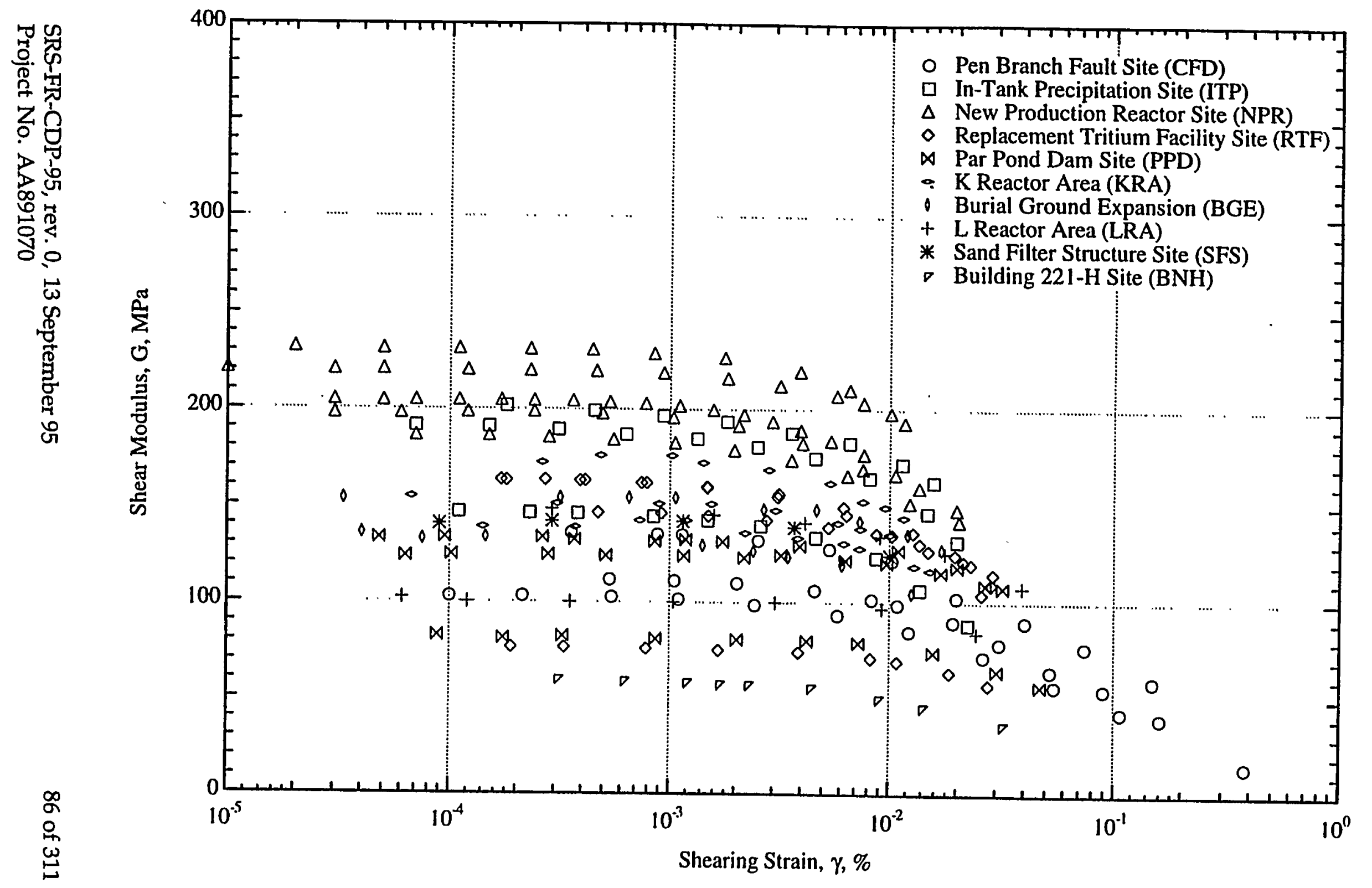

Fig. 24 Summary Plot of All G - $\log \gamma$ Relationships Determined by Resonant Column Testing with the Specimens Confined At or Near the In-Situ Mean Effective Stress for the Dry Branch and Santee
Sands 


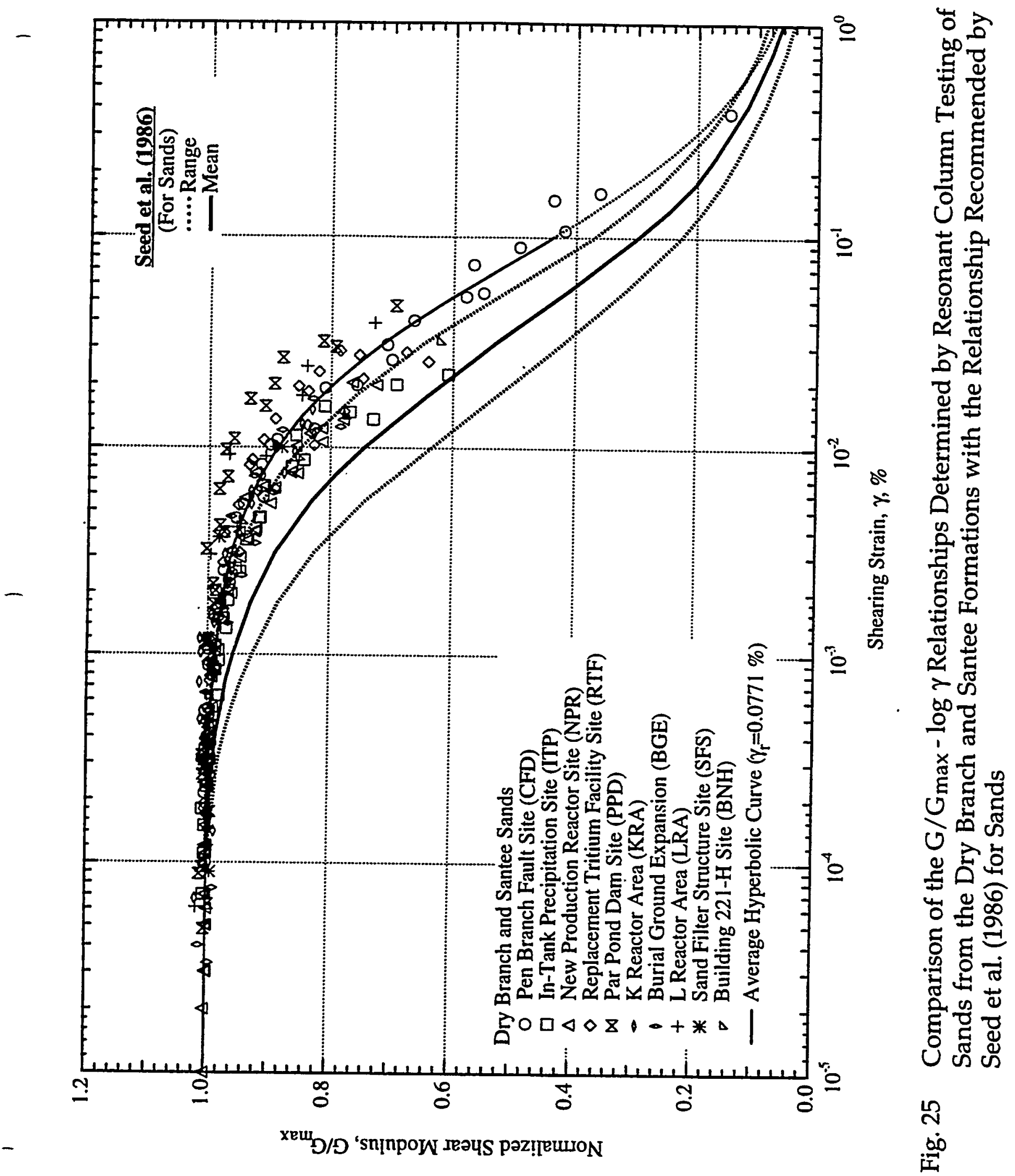

SRS-FR-CDP-95, rev. 0， 13 September 95 Project No. AA891070 


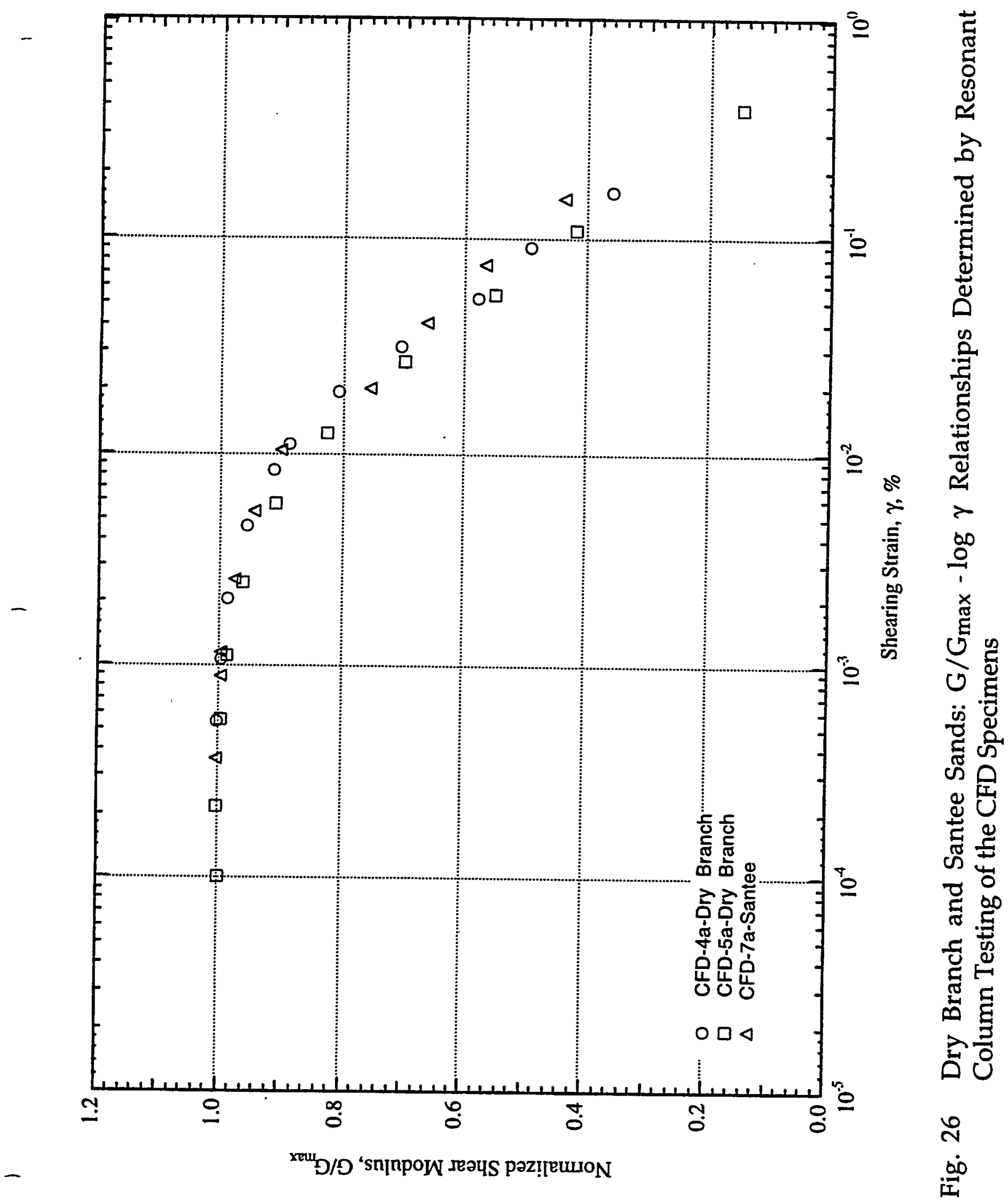

SRS-FR-CDP-95, rev. 0, 13 September 95

Project No. AA891070 


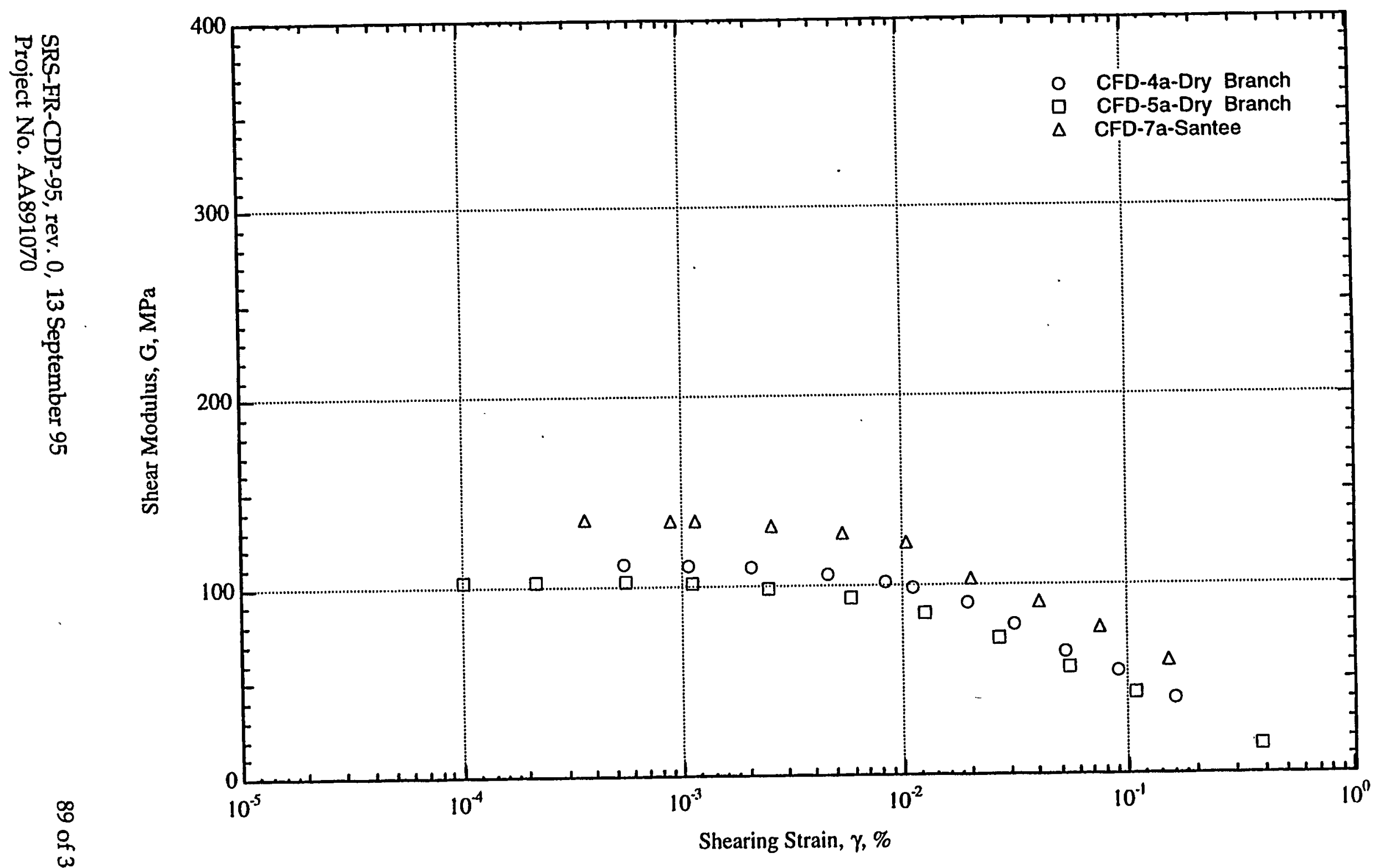

Fig. 27 Dry Branch and Santee Sands: G - $\log \gamma$ Relationships Determined by Resonant Column Testing of the CFD Specimens 


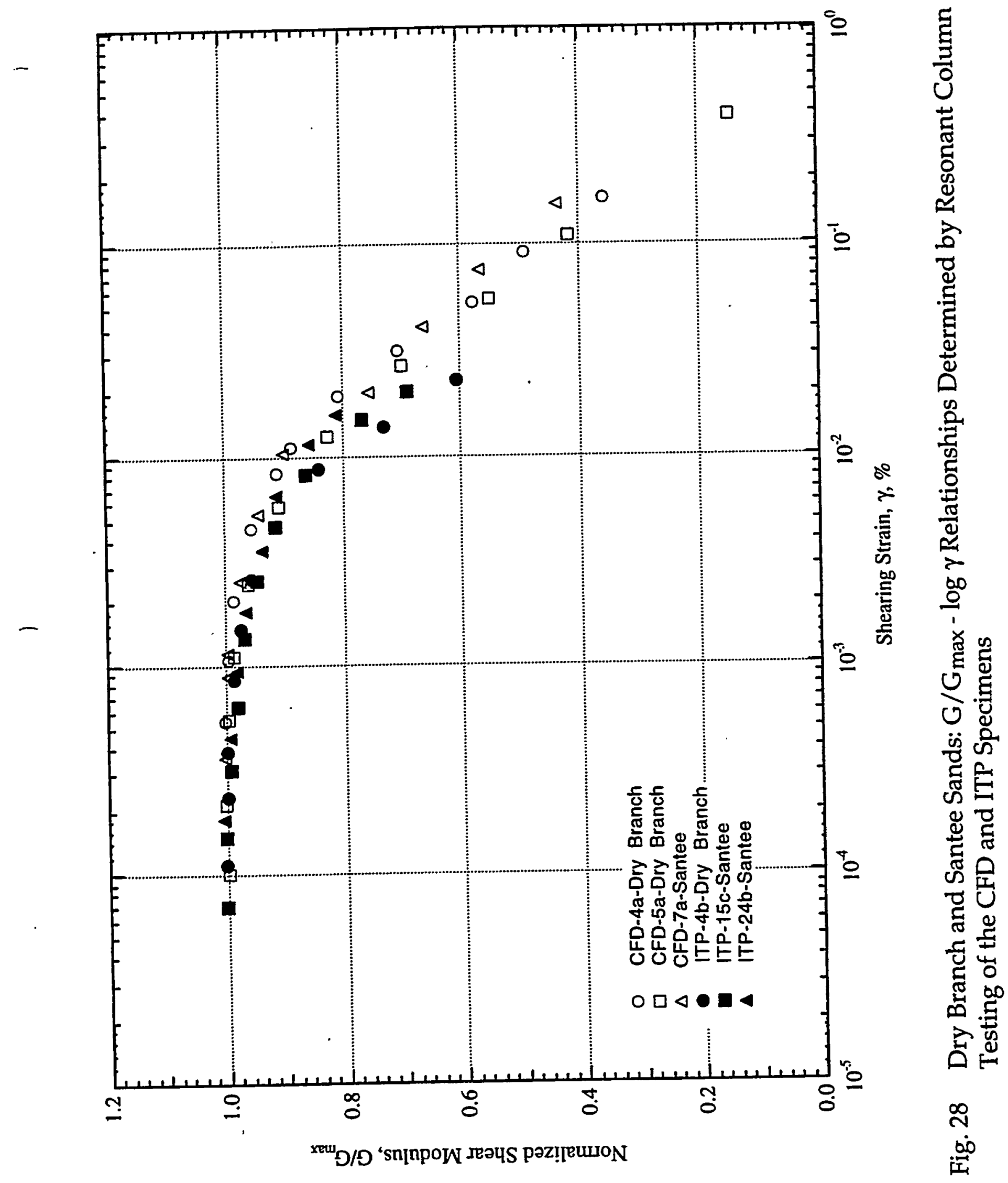

SRS-FR-CDP-95, rev. 0, 13 September 95 


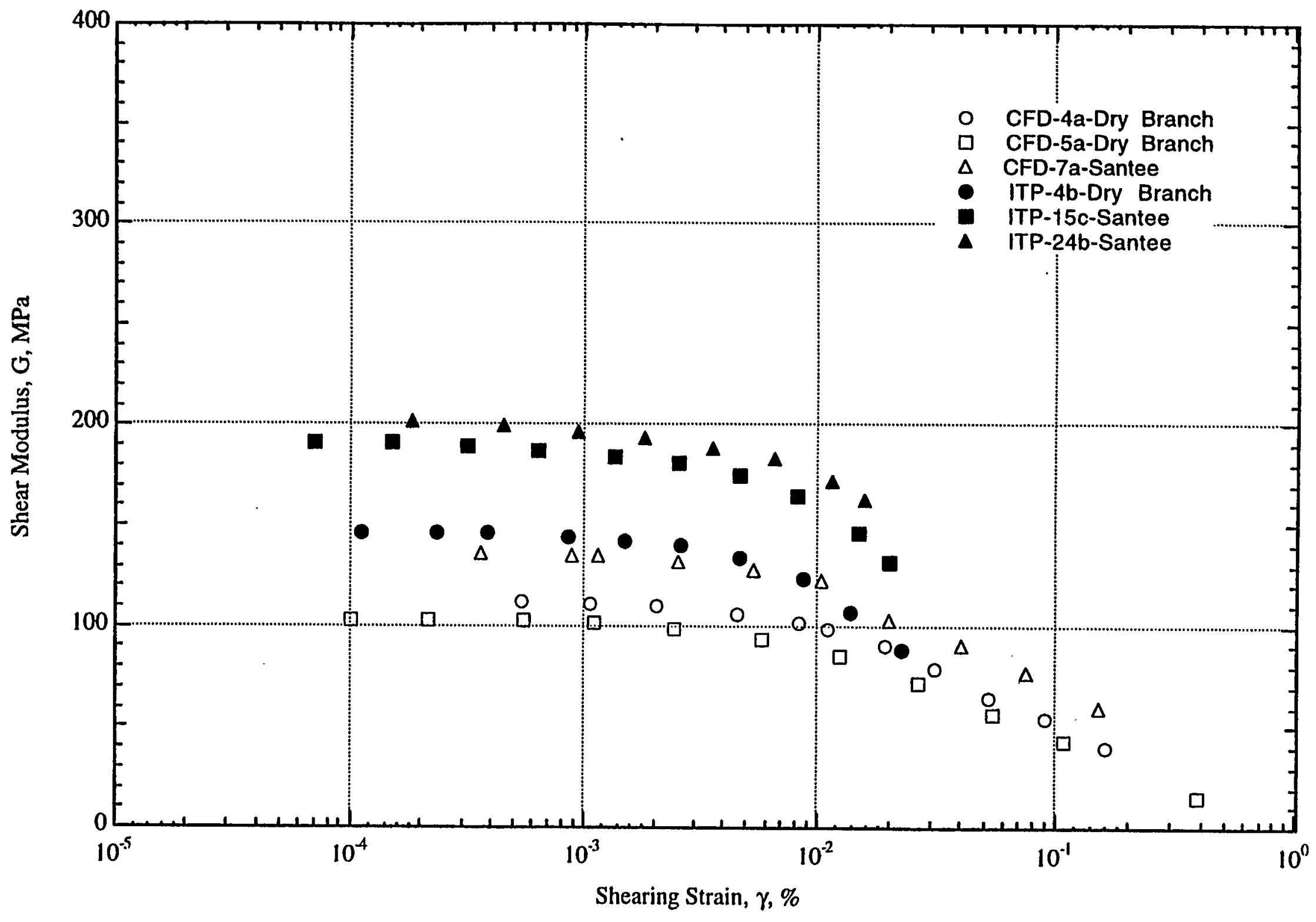

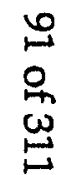

Fig. 29 Dry Branch and Santee Sands: G - $\log \gamma$ Relationships Determined by Resonant Column Testing of the CFD and ITP Specimens 


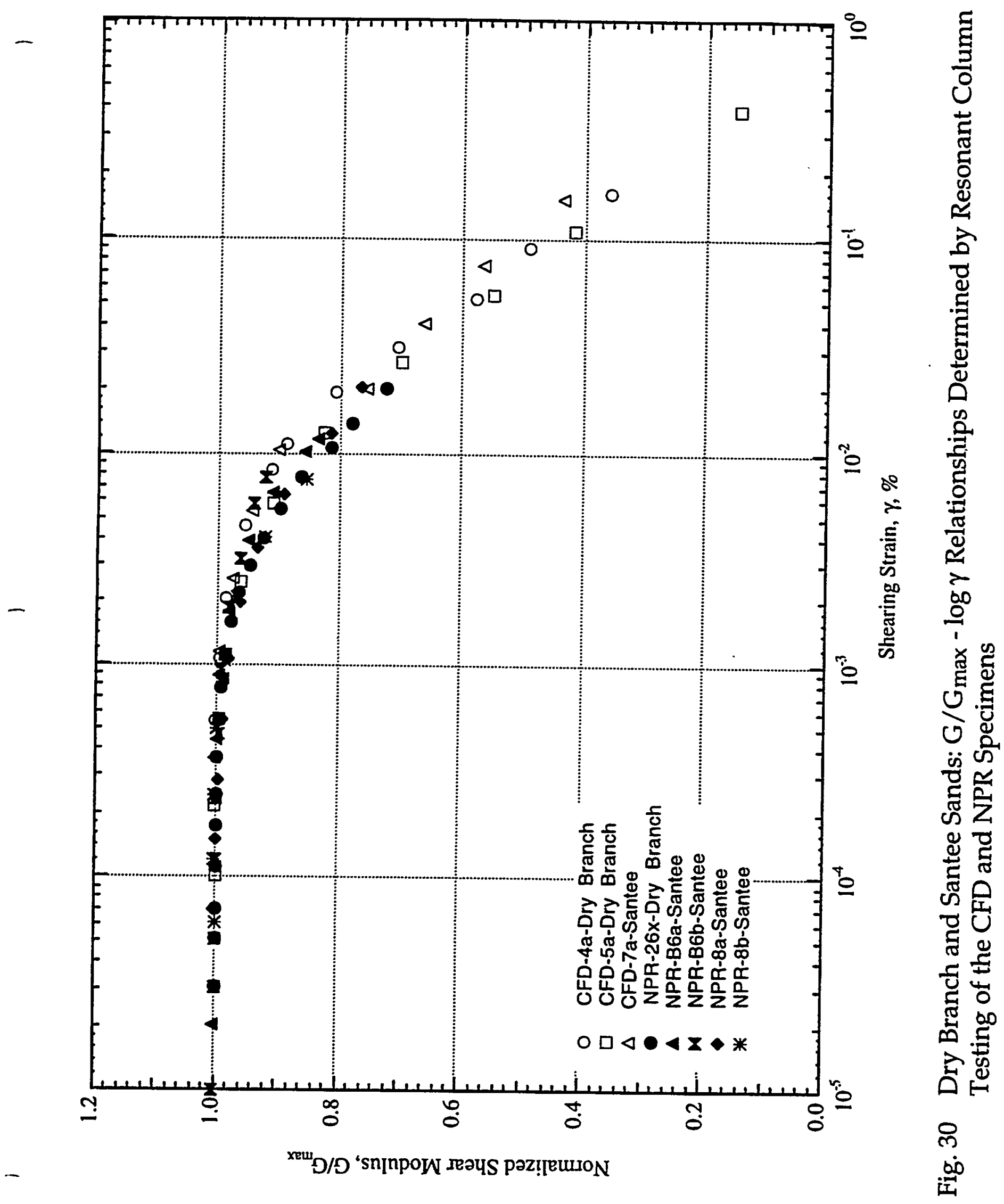

SRS-FR-CDP-95, rev. 0, 13 September 95

Project No. AA891070 


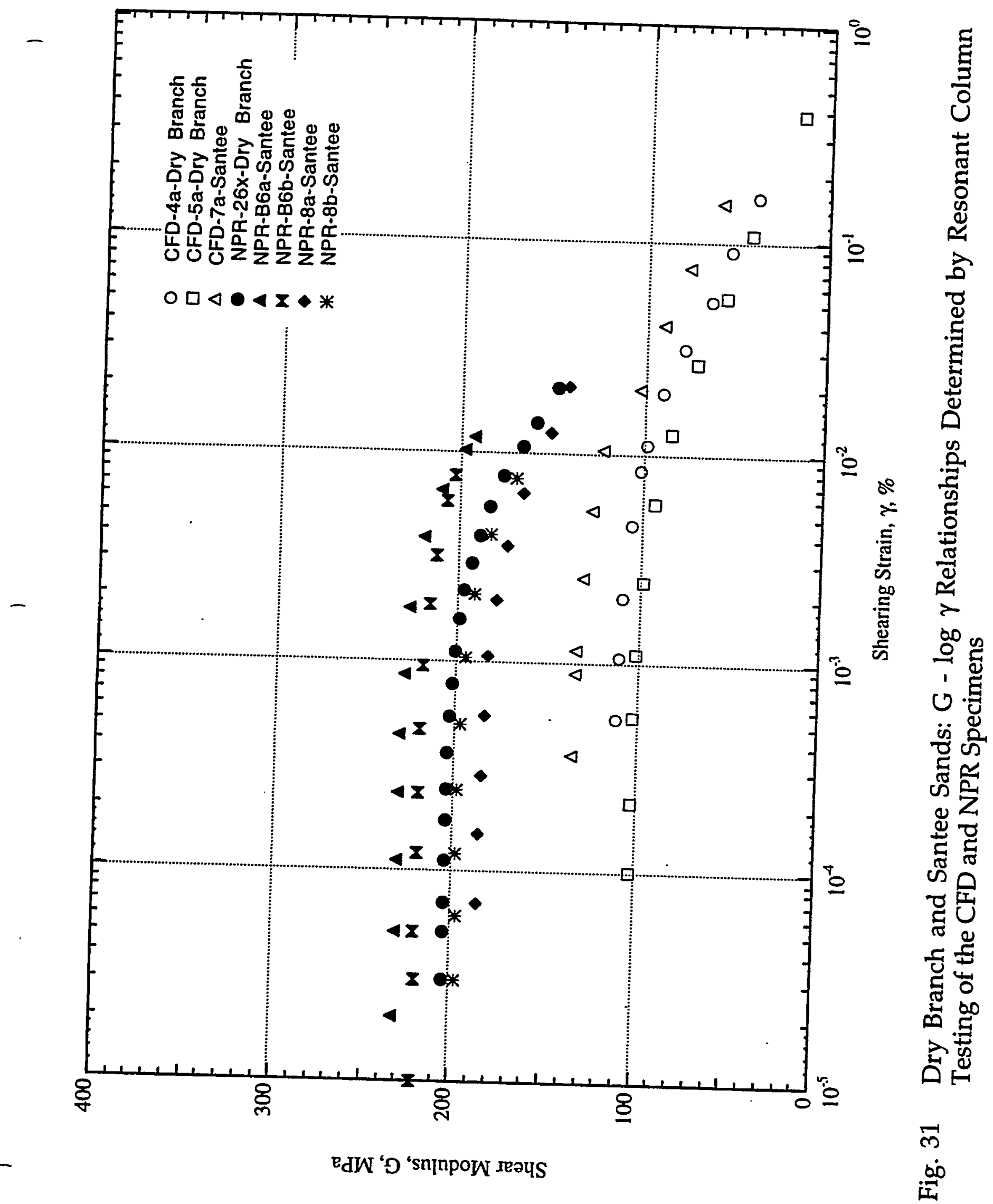

SRS-FR-CDP-95, rev. 0, 13 September 95

Project No. AA891070 


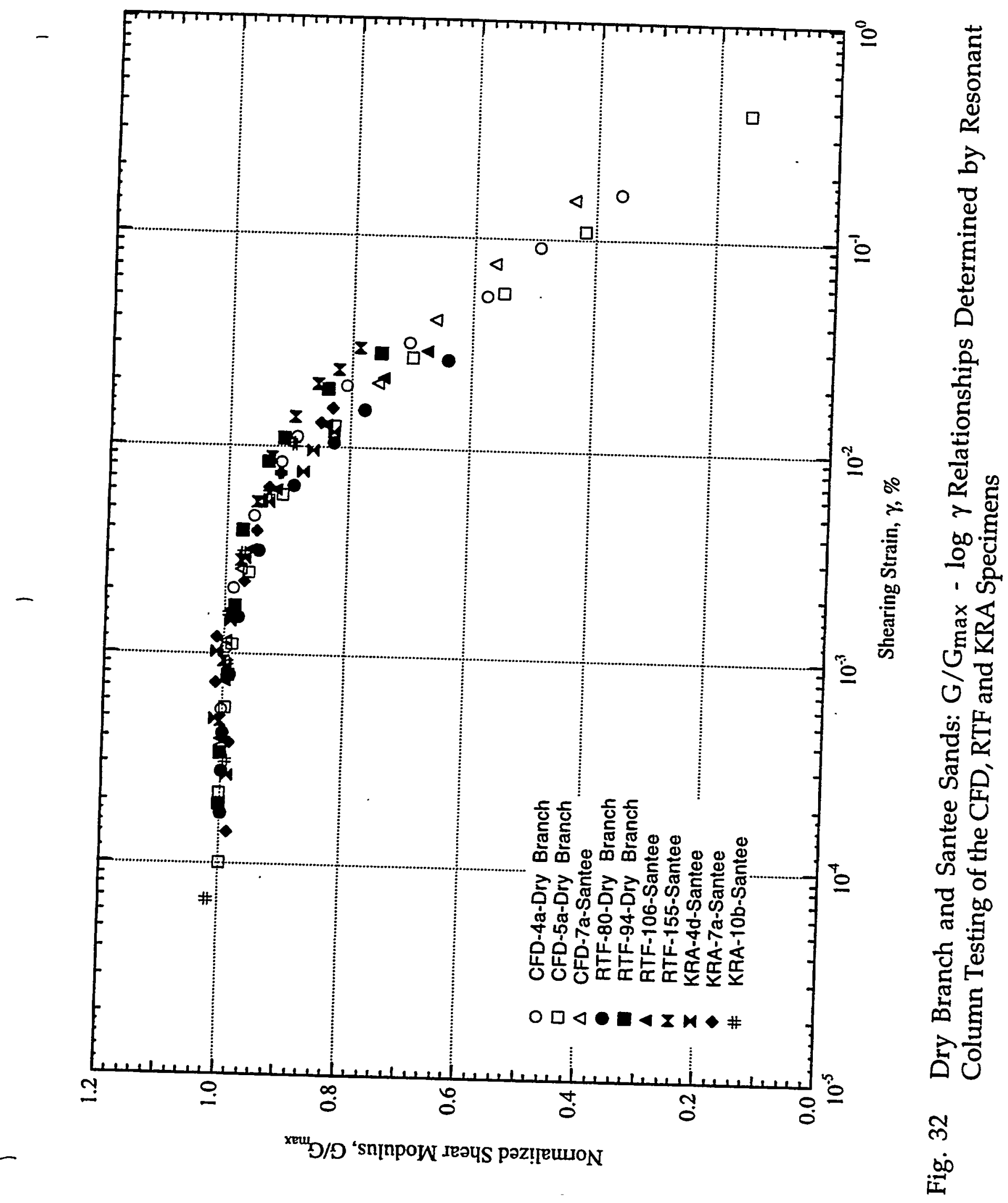

SRS-FR-CDP-95, rev. 0, 13 September 95 Project No. AA891070 


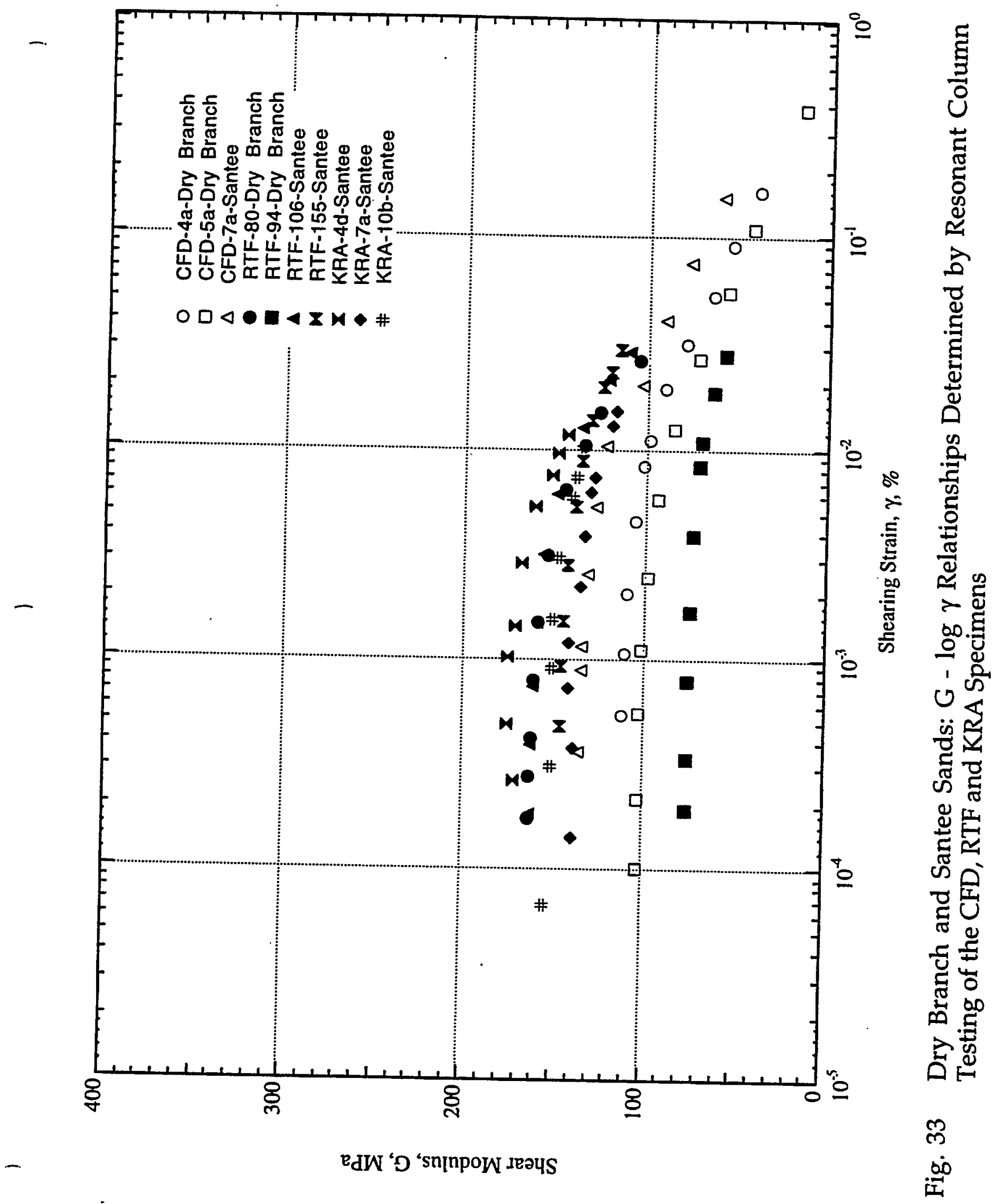

SRS-FR-CDP-95, rev. 0, 13 September 95

Project No. AA891070 


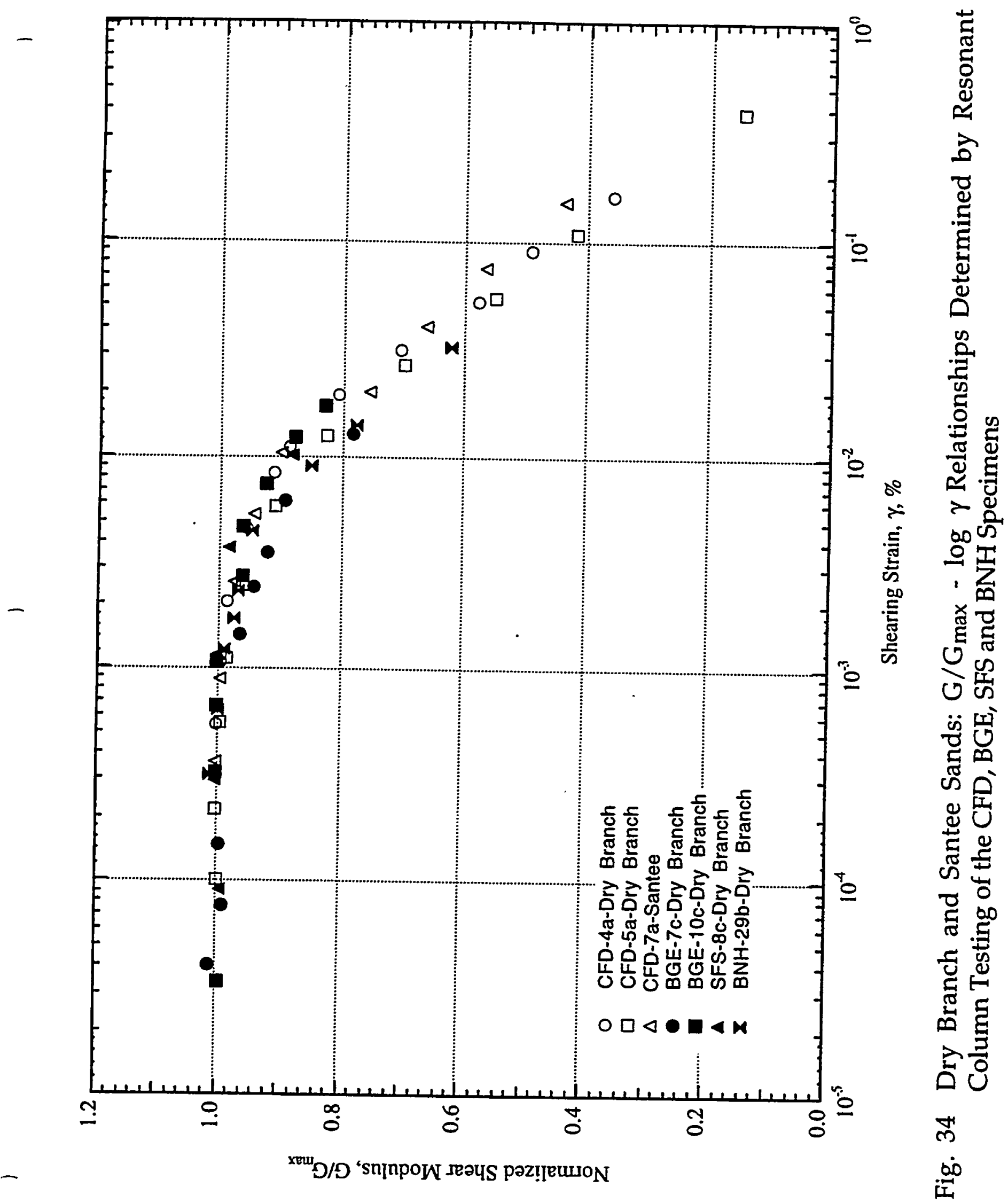

SRS-FR-CDP-95, rev. 0, 13 September 95

Project No. AA891070 


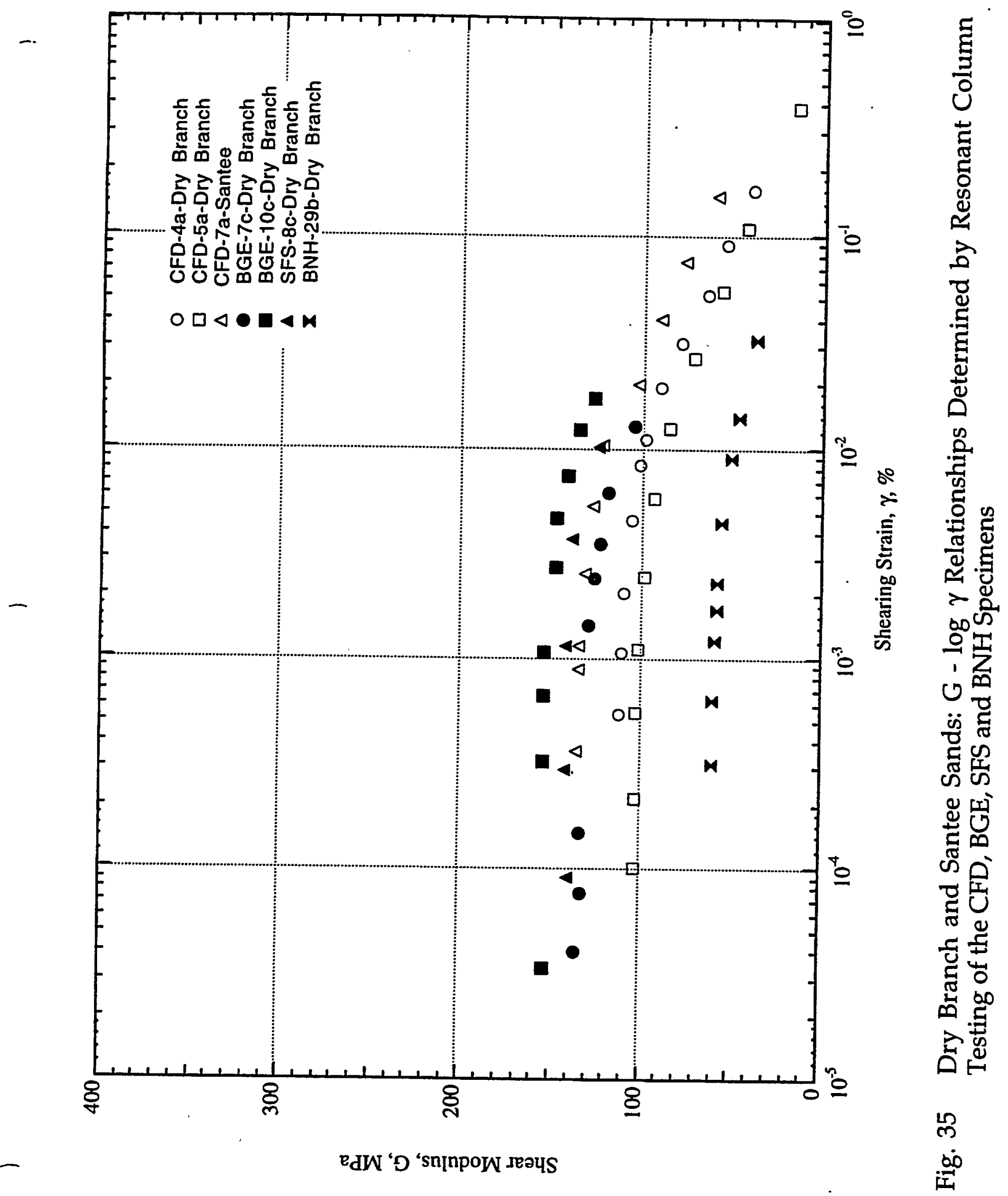

SRS-FR-CDP-95, rev. 0, 13 September 95

Project No. AA891070 


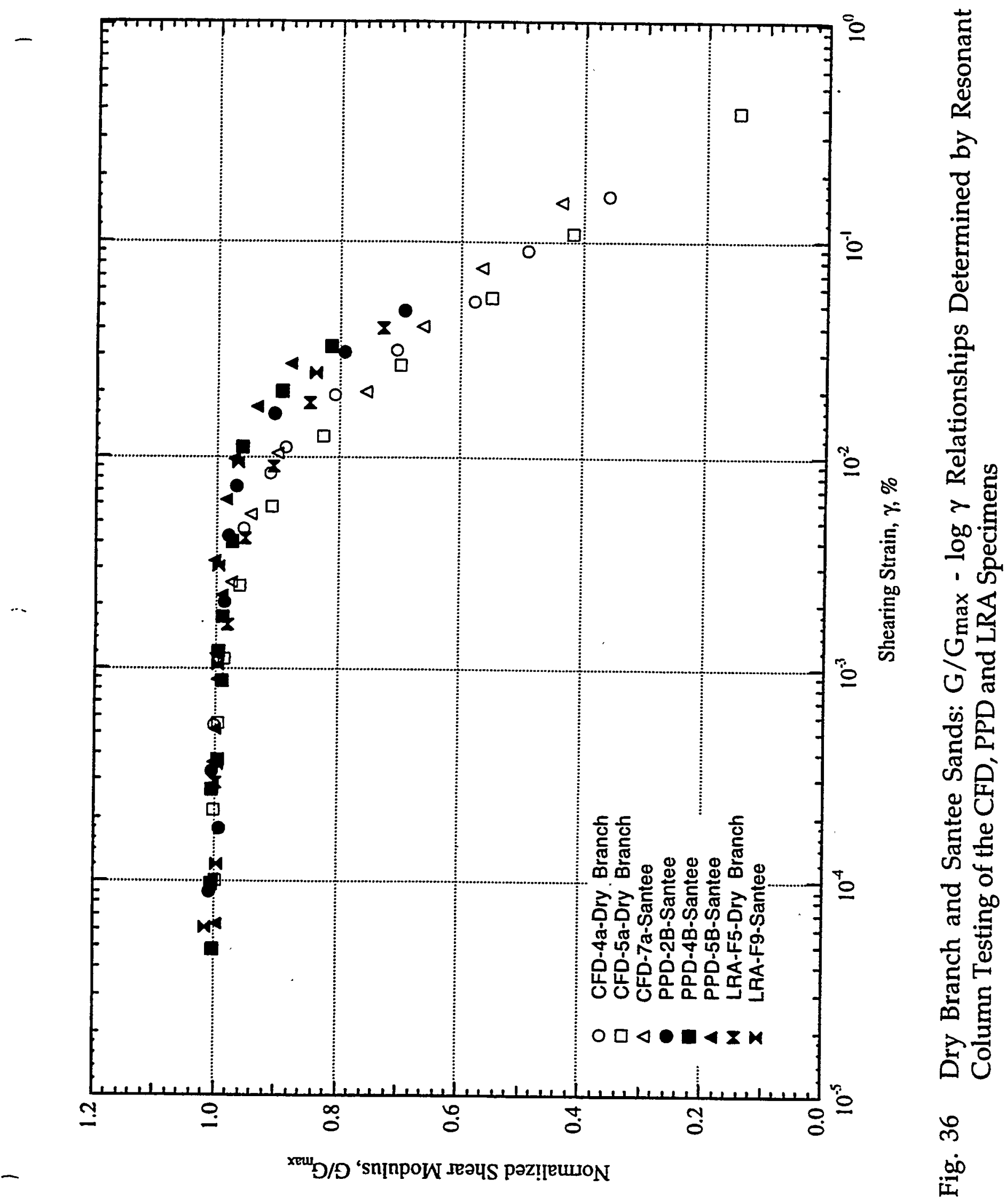

SRS-FR-CDP-95, rev. 0, 13 September 95

Project No. AA891070 


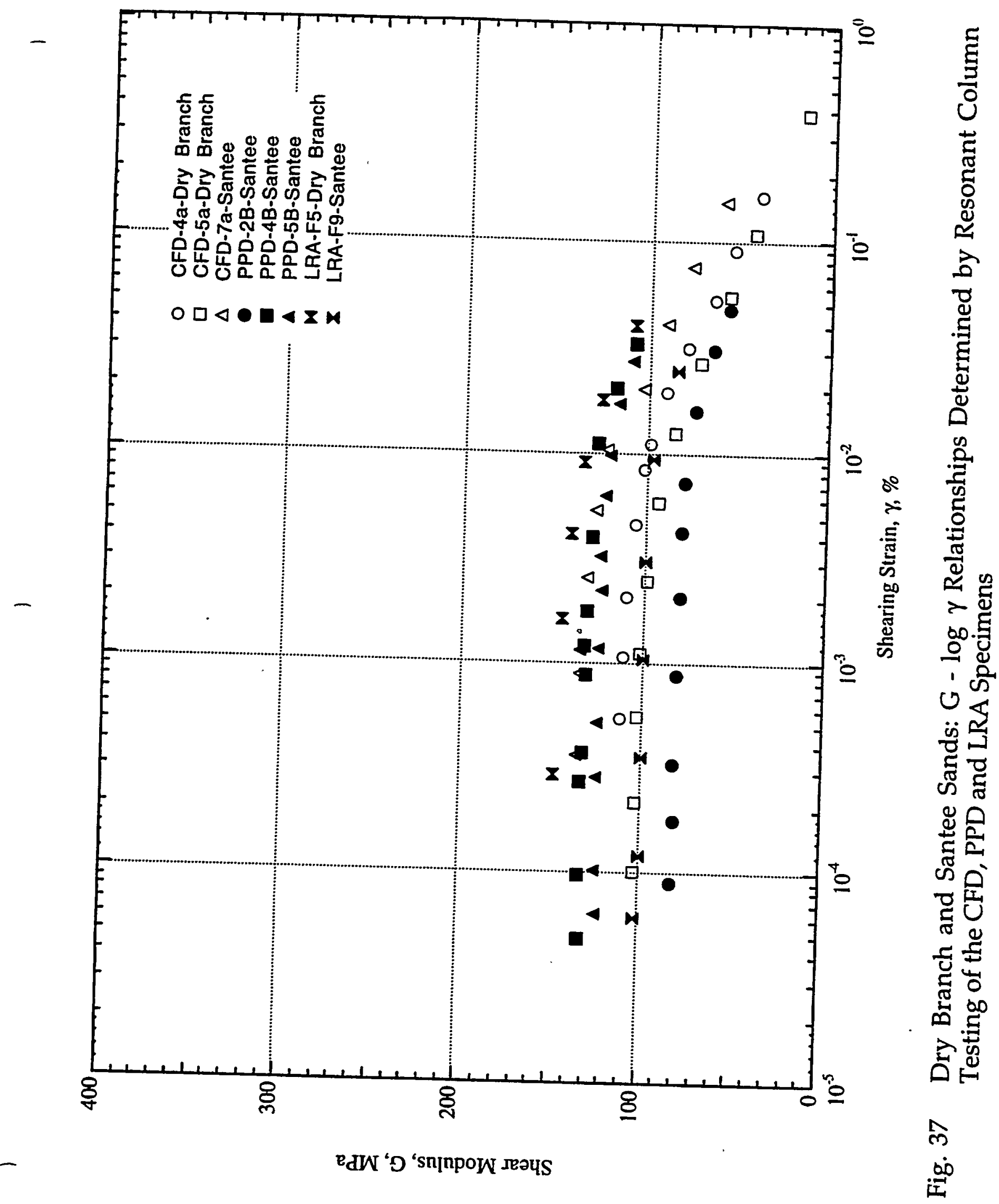

SRS-FR-CDP-95, rev. 0, 13 September 95

Project No. AA891070 


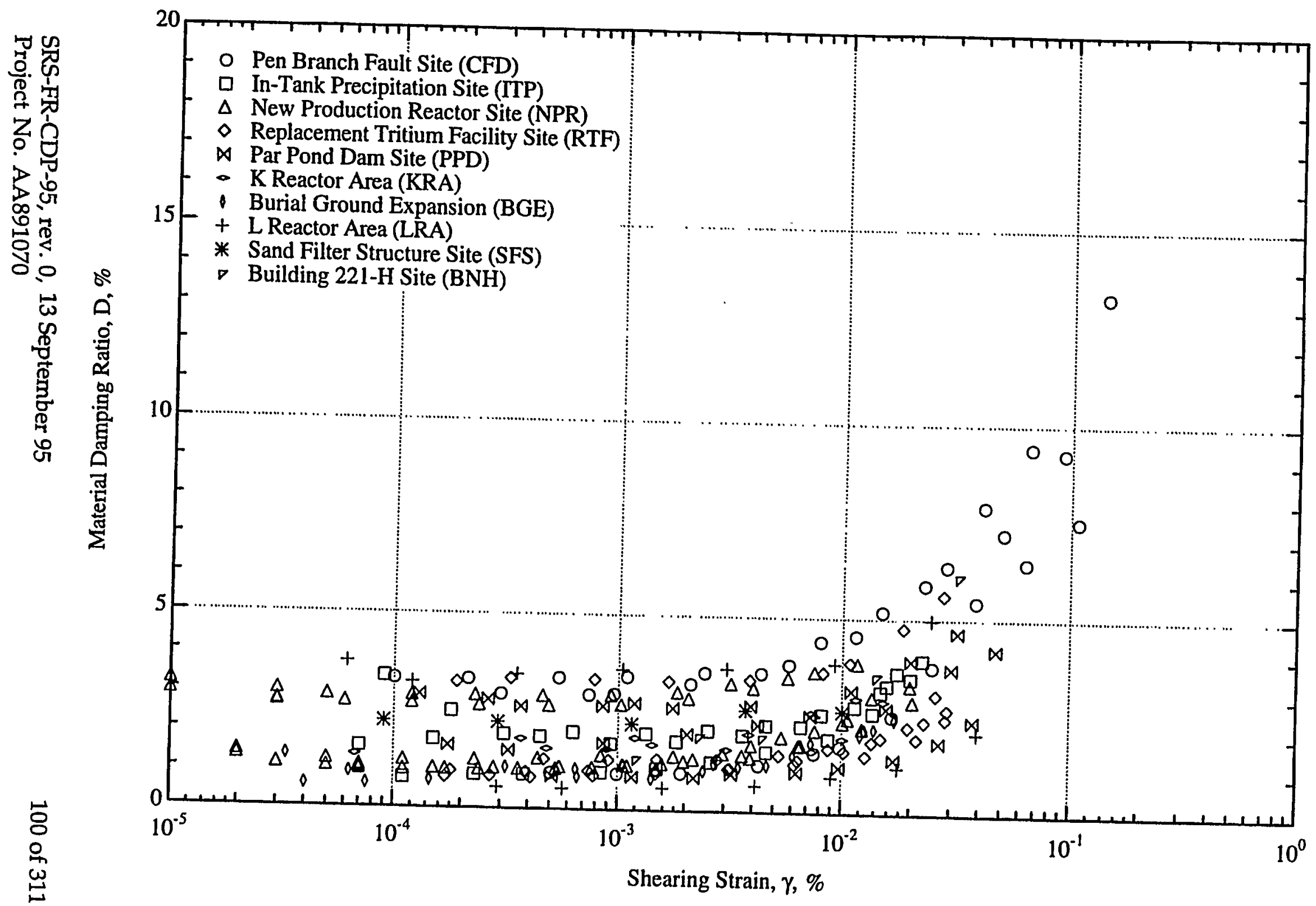

Fig. 38 Summary Plot of All D - $\log \gamma$ Relationships Determined by Resonant Column Testing with the Specimens Confined At or Near the In-Situ Mean Effective Stress for the Dry Branch and Santee
Sands 


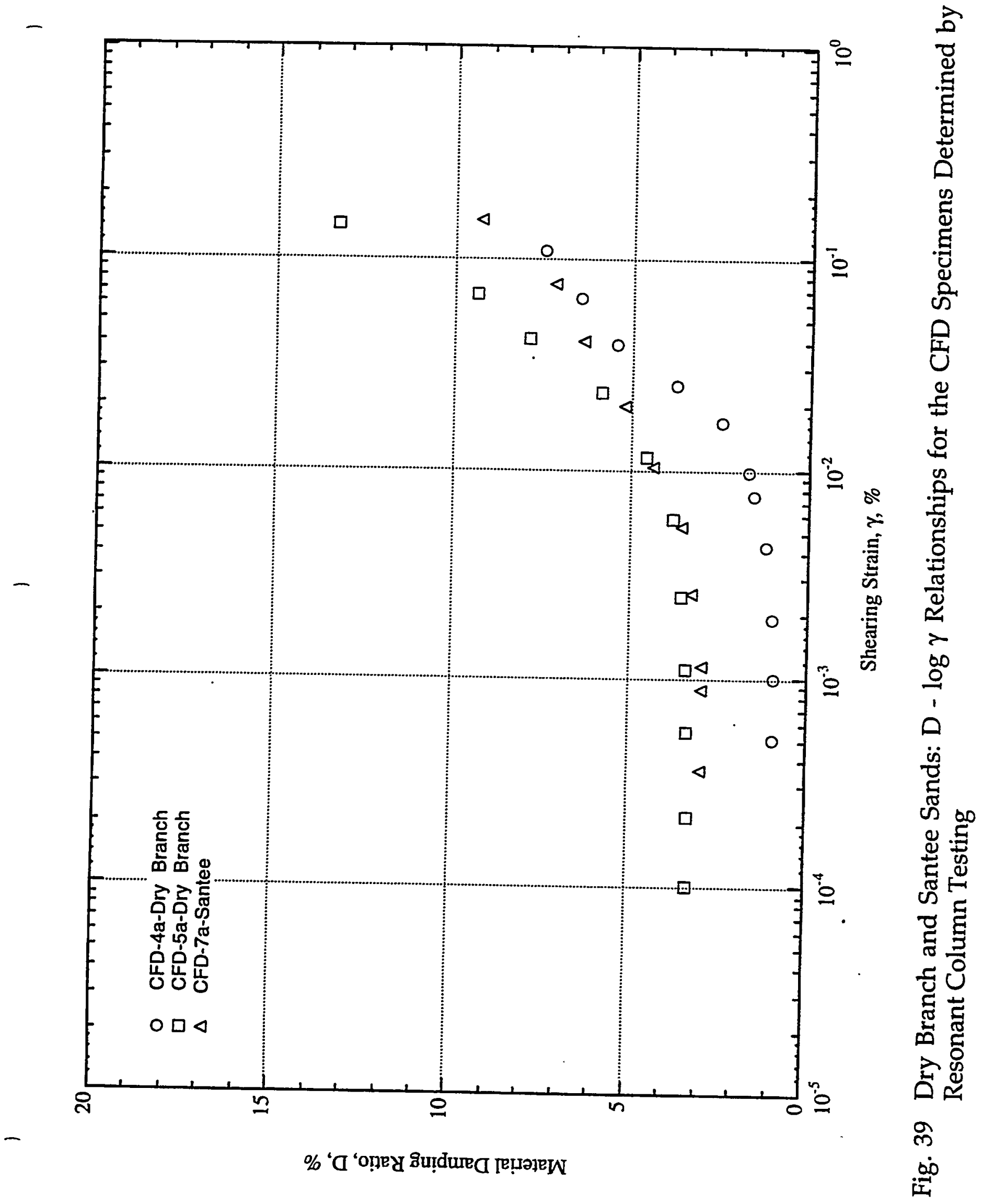

SRS-FR-CDP-95, rev. 0, 13 September 95

Project No. AA891070 


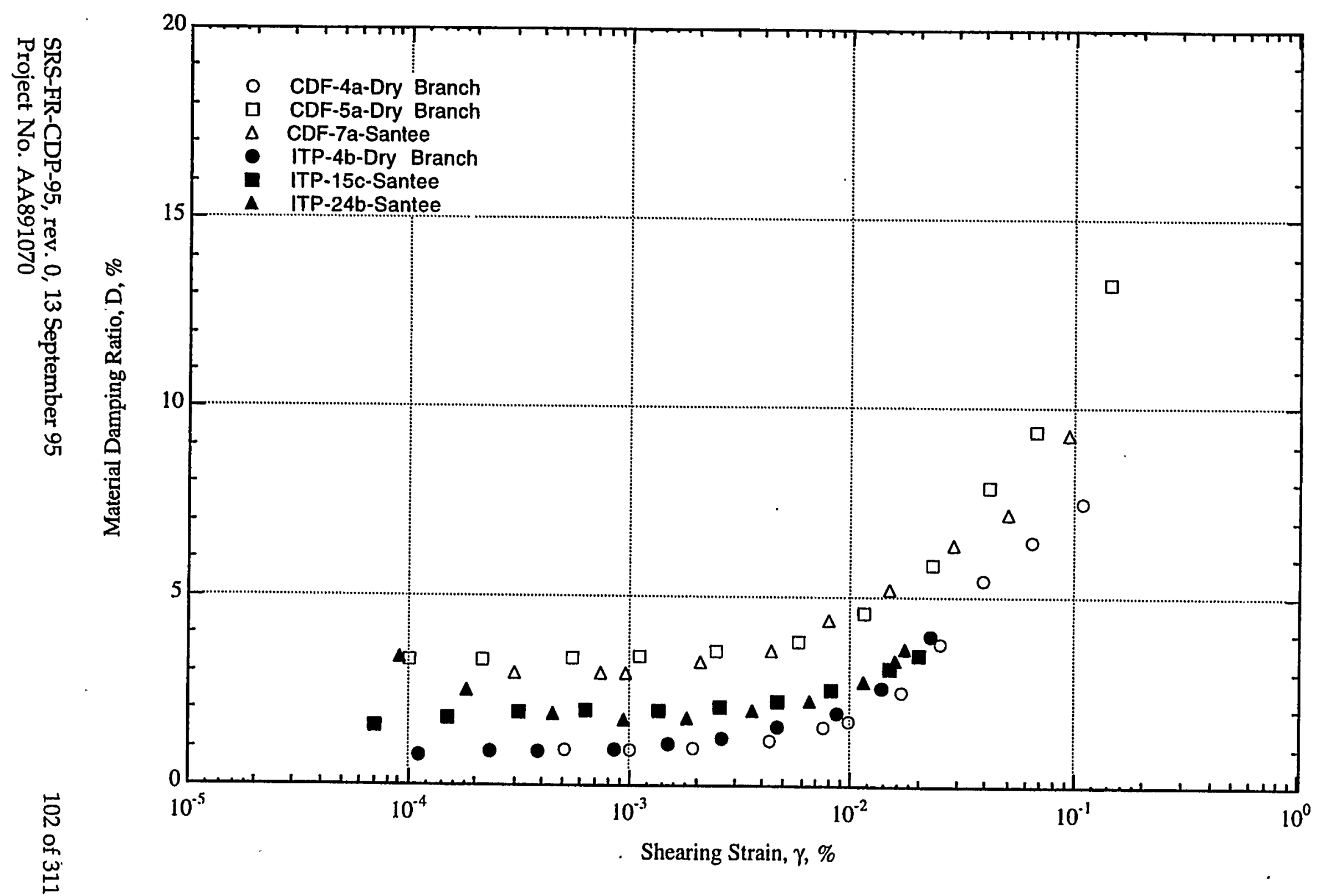

Fig. 40 Dry Branch and Santee Sands: D - $\log \gamma$ Relationships for the CFD and ITP Specimens Determined by Resonant Column Testing 


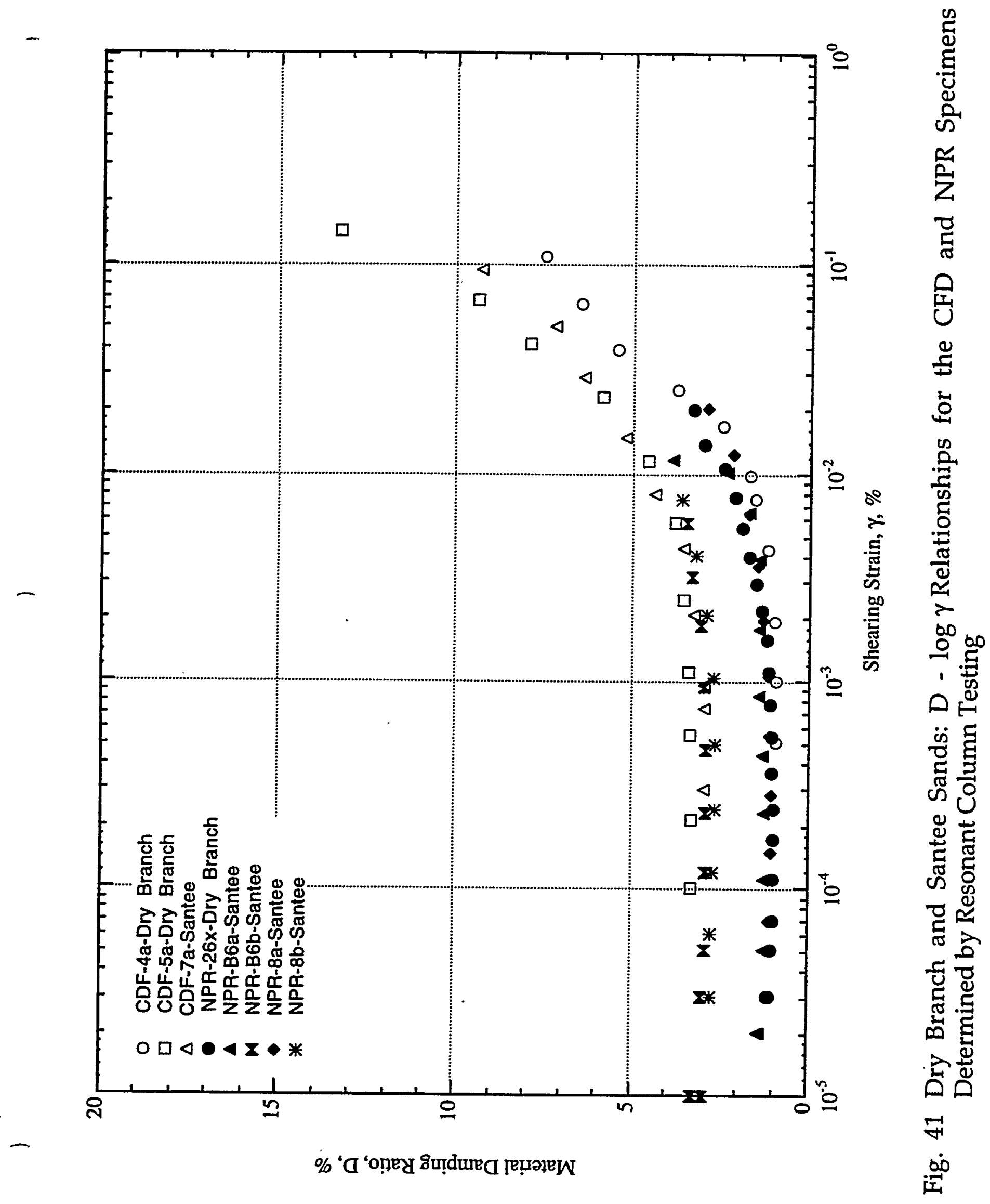

SRS-FR-CDP-95, rev. 0, 13 September 95

Project No. AA891070 


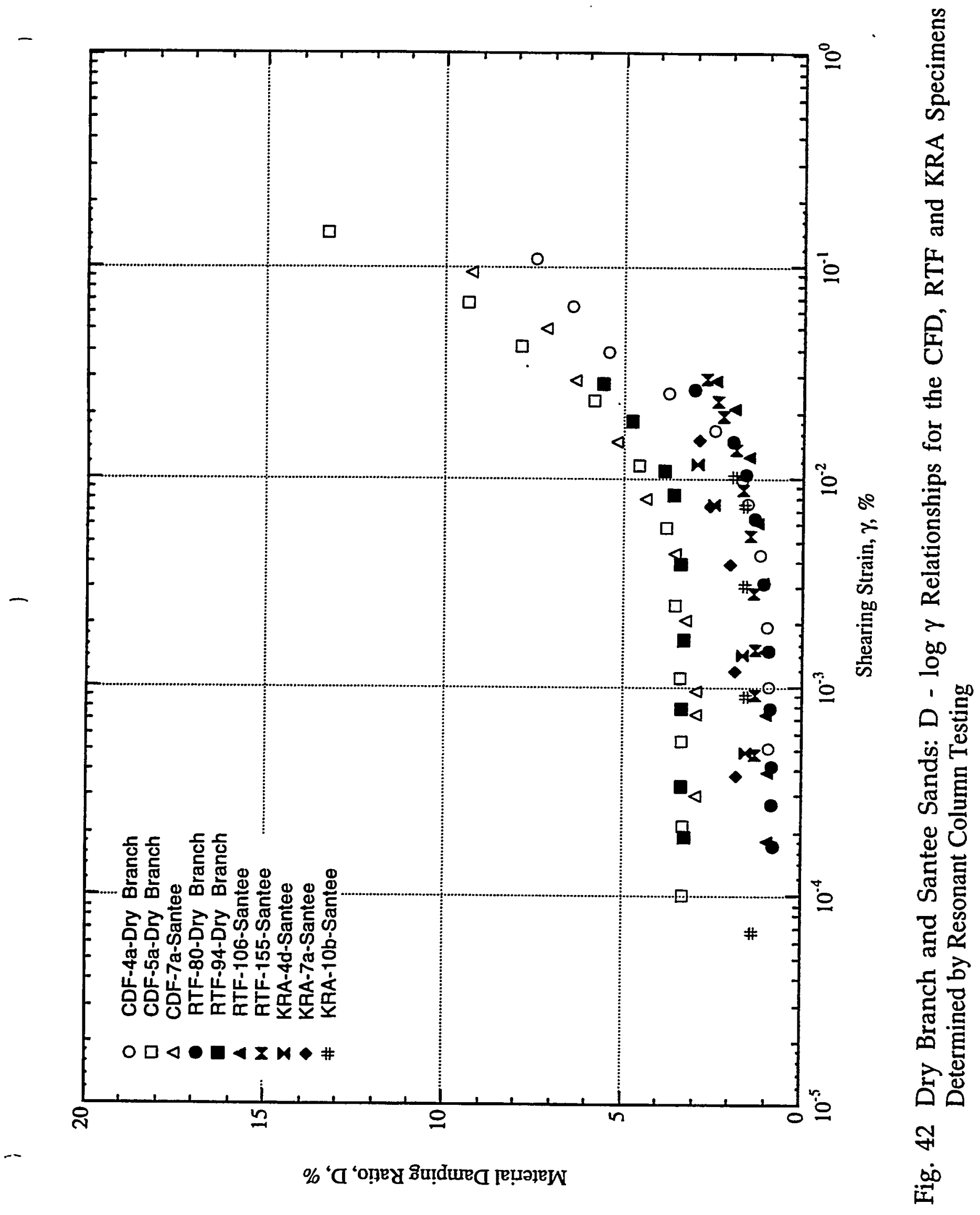

SRS-FR-CDP-95, rev. 0, 13 September 95

104 of 311

Project No. AA891070 


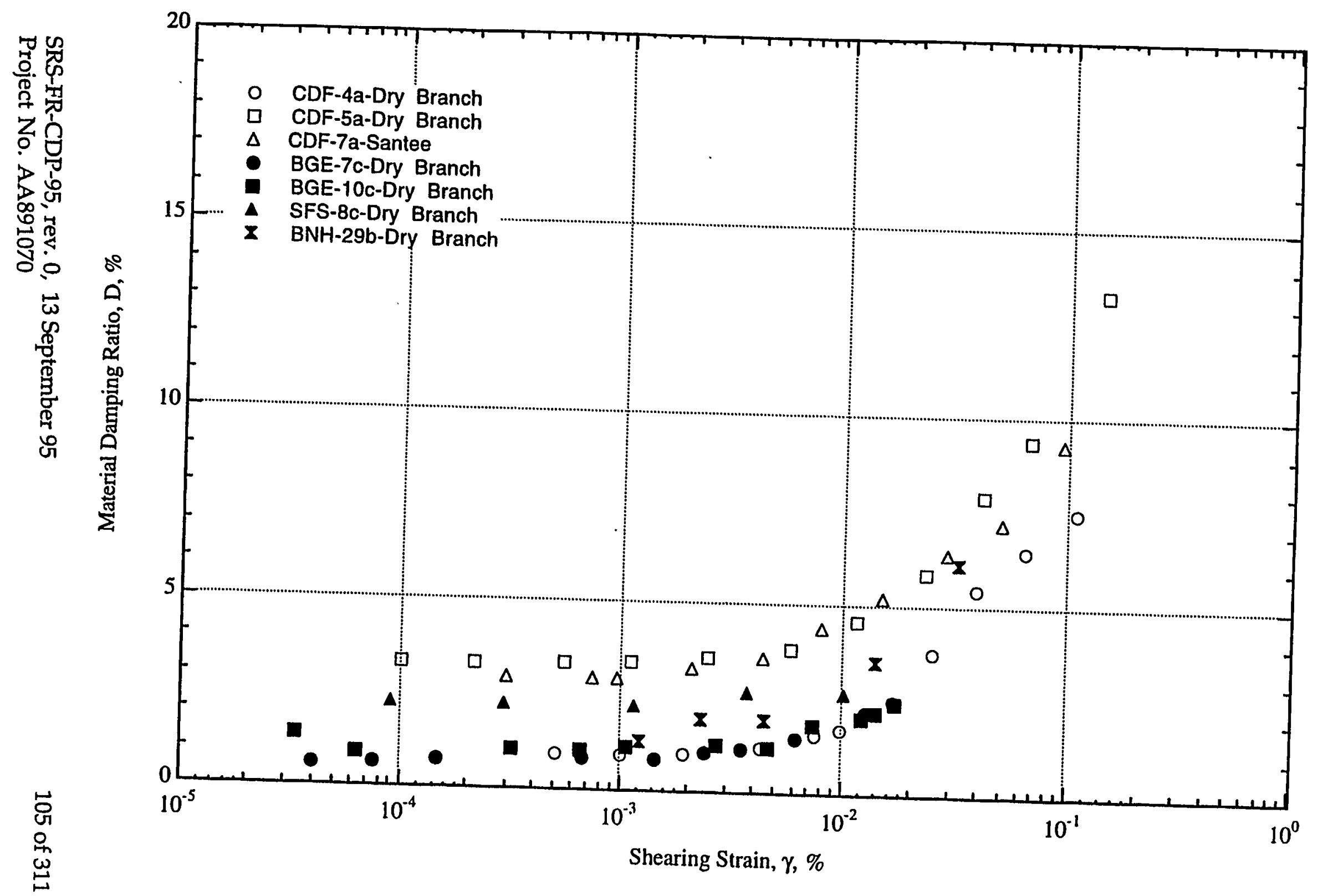

Fig. 43 Dry Branch and Santee Sands: D - log $\gamma$ Relationships for the CFD, BGE, SFS and BNH Specimens
Determined by Resonant Column Testing 


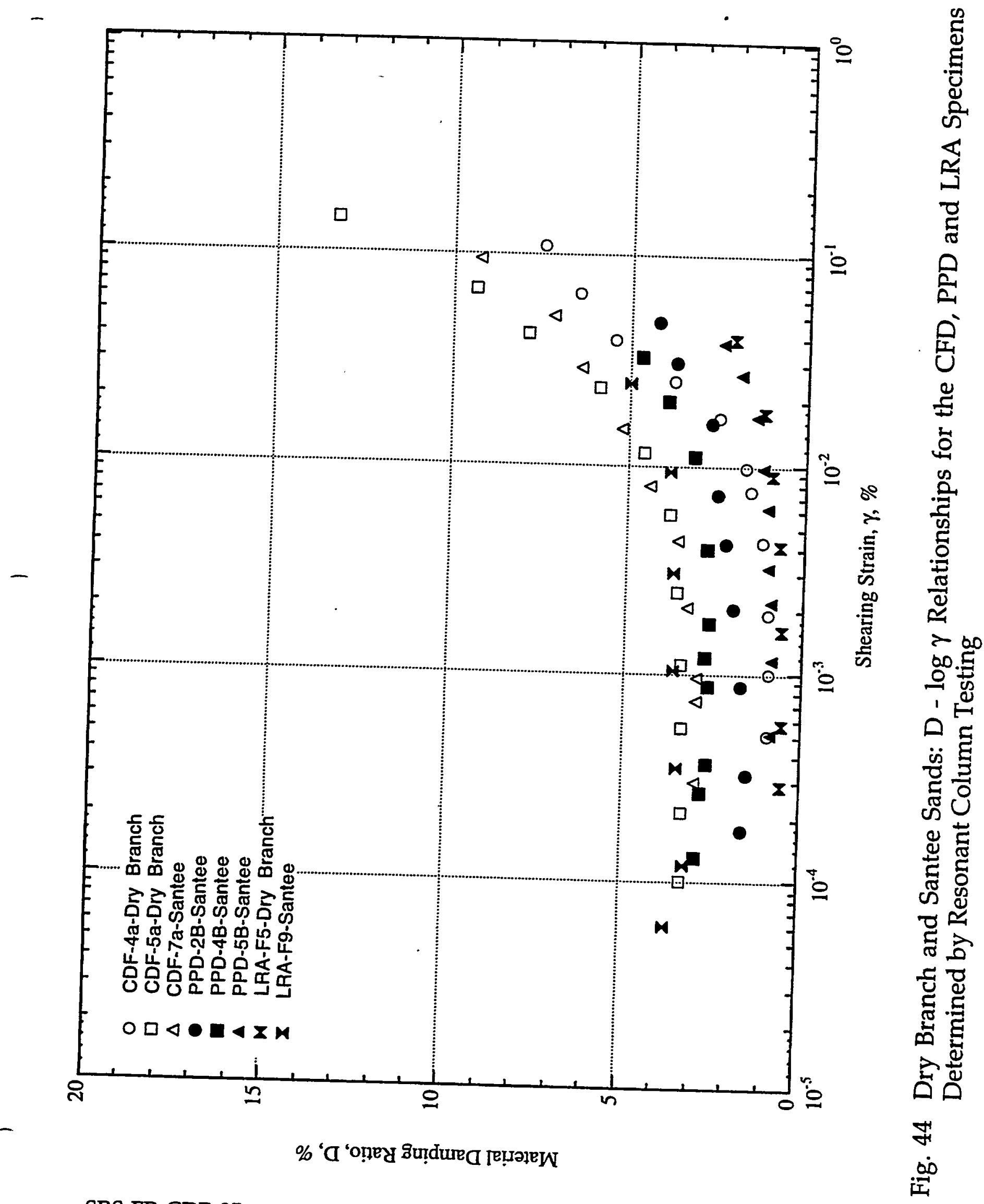

SRS-FR-CDP-95, rev. 0, 13 September 95 Project No. AA891070 

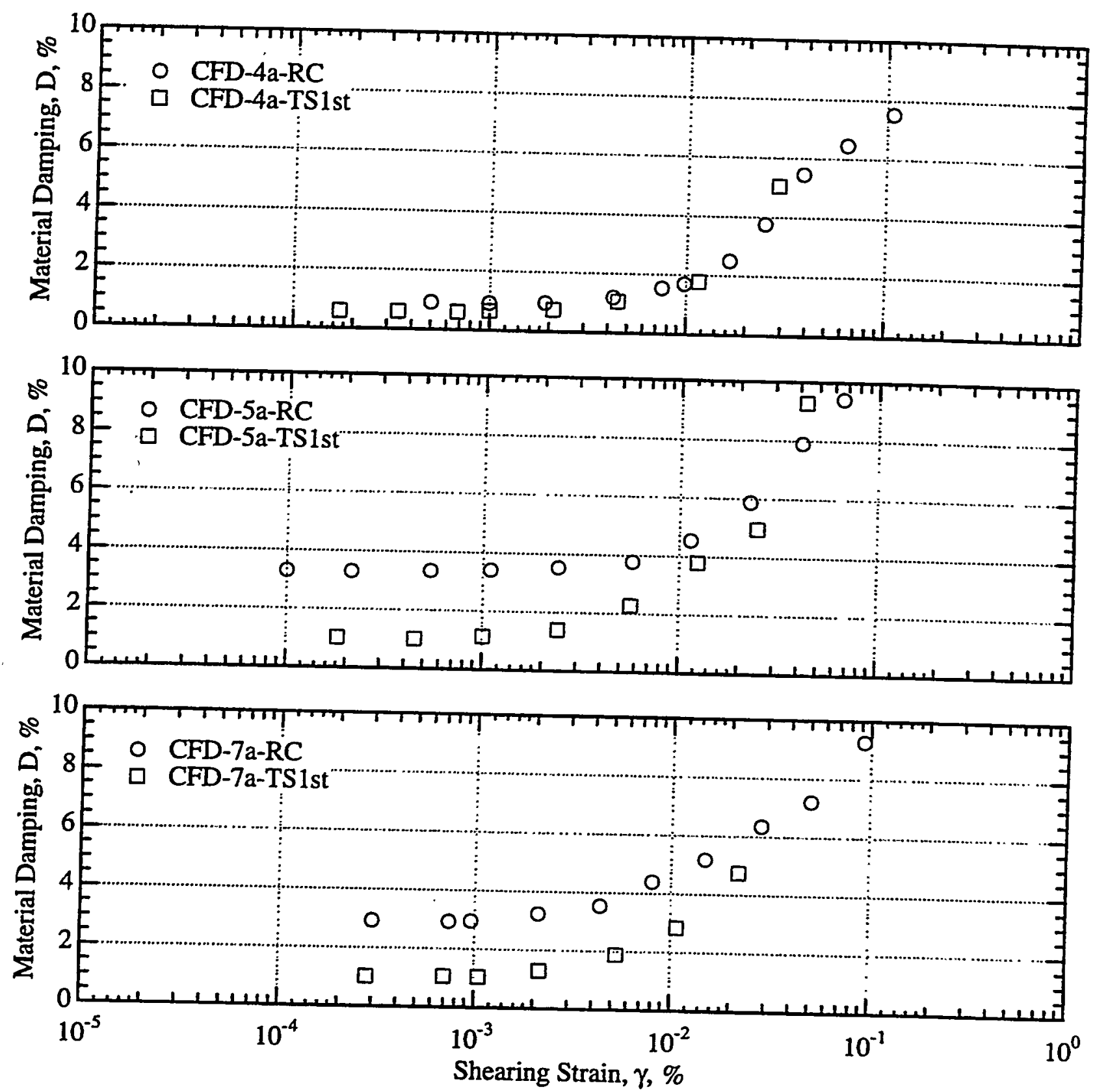

Fig. 45 Comparison of Material Damping Values Determined for the CFD Specimens Using RC and TS Tests; Dry Branch and Santee Sands 

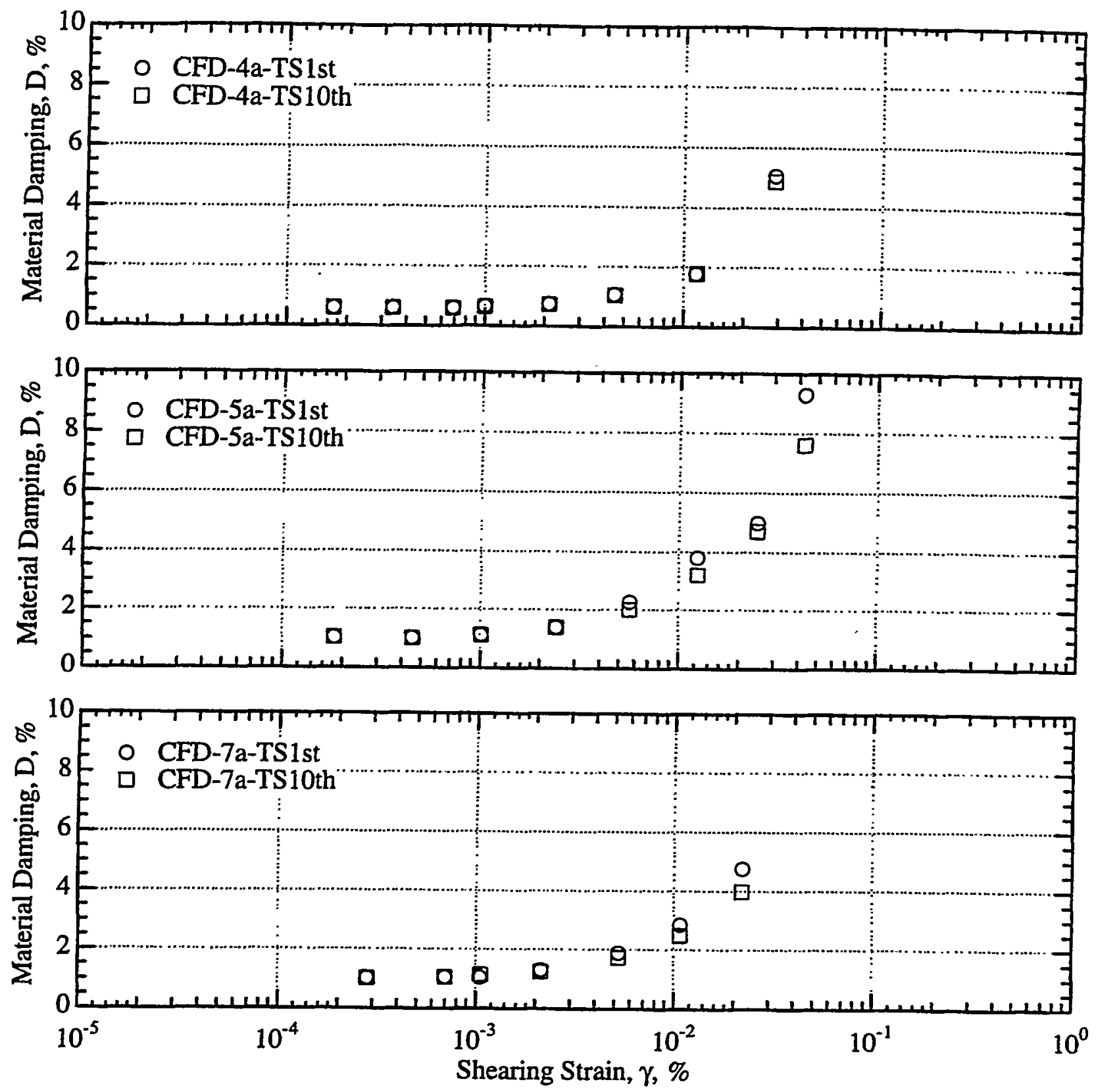

Fig. 46 Influence of Number of Loading Cycles on Material Damping Values Determined for the CFD Specimens Using TS Tests; Dry Branch and Santee Sands 


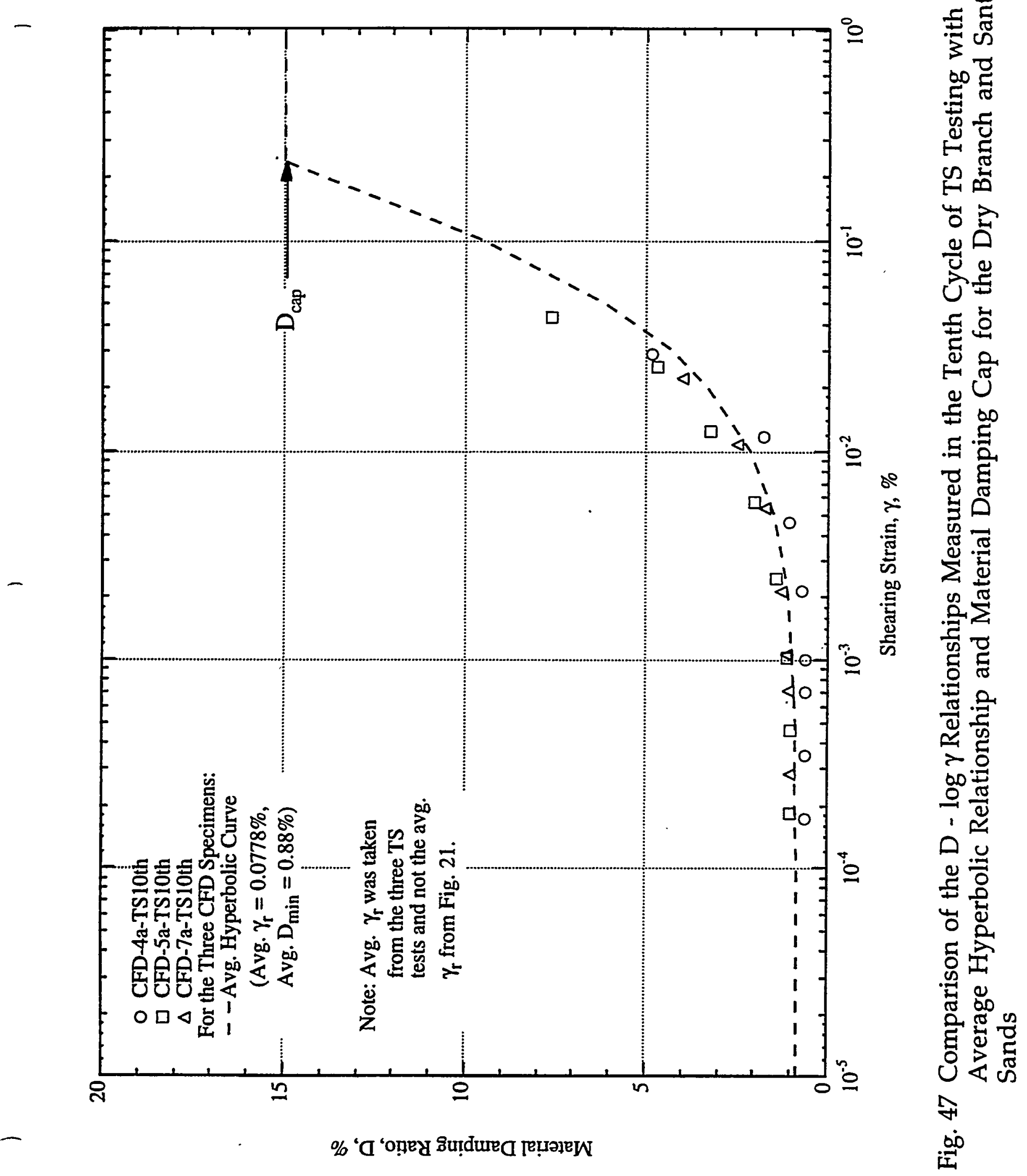

SRS-FR-CDP-95, rev. 0, 13 September 95 


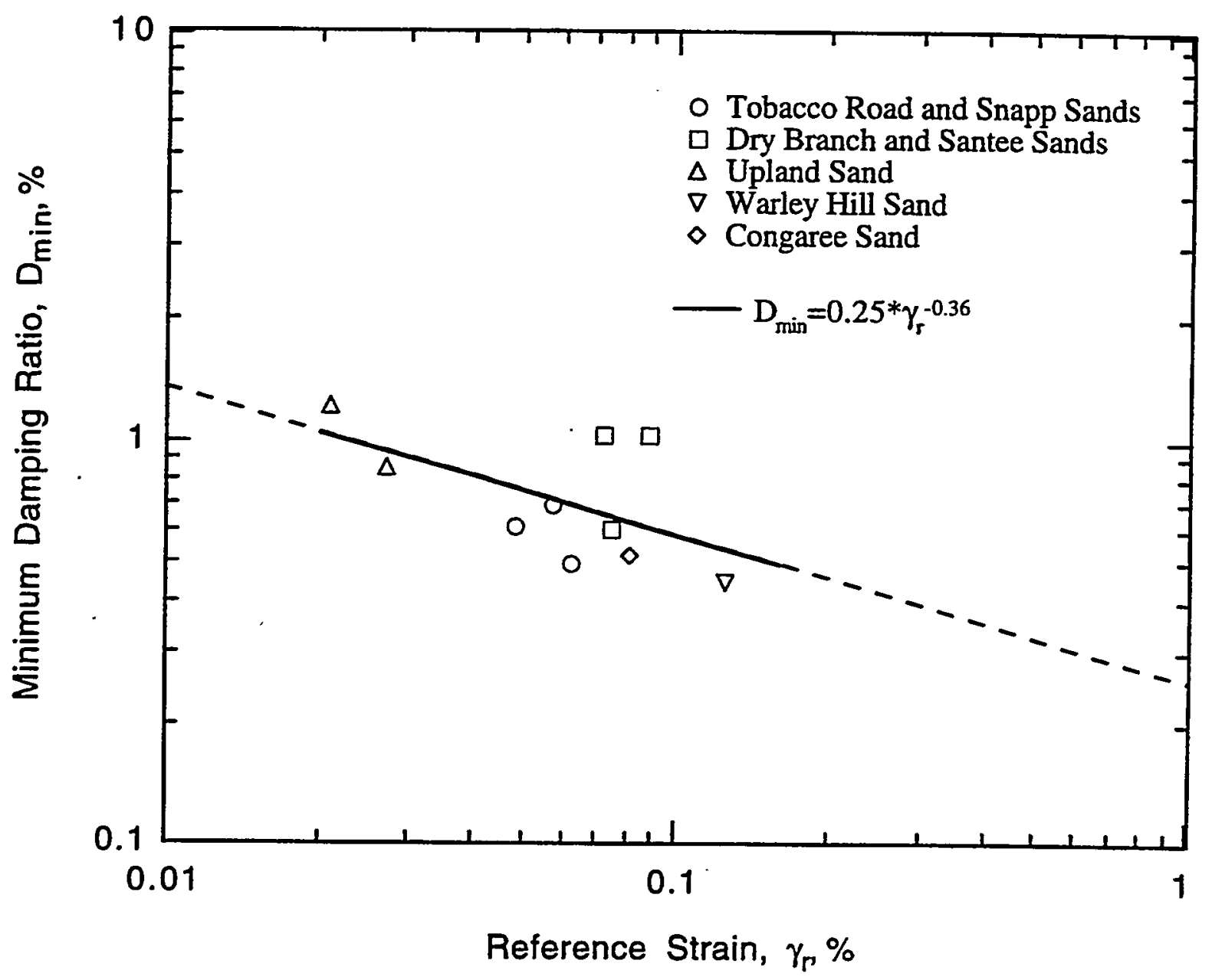

Fig. 48 General Relationship Between $D_{\min }$ and $\gamma_{\mathrm{r}}$ from TS Testing of All Shallow Sand Specimens at SRS 


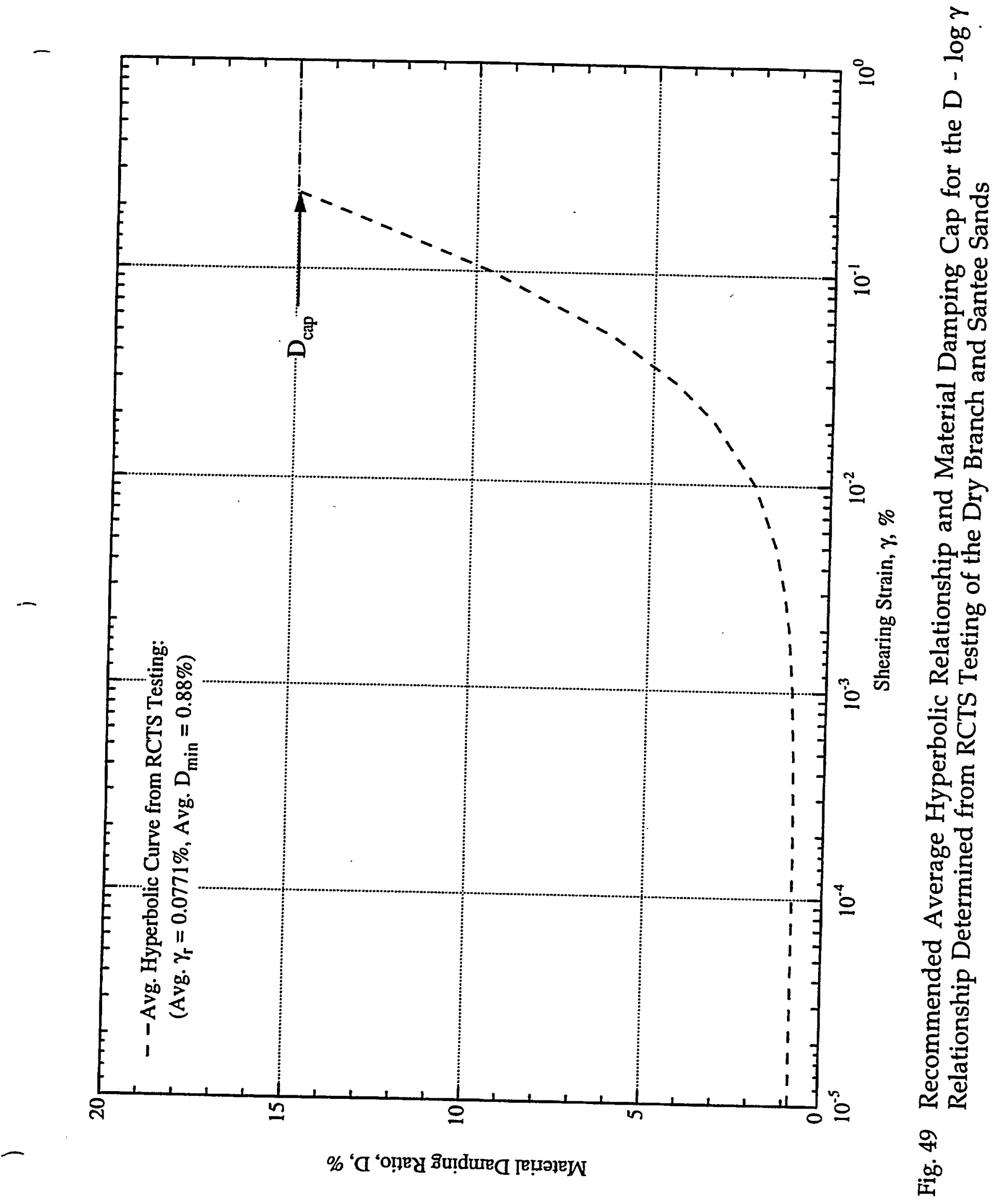

SRS-FR-CDP-95, rev. 0, 13 September 95

Project No. AA891070 

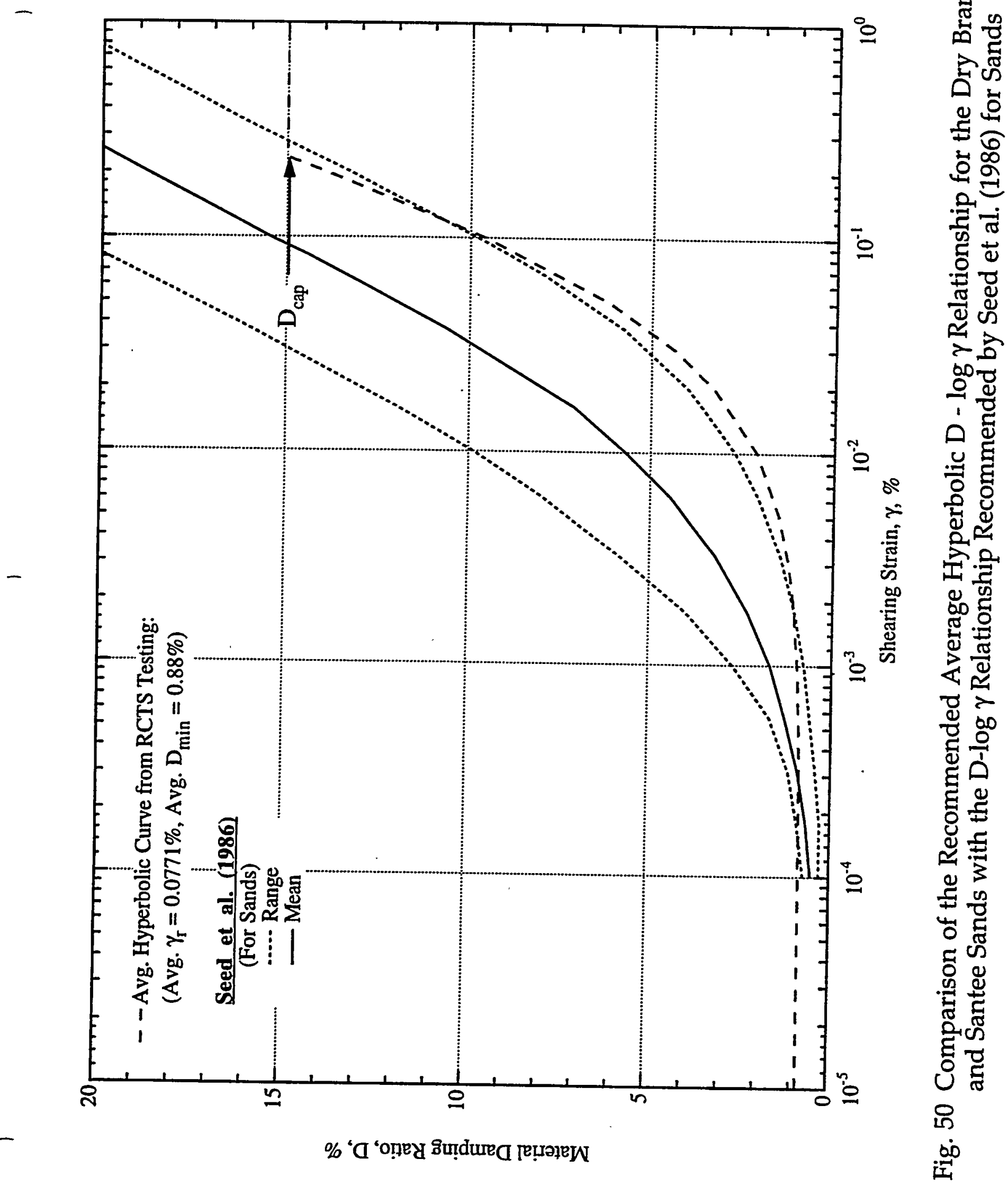

SRS-FR-CDP-95, rev. 0, 13 September 95 Project No. AA891070 


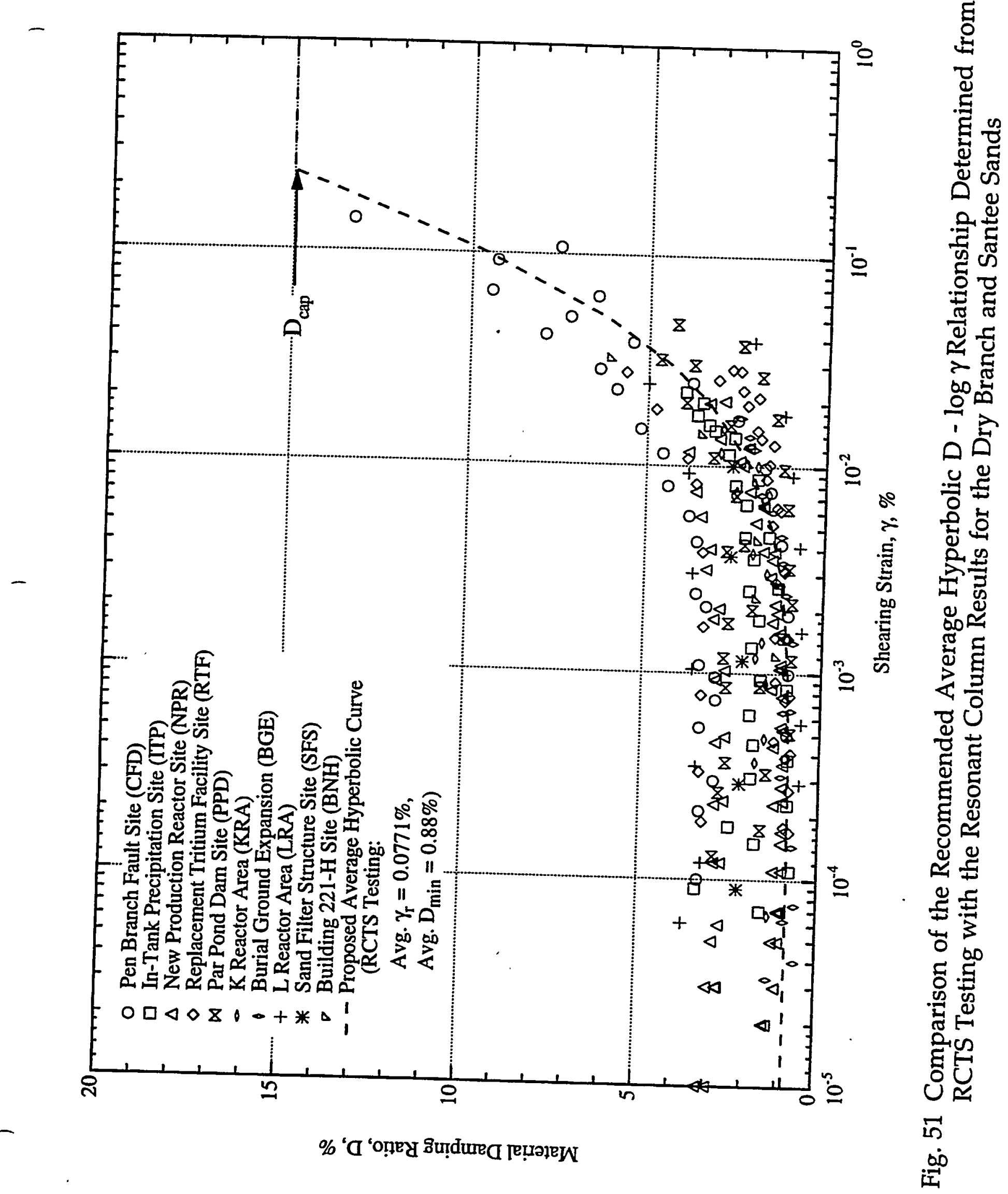

SRS-FR-CDP-95, rev. 0, 13 September 95

Project No. AA891070 


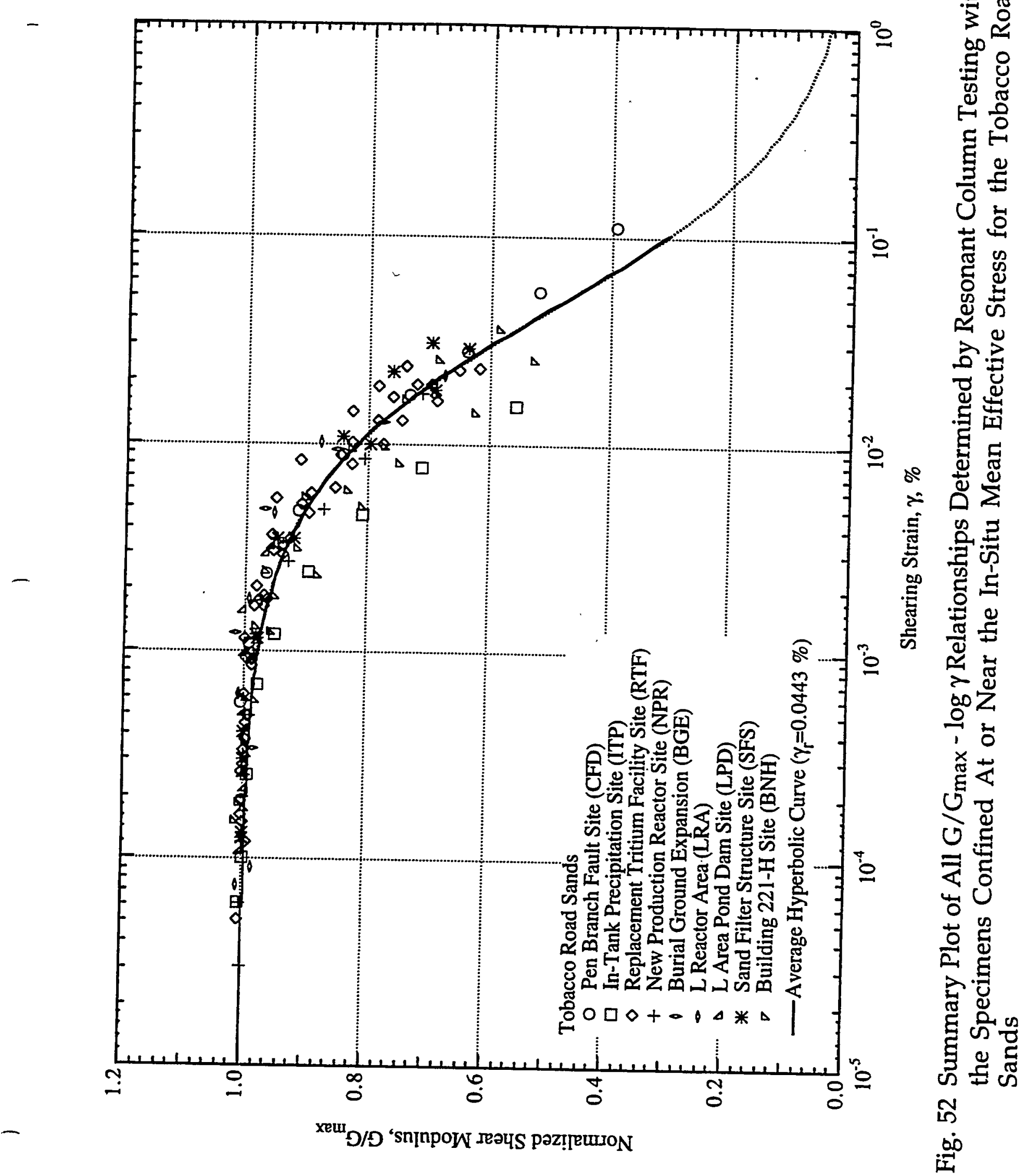

SRS-FR-CDP-95, rev. 0, 13 September 95 Project No. AA891070 


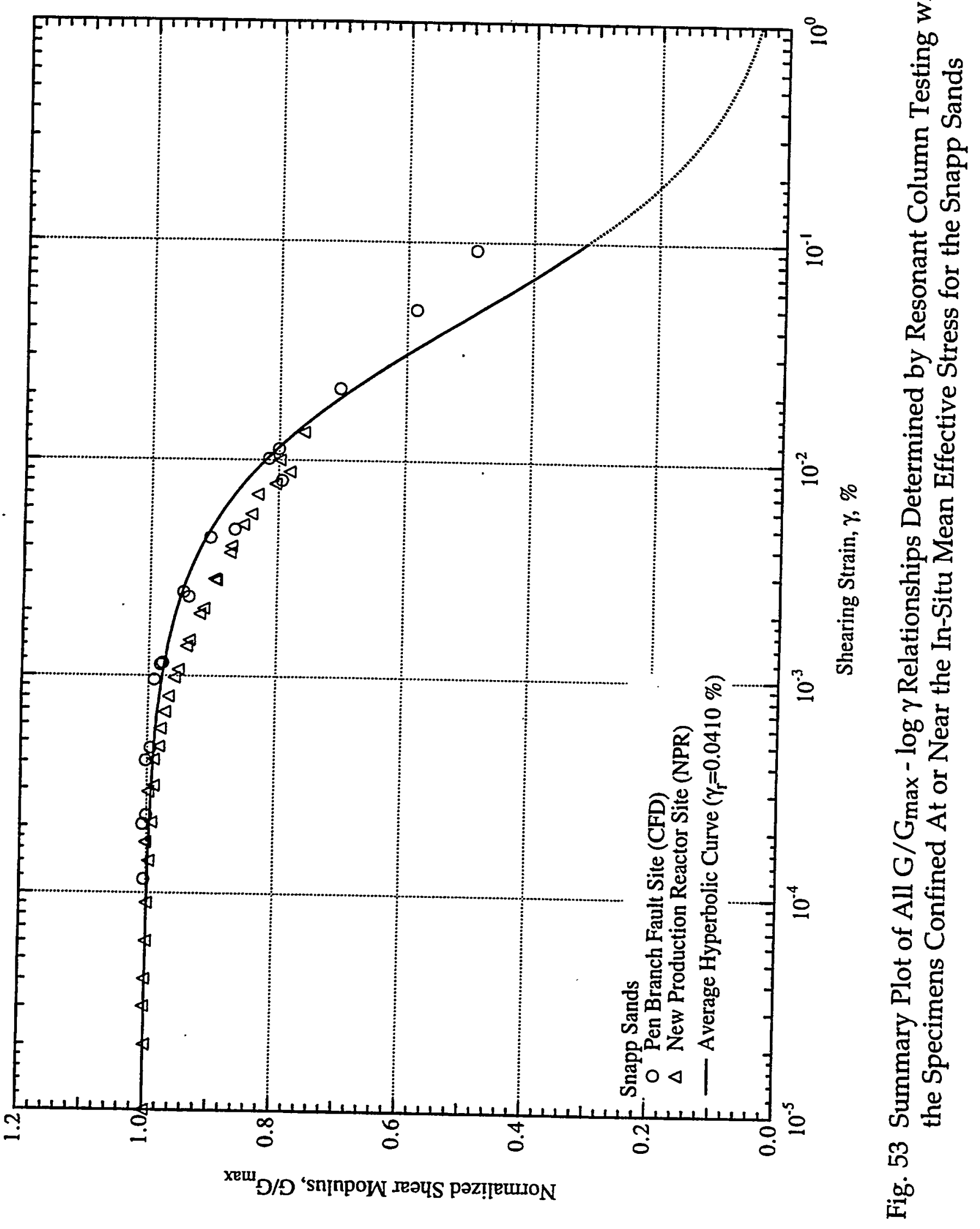

SRS-FR-CDP-95, rev. 0, 13 September 95

Project No. AA891070 


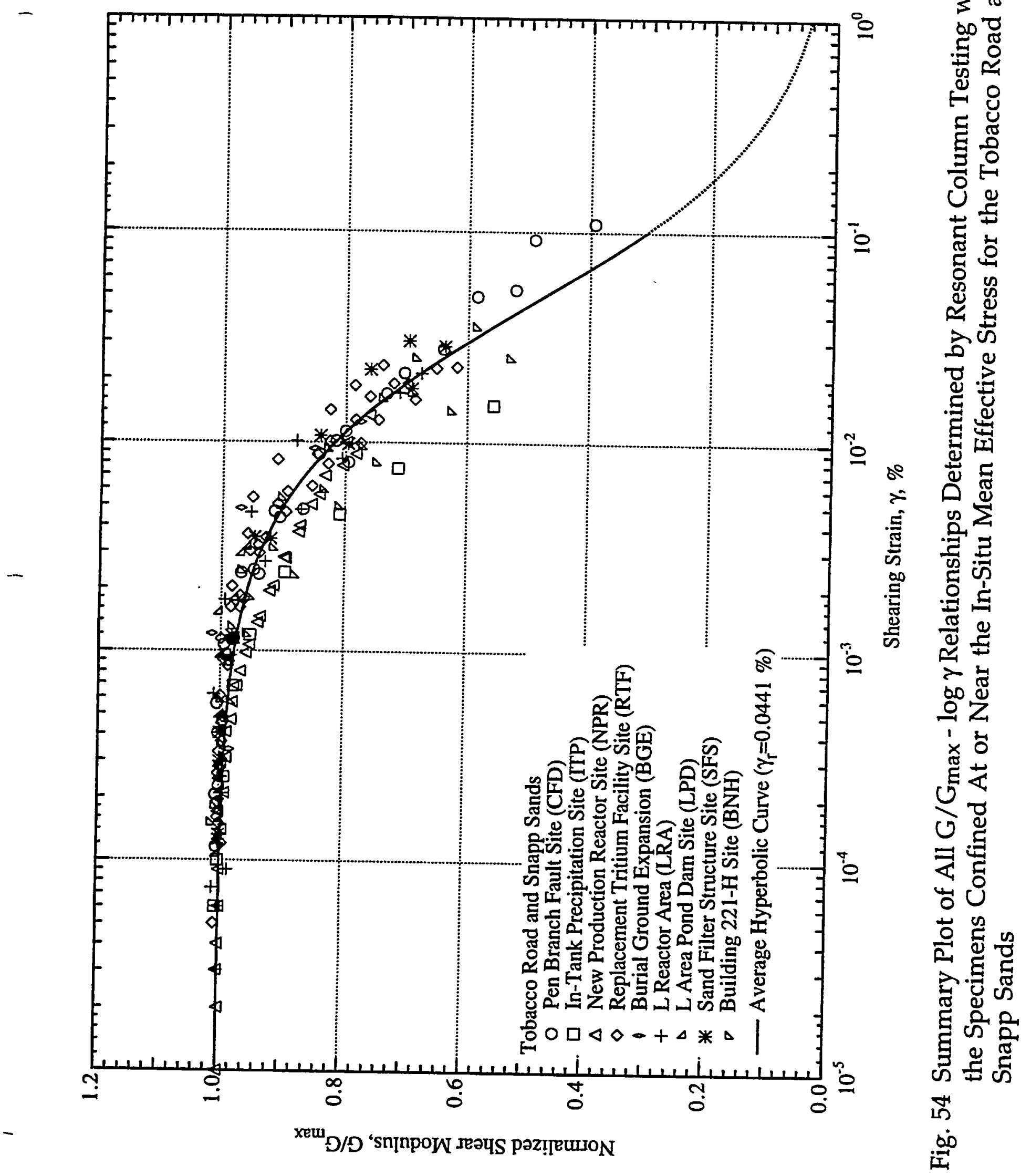

SRS-FR-CDP-95, rev. 0, 13 September 95

Project No. AA891070 


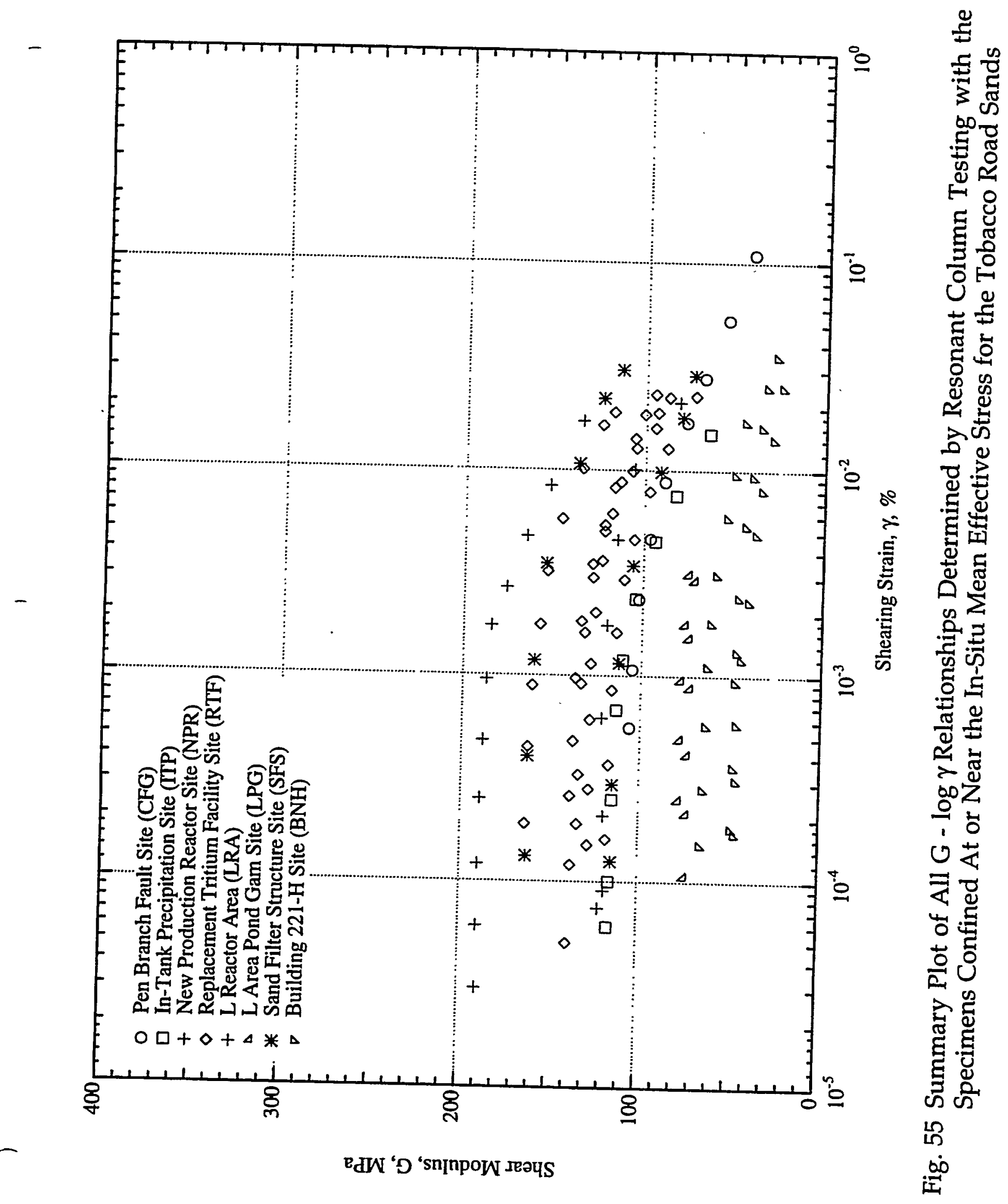

SRS-FR-CDP-95, rev. 0, 13 September 95

Project No. AA891070 


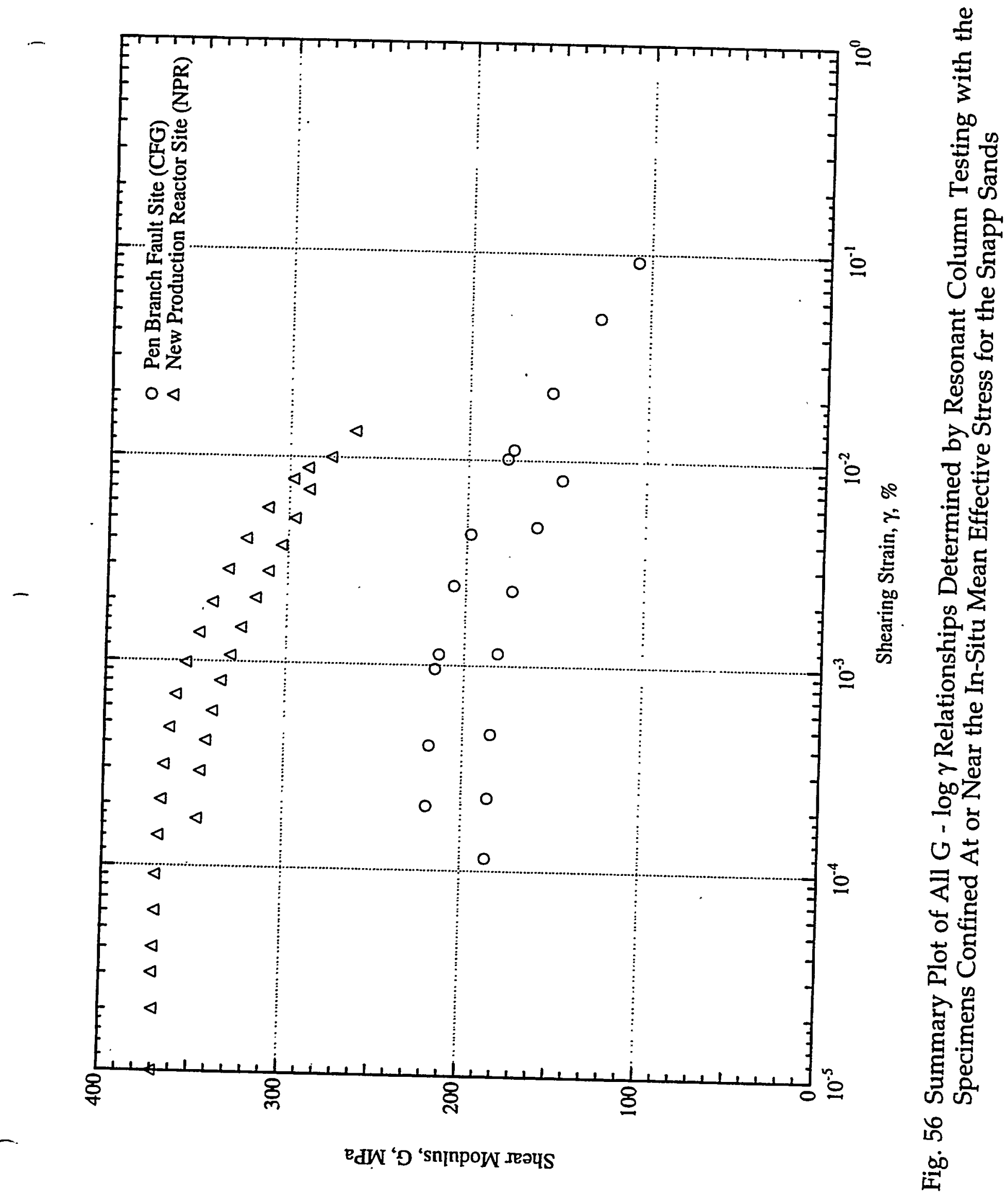

SRS-FR-CDP-95, rev. 0, 13 September 95

Project No. AA891070 


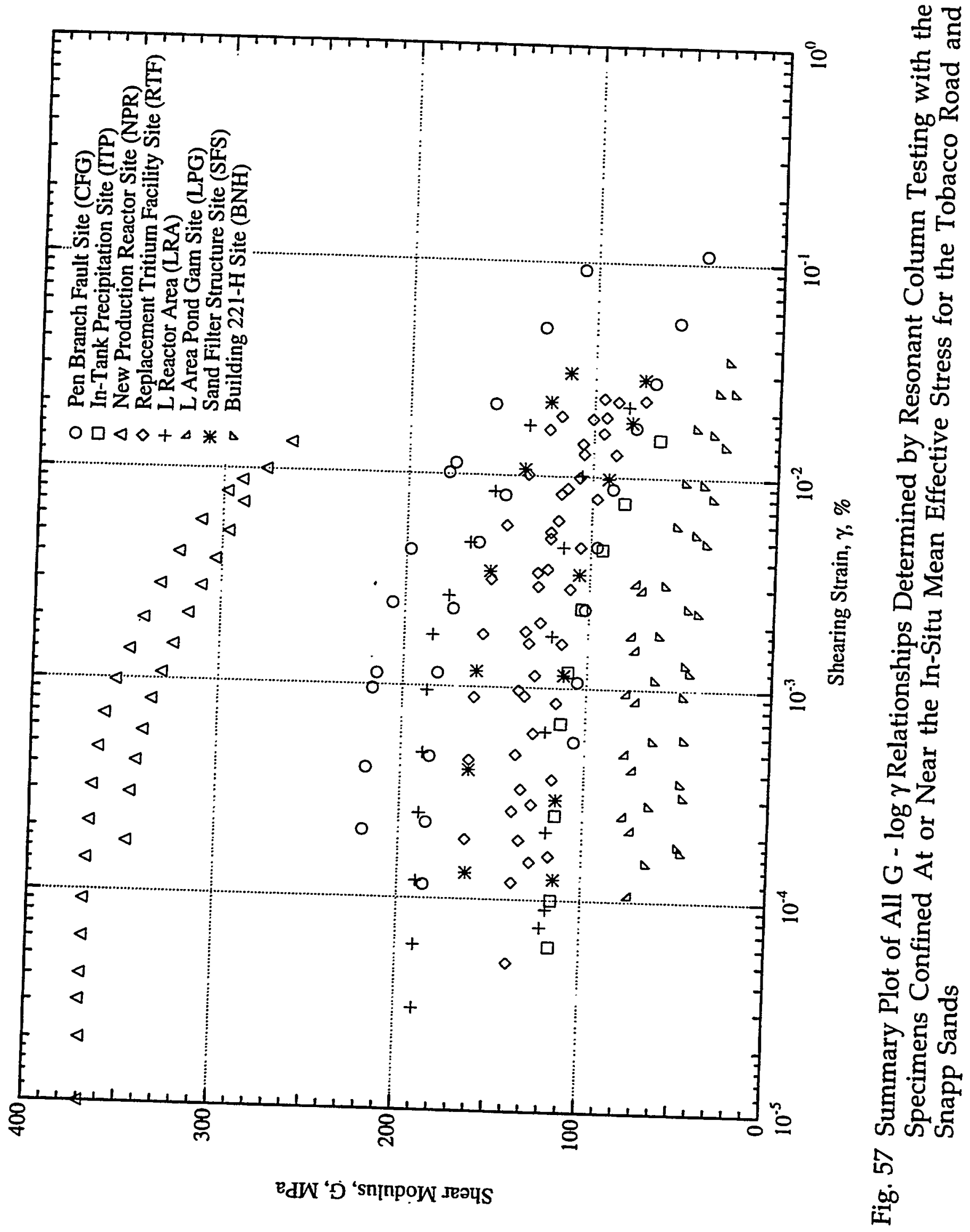

SRS-FR-CDP-95, rev. 0, 13 September 95

Project No. AA891070 


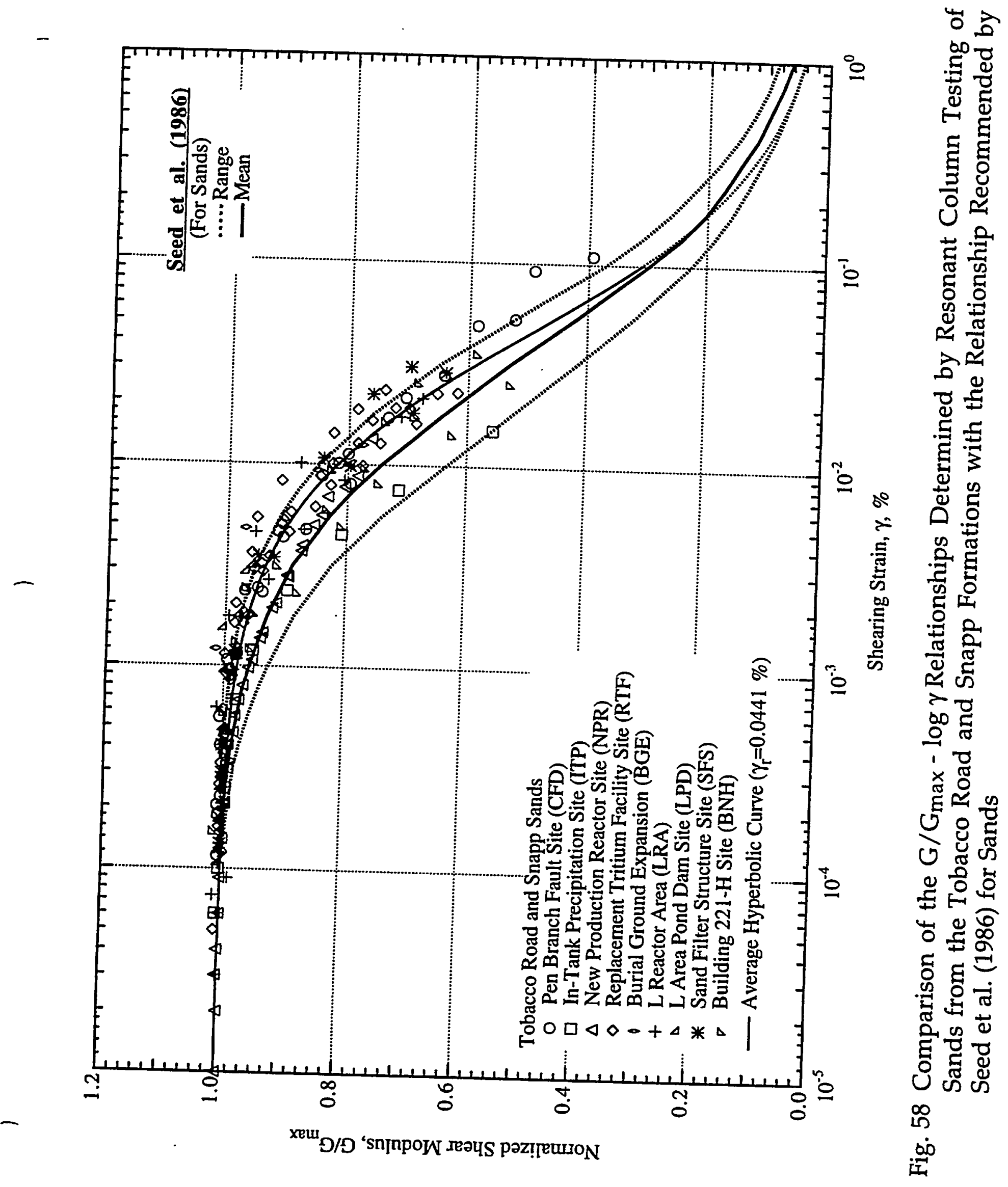

SRS-FR-CDP-95, rev. 0, 13 September 95 


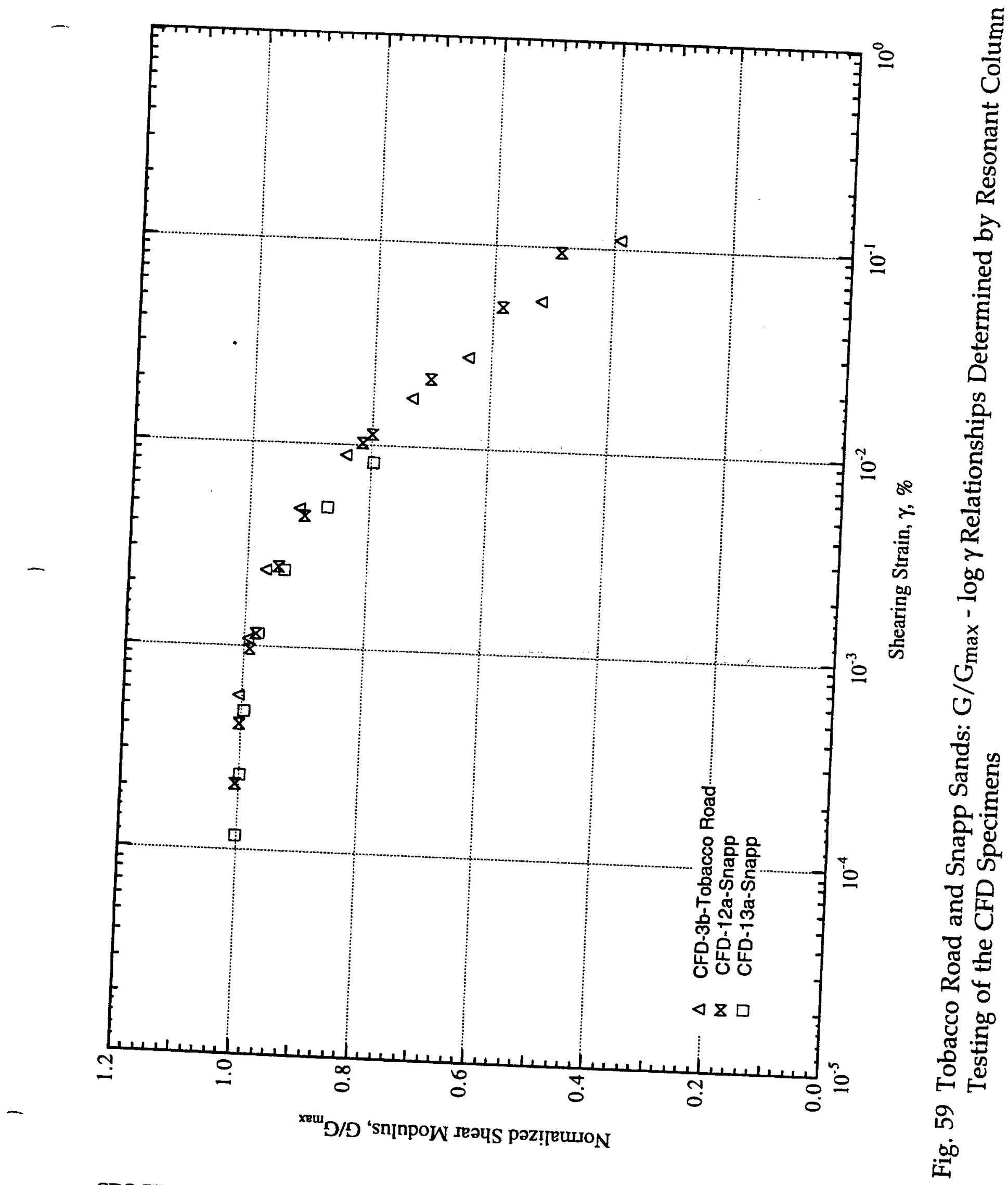

SRS-FR-CDP-95, rev. 0, 13 September 95

Project No. AA891070 


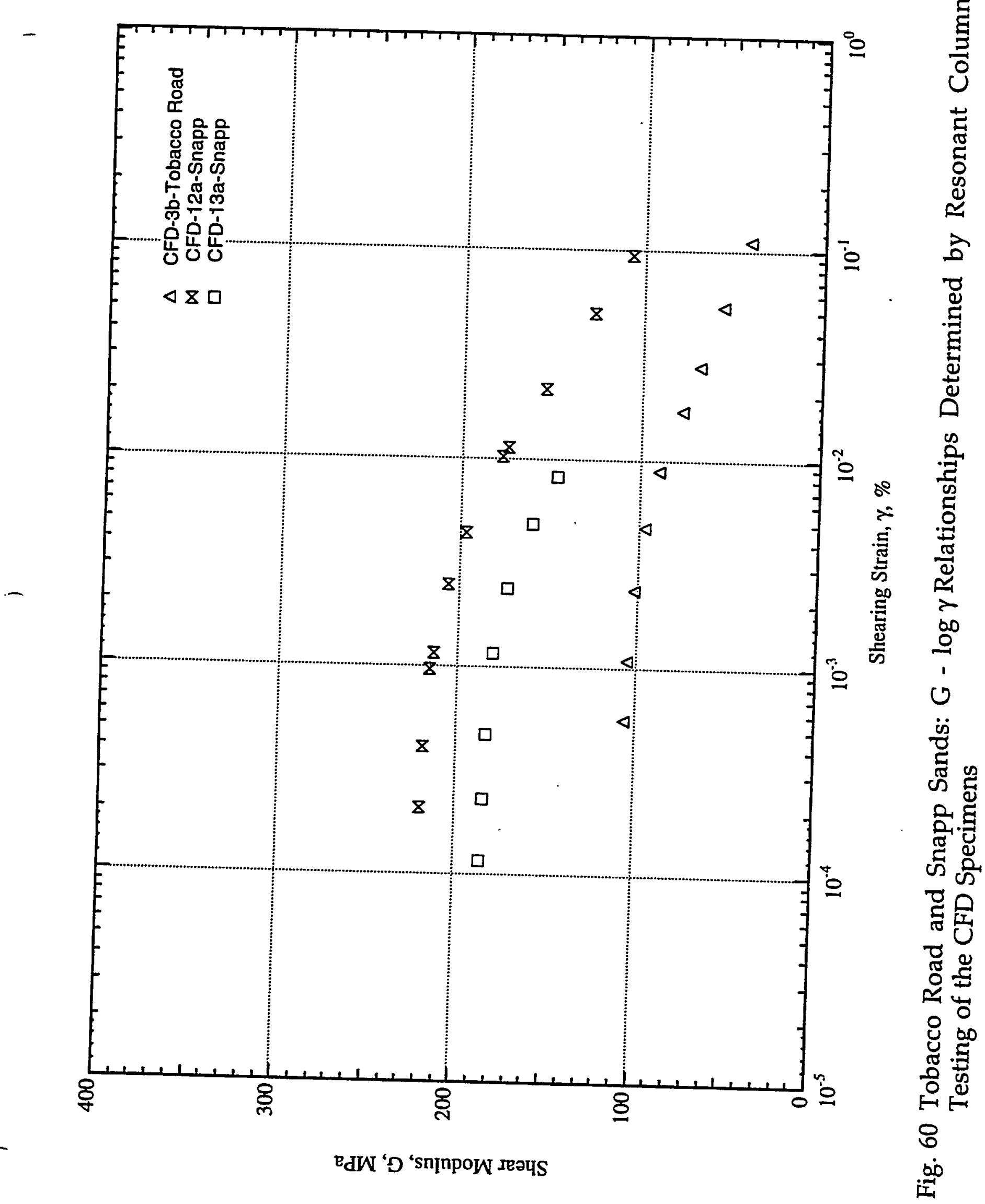

SRS-FR-CDP-95, rev. 0, 13 September 95 Project No. AA891070 


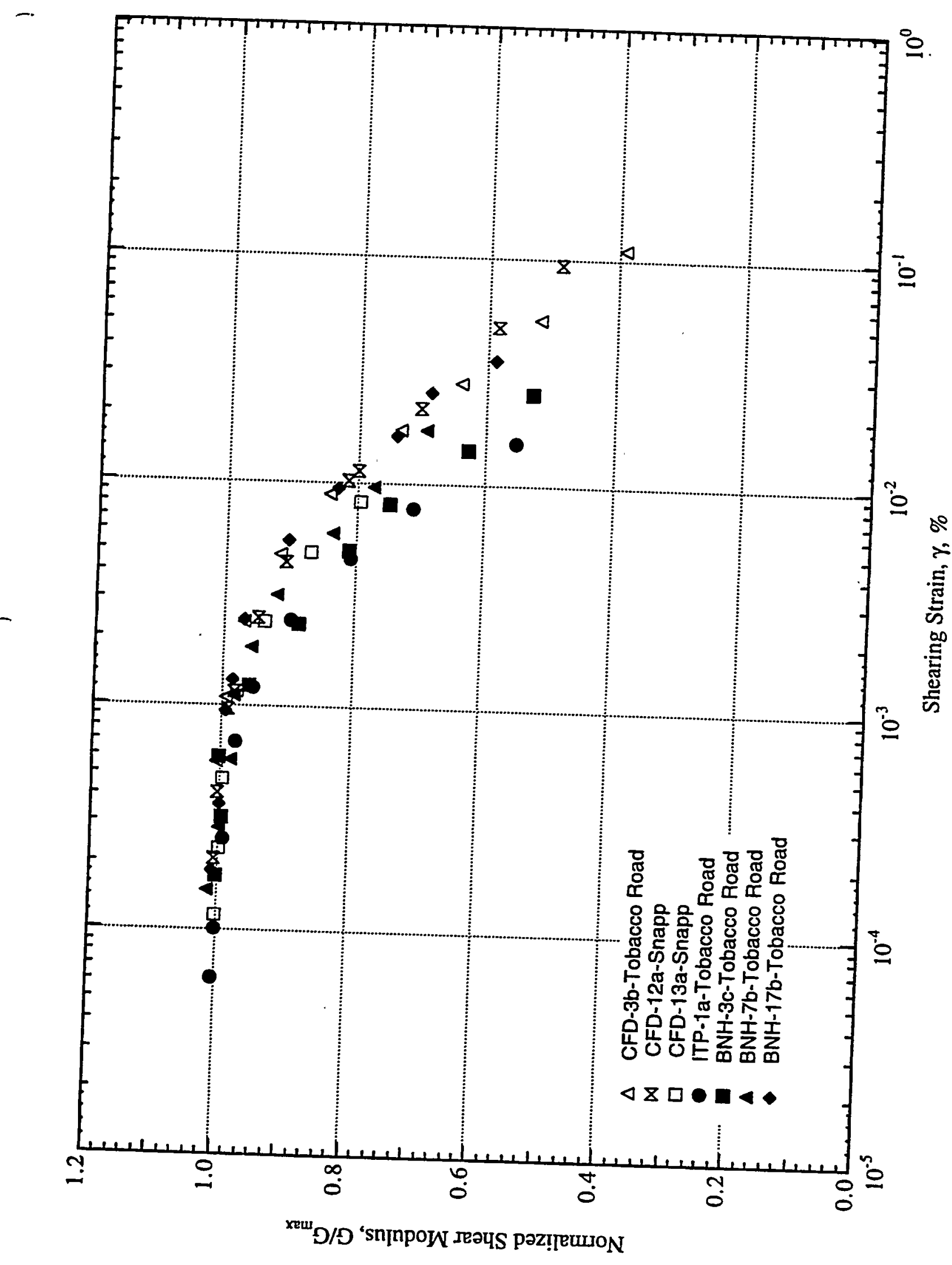

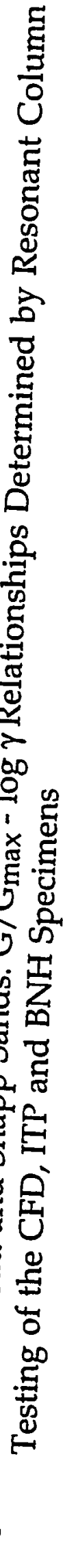

SRS-FR-CDP-95, rev. 0, 13 September 95

Project No. AA891070 


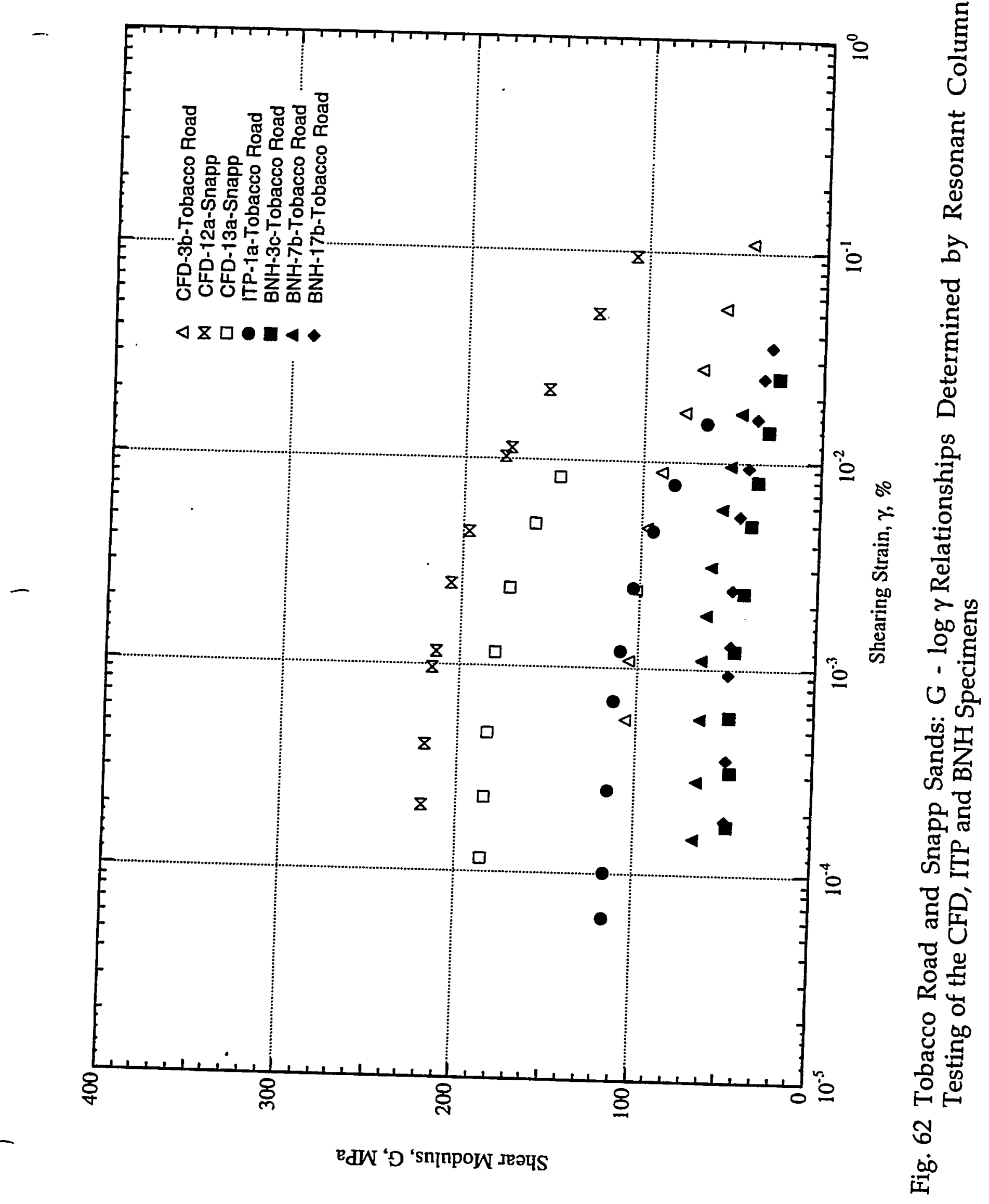

SRS-FR-CDP-95, rev. 0, 13 September 95

Project No. AA891070 


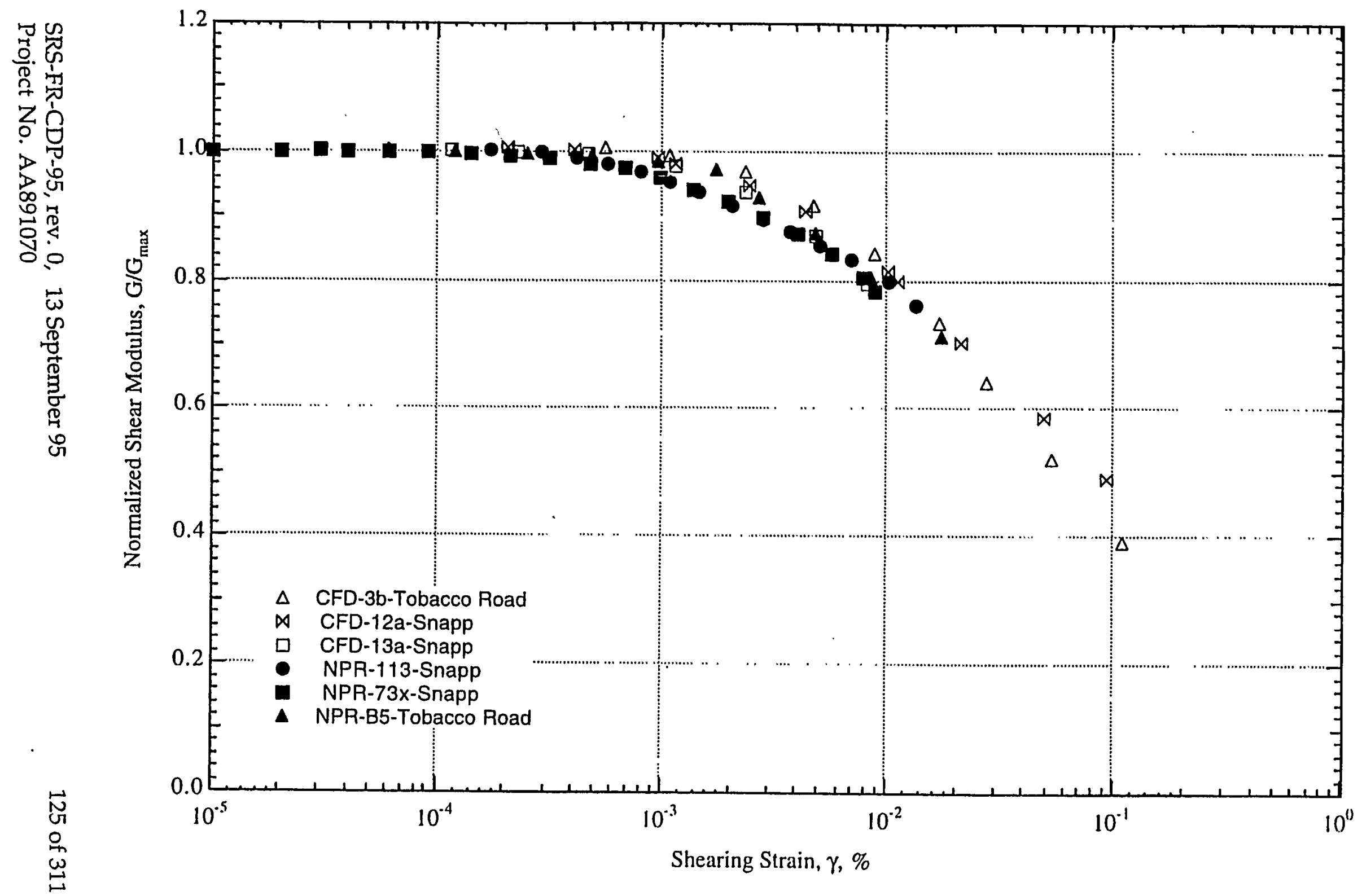

Fig. 63 Tobacco Road and Snapp Sands: $G / G_{\max }-\log \gamma$ Relationships Determined by Resonant Column Testing of the CFD and NPR Specimens 


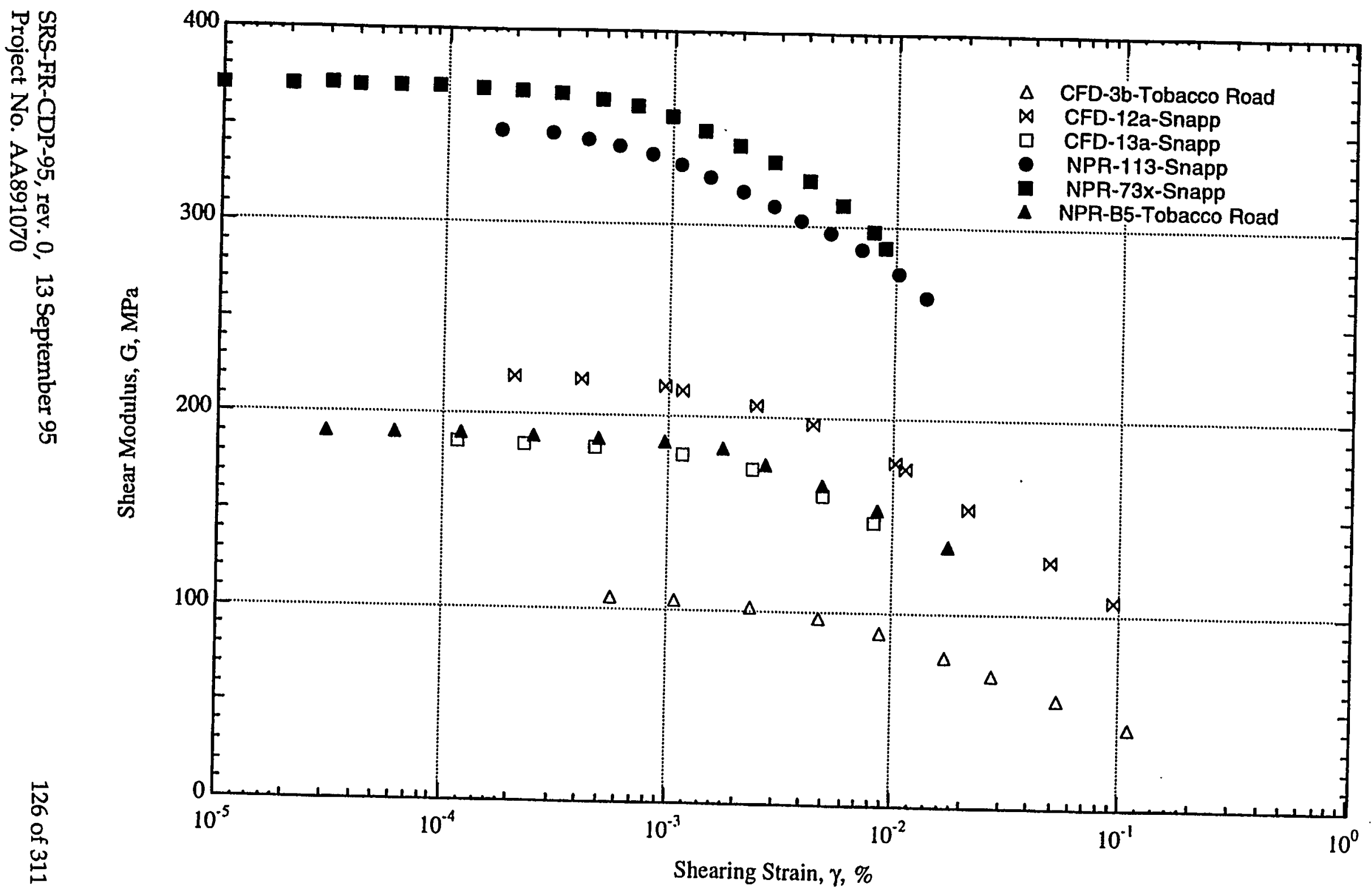

Fig. 64 Tobacco Road and Snapp Sands: G - $\log \gamma$ Relationships Determined by Resonant Column
Testing of the CFD and NPR Specimens 


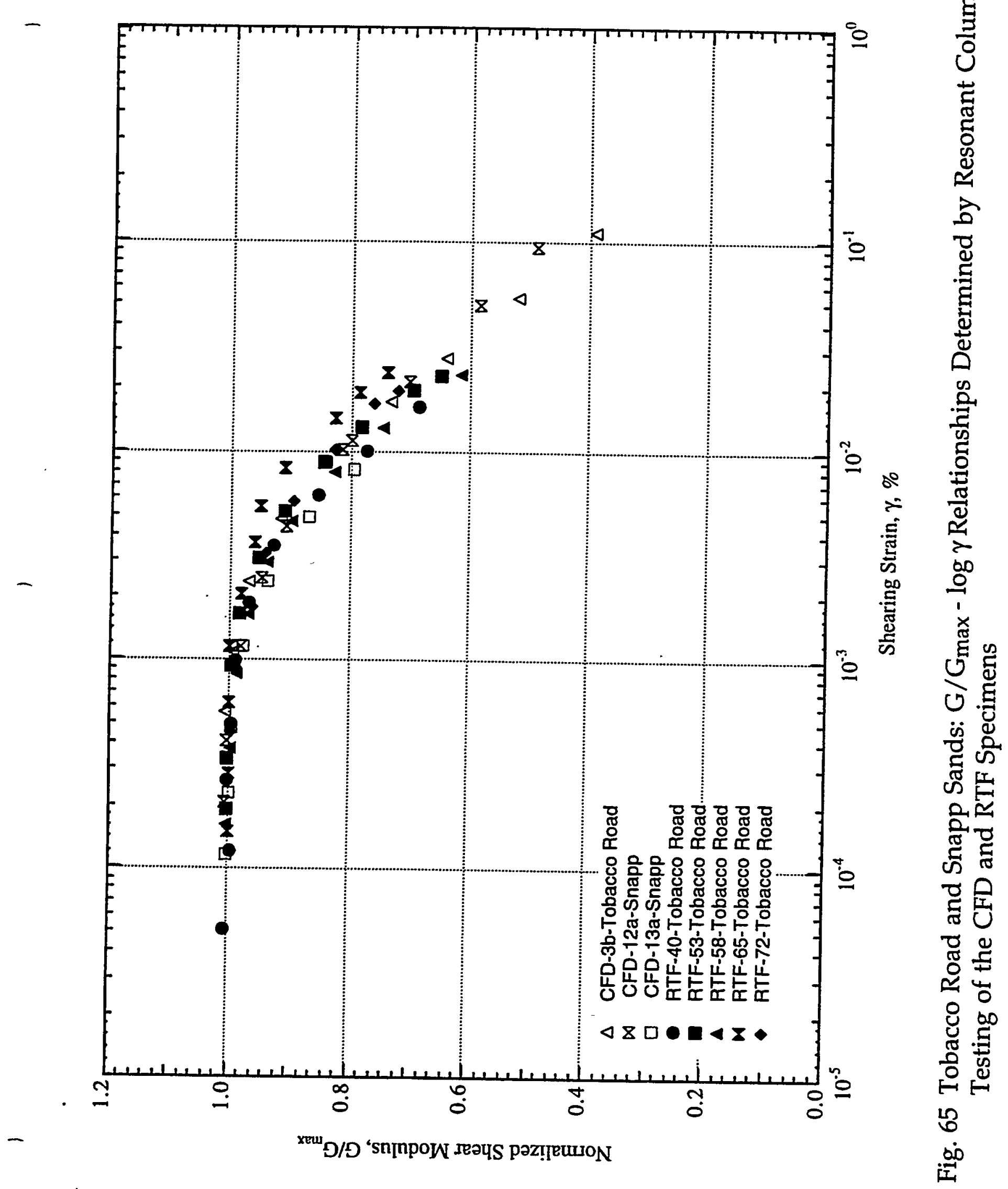

SRS-FR-CDP-95, rev. 0, 13 September 95

Project No. AA891070 


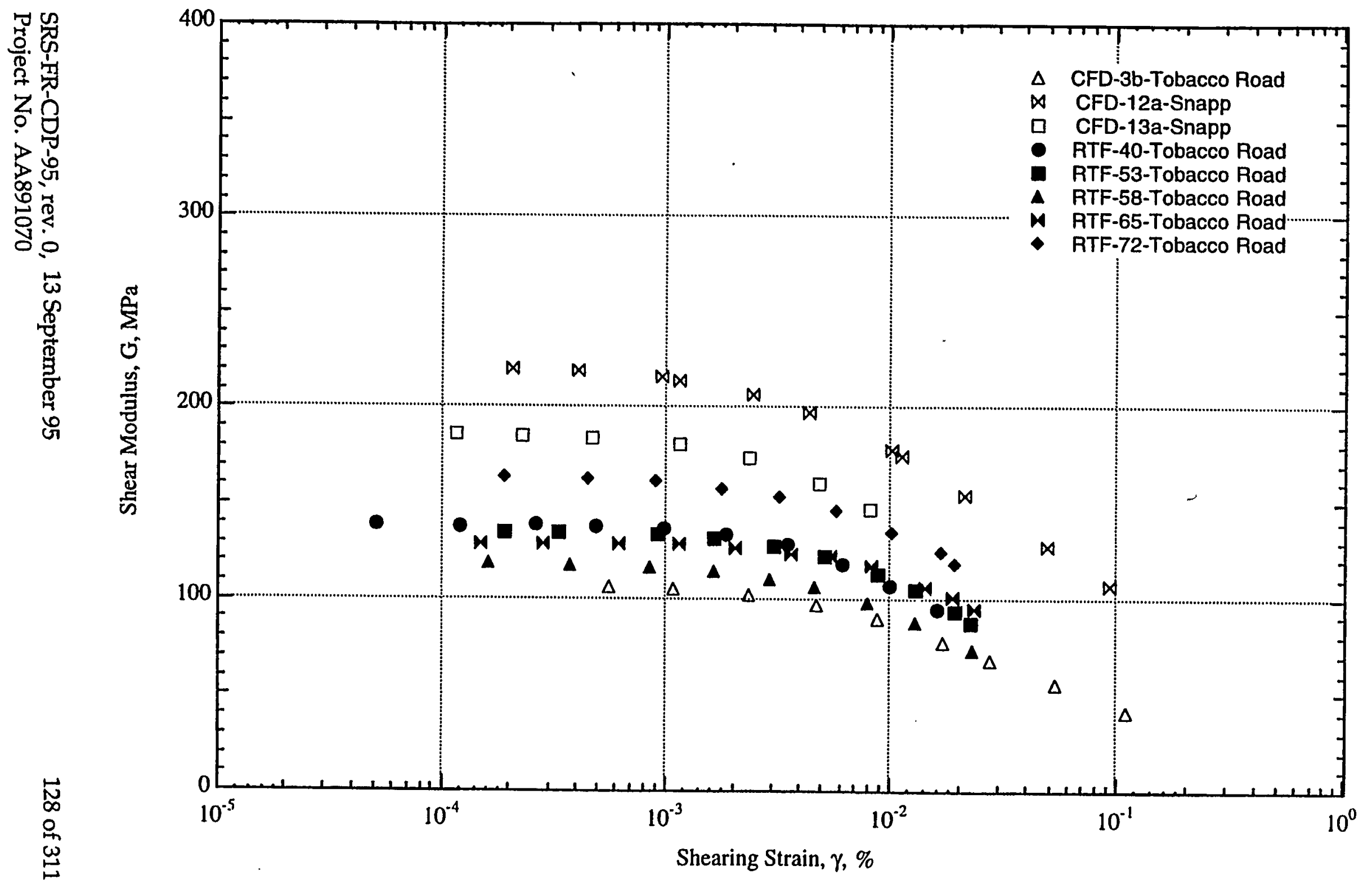

Fig. 66 Tobacco Road and Snapp Sands: G - $\log \gamma$ Relationships Determined by Resonant Column Testing of the CFD and RTF Specimens 


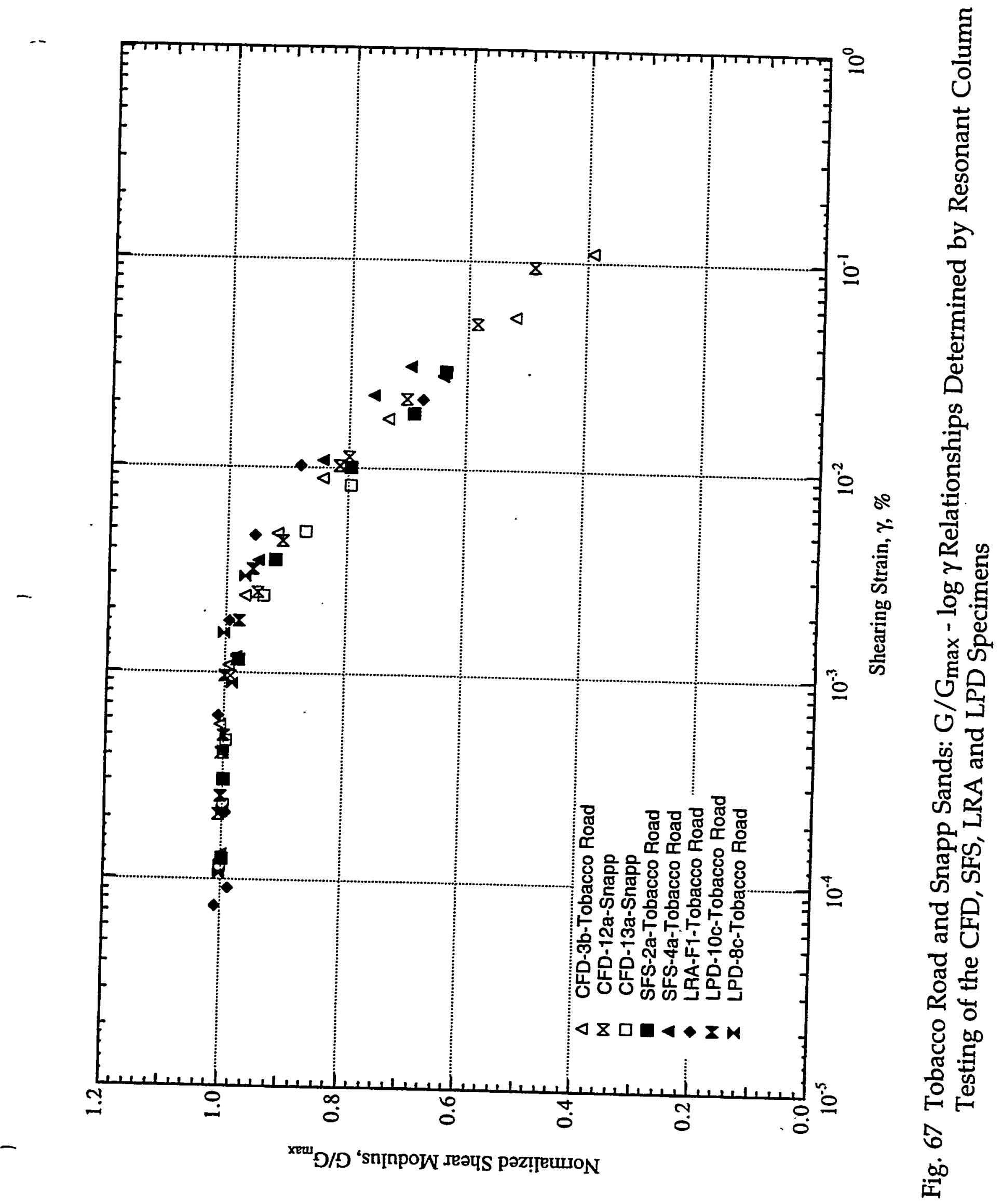

SRS-FR-CDP-95, rew. 0, 13 September 95

Project No. AA891070 


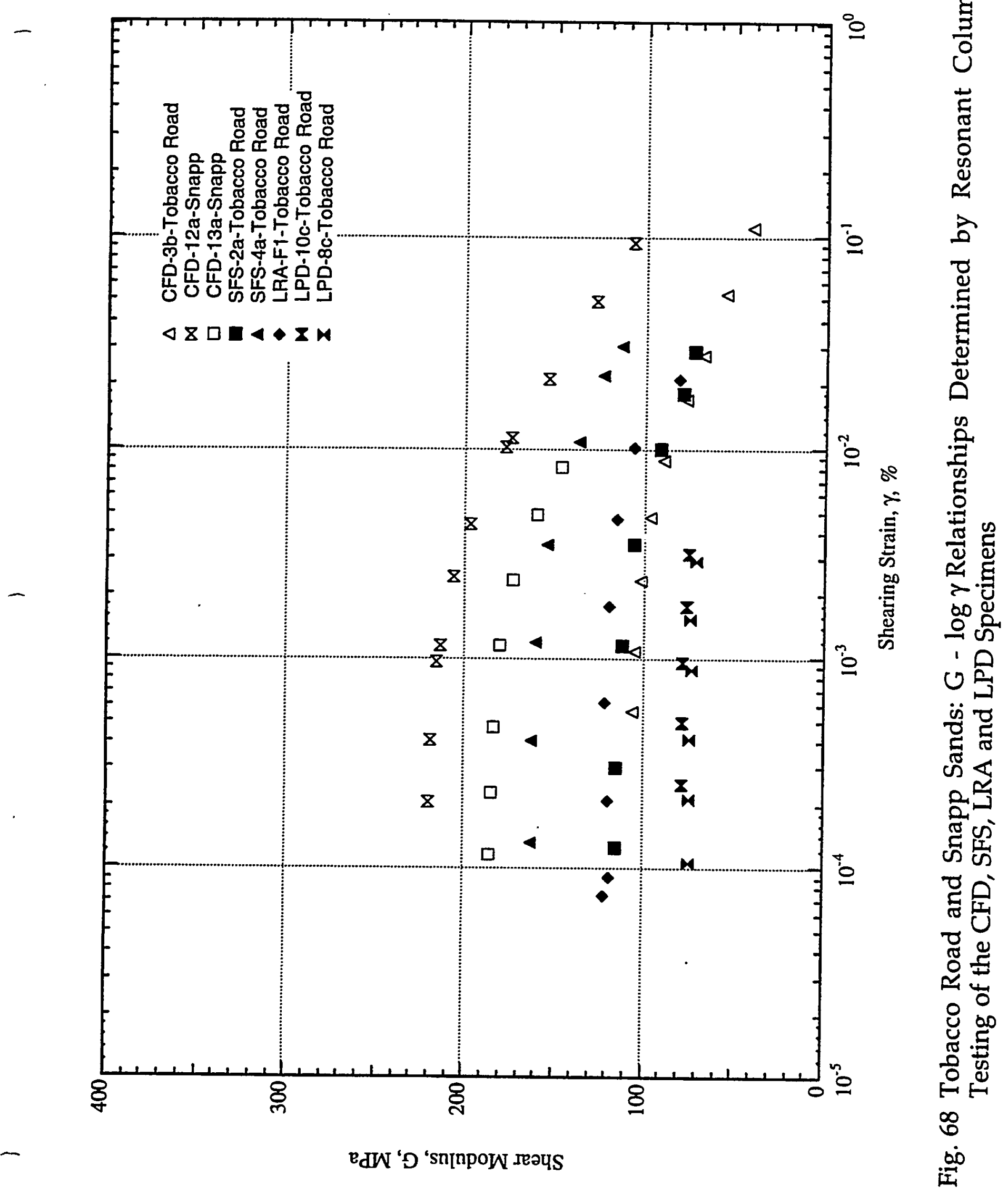

SRS-FR-CDP-95, rev. 0, 13 September 95 


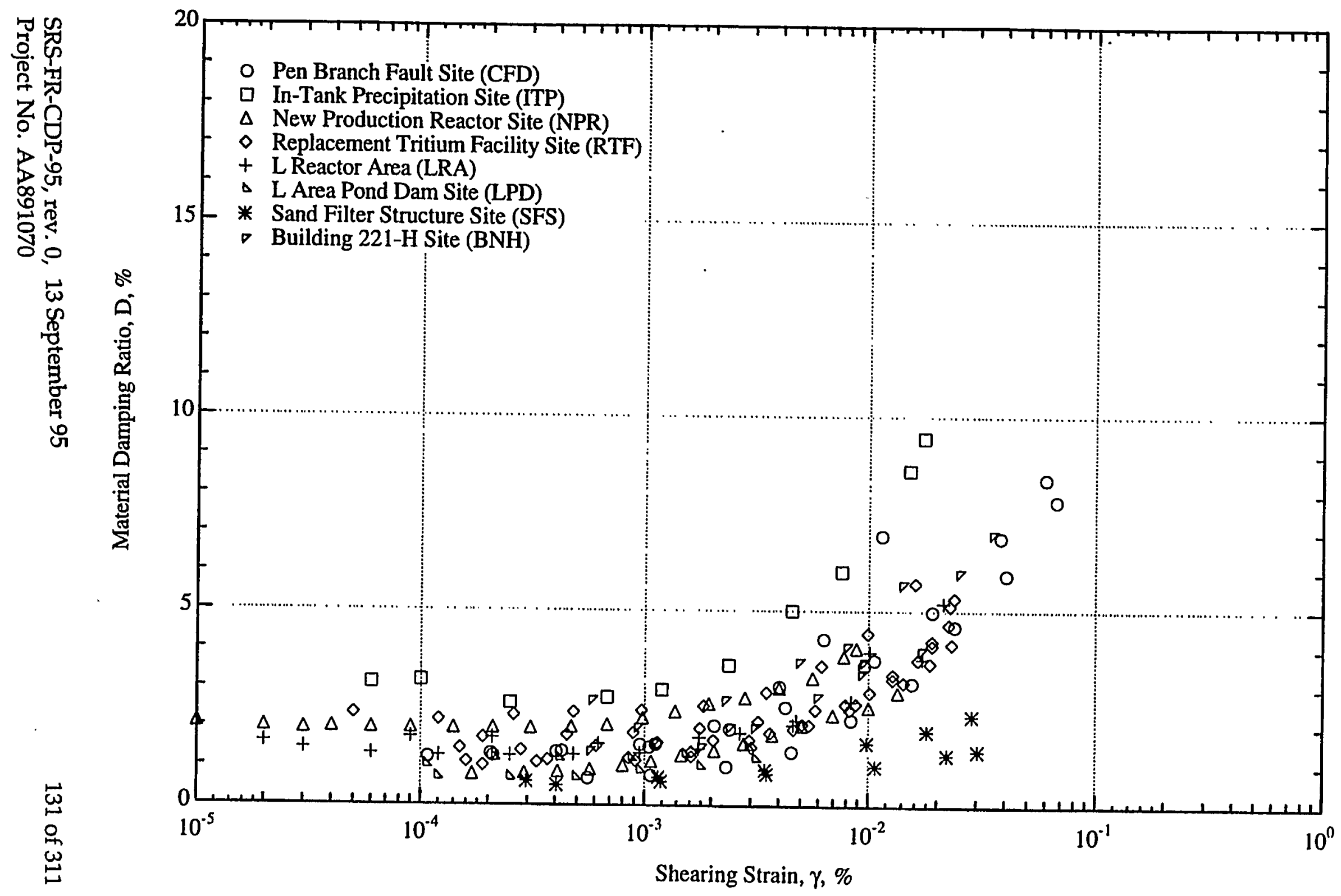

Fig. 69 Summary Plot of All D - $\log \gamma$ Relationships Determined by Resonant Column Testing with the Specimens Confined At or Near the In-Situ Mean Effective Stress for the Tobacco Road and Snapp Sands 


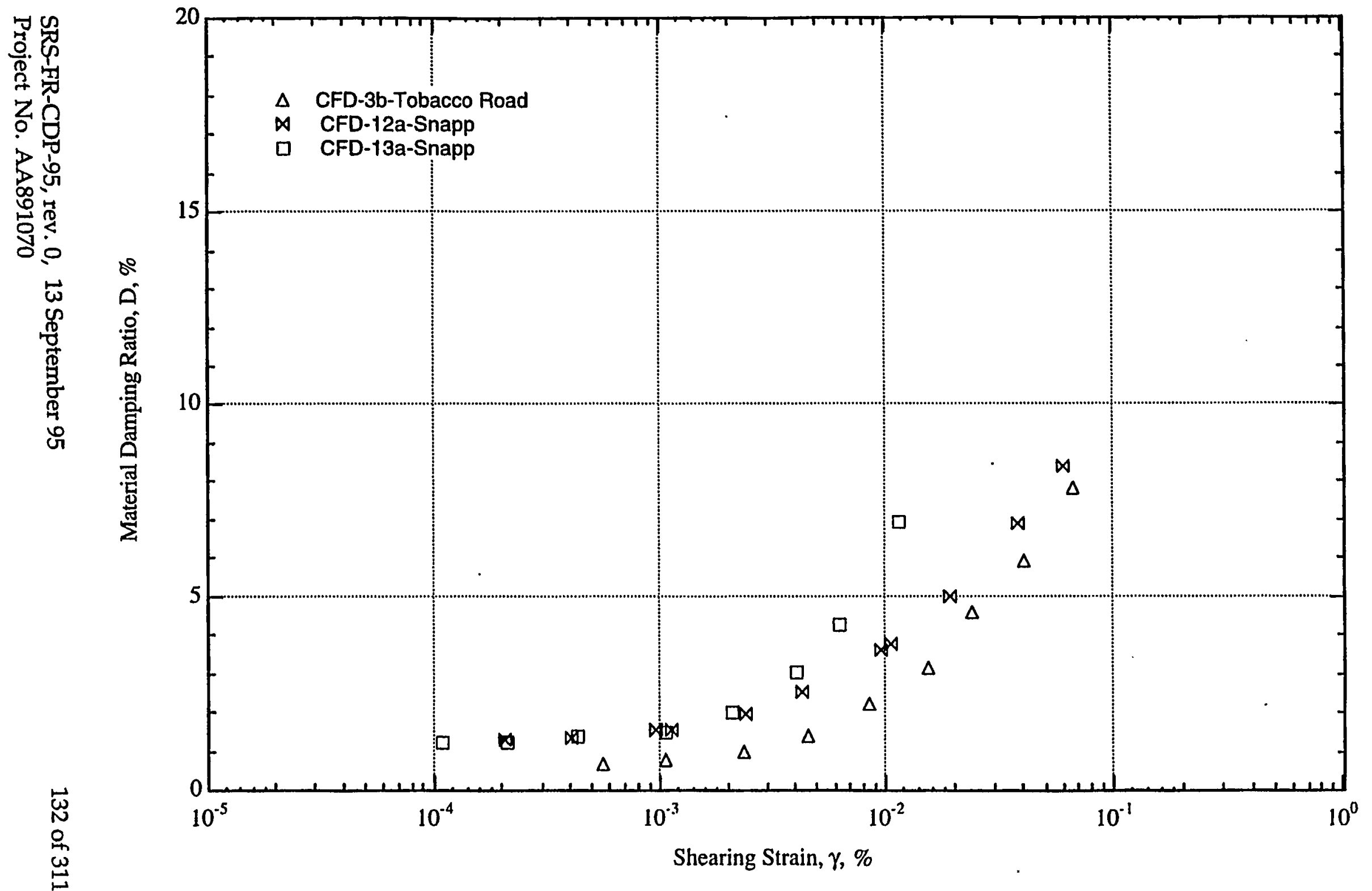

Fig. 70 Tobacco Road and Snapp: D - $\log \gamma$ Relationships for the CFD Specimens Determined by Resonant Column Testing 


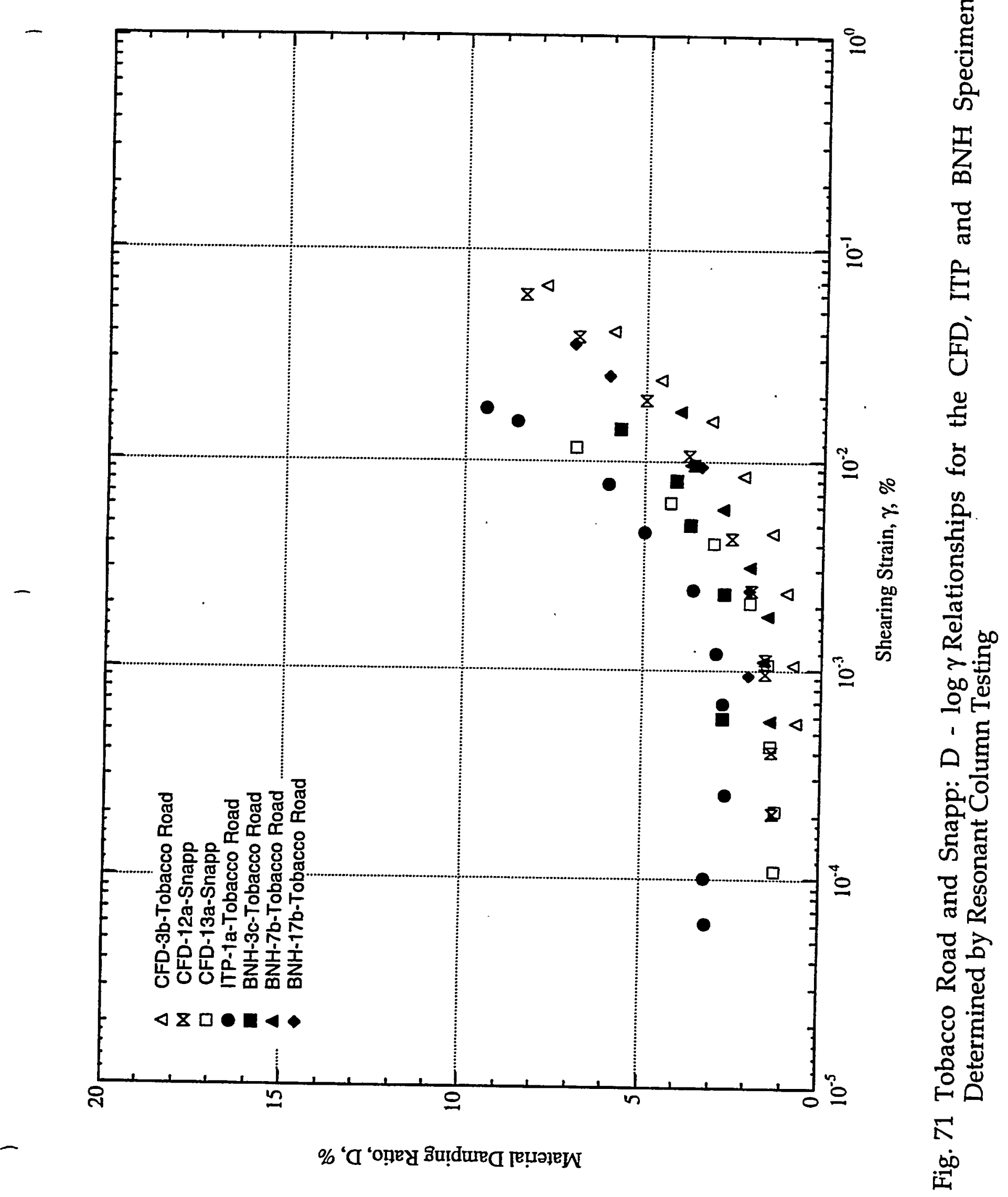

SRS-FR-CDP-95, rev. 0, 13 September 95

Project No. AA891070 


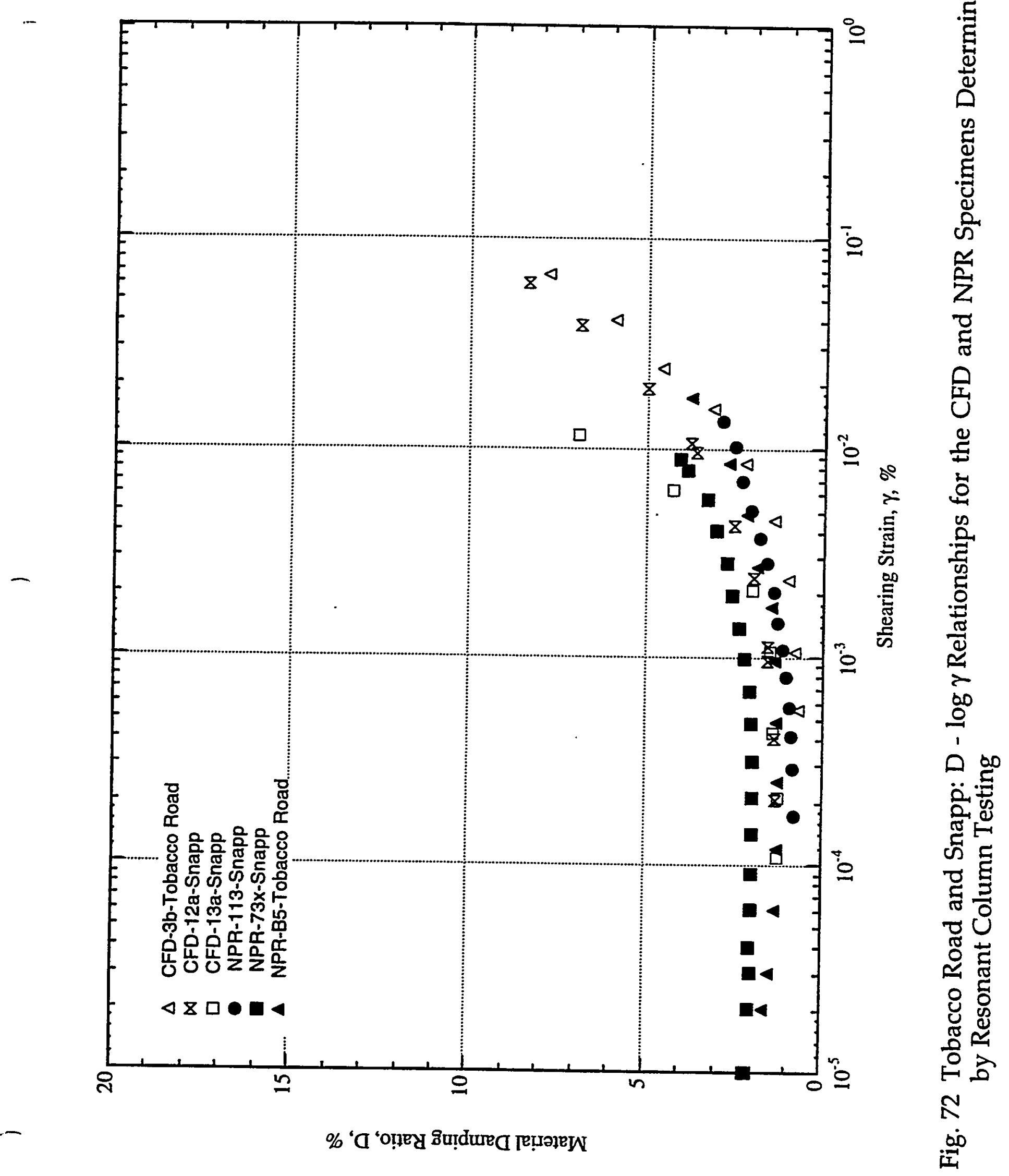

SRS-FR-CDP-95, rev. 0, 13 September 95

Project No. AA891070 


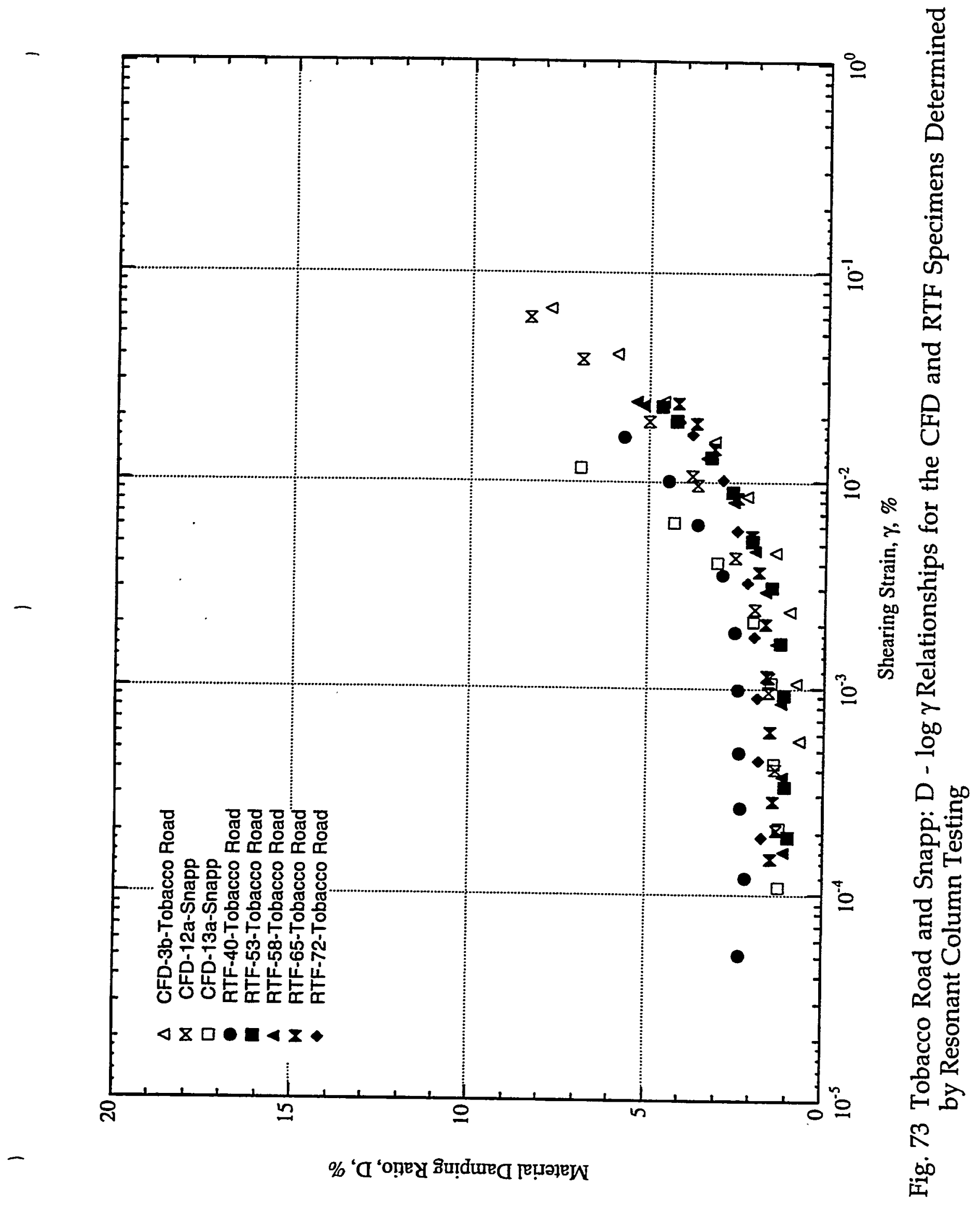

SRS-FR-CDP-95, rev. 0, 13 September 95 


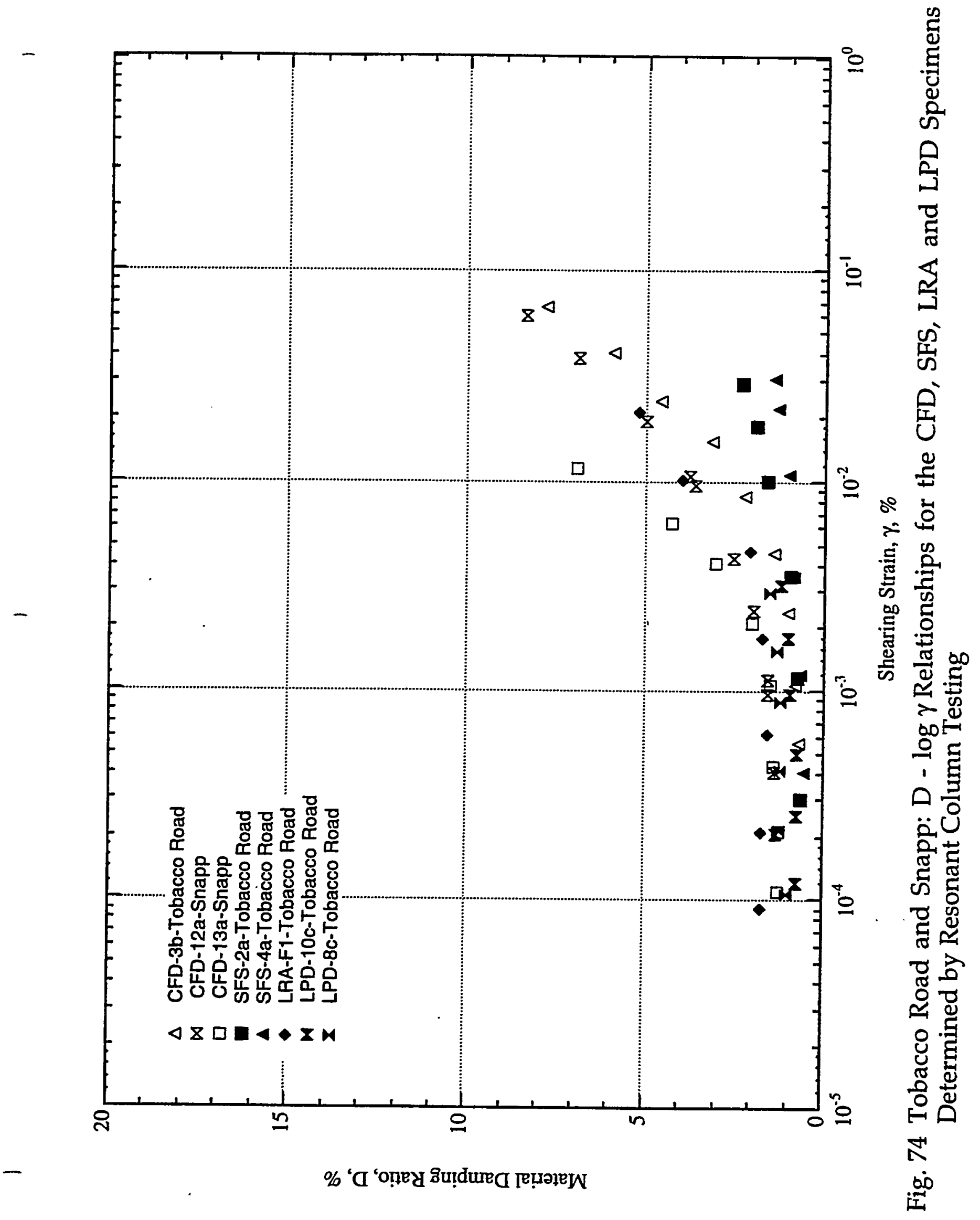

SRS-FR-CDP-95, rev. 0, 13 September 95 

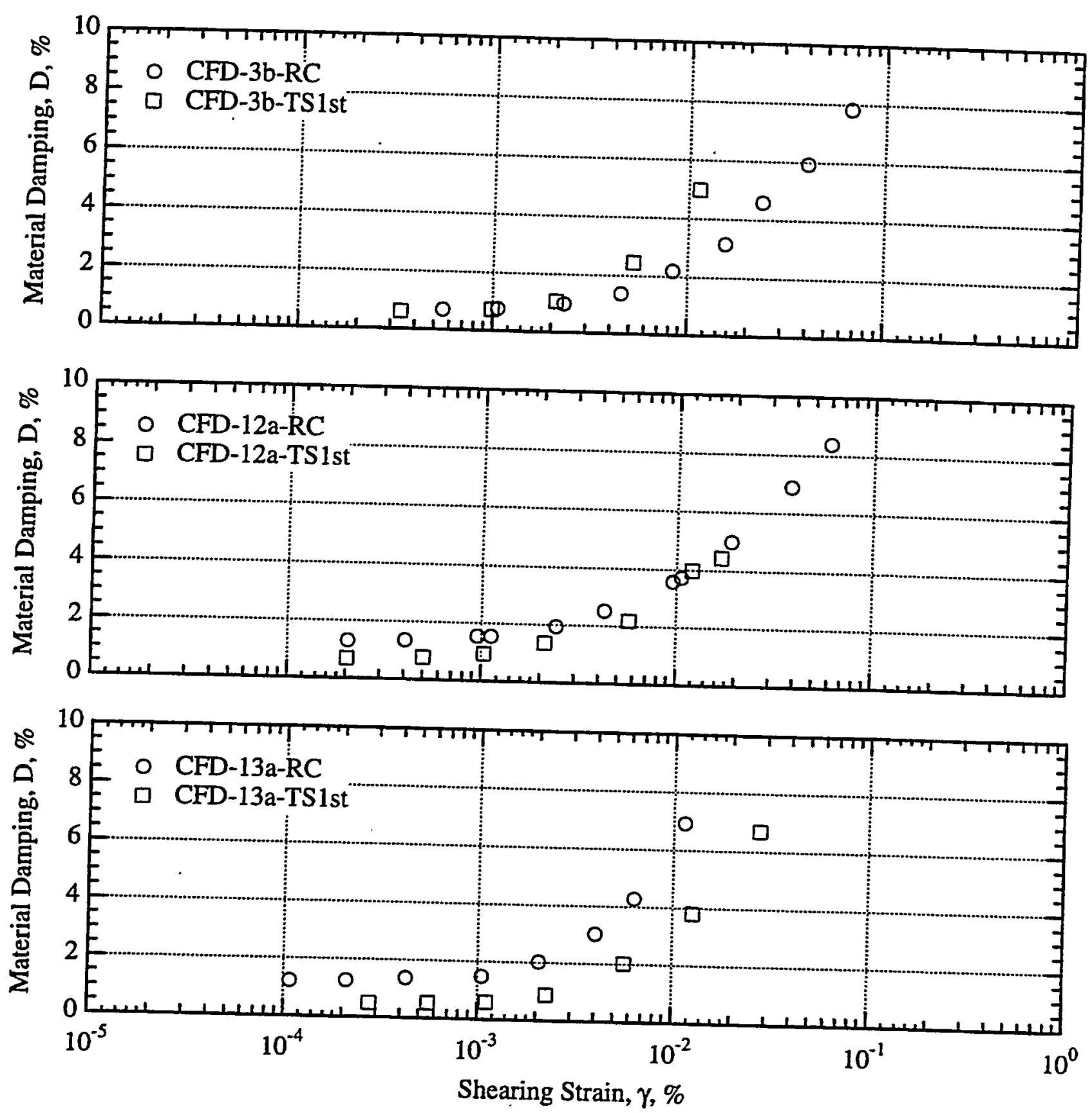

Fig. 75 Comparison of Material Damping Values Determined for the CFD Specimens Using RC and TS Tests; Tobacco Road and Snapp Sands 

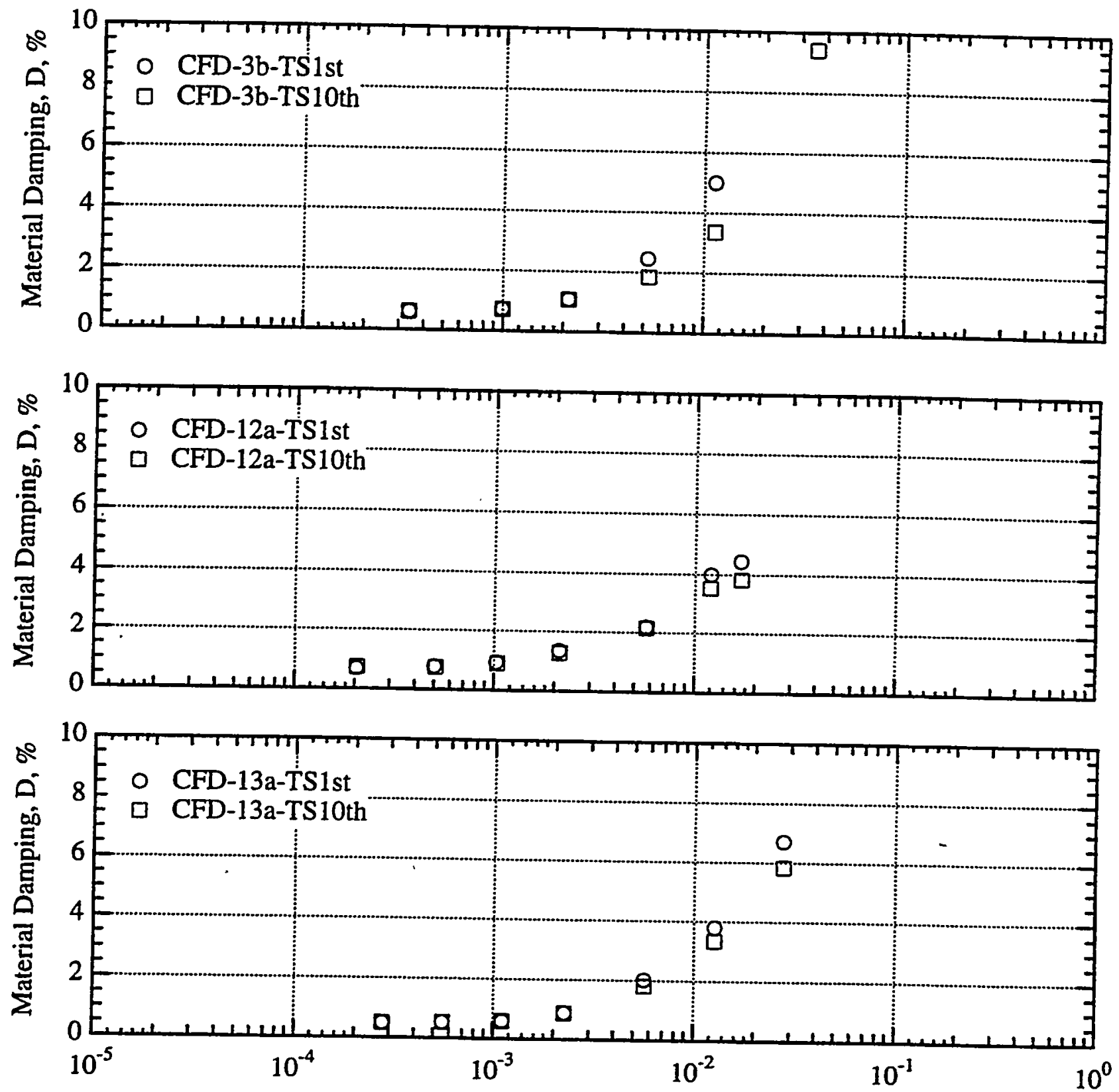

Shearing Strain, $\gamma, \%$

Fig. 76 Influence of Number of Cycles on Material Damping Values Determined for the CFD Specimens Using TS Tests; Tobacco Road and Snapp Sands 


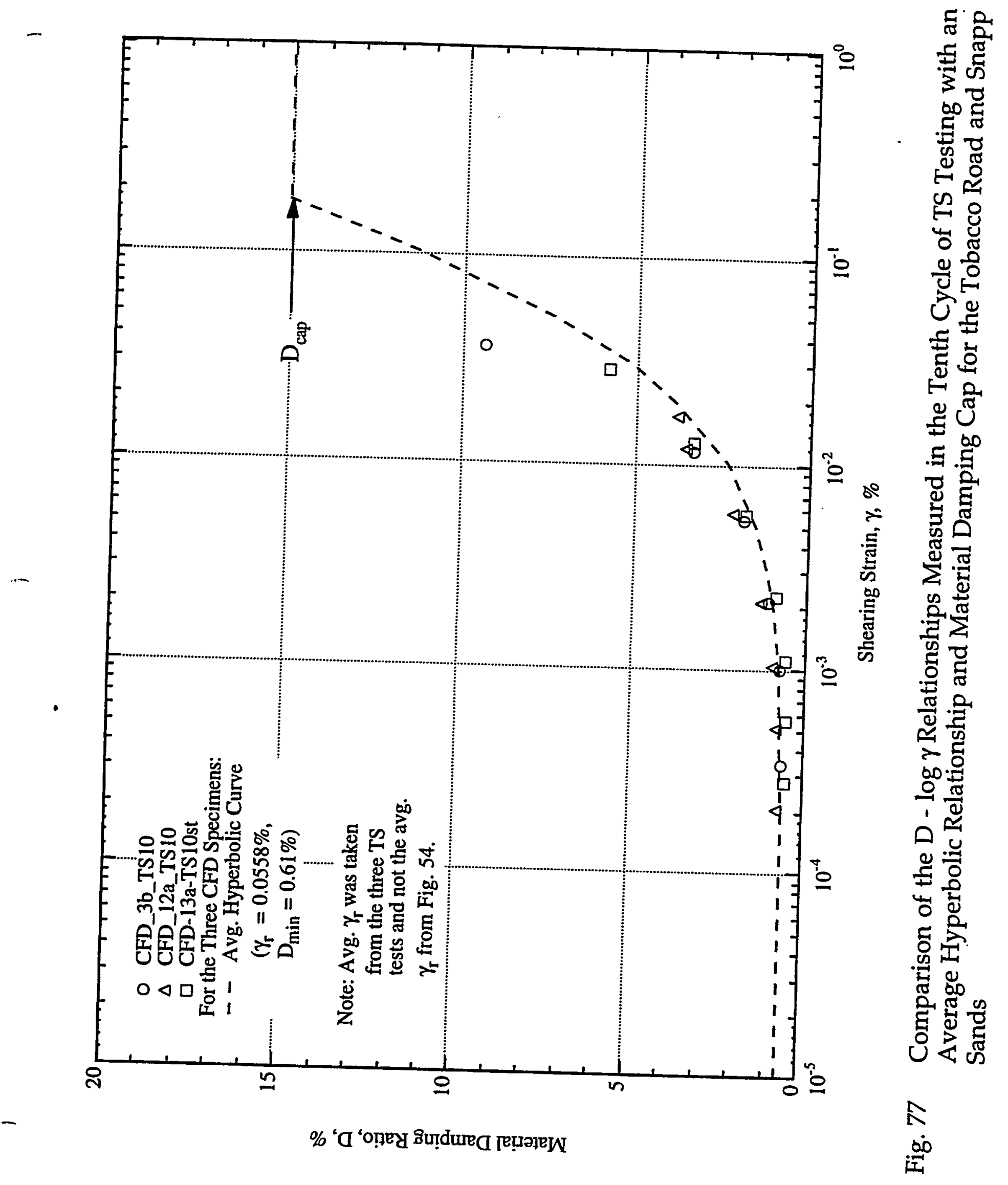

SRS-FR-CDP-95, rev. 0, 13 September 95

Project No. AA891070 


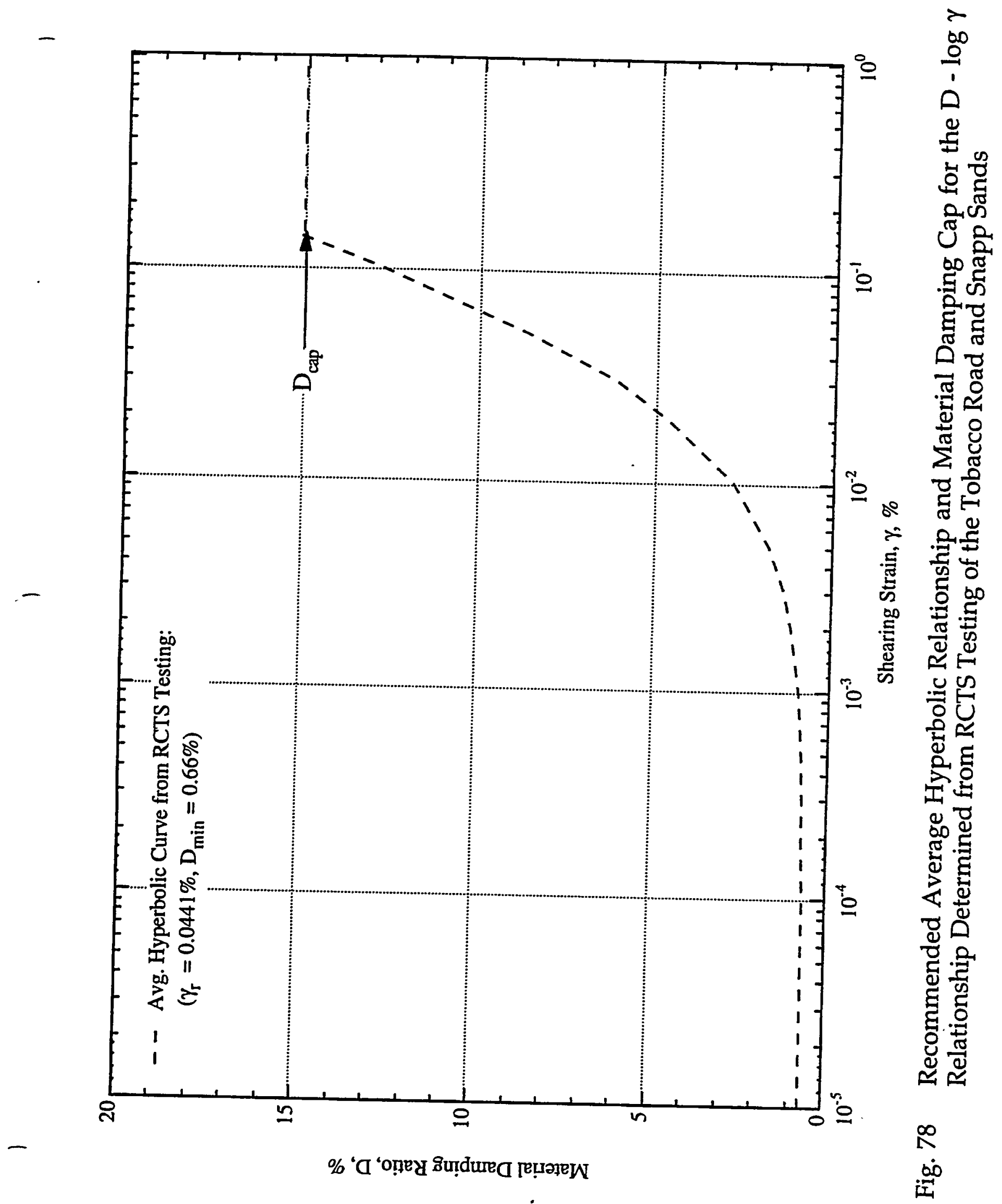

SRS-FR-CDP-95, rev. 0, 13 September 95

Project No. AA891070 


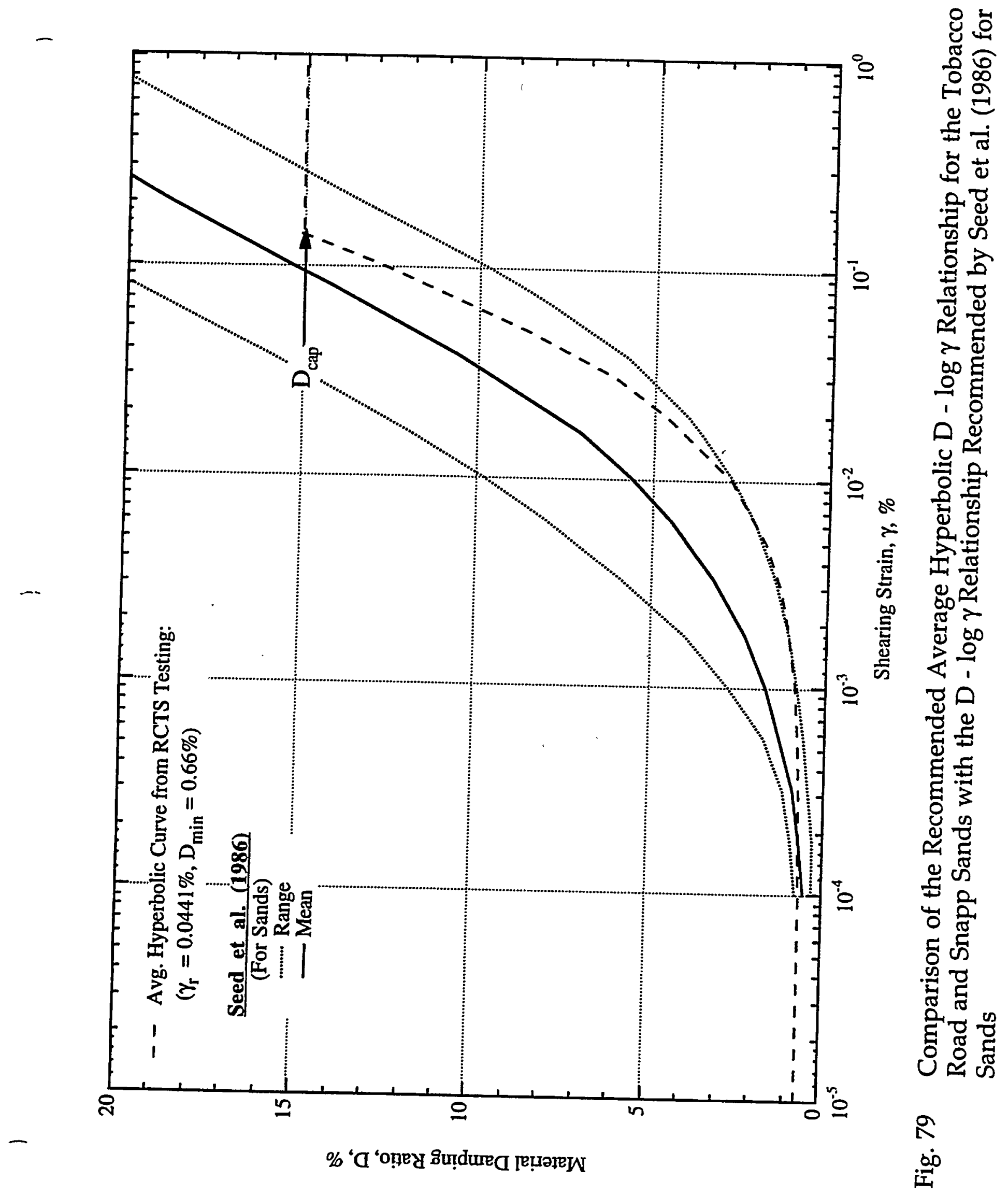

SRS-FR-CDP-95, rev. 0, 13 September 95

Project No. AA891070 


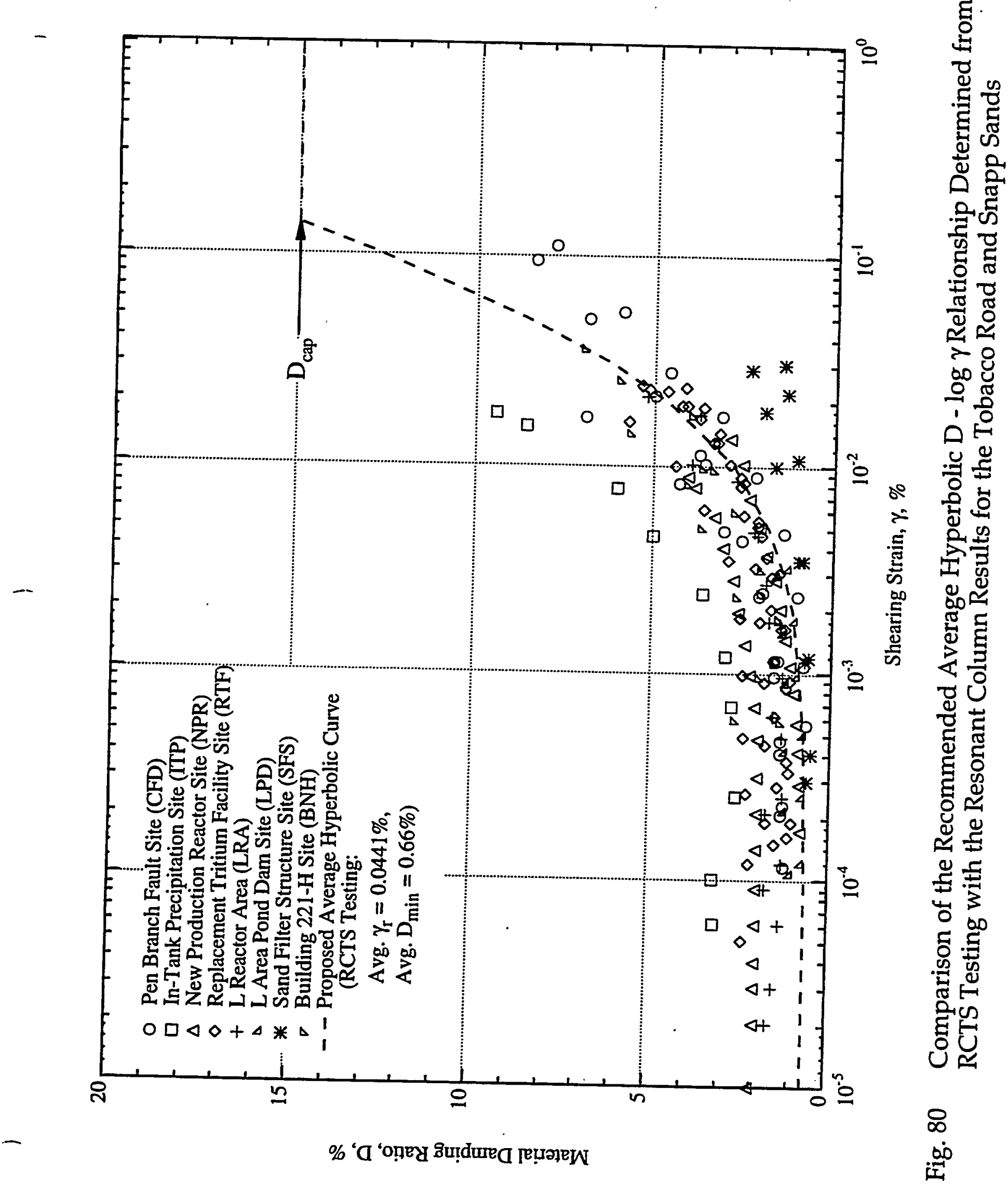

SRS-FR-CDP-95, rev. 0, 13 September 95 Project No. AA891070 


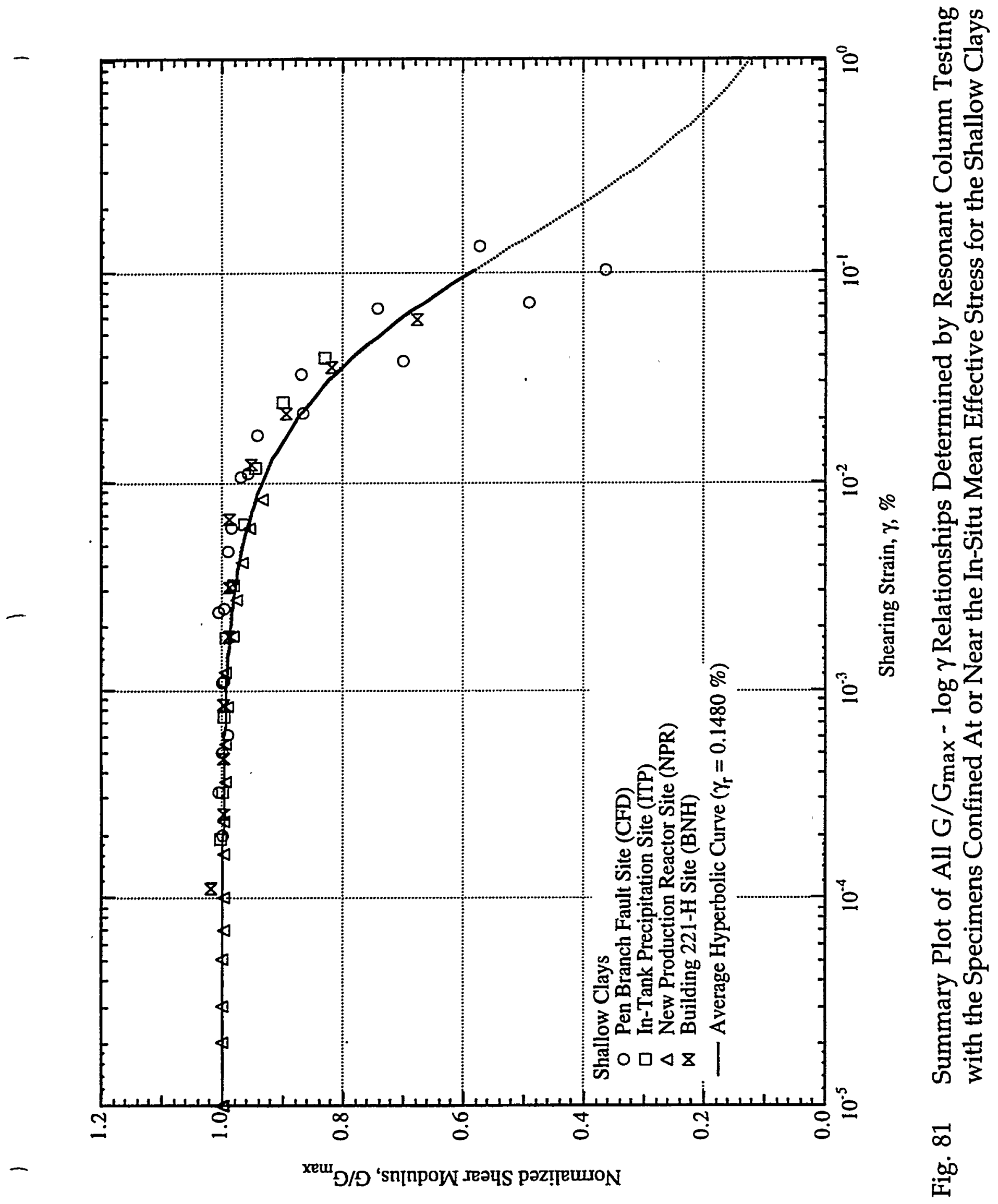

SRS-FR-CDP-95, rev. 0, 13 September 95 


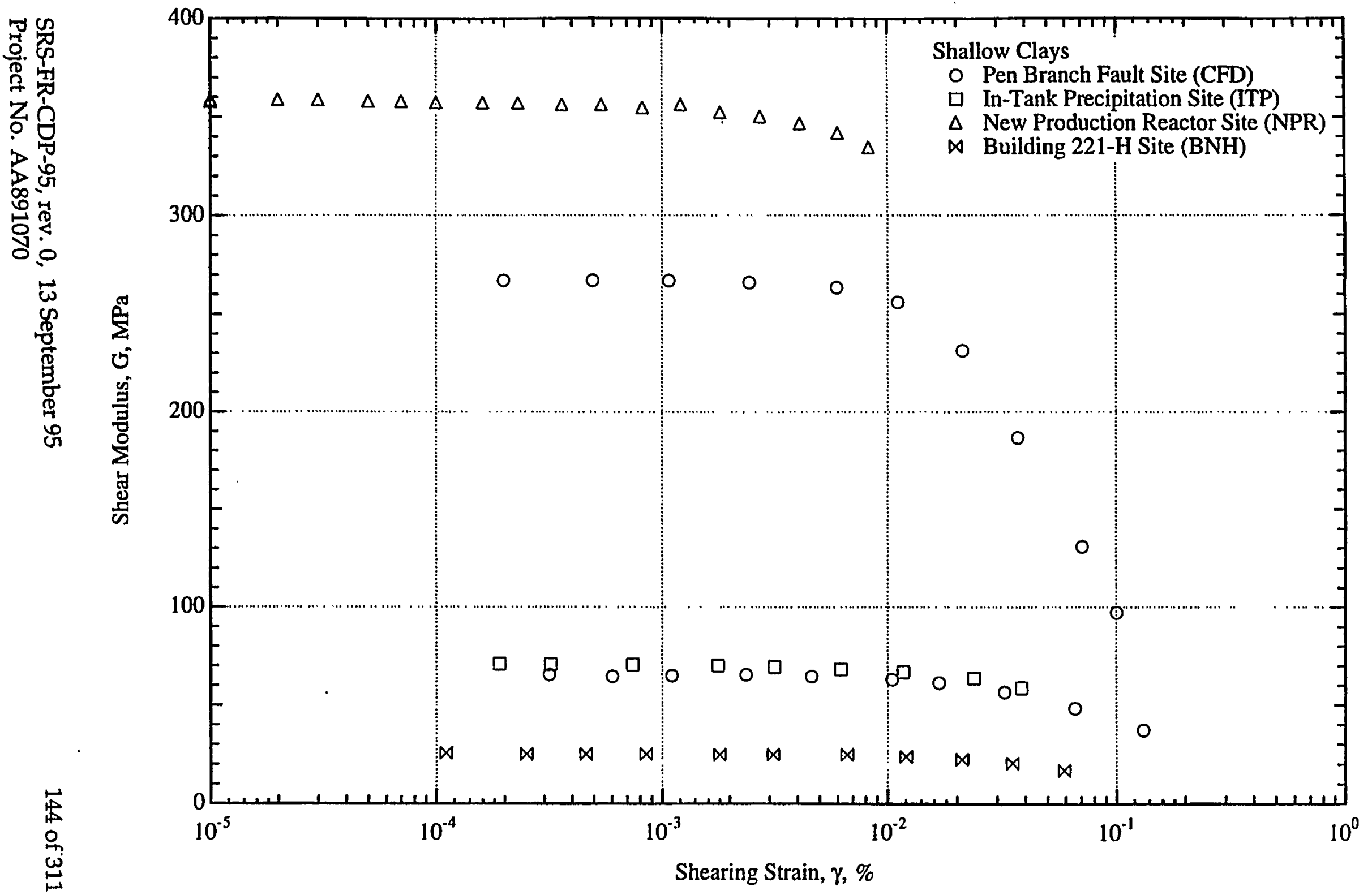

Fig. 82 Summary Plot of All G - $\log \gamma$ Relationships Determined by Resonant Column Testing with the Specimens Confined At or Near the In-Situ Mean Effective Stress for the Shallow Clays 


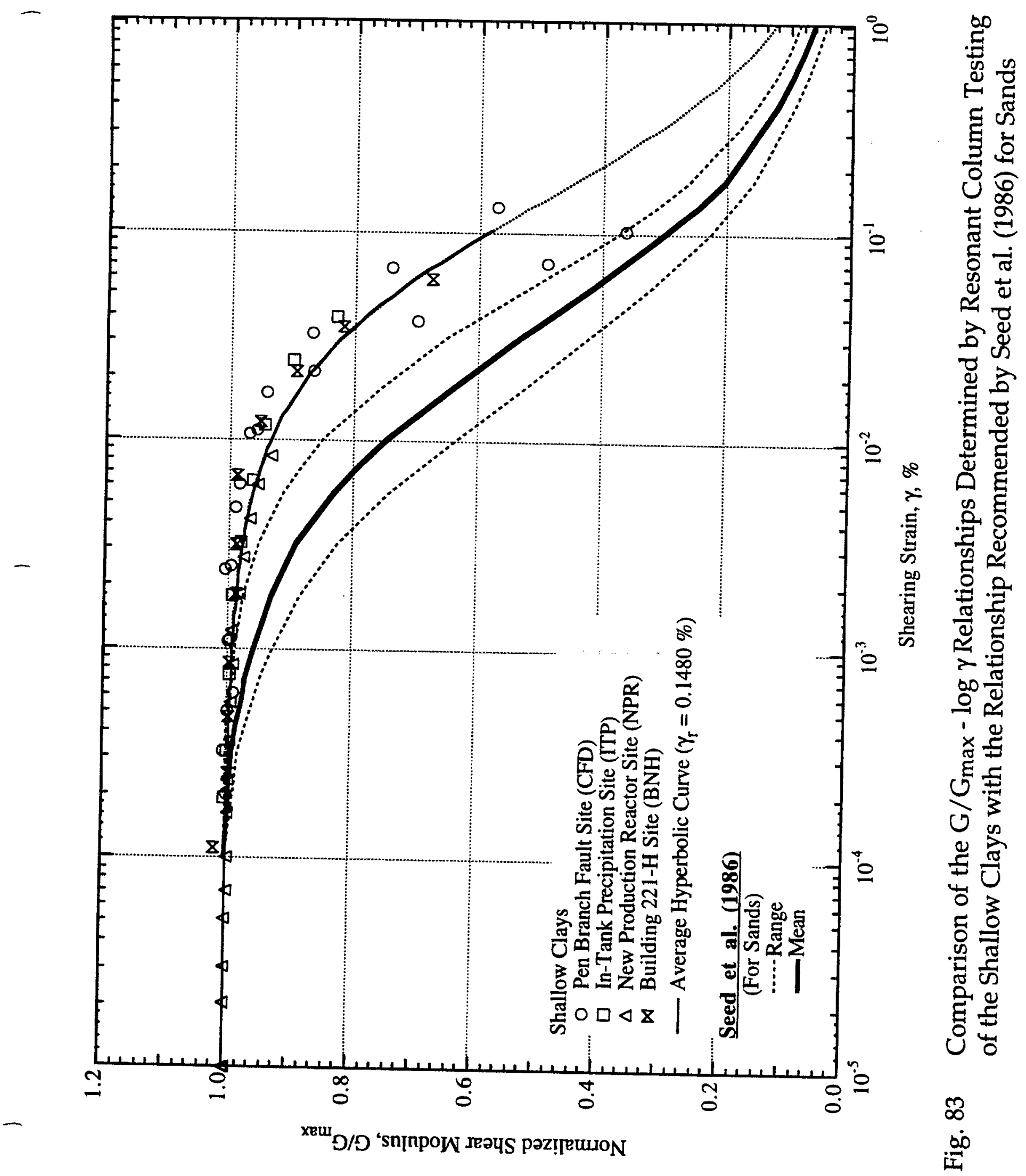

SRS-FR-CDP-95, rev. 0, 13 September 95 Project No. AA891070 


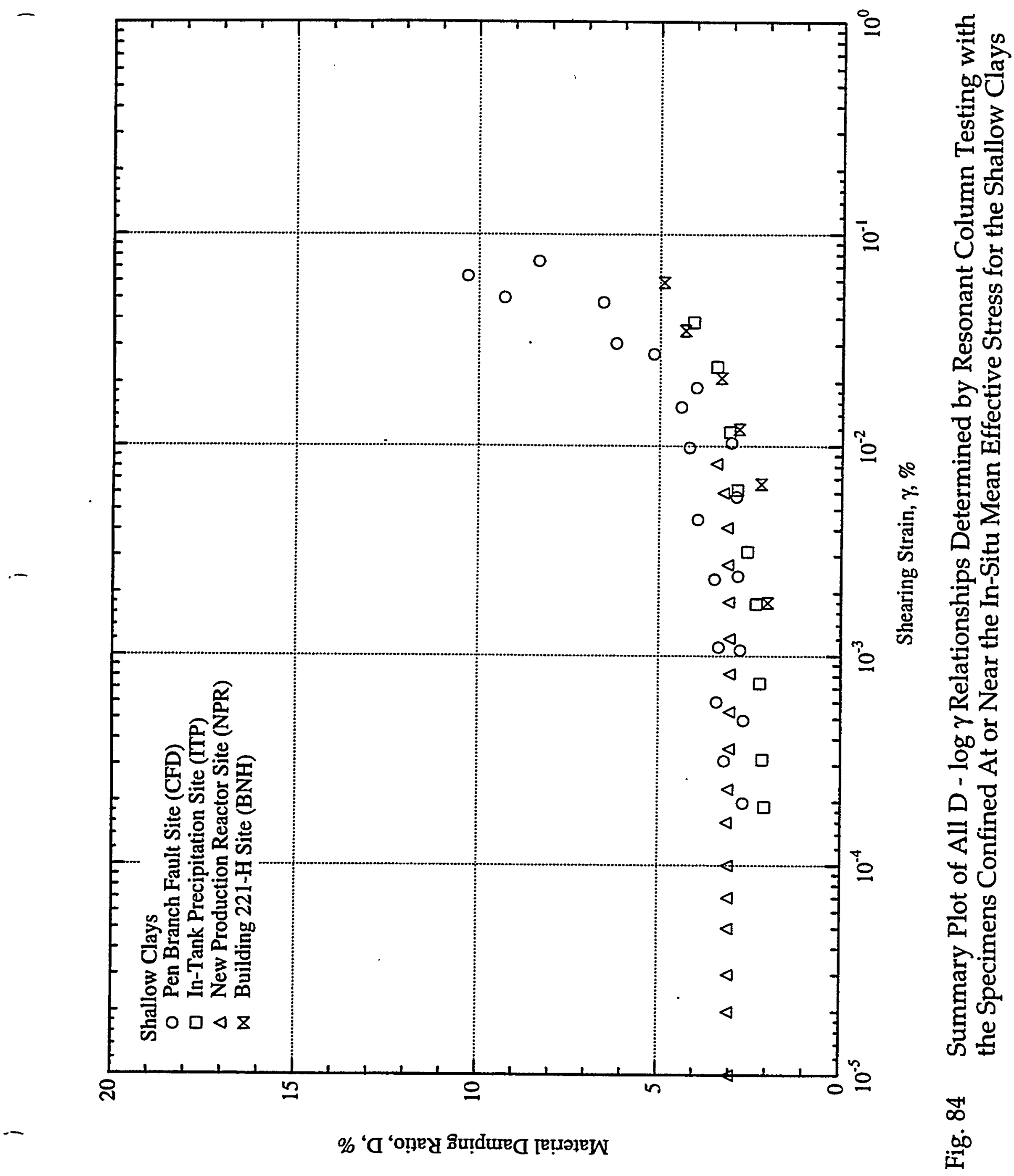




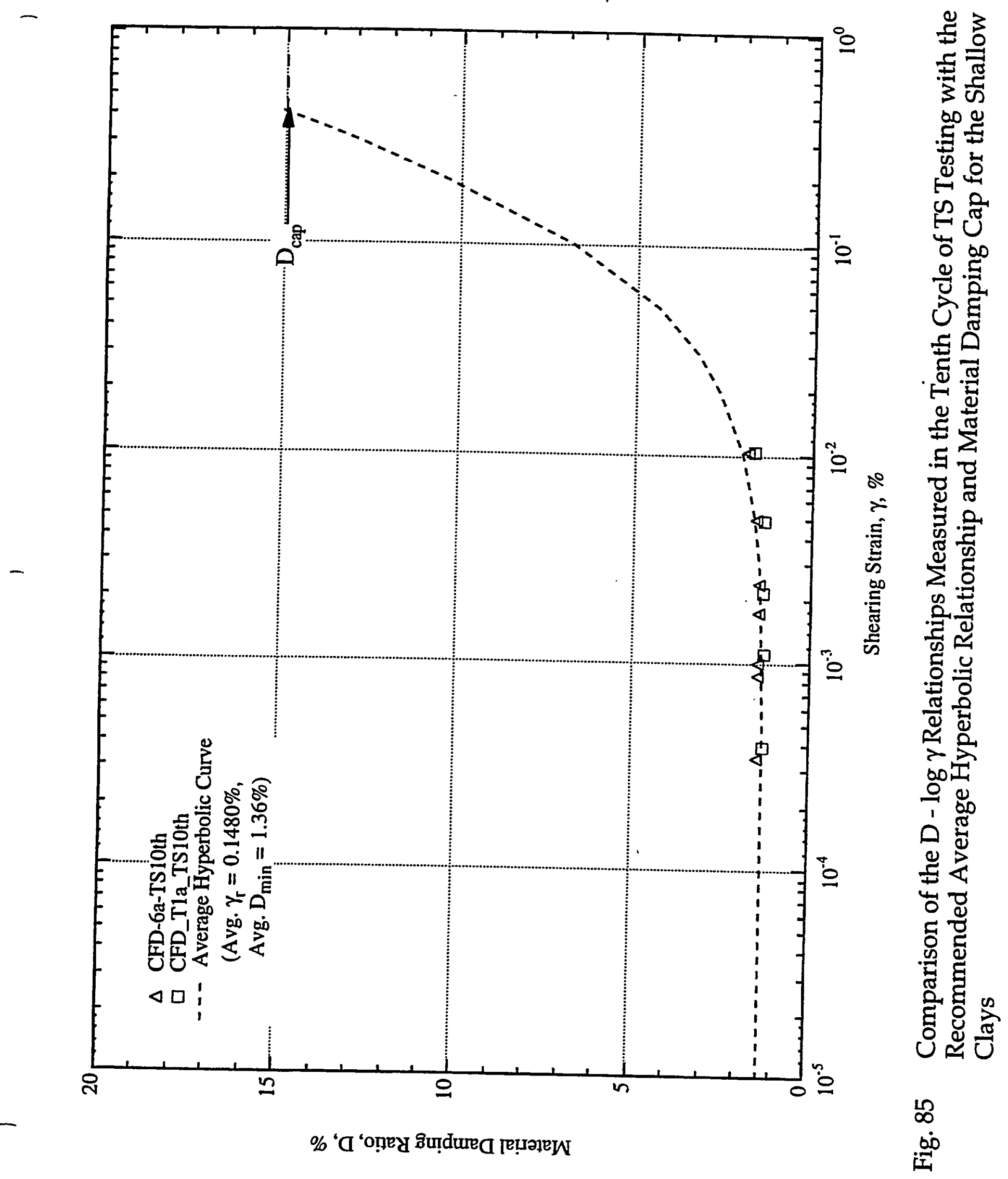

SRS-FR-CDP-95, rev. 0, 13 September 95

Project No. AA891070 


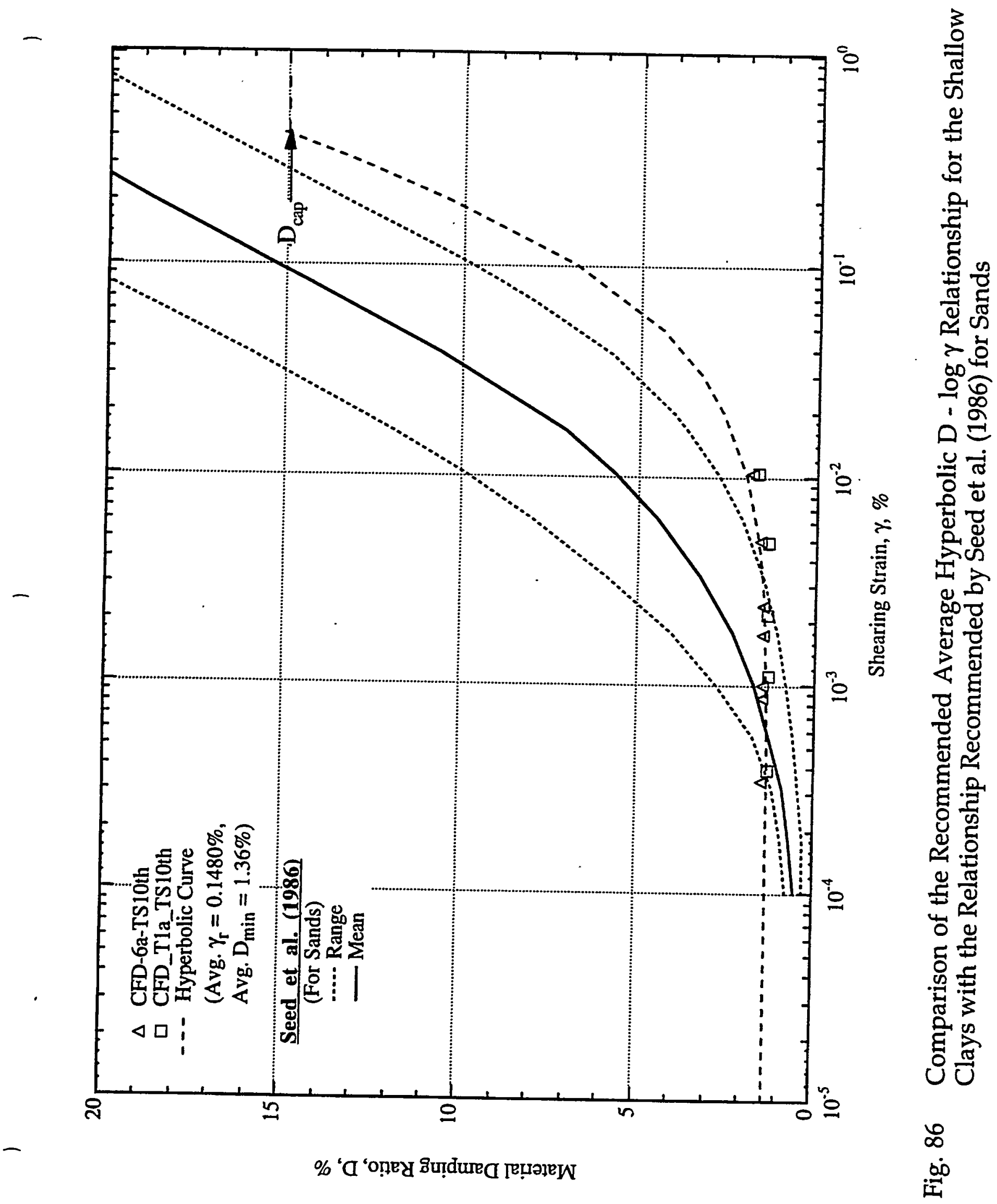

SRS-FR-CDP-95, rev. 0, 13 September 95

Project No. AA891070 


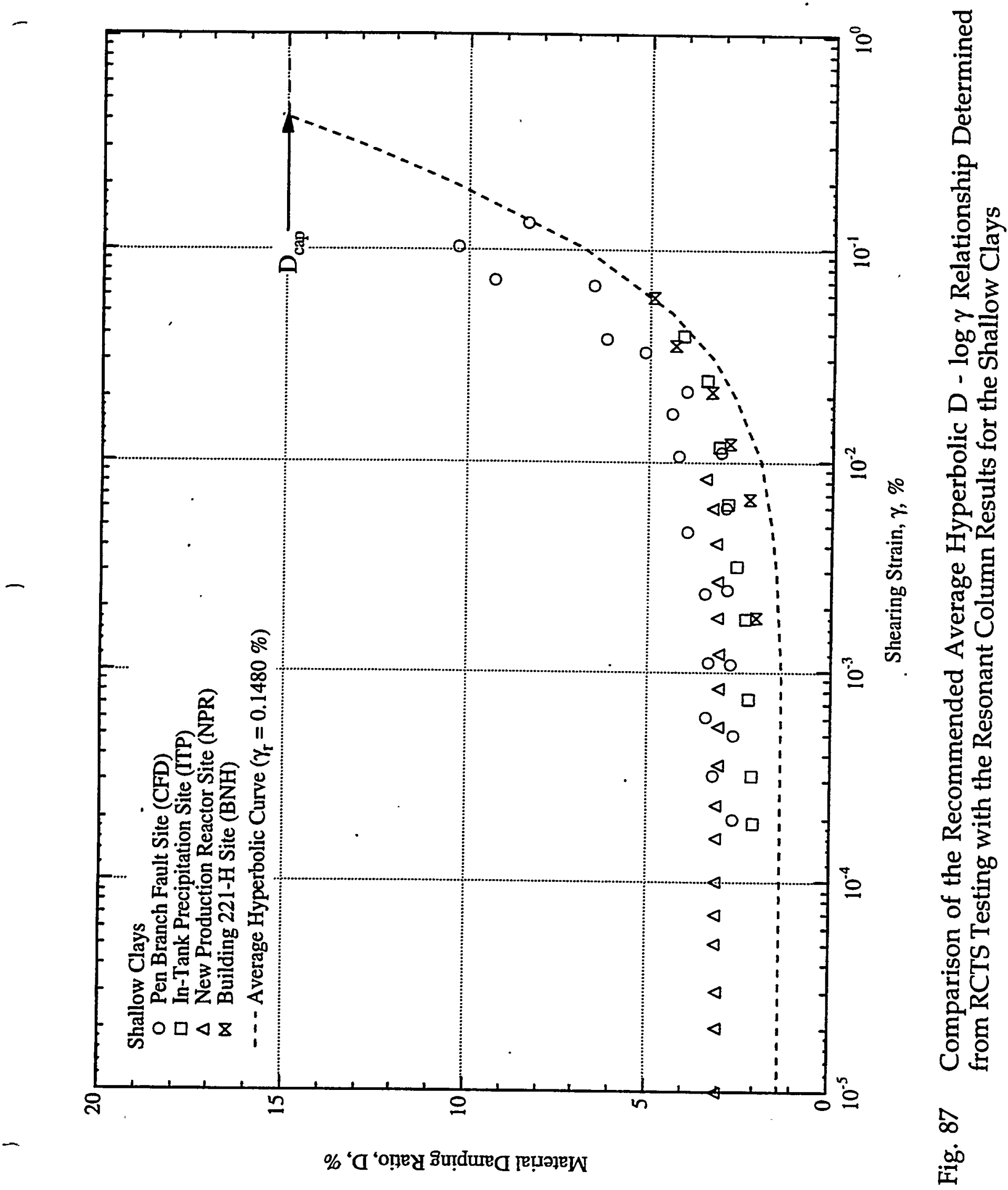



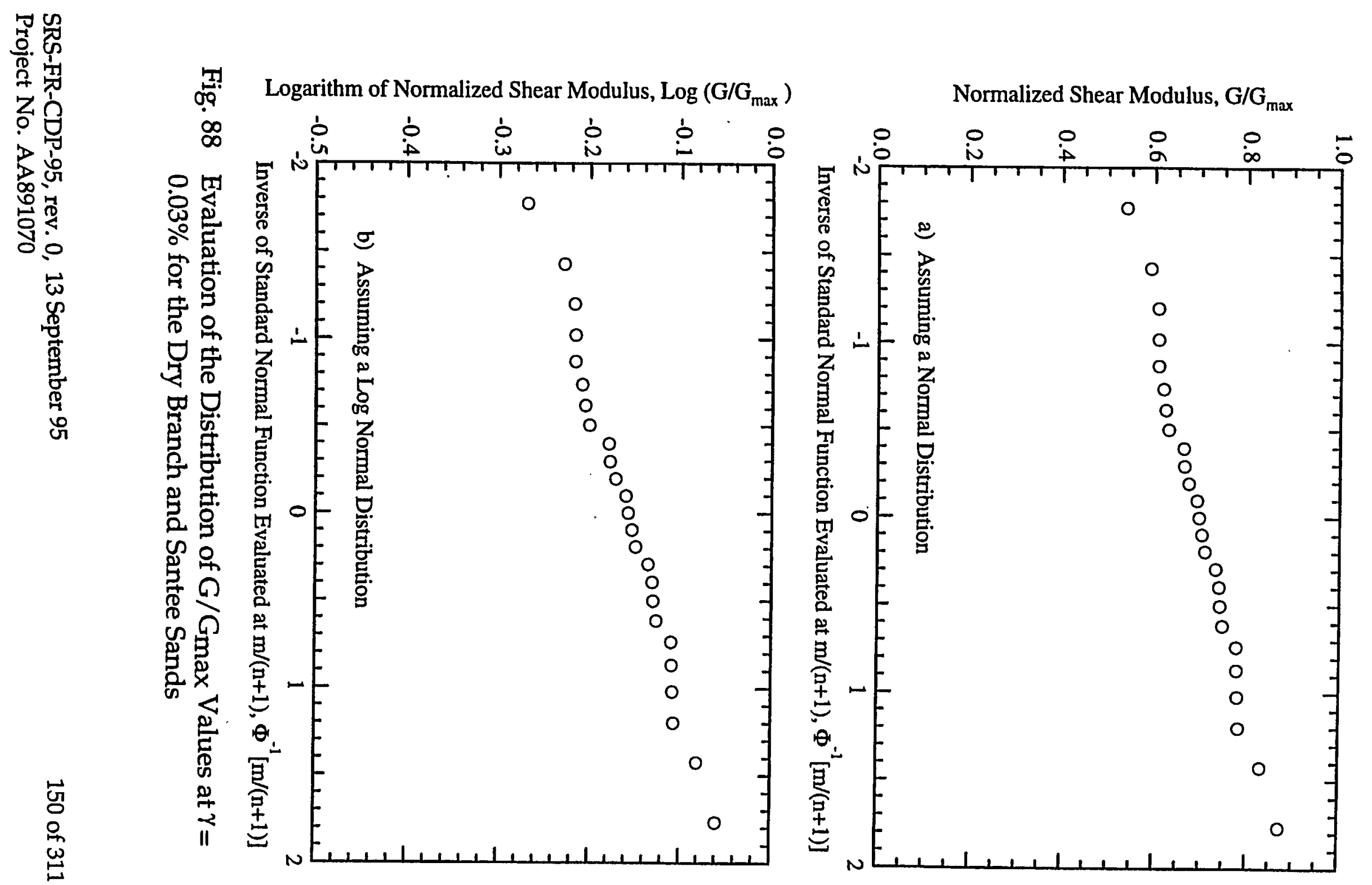

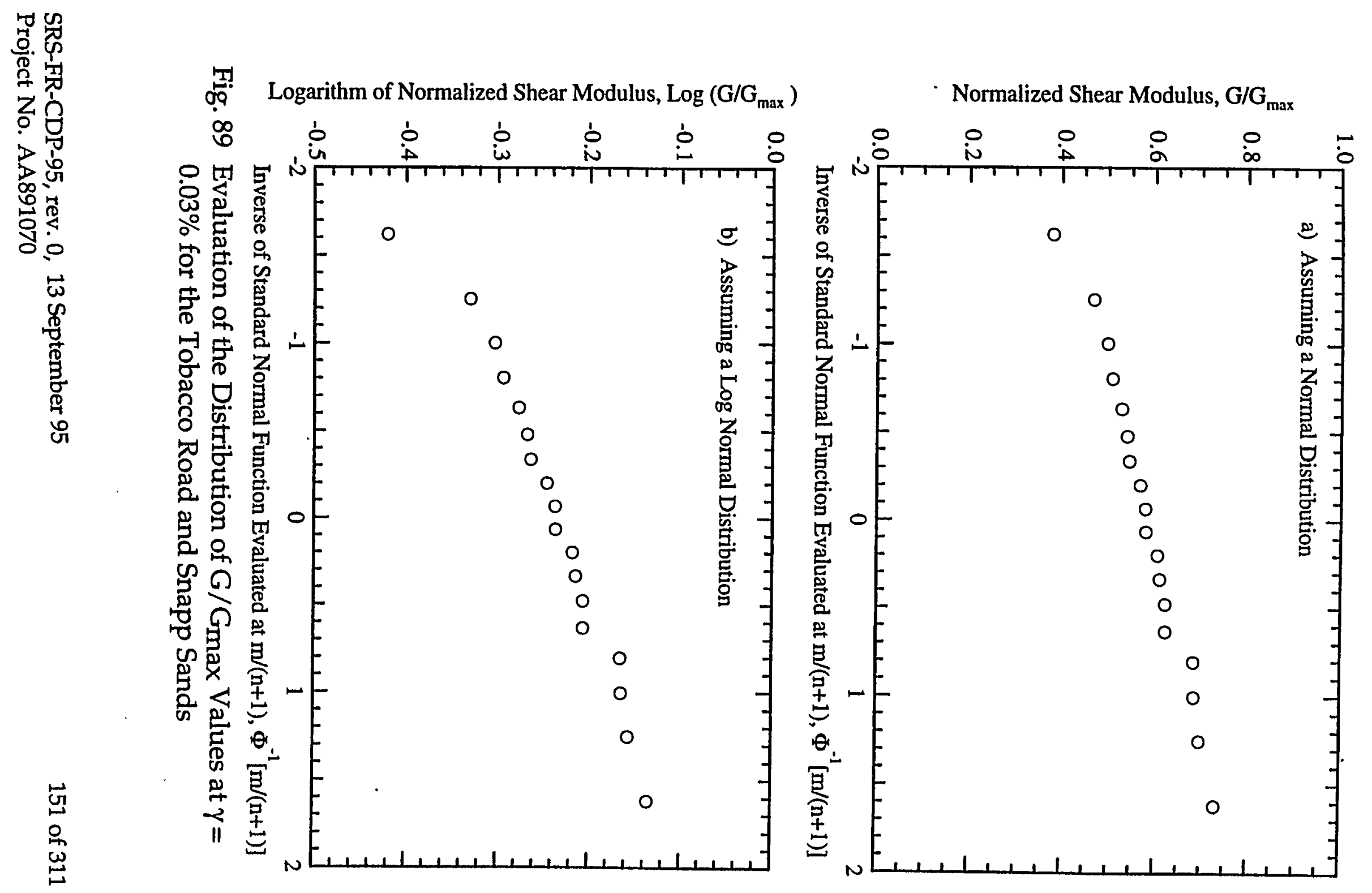


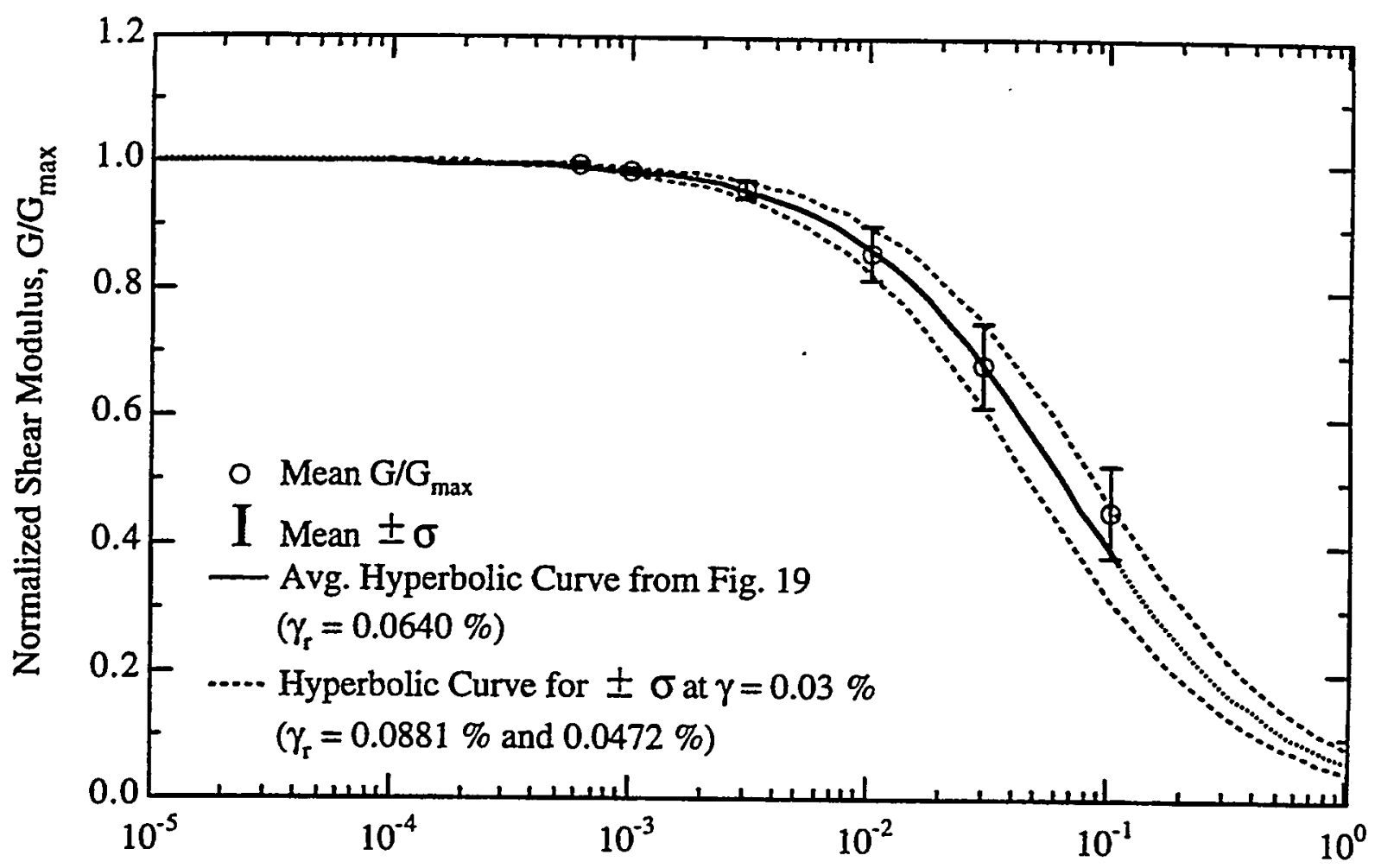

Shearing Strain, $\gamma, \%$

Fig. 90 Statistical Evaluation of the $G / G_{\max }$ Values for the Dry Branch Sands

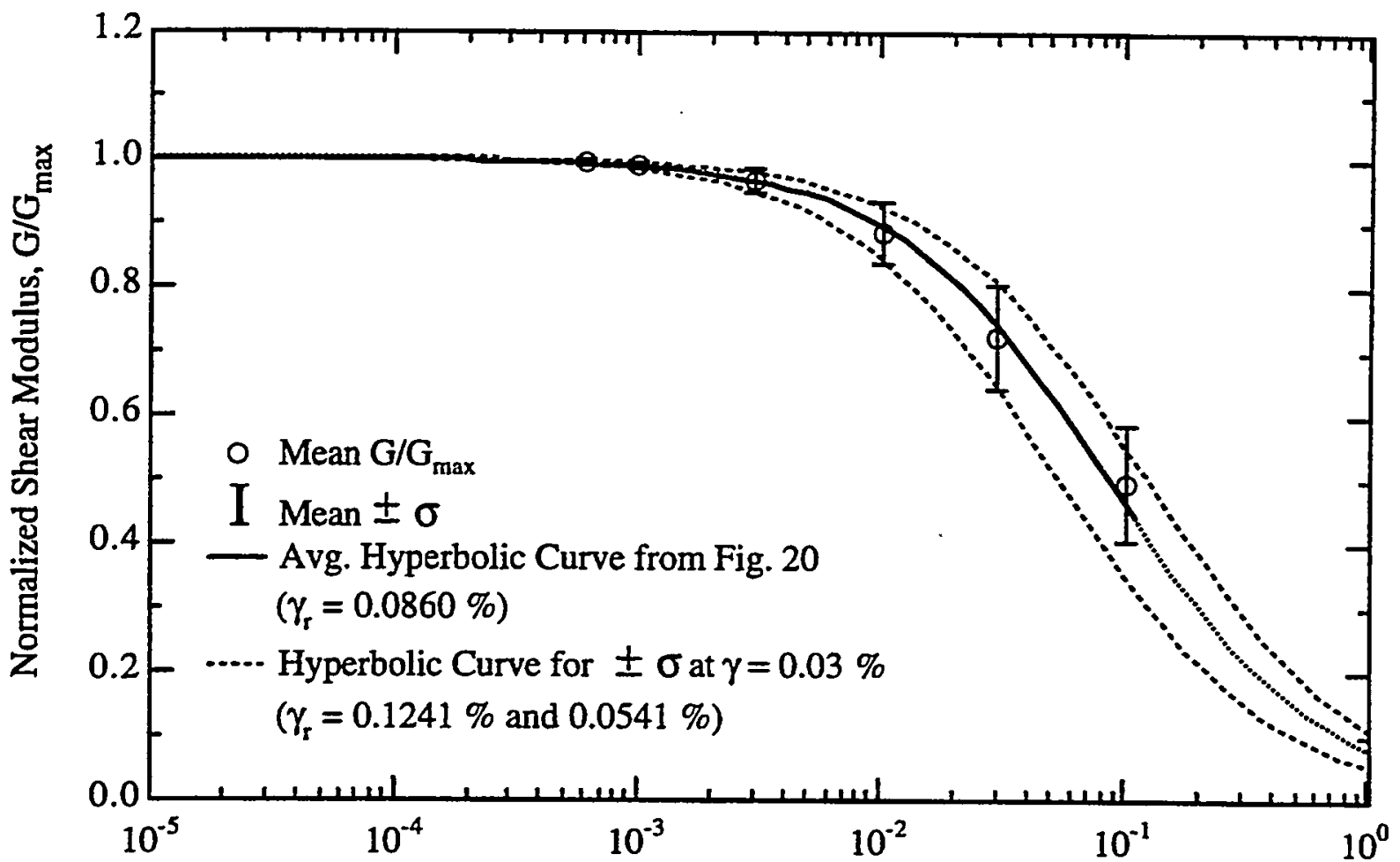

Shearing Strain, $\gamma, \%$

Fig. 91 Statistical Evaluation of the $G / G_{\max }$ Values for the Santee Sands 


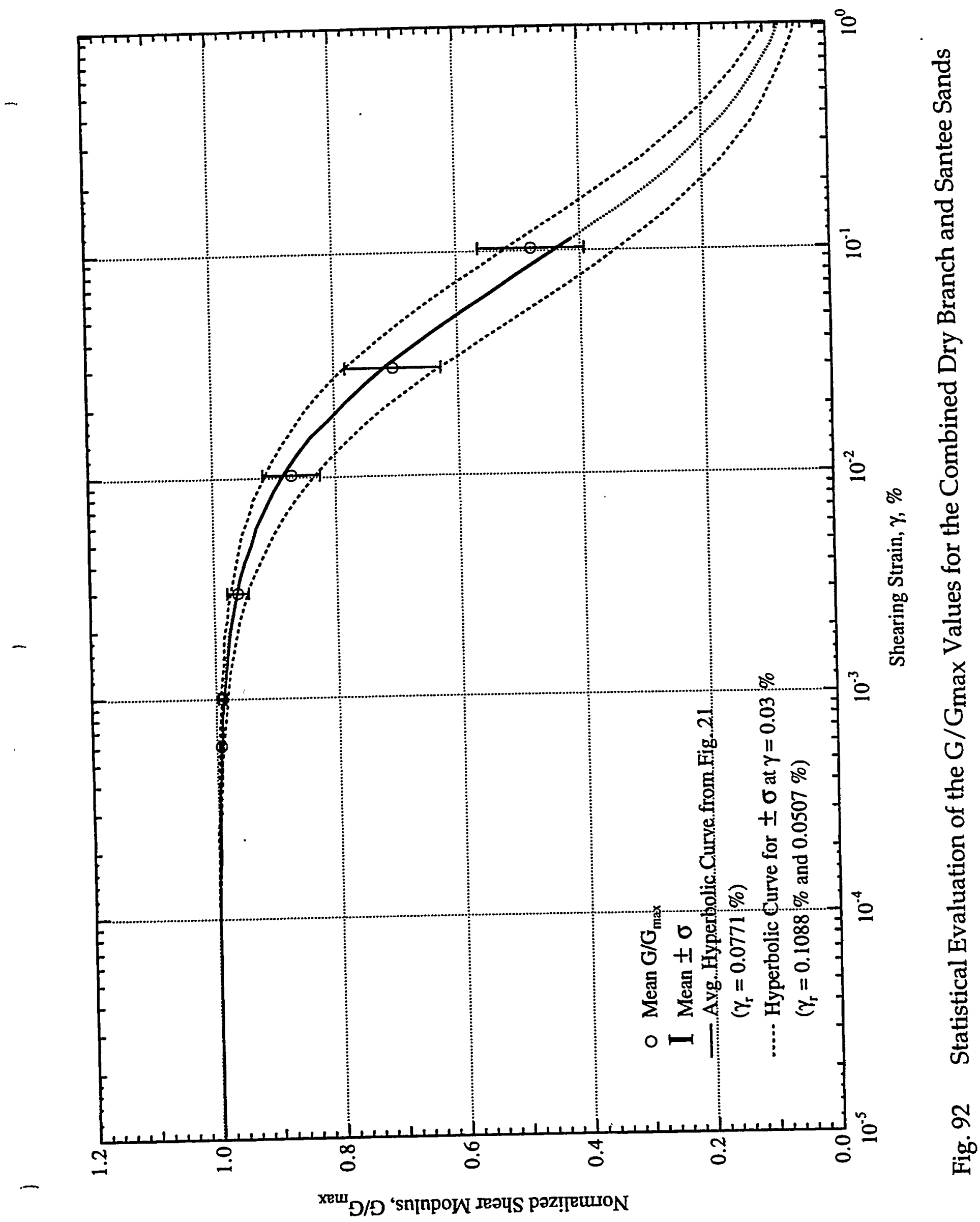

SRS-FR-CDP-95, rev. 0, 13 September 95 


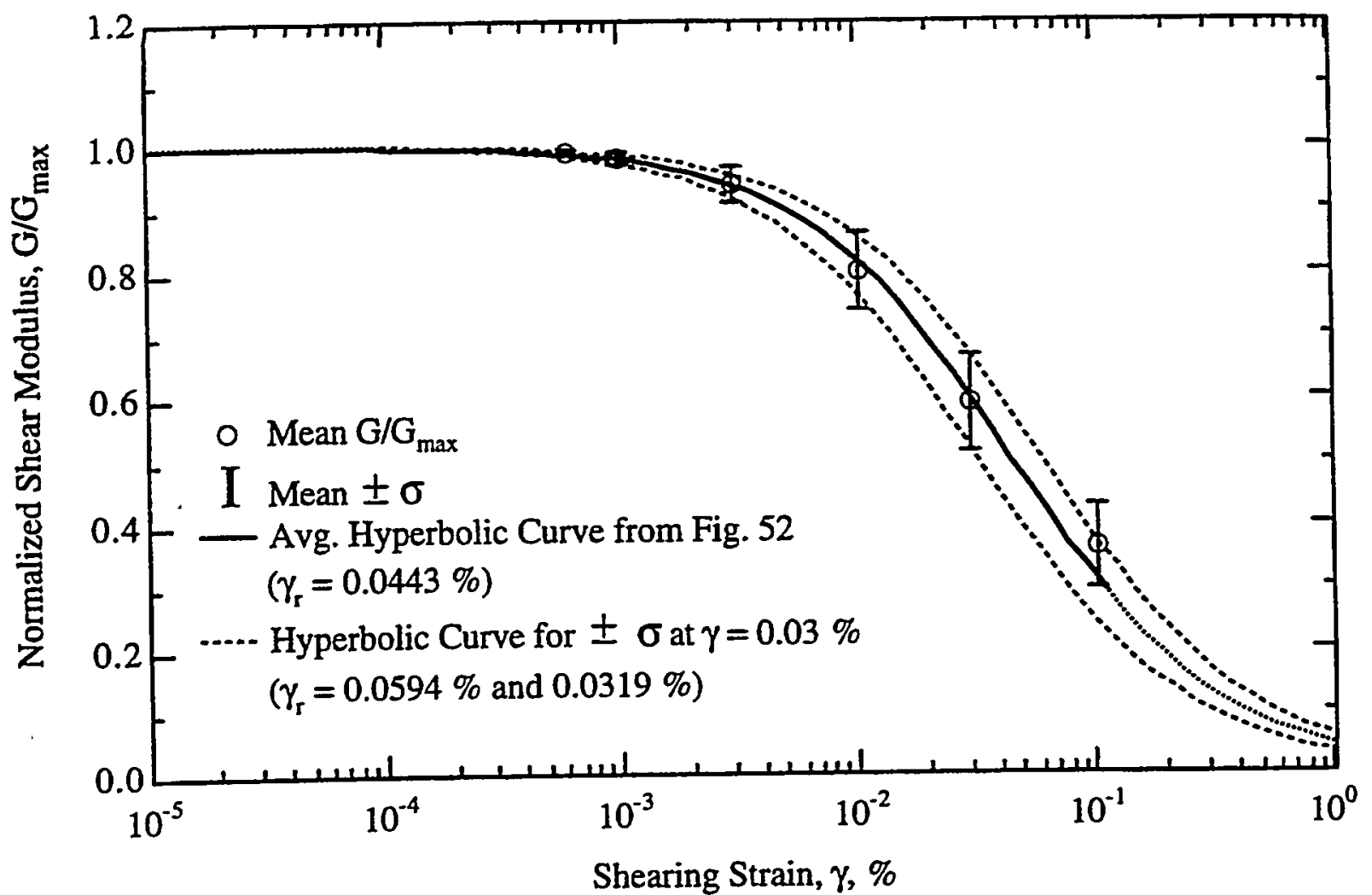

Fig. 93 Statistical Evaluation of the $G / G_{\max }$ Values of the Tobacco Road Sands

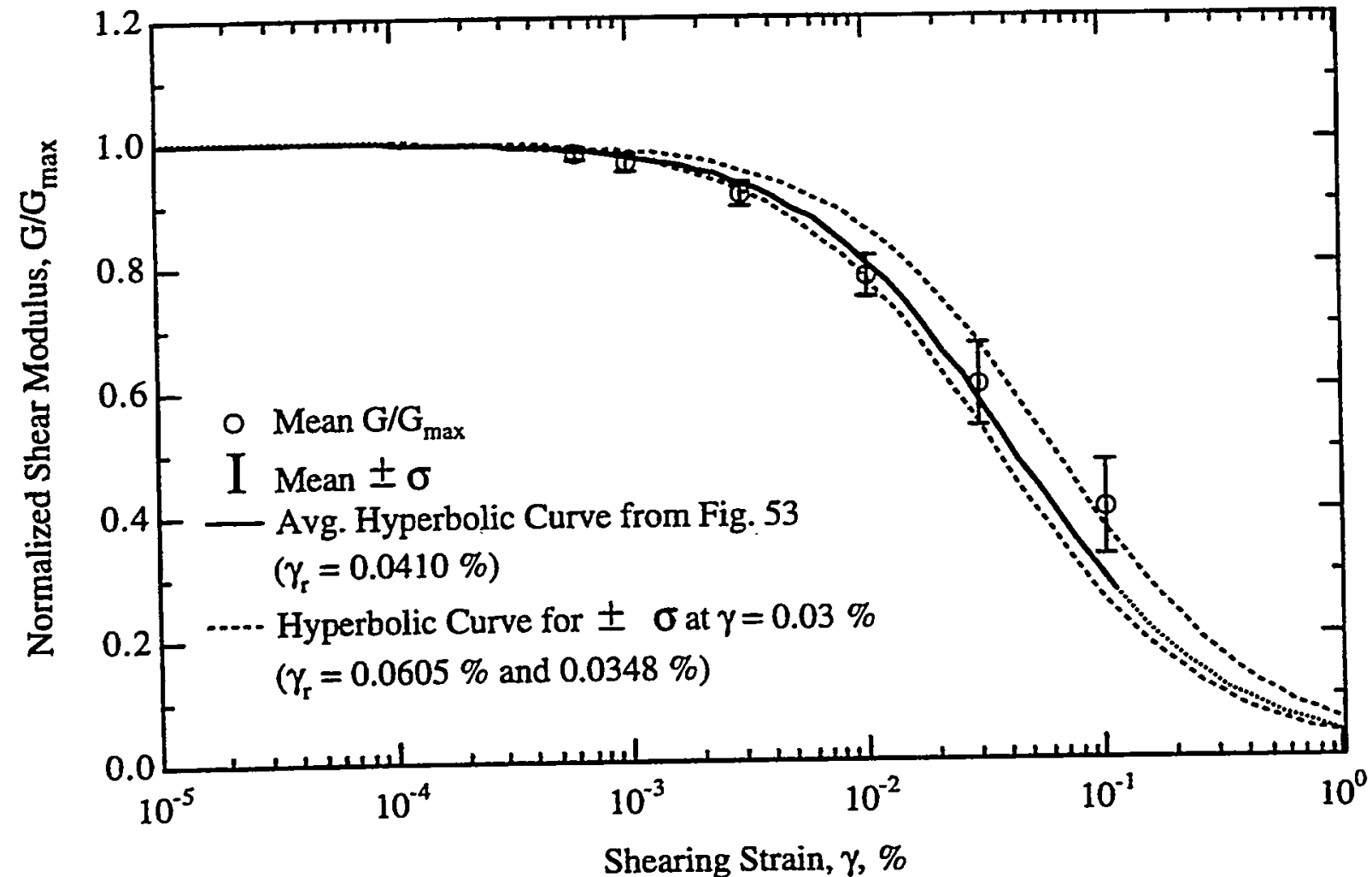

Fig. 94 Statistical Evaluation of the $G / G_{\max }$ Values of the Snapp Sands

SRS-FR-CDP-95, rev. 0, 13 September 95

154 of 311 


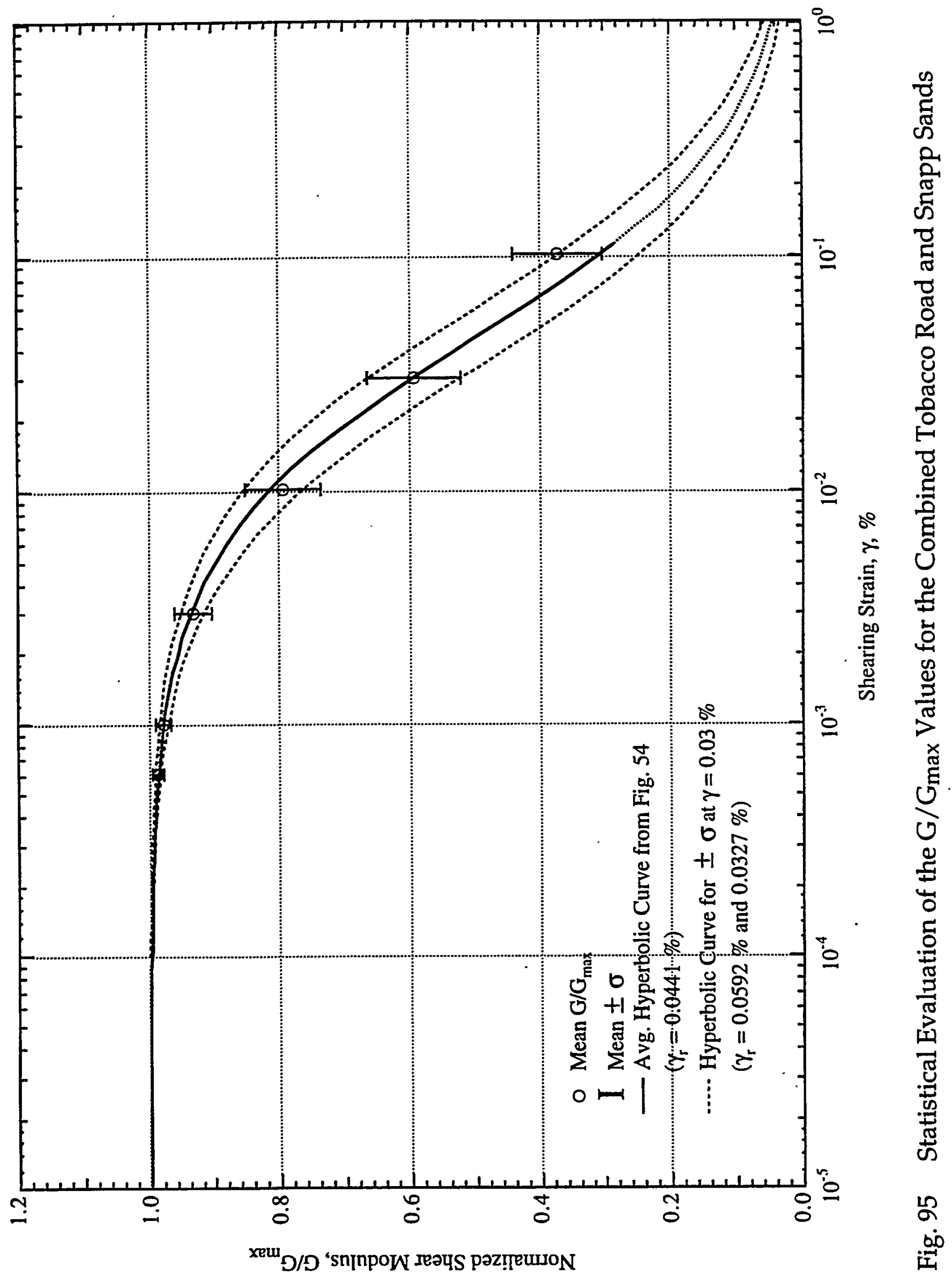

SRS-FR-CDP-95, rev. 0, 13 September 95 


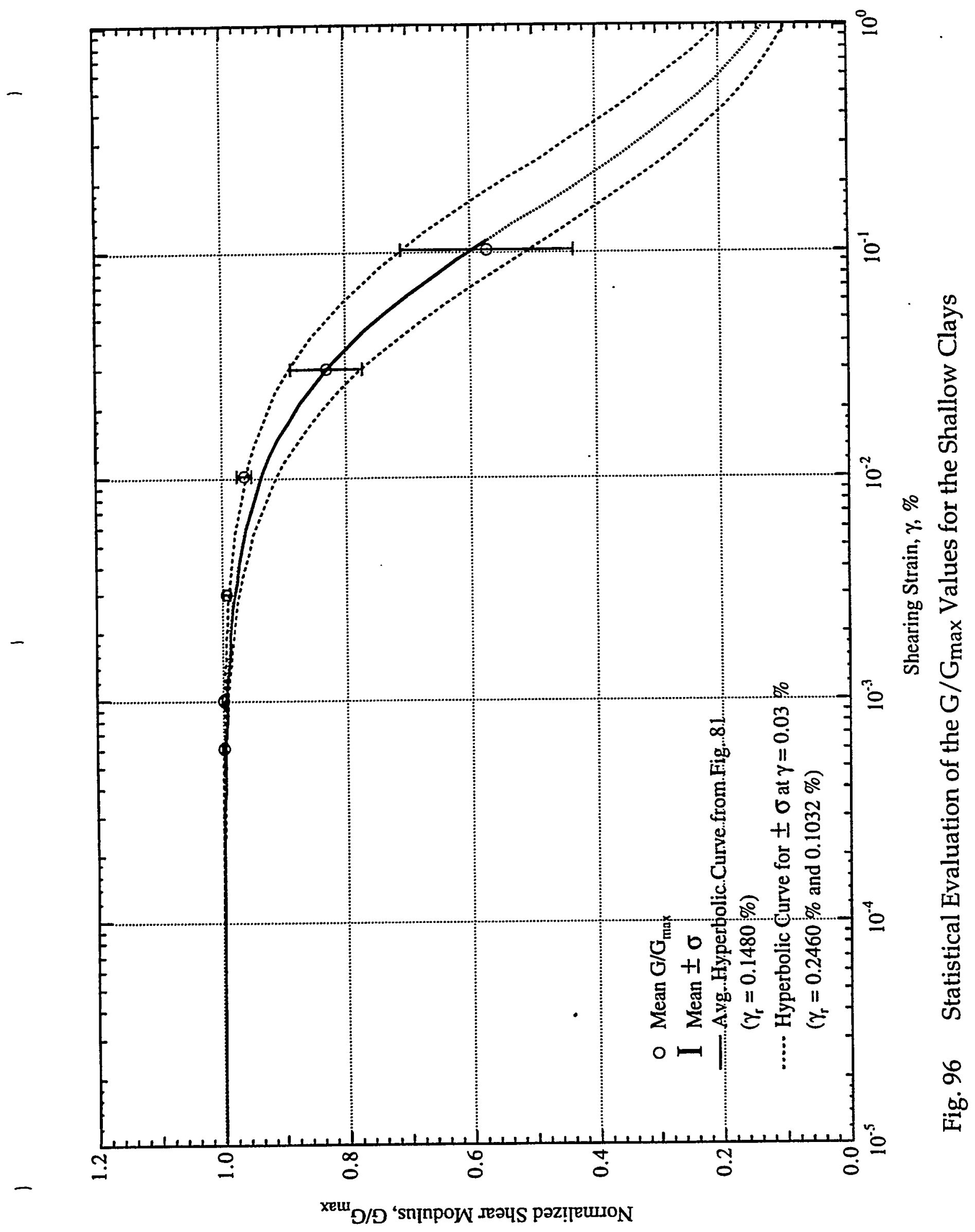

SRS-FR-CDP-95, rev. 0, 13 September 95 


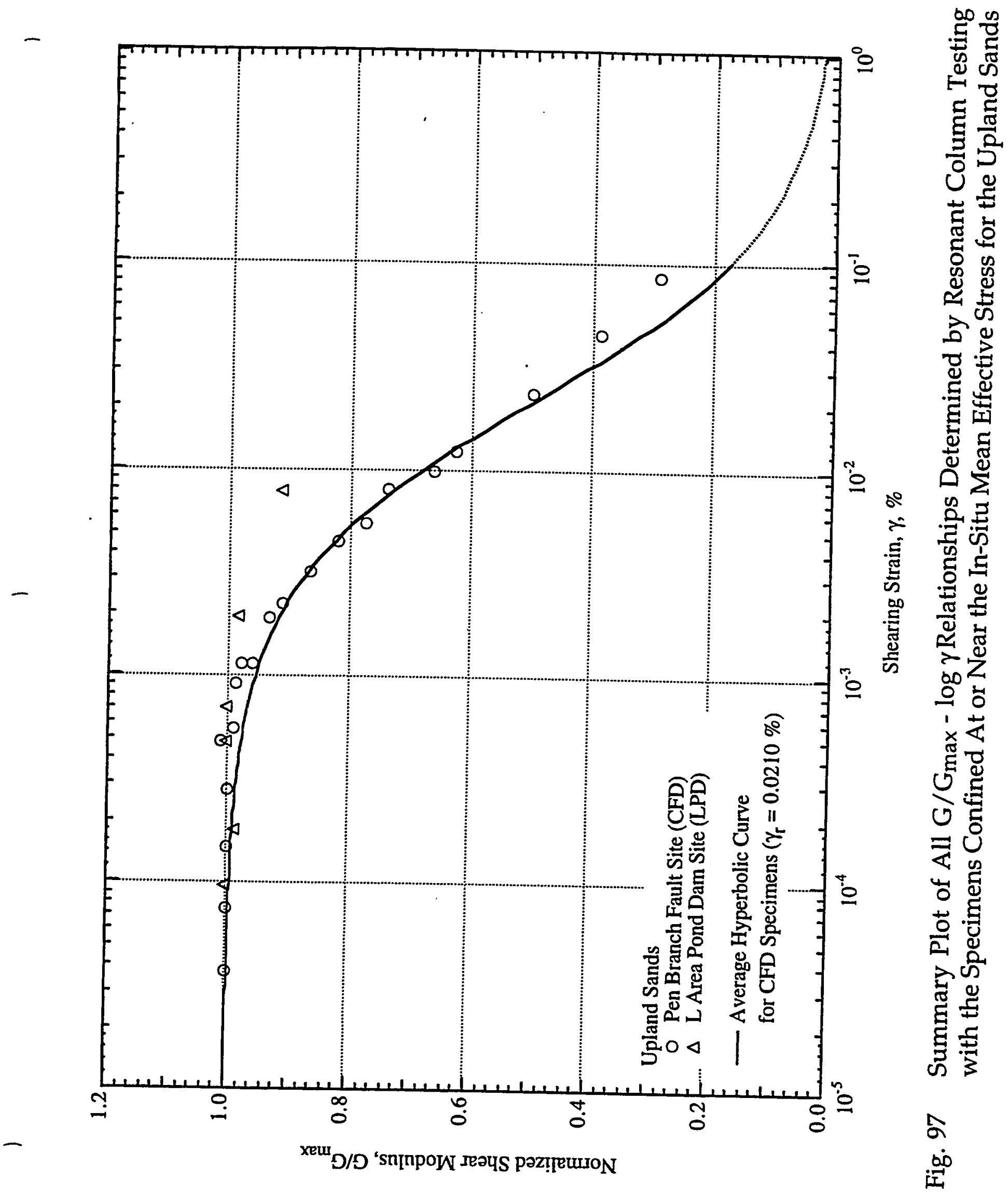

SRS-FR-CDP-95, rev. 0, 13 September 95

Project No. AA891070 


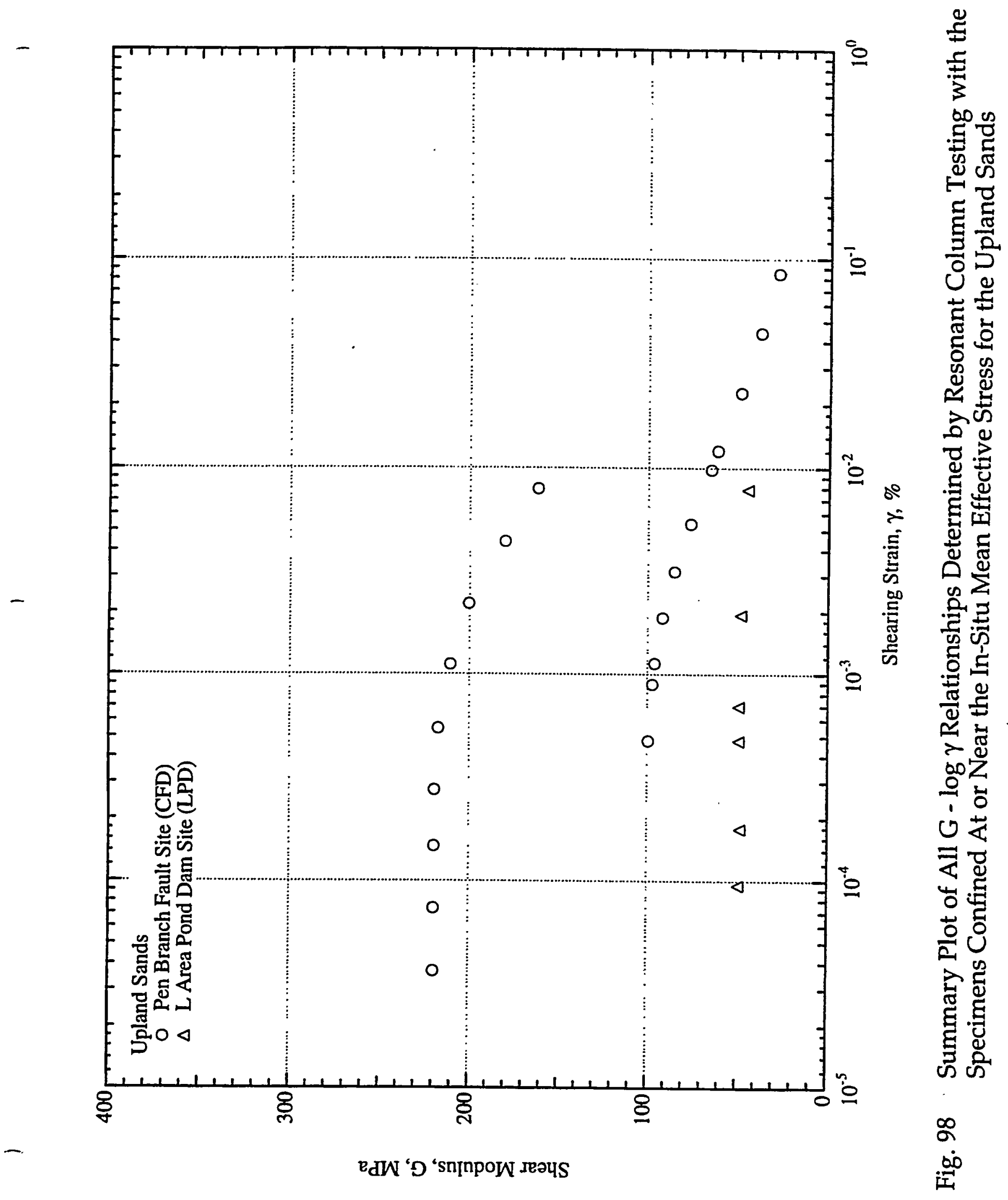

SRS-FR-CDP-95, rev. 0, 13 September 95 


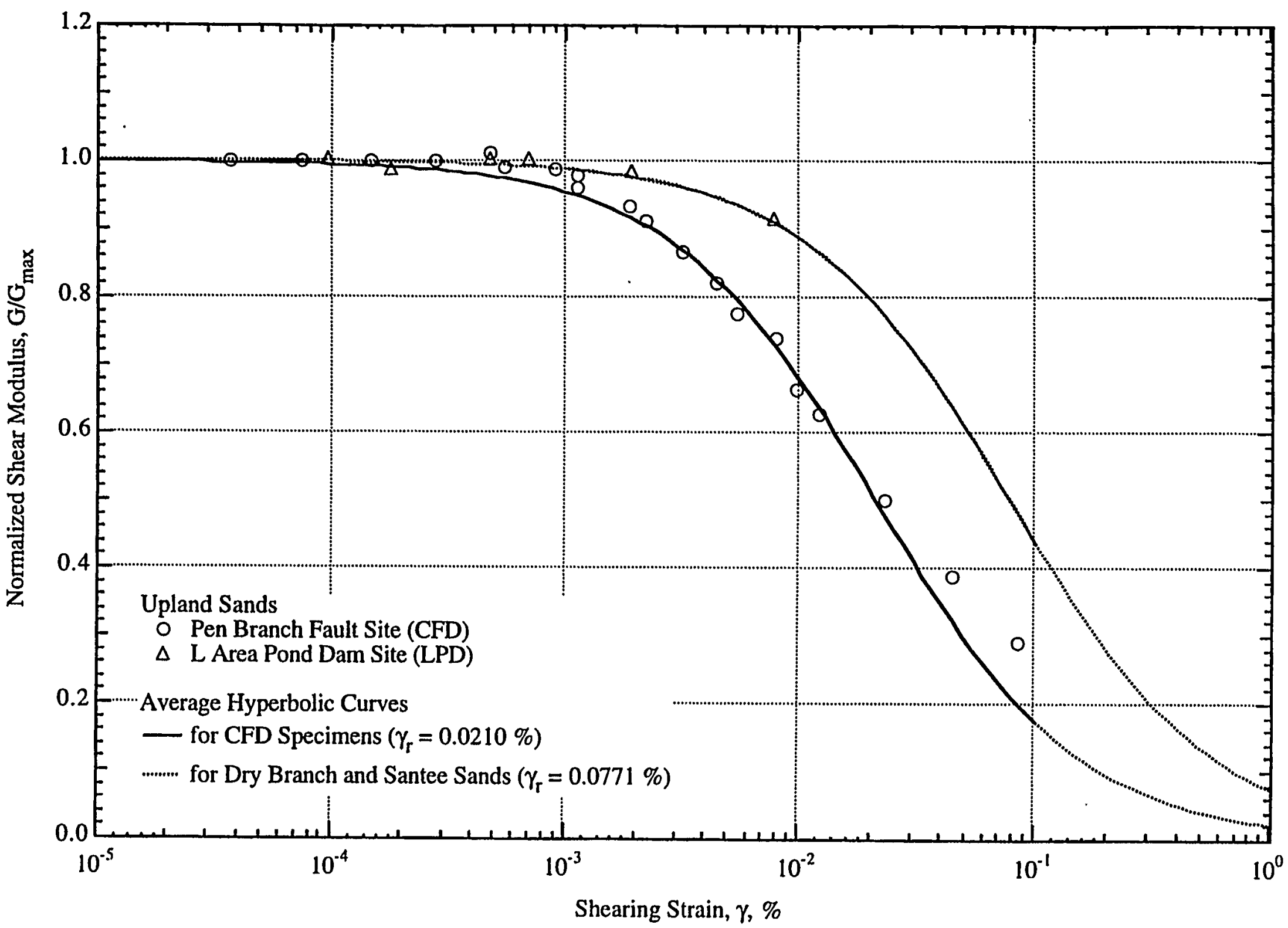

Fig. 99 Comparison of the $\mathrm{G} / \mathrm{G}_{\max }-\log \gamma$ Relationship Determined by Resonant Column Testing of the Softer Upland Sand Specimen with the Average Recommended Hyperbolic Relationship for Dry Branch and Santee Sands 


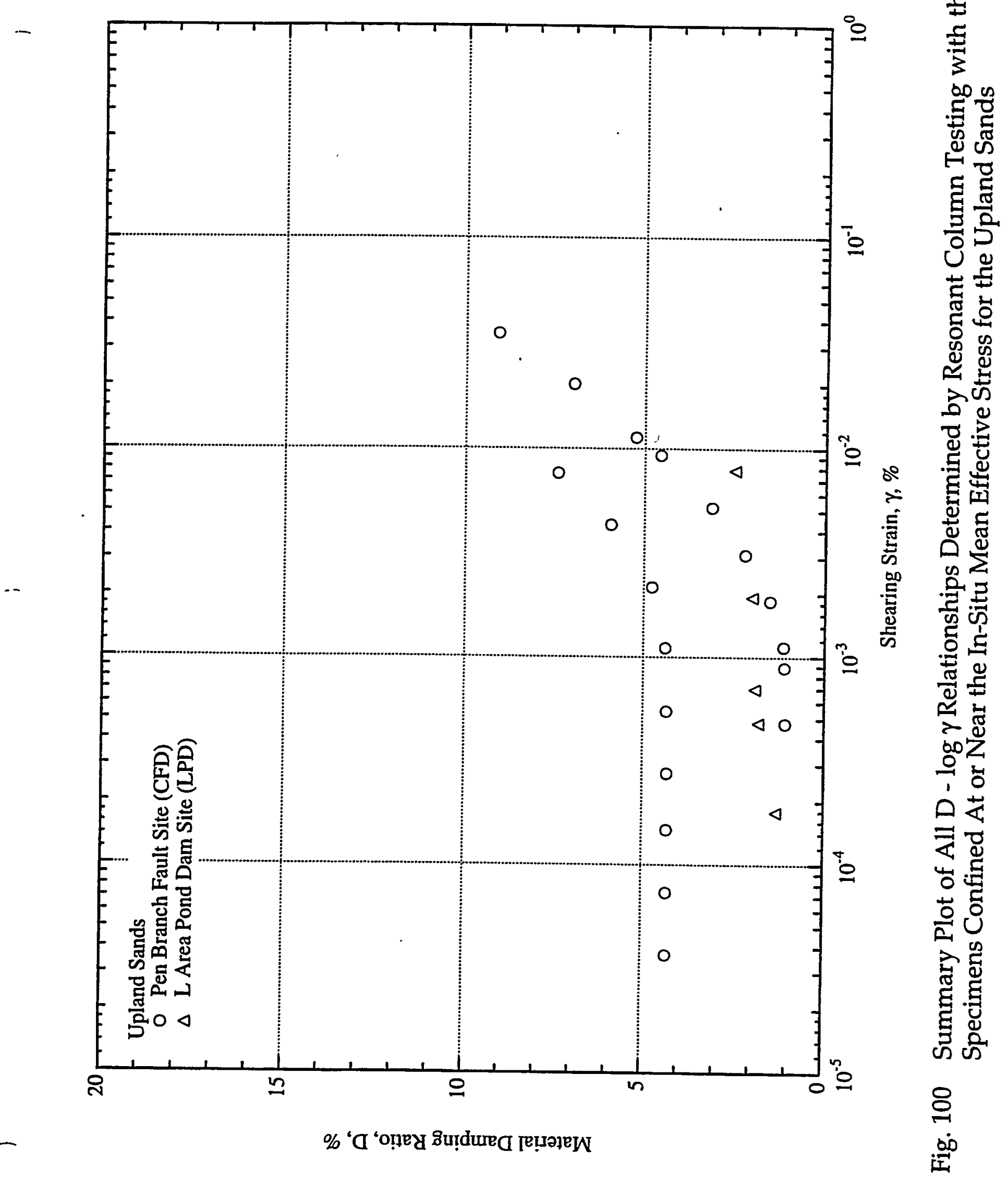

SRS-FR-CDP-95, rev. 0, 13 September 95 


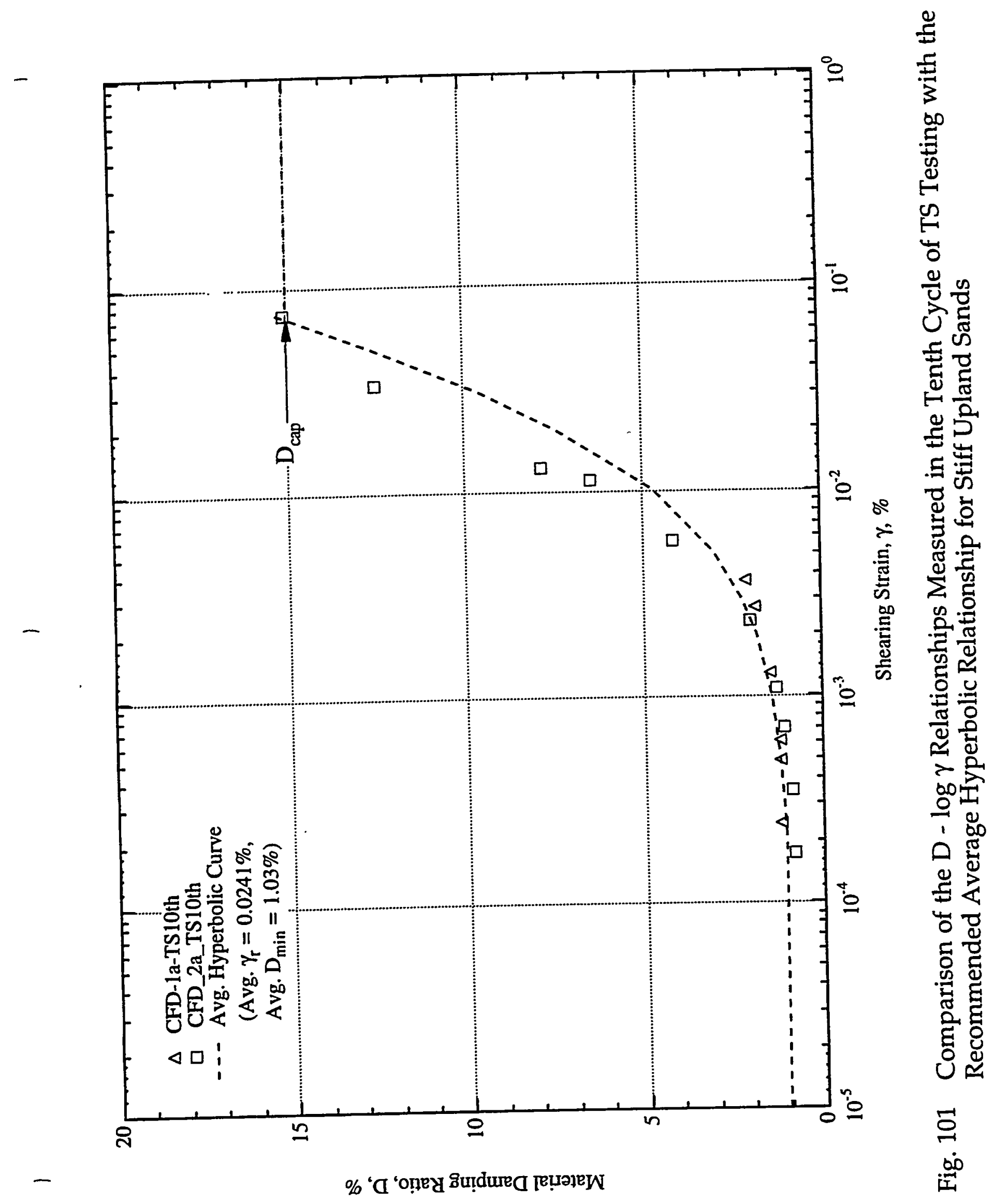

SRS-FR-CDP-95, rev. 0, 13 September 95 


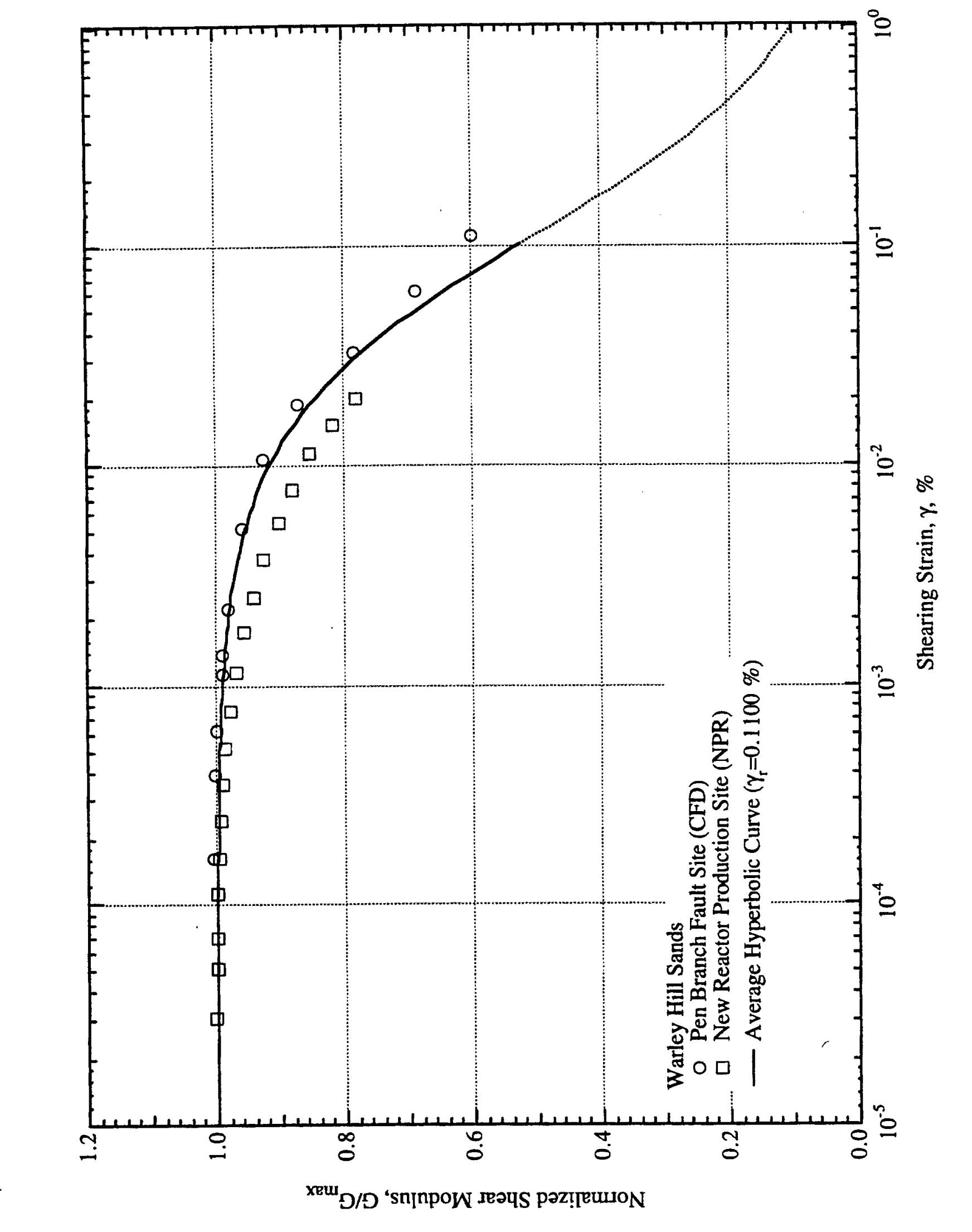

电㹃

is

Q

一
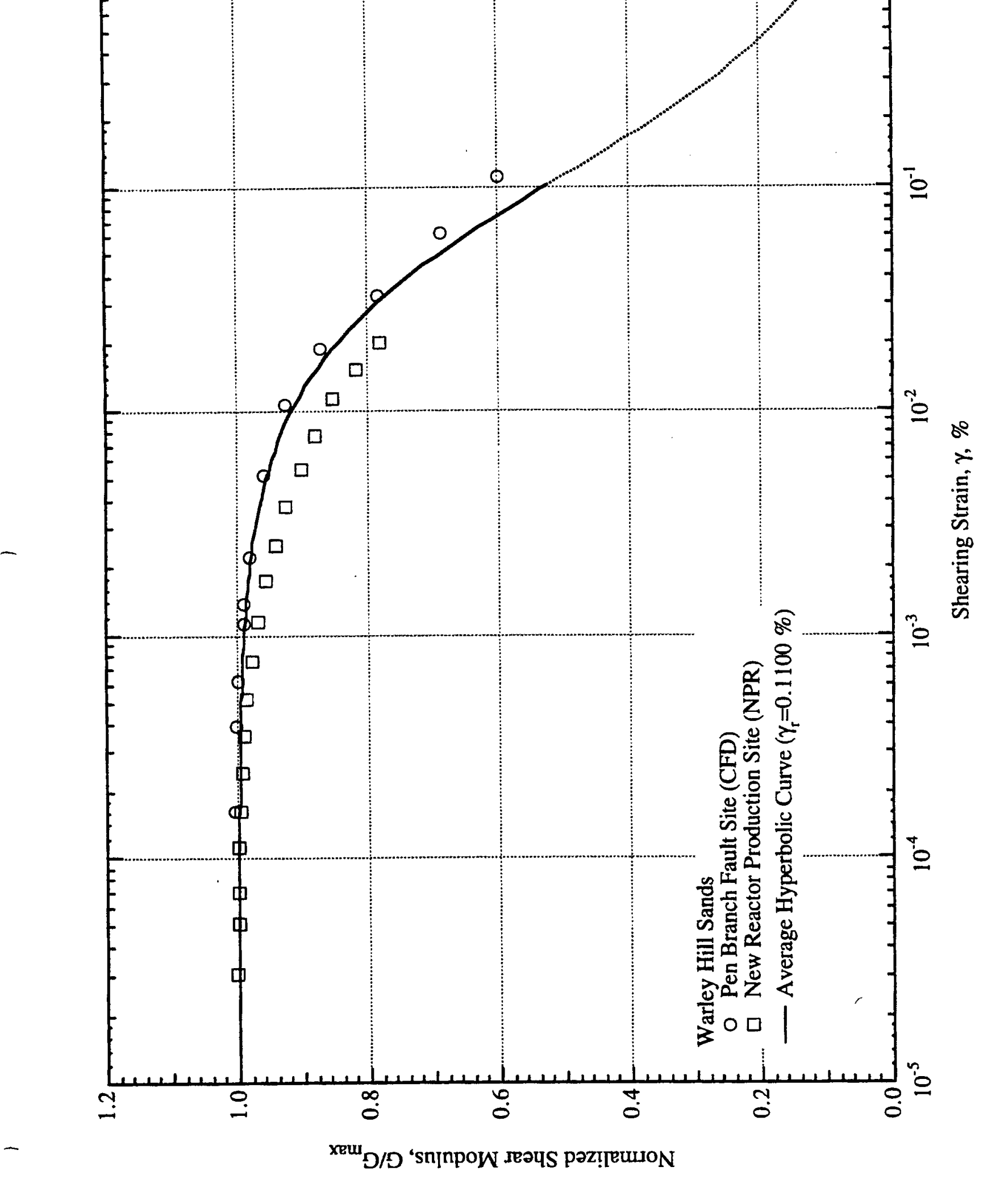

SRS-FR-CDP-95, rev. 0, 13 September 95 


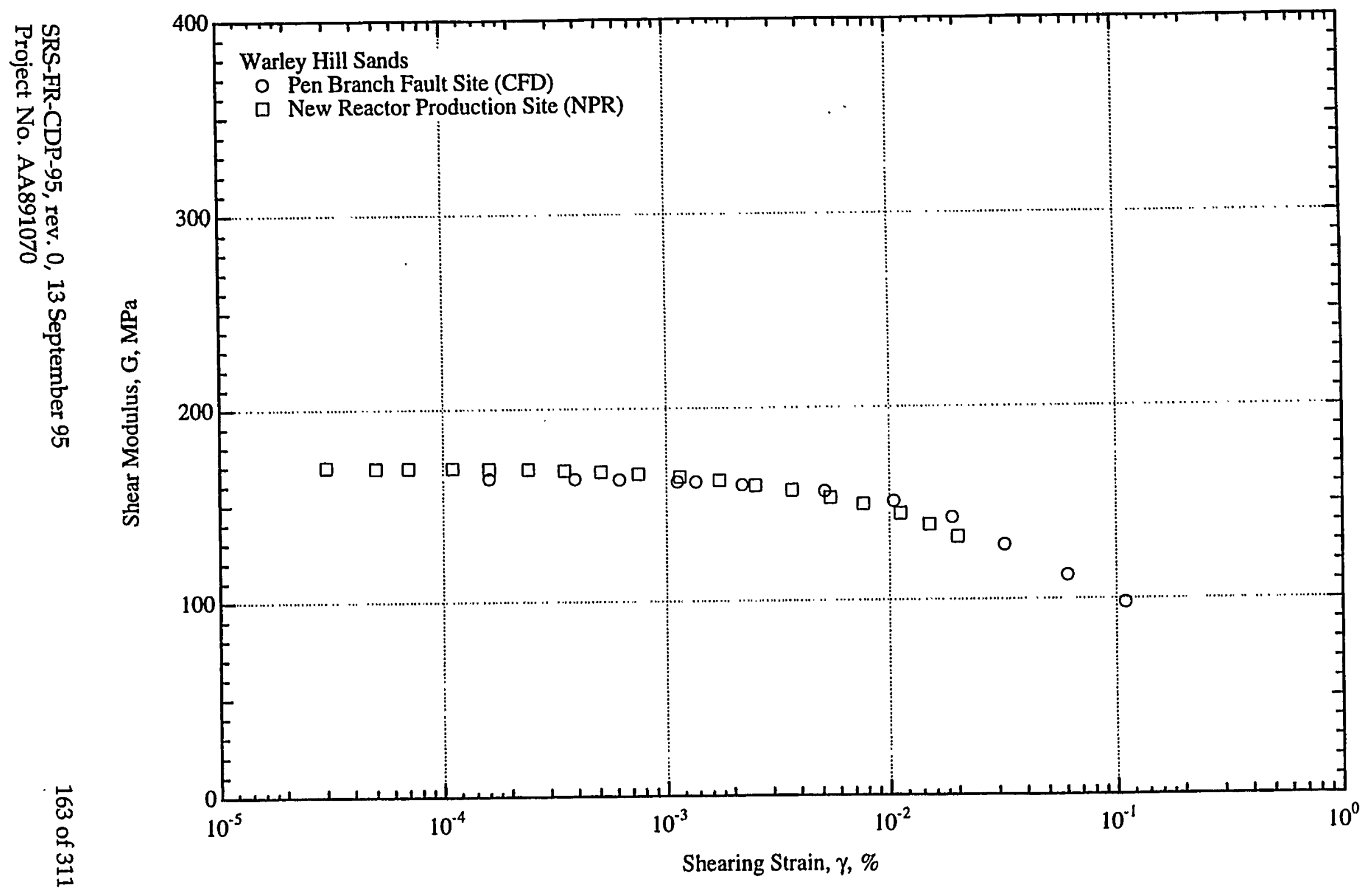

Fig. 103 Summary Plot of All G - $\log \gamma$ Relationships Determined by Resonant Column Testing with the Specimens Confined At or Near the In-Situ Mean Effective Stress for the Warley Hill Sands 


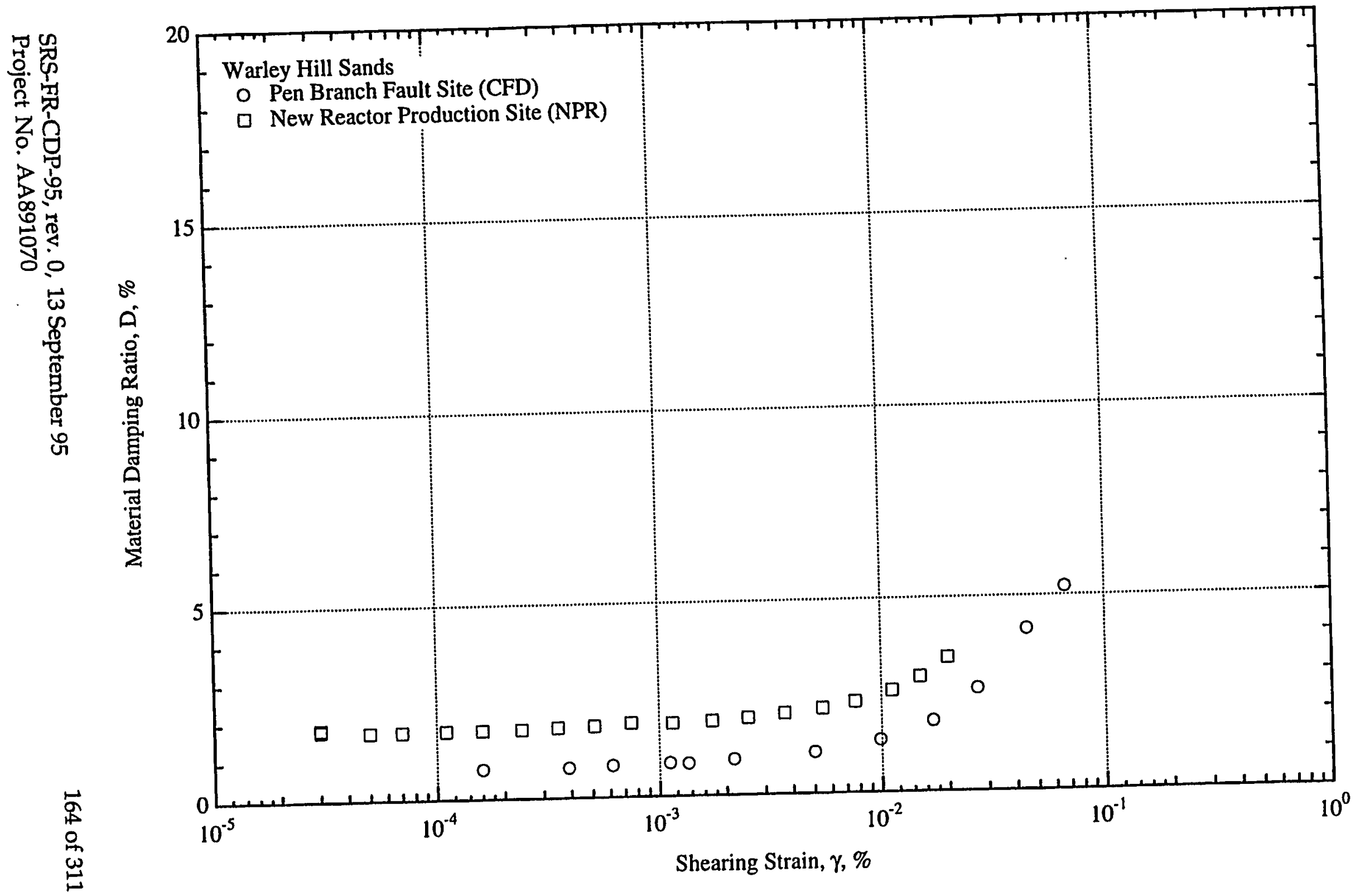

Fig. 104 Summary Plot of All D - $\log \gamma$ Relationships Determined by Resonant Column Testing with the Specimens Confined At or Near the In-Situ Mean Effective Stress for the Warley Hill Sands 


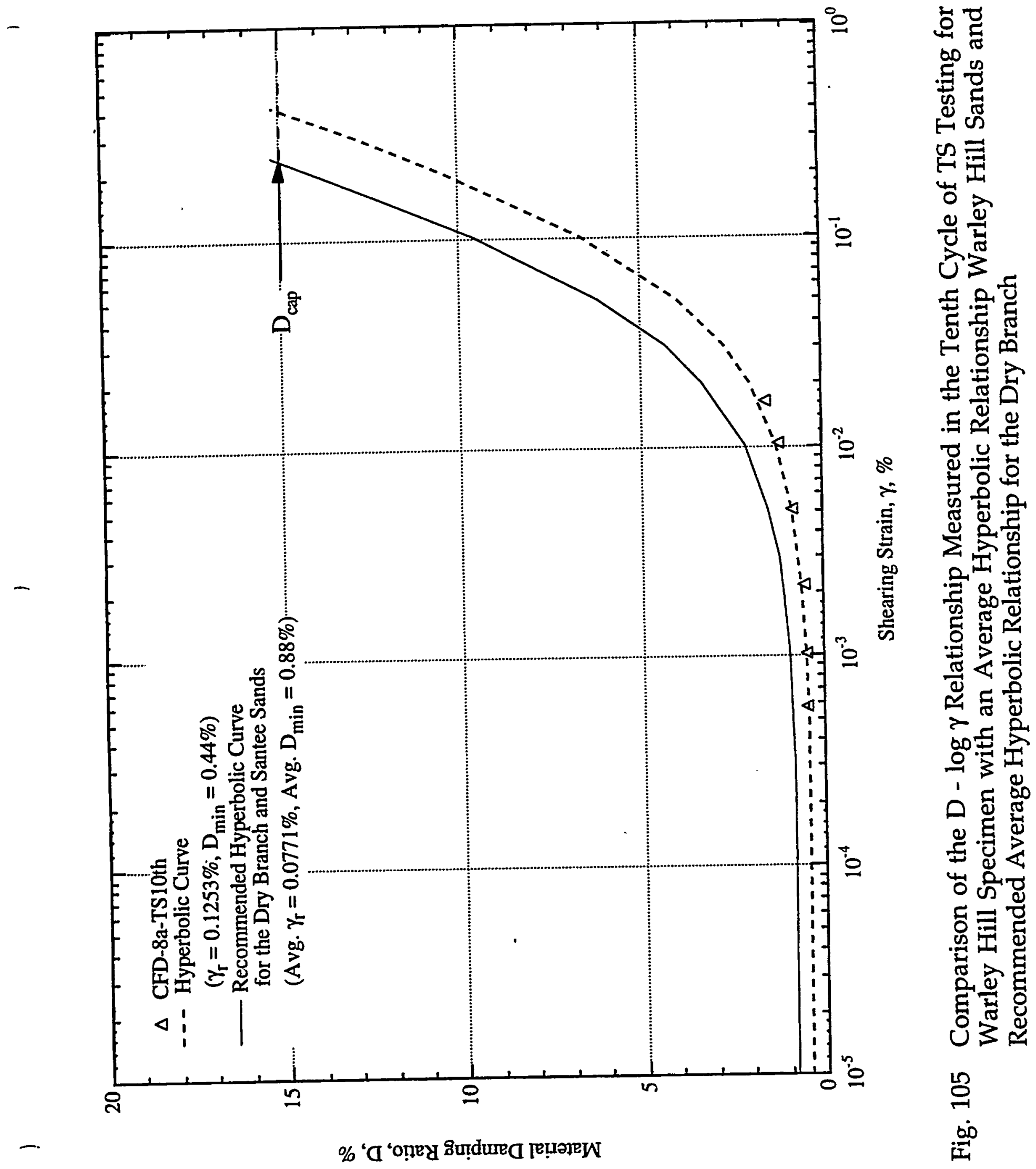

SRS-FR-CDP-95, rev. 0, 13 September 95 


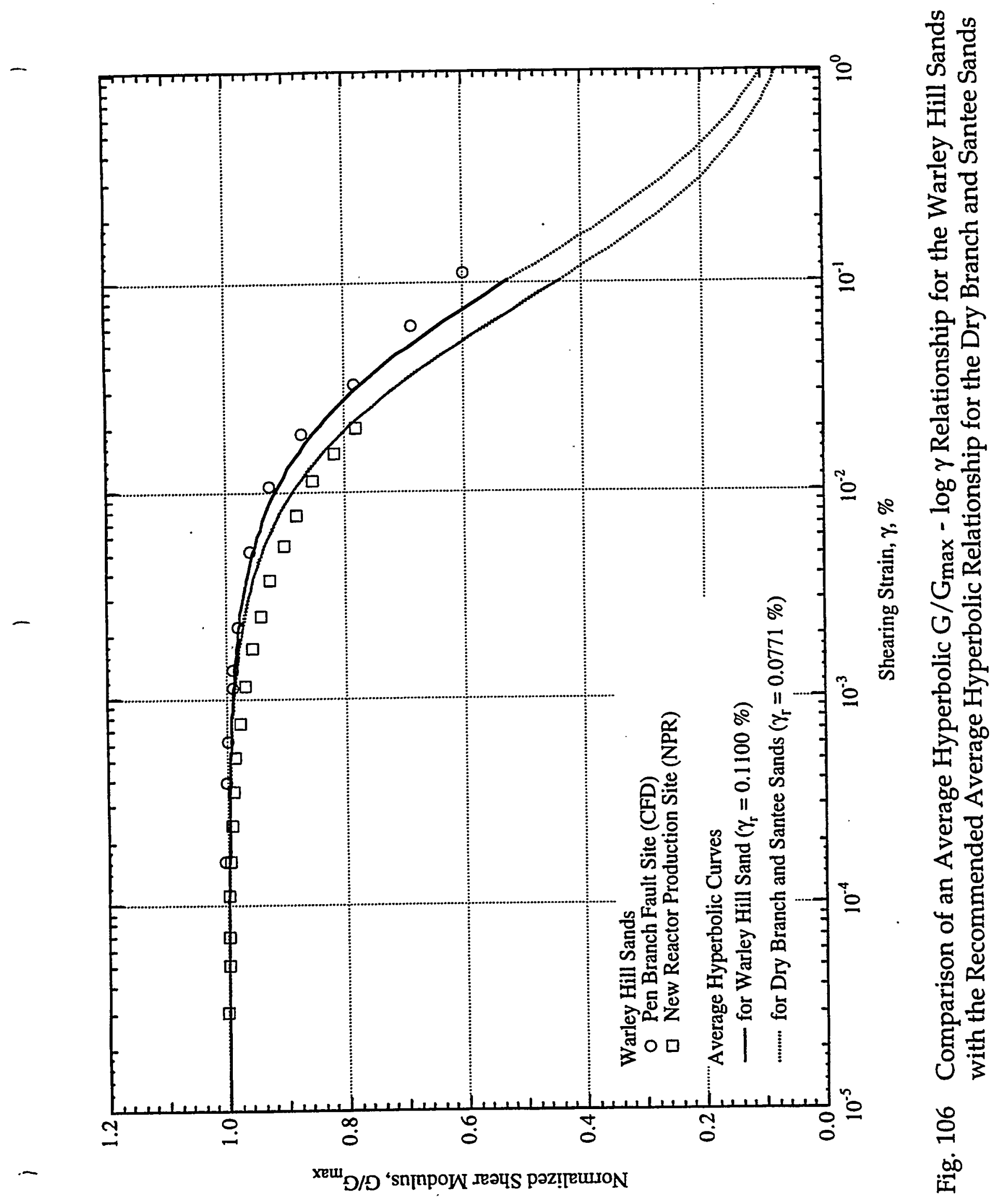

SRS-FR-CDP-95, rev. 0, 13 September 95 


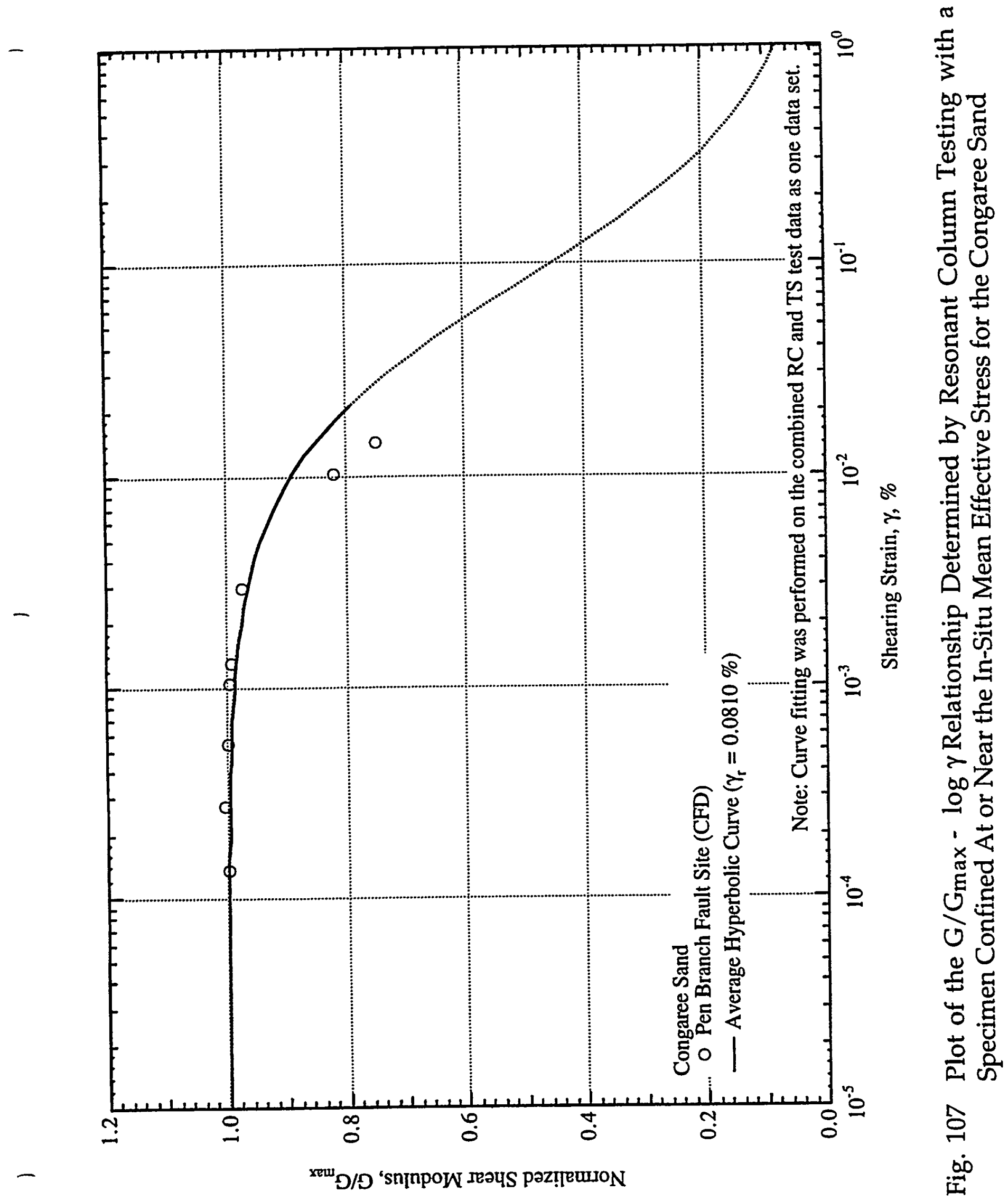

SRS-FR-CDP-95, rev. 0, 13 September 95

167 of 311

Project No. AA891070 


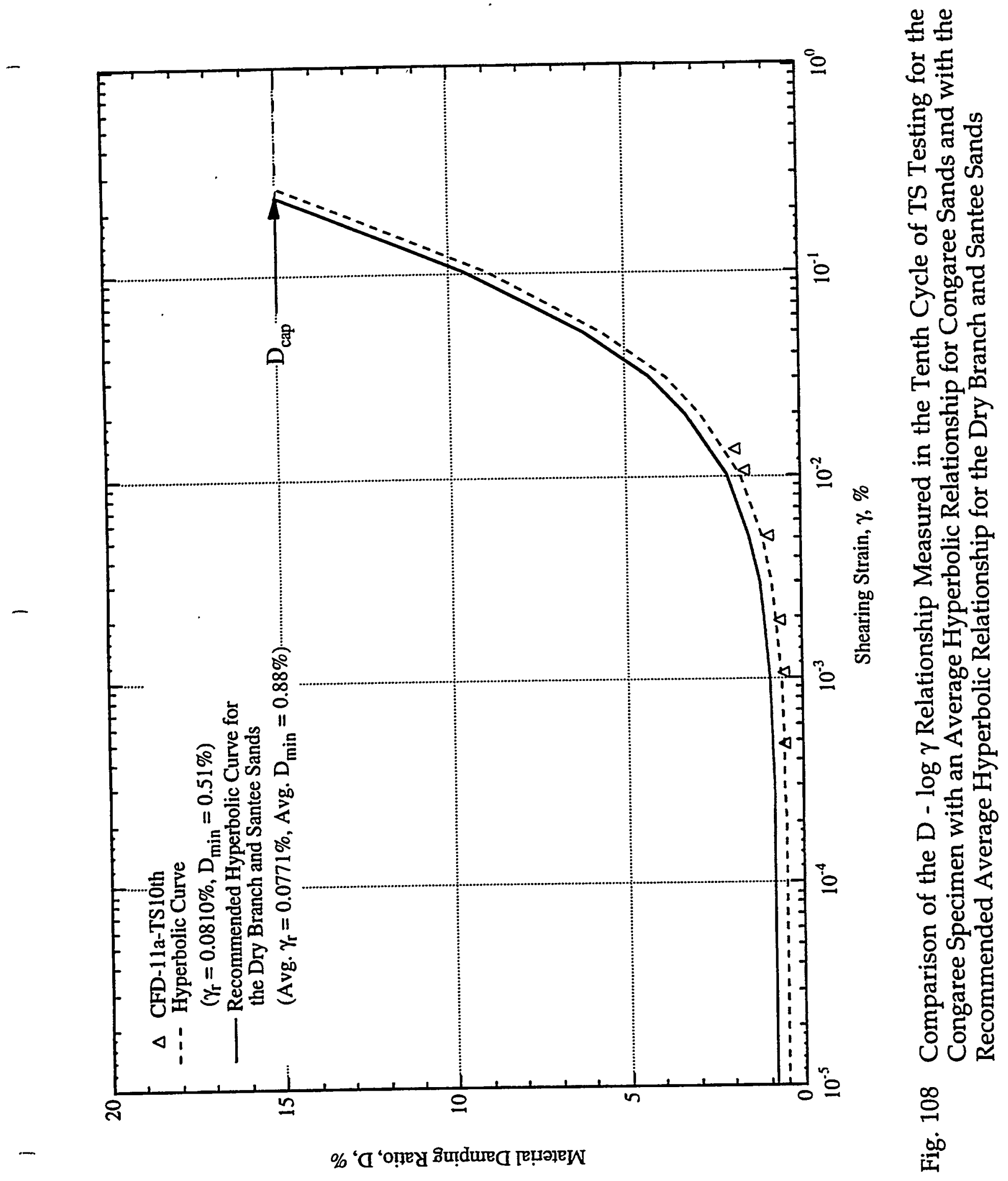

SRS-FR-CDP-95, rev. 0, 13 September 95 


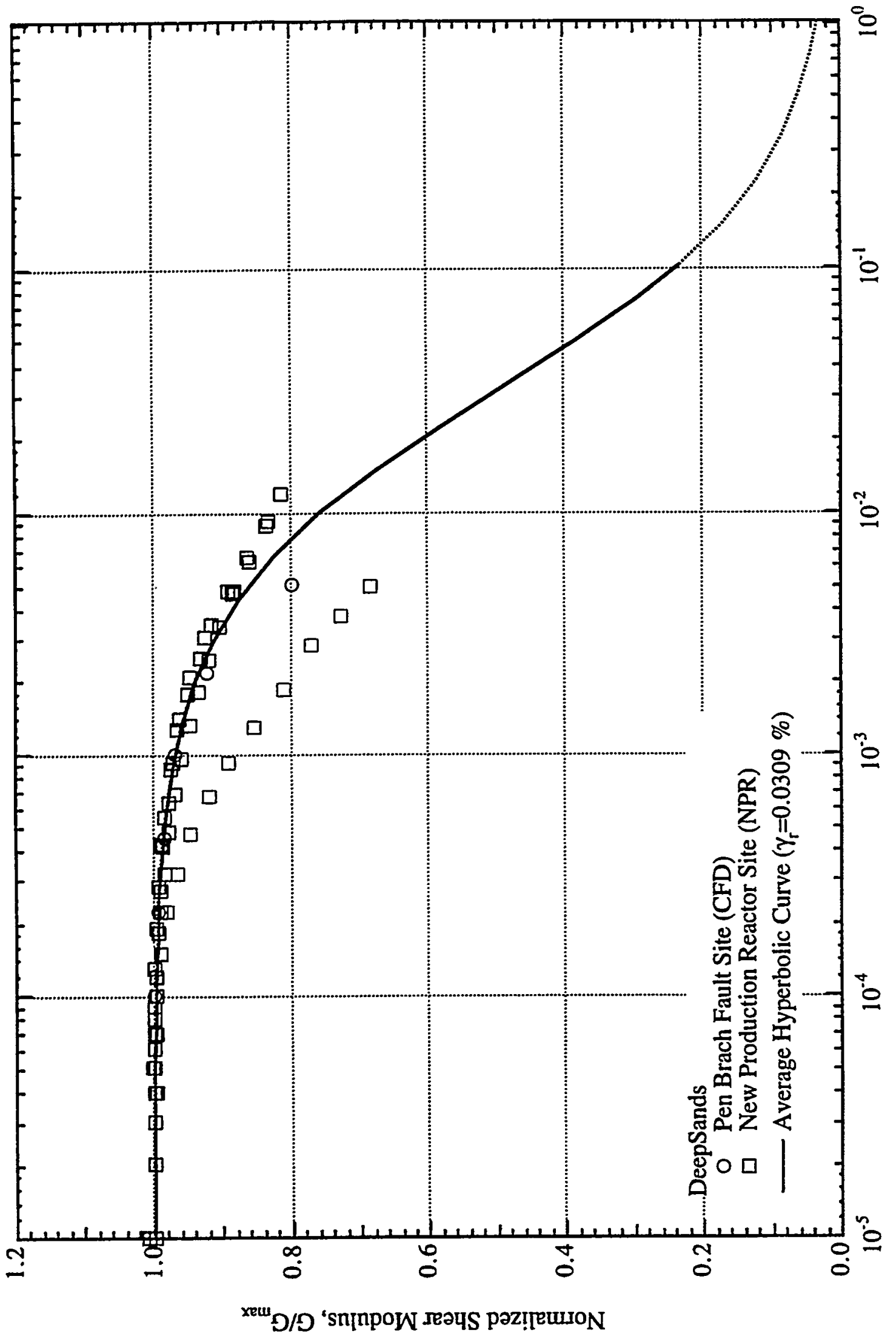

䄵

0

责

造

용

Чळ

공

훙

.

톤

क

Q

?

- क्ष

$\approx \quad \frac{5}{5}$

产 苟 


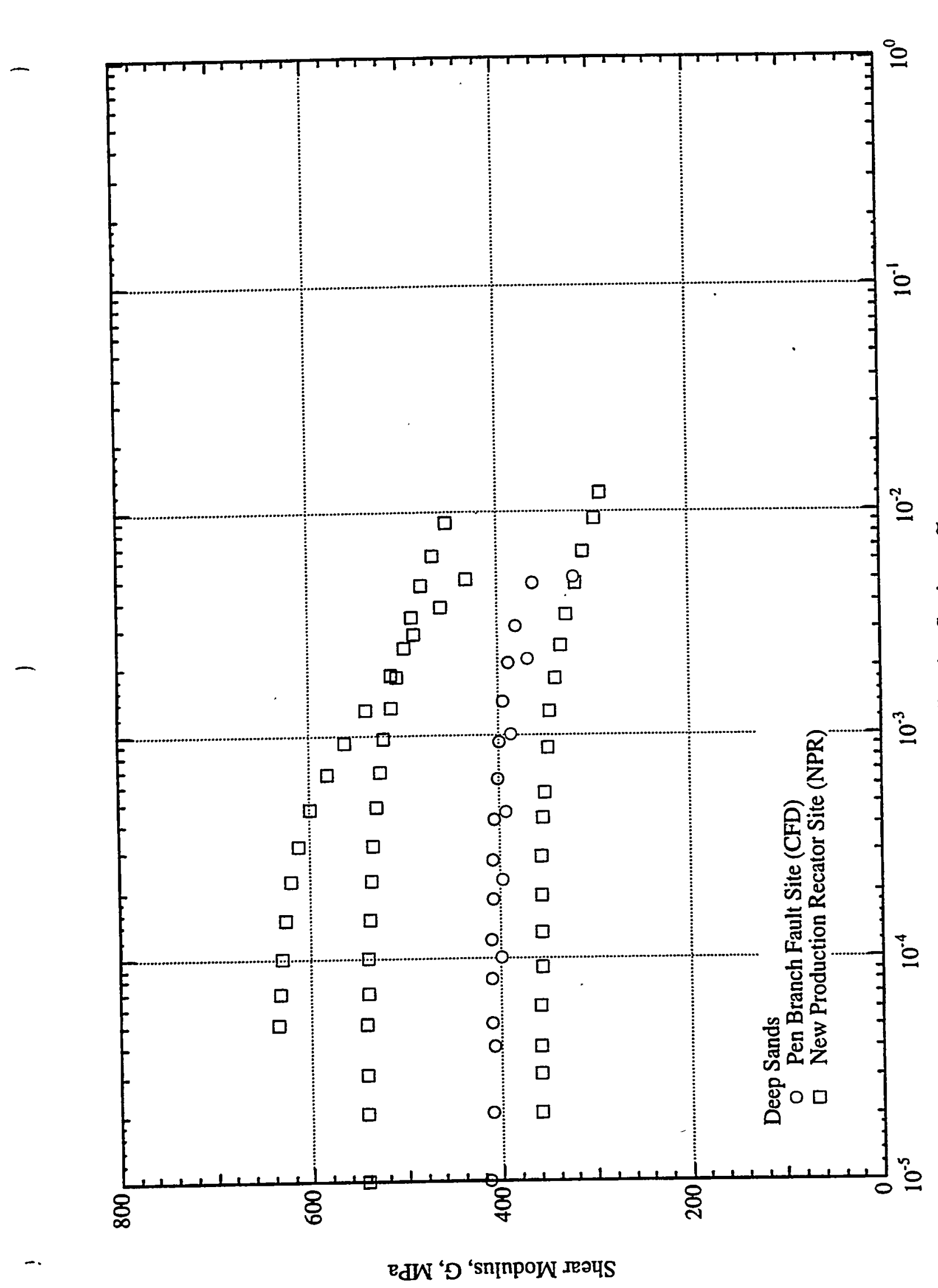

है

0

恶

(a)

es

ยै

๑

온

멍

范

E.

量

혼

屯ै

ค

.

ज点

등 I

奈

$2 \sum$

$>z$

0007

으

ن

娄

แू

范

A

ไี้

E.

点芯

$\stackrel{9}{=}$

道

SRS-FR-CDP-95, rev. 0, 13 September 95

Project No. AA891070 


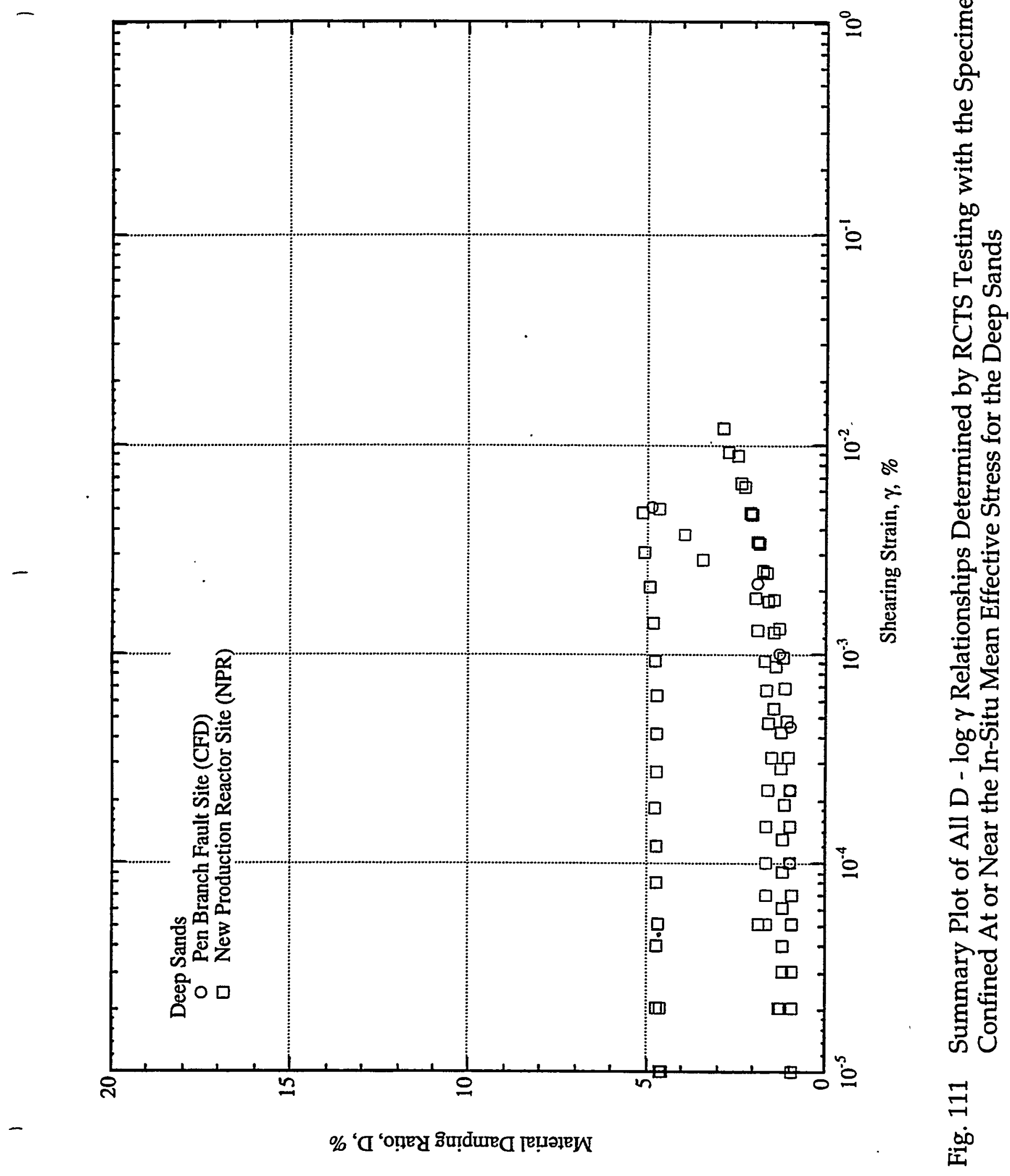

SRS-FR-CDP-95, rev. 0, 13 September 95

171 of 311

Project No. AA891070 


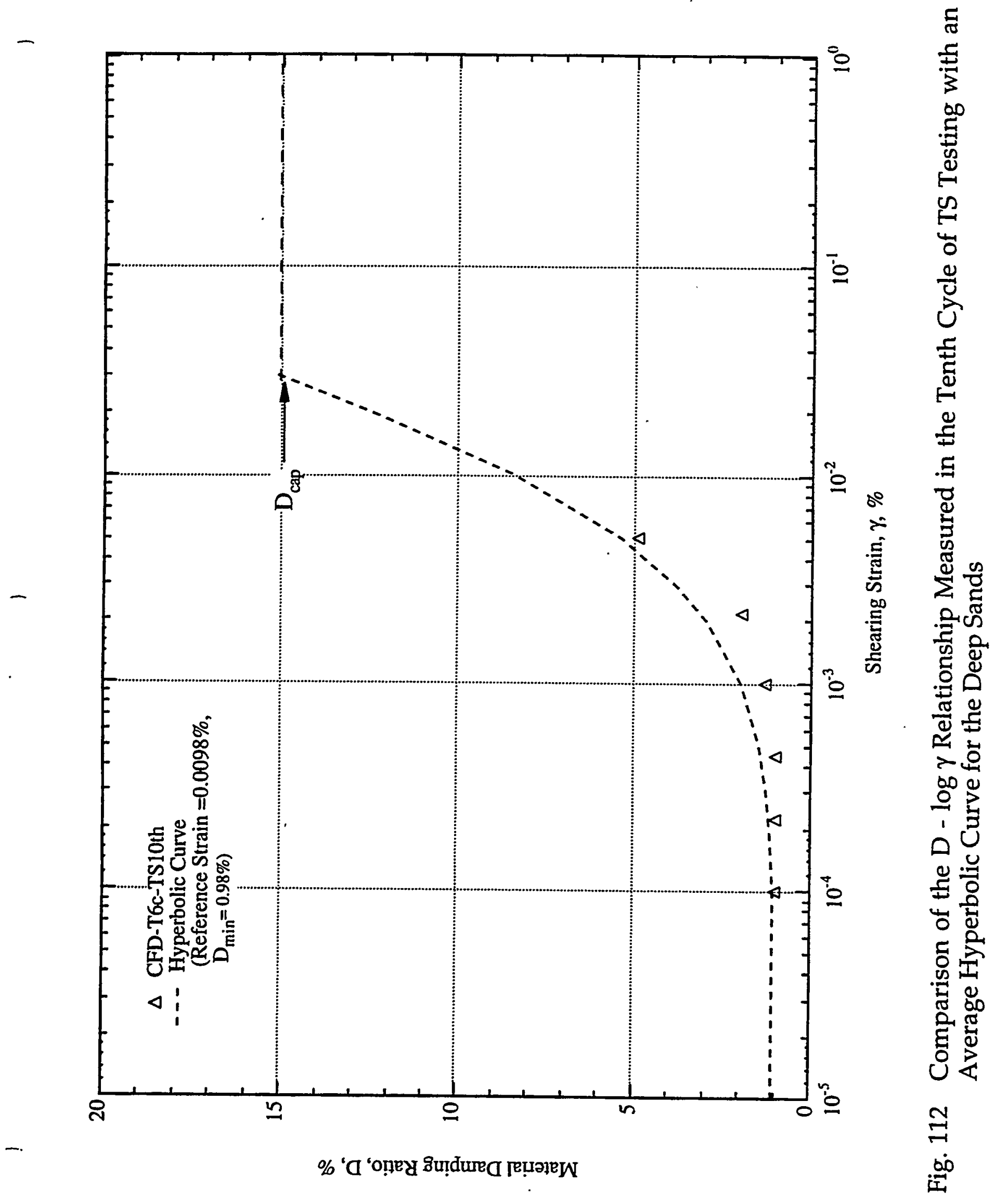

SRS-FR-CDP-95, rev. 0, 13 September 95

172 of 311

Project No. AA891070 


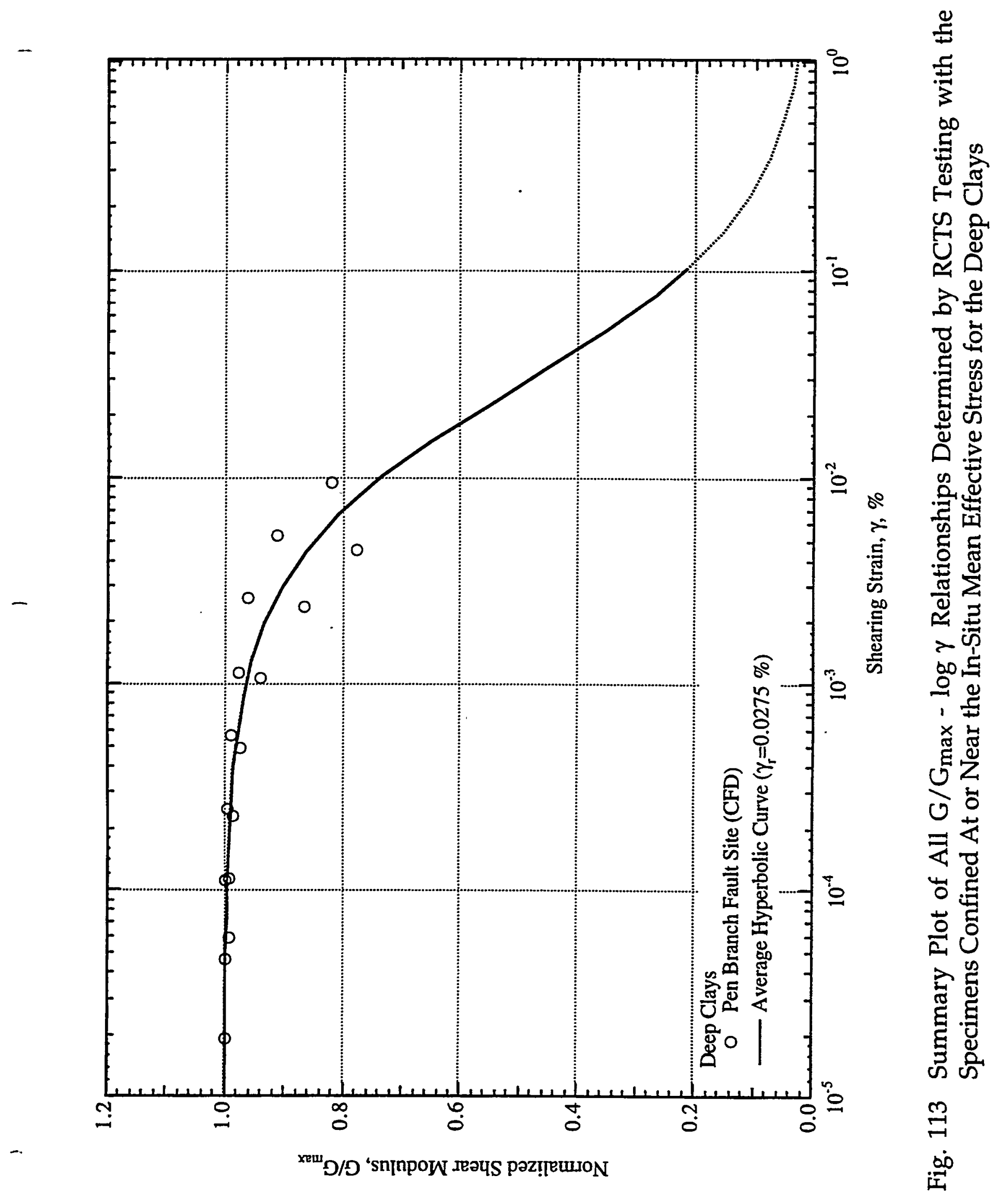

SRS-FR-CDP-95, rev. 0, 13 September 95 


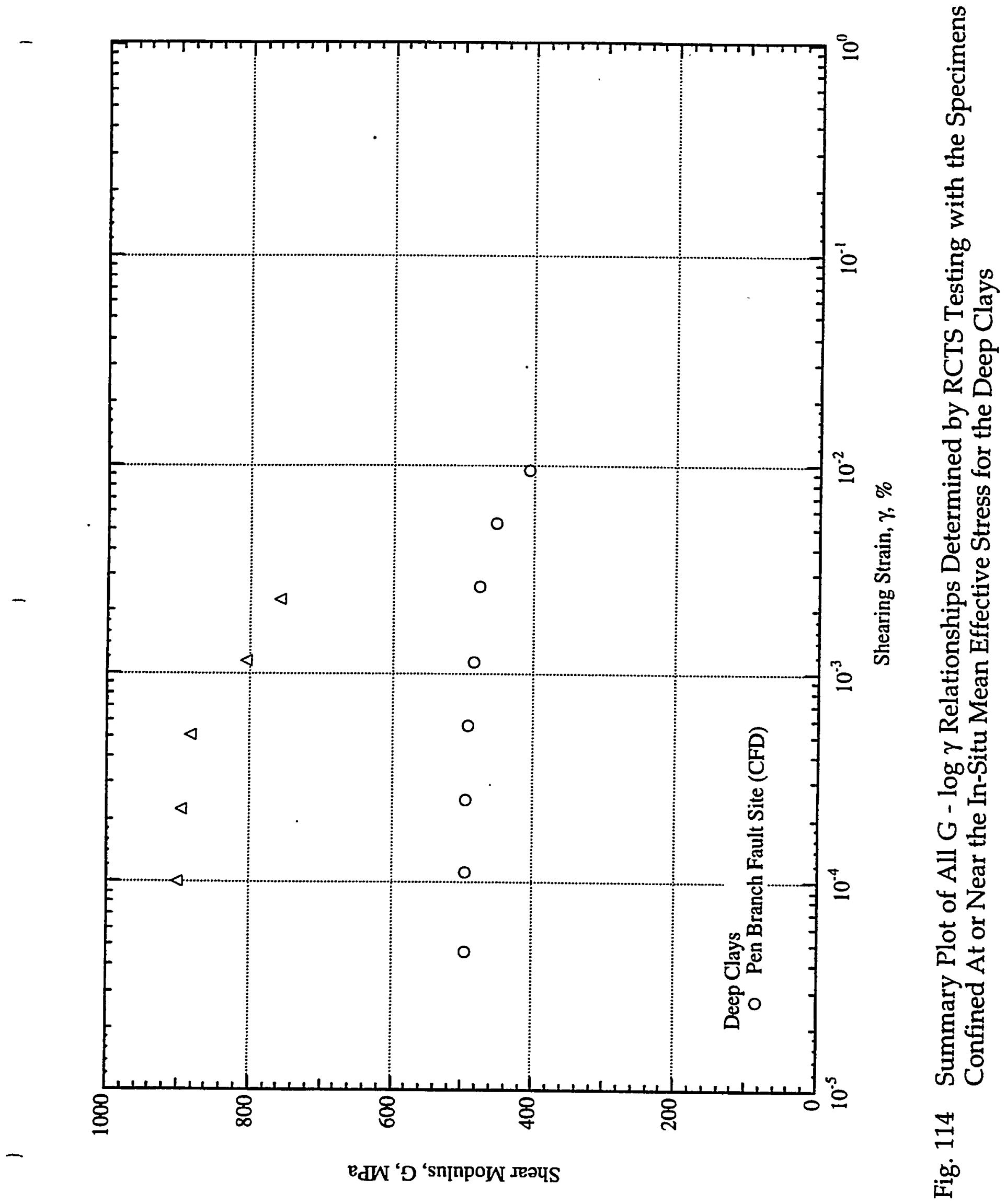

SRS-FR-CDP-95, rev. 0, 13 September 95

Project No. AA891070 


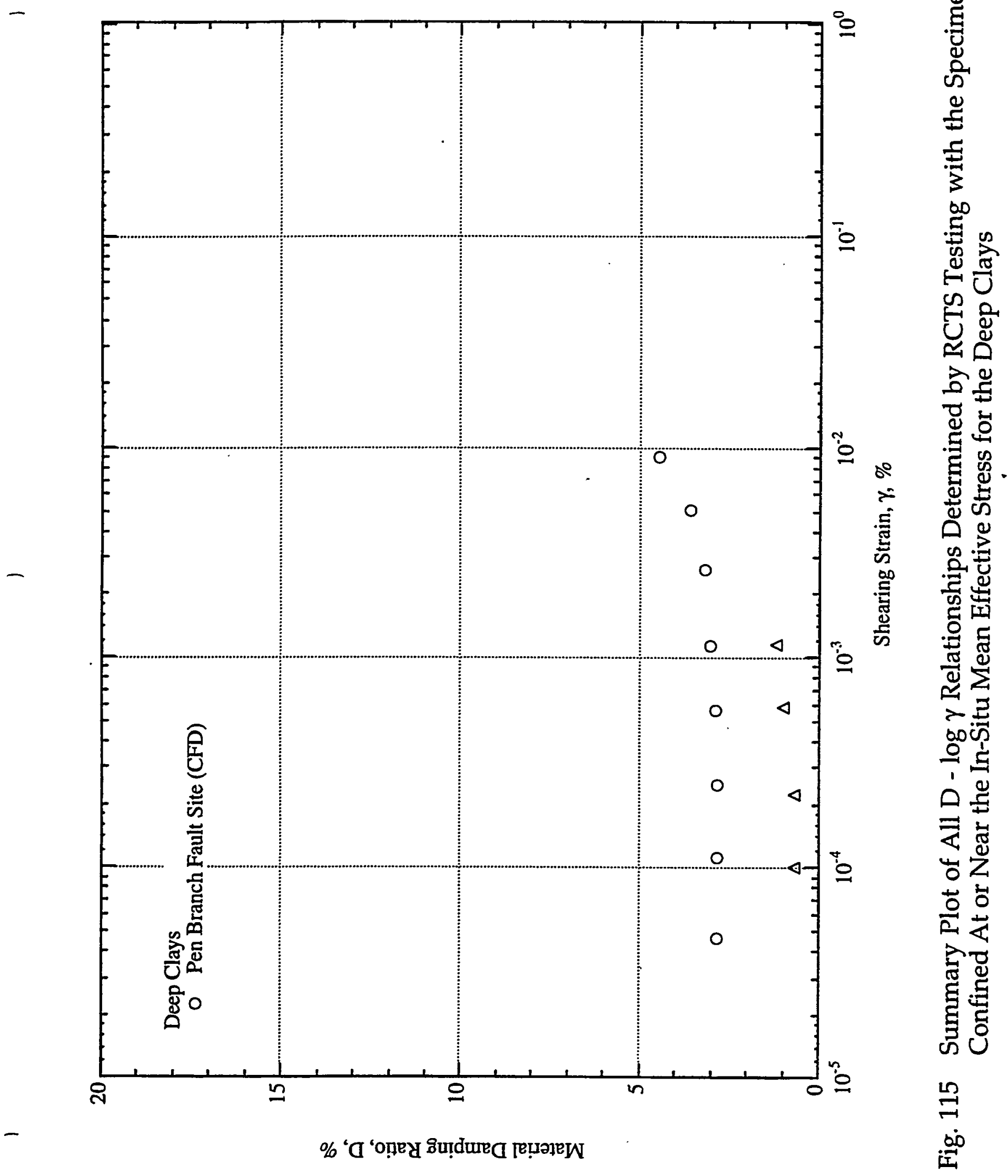

SRS-FR-CDP-95, rev. 0, 13 September 95 


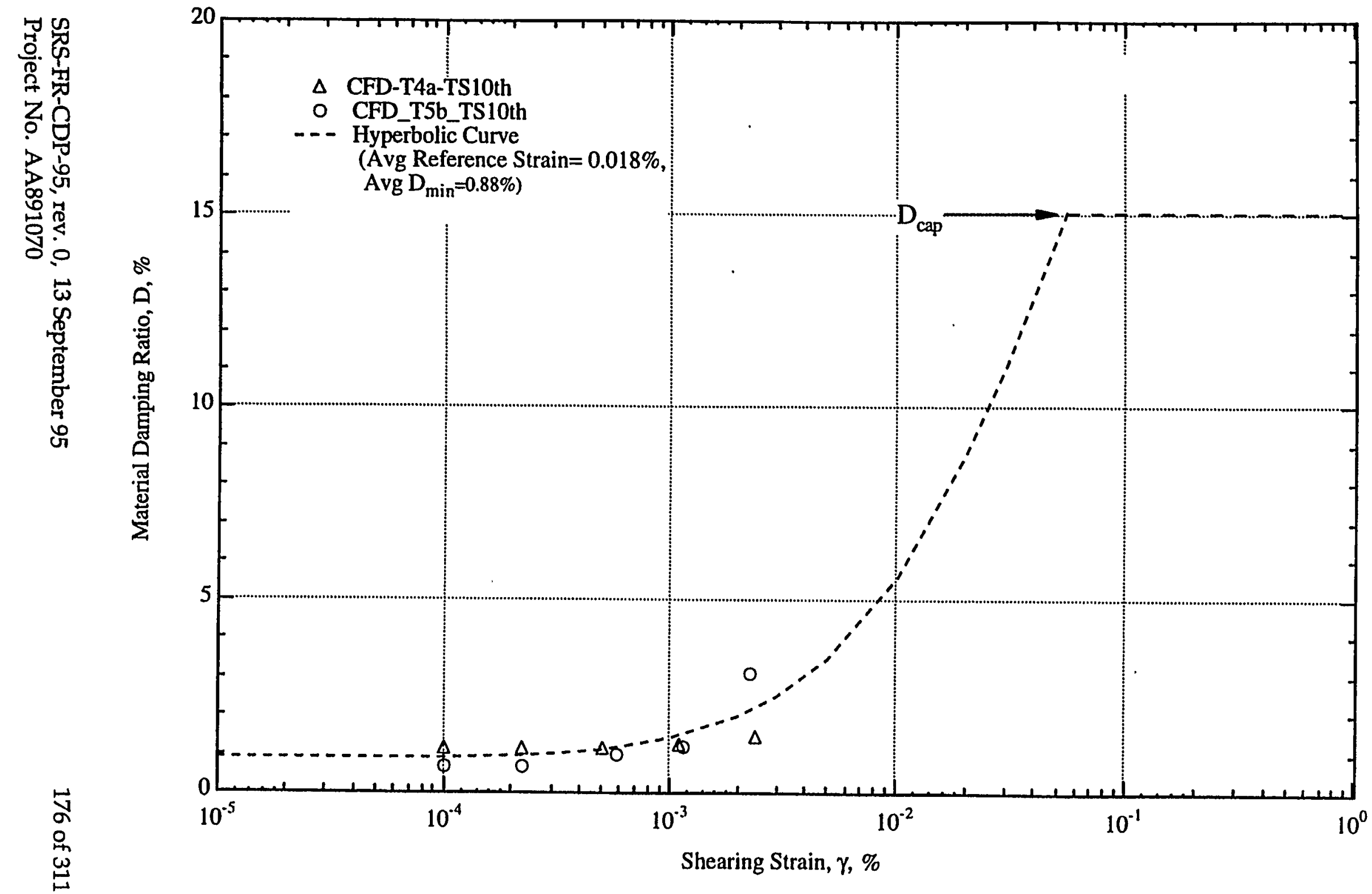

Fig. 116 Comparison of the D - $\log \gamma$ Relationships Measured in the Tenth Cycle of TS Testing with an Average Hyperbolic Curve for the Deep Clays 


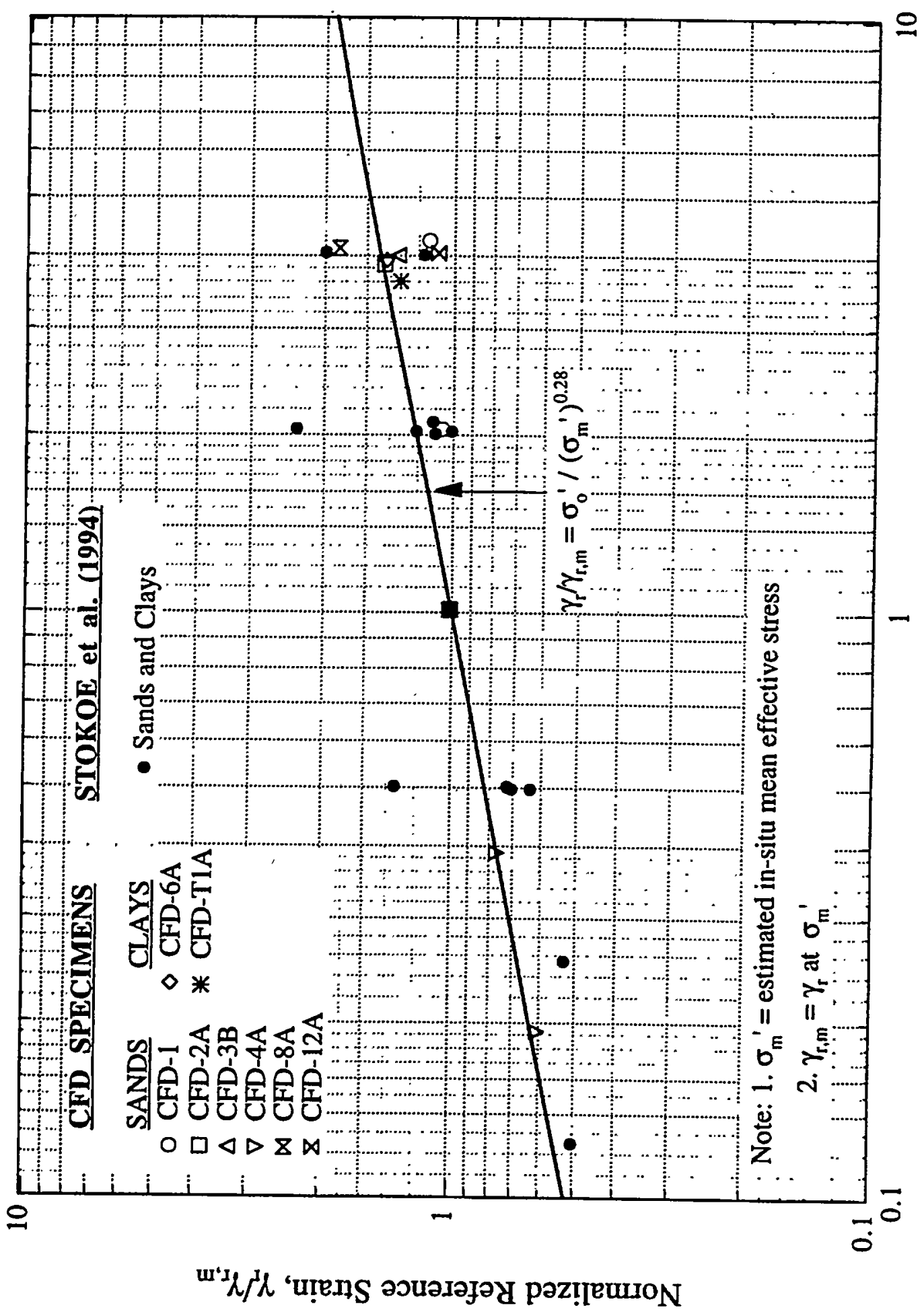

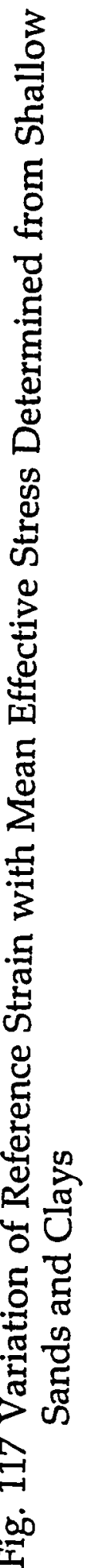




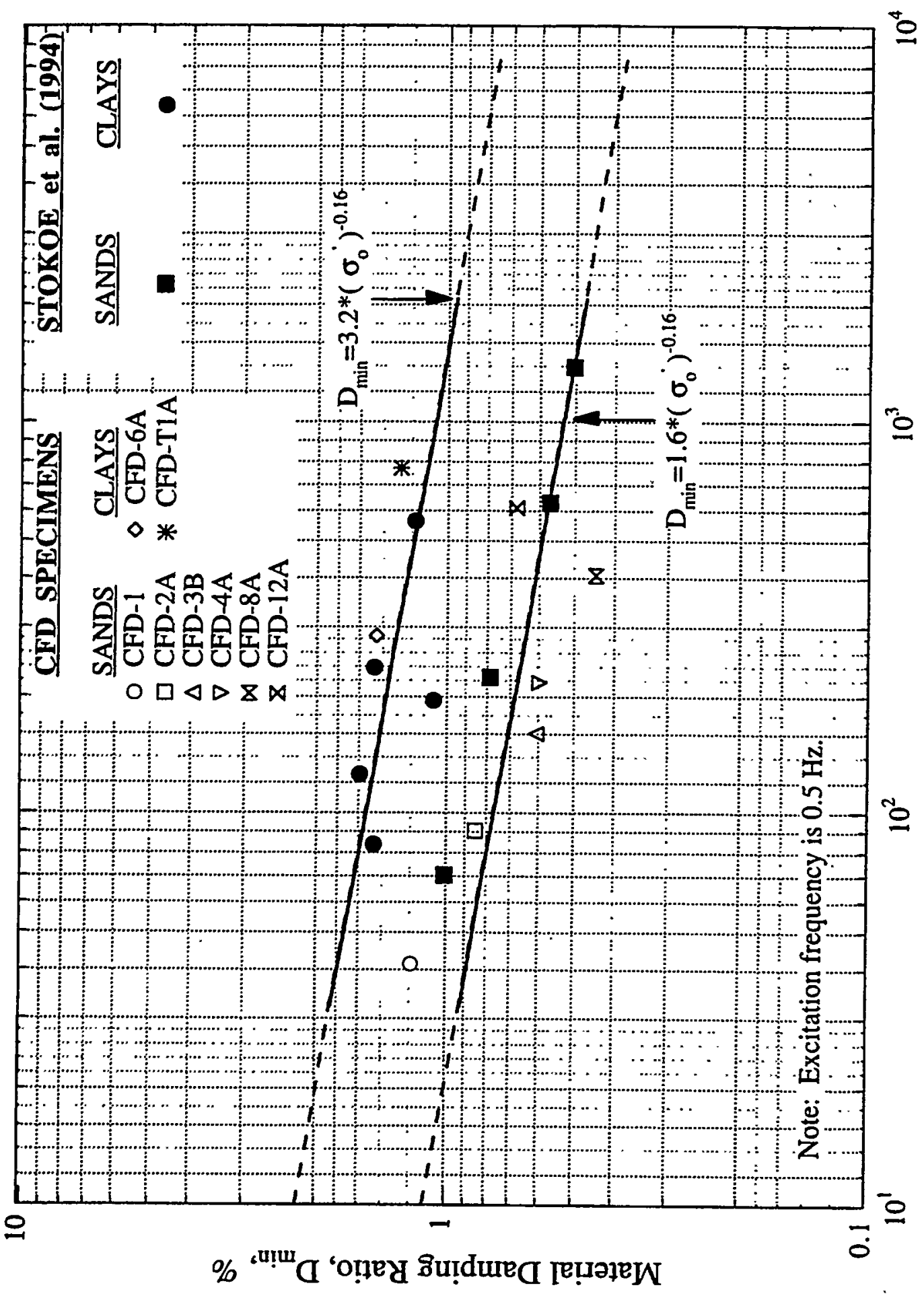

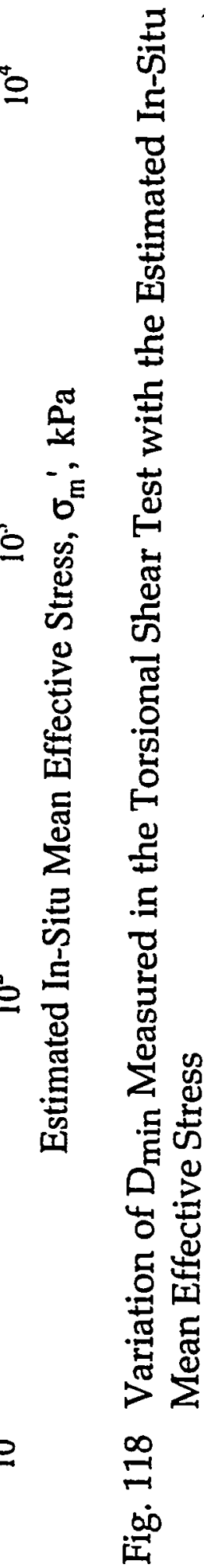

SRS-FR-CDP-95, rev. 0, 13 September 95

178 of 311

Project No. AA891070 

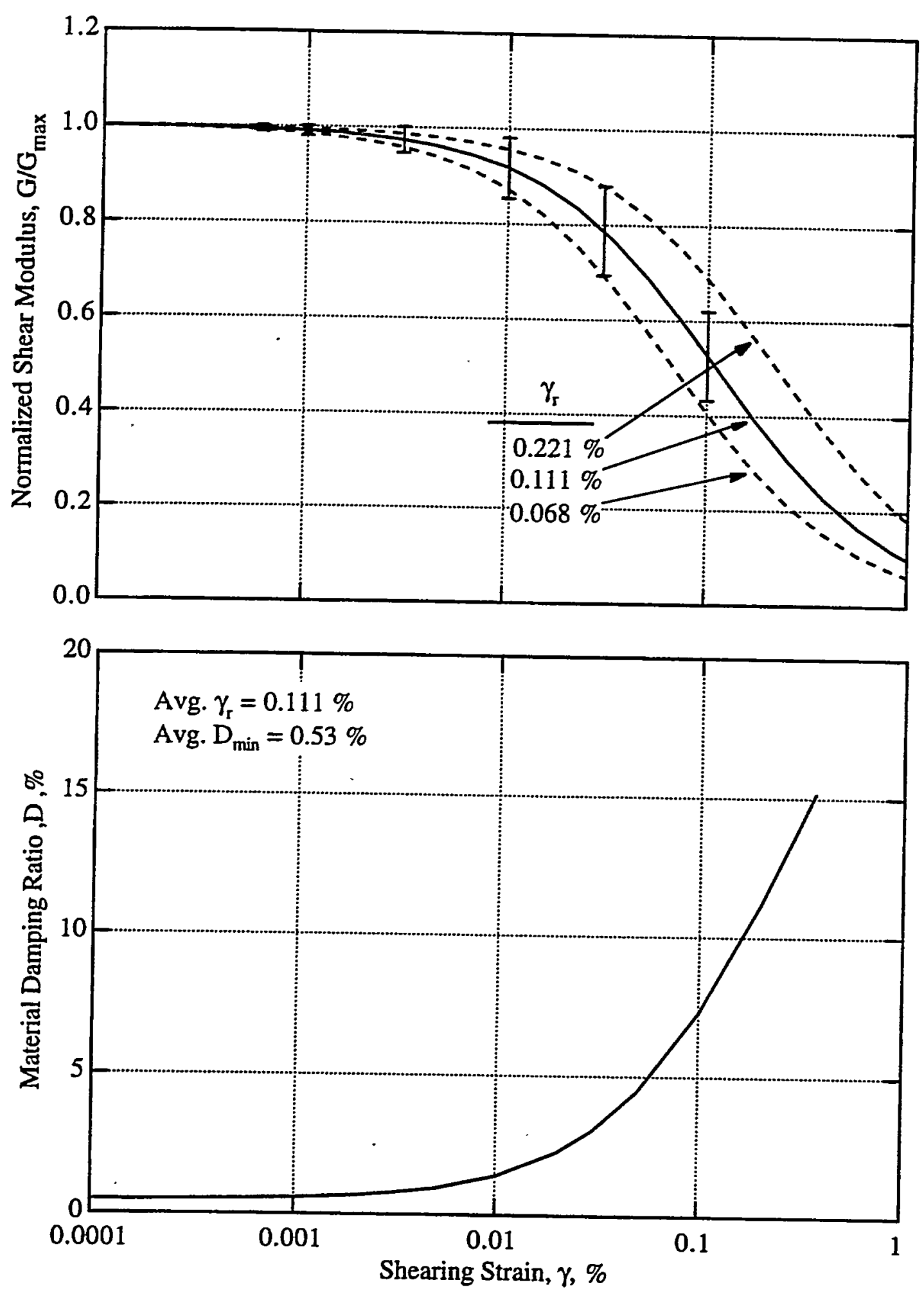

Fig. 119 Predicted G/Gmax $-\log \gamma$ and D - $\log \gamma$ Relationships for Deep Sands at a Depth of $750 \mathrm{ft}(228.6 \mathrm{~m})$ by Extrapolating the Shallow Sands Correction 


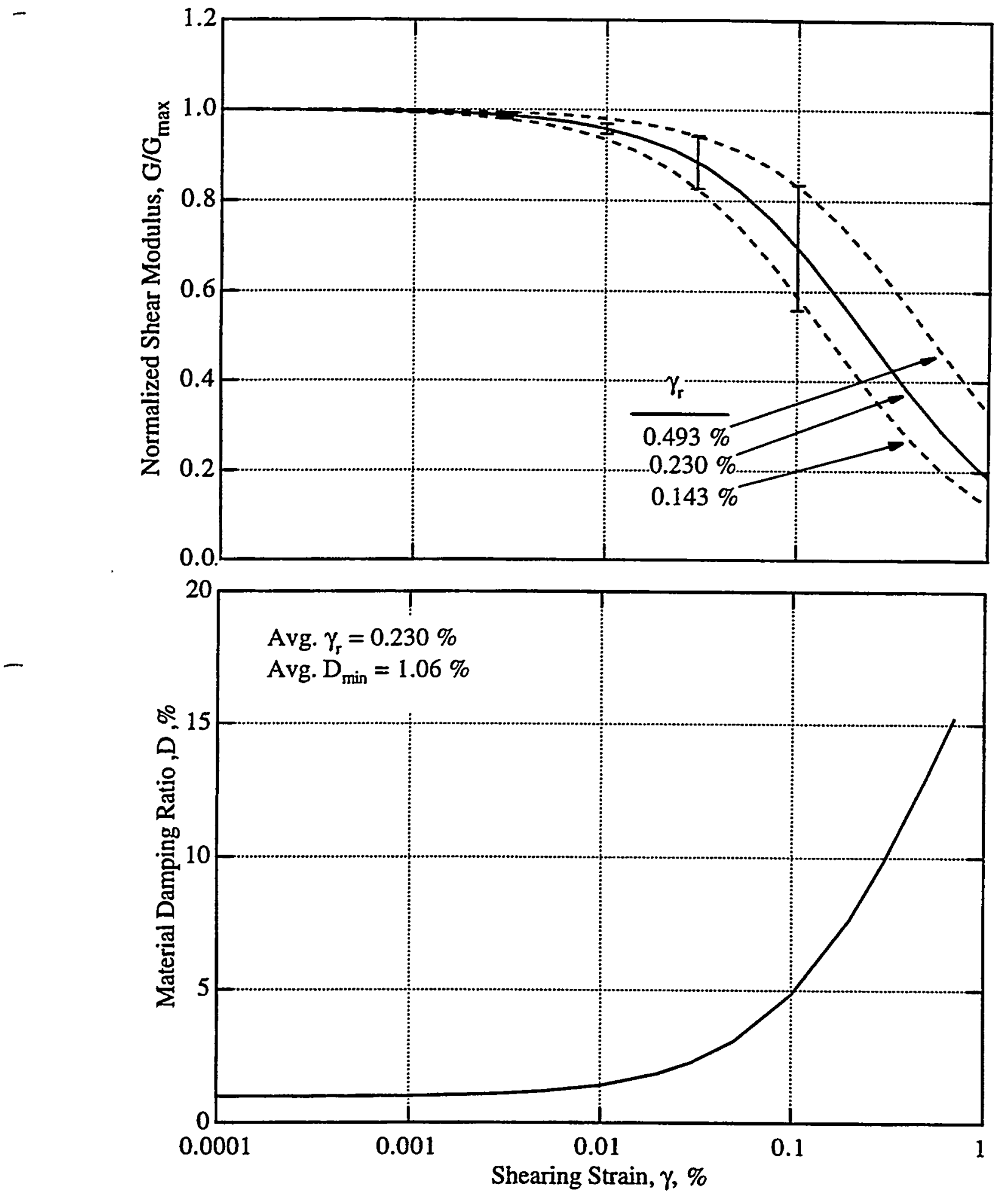

Fig. 120 Predicted G/ $G_{\max }-\log \gamma$ and D - $\log \gamma$ Relationships for Deep Clays at a Depth of $750 \mathrm{ft}(228.6 \mathrm{~m})$ by Extrapolating the Shallow Clays Correction

SRS-FR-CDP-95, rev. 0, 13 September 95 

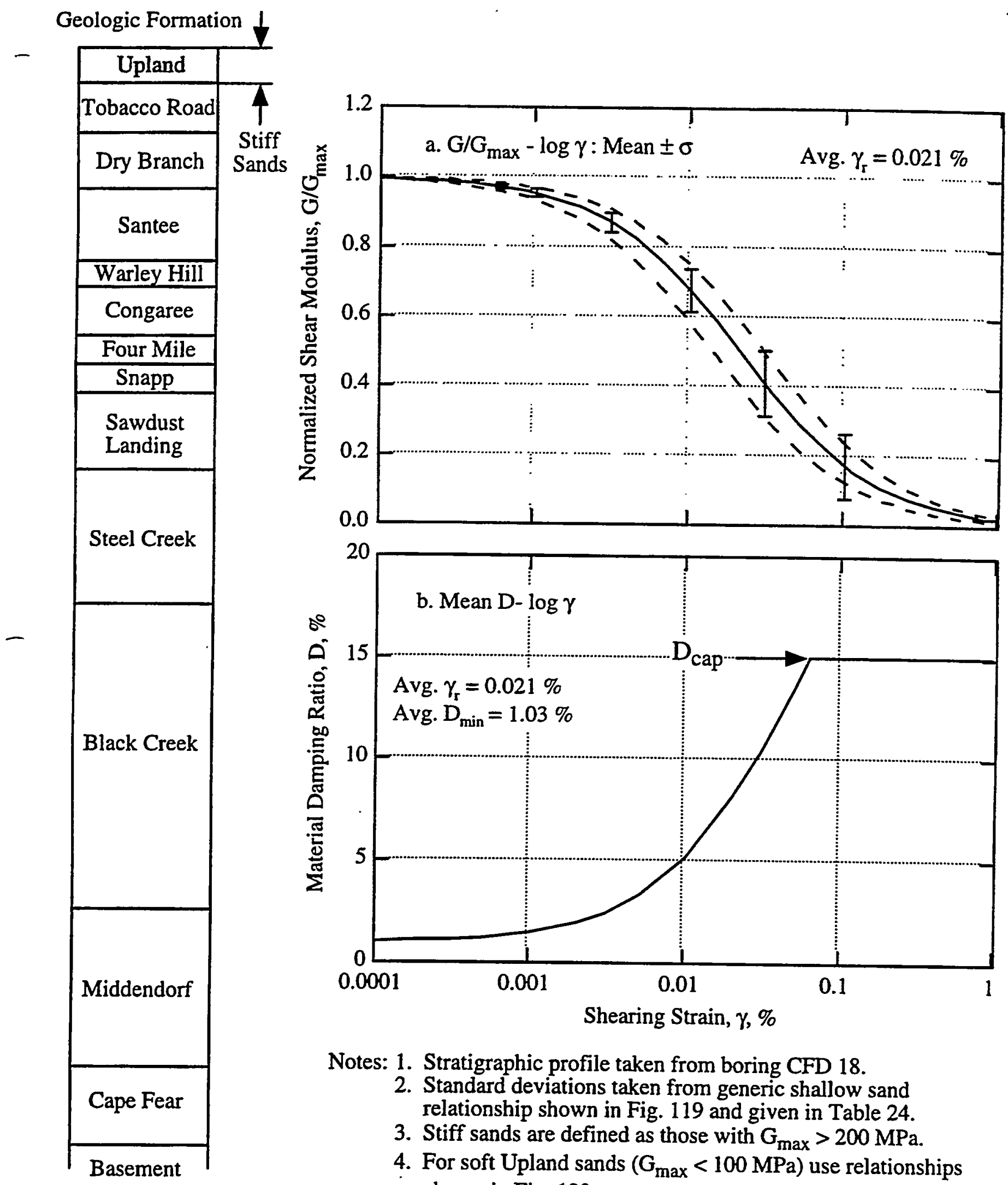

Notes: 1. Stratigraphic profile taken from boring CFD 18.

2. Standard deviations taken from generic shallow sand relationship shown in Fig. 119 and given in Table 24.

3. Stiff sands are defined as those with $G_{\max }>200 \mathrm{MPa}$.

4. For soft Upland sands $\left(G_{\max }<100 \mathrm{MPa}\right)$ use relationships shown in Fig. 123.

5. Values of $D$ evaluated at $f \leq 1 \mathrm{~Hz}$.

Fig. 121 Recommended Generic G/Gmax $-\log \gamma$ and D - log $\gamma$ Relationships for Stiff Upland Sands at SRS

SRS-FR-CDP-95, rev. 0, 13 September 95

181 of 311

Project No. AA891070 
Geologic Formation

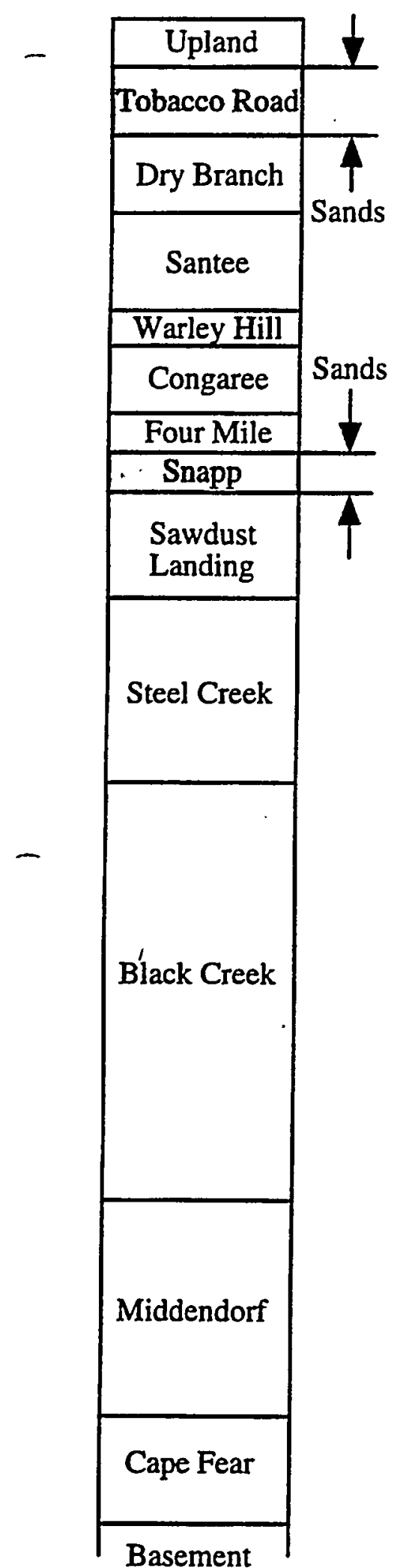
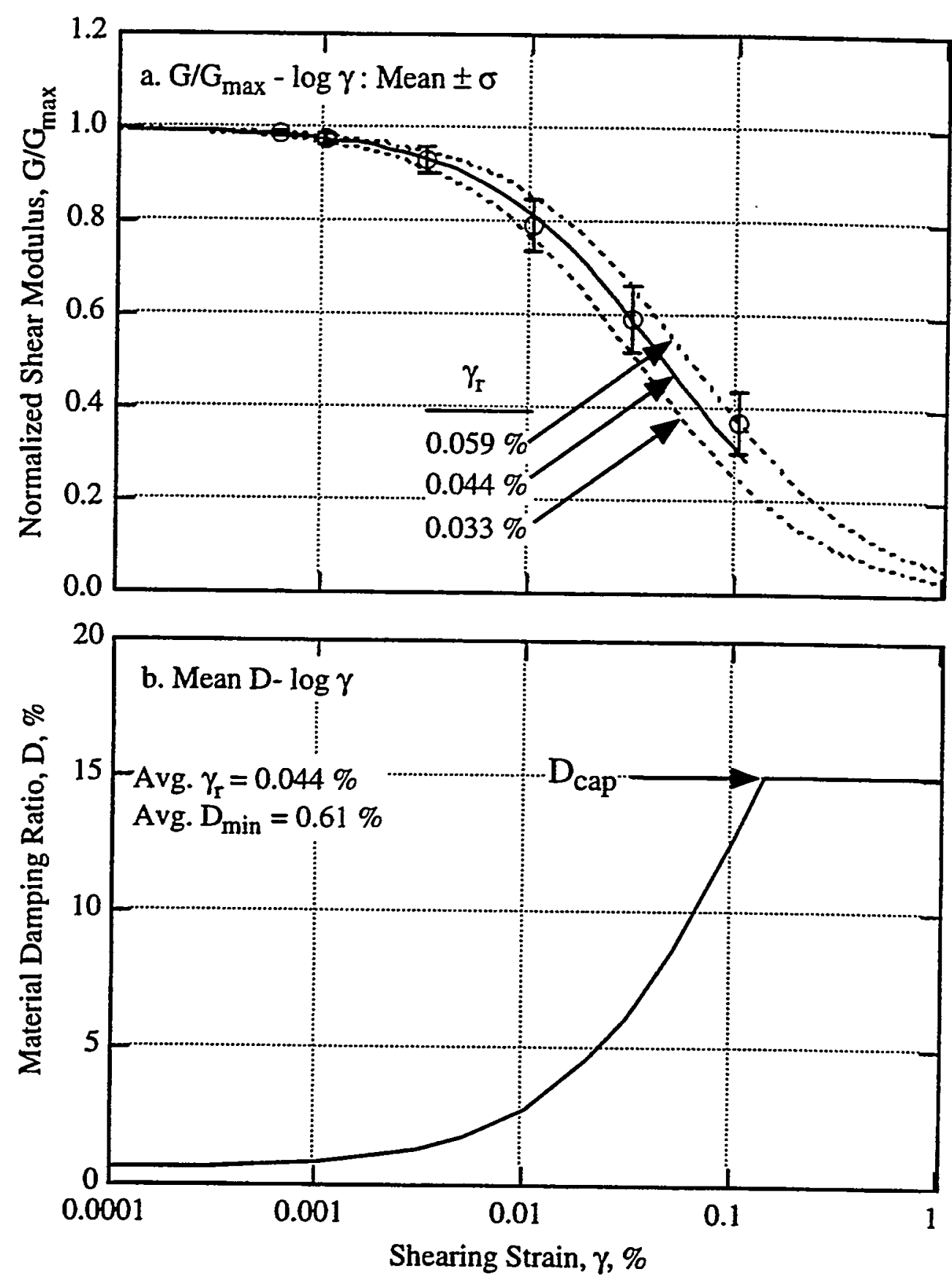

Notes: 1. Stratigraphic profile taken from boring CFD 18.

2. Statistics associated with $\mathrm{G} / \mathrm{G}_{\max }-\log \gamma$ relationship are given in Table 15.

3. Values of $D$ evaluated at $f \leq 1 \mathrm{~Hz}$.

Fig. 122 Recommended Generic G/Gmax - log $\gamma$ and D - log $\gamma$ Relationships for Tobacco Road and Snapp Sands at SRS 


\begin{tabular}{|c|}
\hline Upland \\
\hline Tobacco Road \\
\hline Dry Branch \\
\hline Santee \\
\hline Sarley Hill \\
\hline Congaree \\
\hline Four Mile \\
\hline Sapp \\
\hline Landing \\
\hline Bast \\
\hline Biddendorf \\
\hline
\end{tabular}
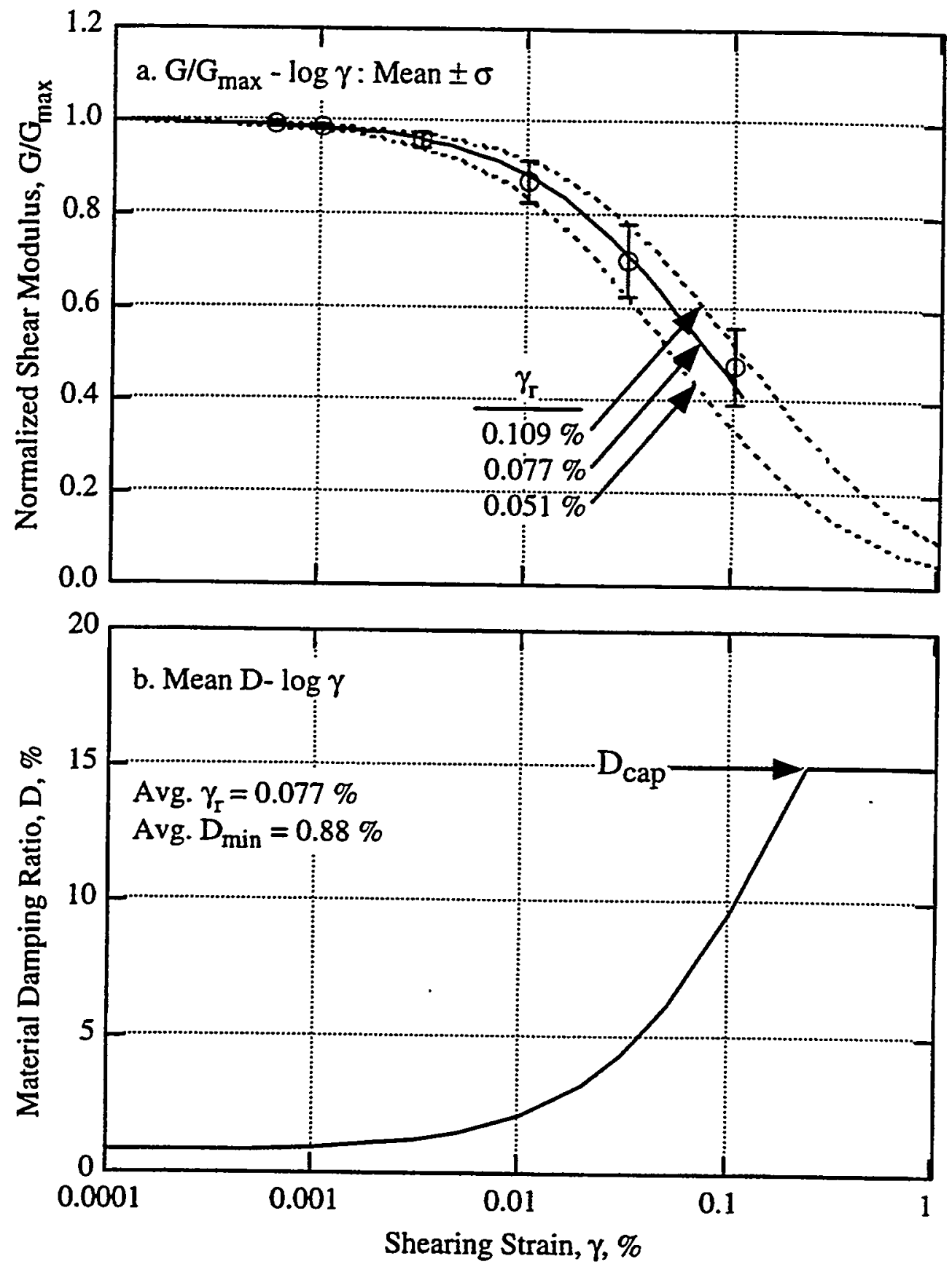

Notes: 1. Stratigraphic profile taken from boring CFD 18.

2. These relationships are also proposed for use with soft $\left(G_{\max }<100 \mathrm{MPa}\right.$ ) Upland sands.

3. Statistics associated with $G / G_{\max }-\log \gamma$ relationship are given in Table 12.

4. Values of $D$ evaluated at $f \leq 1 \mathrm{~Hz}$.

Fig. 123 Recommended Generic G/G $\max -\log \gamma$ and D - log $\gamma$ Relationships for Dry Branch, Santee, Warlev Hill and Congaree Sands at SRS

SRS-FR-CDP-95, rev. 0, 13 September 95 
Geologic Formation

\begin{tabular}{|c|}
\hline Upland \\
\hline Tobacco Road \\
\hline Dry Branch \\
\hline Santee \\
\hline Warley Hill \\
\hline Congaree \\
\hline Four Mile \\
\hline Snapp \\
\hline Sawdust \\
\hline Landing \\
\hline Steel Creek \\
\hline Biddendorf \\
\hline
\end{tabular}
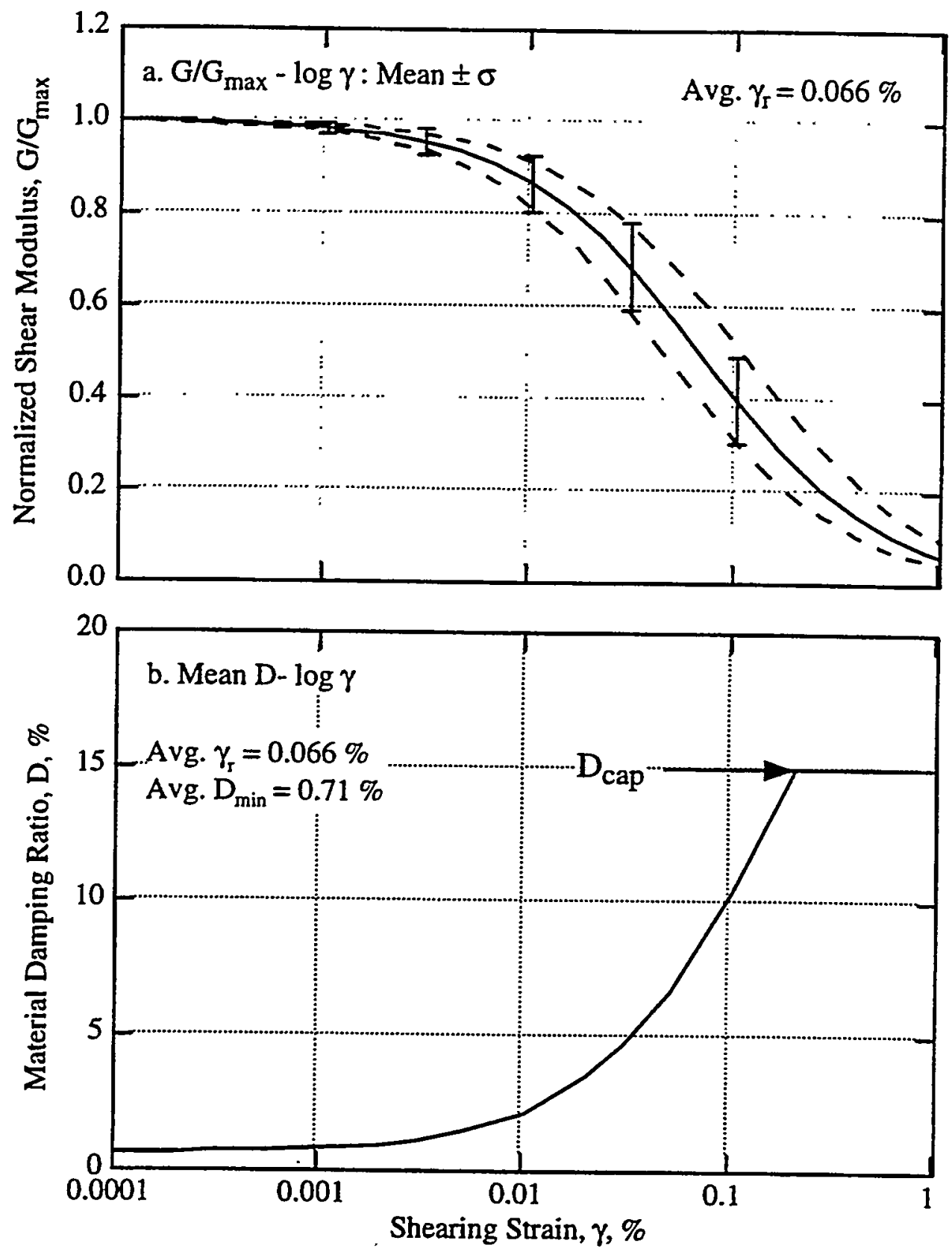

Notes: 1. Stratigraphic profile taken from boring CFD 18.

2. Average depth of "shallow" sand specimens is $116 \mathrm{ft}(35.4 \mathrm{~m})$.

3. Upland sands were not used in calculating these relationships.

4. Statistics associated with $\mathrm{G} / \mathrm{G}_{\max }-\log \gamma$ relationship are given in Table 24.

5. Relationships should not be used for sands with a significant amount of cementation.

6. Values of D evaluated at $\mathrm{f} \leq 1 \mathrm{~Hz}$.

- Fig. 124 Recommended Generic G/Gmax - $\log \gamma$ and D - $\log \gamma$ Relationships for Four Mile Sands and Any Other Unrepresented Shallow Sand Formation at SRS

SRS-FR-CDP-95, rev. 0, 13 September 95

184 of 311

Project No. AA891070 
Geologic Formation

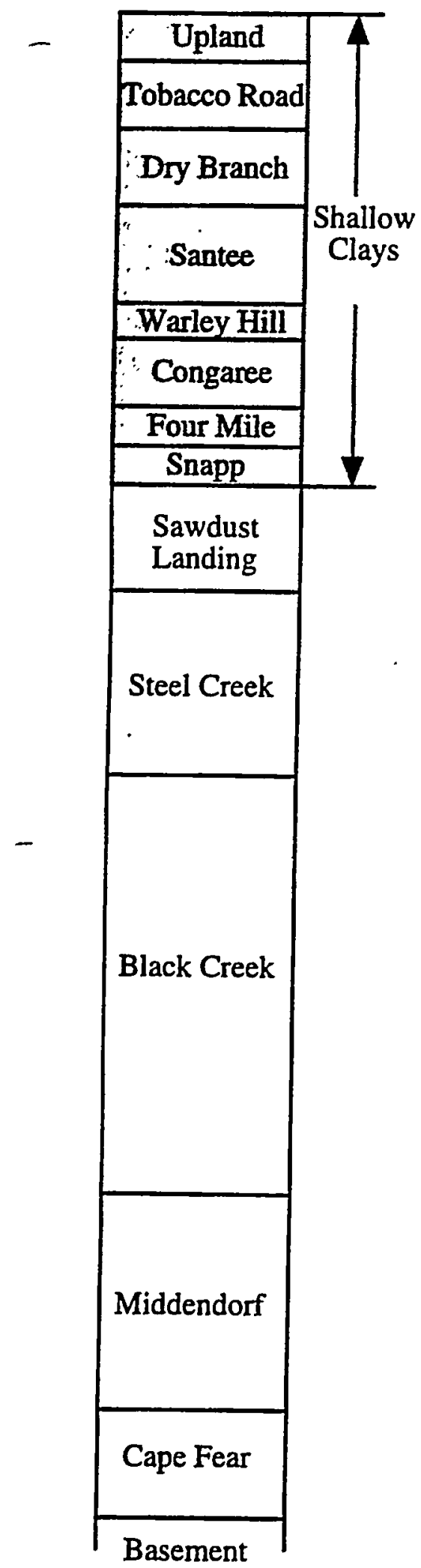
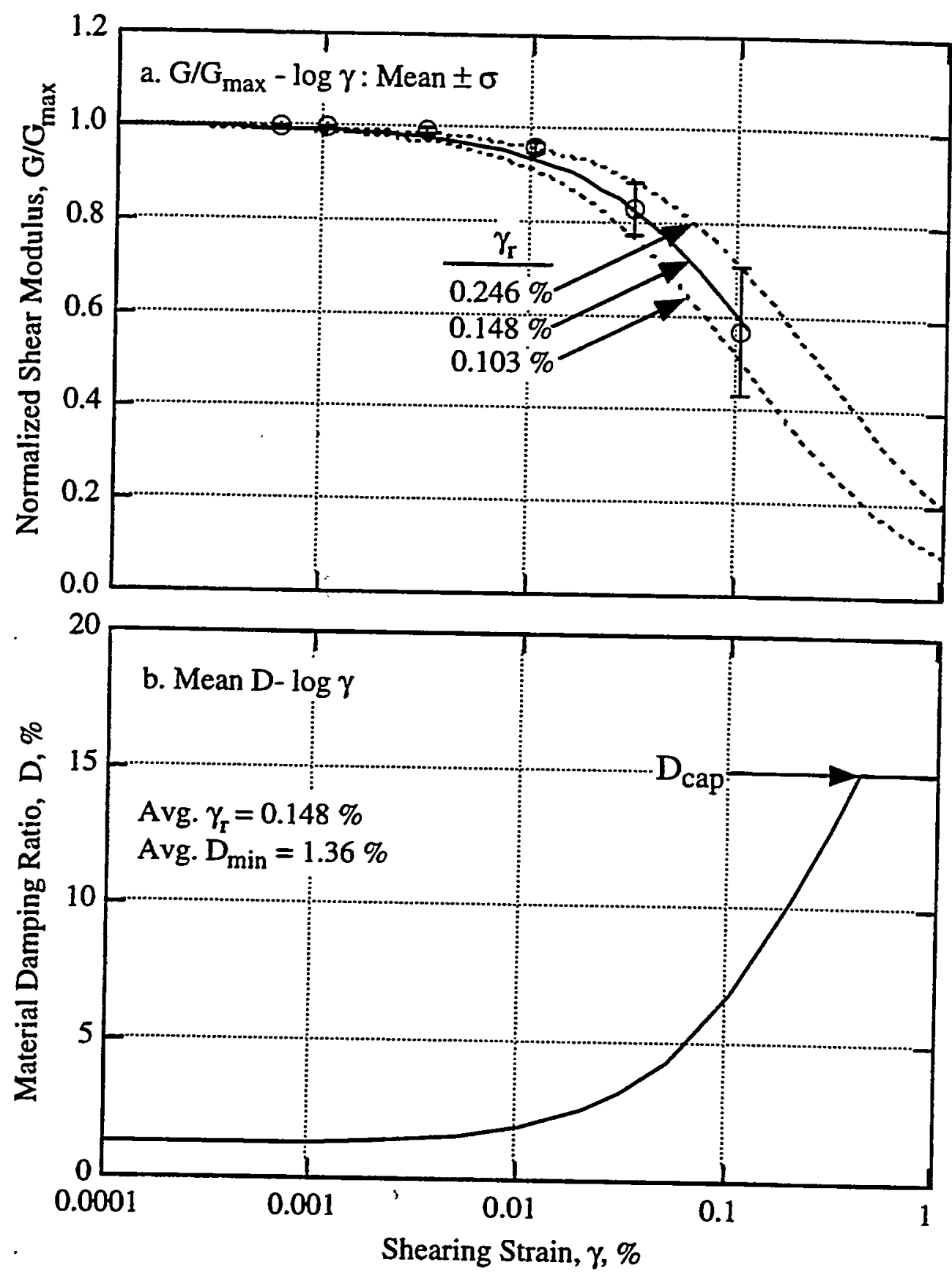

Notes: 1. Stratigraphic profile taken from boring CFD 18.

2. Average depth of "shallow" specimens is $156 \mathrm{ft}(47.6 \mathrm{~m})$.

3. Statistics associated with $\mathrm{G} / \mathrm{G}_{\max }-\log \gamma$ relationship are given in Table 16.

4. Values of $D$ evaluated at $f \leq 1 \mathrm{~Hz}$.

- Fig. 125 Recommended Generic G/G $G_{\max }-\log \gamma$ and D - log $\gamma$ Relationships for Shallow Clays at SRS

SRS-FR-CDP-95, rev. 0, 13 September 95

Project No. AA891070 
Geologic Formation
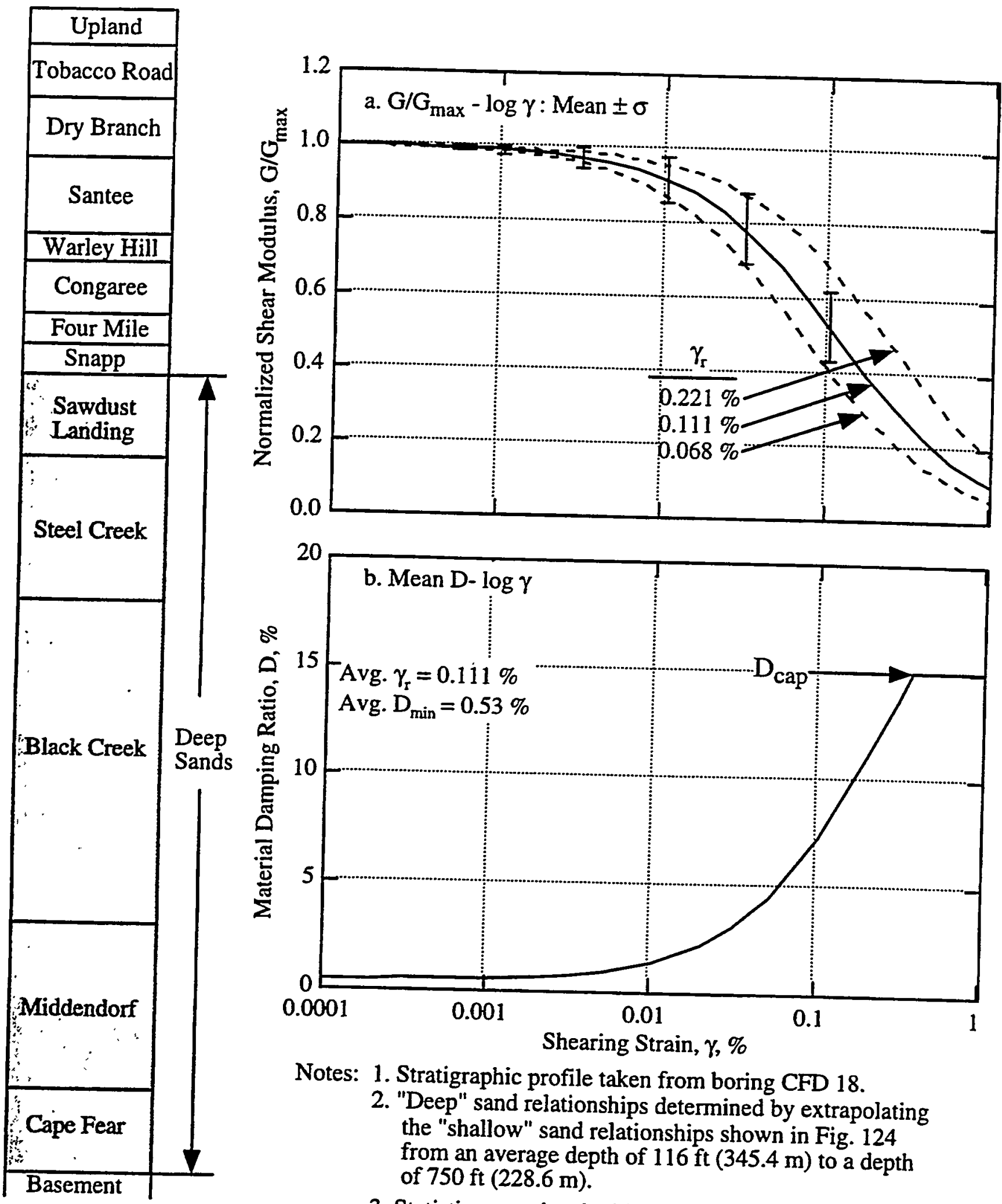

Notes: 1. Stratigraphic profile taken from boring CFD 18.

2. "Deep" sand relationships determined by extrapolating the "shallow" sand relationships shown in Fig. 124 from an average depth of $116 \mathrm{ft}(345.4 \mathrm{~m})$ to a depth of $750 \mathrm{ft}(228.6 \mathrm{~m})$.

3. Statistics associated with $\mathrm{G} / \mathrm{G}_{\max }-\log \gamma$ relationship are given in Table 24.

4. Values of $D$ evaluated at $f \leq 1 \mathrm{~Hz}$.

Fig. 126 Recommended Generic G/G $\max -\log \gamma$ and D - $\log \gamma$ Relationships for the Deep Sands at SRS

SRS-FR-CDP-95, rev. 0, 13 September 95

Project No. AA891070 
Geologic Formation
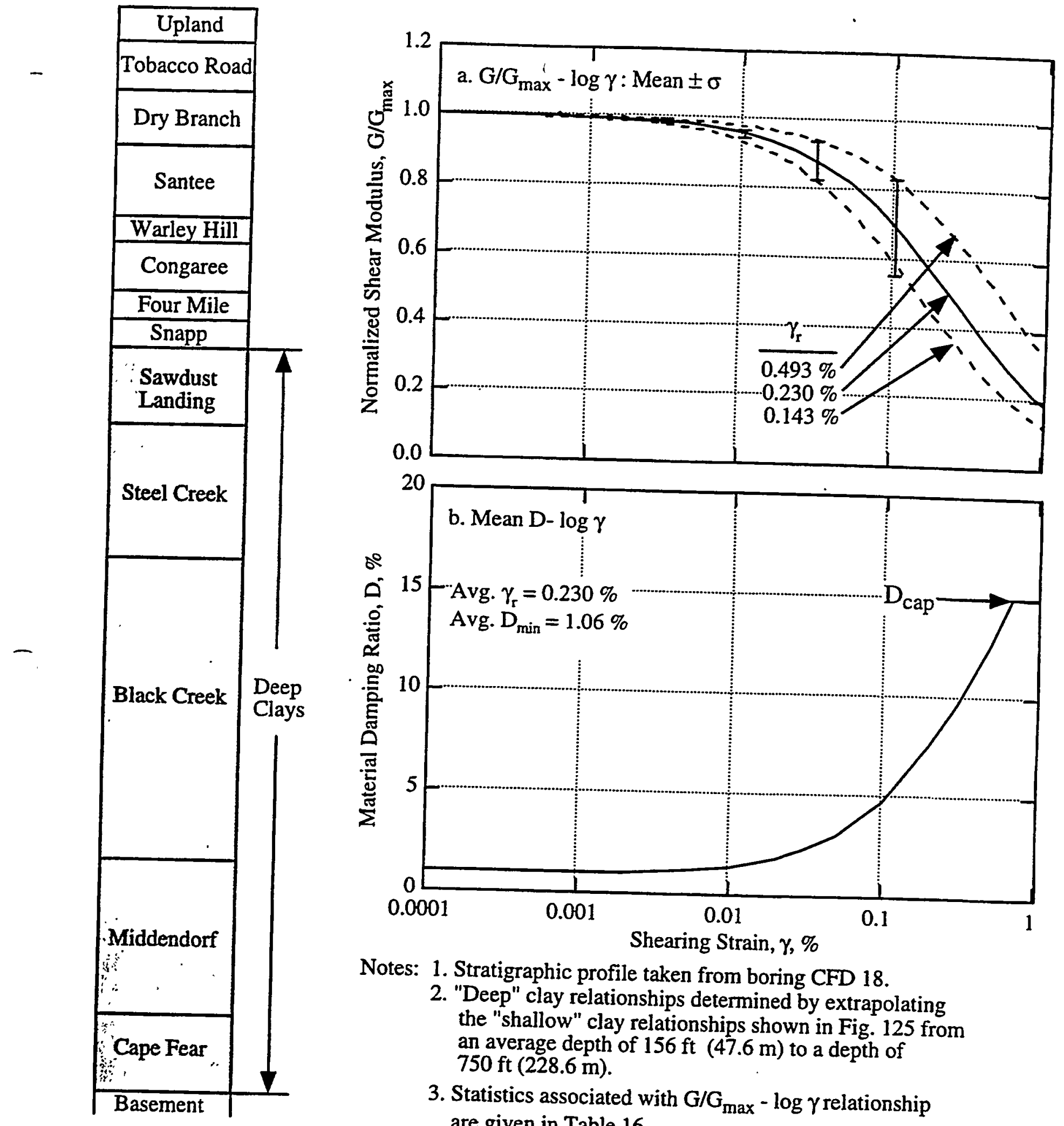

Notes: 1. Stratigraphic profile taken from boring CFD 18.

2. "Deep" clay relationships determined by extrapolating the "shallow" clay relationships shown in Fig. 125 from an average depth of $156 \mathrm{ft}(47.6 \mathrm{~m})$ to a depth of $750 \mathrm{ft}(228.6 \mathrm{~m})$.

3. Statistics associated with $\mathrm{G} / \mathrm{G}_{\max }-\log \gamma$ relationship are given in Table 16.

4. Values of $D$ evaluated at $f \leq 1 \mathrm{~Hz}$.

Fig. 127 Recommended Generic G/G $\max -\log \gamma$ and D $-\log \gamma$ Relationships for the Deep Clays at SRS 


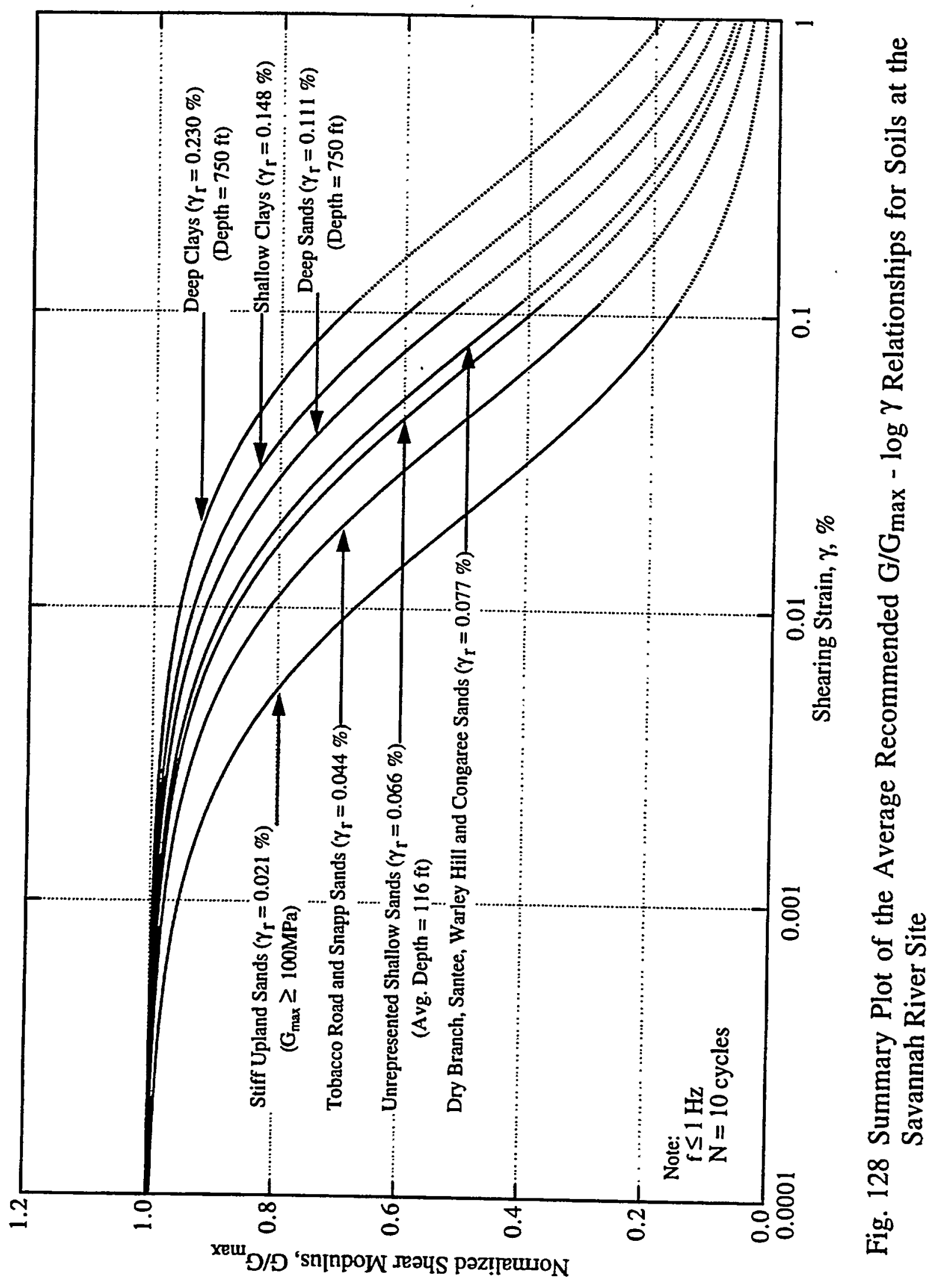




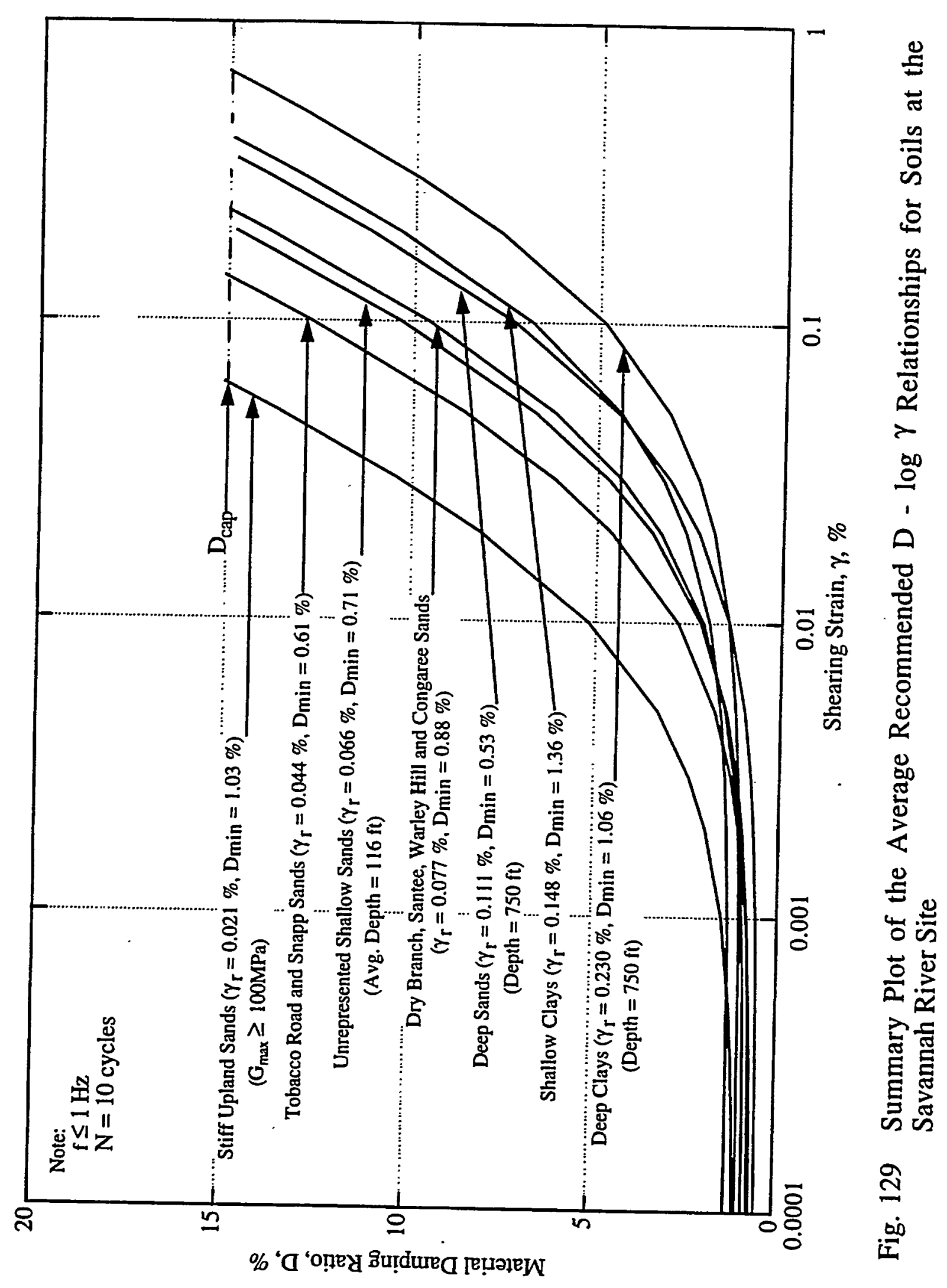




\section{Appendix A \\ Data That Were Deleted From The Correlation Study}




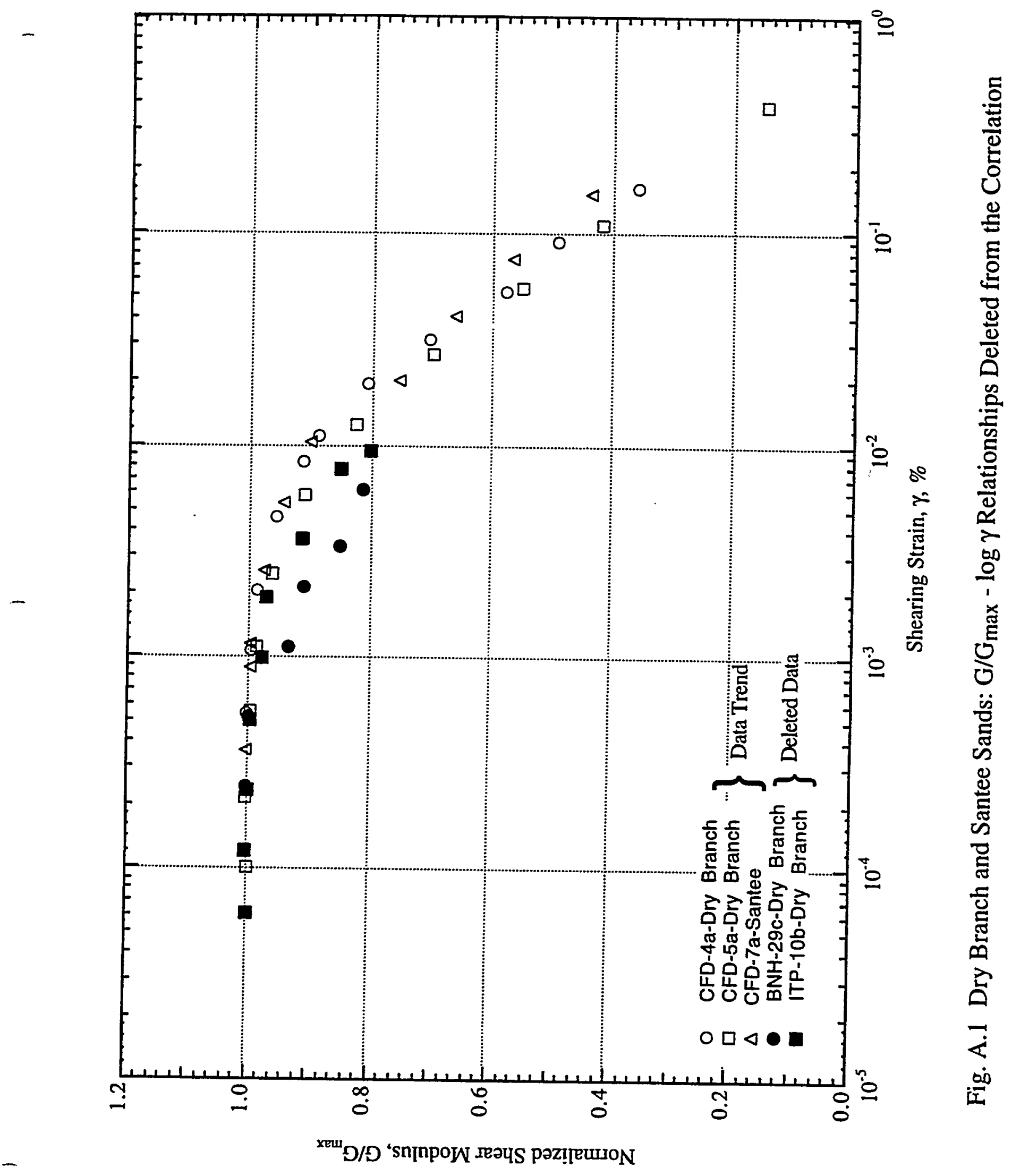

SRS-FR-CDP-95, rev. 0, 13 September 95 Project No. AA891070 


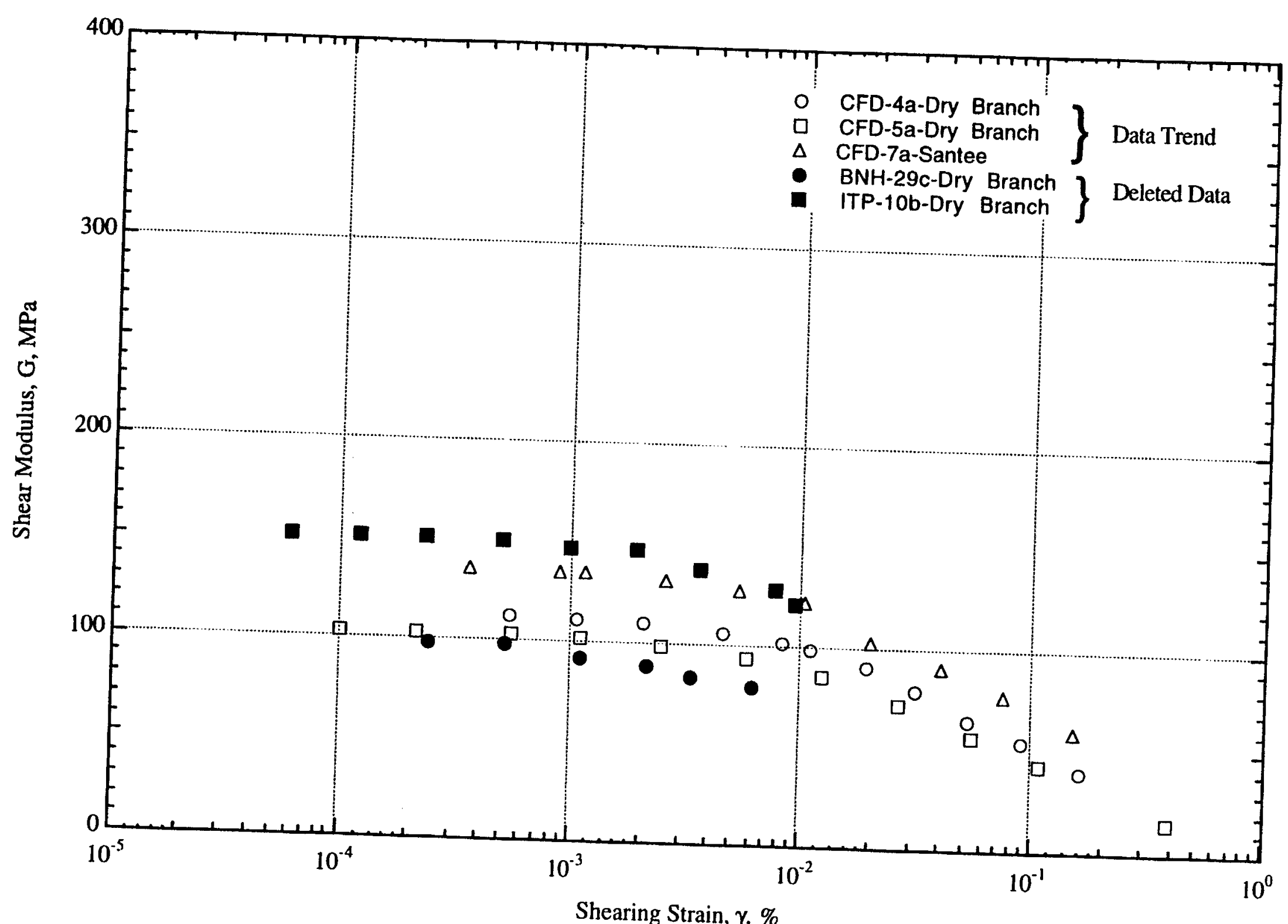

Fig. A.2 Dry Branch and Santee Sands: G - $\log \gamma$ Relationships Deleted from the Correlation 


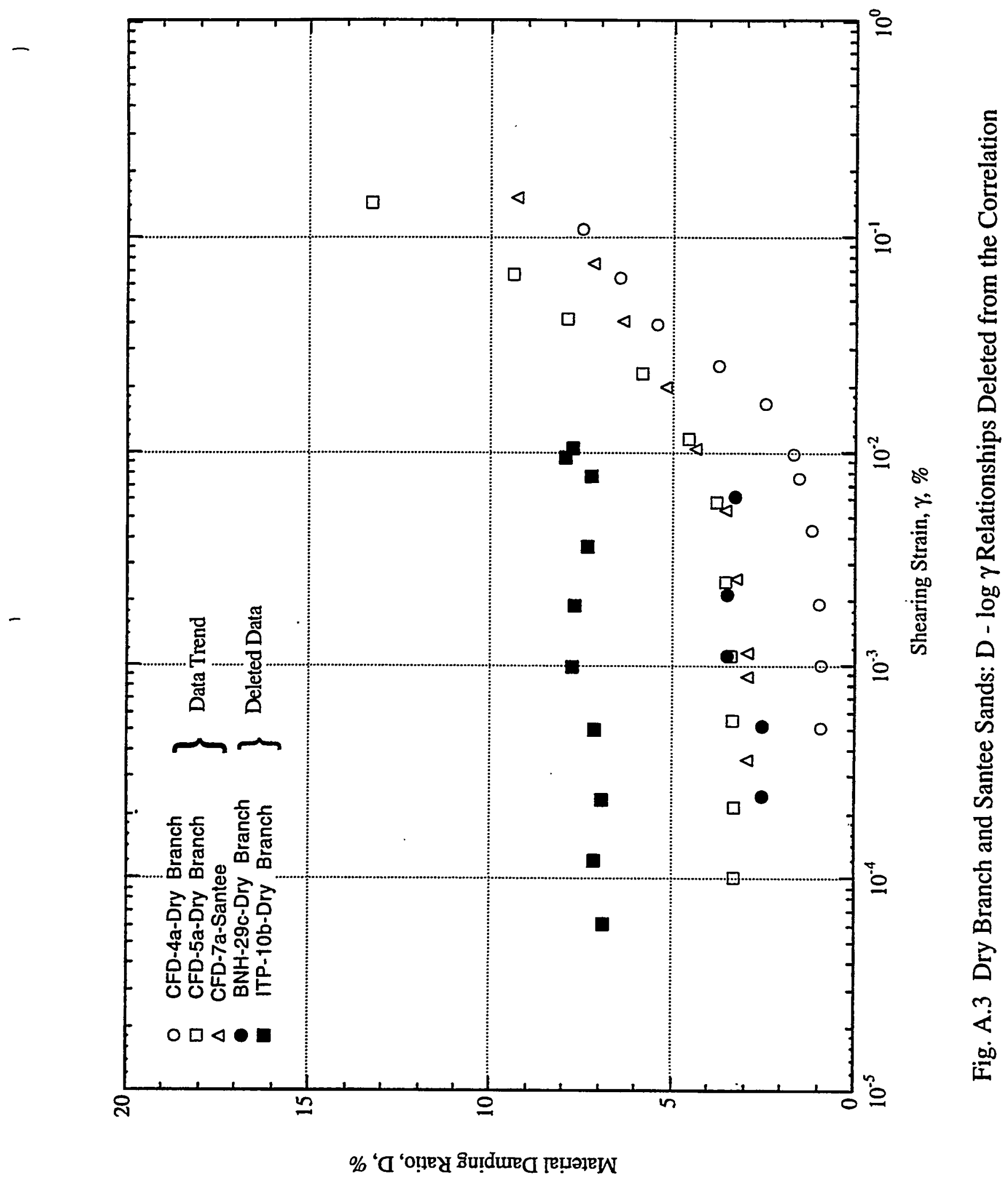

SRS-FR-CDP-95, rev. 0, 13 September 95 


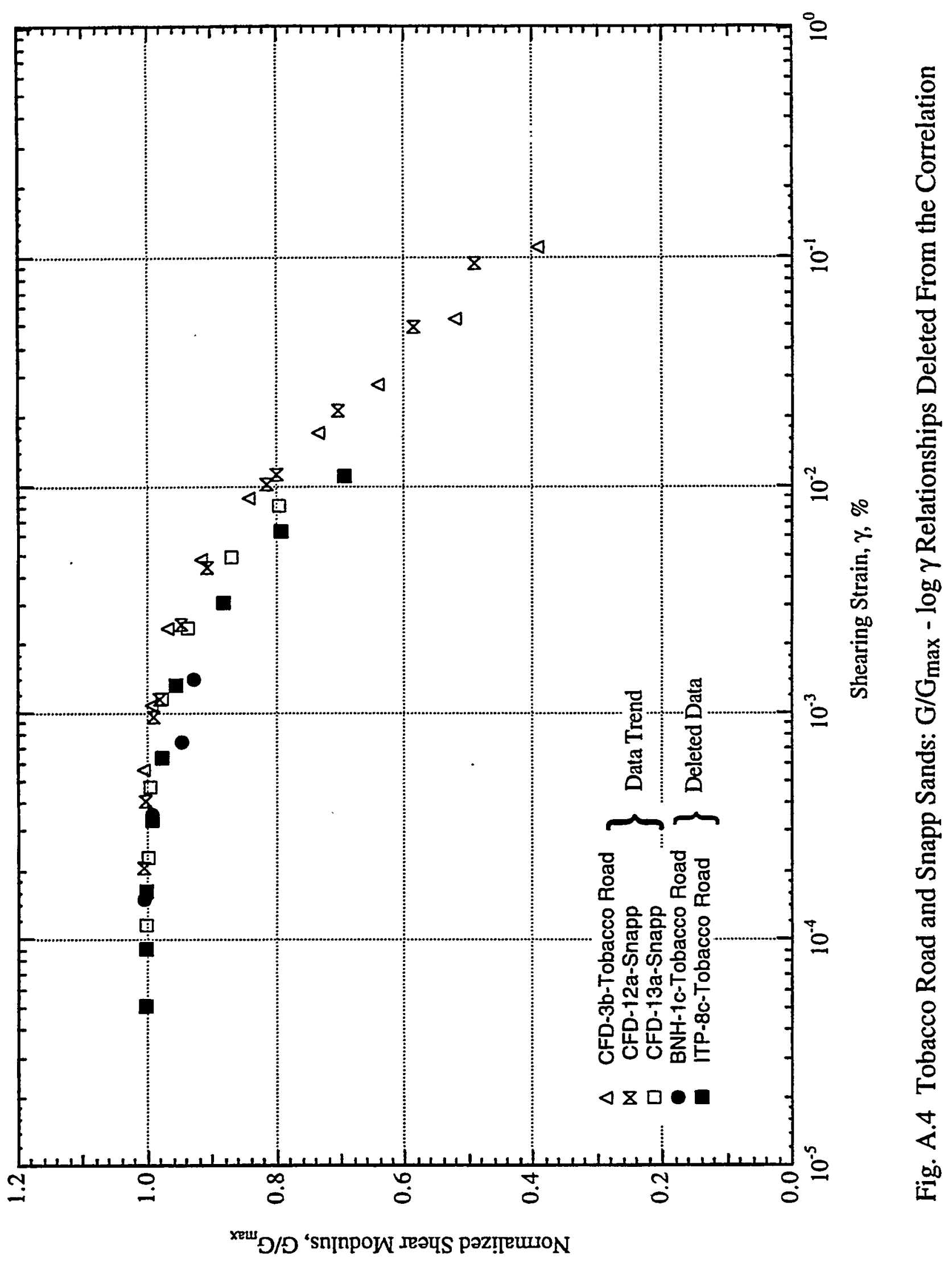

SRS-FR-CDP-95, rev. 0, 13 September 95 


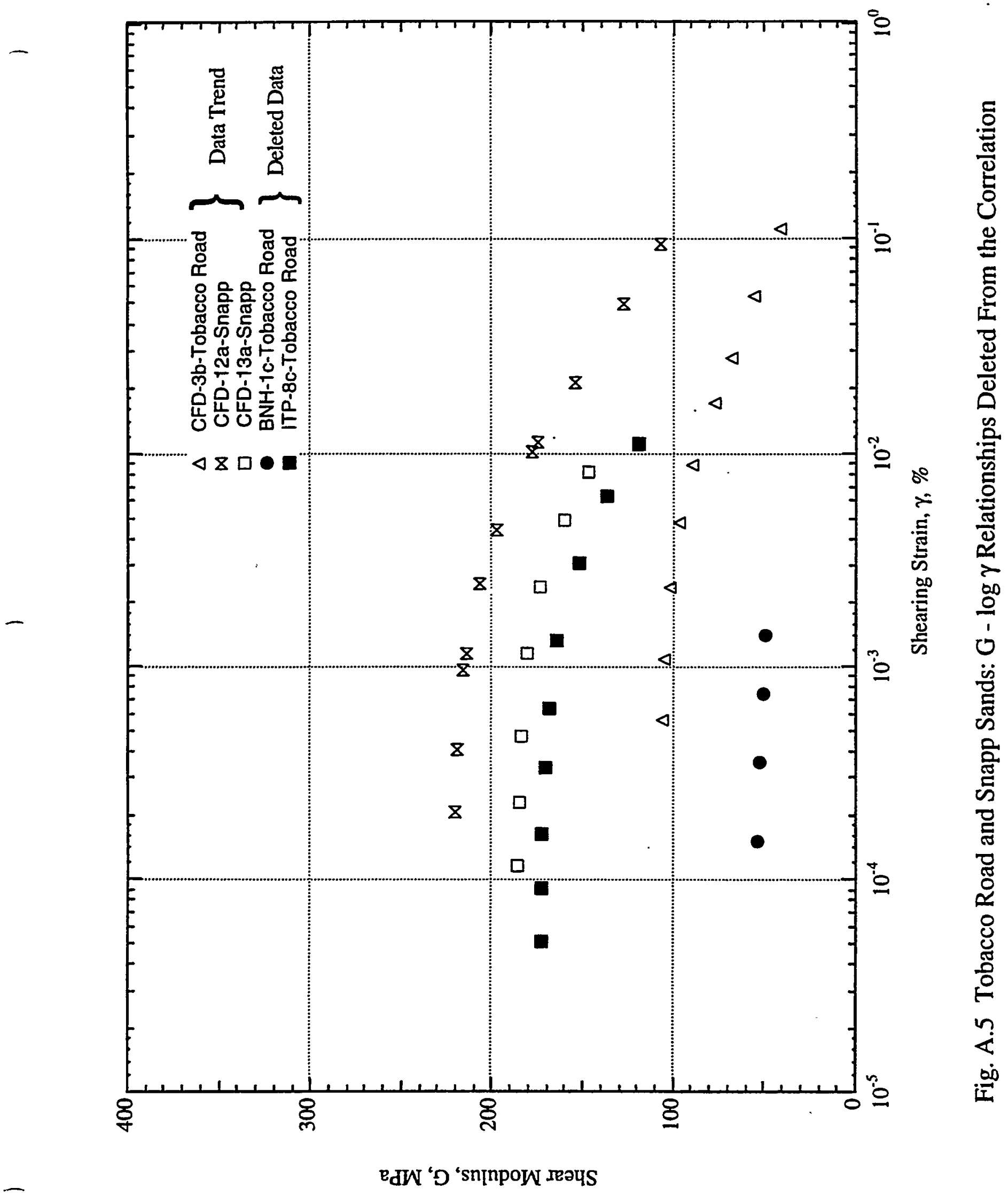

SRS-FR-CDP-95, rev. 0, 13 September 95 


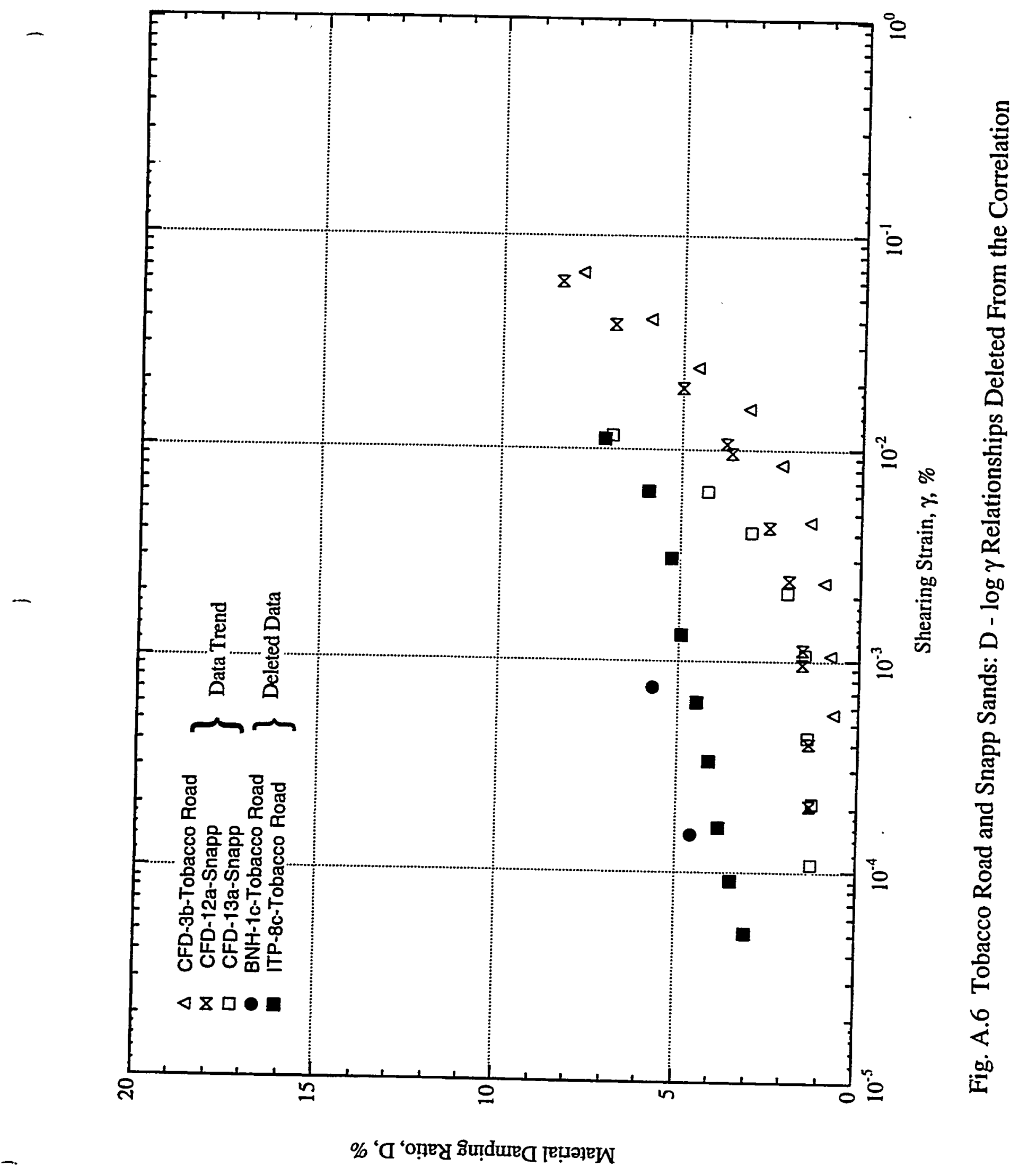

SRS-FR-CDP-95, rev. 0, 13 September 95

Project No. AA891070 


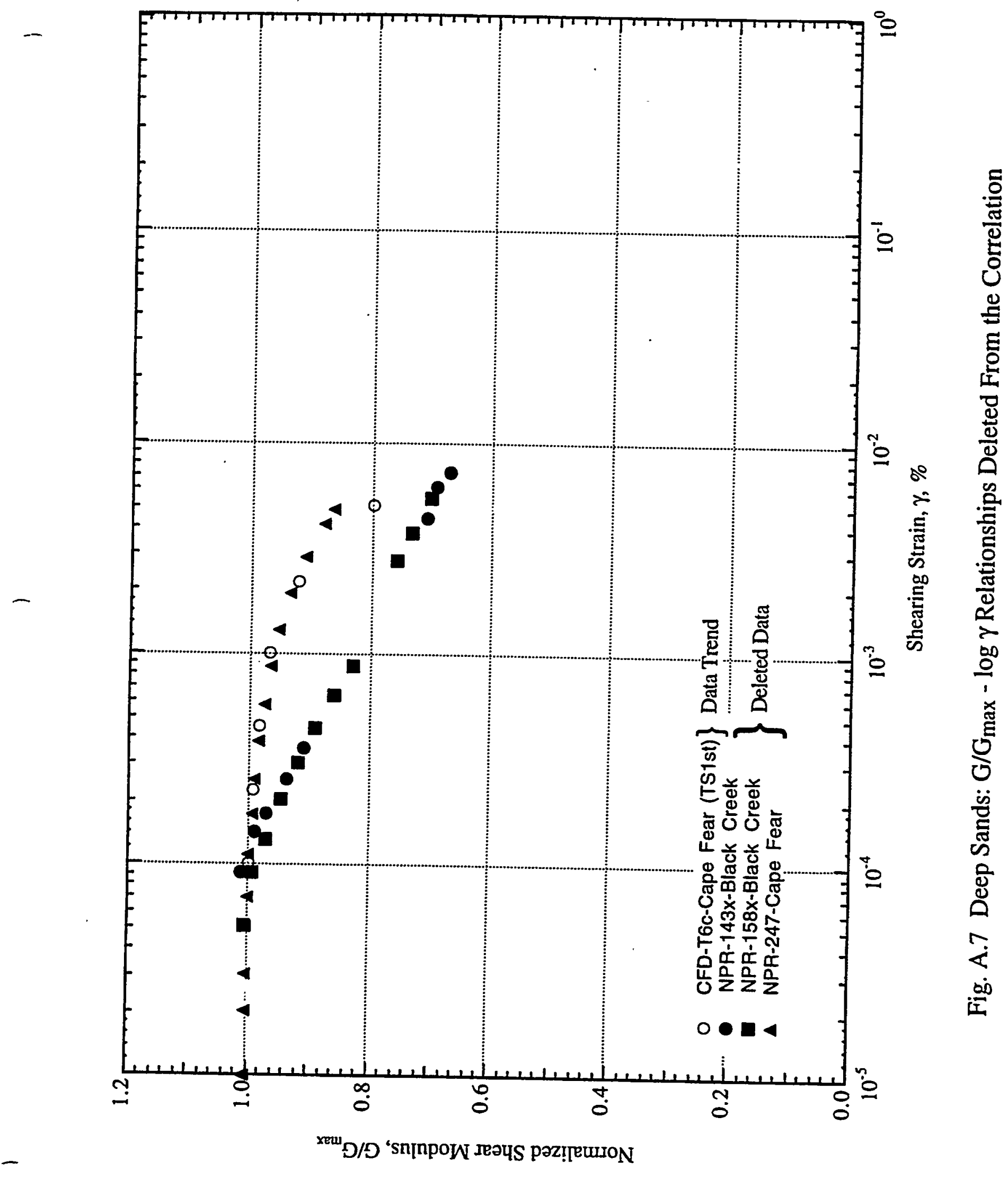

SRS-FR-CDP-95, rev. 0, 13 September 95

Project No. AA891070 


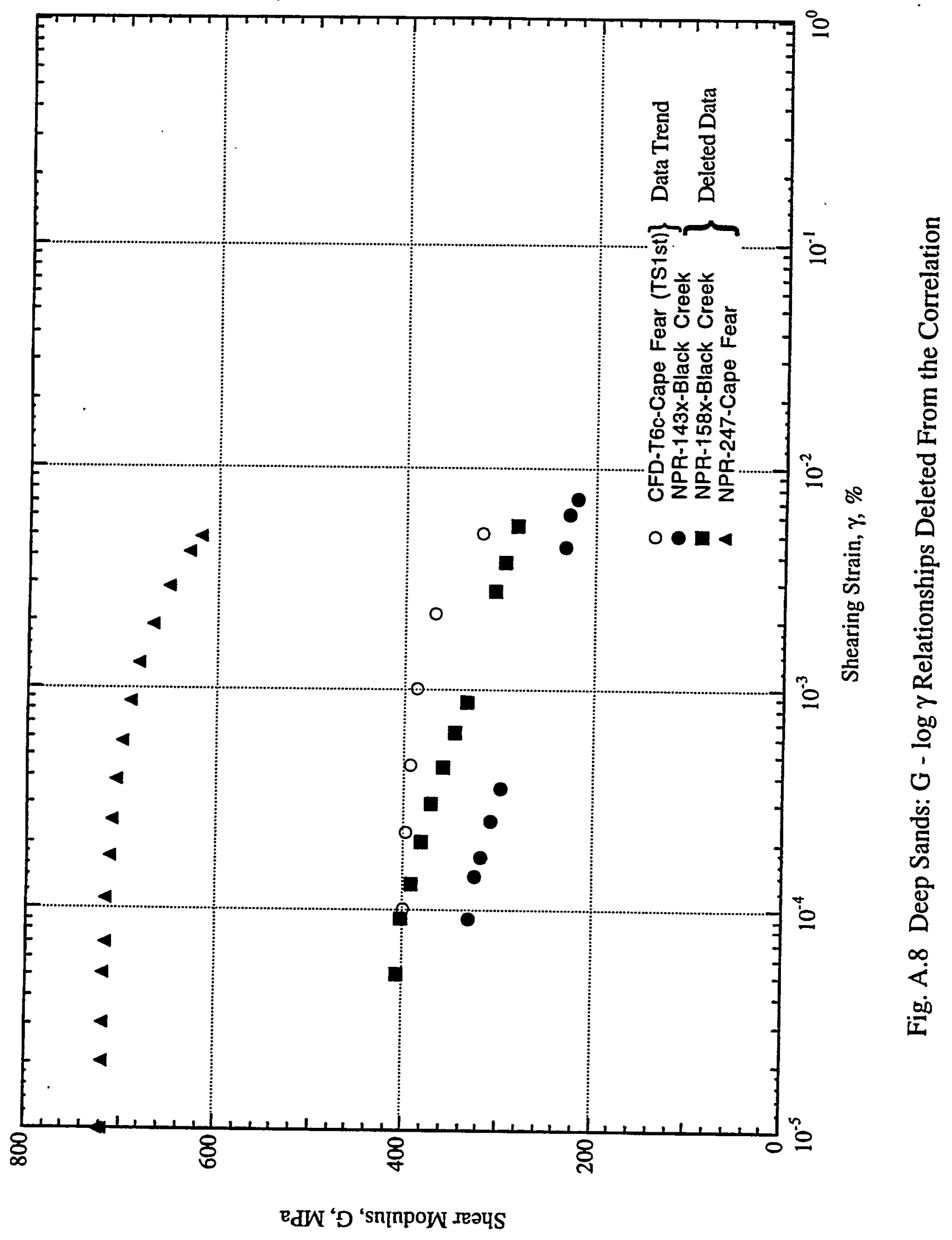

SRS-FR-CDP-95, rev. 0, 13 September 95

Project No. AA891070 


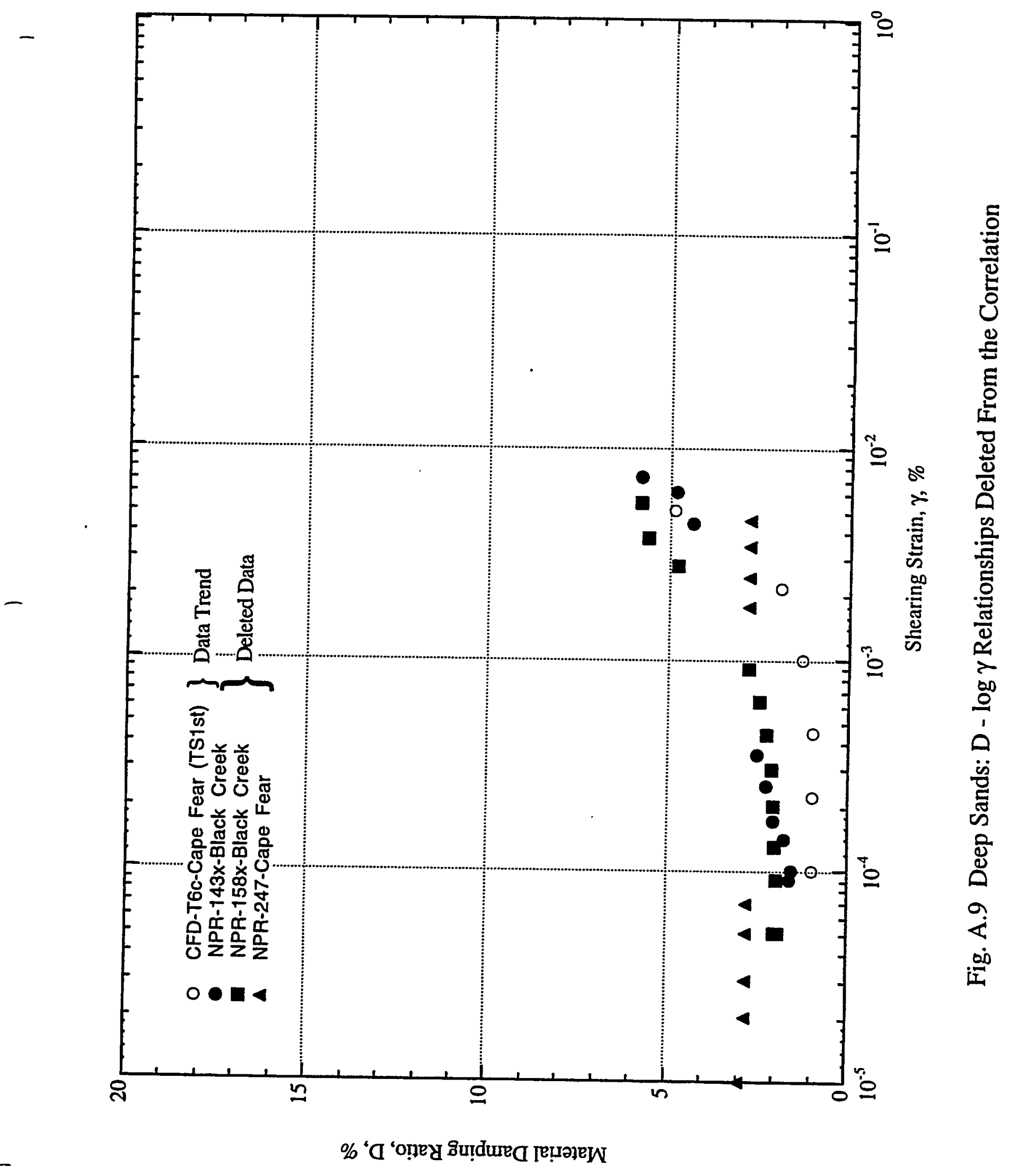

SRS-FR-CDP-95, rev. 0, 13 September 95

Project No. AA891070 


\section{Appendix B}

Nonlinear Dynamic Properties of Similar Soils Evaluated With The RCTS Equipment at UTA 
Table B. 1. Initial Properties of Specimens Presented in Appendix B

\begin{tabular}{|c|c|c|c|c|c|c|c|c|c|c|c|c|c|c|c|}
\hline $\begin{array}{l}\text { Sample } \\
\text { Number }\end{array}$ & $\begin{array}{c}\text { Depth } \\
\mathrm{ft} \\
(\mathrm{m}) \\
\end{array}$ & $\begin{array}{c}\text { Soil/Rock Type } \\
\text { (Unified Soil } \\
\text { Classification) } \\
\end{array}$ & $\begin{array}{l}\mathrm{LL} \\
\% \\
\end{array}$ & $\begin{array}{l}\mathrm{PT} \\
\% \\
\end{array}$ & $\begin{array}{l}\mathrm{D}_{10} \\
\mathrm{~mm}\end{array}$ & $\begin{array}{l}\mathrm{D}_{30} \\
\mathrm{~mm} \\
\end{array}$ & $\begin{array}{l}\mathrm{D}_{60} \\
\mathrm{~mm}\end{array}$ & $\begin{array}{c}\mathrm{R}_{200} \\
\% \\
\end{array}$ & $\begin{array}{c}\text { Water } \\
\text { Content } \\
\% \\
\end{array}$ & $\begin{array}{c}\text { Total } \\
\text { Unit Weight } \\
\mathrm{pcf}\left(\mathrm{g} / \mathrm{cm}^{3}\right)\end{array}$ & $\begin{array}{c}\text { Void } \\
\text { Ratio } \\
\text { e }\end{array}$ & $\begin{array}{l}\text { Dia. } \\
\mathrm{cm}\end{array}$ & $\begin{array}{l}\text { Height } \\
\mathrm{cm}\end{array}$ & $\begin{array}{l}\text { Specific } \\
\text { Gravity } \\
G_{S}{ }^{2}\end{array}$ & $\begin{array}{c}\text { Degree of } \\
\text { Saturation } \\
\%\end{array}$ \\
\hline $\mathrm{T} 1^{6}$ & $\begin{array}{l}17.5 \\
(5.3)\end{array}$ & $\begin{array}{l}\text { Silty Sand } \\
(\mathrm{SM})\end{array}$ & \multicolumn{2}{|c|}{ non-plastic } & - & - & 0.11 & 66 & 19.9 & $\begin{array}{c}120 \\
(1.92)\end{array}$ & 0.69 & 5.03 & 10.07 & 2.65 & 76 \\
\hline$T 2^{6}$ & $\begin{array}{c}30 \\
(9.1)\end{array}$ & $\begin{array}{l}\text { Sand with Silt } \\
\text { (SP-SM) }\end{array}$ & \multicolumn{2}{|c|}{ non-plastic } & 0.10 & 0.18 & 0.26 & 91 & 21.3 & $\begin{array}{c}120 \\
(1.92)\end{array}$ & 0.67 & 3.78 & 7.58 & 2.65 & 84 \\
\hline$T 3^{6}$ & $\begin{array}{c}60 \\
(18.3) \\
\end{array}$ & $\begin{array}{l}\text { Fat Clay } \\
(\mathrm{CH}) \\
\end{array}$ & 51 & 26 & - & - & - & $T$ & 50.2 & $\begin{array}{c}108 \\
(1.73)\end{array}$ & 1.34 & 5.11 & 10.10 & 2.70 & $100^{3}$ \\
\hline G2-1 7 & $\begin{array}{c}20 \\
(6.1)\end{array}$ & $\begin{array}{c}\text { Lean Clay } \\
\text { (CL) }\end{array}$ & 43 & 23 & - & - & - & 14 & 27.0 & $121(1.94)$ & 0.76 & 3.81 & 7.62 & 2.70 & 96 \\
\hline G5-17 & $\begin{array}{c}120 \\
(36.6)\end{array}$ & $\begin{array}{l}\text { Sandy Silt } \\
(\mathrm{ML})\end{array}$ & \multicolumn{2}{|c|}{ non- plastic } & - & - & - & 38 & 19.1 & $131(2.10)$ & 0.51 & 3.82 & 7.52 & 2.65 & 100 \\
\hline HQ146 ${ }^{4,8}$ & $\begin{array}{c}662 \\
(202)\end{array}$ & Basalt & - & - & - & - & - & - & - & $143(2.29)$ & 0.20 & 2.54 & 4.99 & 2.75 & $0^{5}$ \\
\hline
\end{tabular}

1. $R_{200}=$ Percent of soil sample by weight remaining on $\# 200$ sieve

2. Specific gravity was assumed.

3. Degree of saturation slightly exceeds $100 \%$.

4. Epoxy glue was used to fix the specimen to the end platens of the test equipment.

5. Degree of saturation was assumed because water content was not determined.

6. From Geotechnical Engineering Report GR93-4, Geotechnical Engincering Center, Civil Engineering Department, The University of Texas at Austin

7. From Geotechnical Engineering Report GR93-5, Geotechnical Engincering Center, Civil Engineering Department, The University of Texas at Austin

8. From Geotechnical Engineering Report GR93-7. Geotechnical Engineering Center, Civil Engineering Department, The University of Texas at Austin 


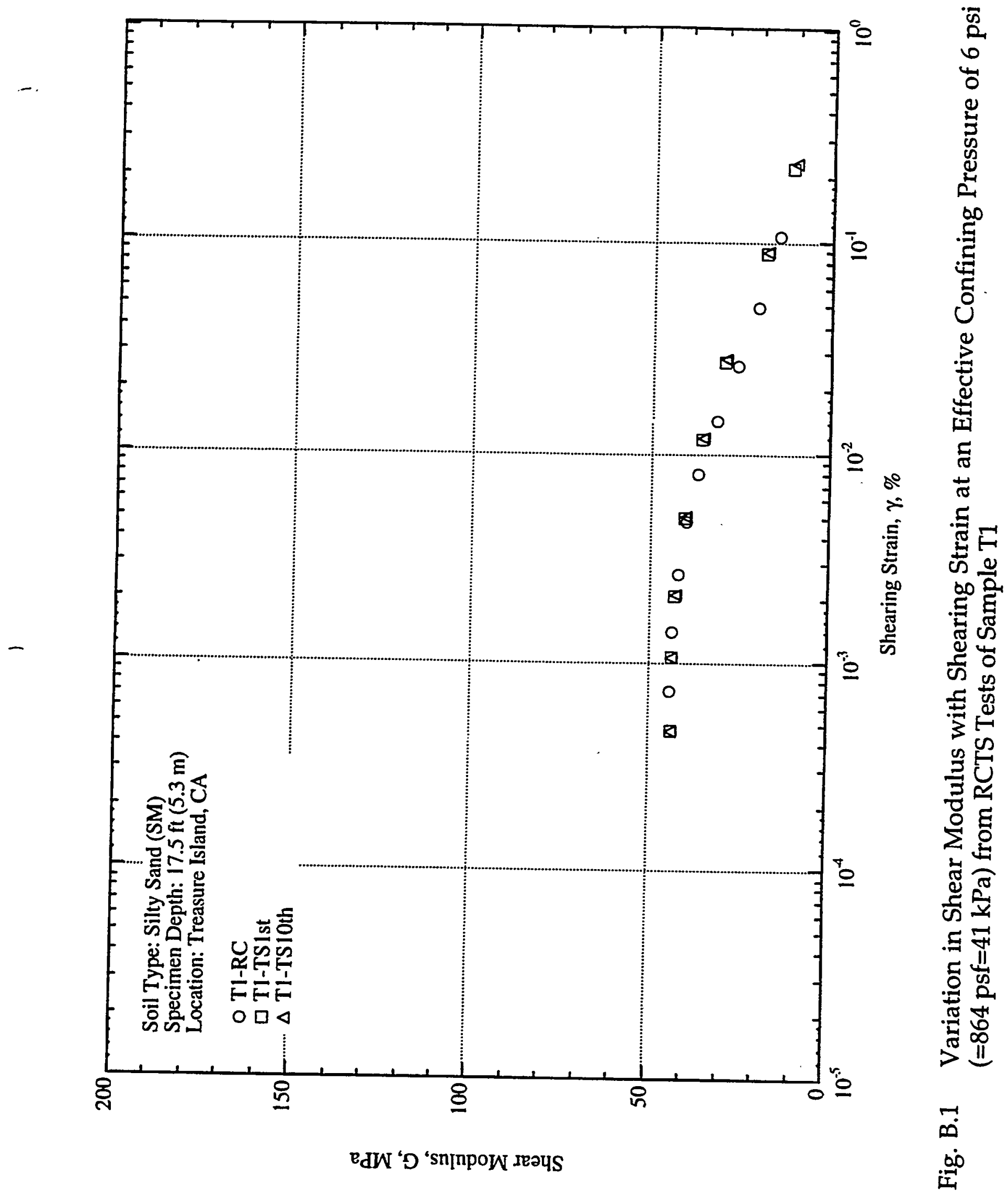

SRS-FR-CDP-95, rev. 0, 13 September 95 Project No. AA891070 


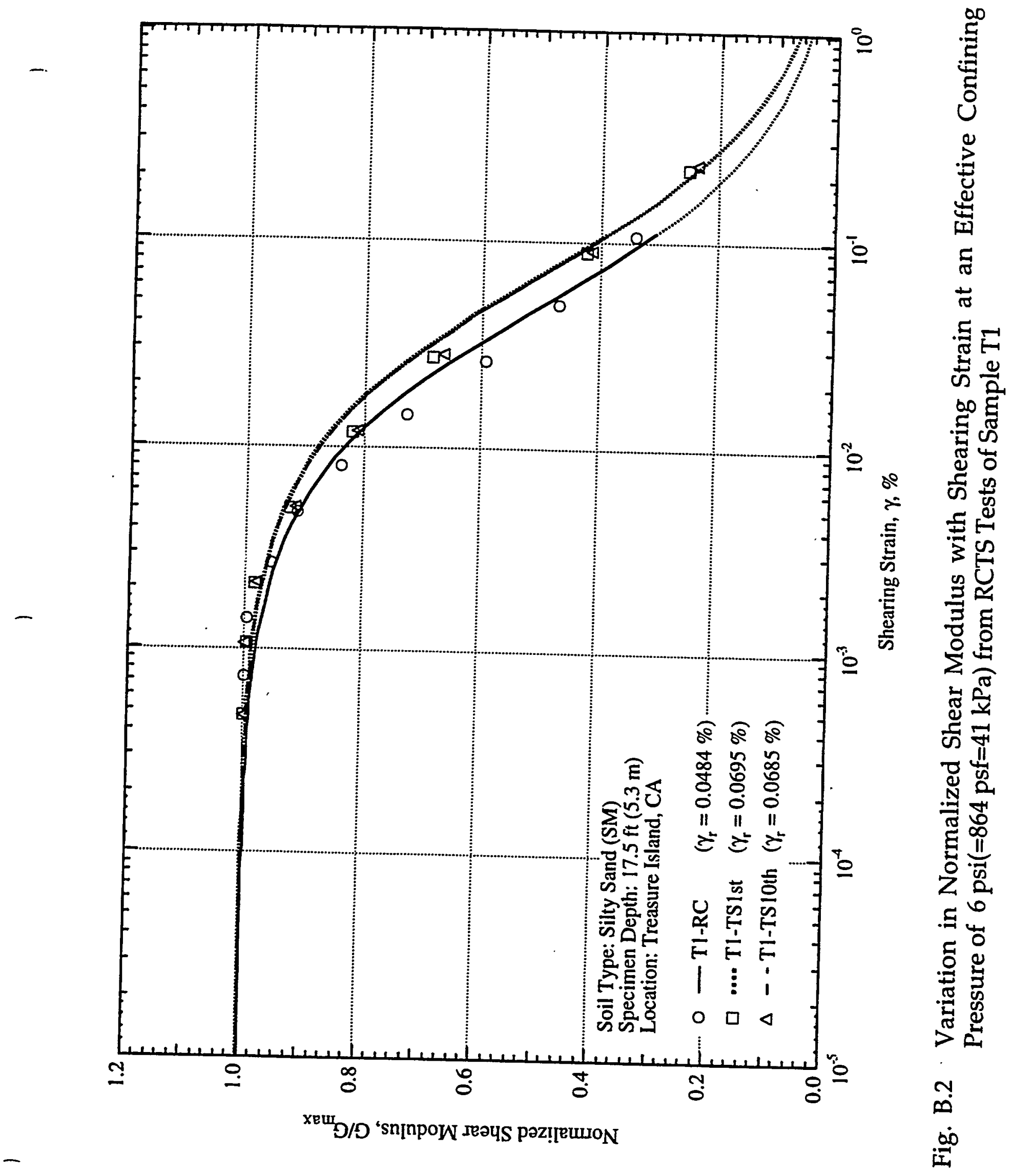

SRS-FR-CDP-95, rev. 0, 13 September 95 Project No. AA891070 


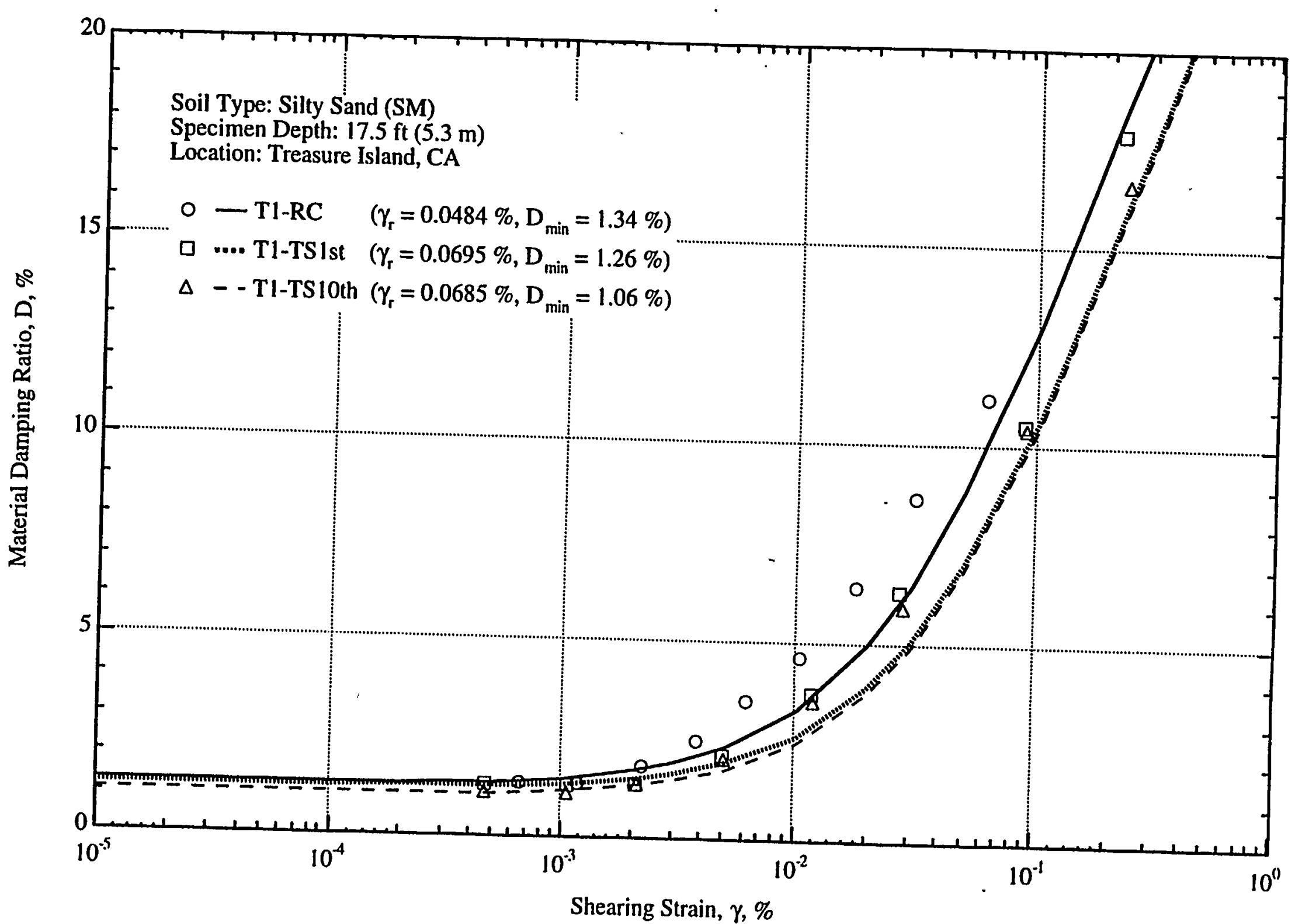

Fig. B.3 Variation in Material Damping Ratio with Shearing Strain at an Effective Confining Pressure of
$6 \mathrm{psi}(=864 \mathrm{psf}=41 \mathrm{kPa})$ from RCTS Tests of Sample T1 


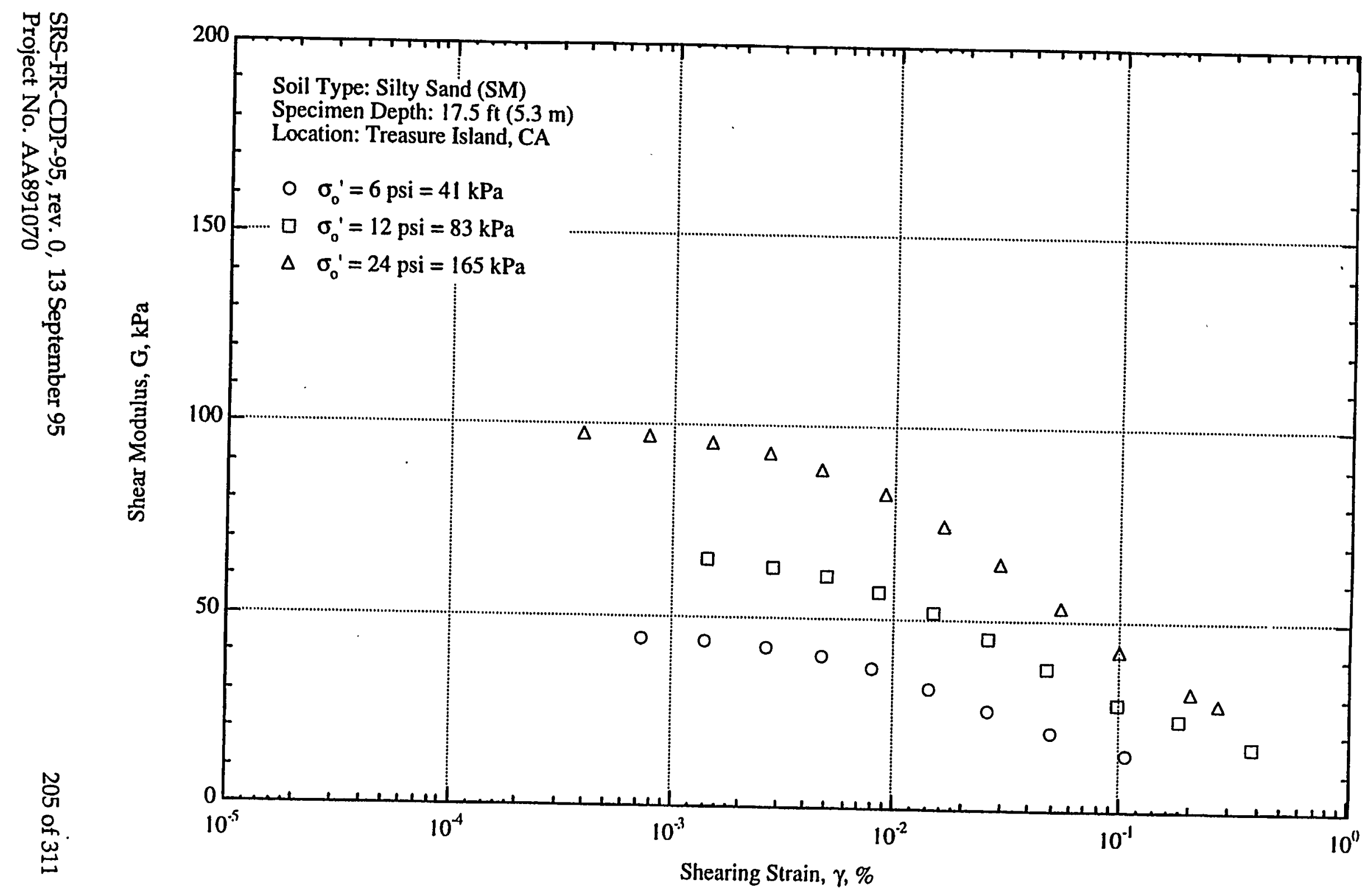

Fig. B.4 Variation in Shear Modulus with Shearing Strain and Effective Confining Pressure from
Resonant Column Tests of Sample T1 

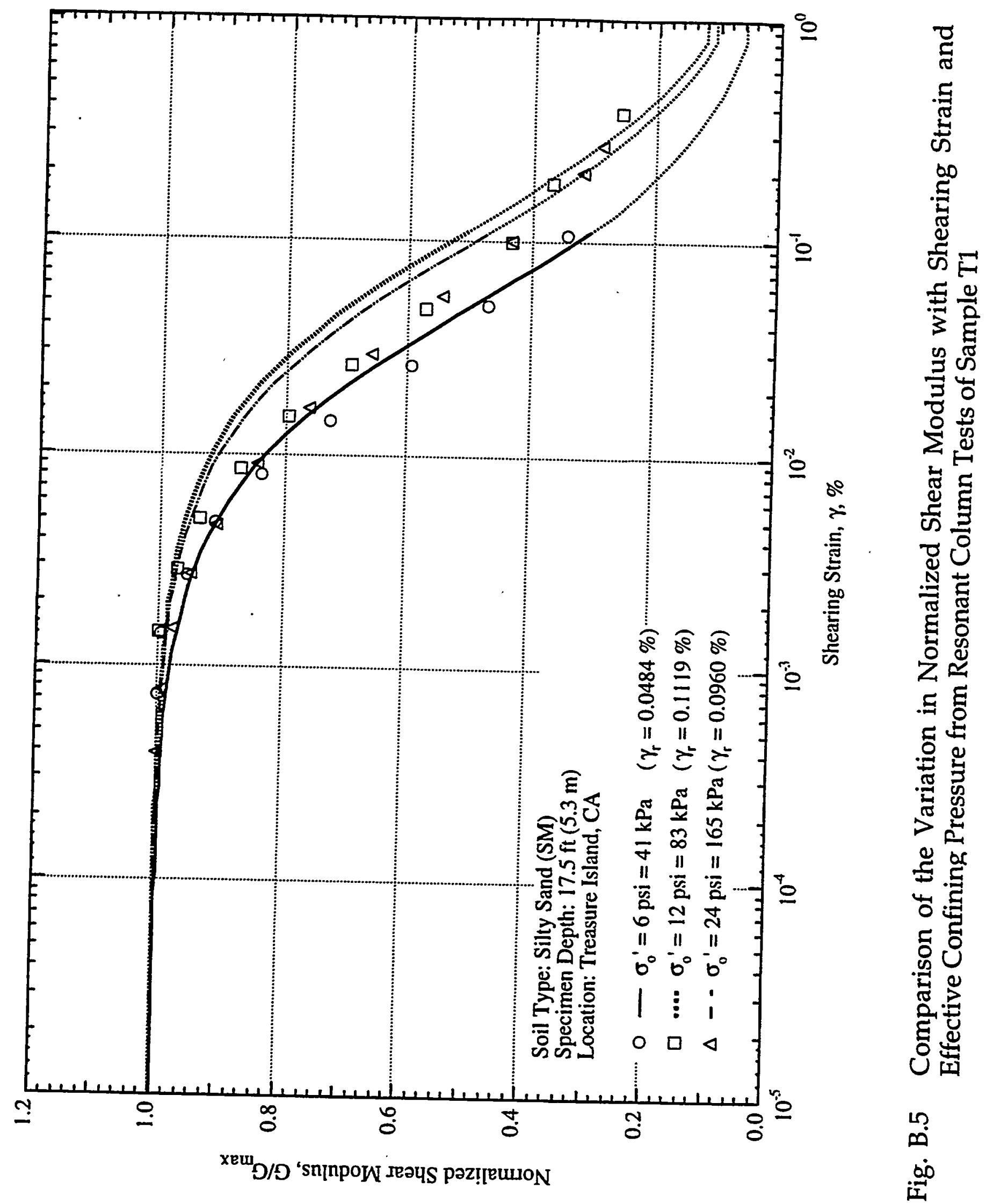

SRS-FR-CDP-95, rev. 0, 13 September 95 Project No. AA891070 


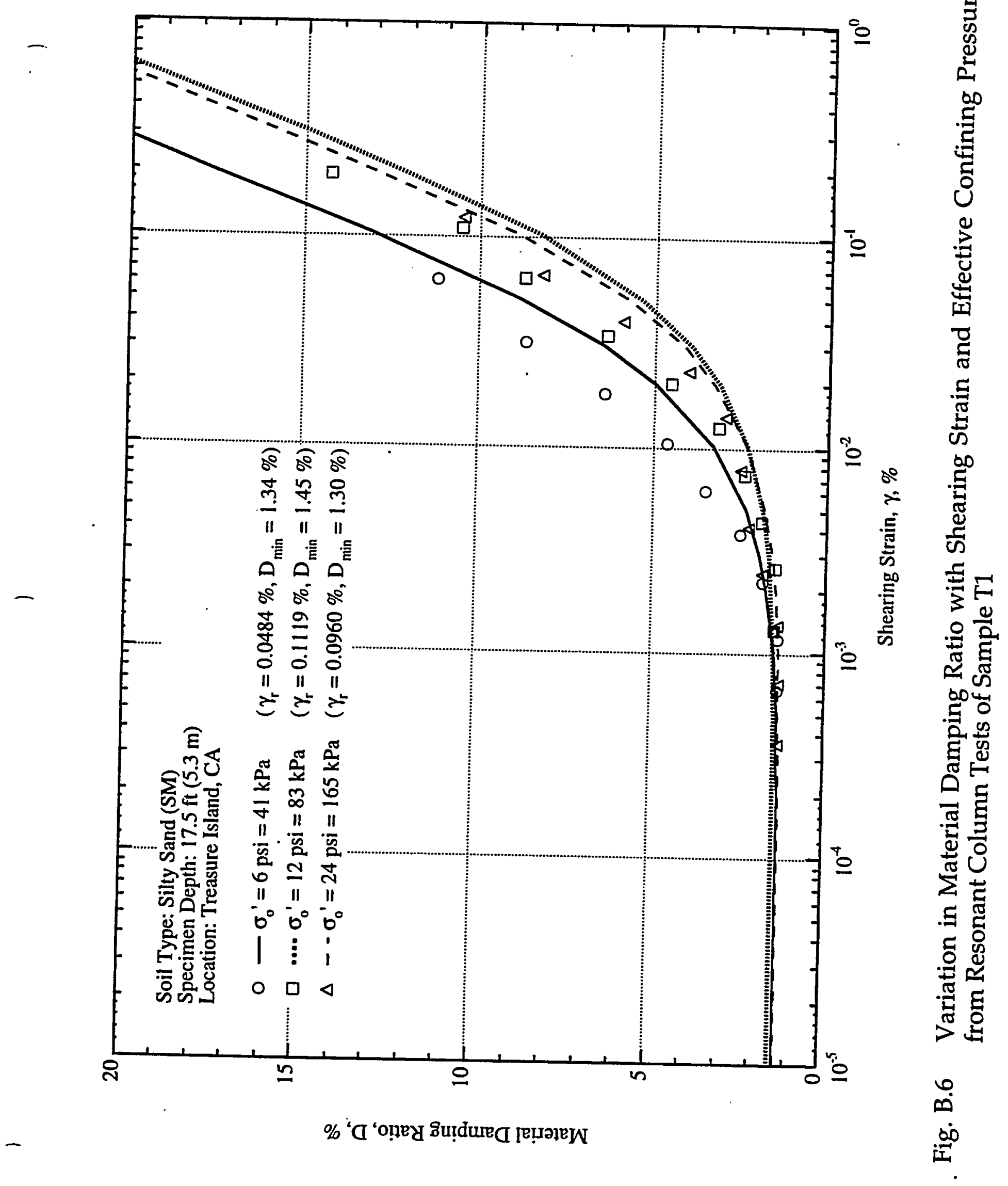




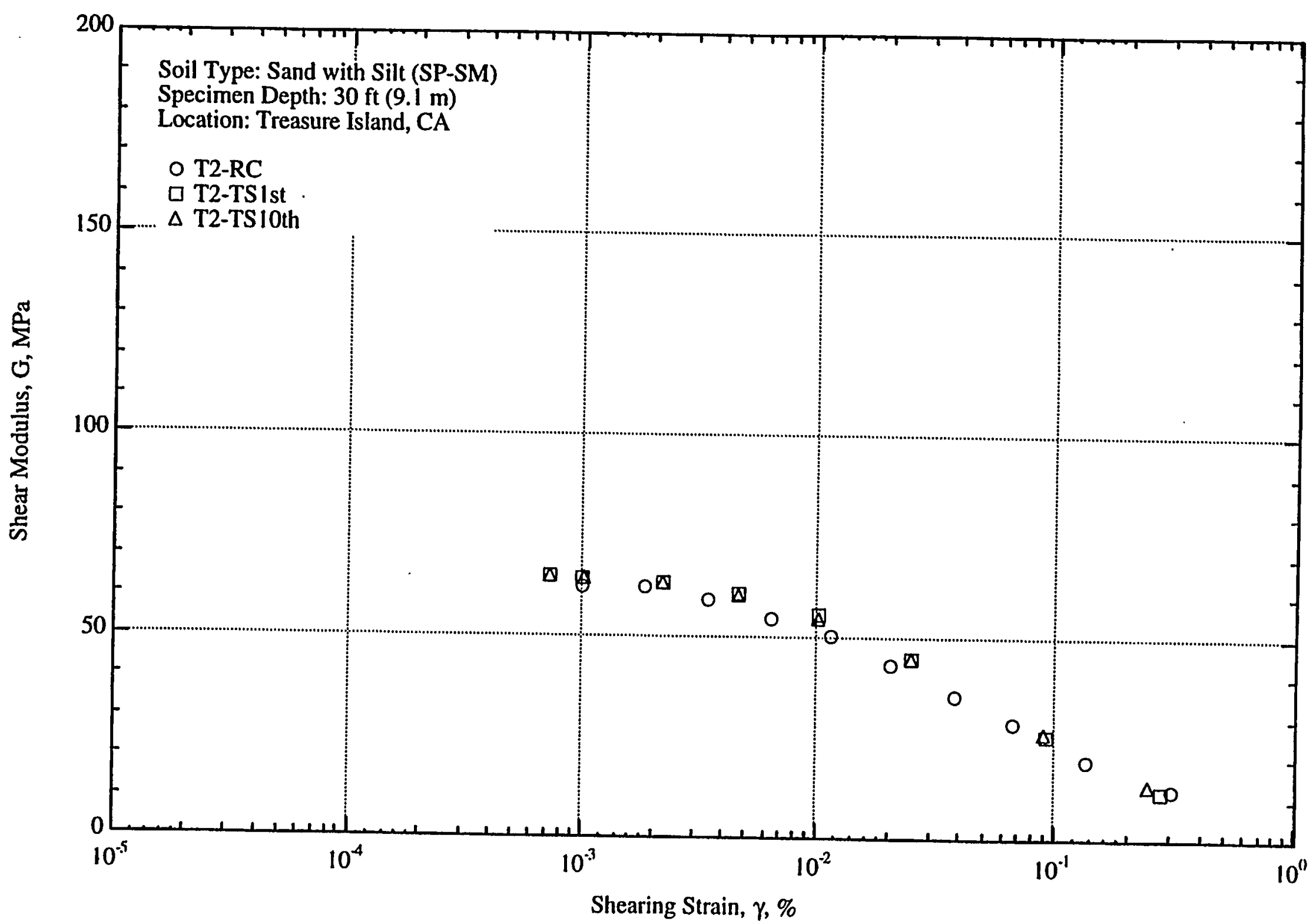

Fig. B.7 Variation in Shear Modulus with Shearing Strain at an Effective Confining Pressure of 10 psi $(=1.44 \mathrm{ksf}=69 \mathrm{kPa})$ from RCTS Tests of Sample T2 


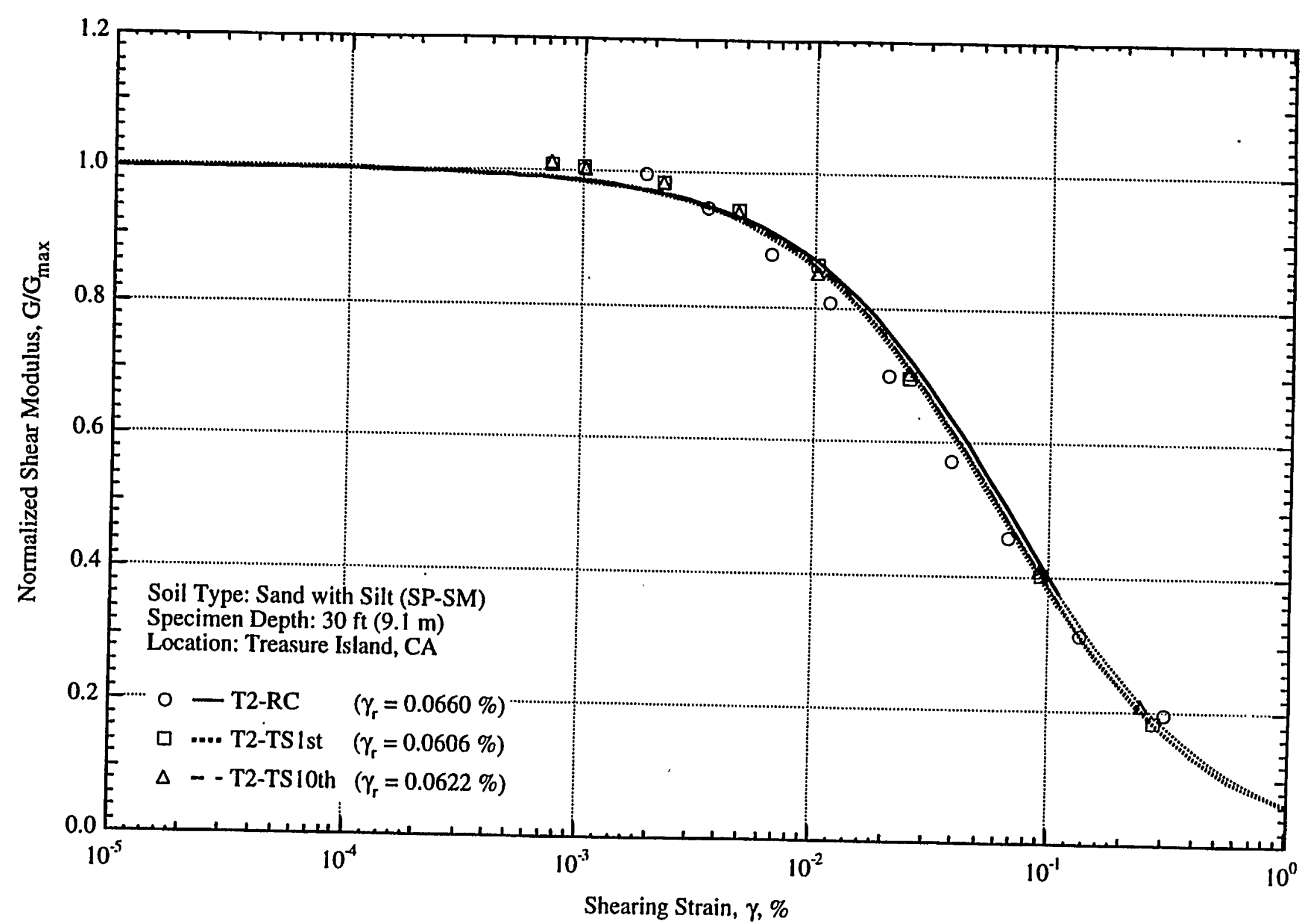
Fig. B.8 Variation in Normalized Shear Modulus with Shearing Strain at an Effective Confining
Pressure of $10 \mathrm{psi}(=1.44 \mathrm{ksf}=69 \mathrm{kPa})$ from RCTS Tests of Sample T2 


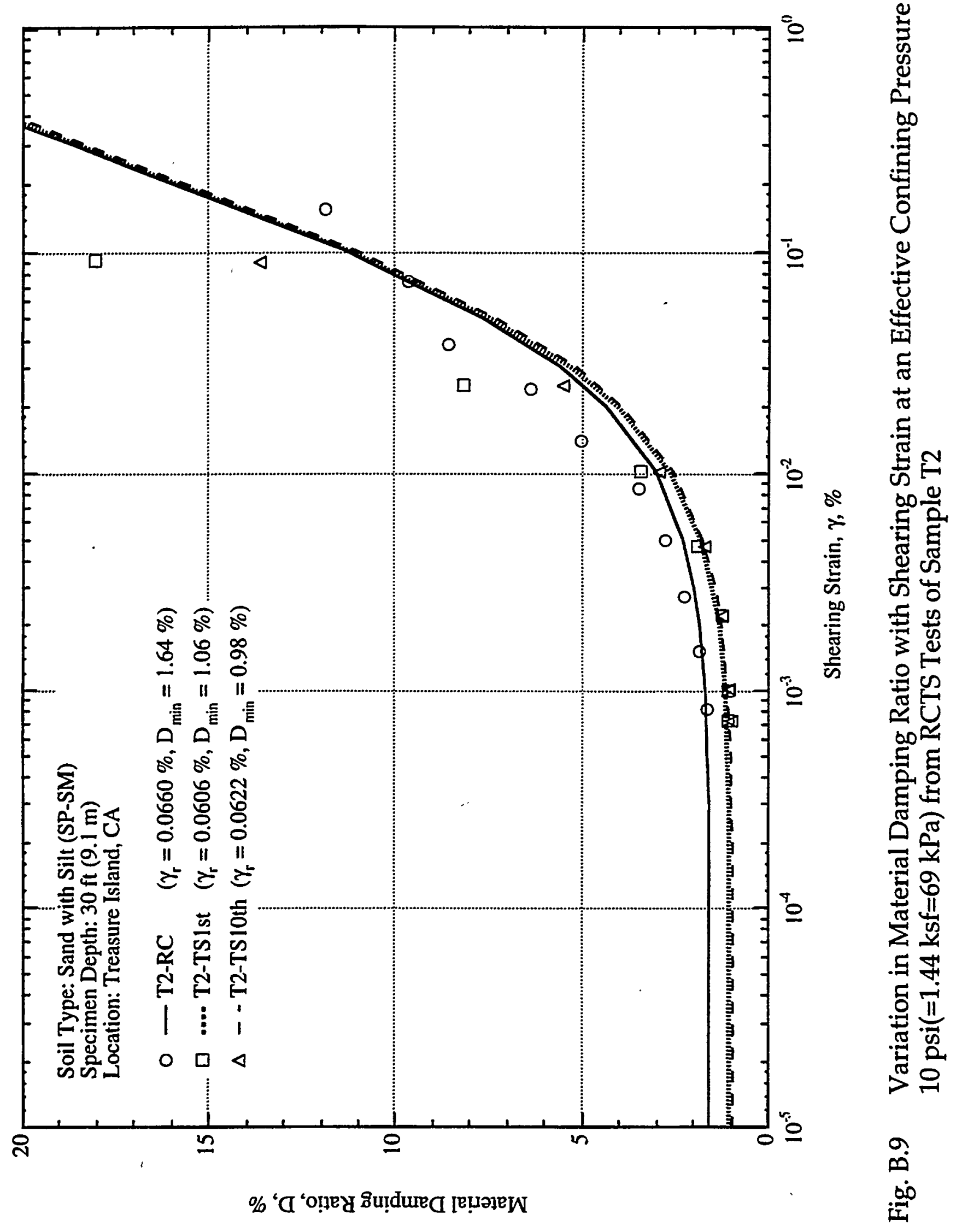

SRS-FR-CDP-95, rev. 0, 13 September 95 


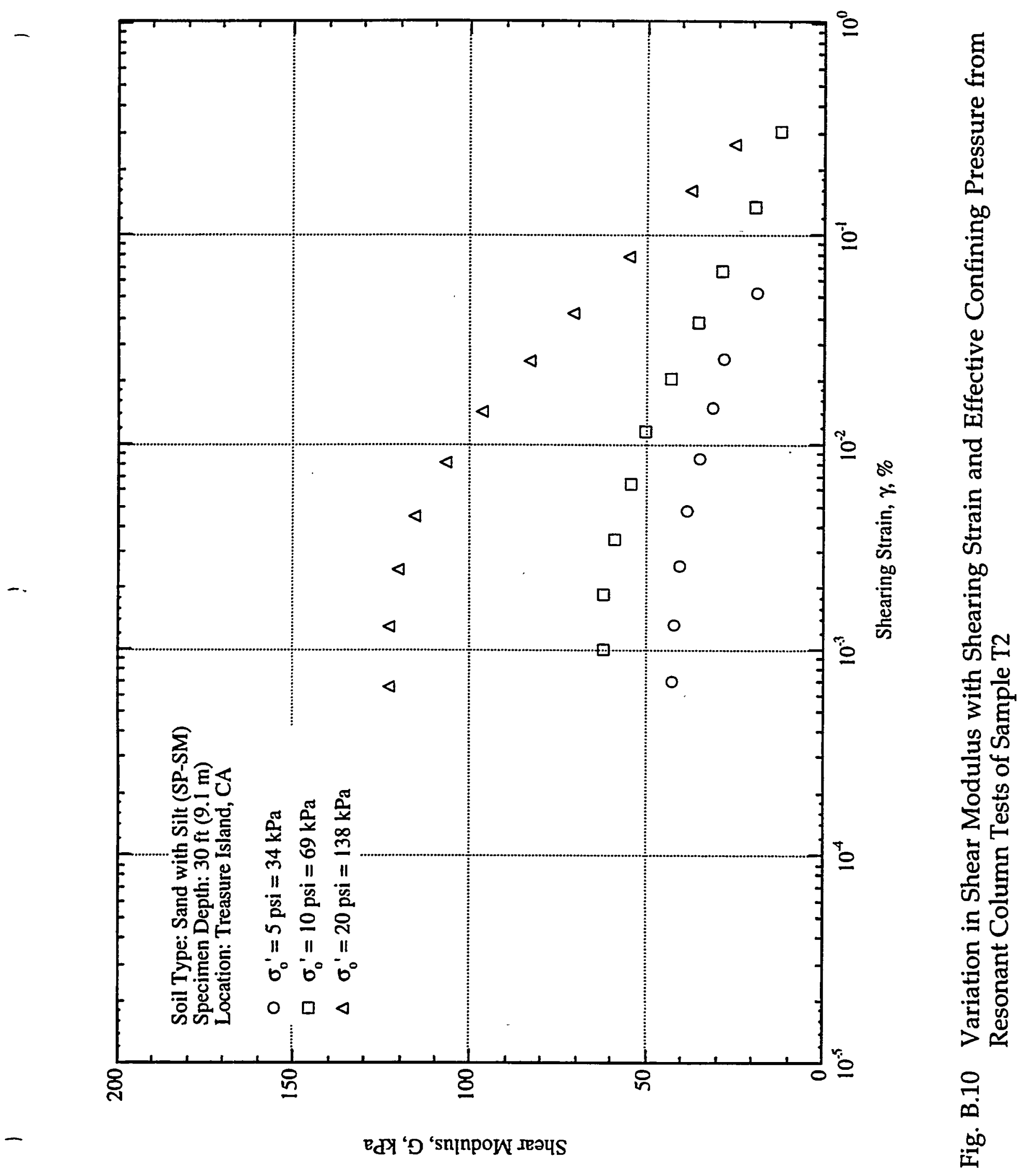




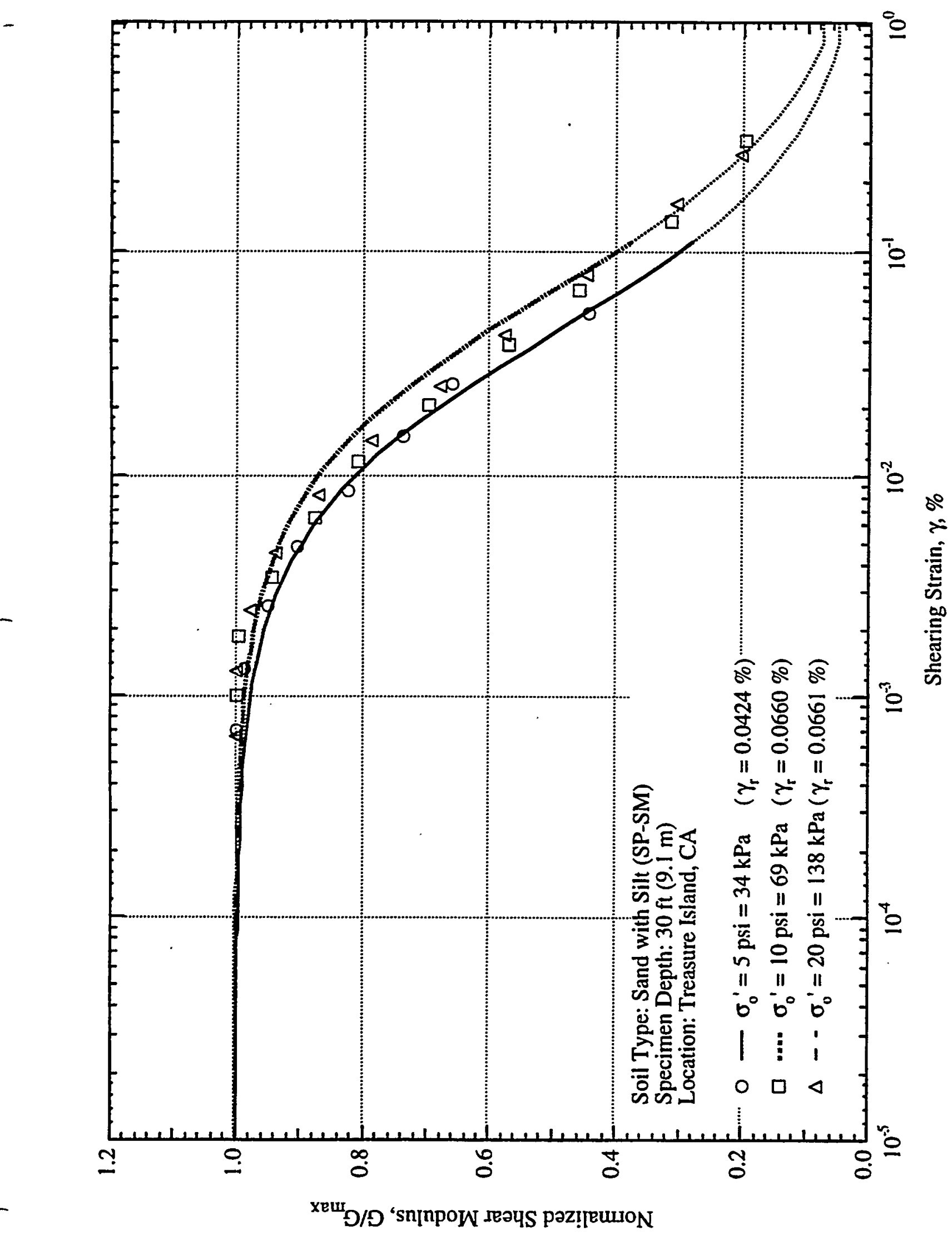

疋

号

营

产 $\frac{0}{3}$

요

光

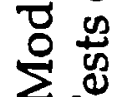

(1)

$-$

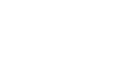

SRS-FR-CDP-95, rev. 0, 13 September 95 


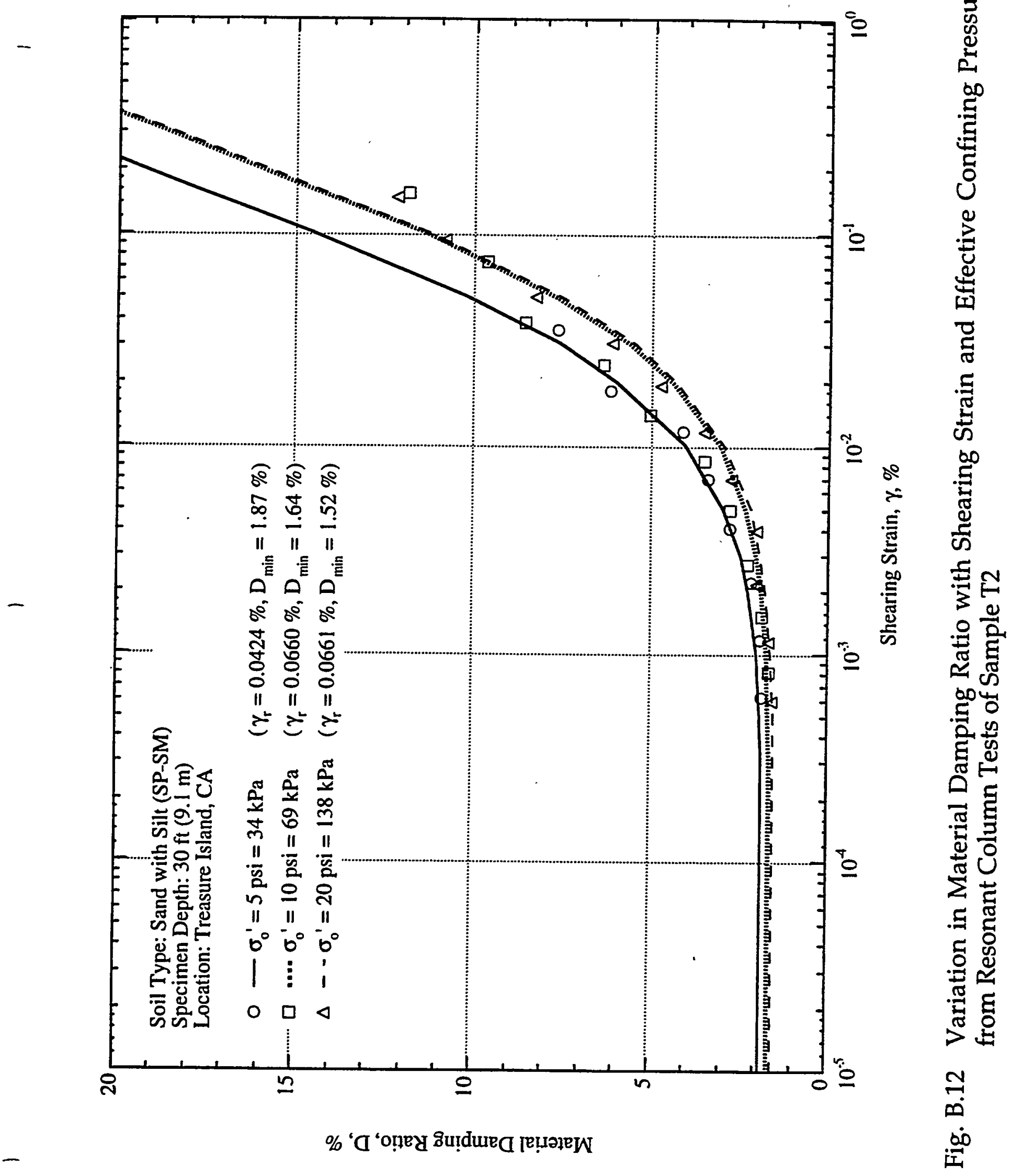




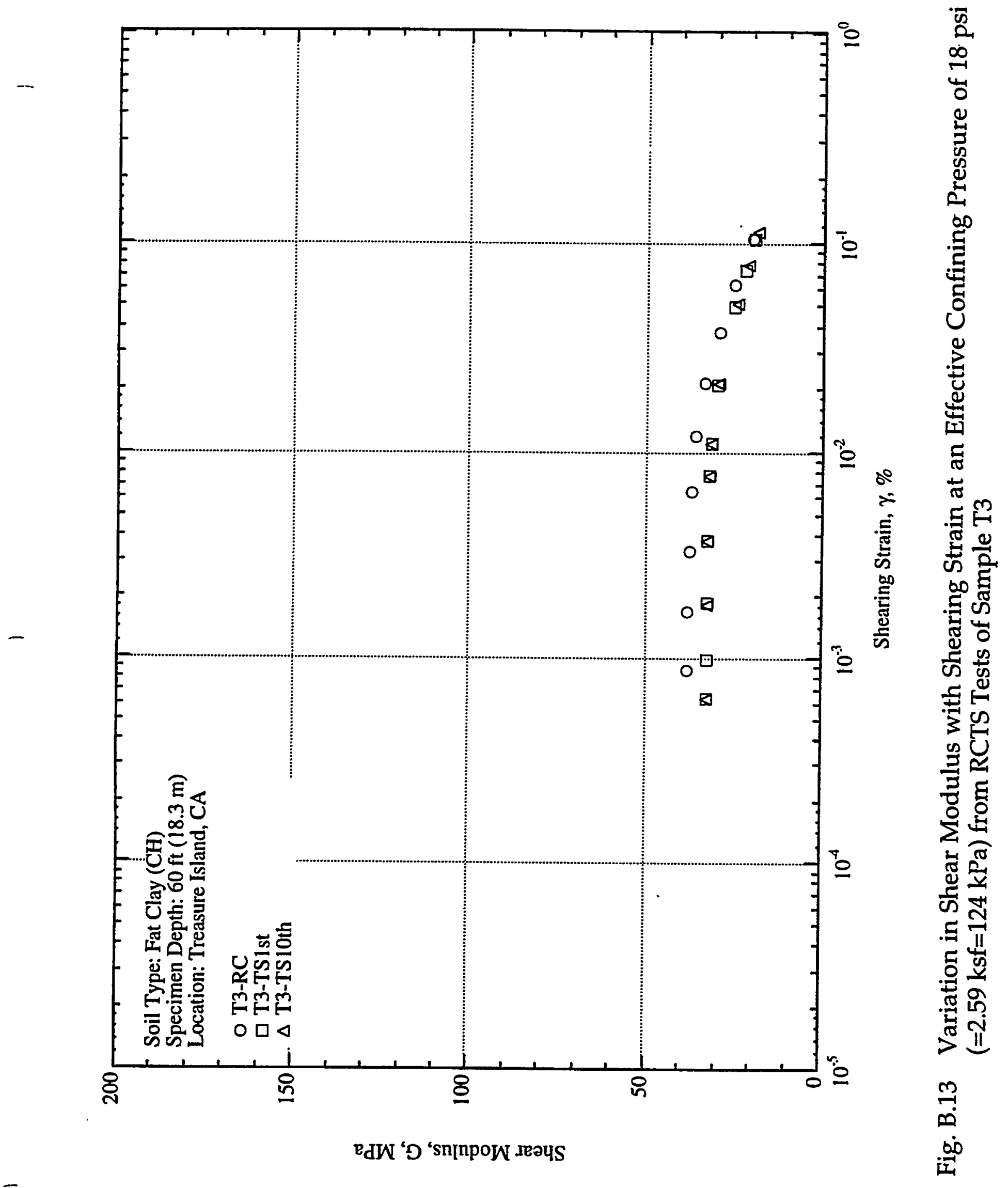




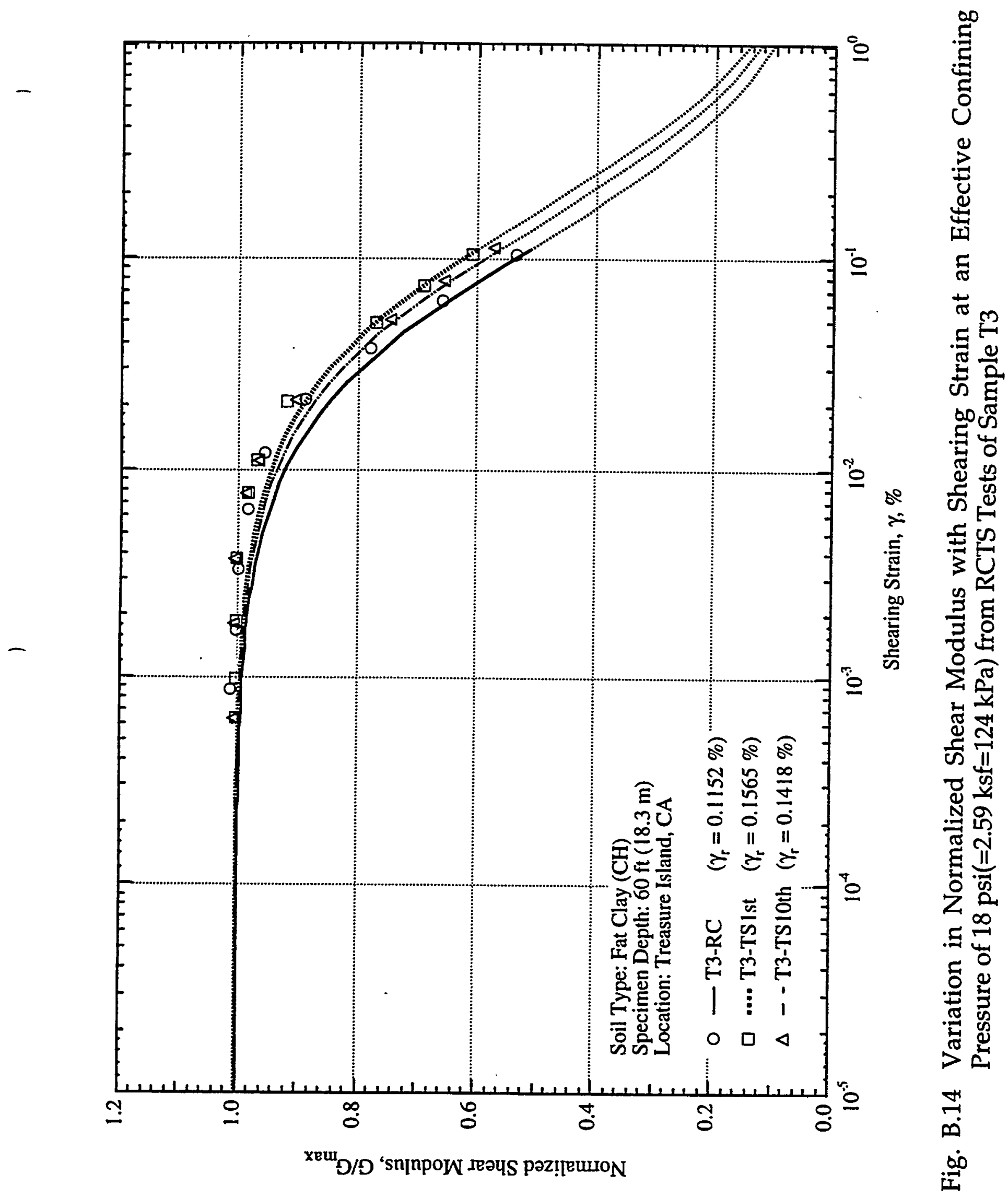




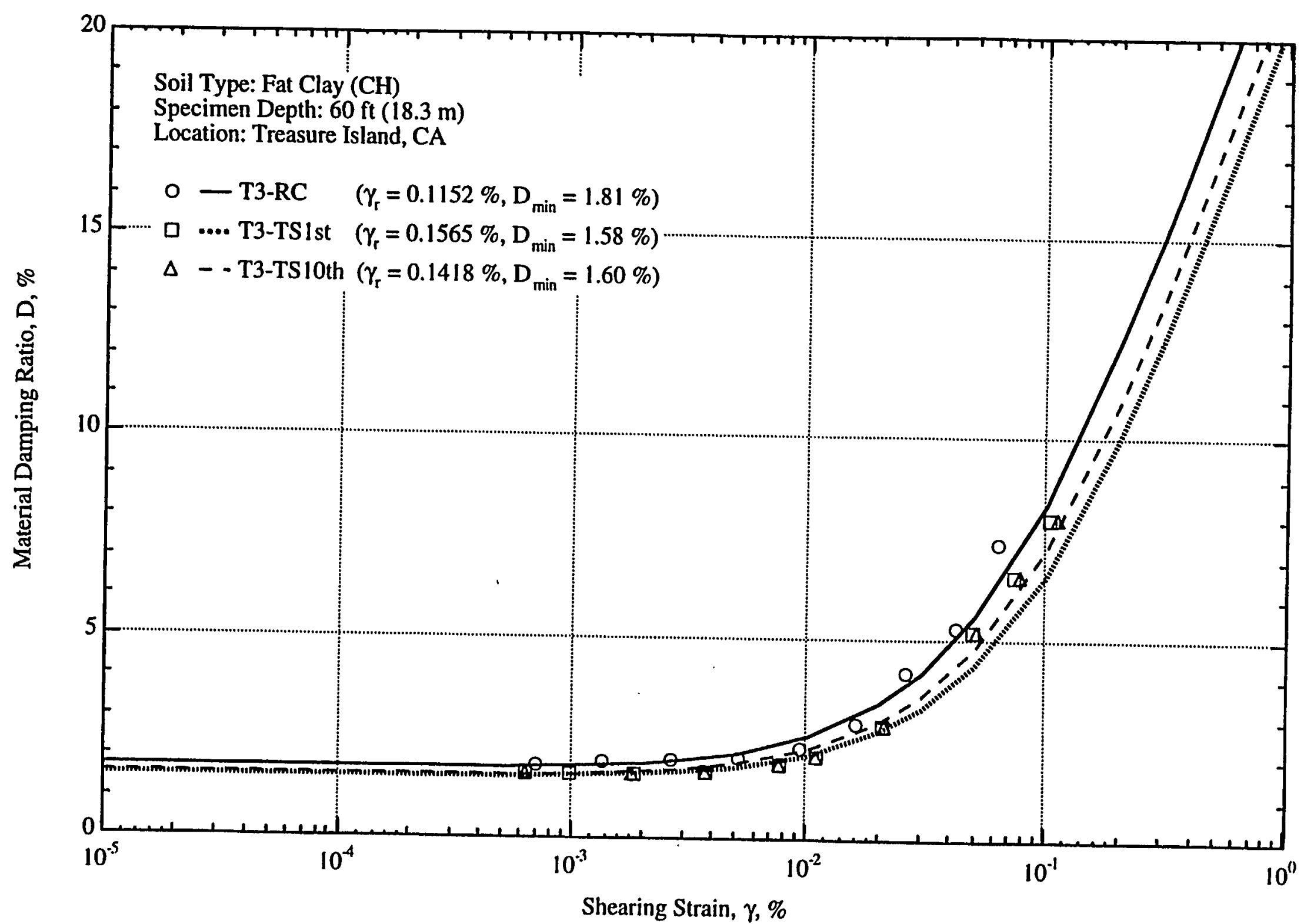

Fig. B.15 Variation in Material Damping Ratio with Shearing Strain at an Effective Confining Pressure of $18 \mathrm{psi}(=2.59 \mathrm{ksf}=124 \mathrm{kPa})$ from RCTS Tests of Sample T3 


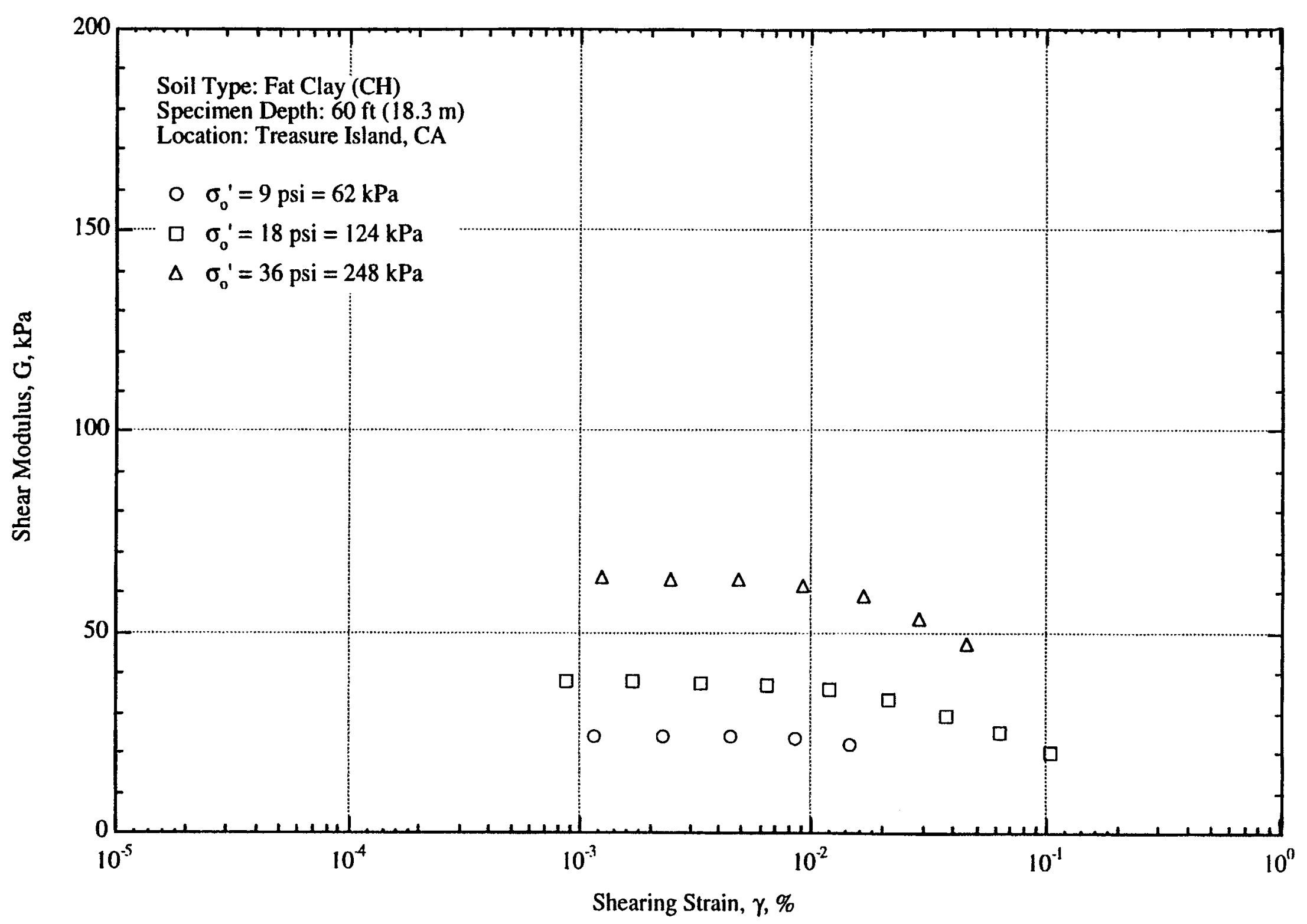

Fig. B.16 Variation in Shear Modulus with Shearing Strain and Effective Confining Pressure from Resonant Column Tests of Sample T3 

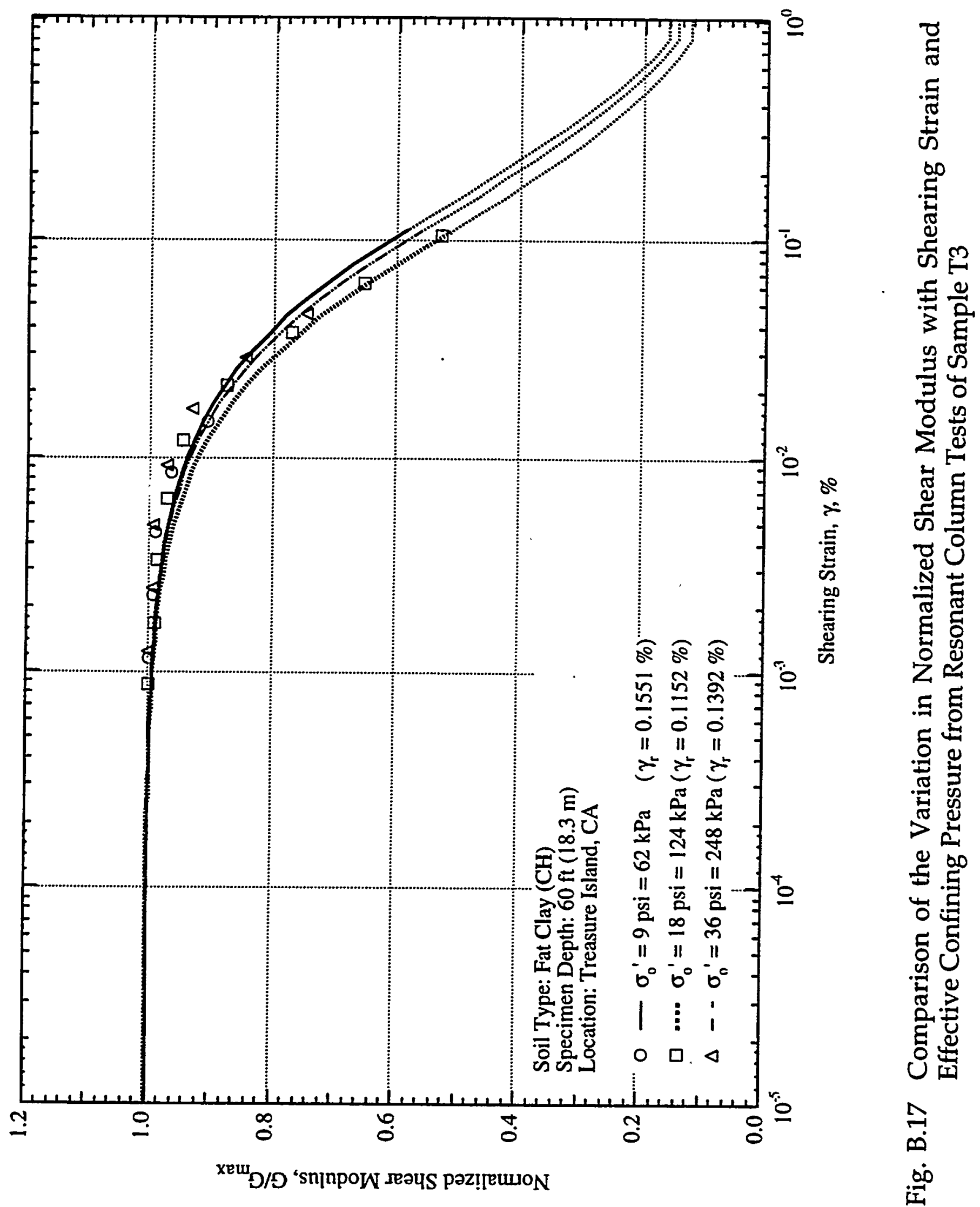

SRS-FR-CDP-95, rev. 0, 13 September 95 Project No. AA891070 


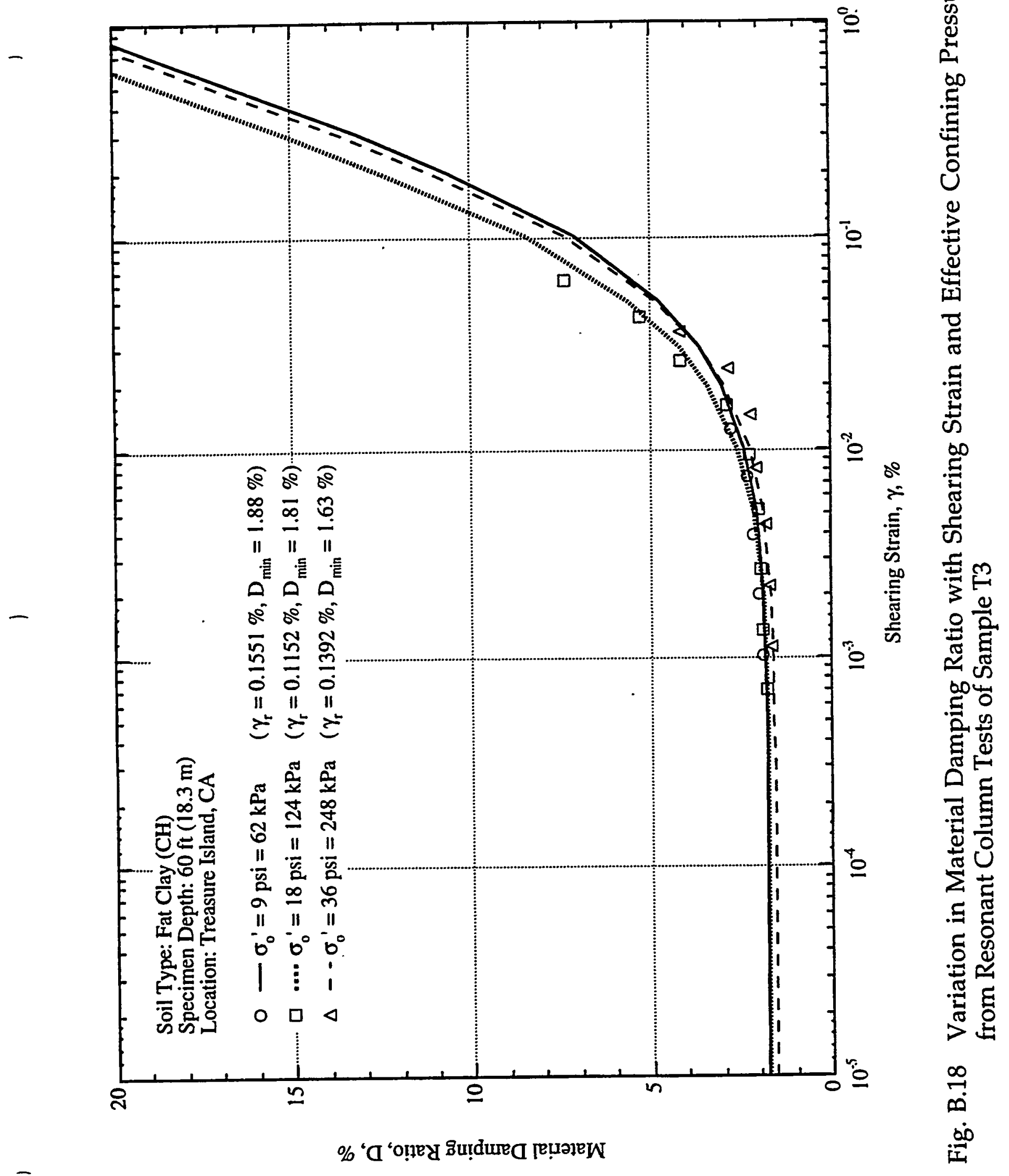

SRS-FR-CDP-95, rev. 0, 13 September 95 


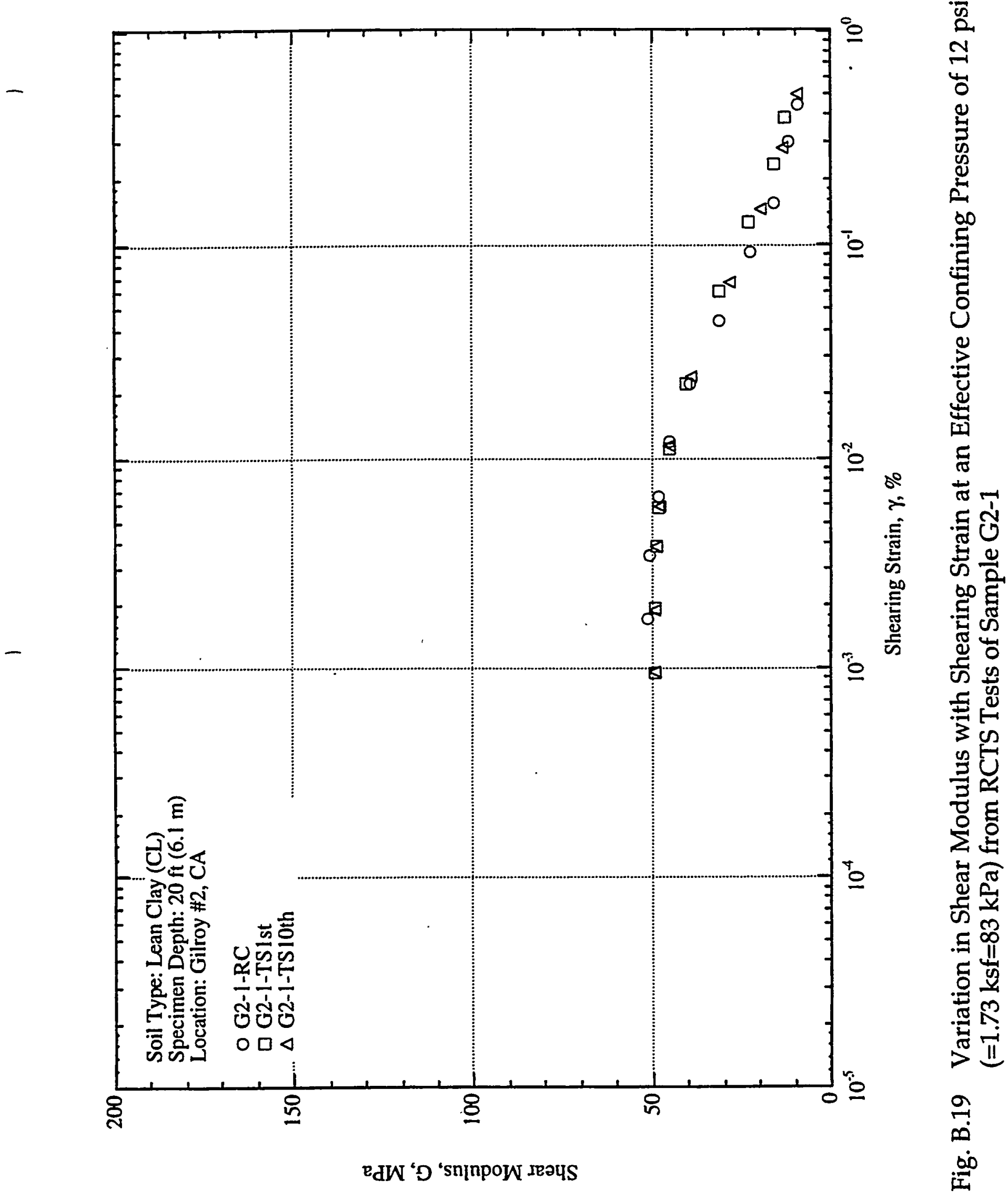

SRS-FR-CDP-95, rev. 0, 13 September 95 


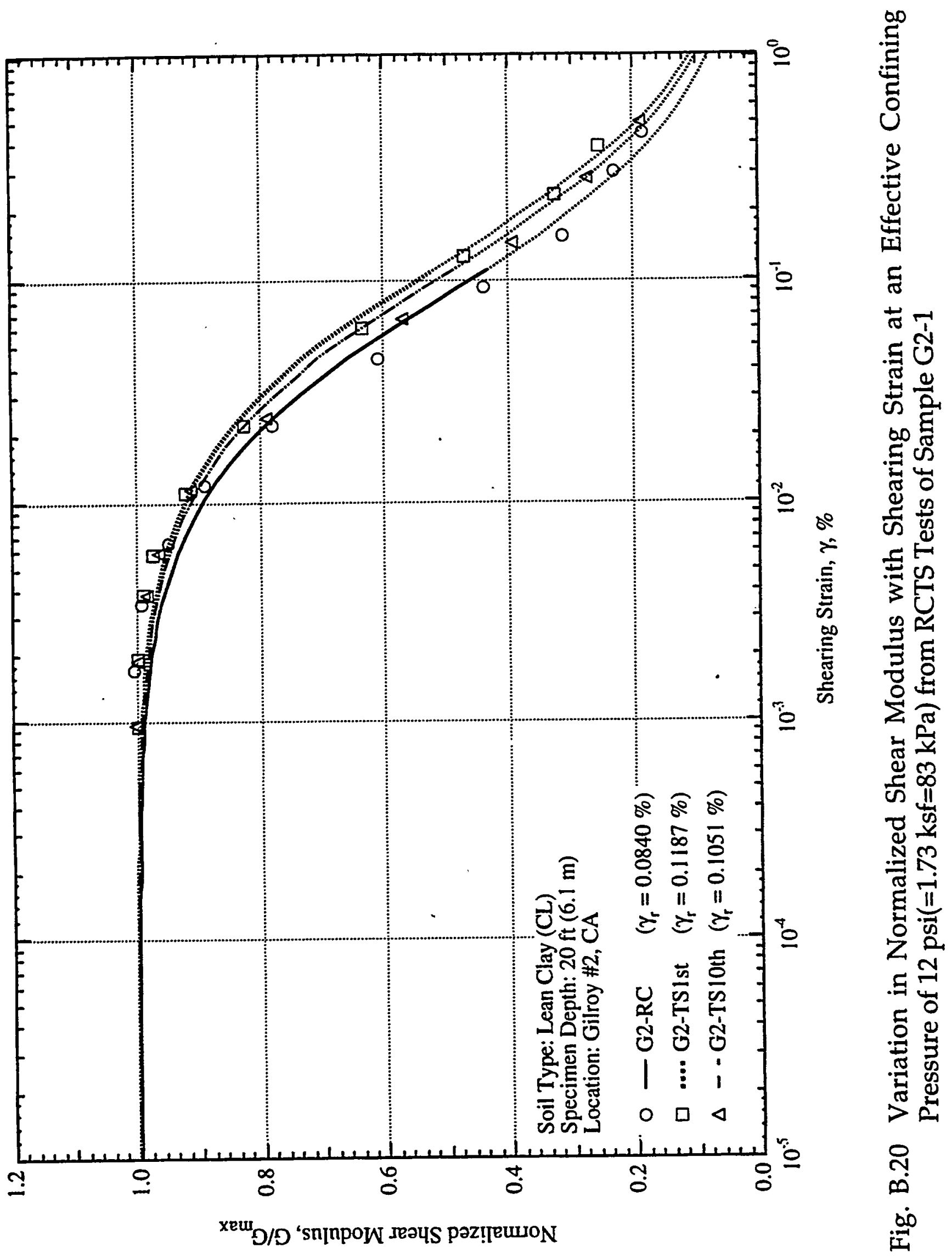

SRS-FR-CDP-95, rev. 0, 13 September 95 


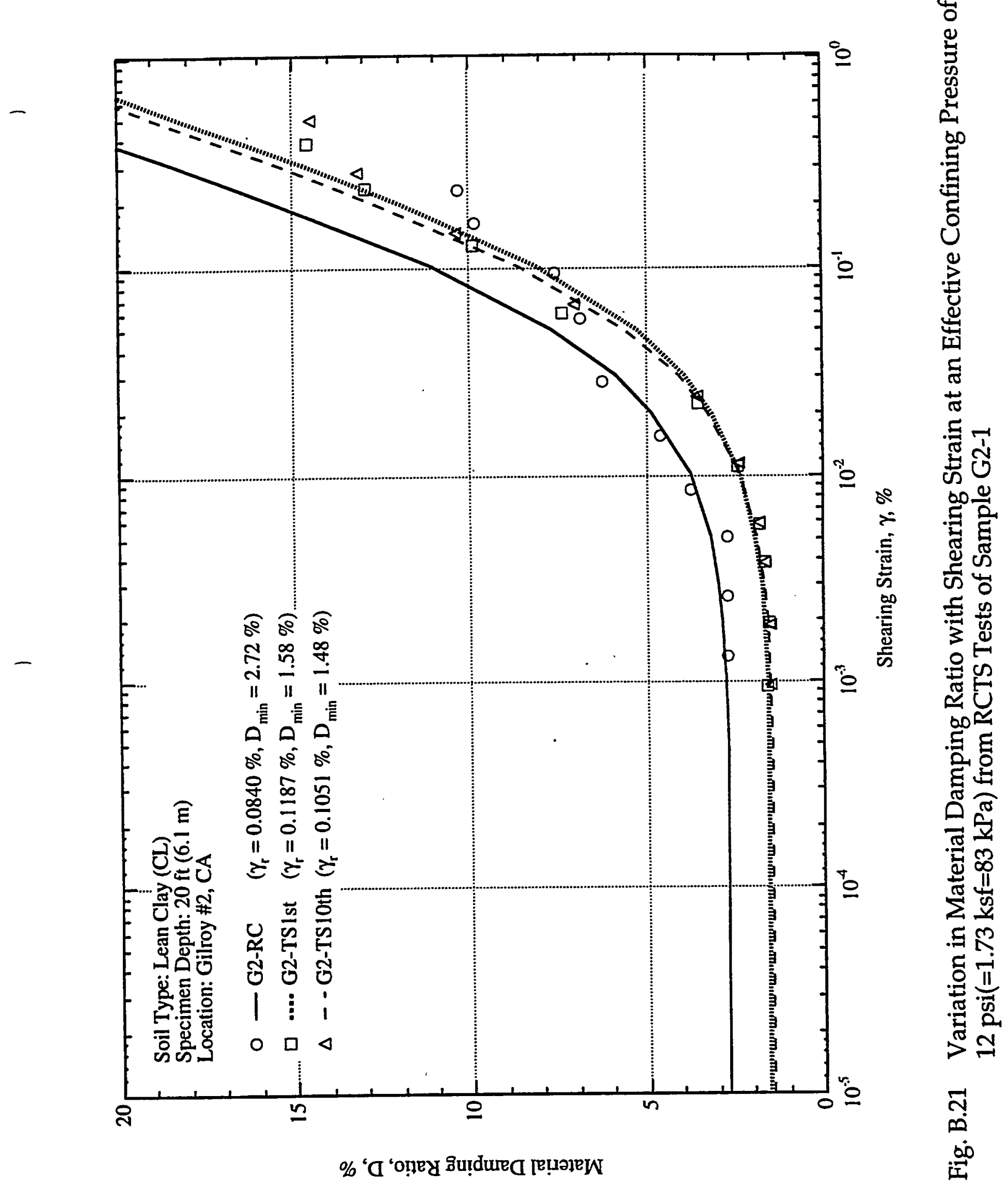

SRS-FR-CDP-95, rev. 0, 13 September 95 


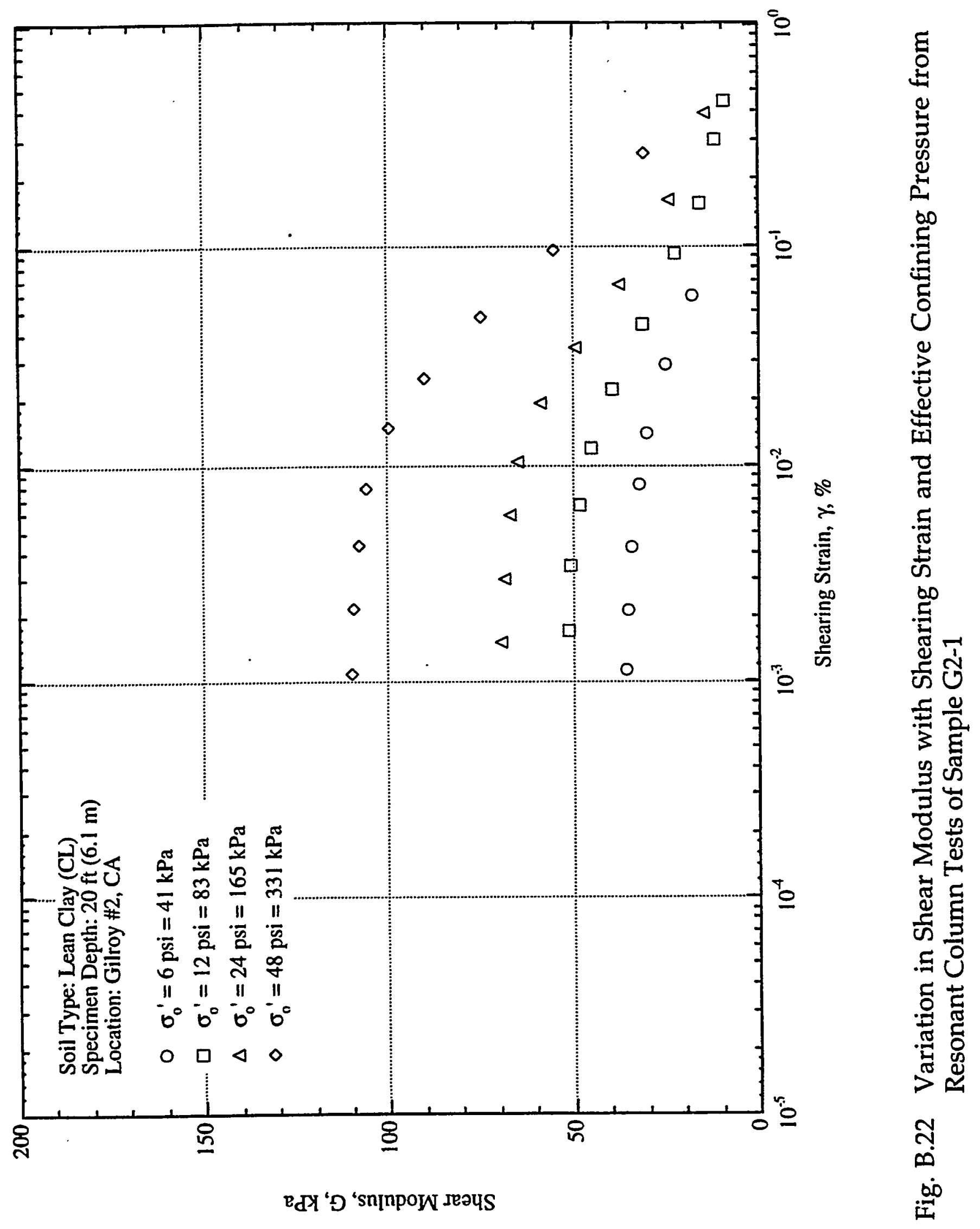

SRS-FR-CDP-95, rev. 0, 13 September 95 


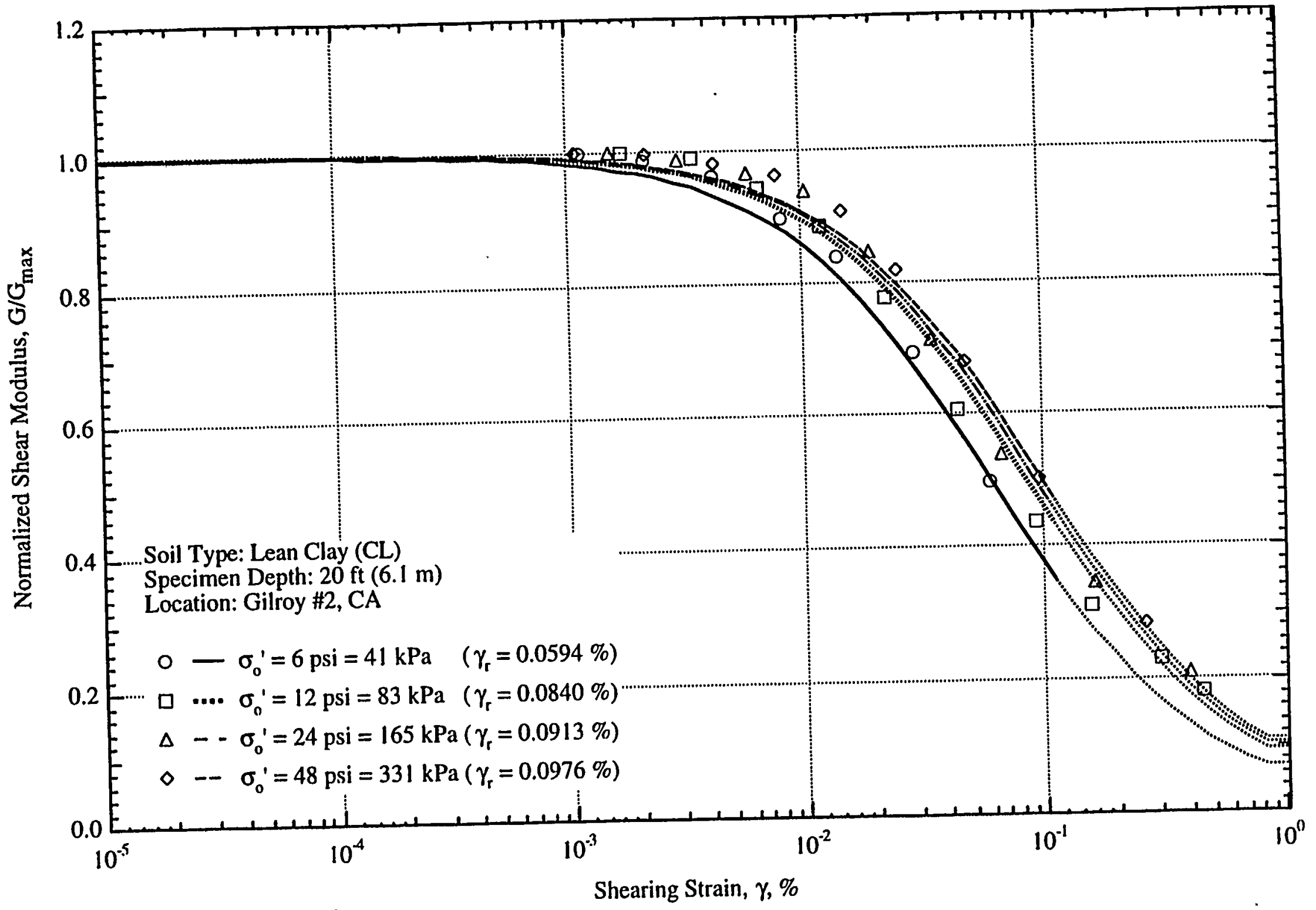

Fig. B.23 Comparison of the Variation in Normalized Shear Modulus with Shearing Strain and Effective Confining Pressure from Resonant Column Tests of Sample G2-1 


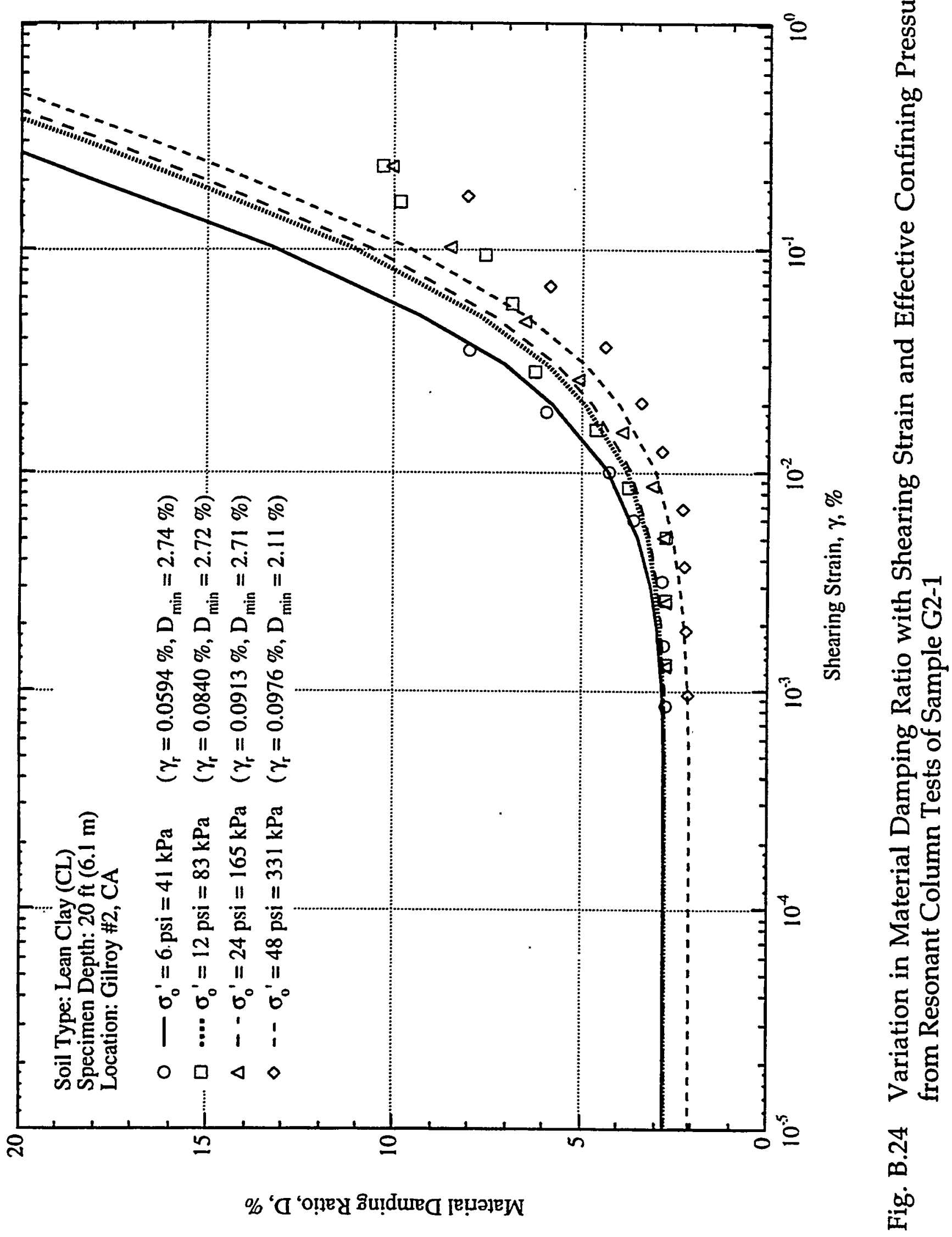

SRS-FR-CDP-95, rev. 0, 13 September 95

Project No. AA891070 


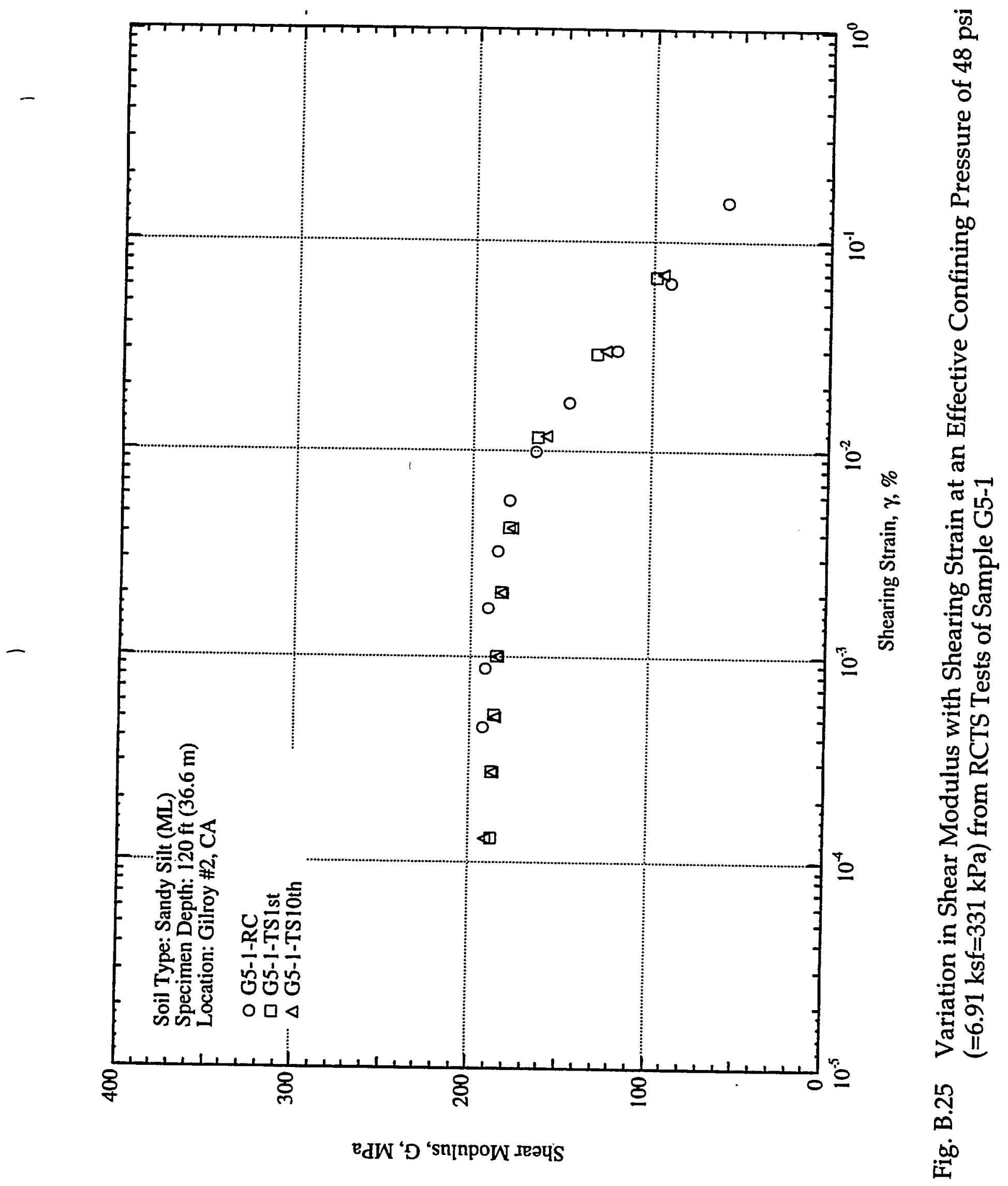

SRS-FR-CDP-95, rev. 0, 13 September 95

Project No. AA891070 


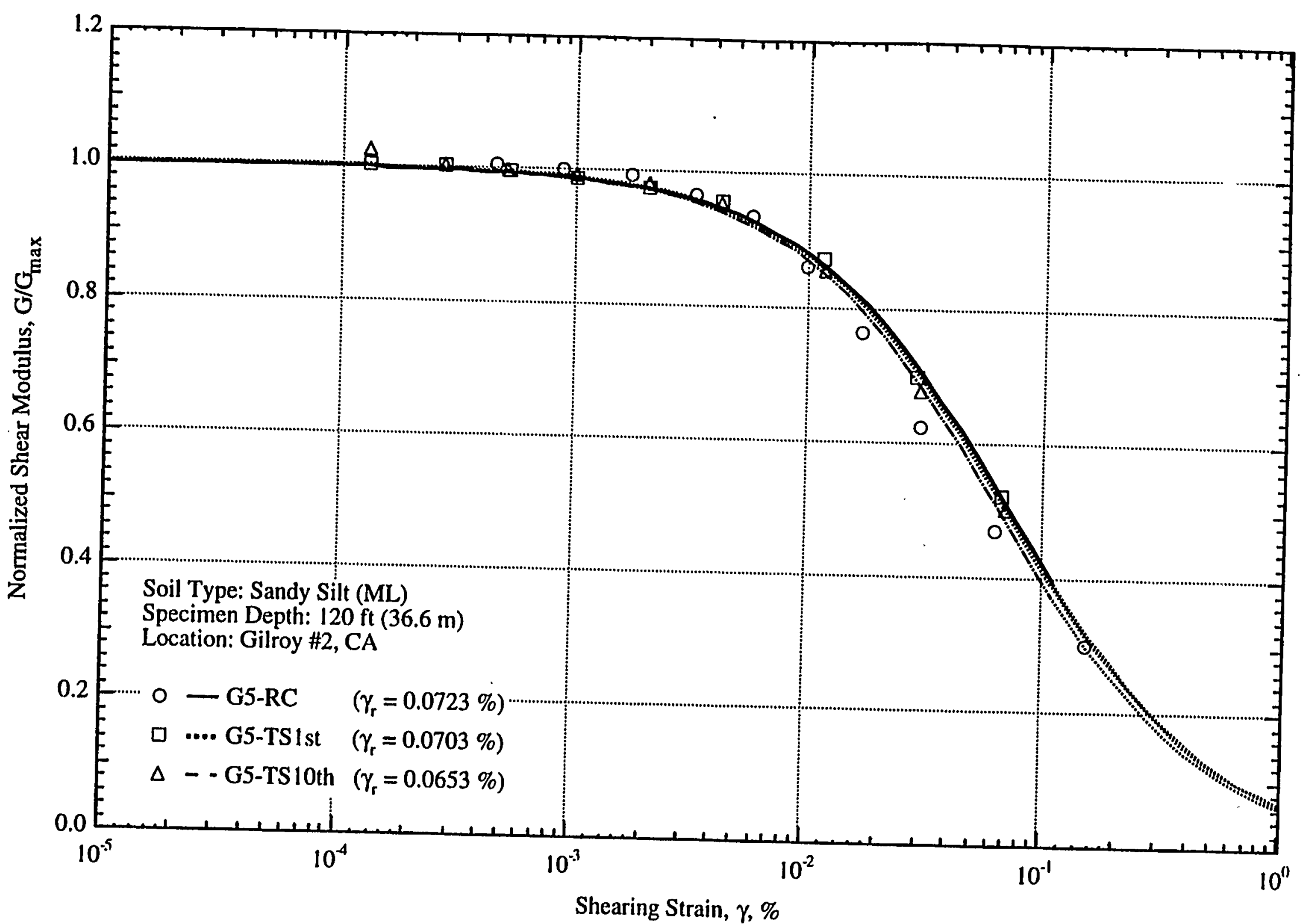

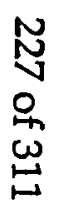

Shearing Strain, $\gamma, \%$ Fig. B.26 Variation in Normalized Shear Modulus with Shearing Strain at an Effective Confining
Pressure of $48 \mathrm{psi}(=6.91 \mathrm{ksf}=331 \mathrm{kPa})$ from RCTS Tests of Sample G5-1 


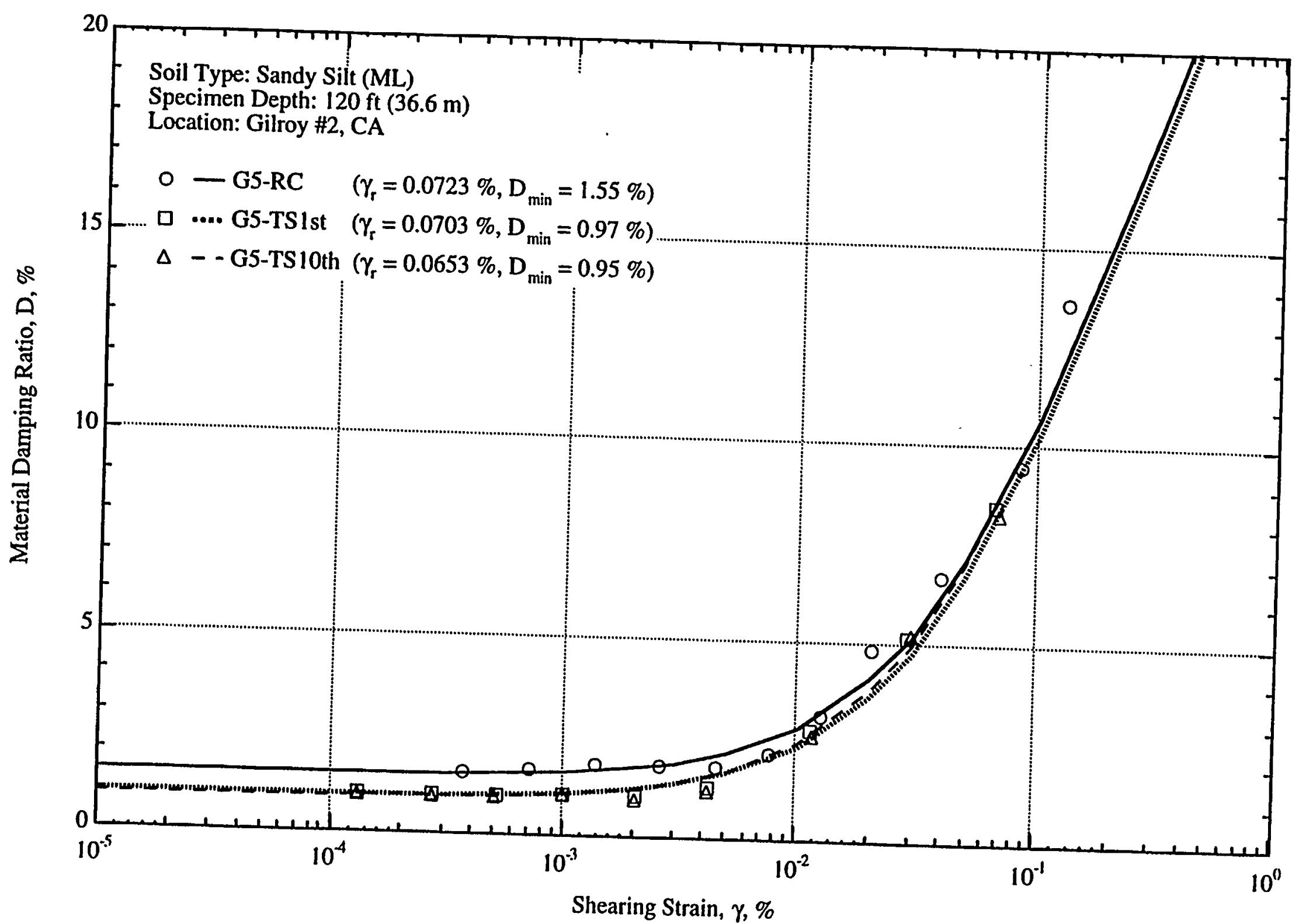

Fig. B.27 Variation in Material Damping Ratio with Shearing Strain at an Effective Confining Pressure of
$48 \mathrm{psi}(=6.91 \mathrm{ksf}=331 \mathrm{kPa})$ from RCTS Tests of Sample $\mathrm{G}-1$ 

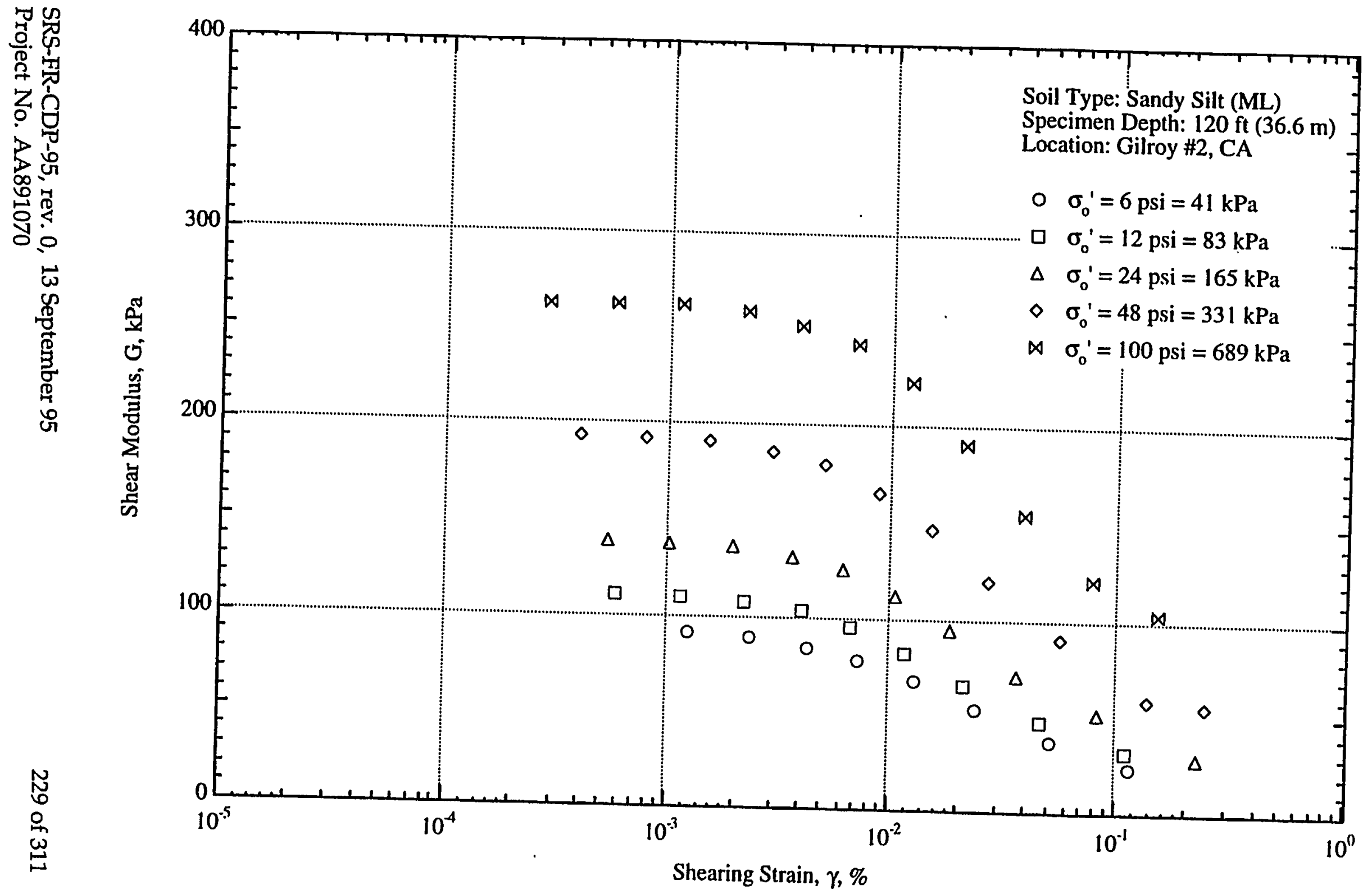

Fig. B.28 Variation in Shear Modulus with Shearing Strain and Effective Confining Pressure from
Resonant Column Tests of Sample G5-1 

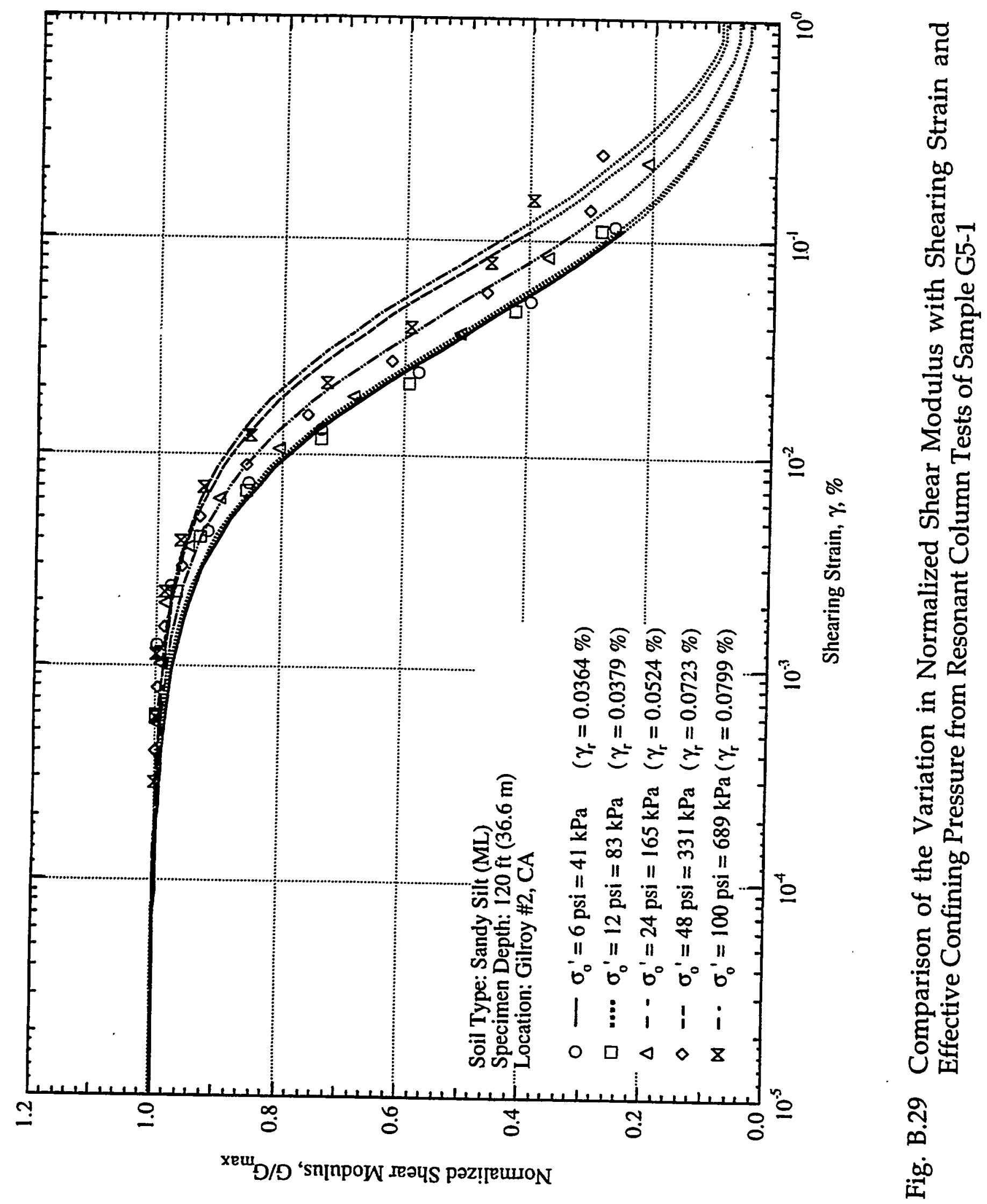

SRS-FR-CDP-95, rev. 0, 13 September 95

Project No. AA891070 


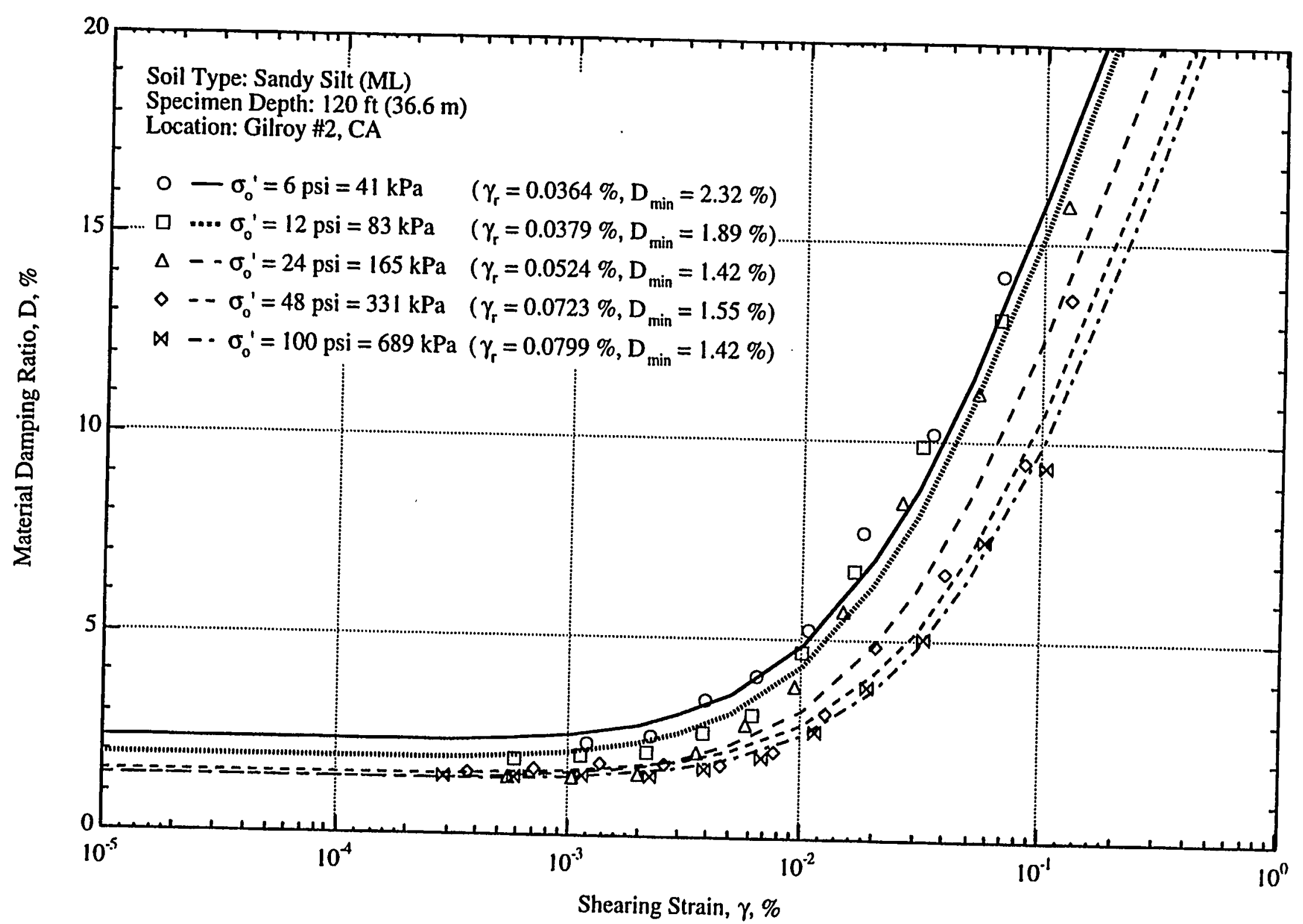

Fig. B.30 Variation in Material Damping Ratio with Shearing Strain and Effective Confining Pressure from Resonant Column Tests of Sample G5-1 


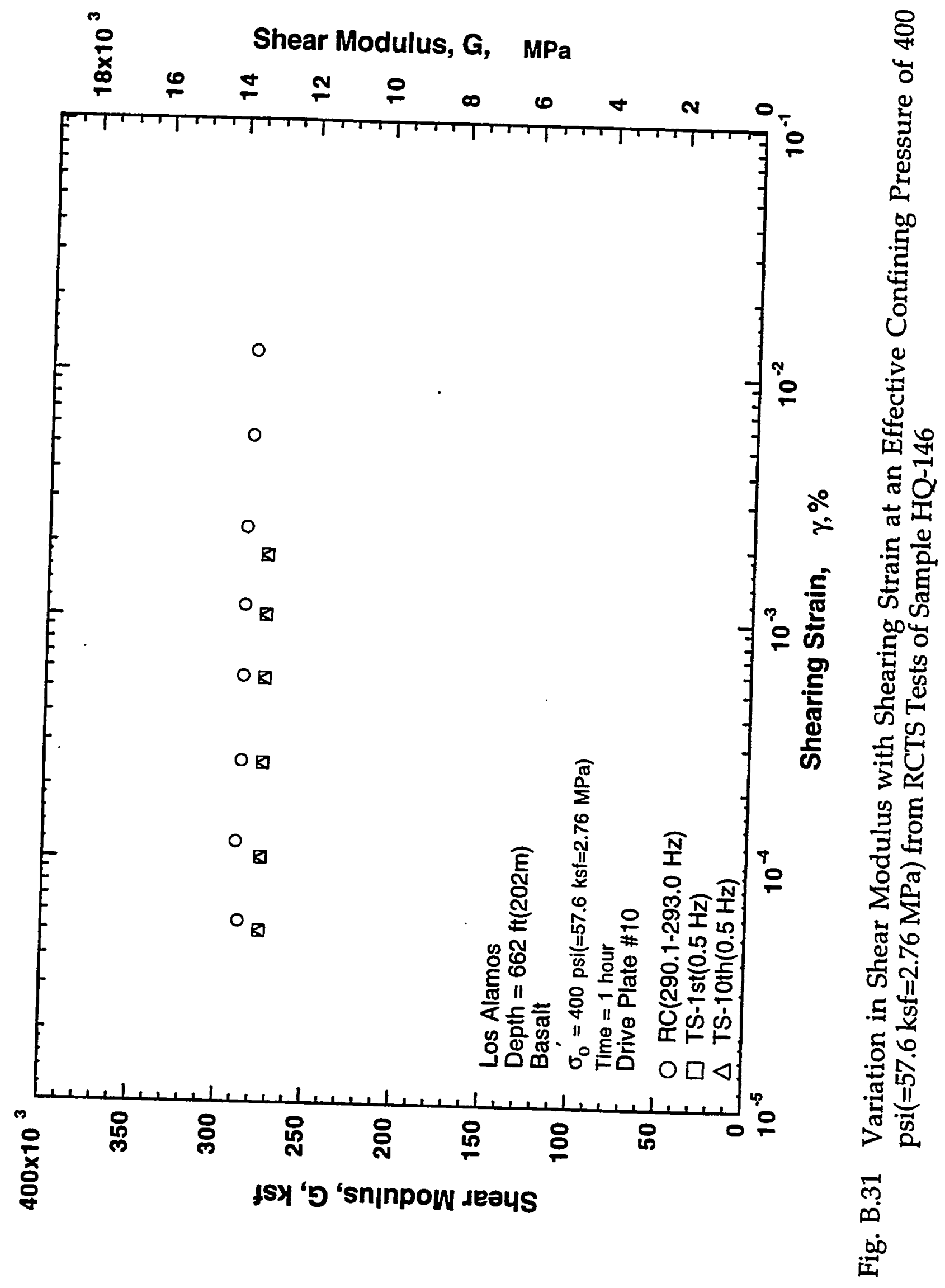




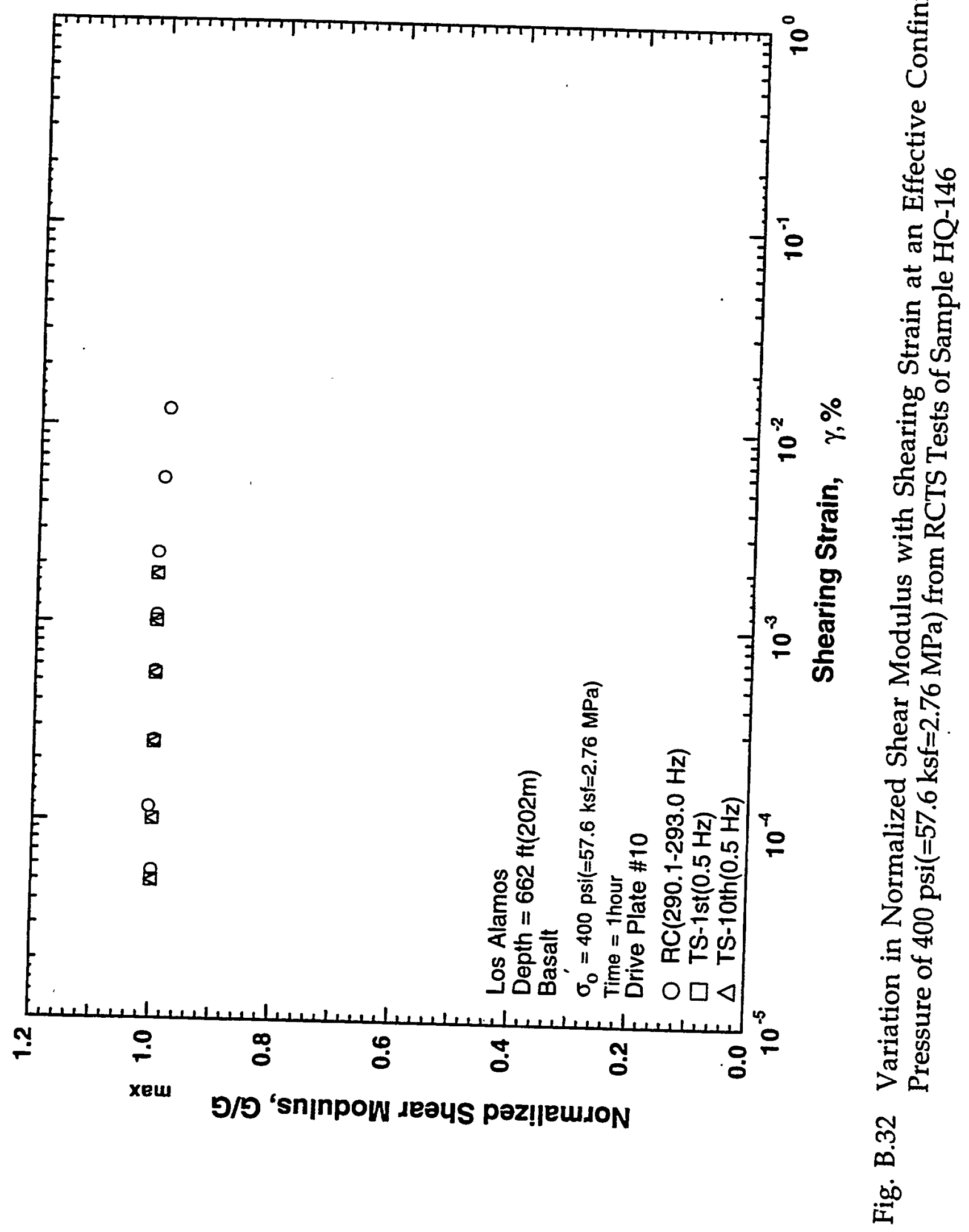

SRS-FR-CDP-95, rev. 0, 13 September 95

Project No. AA891070 


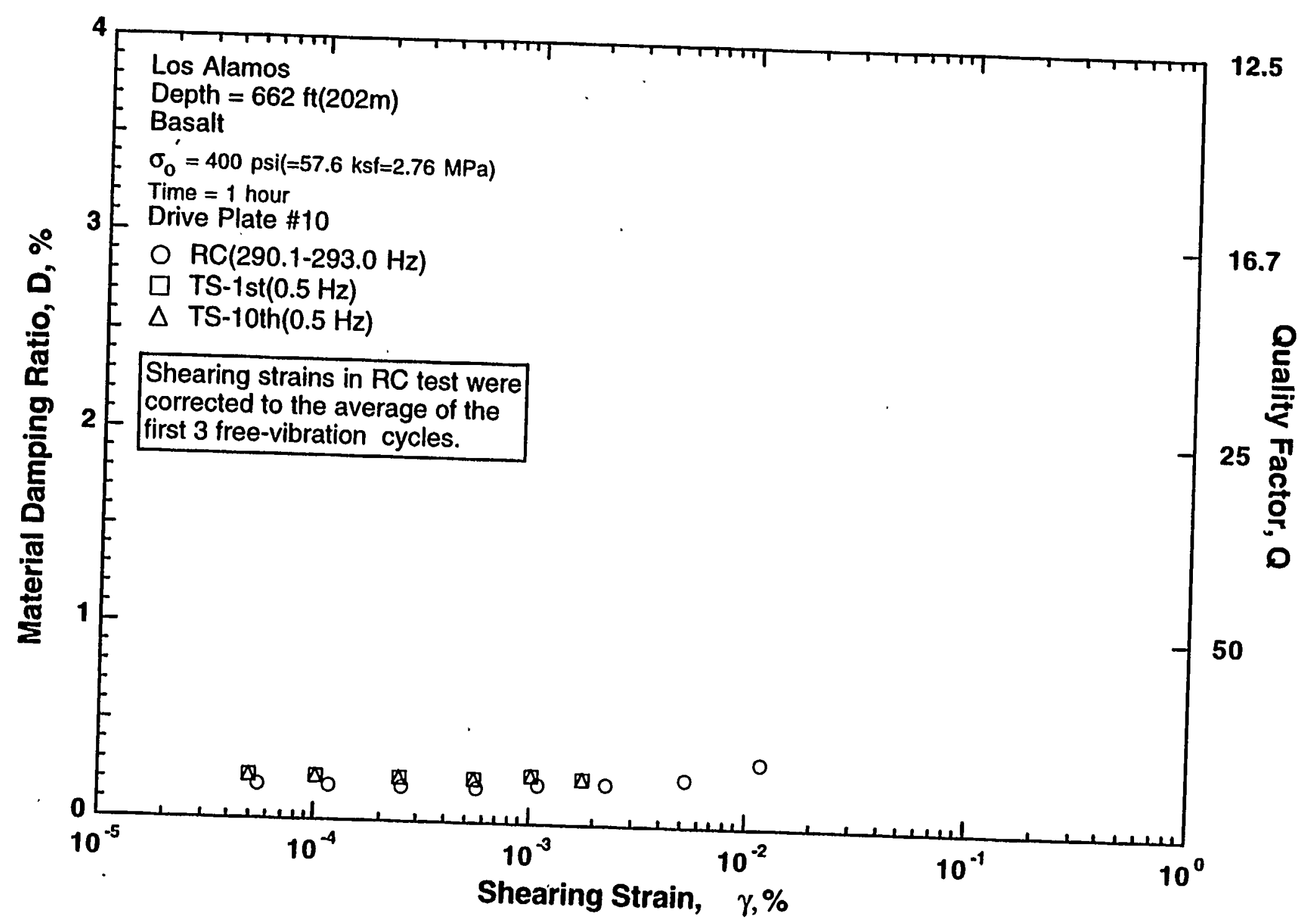

Fig. B.33 Variation in Material Damping Ratio with Shearing Strain at an Effective Confining Pressure of $400 \mathrm{psi}(=57.6 \mathrm{ksf}=2.76 \mathrm{MPa})$ from RCTS Tests of Sample HQ-146 


\section{Appendix C}

\section{Effects of Excitation Frequency, Number of Loading Cycles and Confining Pressure on the Dynamic Properties of Dry Branch and Santee Sands (Specimens CFD-4a, CFD-5a, and CFD-7a)}




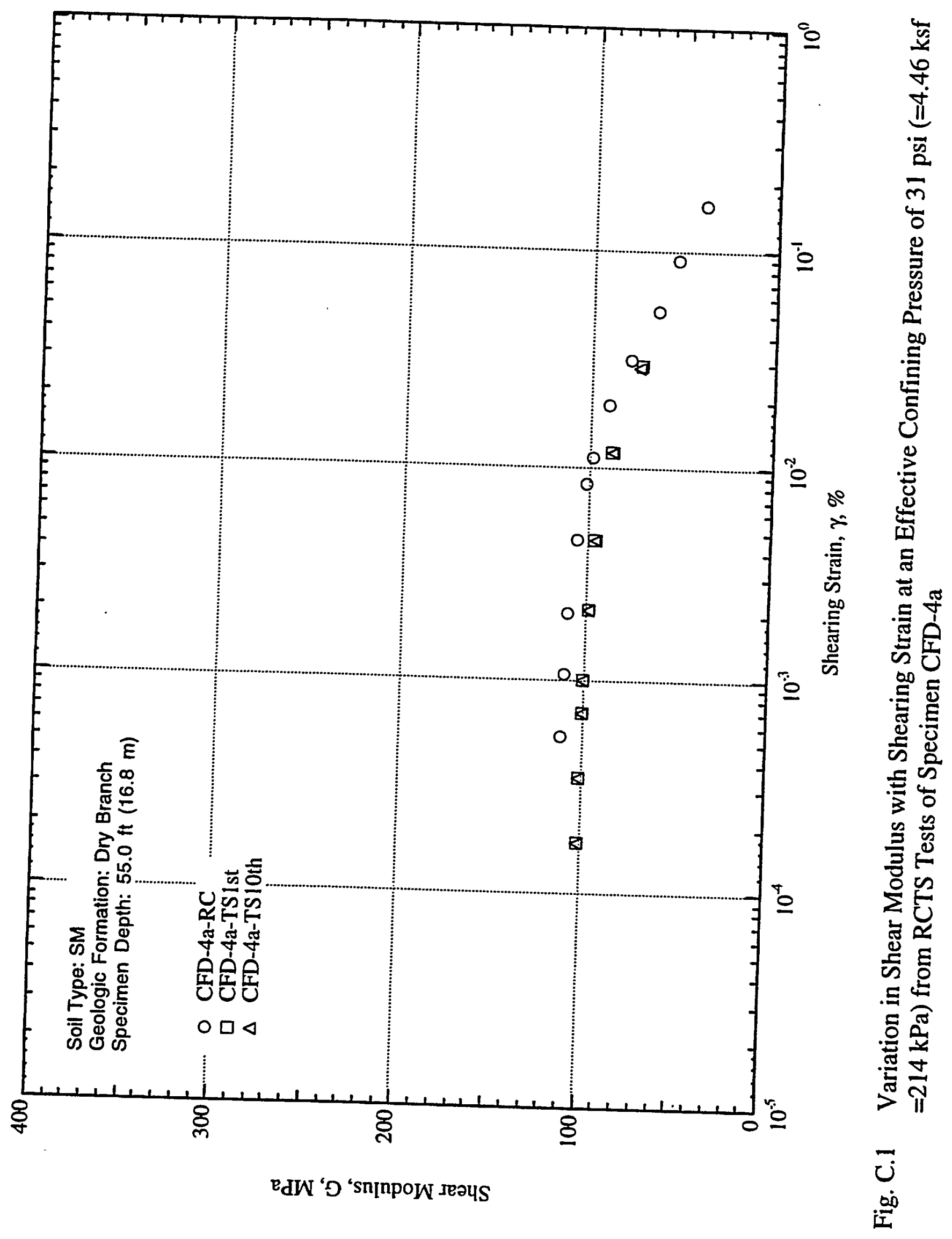

SRS-FR-CDP-95, rev. 0, 13 September 95

Project No. AA891070 


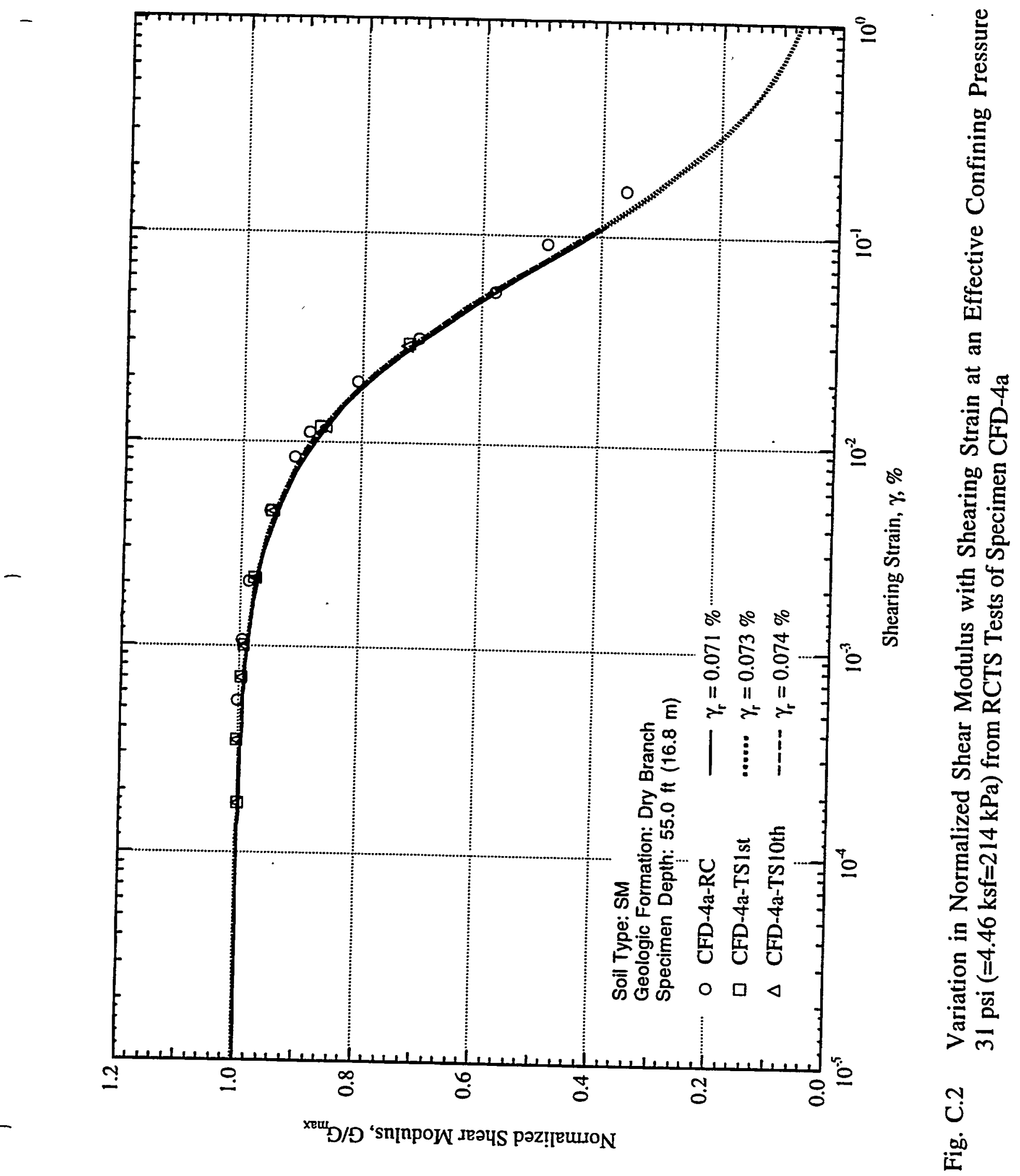

SRS-FR-CDP-95, rev. 0, 13 September 95

Project No. AA891070 


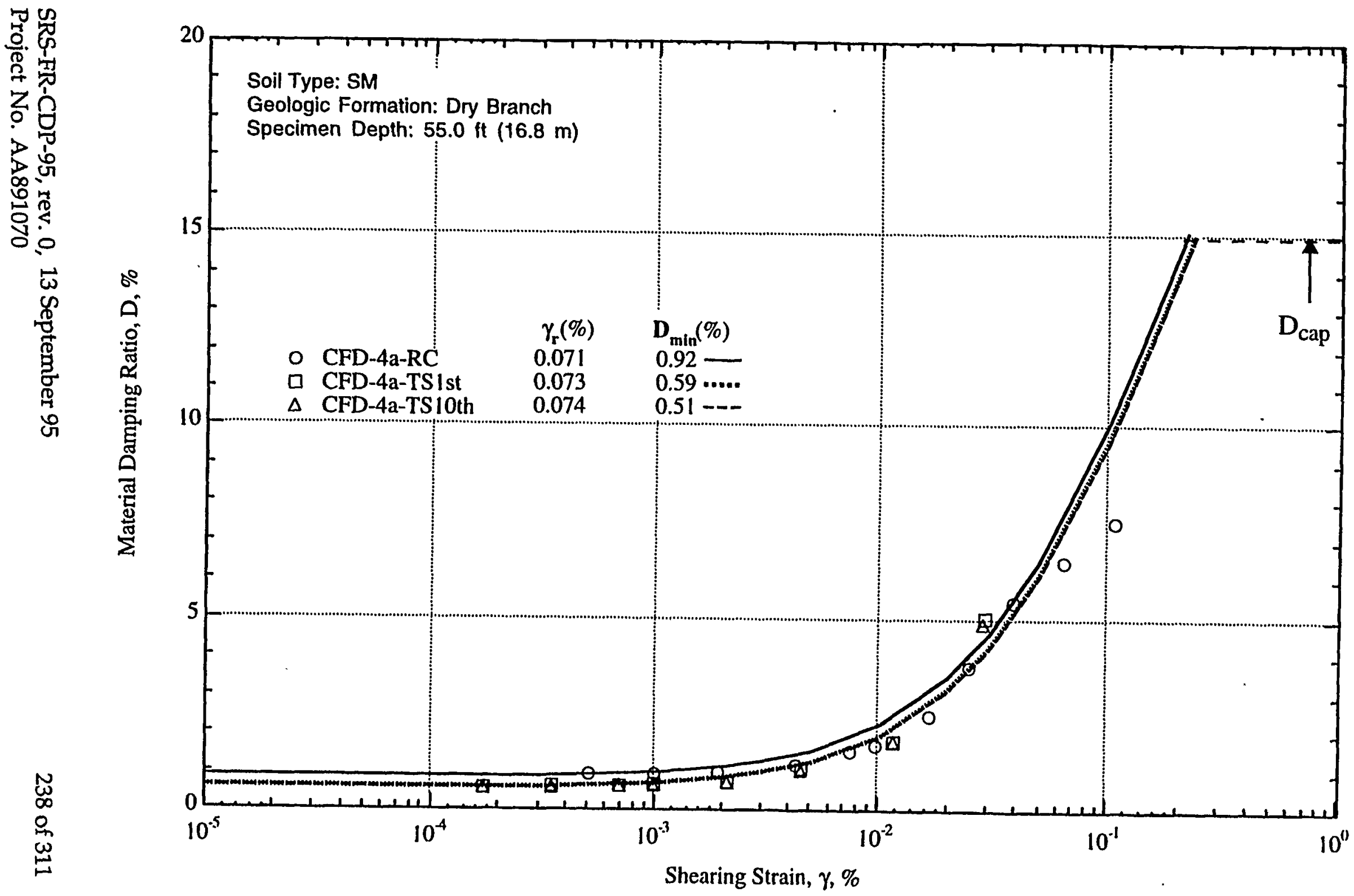

Fig. C.3 Variation in Material Damping Ratio with Shearing Strain at an Effective Confining Pressure of $31 \mathrm{psi}$ $(=4.46 \mathrm{ksf}=214 \mathrm{kPa})$ from RCTS Tests of Specimen CFD $-4 \mathrm{a}$ 


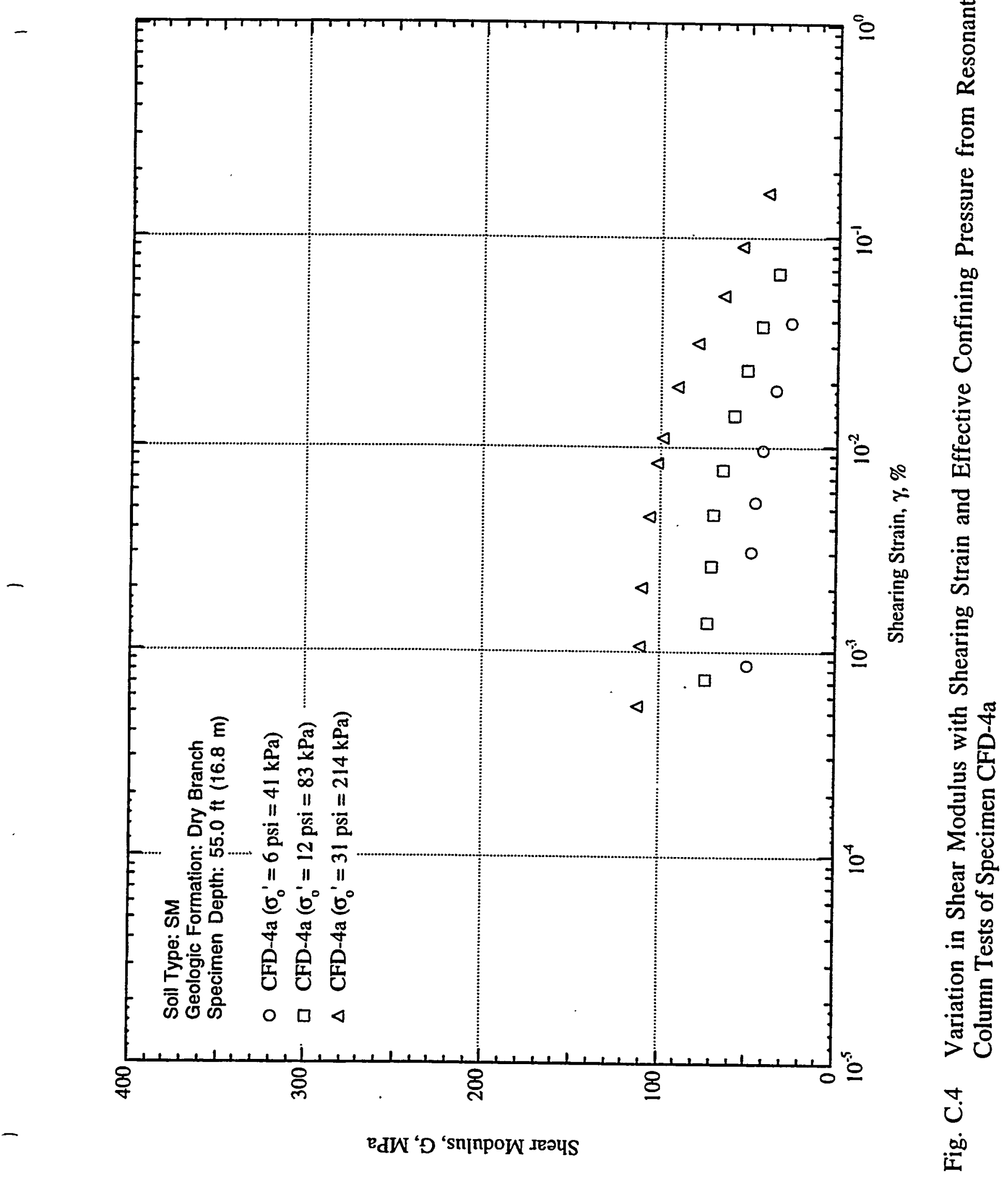

SRS-FR-CDP-95, rev. 0, 13 September 95

Project No. AA891070 


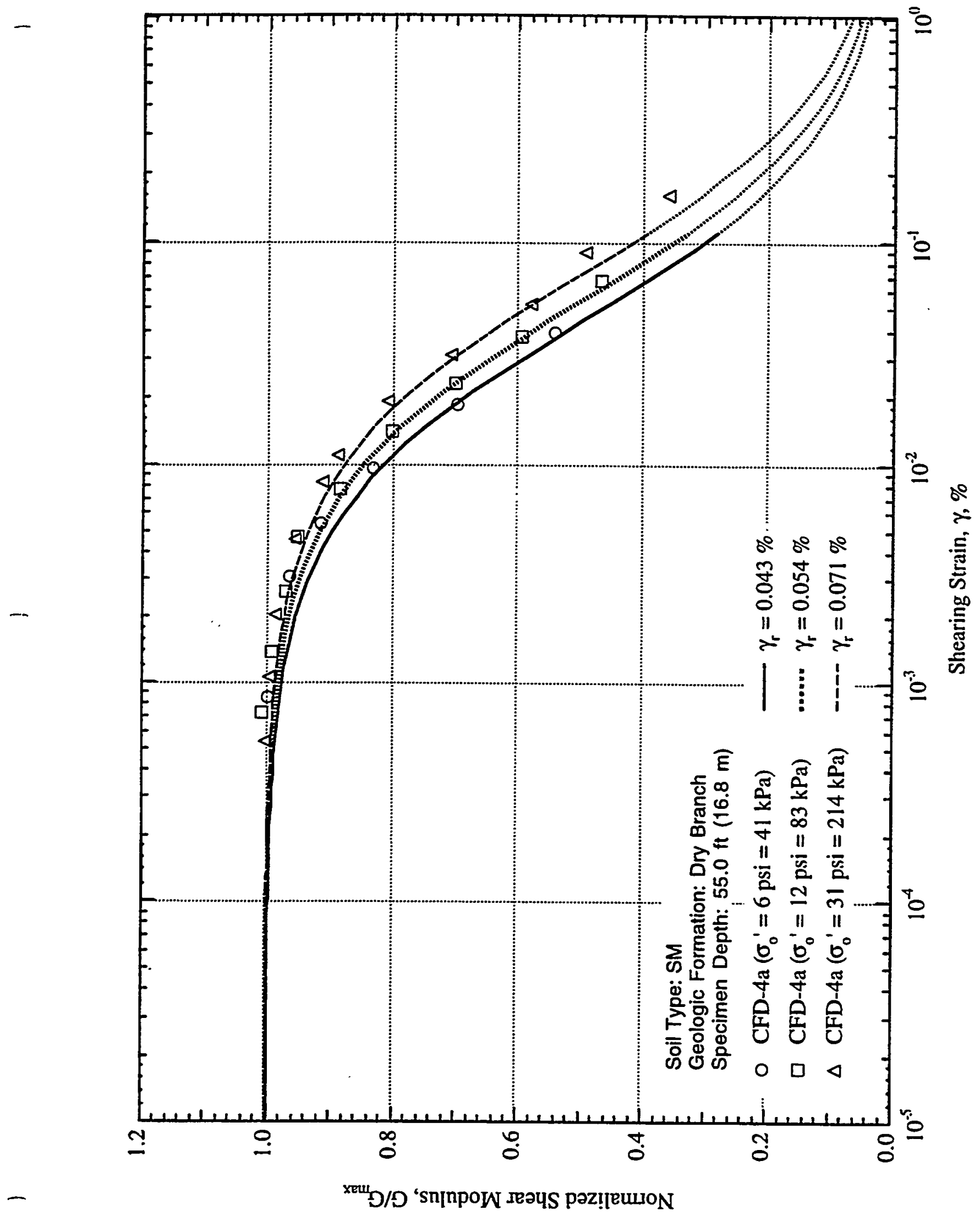

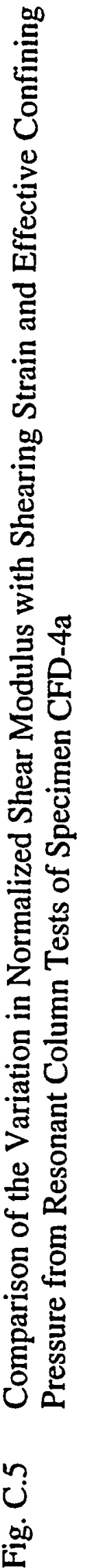




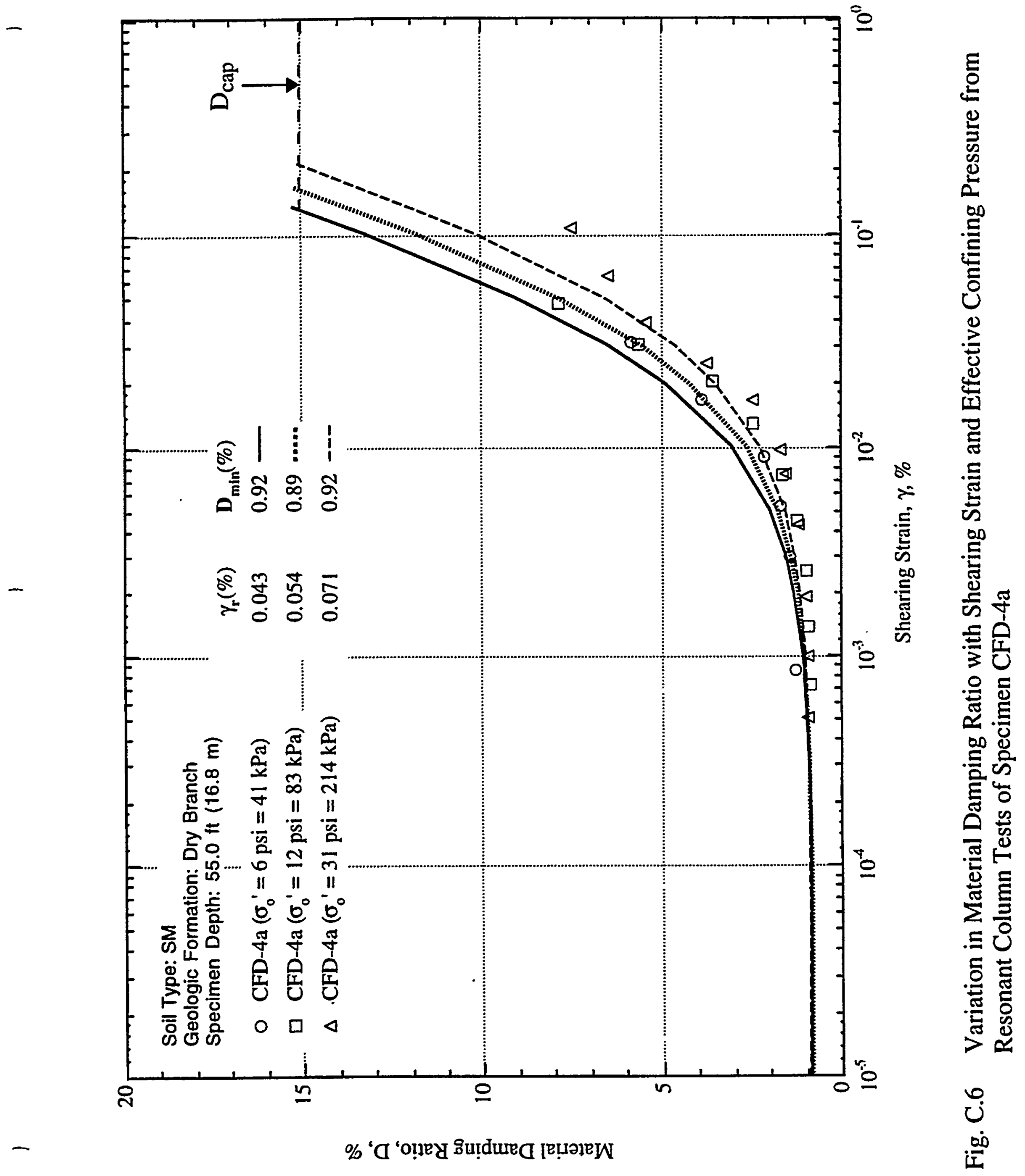

SRS-FR-CDP-95, rev. 0, 13 September 95 


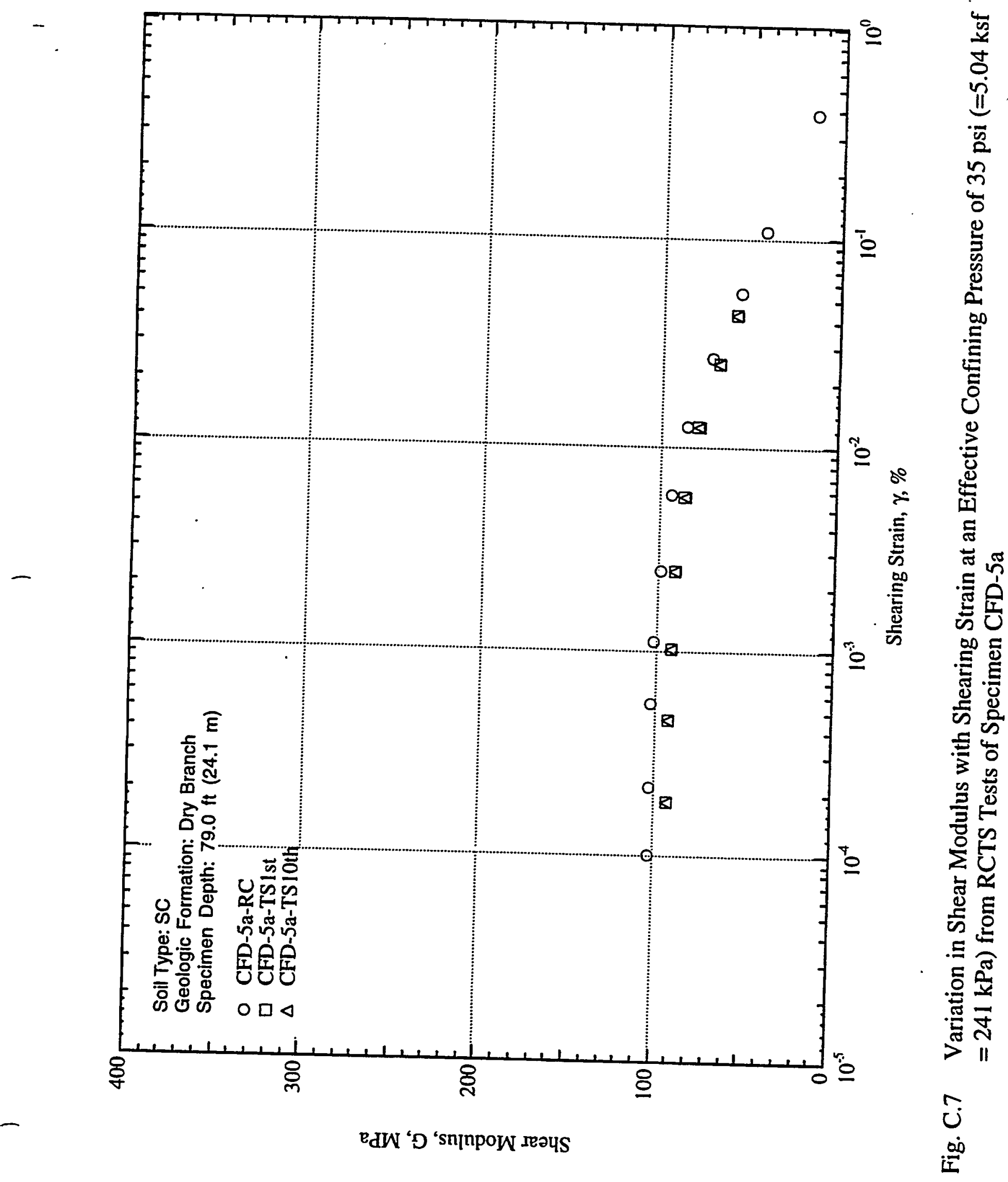

SRS-FR-CDP-95, rev. 0, 13 September 95

Project No. AA891070 


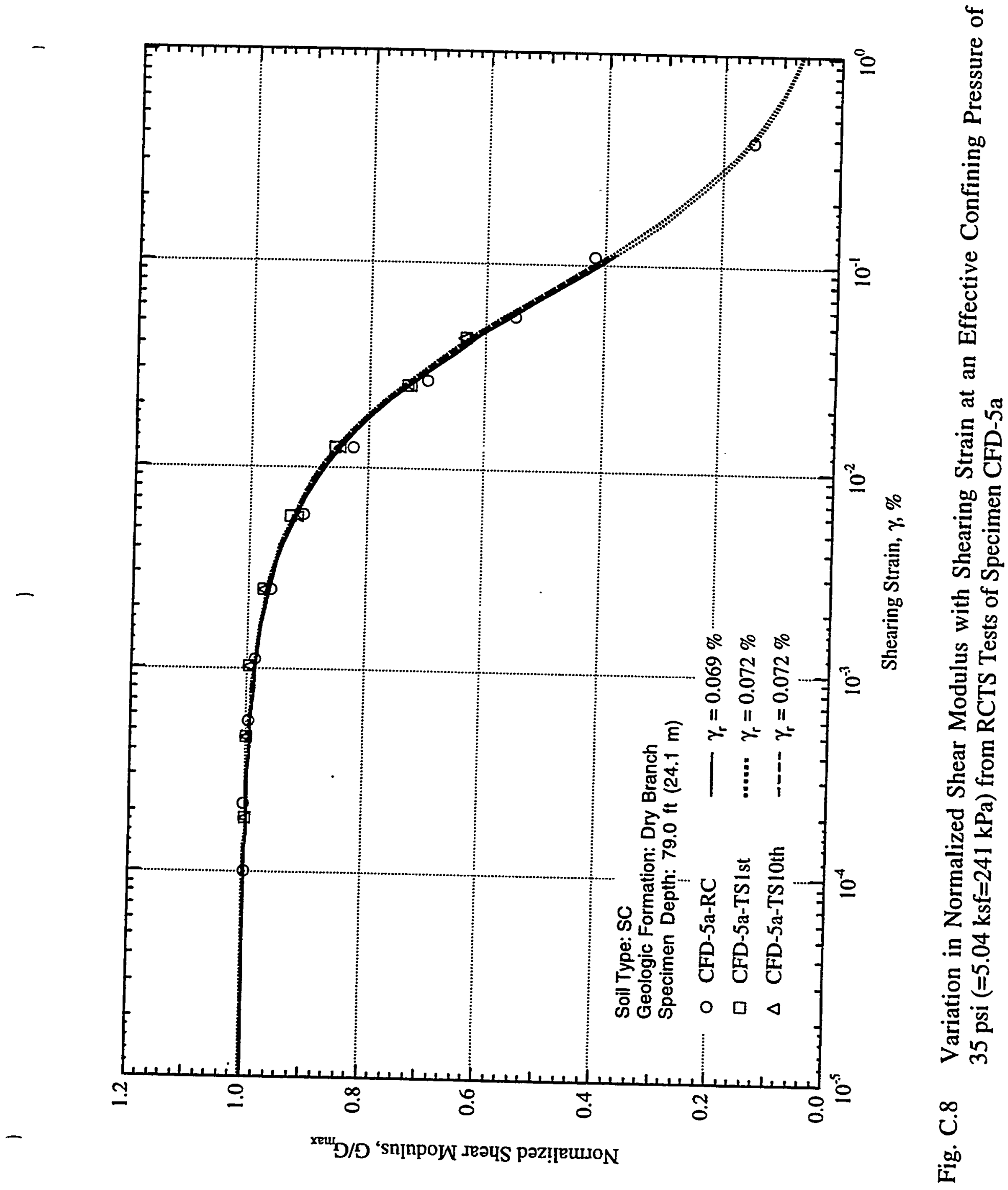

SRS-FR-CDP-95, rev. 0, 13 September 95

Project No. AA891070 


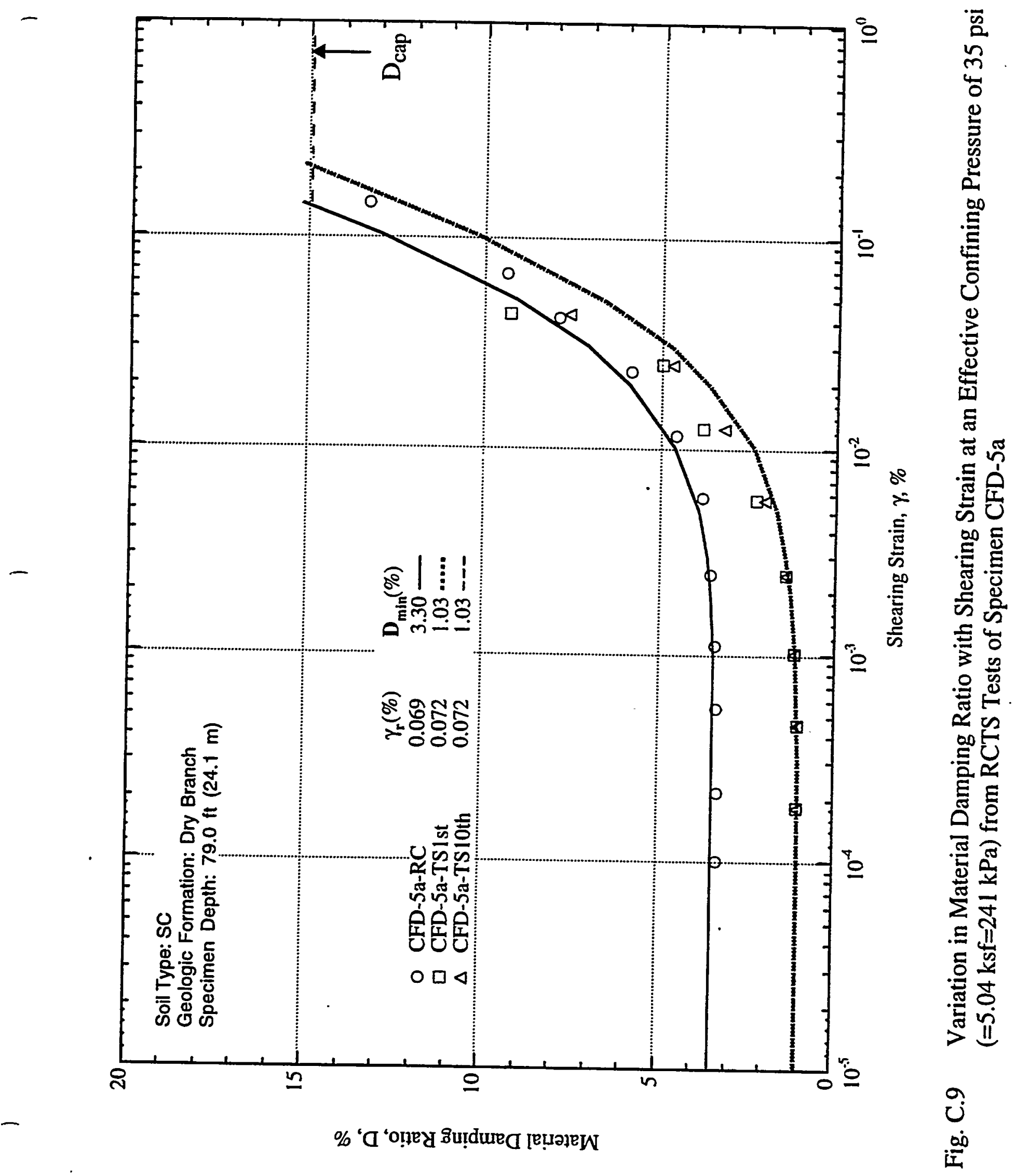




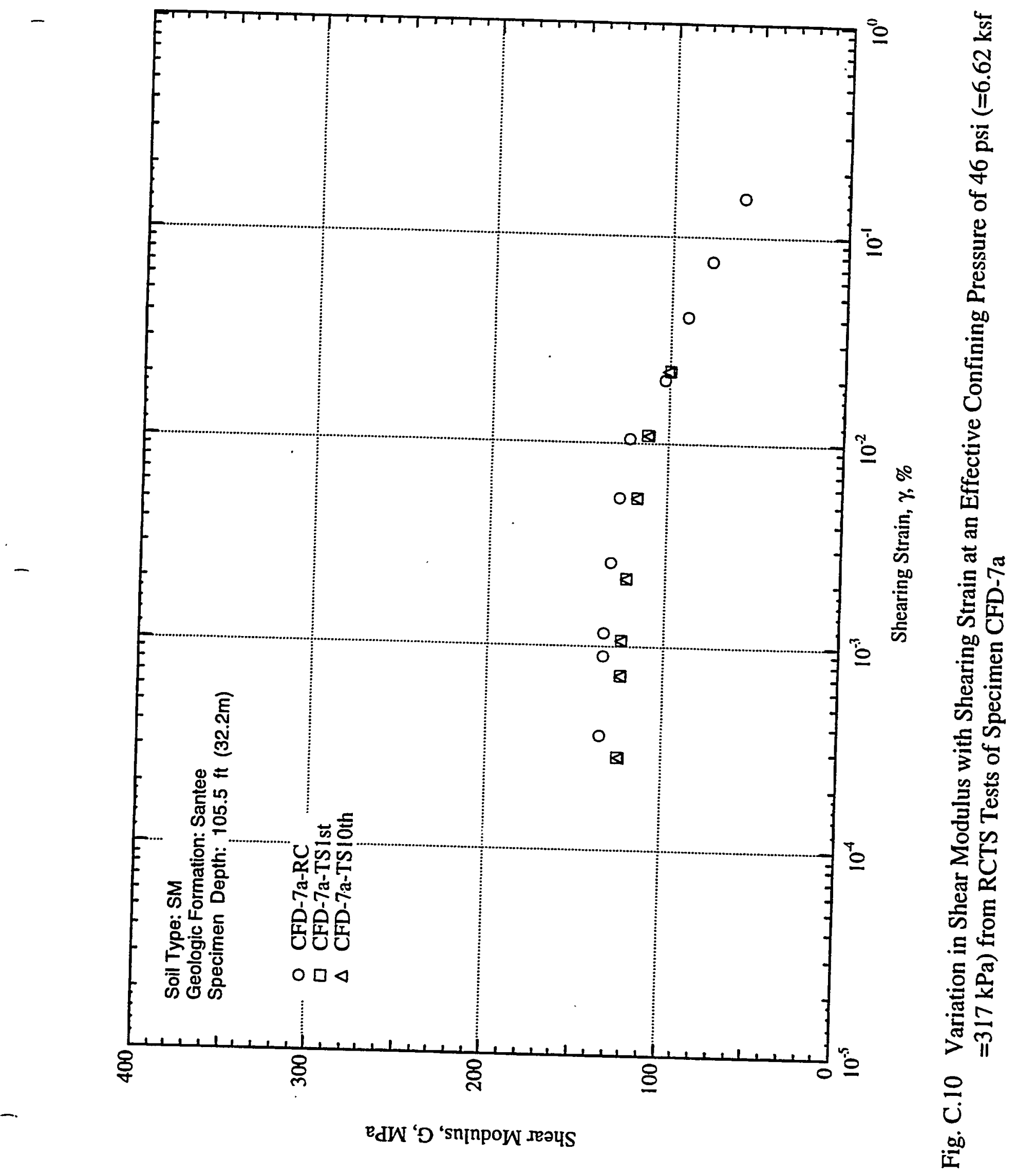

SRS-FR-CDP-95, rev. 0, 13 September 95

Project No. AA891070 


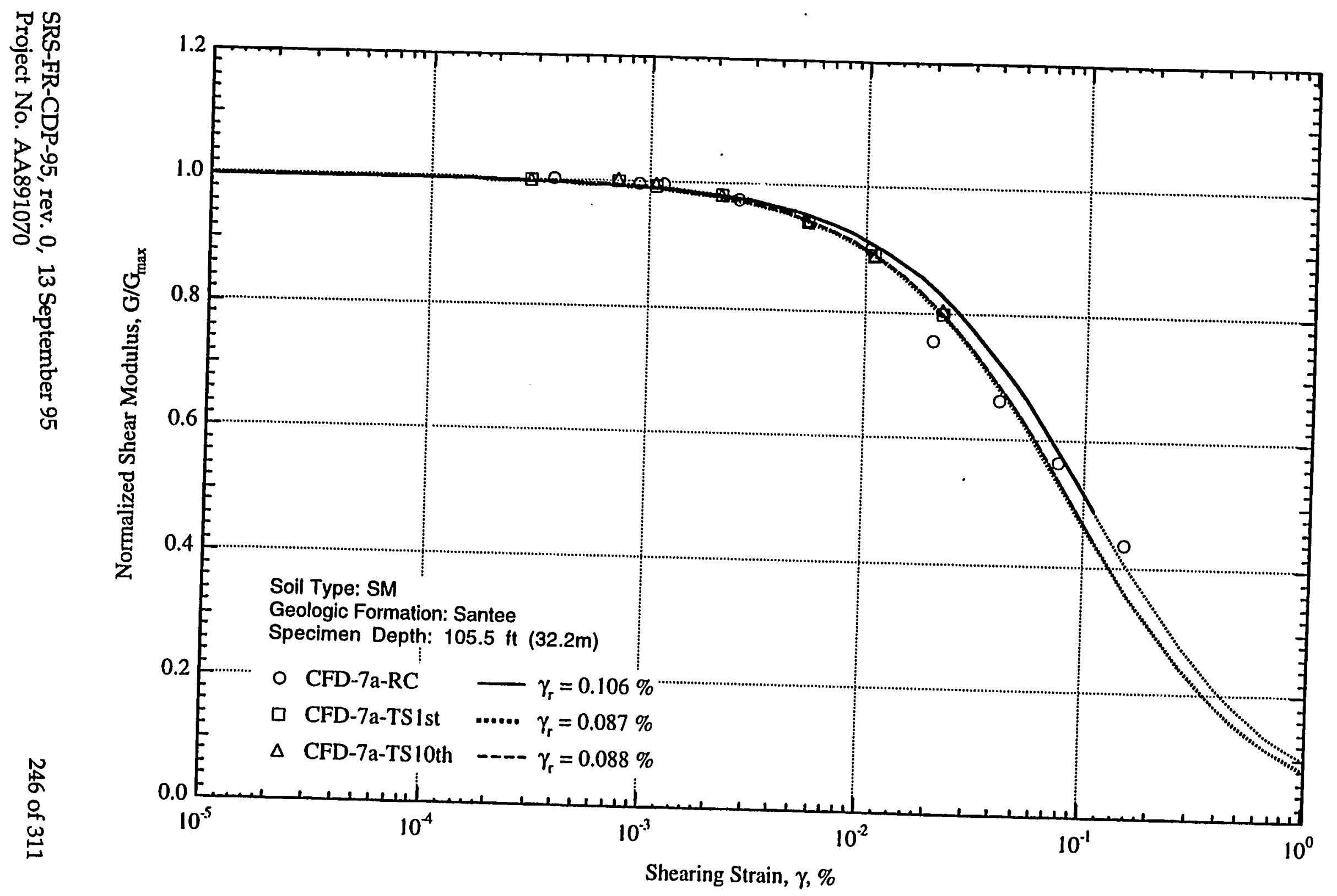

Fig. C.11 Variation in Normalized Shear Modulus with Shearing Strain at an Effective Confining Pressure of
$46 \mathrm{psi}(=6.62 \mathrm{ksf}=317 \mathrm{kPa})$ from RCTS Tests of Specimen CFD-7a 


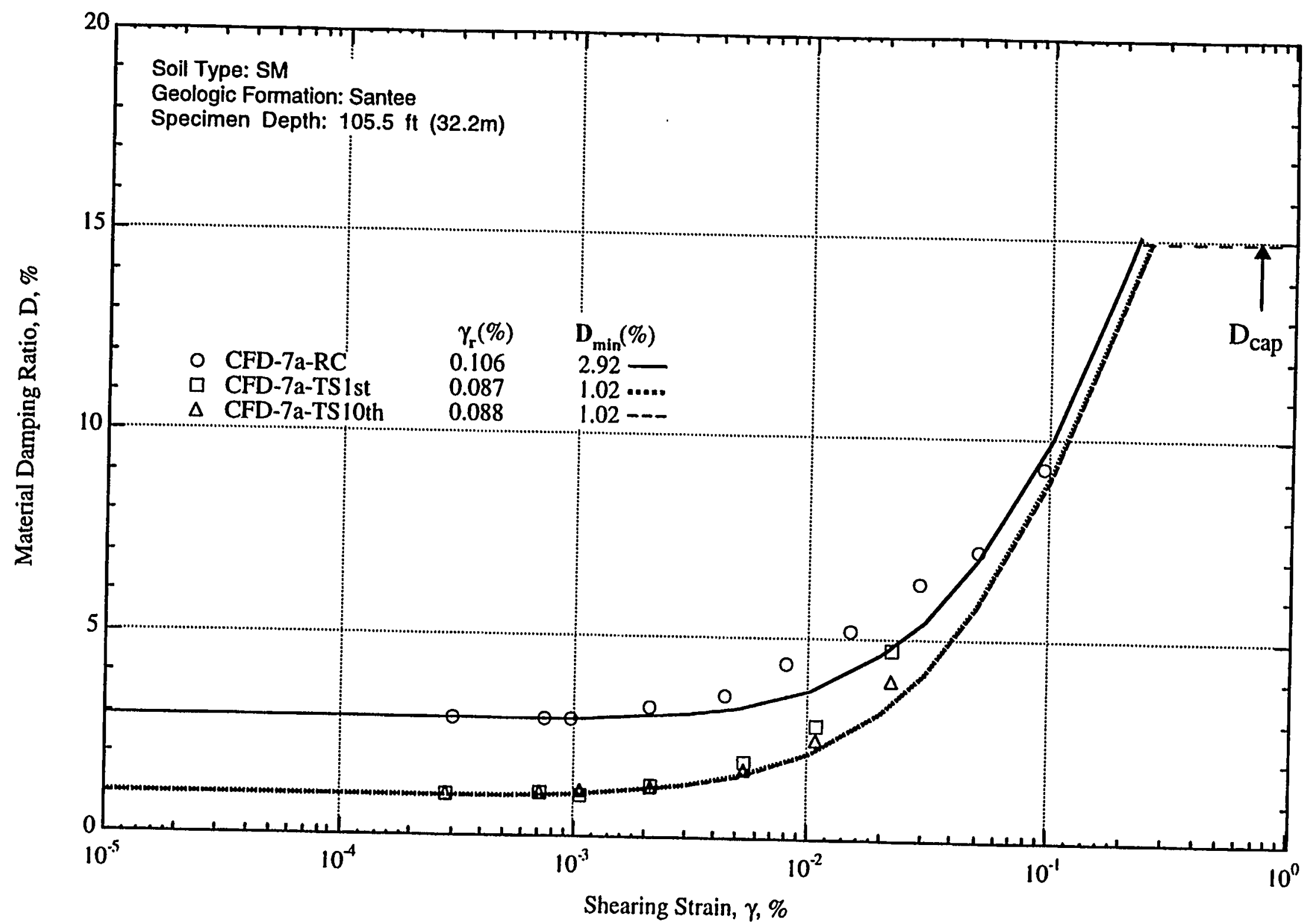

Fig. C.12 Variation in Material Damping Ratio with Shearing Strain at an Effective Confining Pressure of 46 psi
$(=6.62 \mathrm{ksf}=317 \mathrm{kPa})$ from RCTS Tests of Specimen CFD-7a 


\section{Appendix D}

\section{Effects of Excitation Frequency, Number of}

Loading Cycles and Confining Pressure on the Dynamic Properties of Tobacco Road and Snapp Sands (Specimens CFD-3b, CFD-12a, and CFD-13a) 


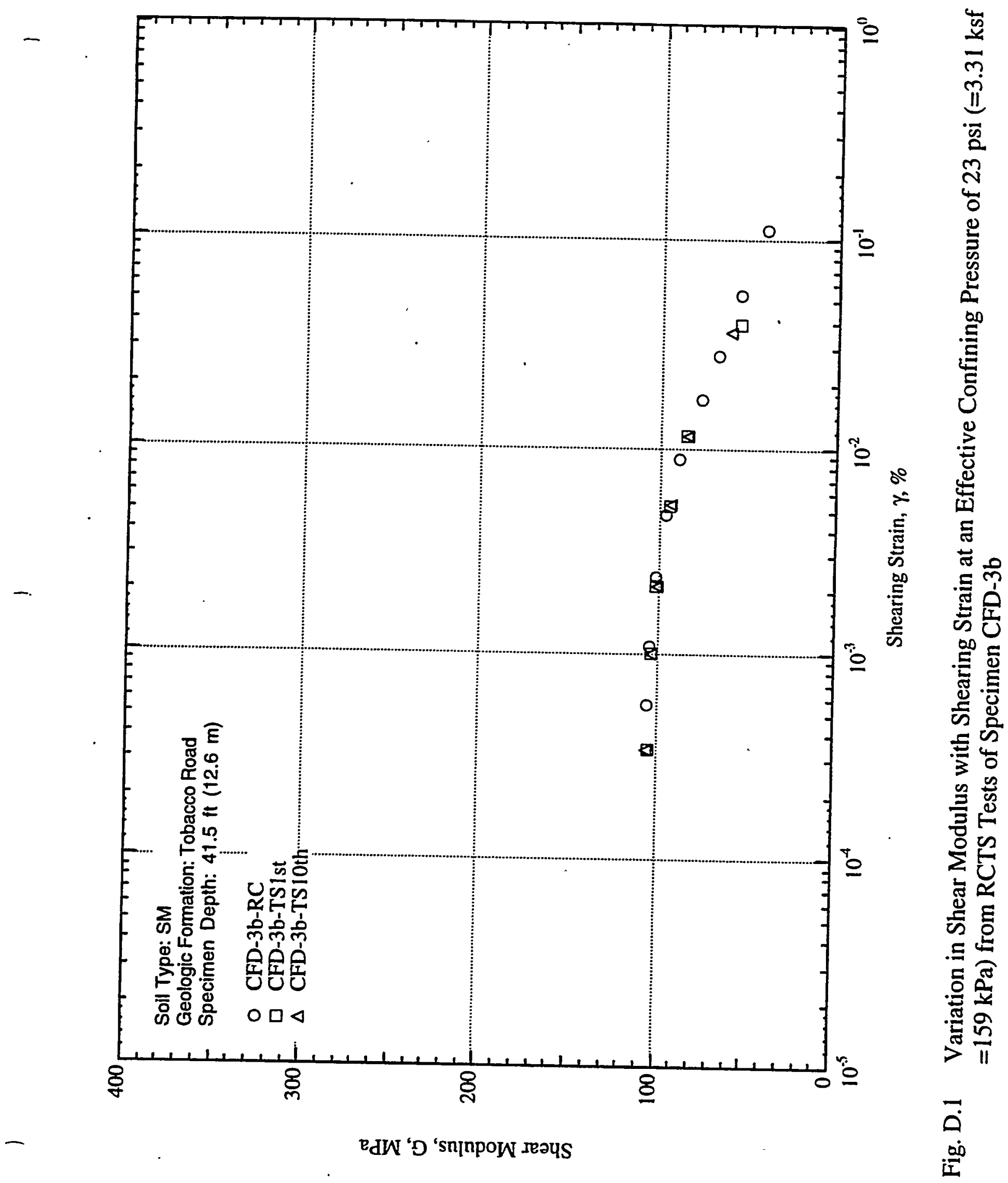

SRS-FR-CDP-95, rev. 0, 13 September 95

Project No. AA891070 


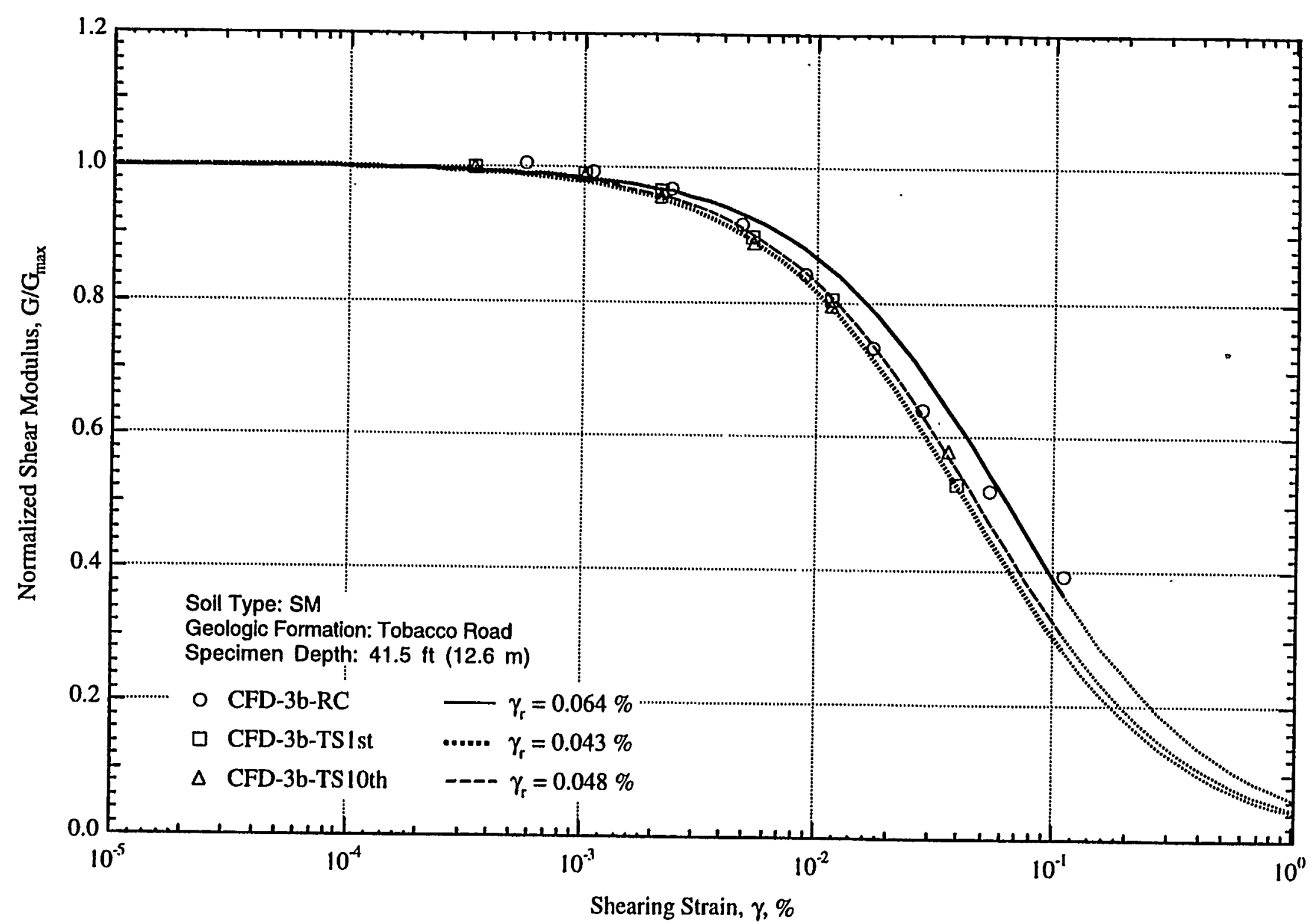

Fig. D.2 Variation in Normalized Shear Modulus with Shearing Strain at an Effective Confining Pressure of $23 \mathrm{psi}(=3.31 \mathrm{ksf}=159 \mathrm{kPa})$ from RCTS Tests of Specimen CFD-3b 


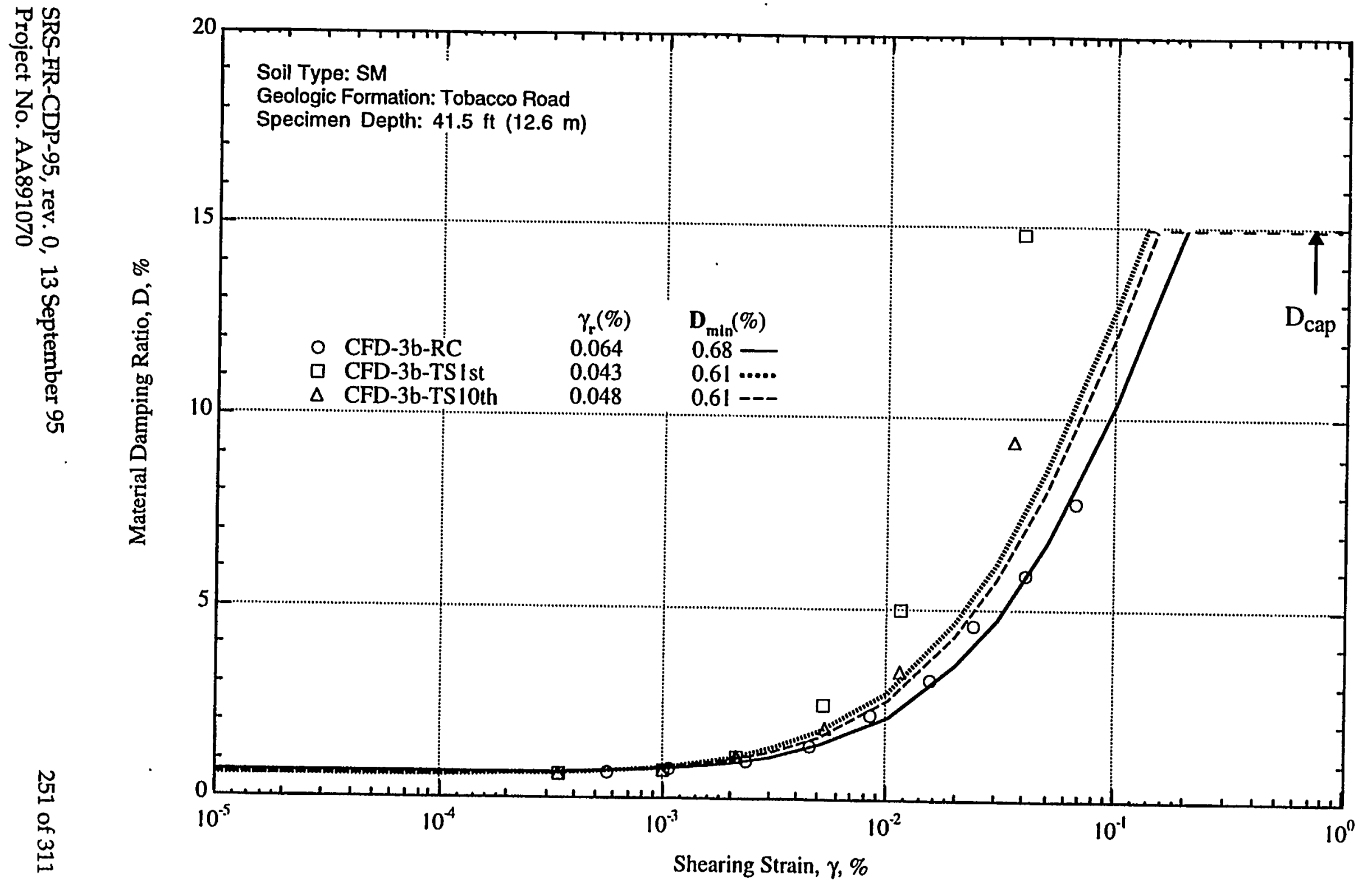

Fig. D.3 Variation in Material Damping Ratio with Shearing Strain at an Effective Confining Pressure of $23 \mathrm{psi}$ $(=3.31 \mathrm{ksf}=159 \mathrm{kPa})$ from RCTS Tests of Specimen CFD-3b 


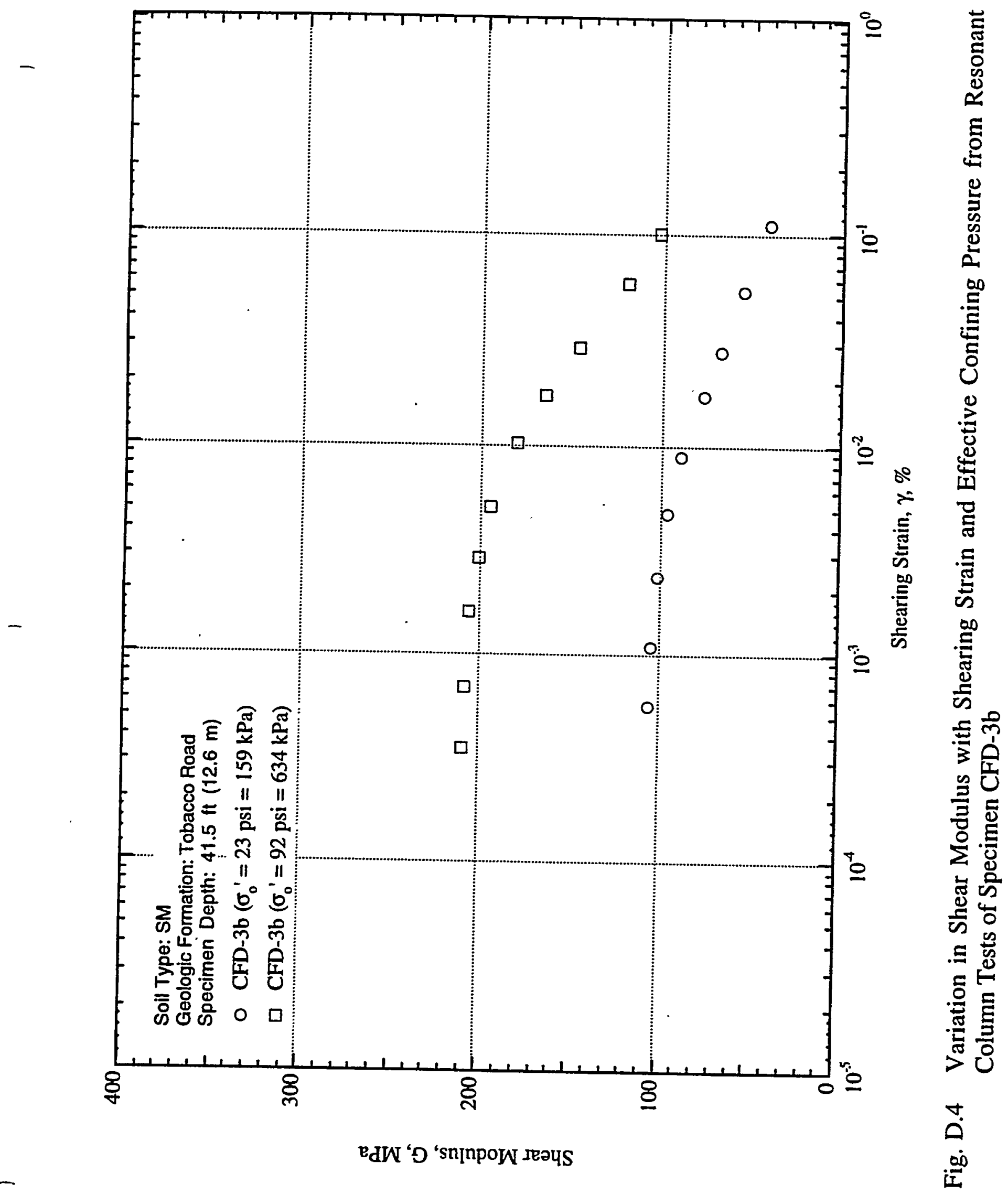

SRS-FR-CDP-95, rev. 0, 13 September 95

Project No. AA891070 


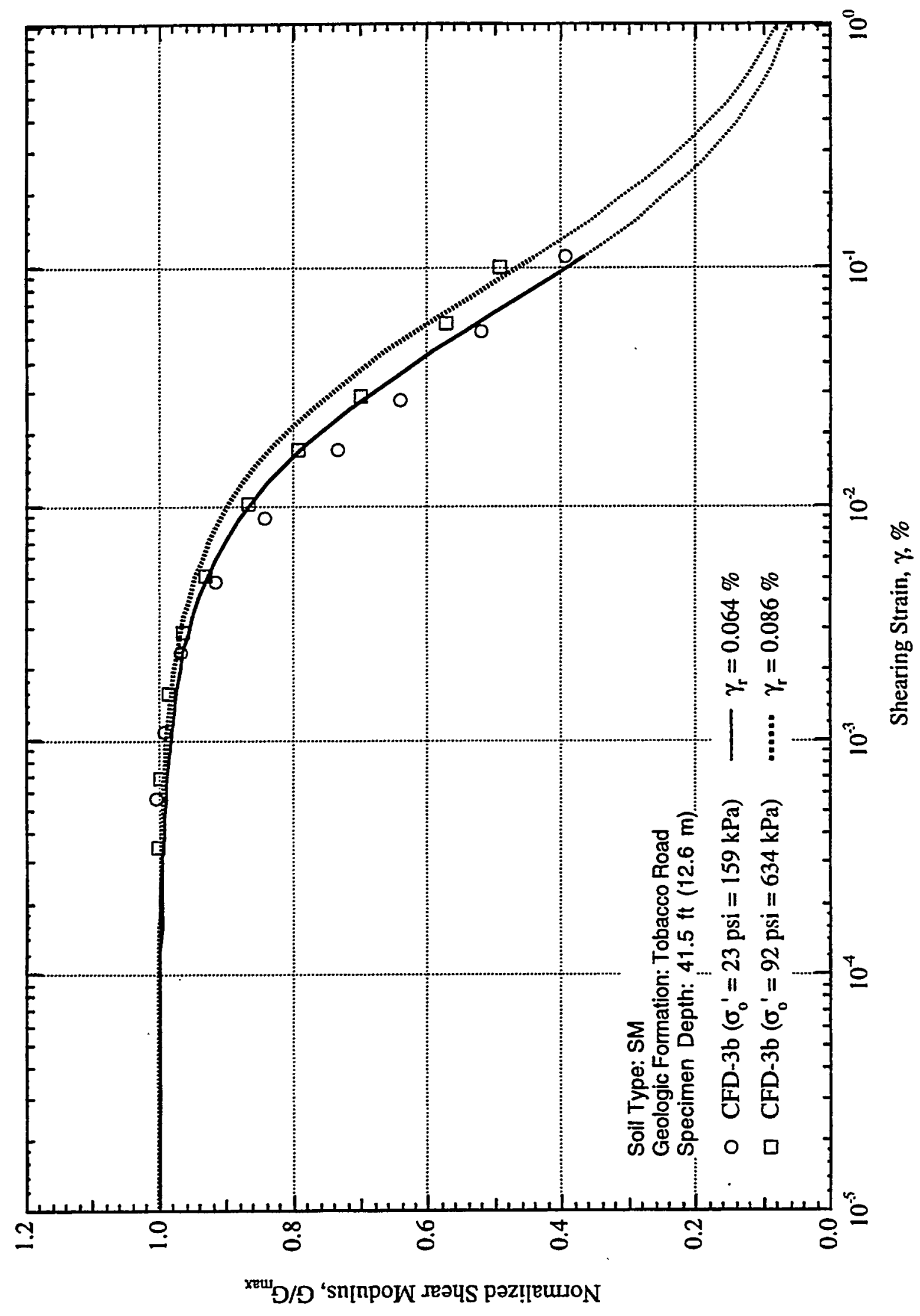

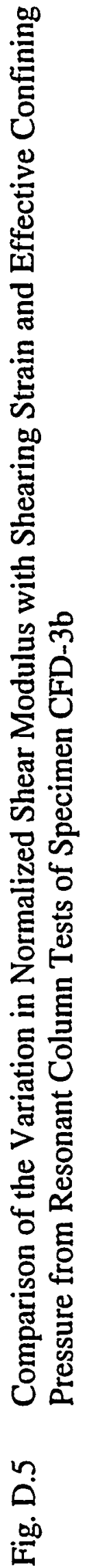

SRS-FR-CDP-95, rev. 0, 13 September 95 


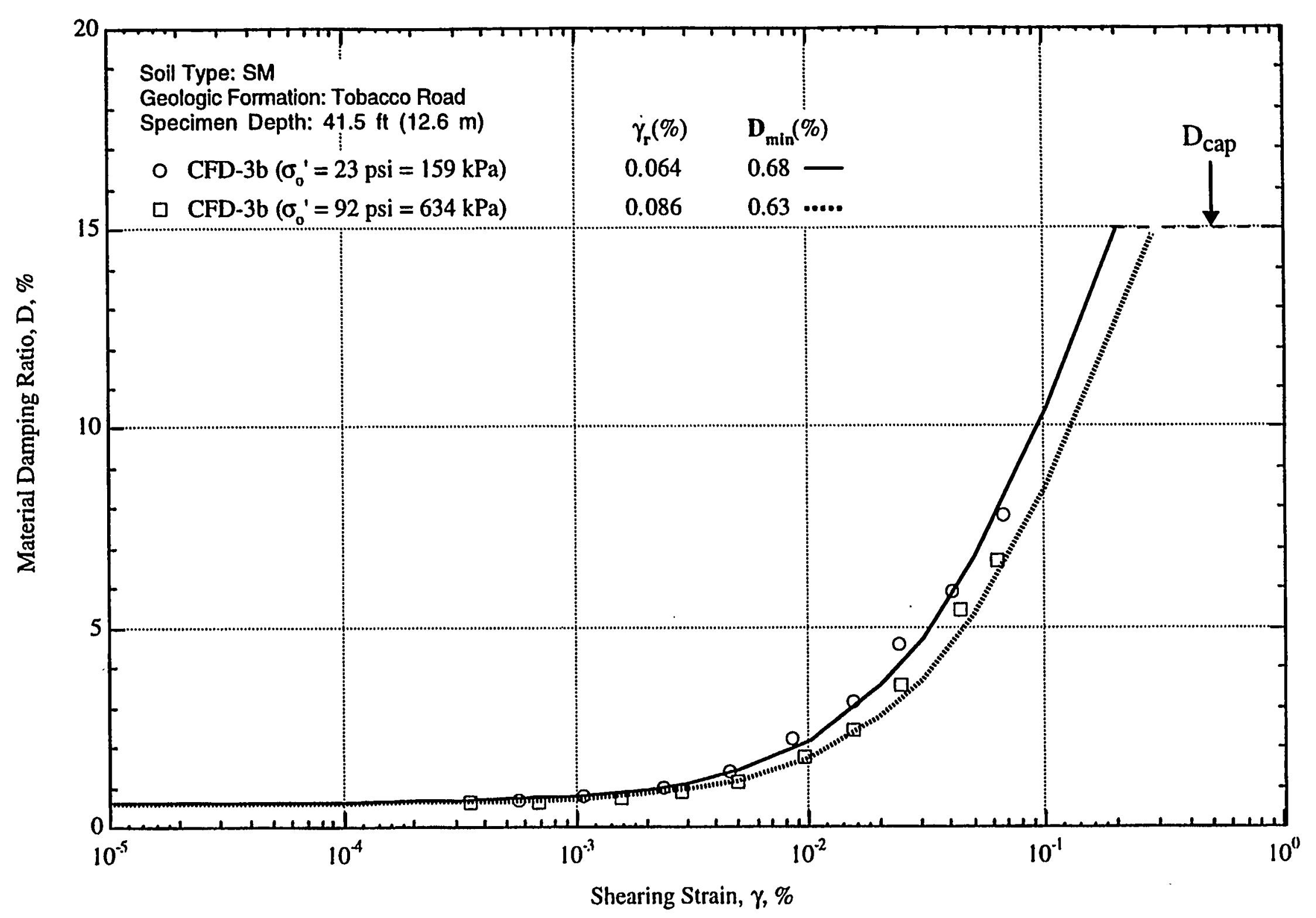

Fig. D.6 Variation in Material Damping Ratio with Shearing Strain and Effective Confining Pressure from . Resonant Column Tests of Specimen CFD-3b 


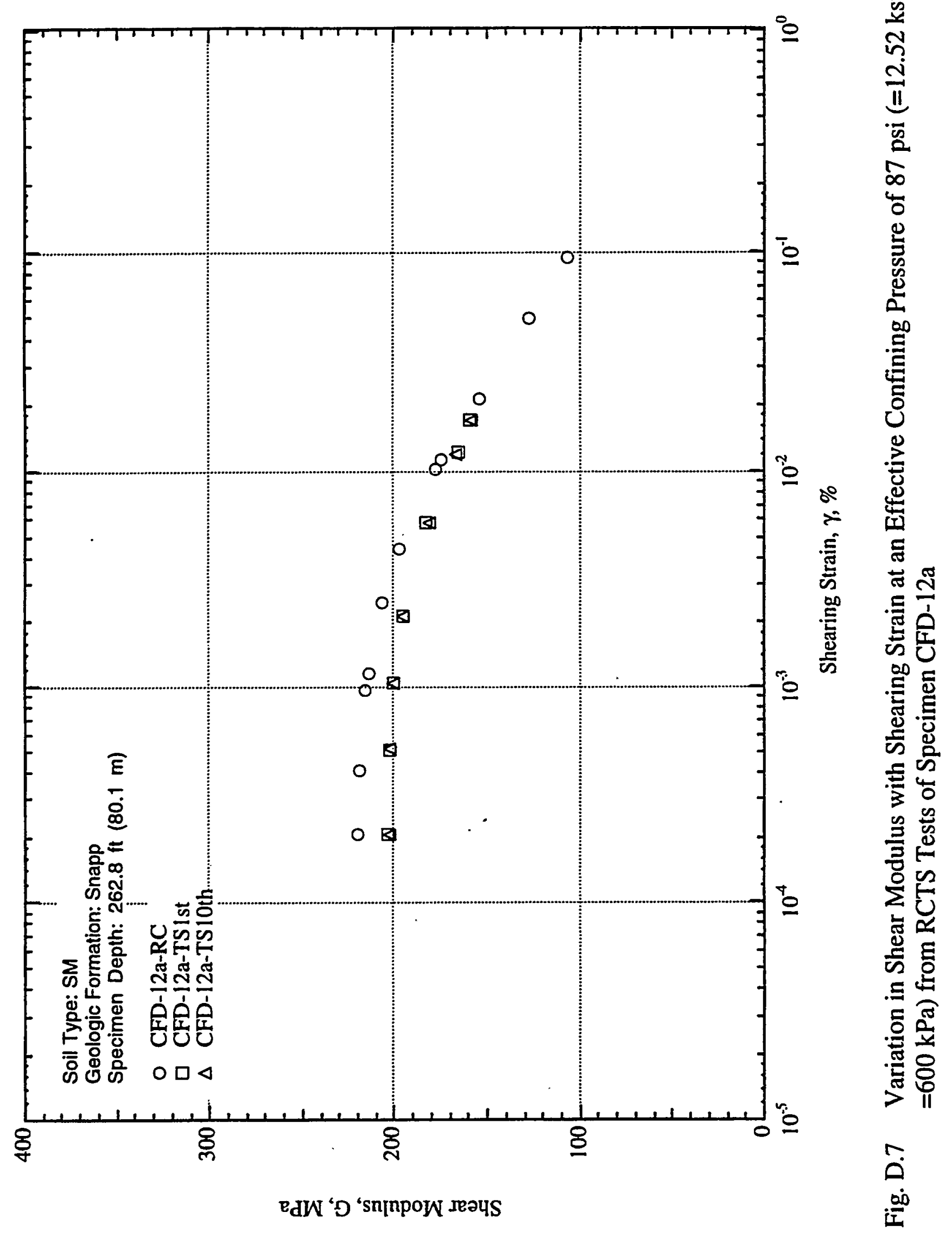

SRS-FR-CDP-95, rev. 0, 13 September 95 


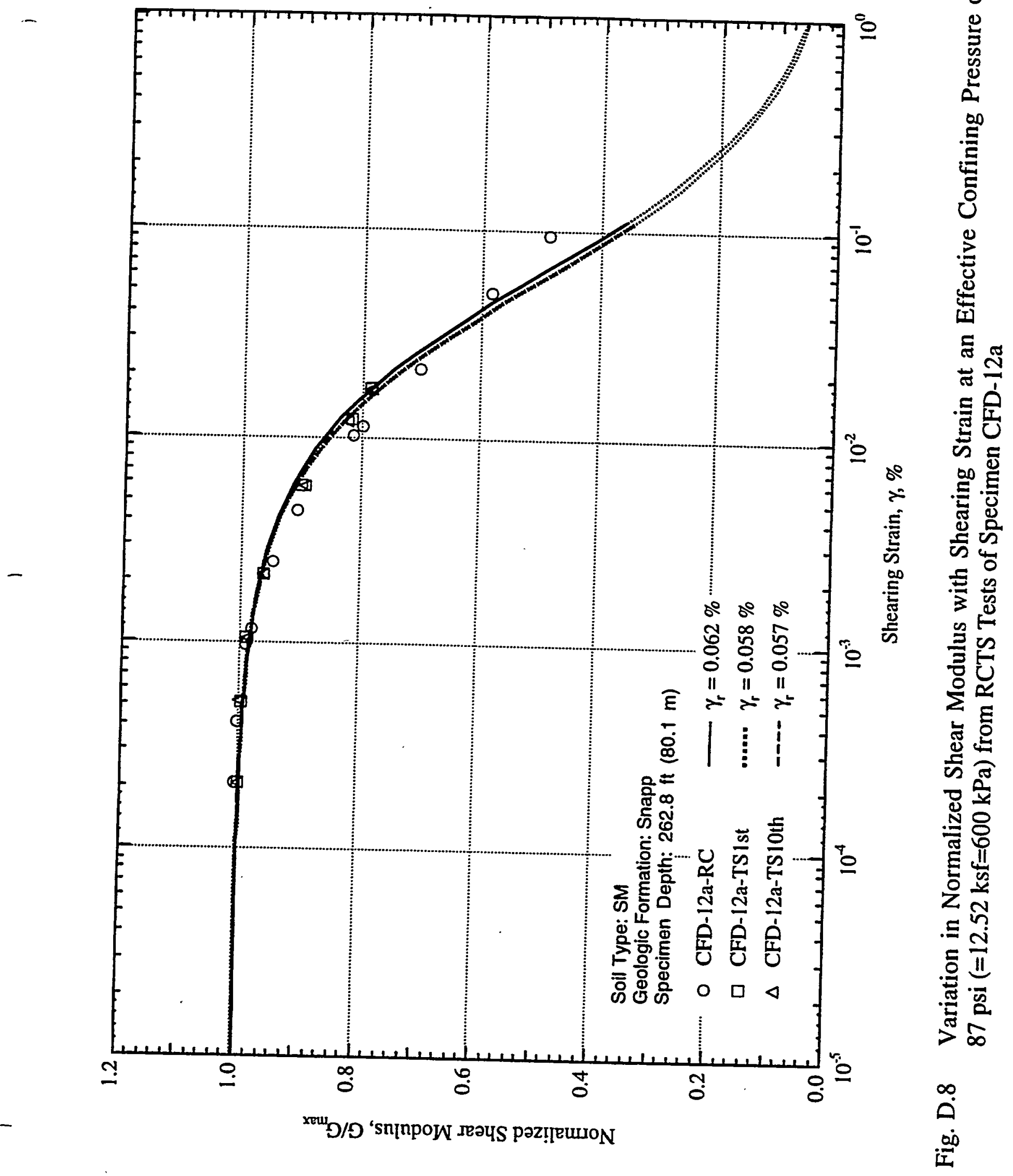




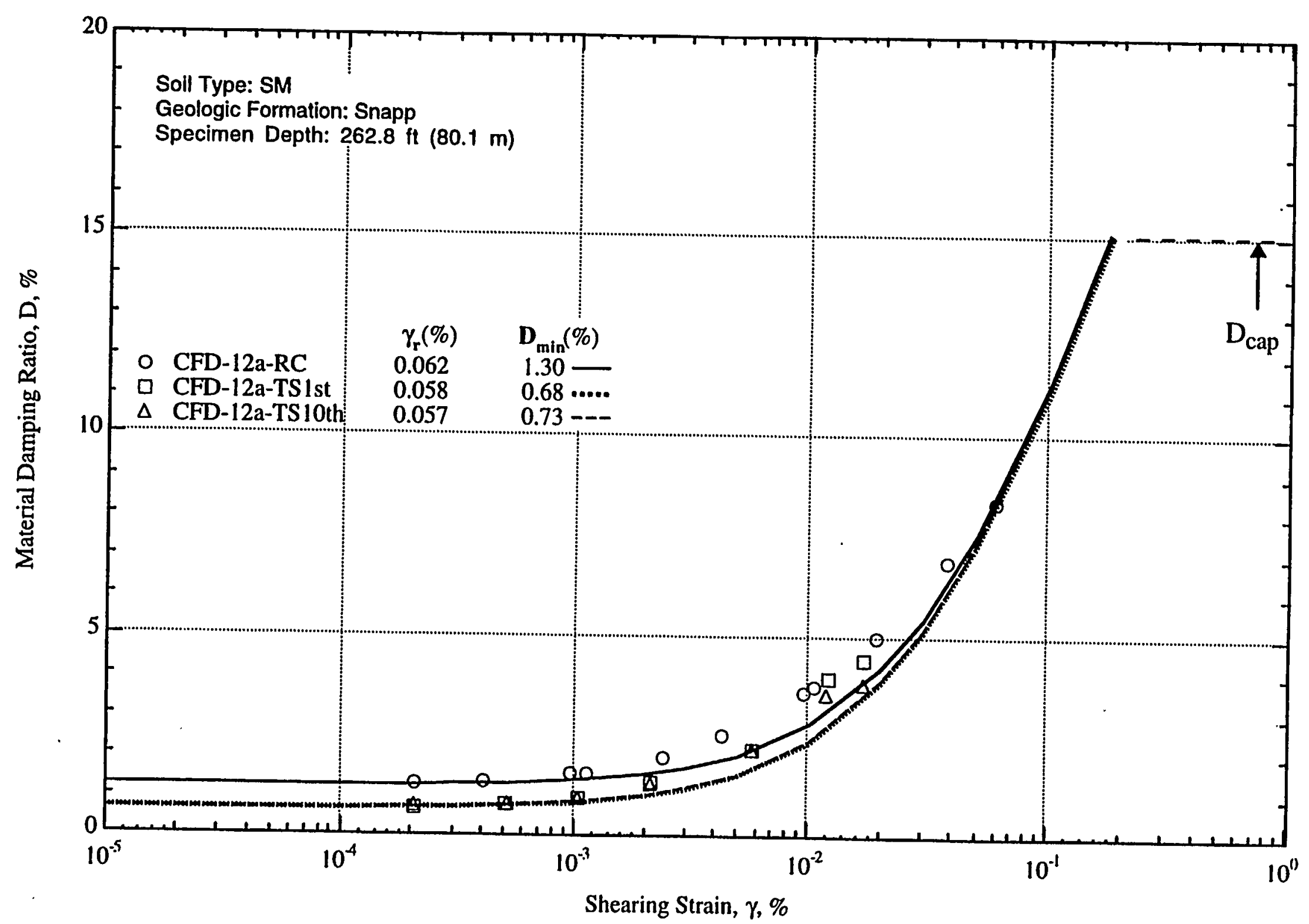

Fig. D.9 Variation in Material Damping Ratio with Shearing Strain at an Effective Confining Pressure of 87 psi $(=12.52 \mathrm{ksf}=600 \mathrm{kPa})$ from RCTS Tests of Specimen CFD-12a 


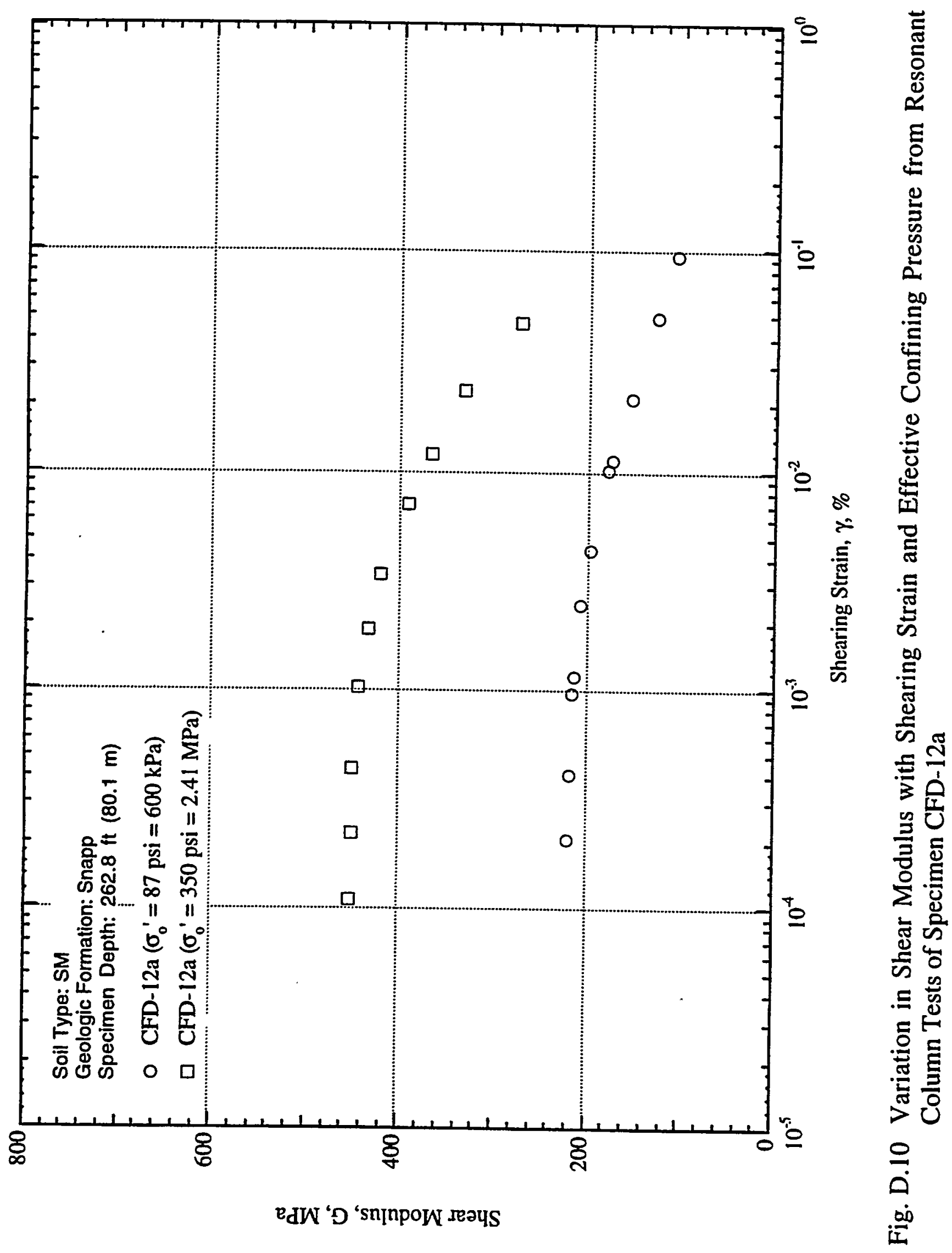

SRS-FR-CDP-95, rev. 0, 13 September 95

Project No. AA891070 


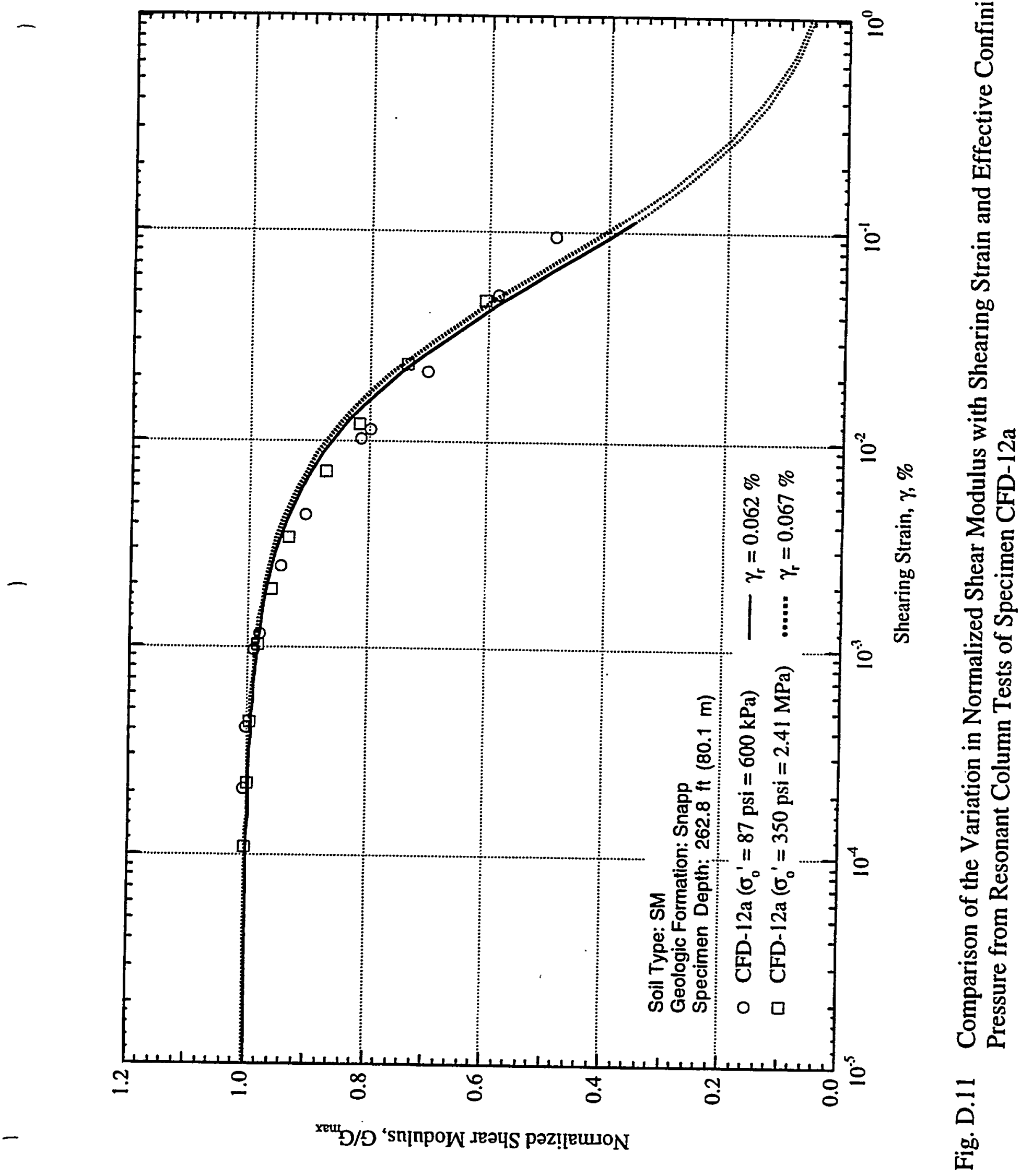

SRS-FR-CDP-95, rev. 0, 13 September 95 Project No. AA891070 


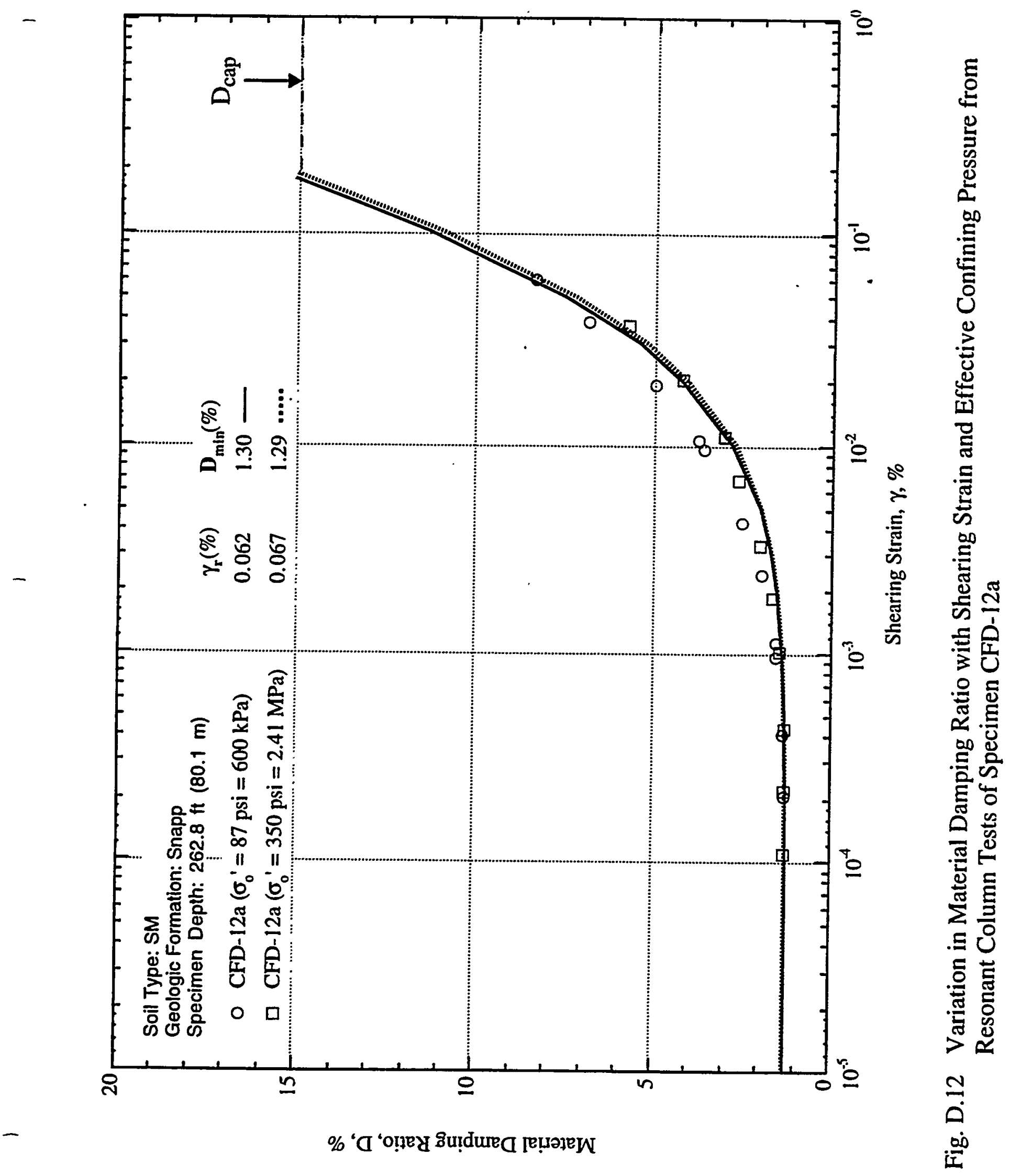




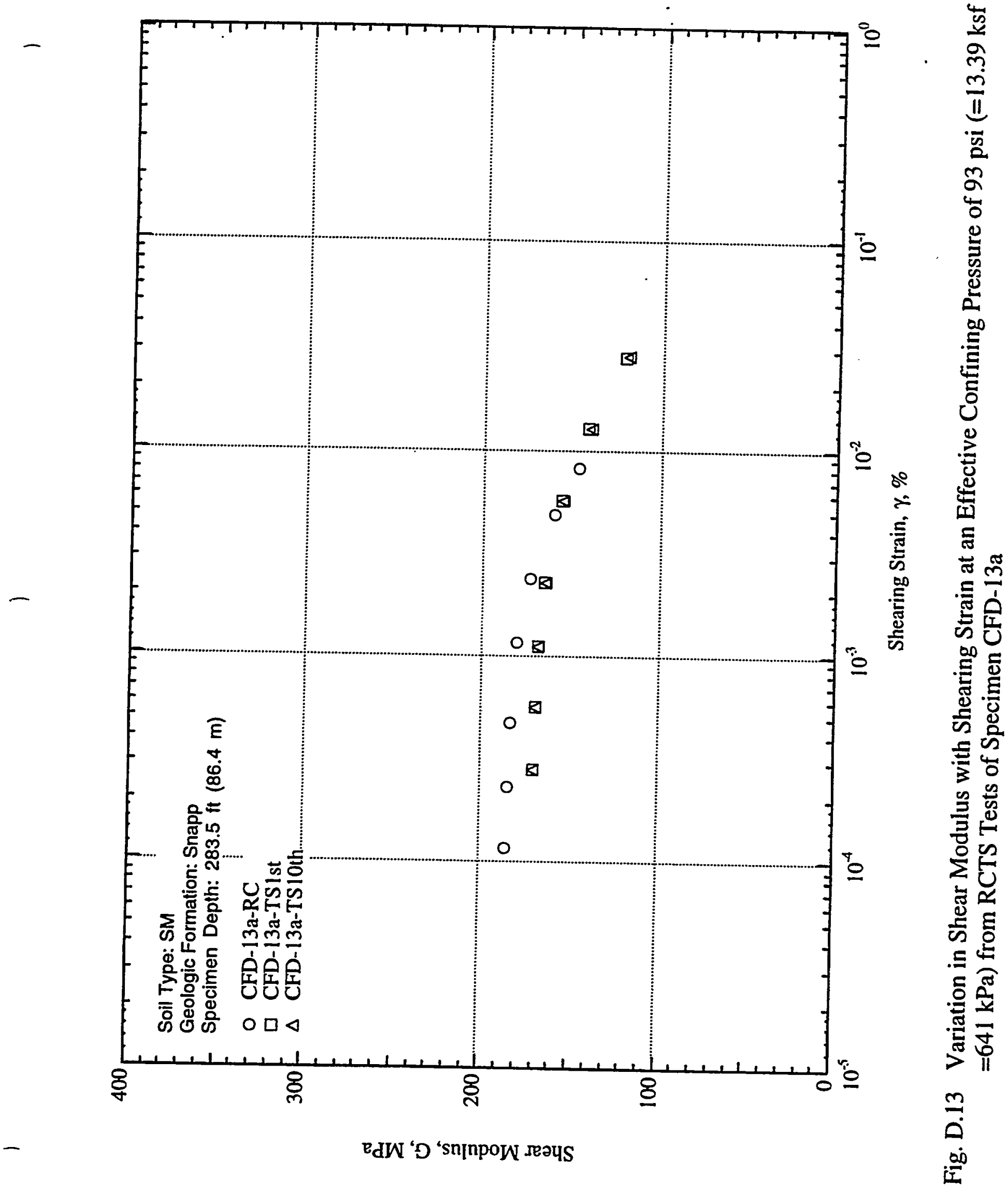

SRS-FR-CDP-95, rev. 0, 13 September 95 


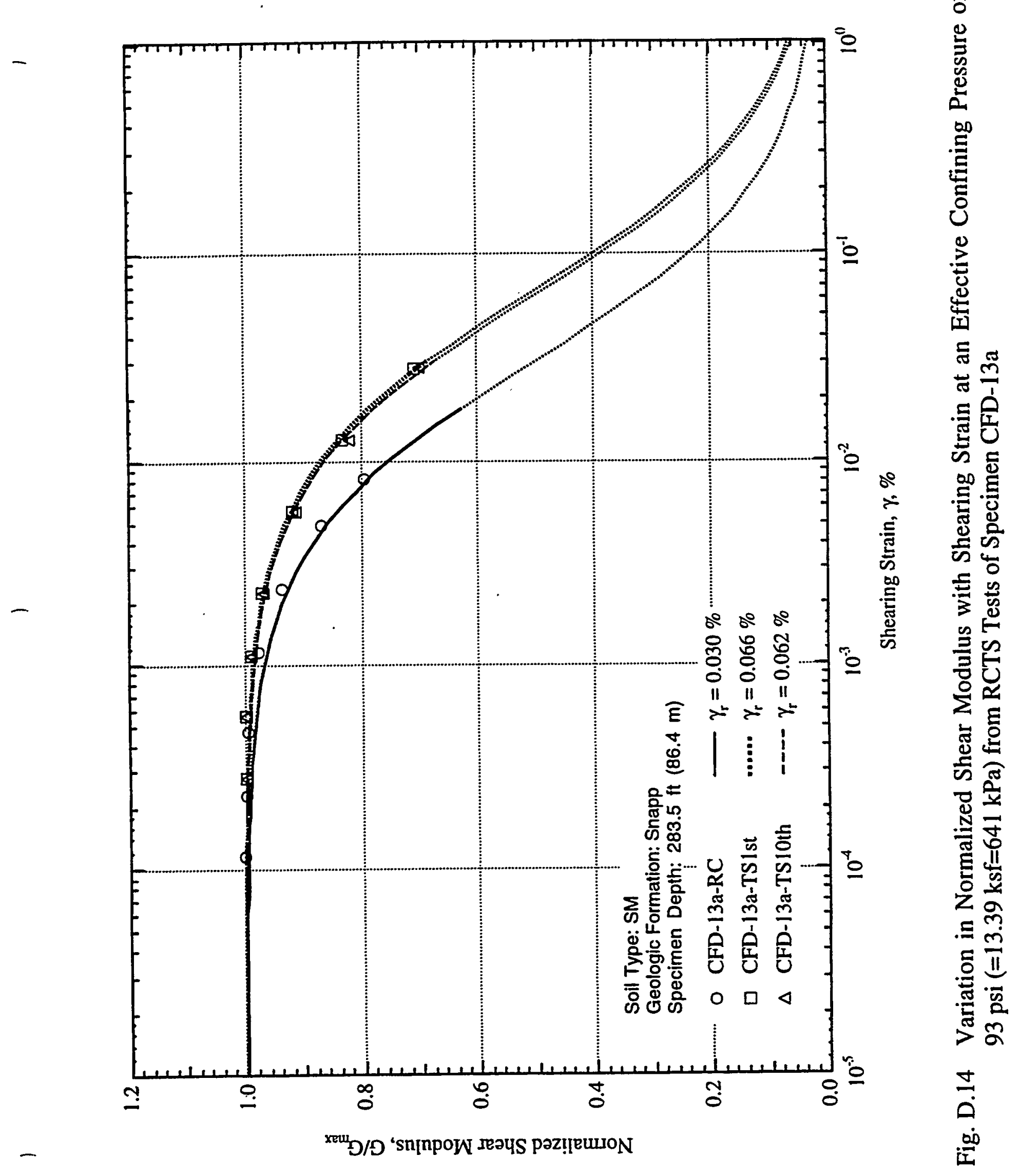

SRS-FR-CDP-95, rev. 0, 13 September 95 


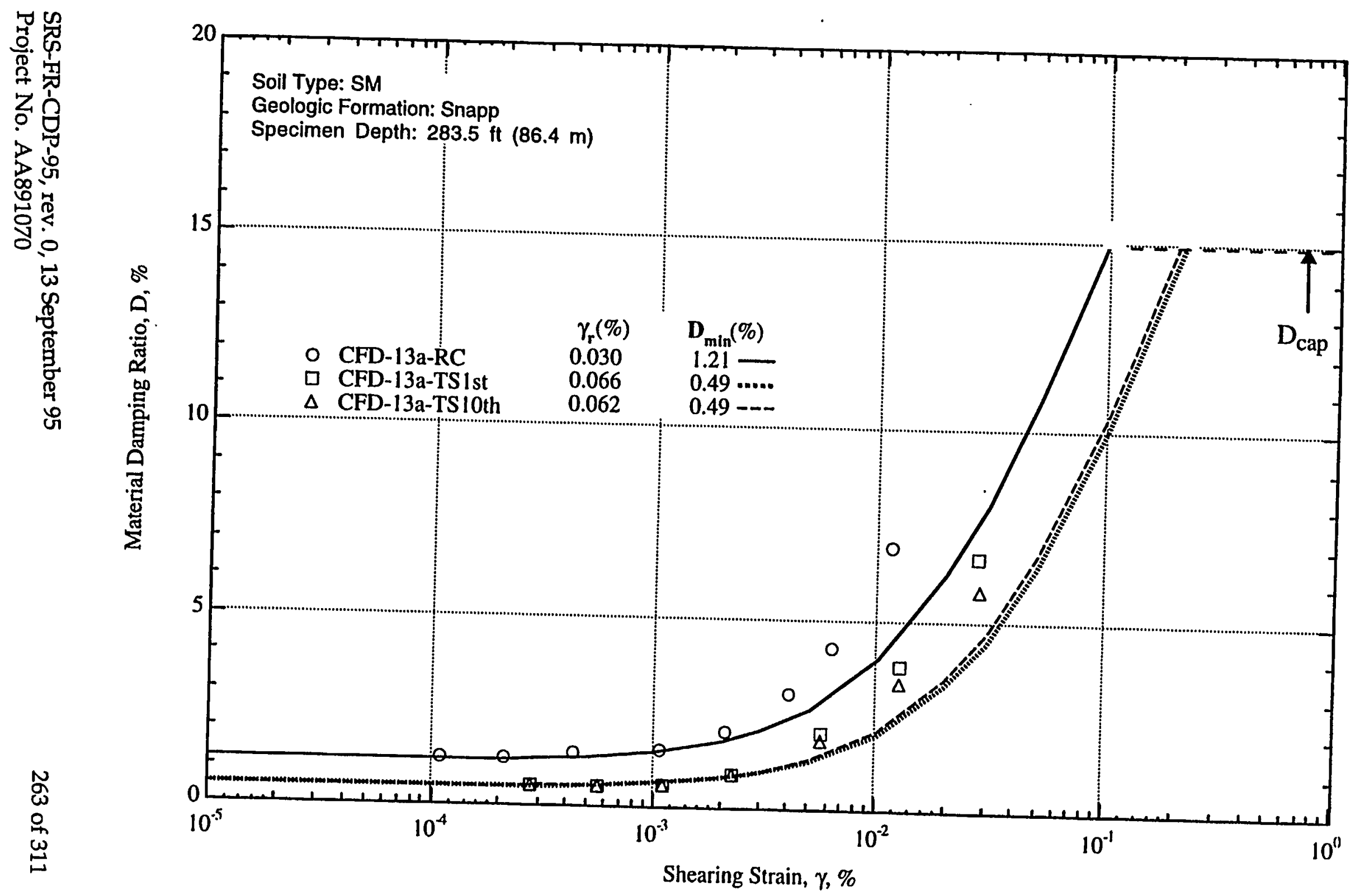

Fig. D.15 Variation in Material Damping Ratio with Shearing Strain at an Effective Confining Pressure of 93 psi
$(=13.39 \mathrm{ksf}=641 \mathrm{kPa})$ from RCTS Tests of Specimen CFD-13a 


\section{Appendix E \\ Effects of Excitation Frequency, Number of Loading Cycles and Confining Pressure on the Dynamic Properties of Shallow Clays (Specimens CFD-6a and CFD-T1a) 250}




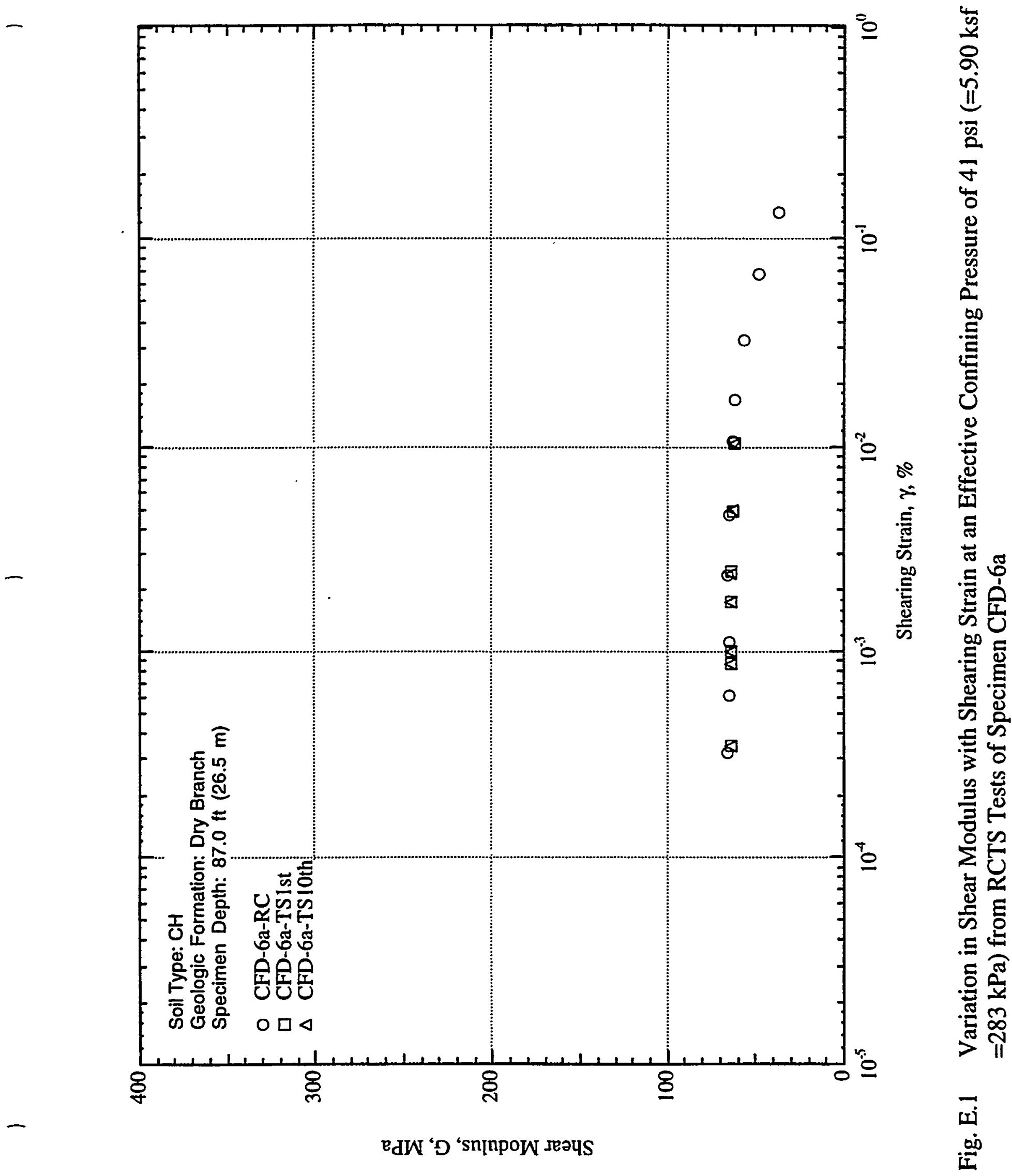

SRS-FR-CDP-95, rev. 0, 13 September 95

265 of 311

Project No. AA891070 


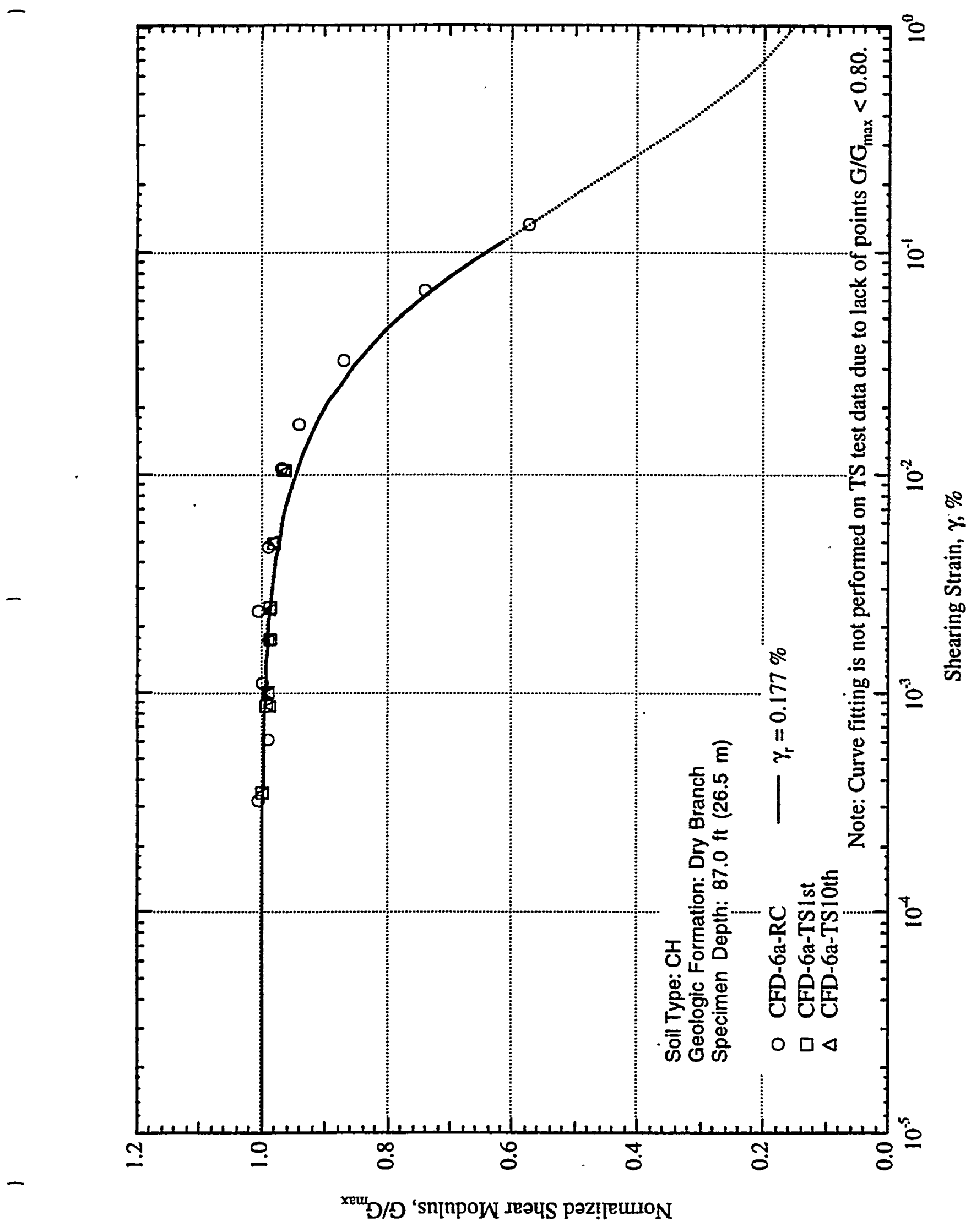

4

บี $\infty$ 


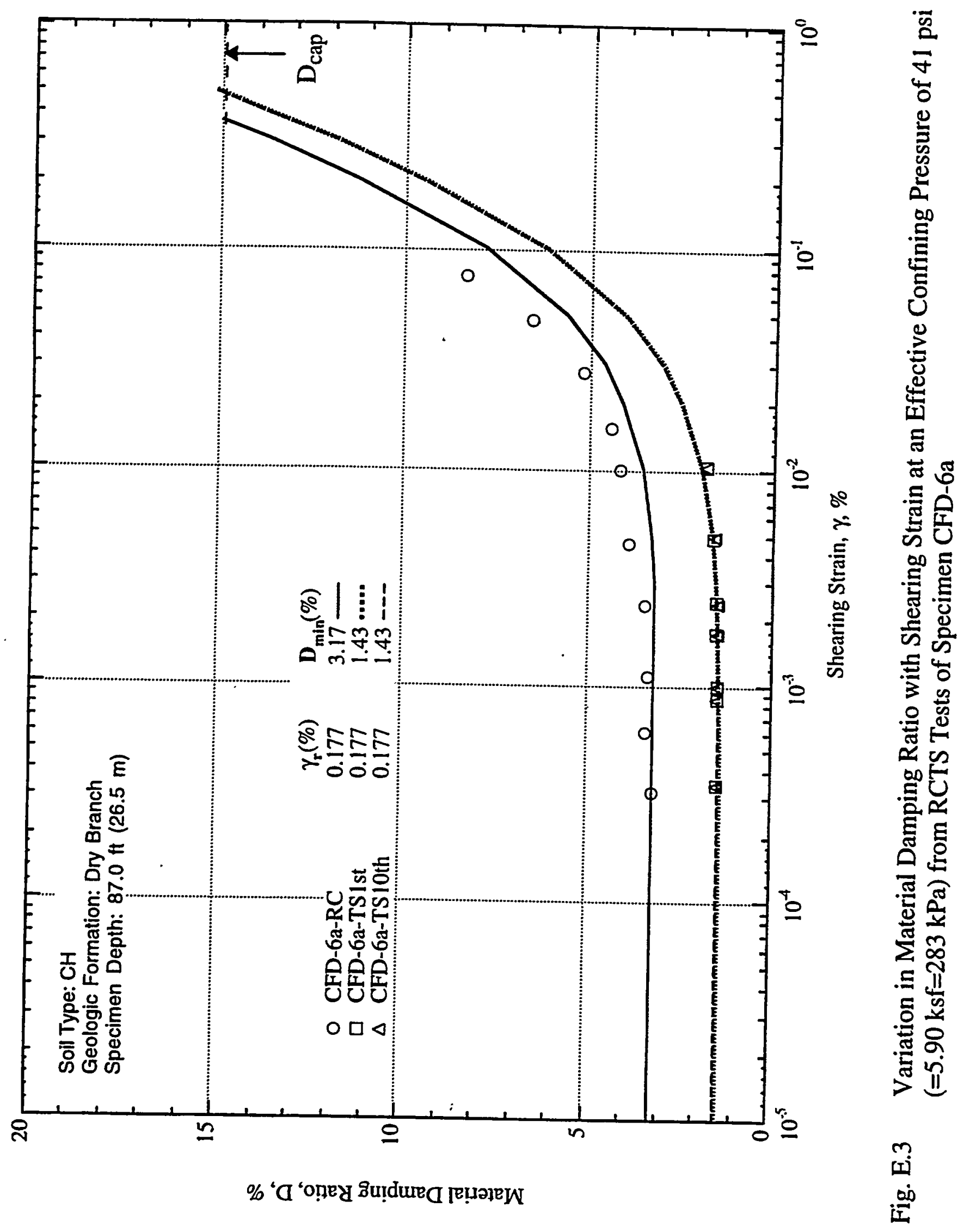

SRS-FR-CDP-95, rev. 0, 13 September 95

Project No. AA891070 

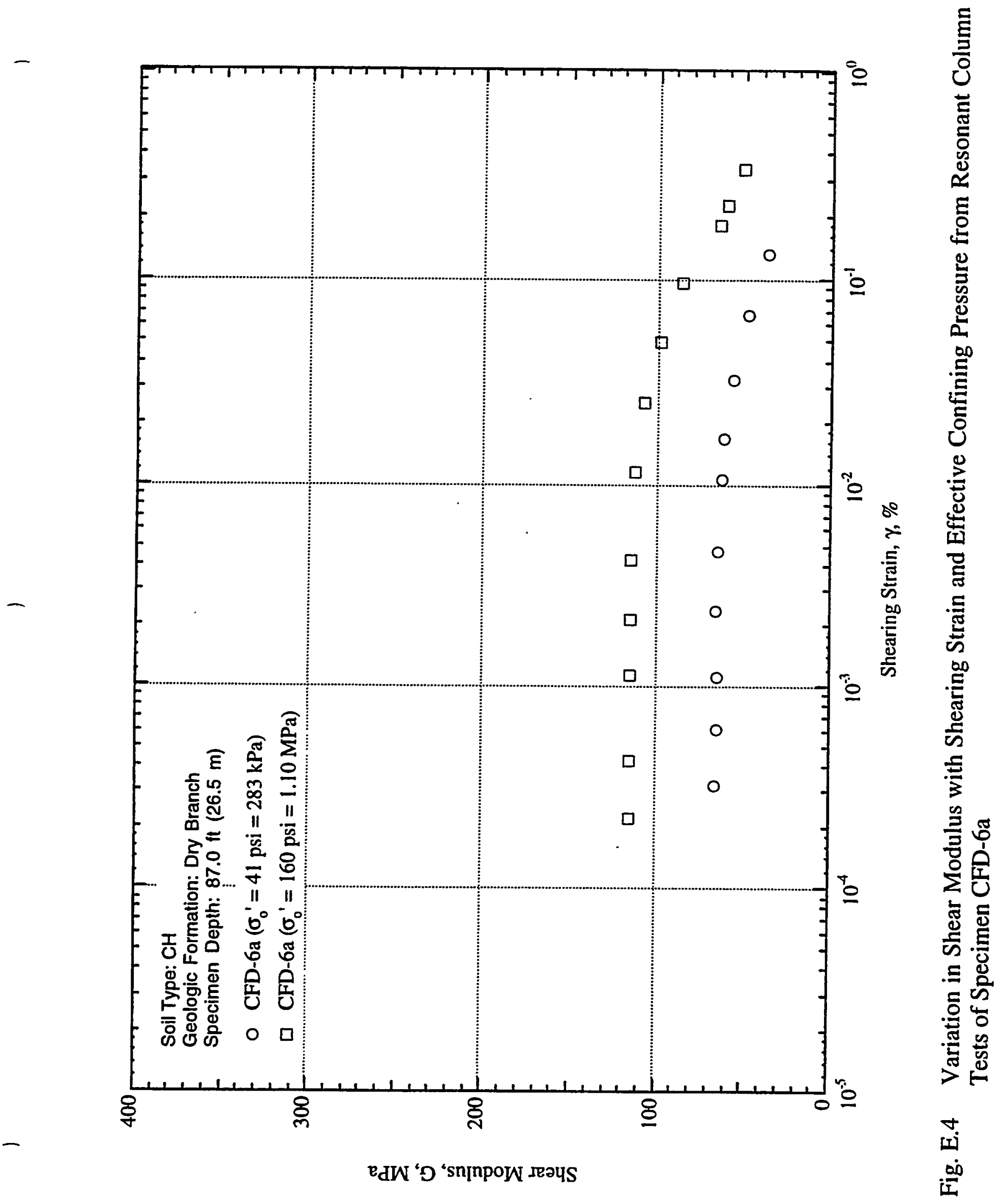

SRS-FR-CDP-95, rev. 0, 13 September 95

Project No. AA891070 


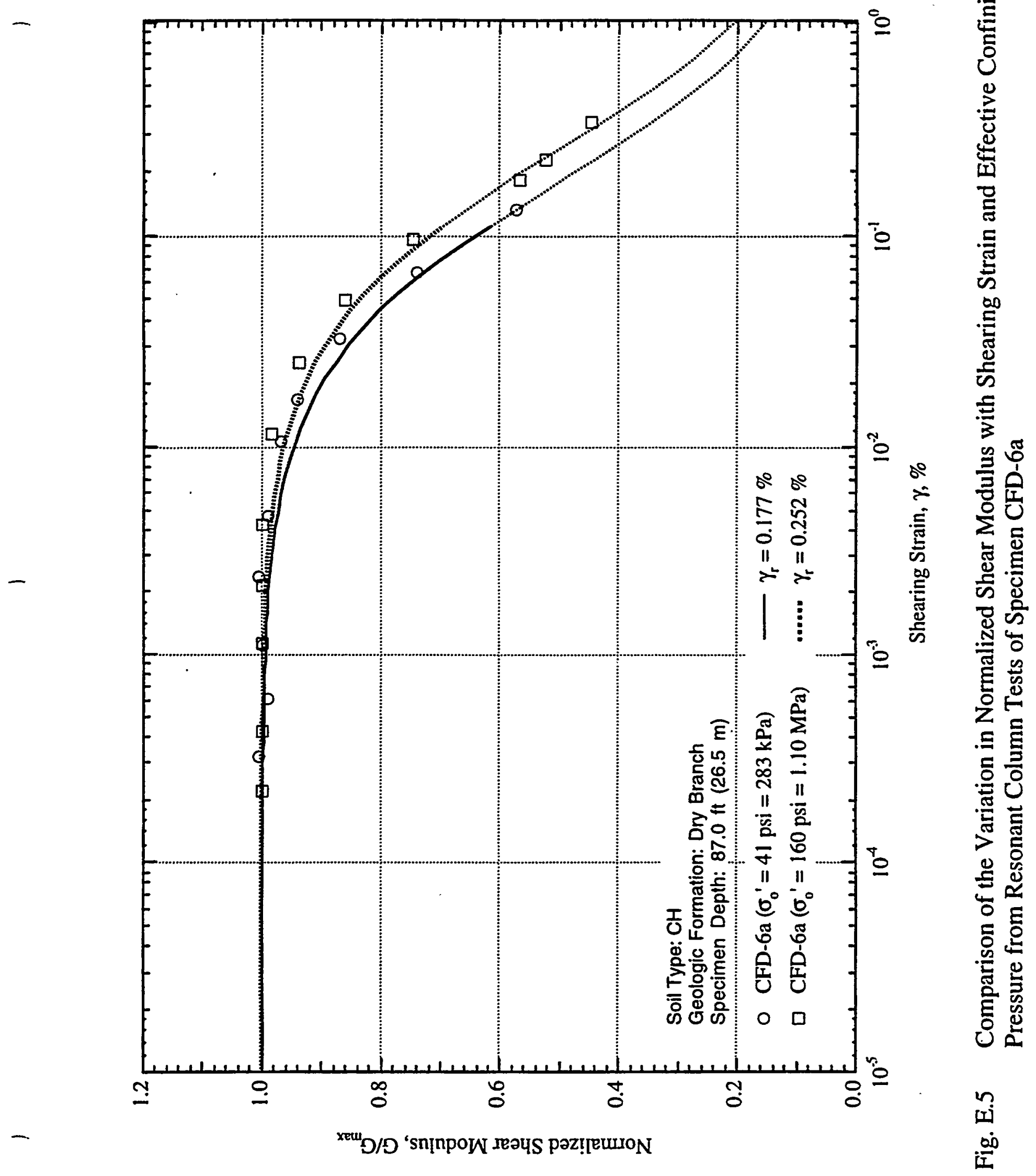

SRS-FR-CDP-95, rev. 0, 13 September 95 

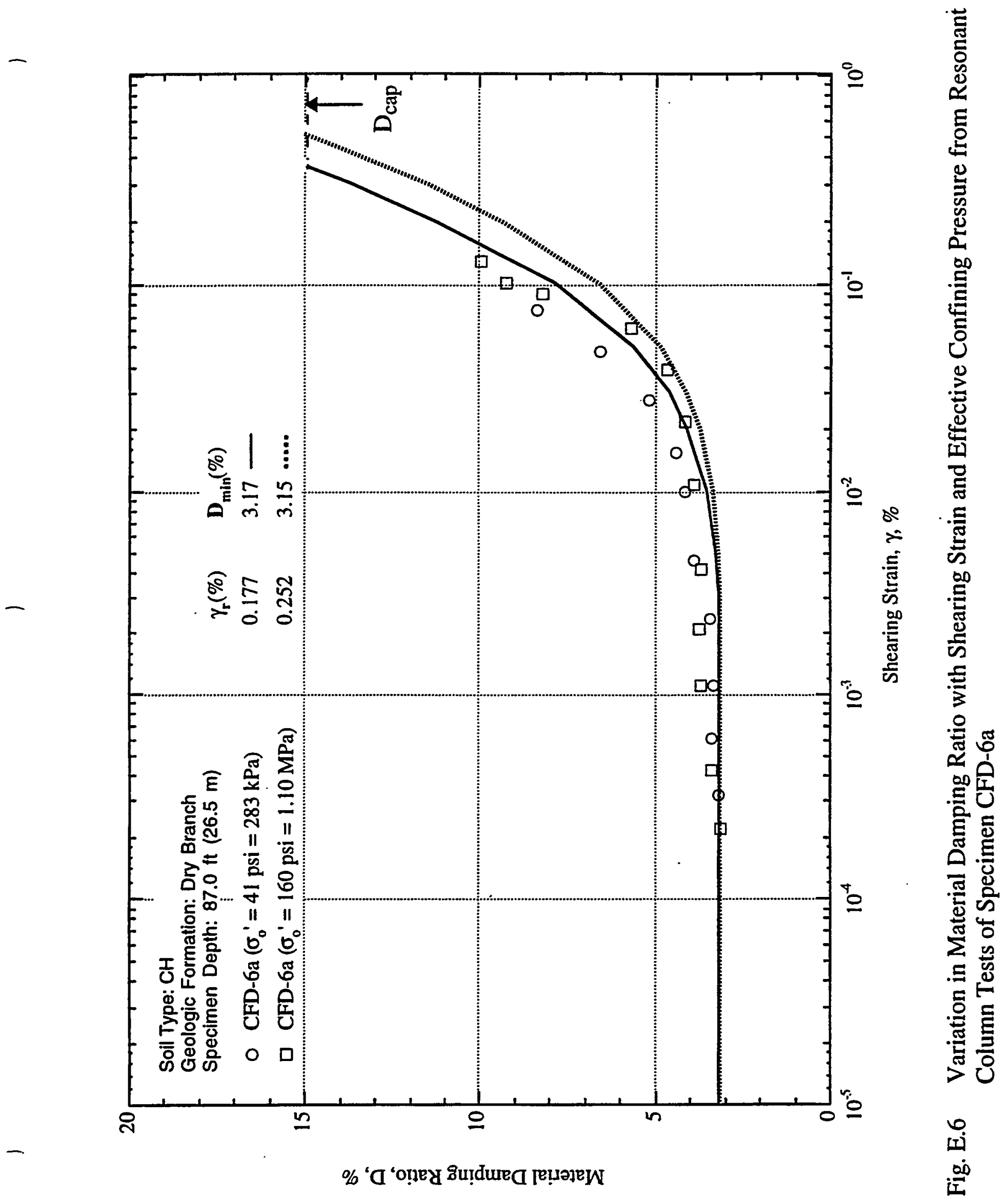

SRS-FR-CDP-95, rev. 0, 13 September 95 


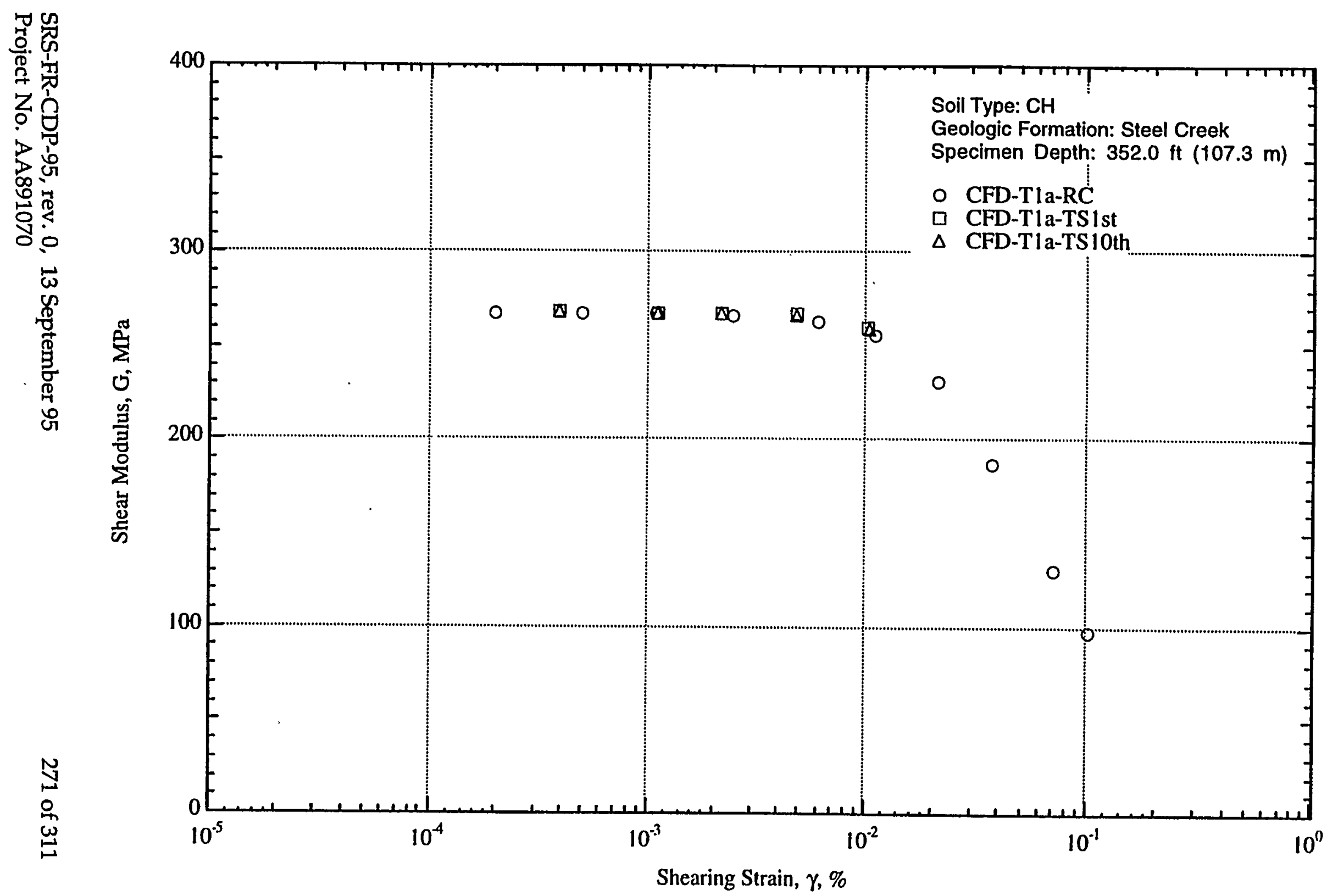

Fig. E.7 Variation in Shear Modulus with Shearing Strain at an Effective Confining Pressure of 111 psi $(=15.98 \mathrm{ksf}$ $=765 \mathrm{kPa}$ ) from RCTS Tests of Specimen CFD-Tla 

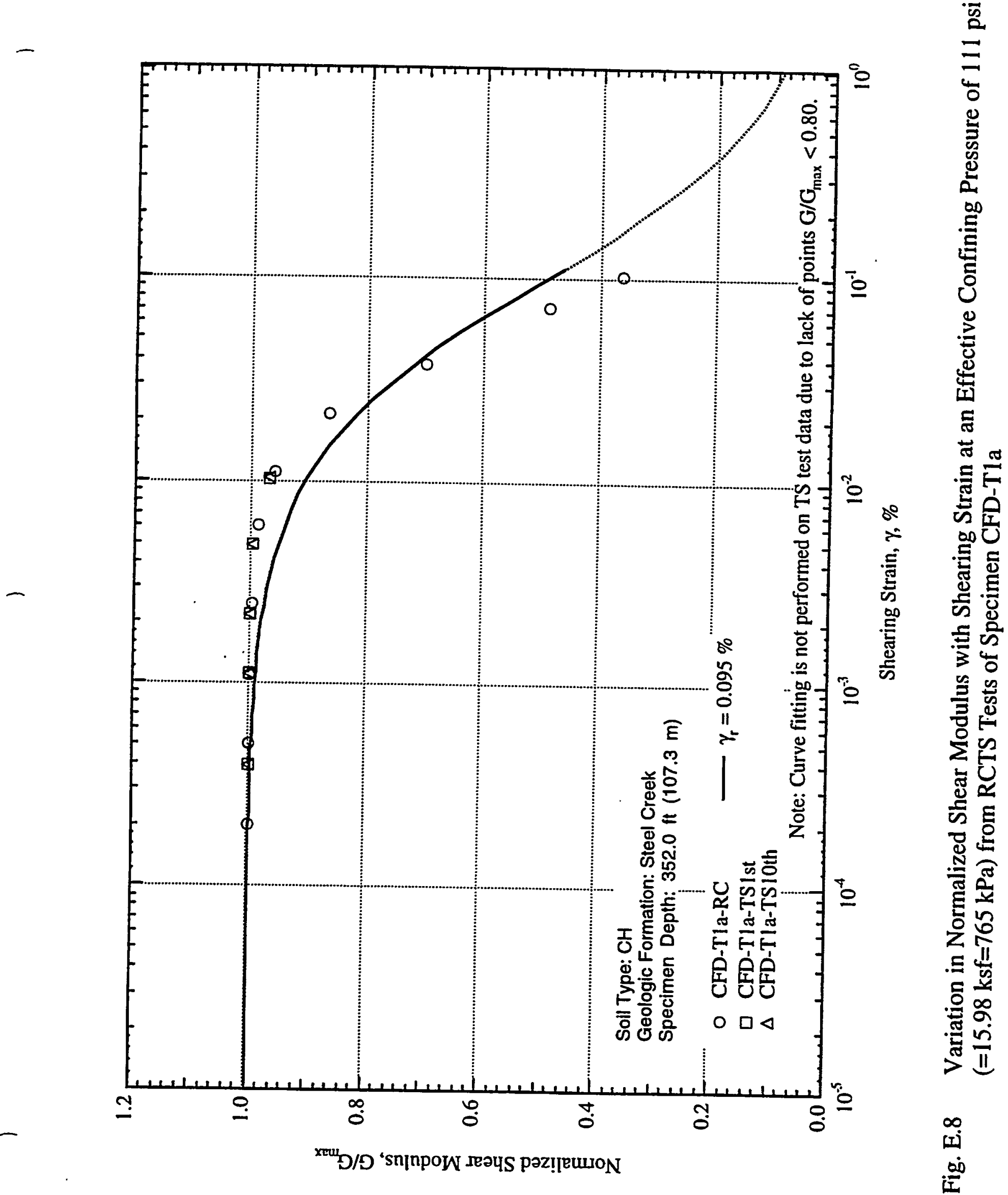

SRS-FR-CDP-95, rev. 0, 13 September 95 Project No. AA891070 


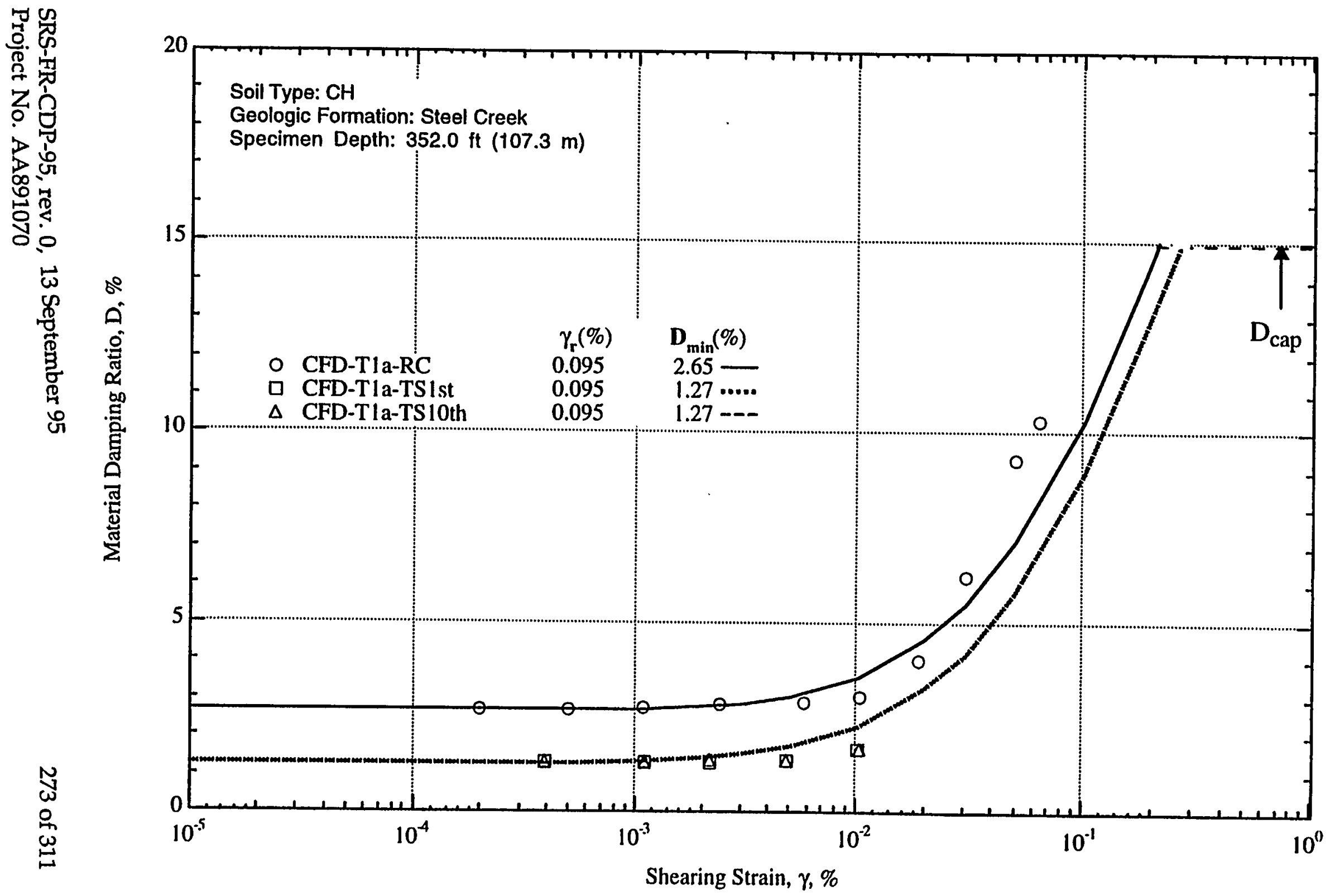

Fig. E.9 Variation in Material Damping Ratio with Shearing Strain at an Effective Confining Pressure of $111 \mathrm{psi}$ $(=15.98 \mathrm{ksf}=765 \mathrm{kPa})$ from RCTS Tests of Specimen CFD-T1a 


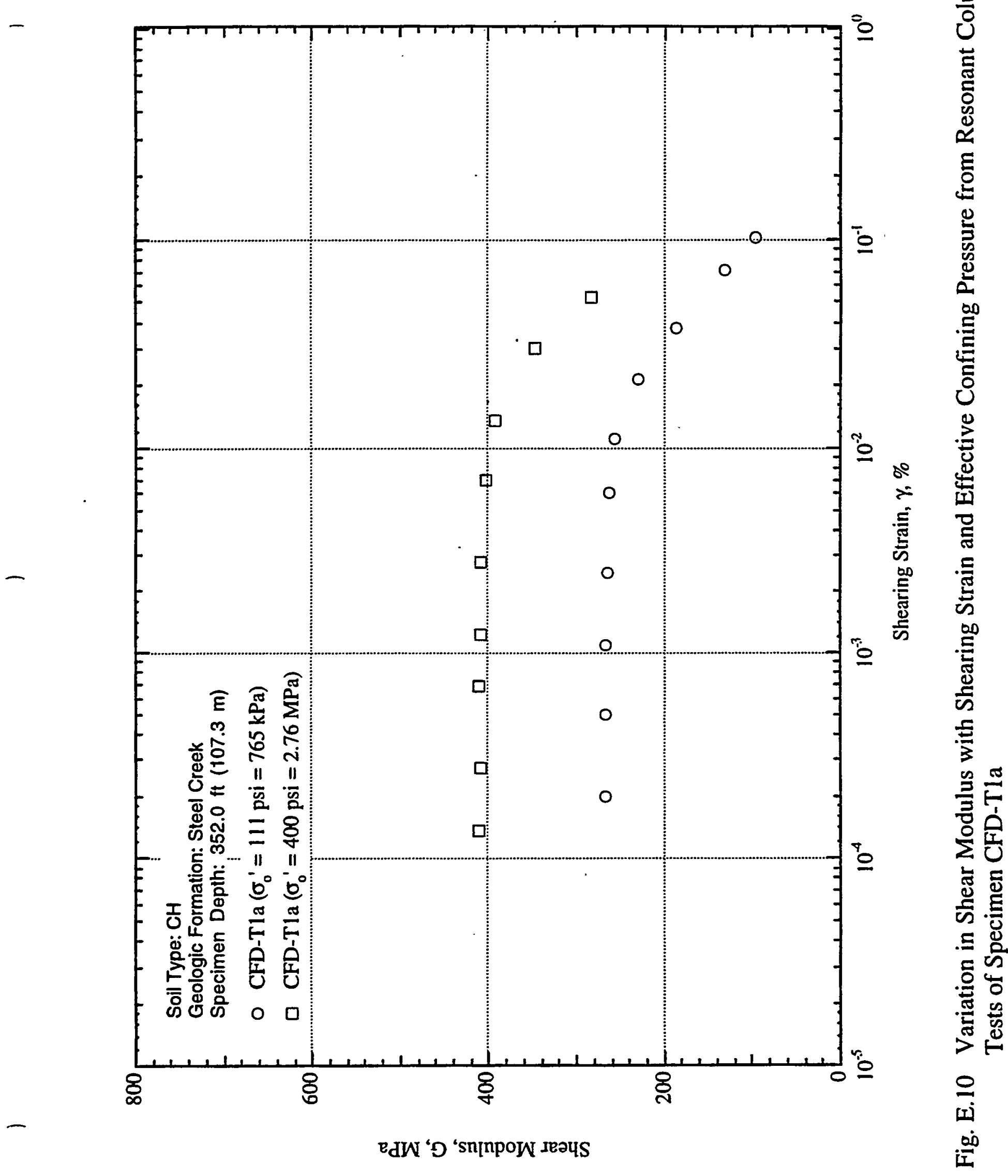

SRS-FR-CDP-95, rev. 0, 13 September 95 


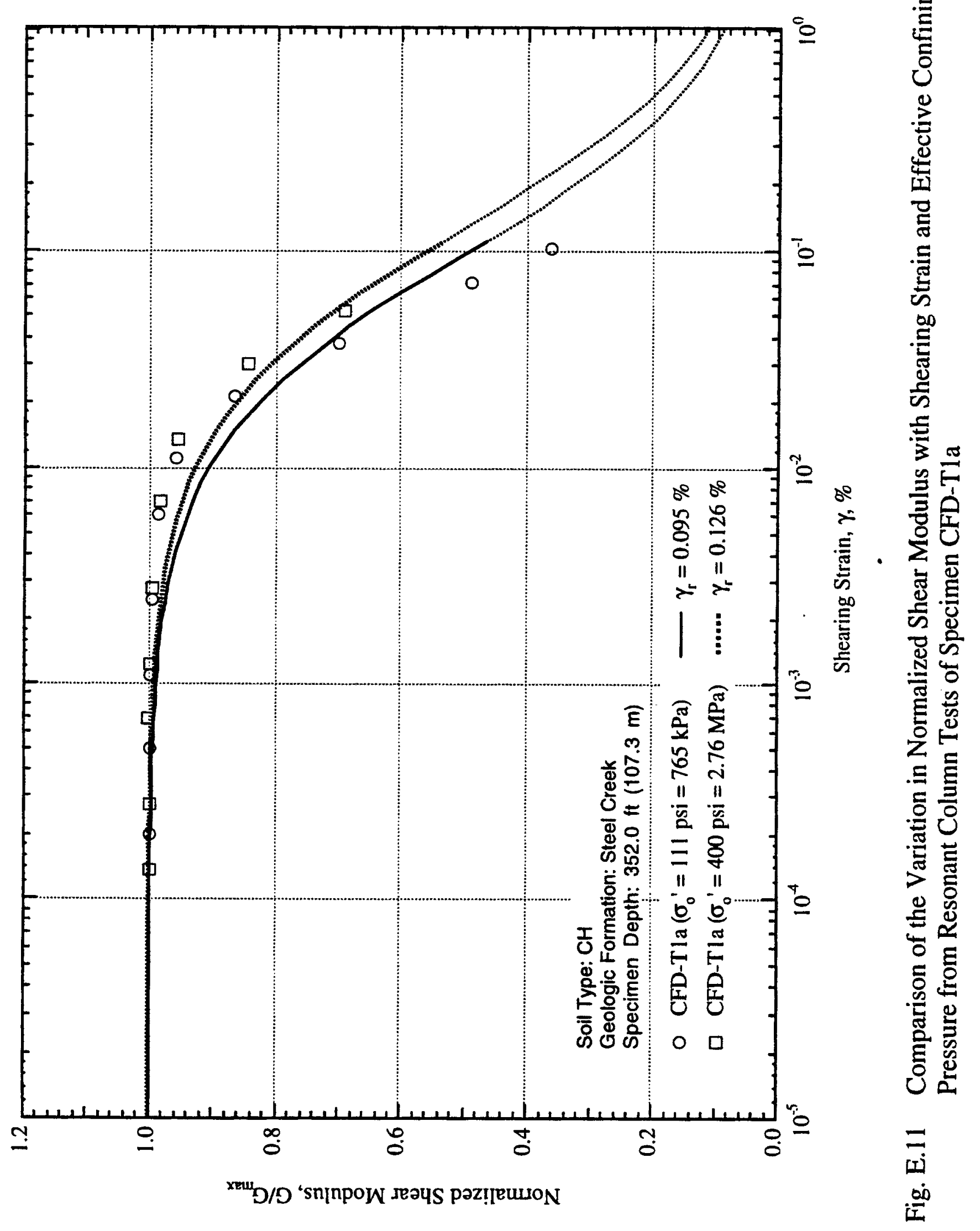

SRS-FR-CDP-95, rev. 0, 13 September 95 


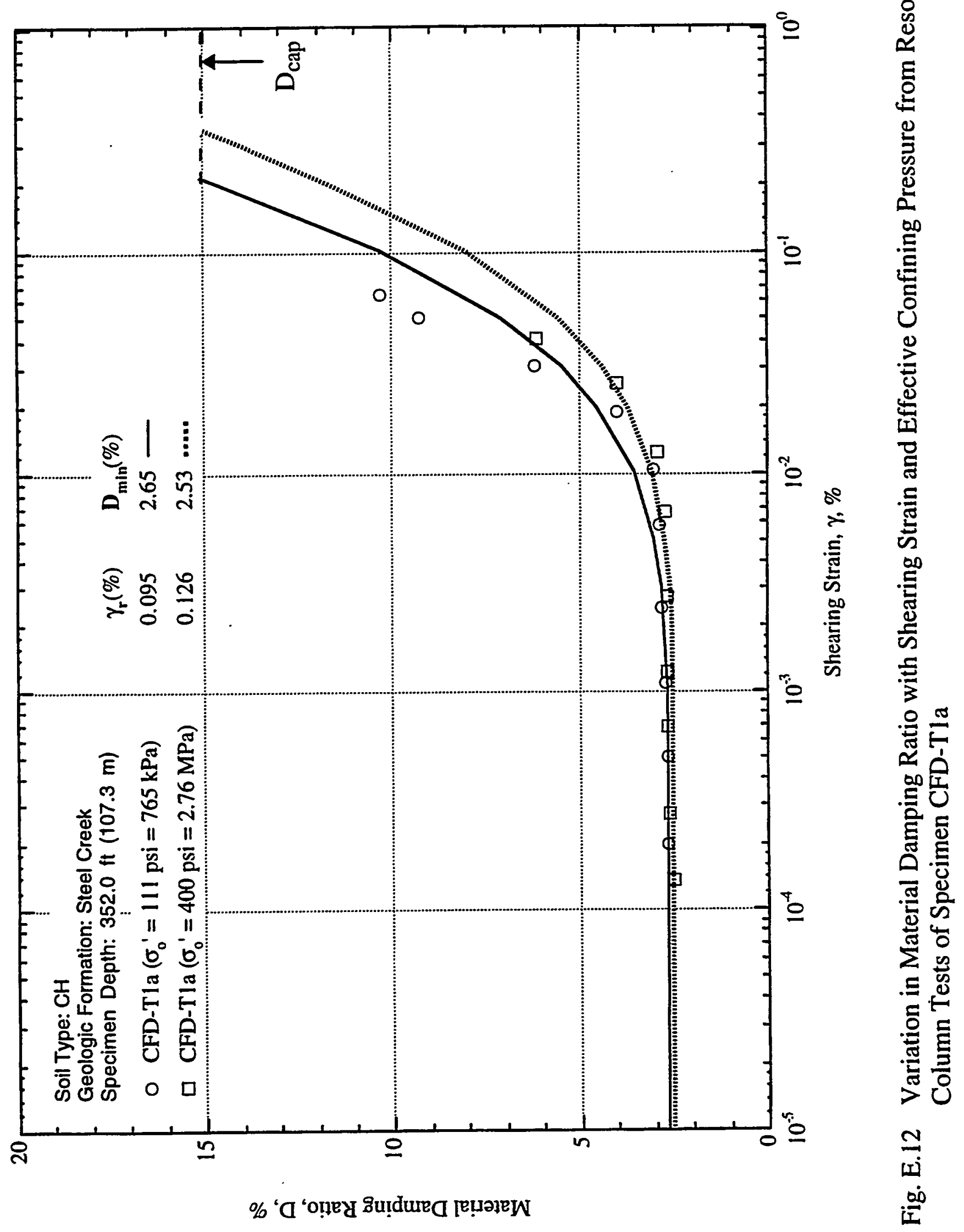

SRS-FR-CDP-95, rev. 0, 13 September 95 


\section{Appendix F}

\section{Effects of Excitation Frequency, Number of Loading Cycles and Confining Pressure on the Dynamic Properties of Upland Sands (Specimens CFD-1a and CFD-2a)}




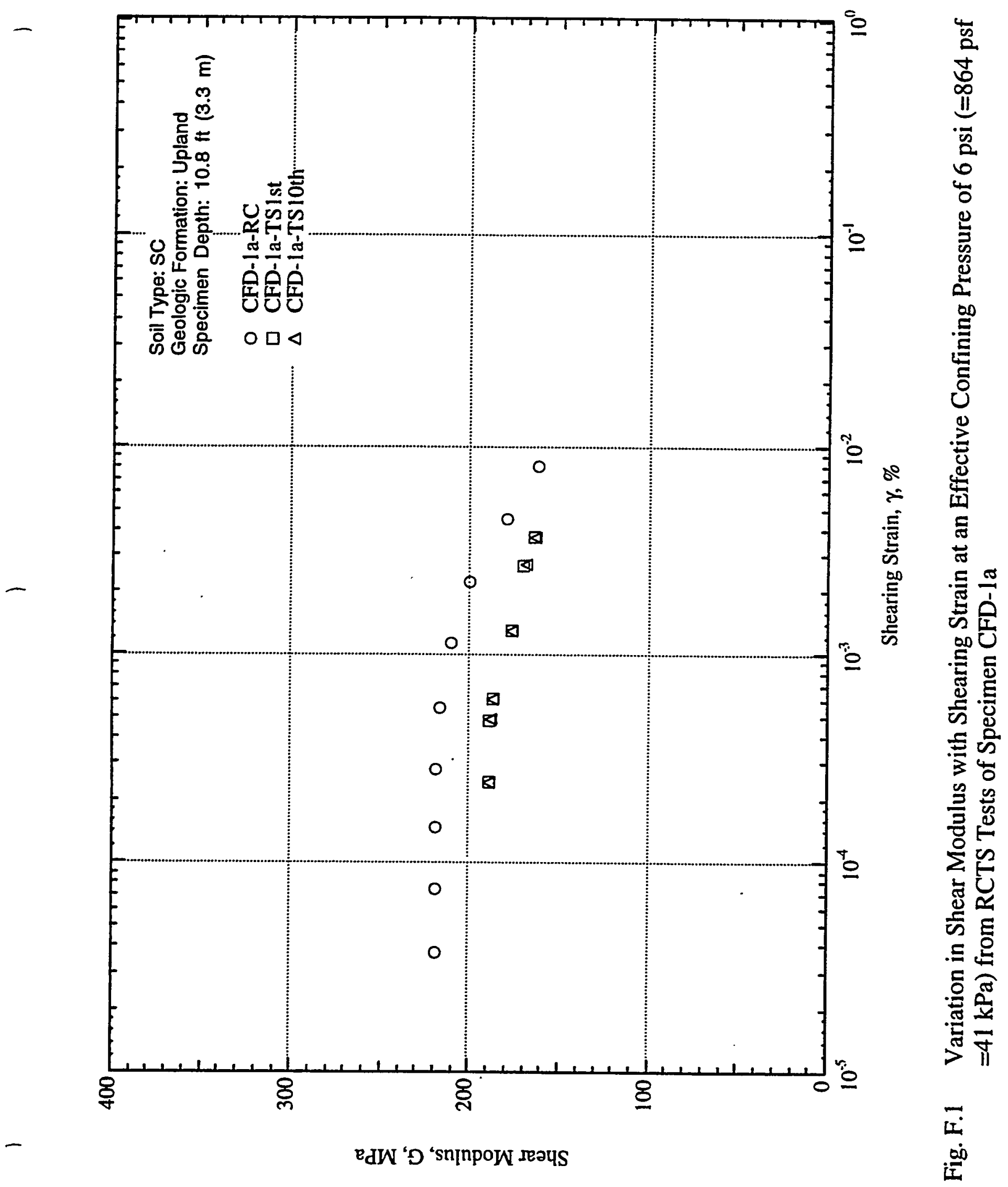

SRS-FR-CDP-95, rev. 0, 13 September 95 


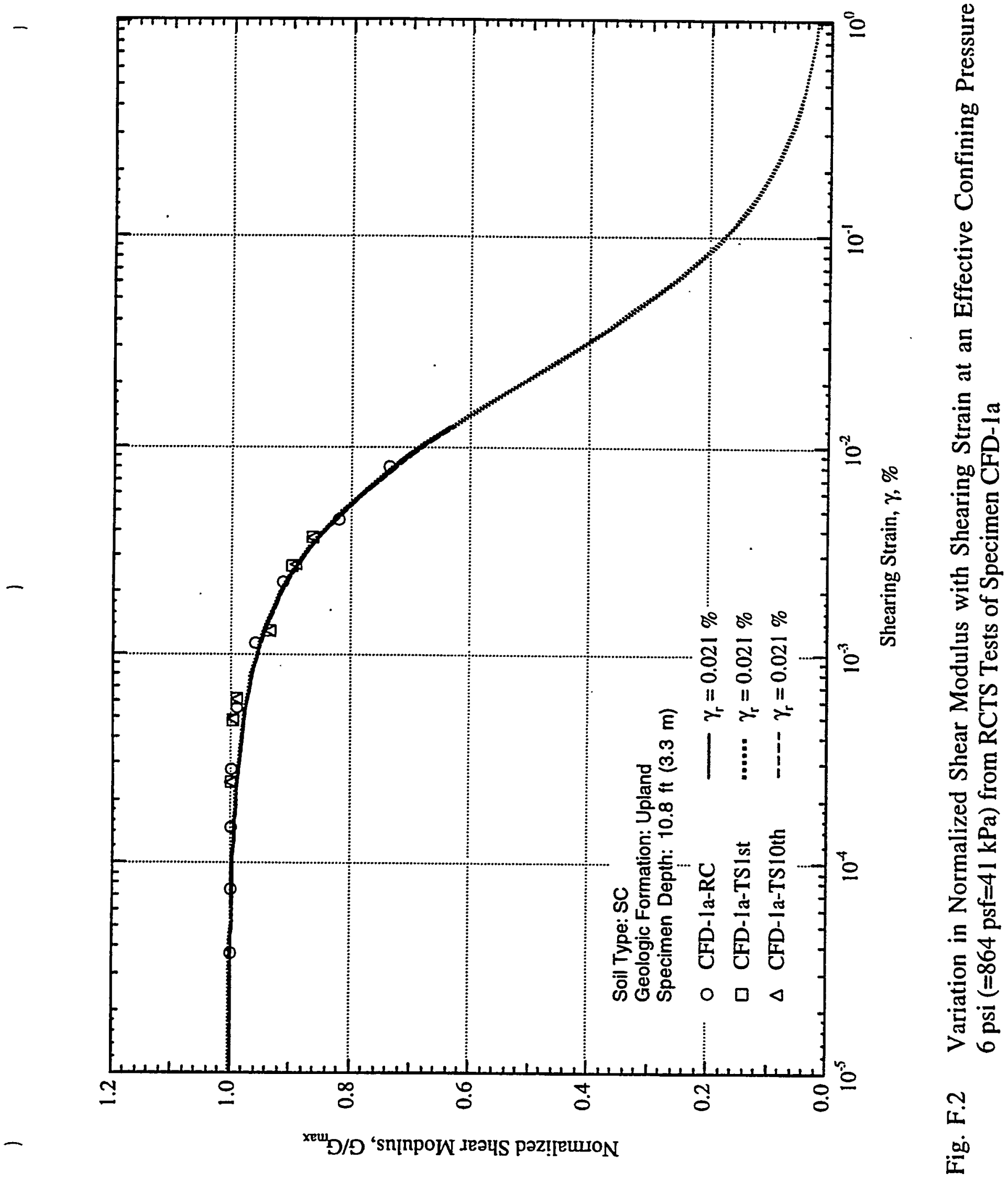

SRS-FR-CDP-95, rev. 0, 13 September 95 


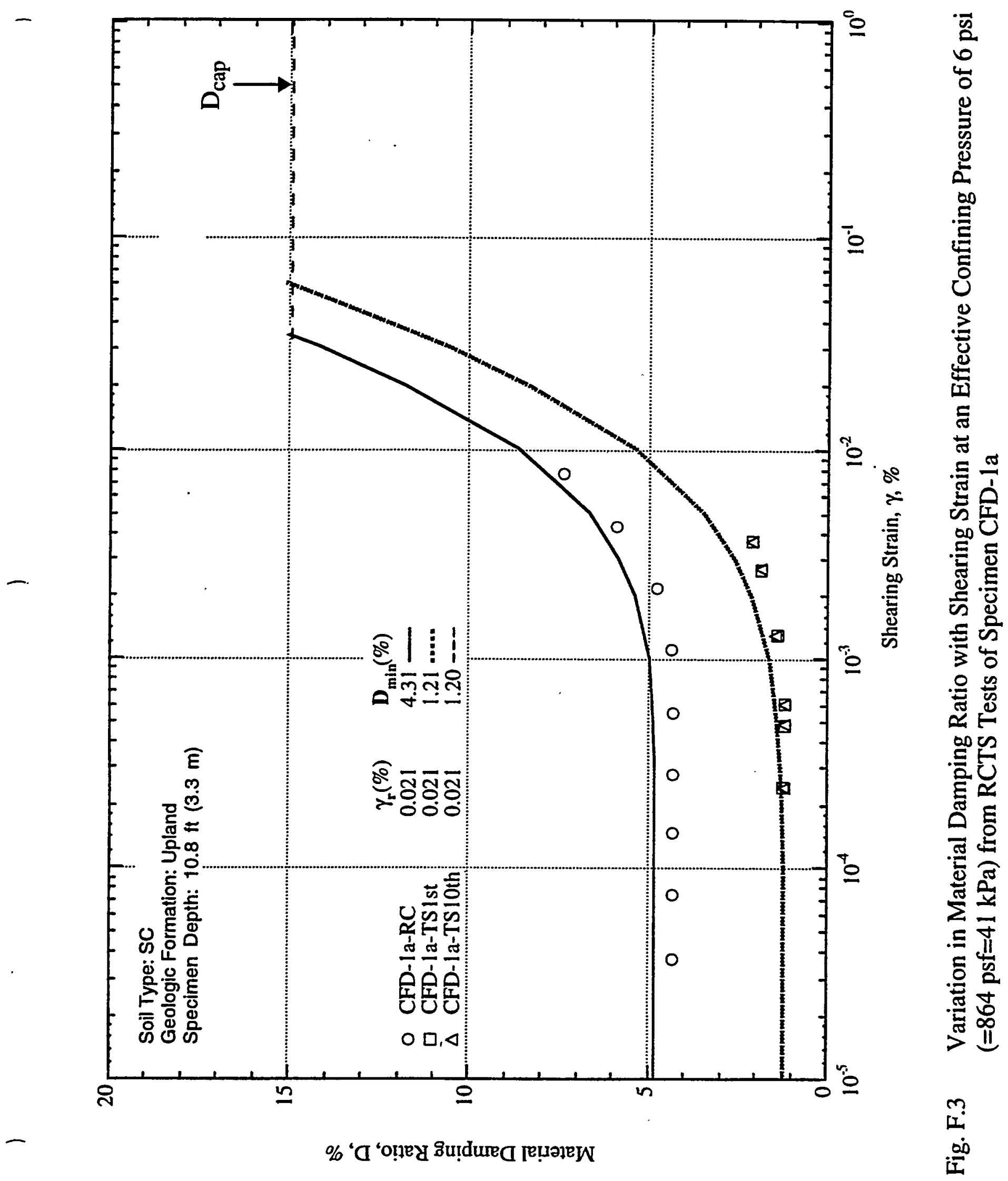

SRS-FR-CDP-95, rev. 0, 13 September 95 


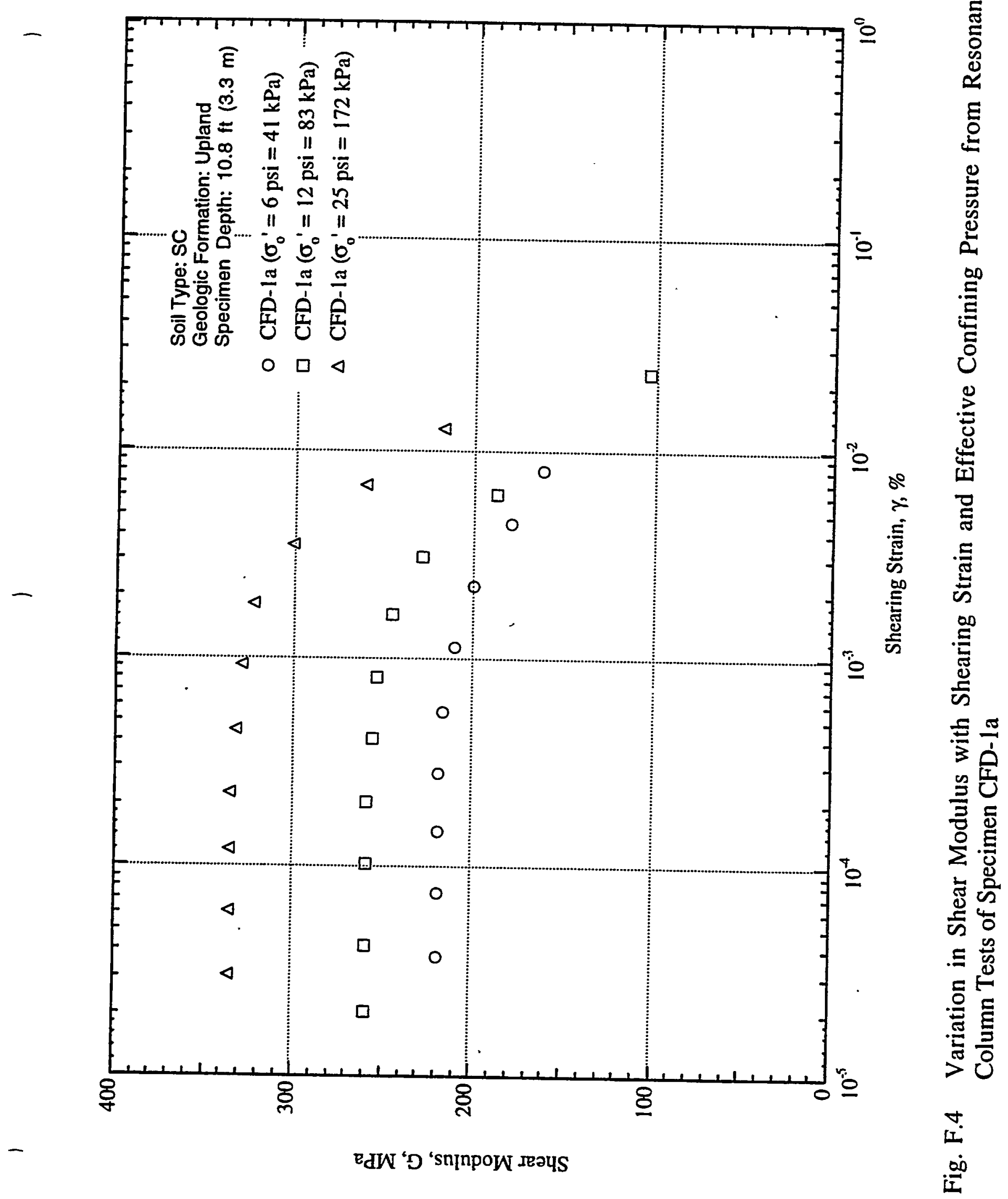

SRS-FR-CDP-95, rev. 0, 13 September 95

Project No. AA891070 


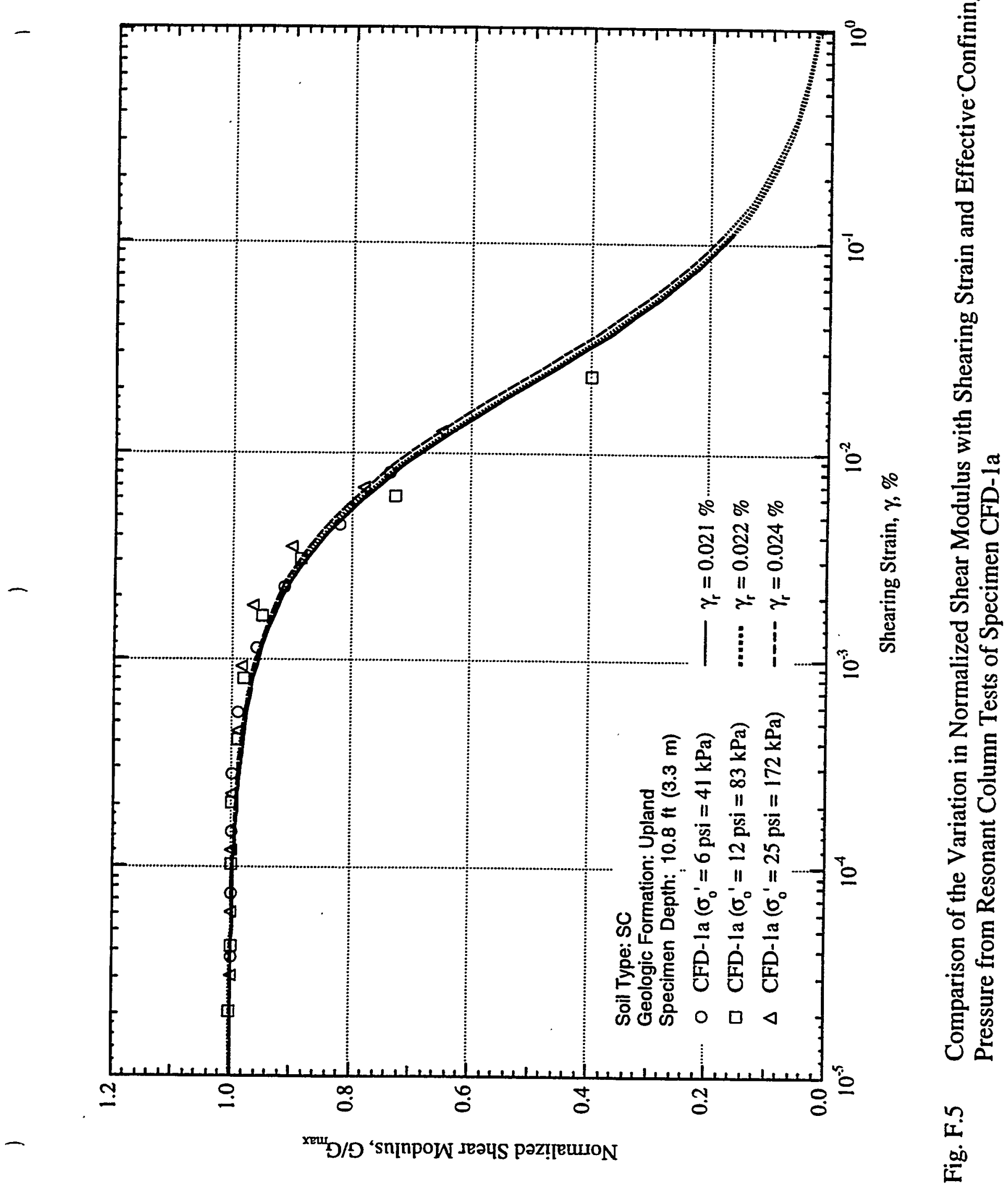

SRS-FR-CDP-95, rev. 0, 13 September 95 Project No. AA891070 


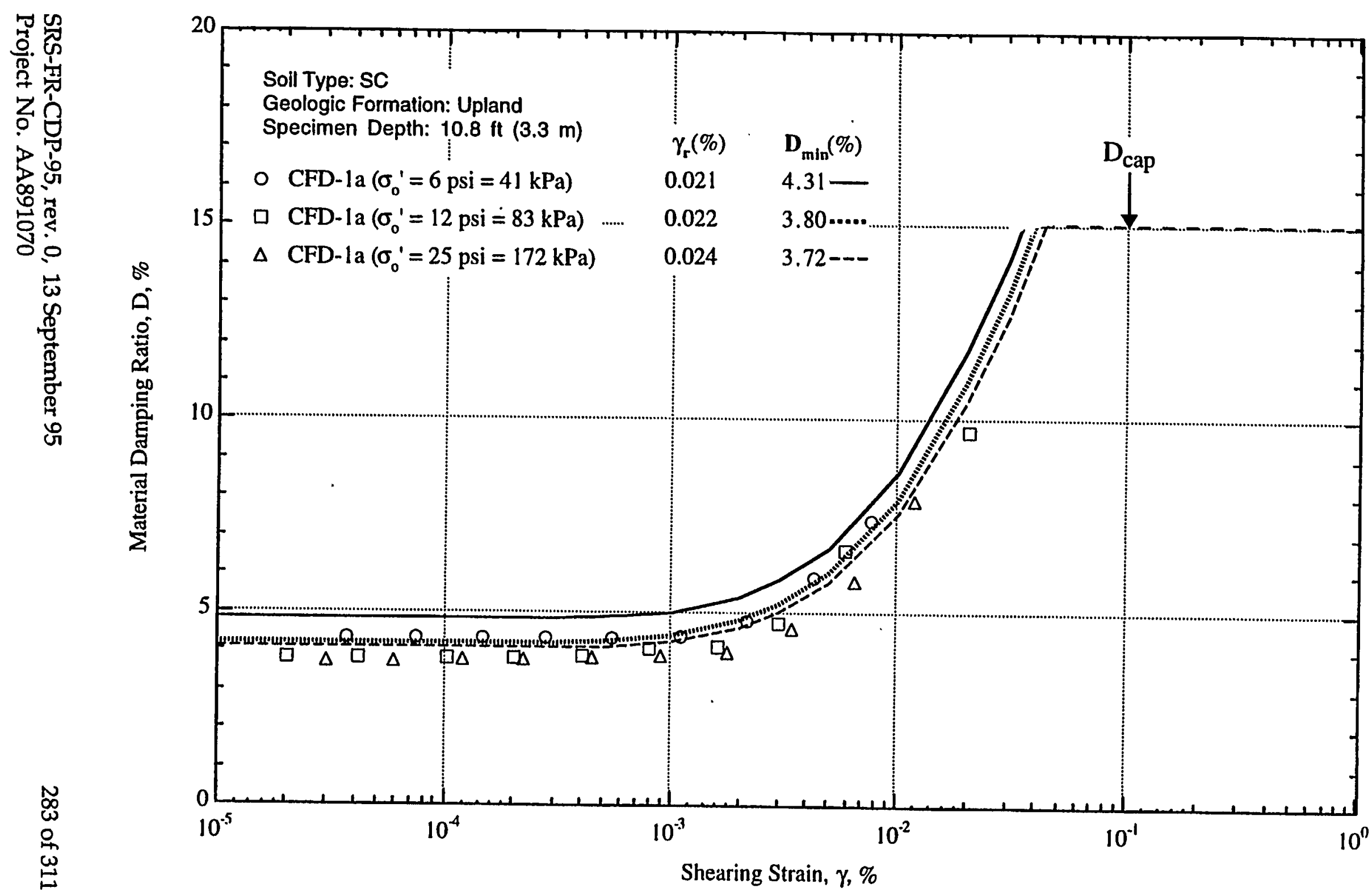

Fig. F.6 Variation in Material Damping Ratio with Shearing Strain and Effective Confining Pressure from Resonant Column Tests of Specimen CFD-1a 


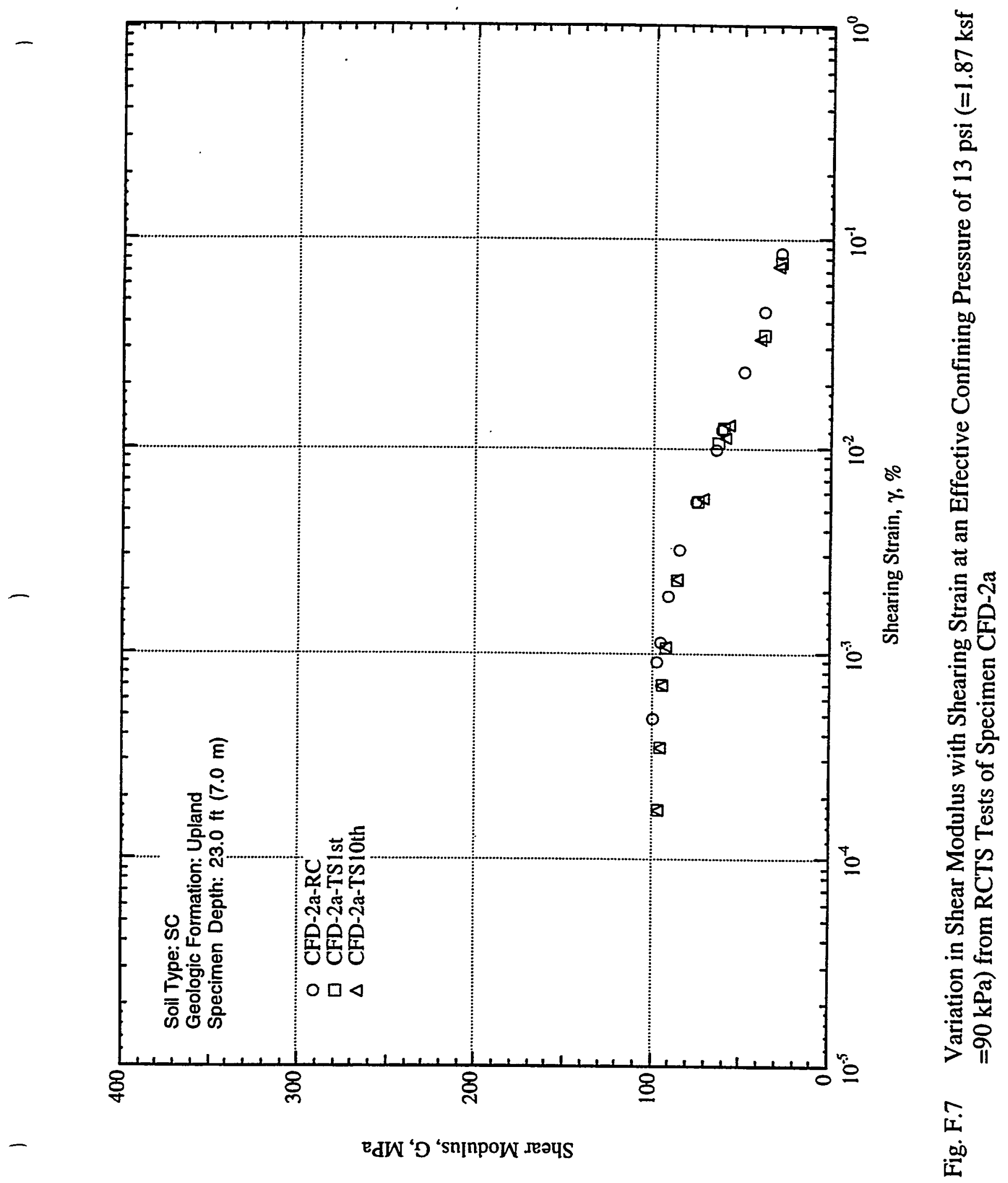

SRS-FR-CDP-95, rev. 0, 13 September 95

Project No. AA891070 


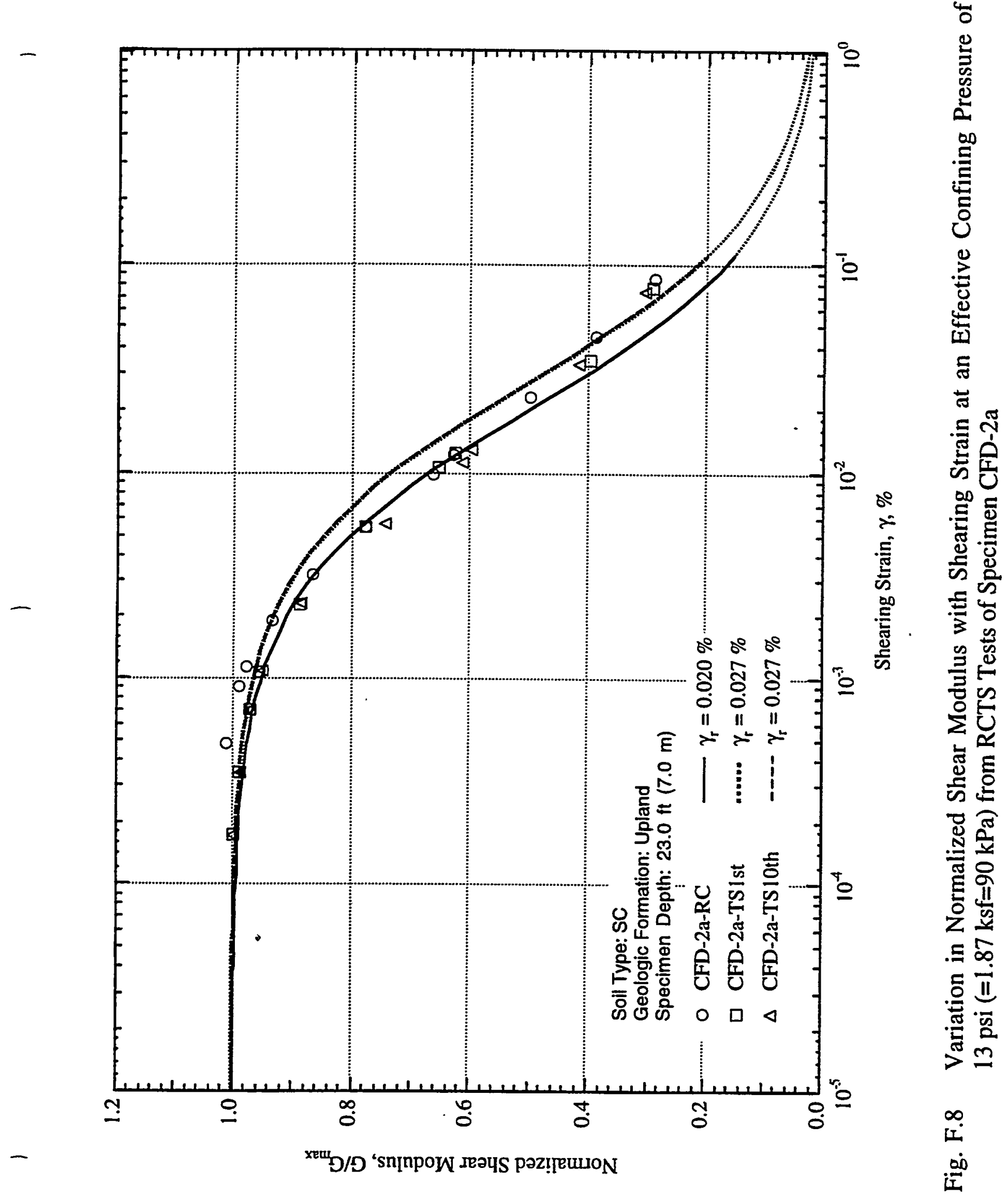

SRS-FR-CDP-95, rev. 0, 13 September 95 


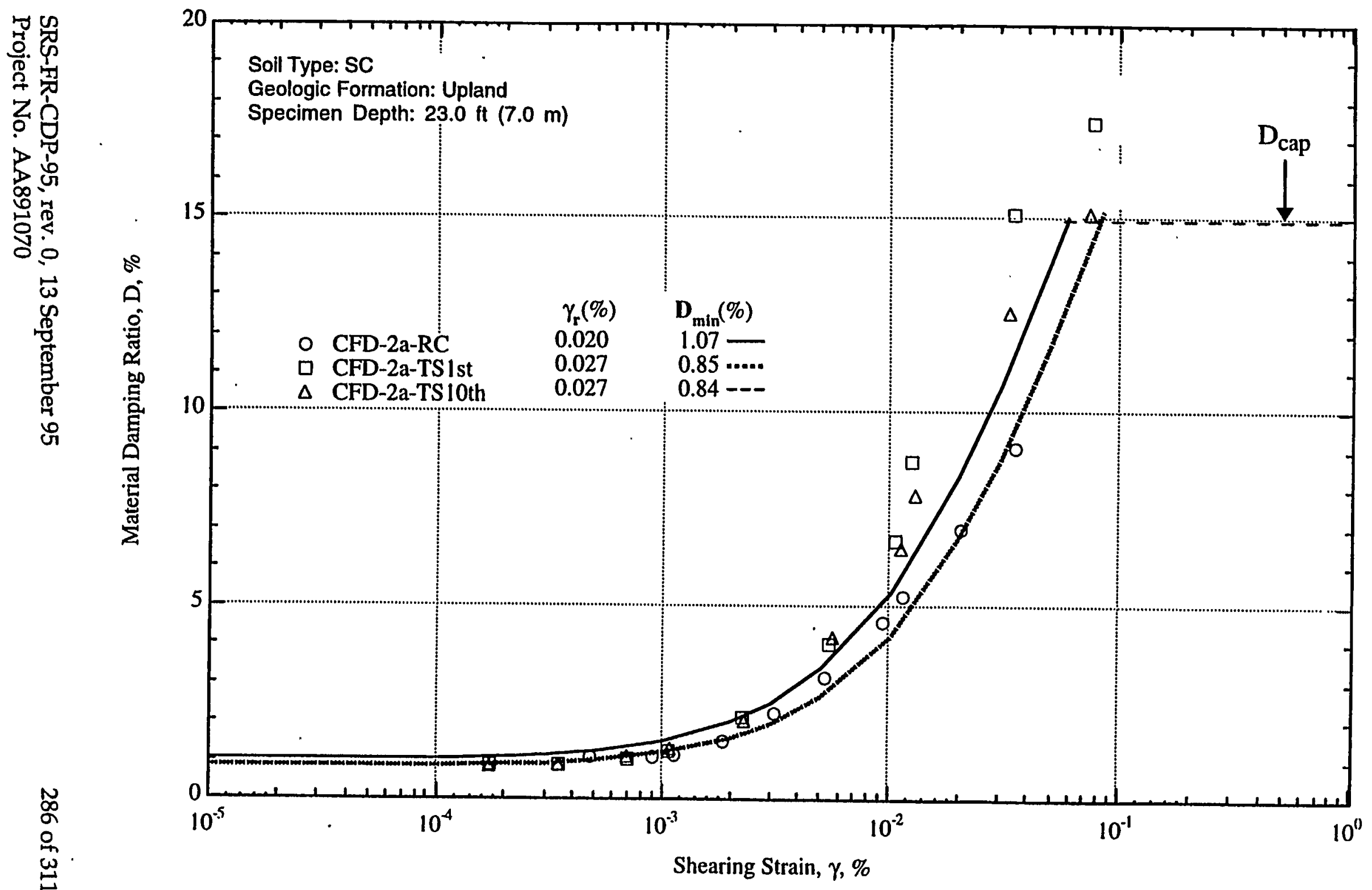

Fig. F.9 Variation in Material Damping Ratio with Shearing Strain at an Effective Confining Pressure of 13 psi $(=1.87 \mathrm{ksf}=90 \mathrm{kPa})$ from RCTS Tests of Specimen CFD-2a 


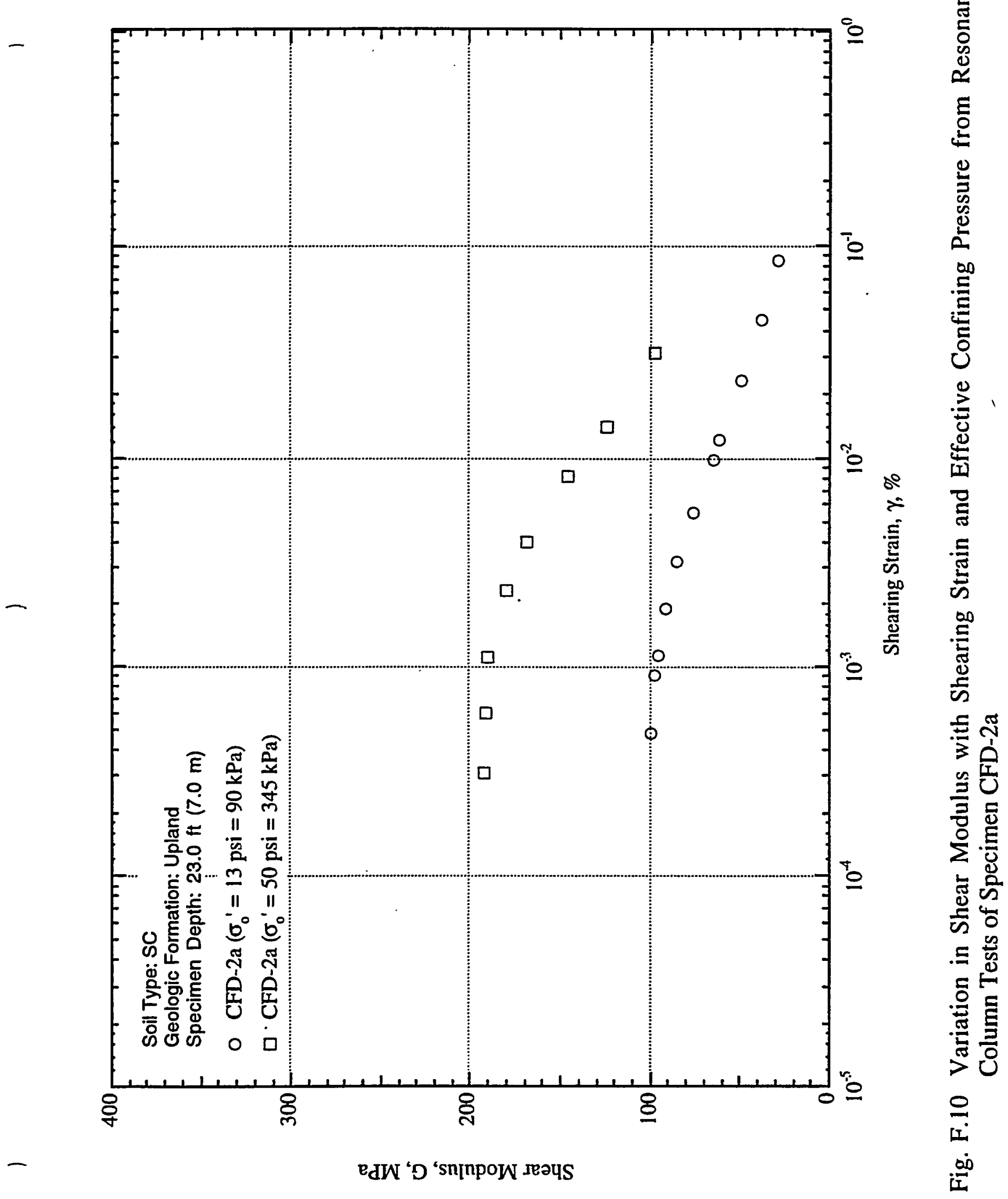




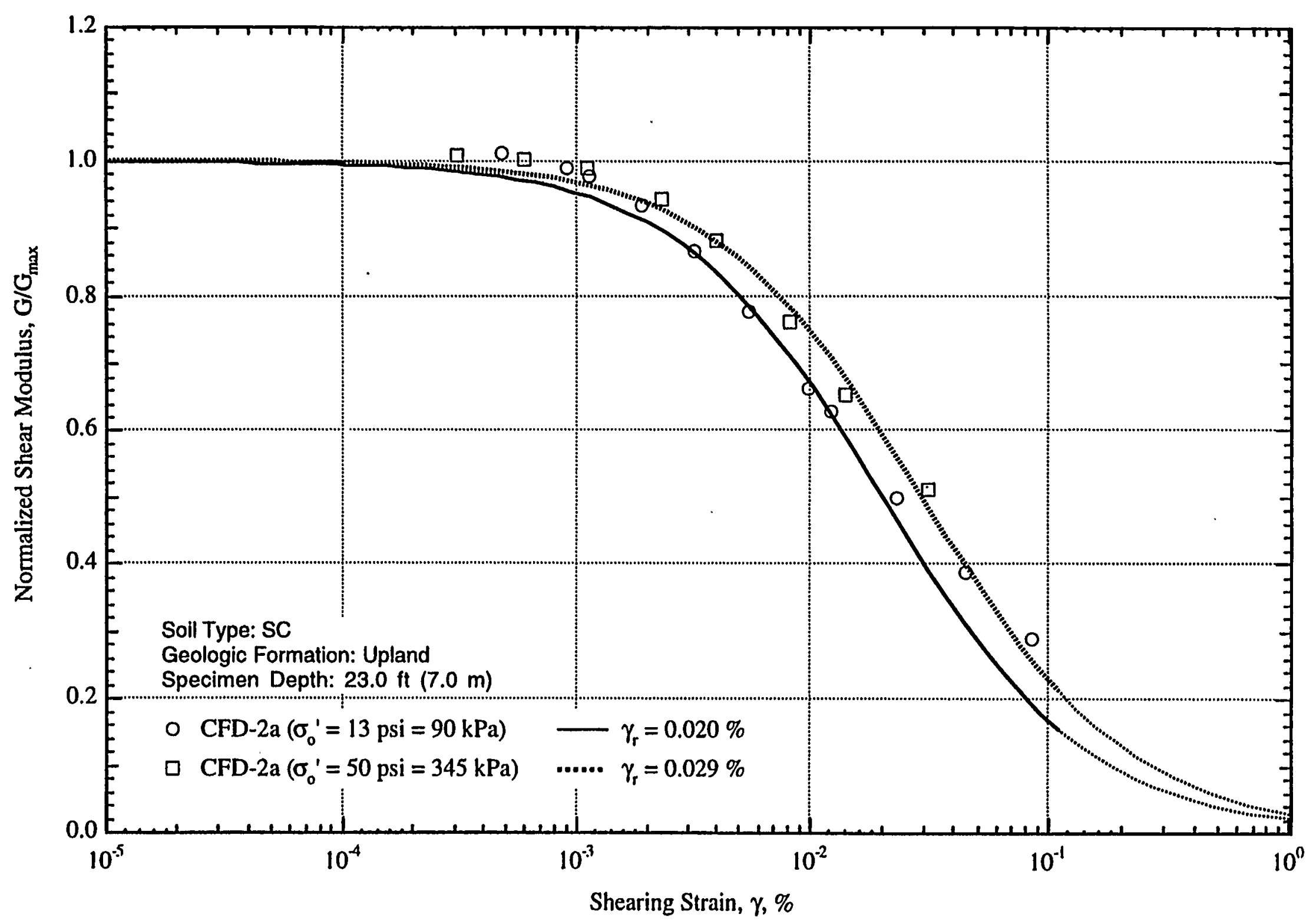

Fig. F.11 Comparison of the Variation in Normalized Shear Modulus with Shearing Strain and Effective Confining Pressure from Resonant Column Tests of Specimen CFD-2a 


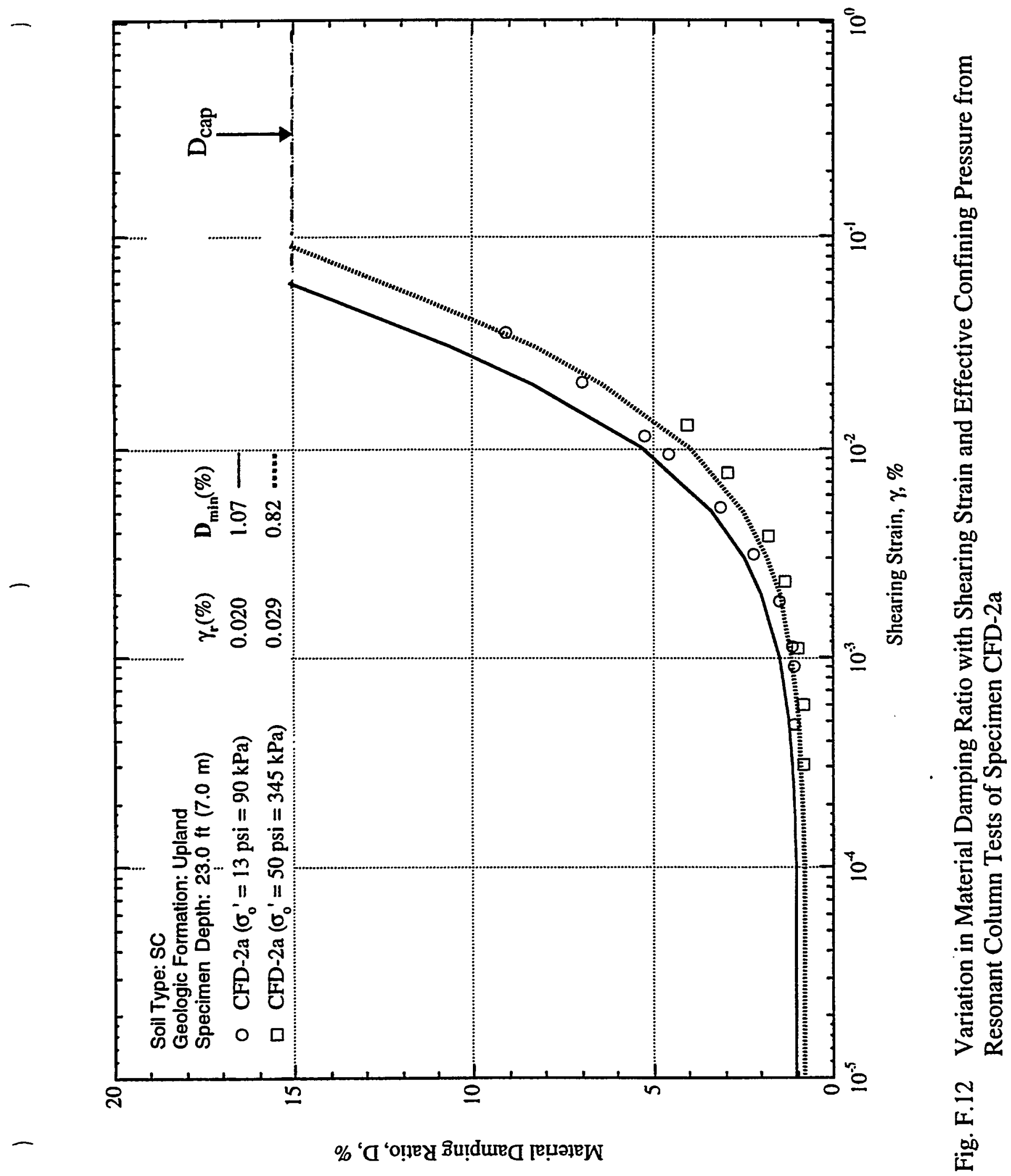




\section{Appendix G}

\section{Effects of Excitation Frequency and Number of Loading Cycles and Confining Pressure on the Dynamic Properties of Warley Hill Sands (Specimen CFD-8a)}




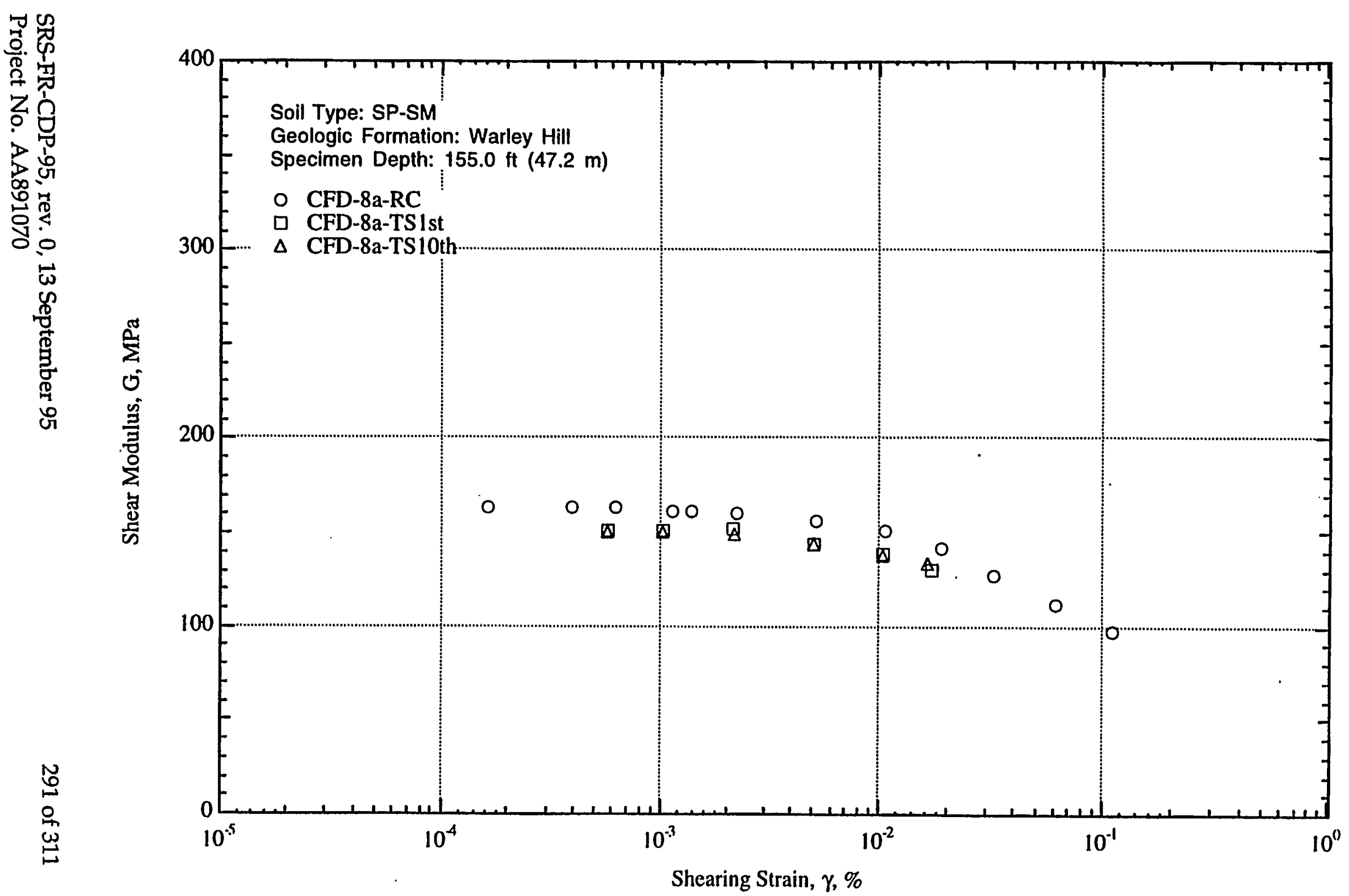

Fig. G.1 Variation in Shear Modulus with Shearing Strain at an Effective Confining Pressure of 59 psi $(=8.49 \mathrm{ksf}$ $=407 \mathrm{kPa}$ ) from RCTS Tests of Specimen CFD-8a 


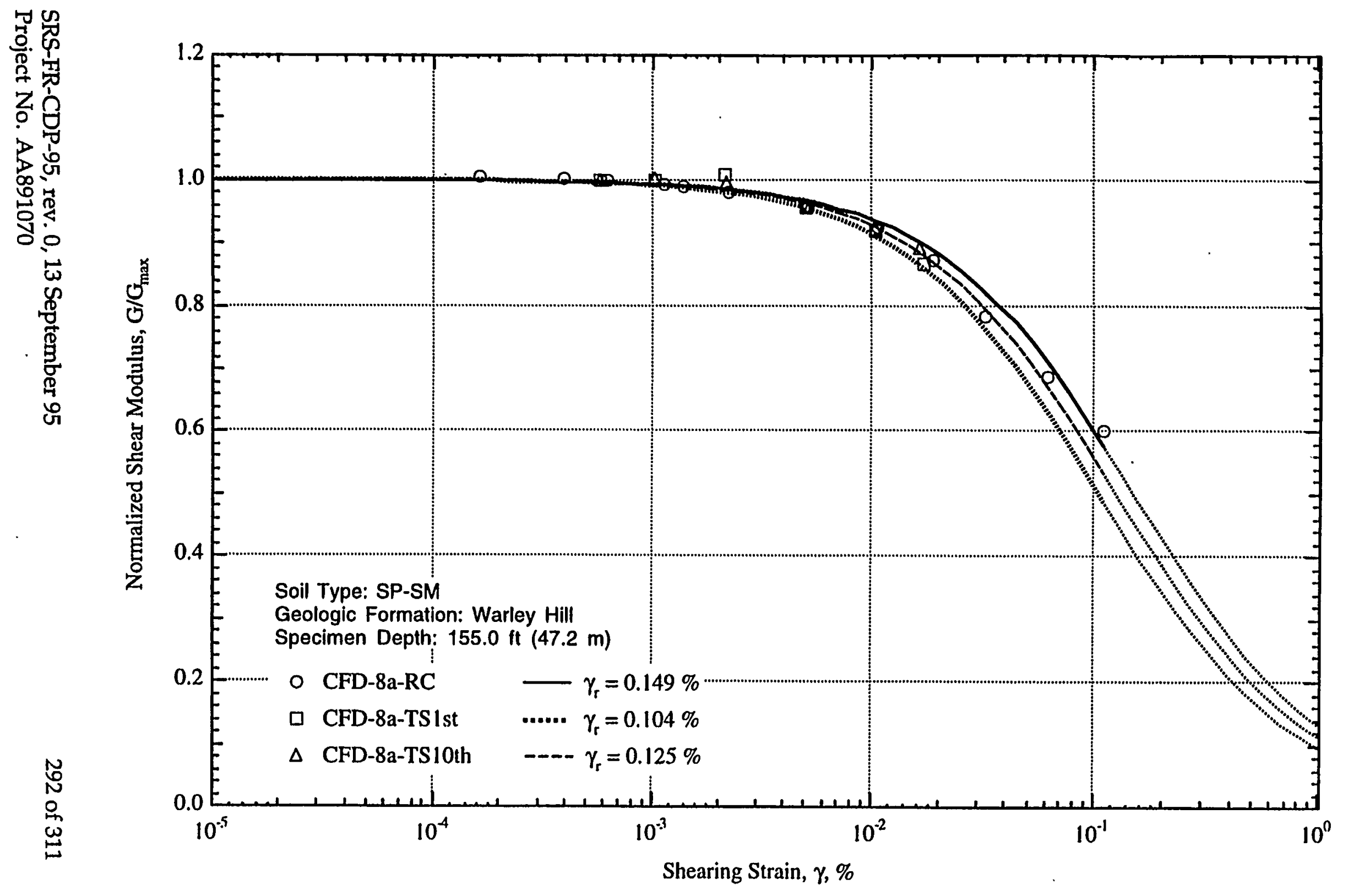

Fig. G.2 Variation in Normalized Shear Modulus with Shearing Strain at an Effective Confining Pressure of $59 \mathrm{psi}(=8.49 \mathrm{ksf}=407 \mathrm{kPa})$ from RCTS Tests of Specimen CFD-8a 


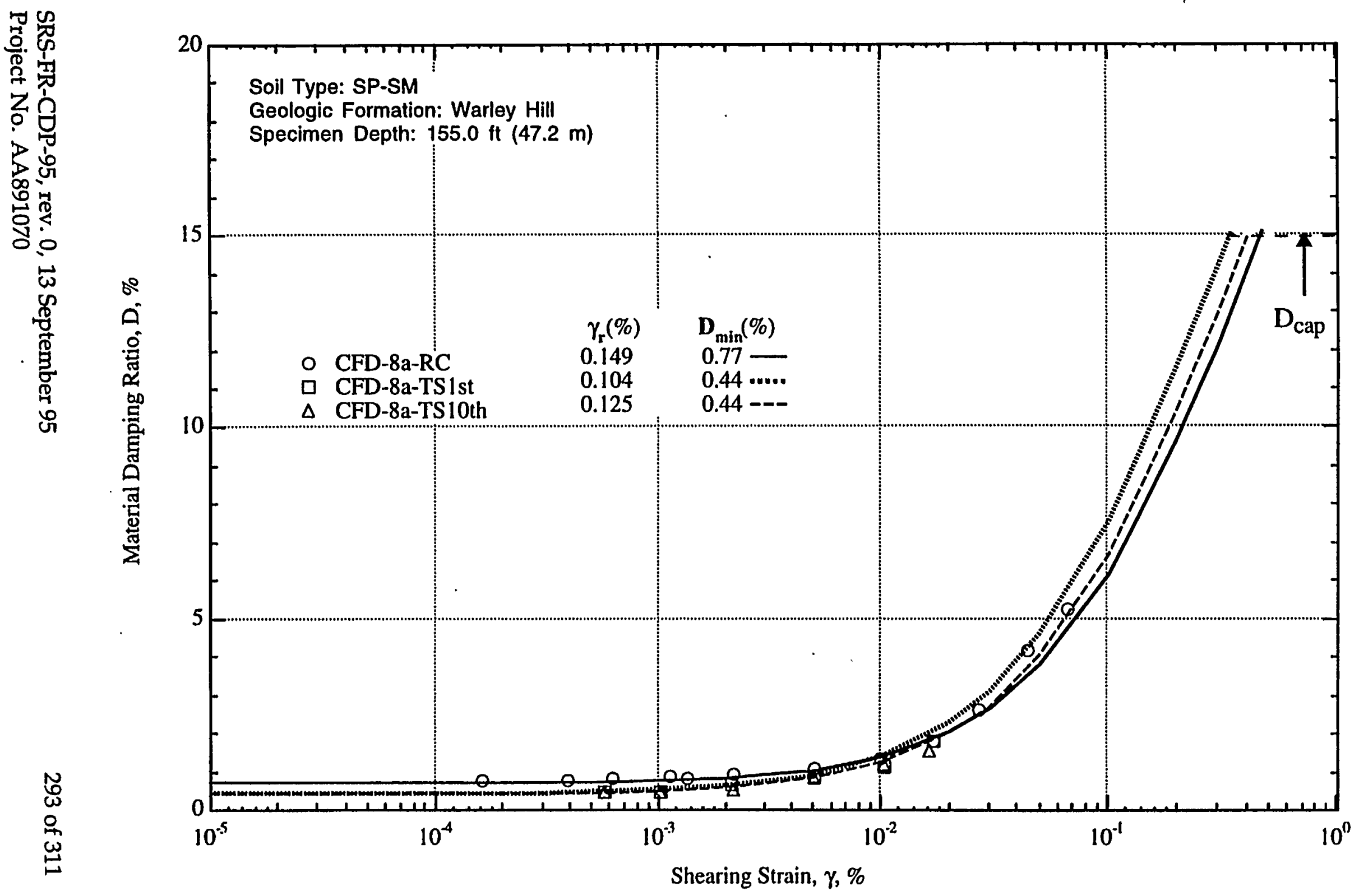

Fig. G.3 Variation in Material Damping Ratio with Shearing Strain at an Effective Confining Pressure of 59 psi $(=8.49 \mathrm{ksf}=407 \mathrm{kPa})$ from RCTS Tests of Specimen CFD-8a 


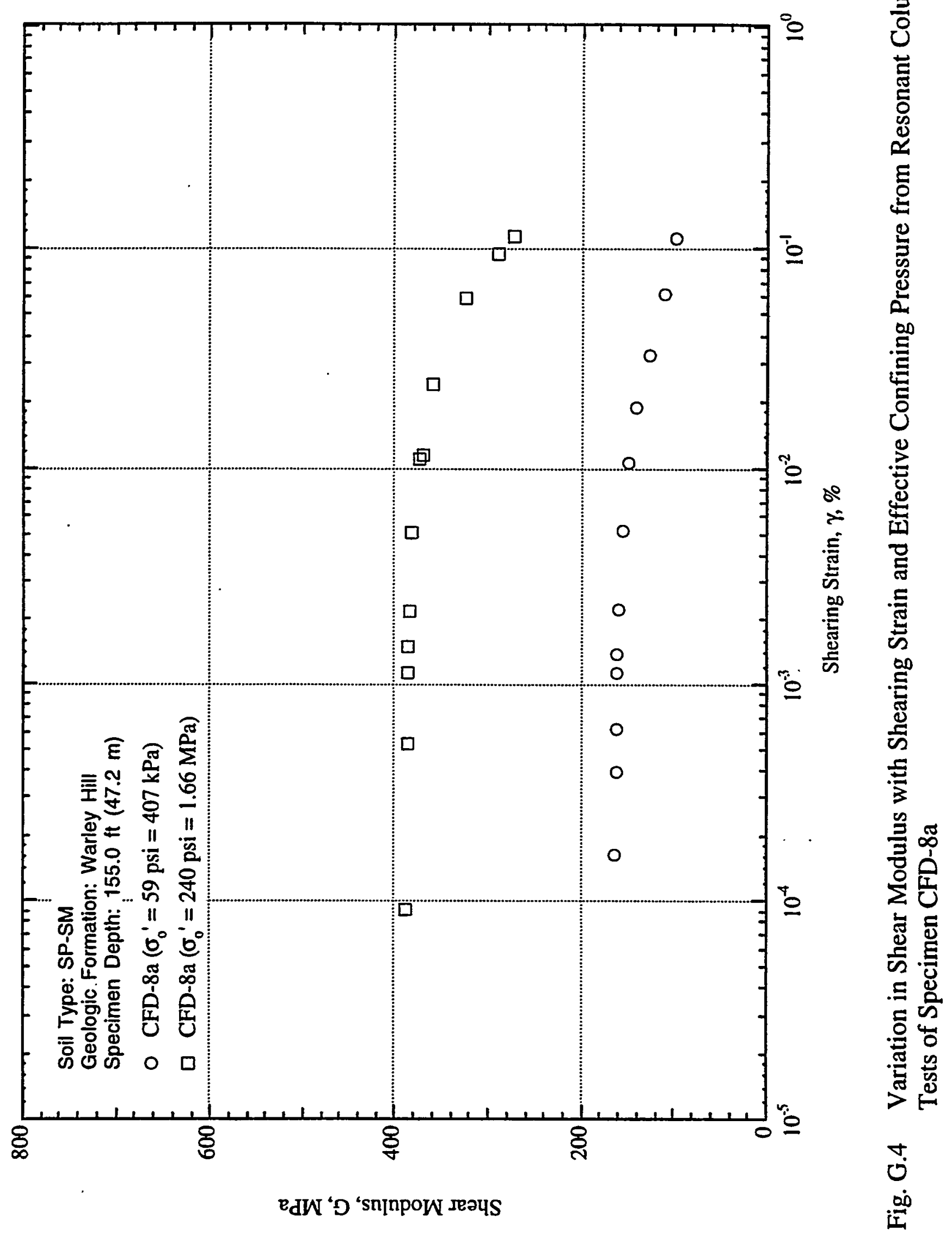

SRS-FR-CDP-95, rev. 0, 2713 September 95

Project No. AA891070 


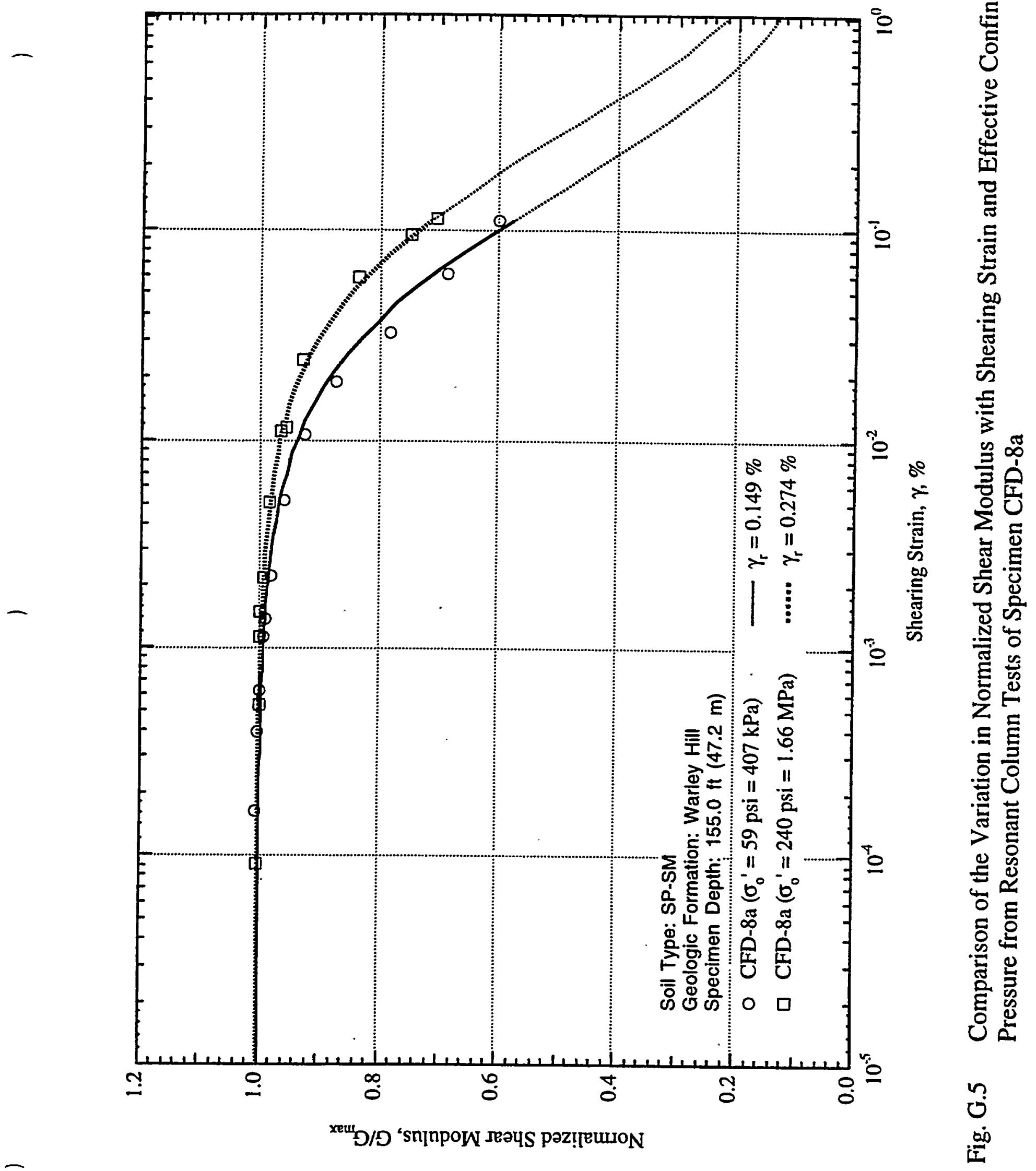

SRS-FR-CDP-95, rev. 0, 2713 September 95

Project No. AA891070 


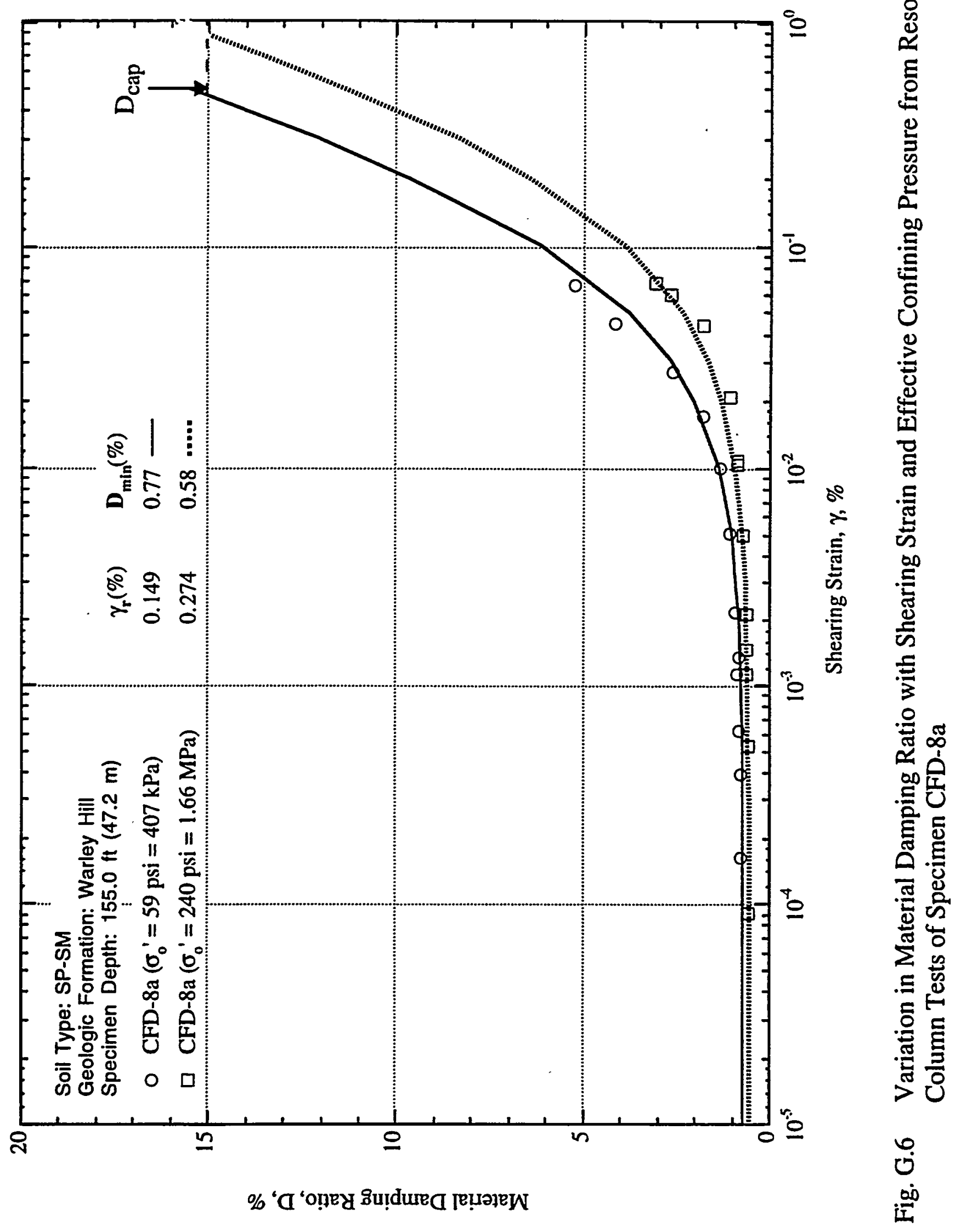

SRS-FR-CDP-95, rev. 0, 13 September 95 


\section{Appendix $\mathrm{H}$ \\ Effects of Excitation Frequency and Number of Loading Cycles on the Dynamic Properties of Congaree Sands}

(Specimen CFD-11a) 


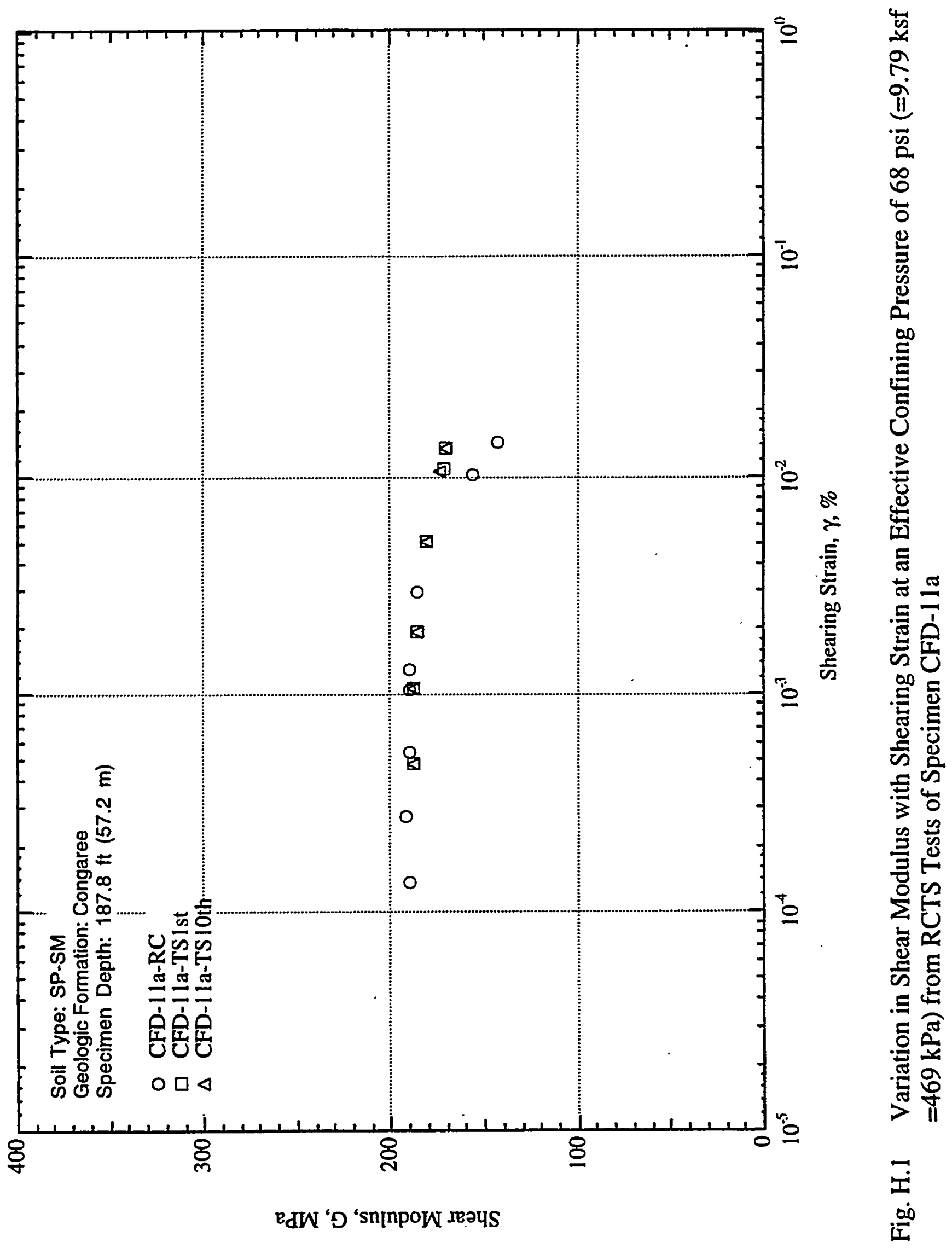

SRS-FR-CDP-95, rev. 0, 13 September 95 


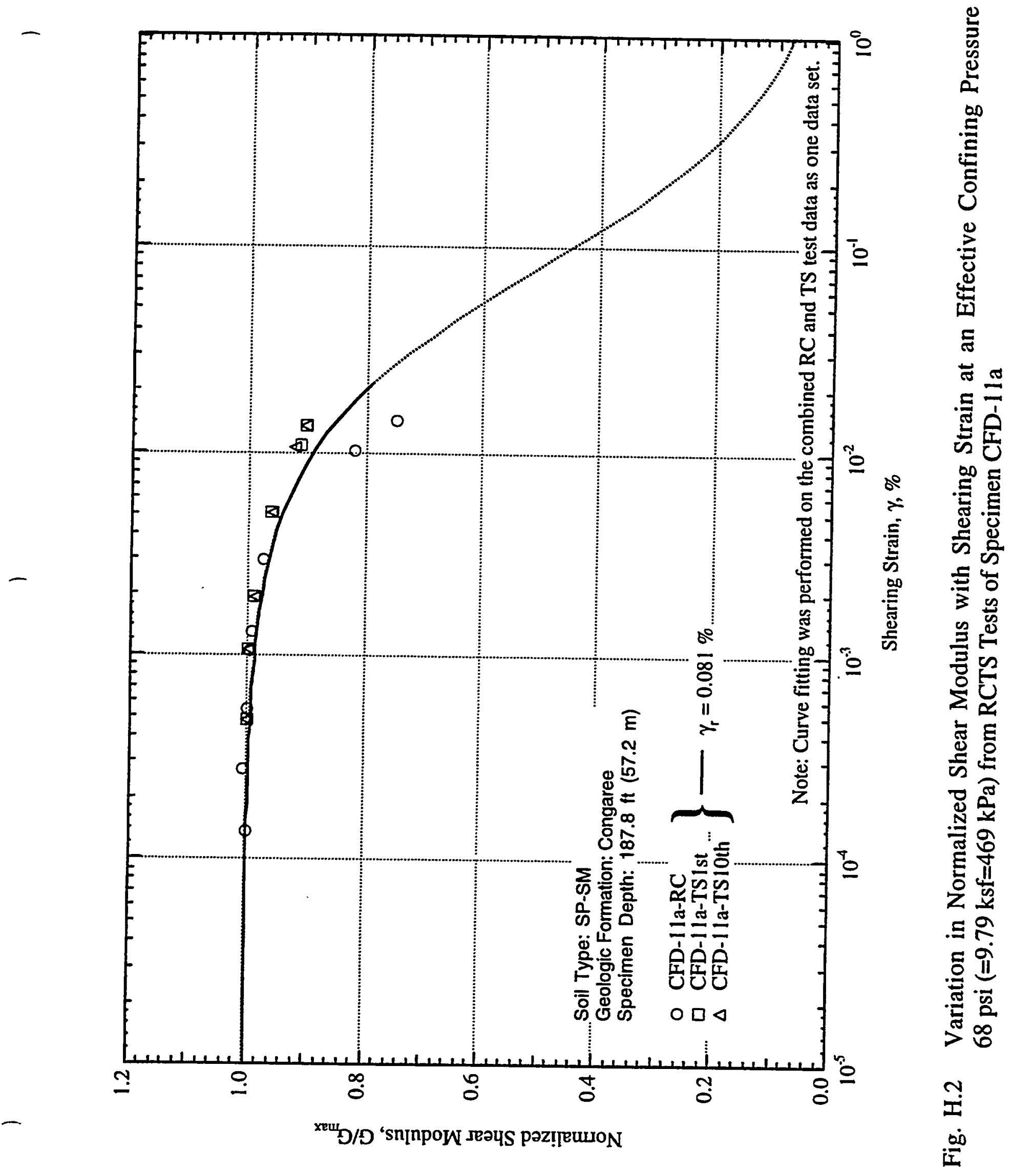

SRS-FR-CDP-95, rev. 0, 13 September 95 


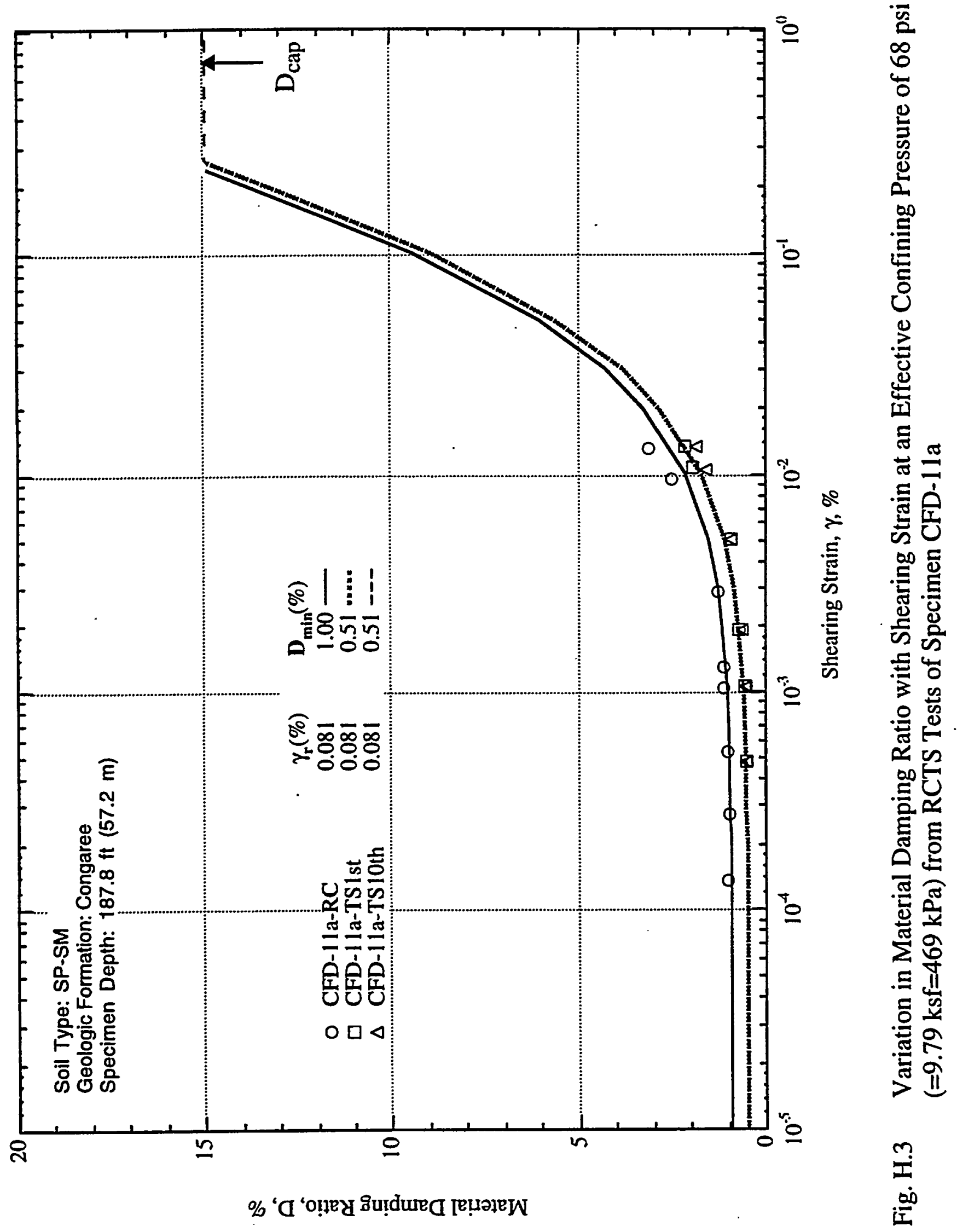

SRS-FR-CDP-95, rev. 0, 13 September 95 


\section{Appendix I}

\section{Effects of Excitation Frequency and Number of Loading Cycles on the Dynamic Properties of Deep Sands (Specimens CFD-T6c)}



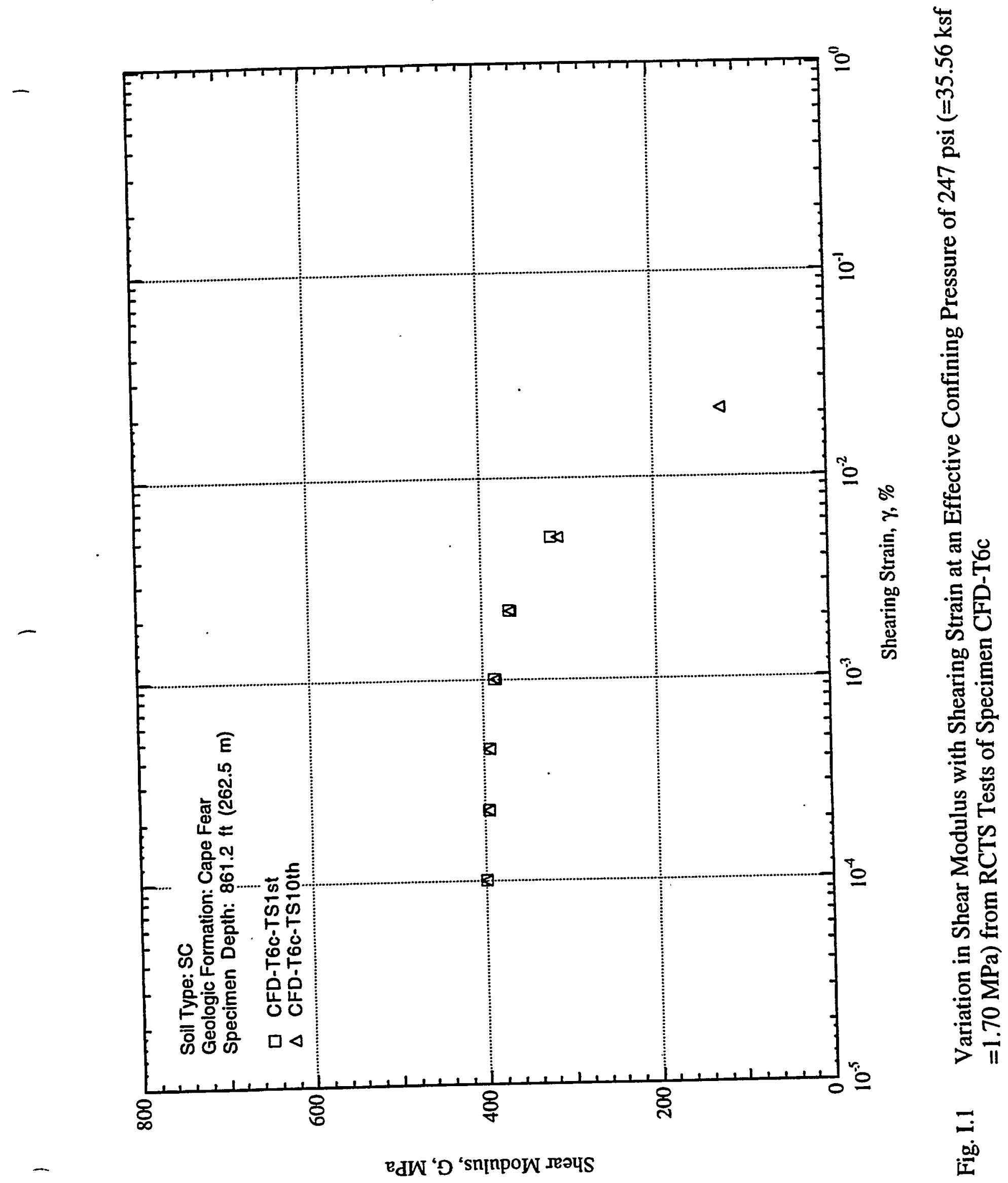

SRS-FR-CDP-95, rev. 0, 13 September 95 


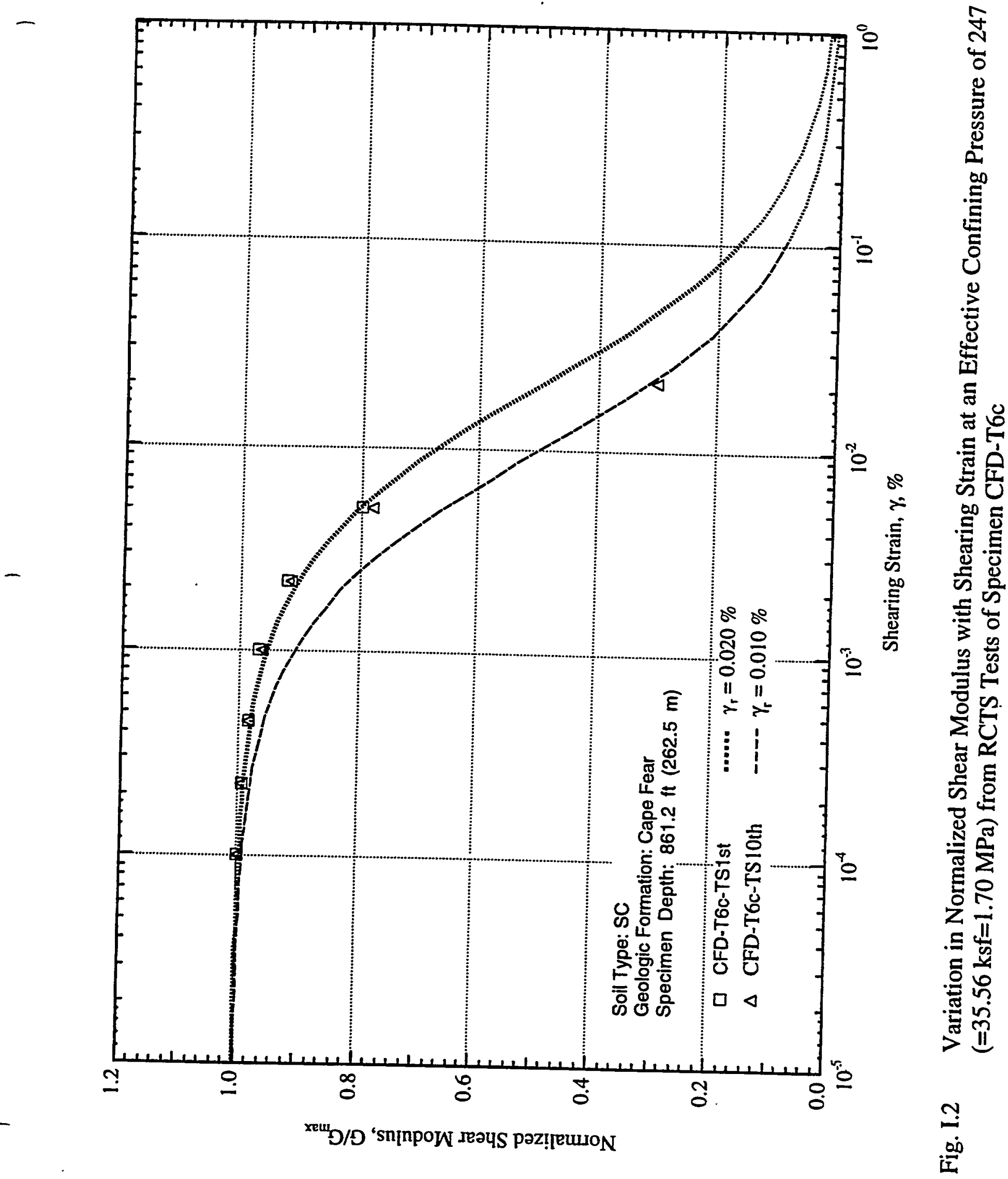




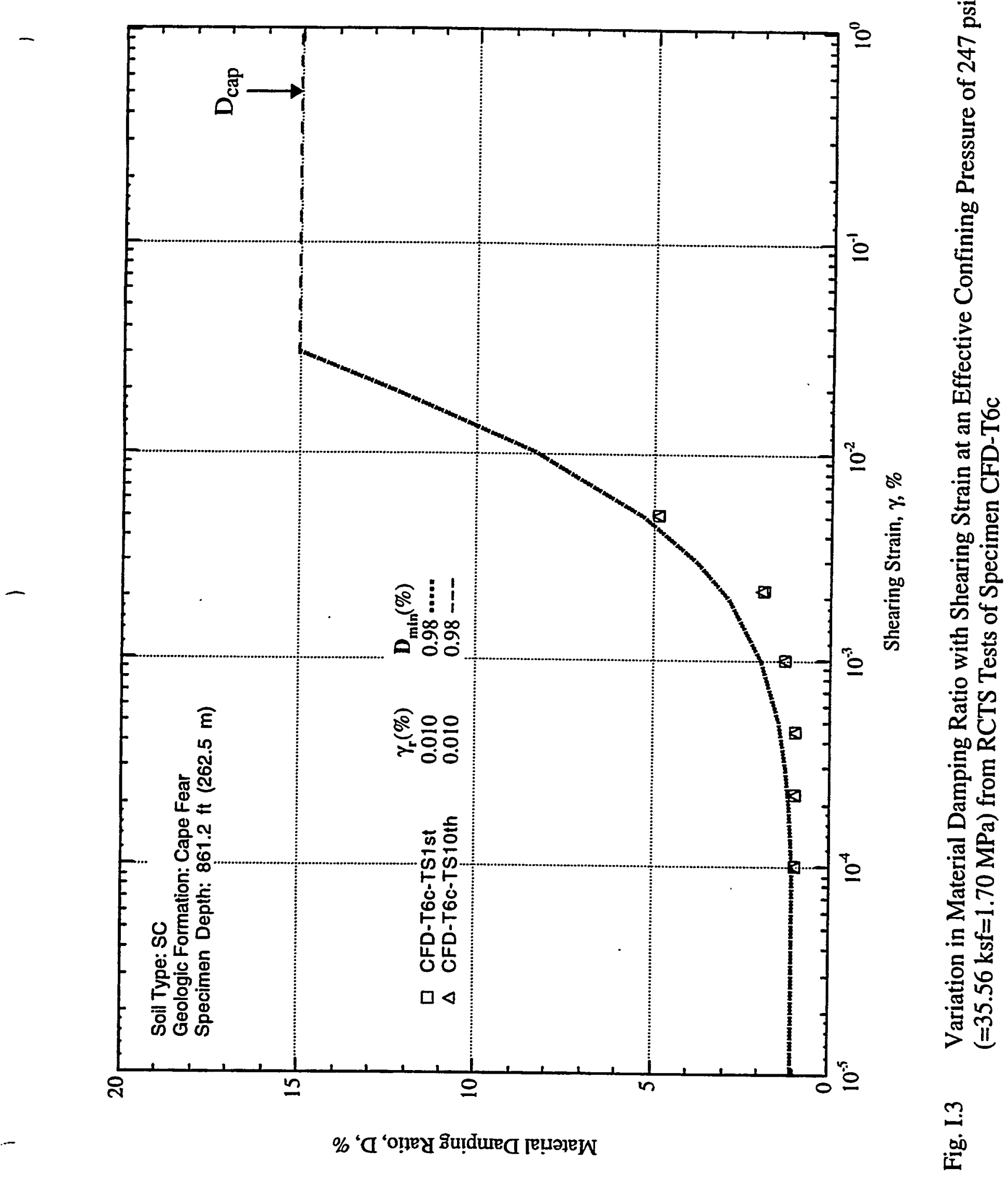


Appendix J

Effects of Excitation Frequency and Number of Loading Cycles on the Dynamic Properties of Deep Clays (Specimens CFD-T4a and CFD-T5b) 


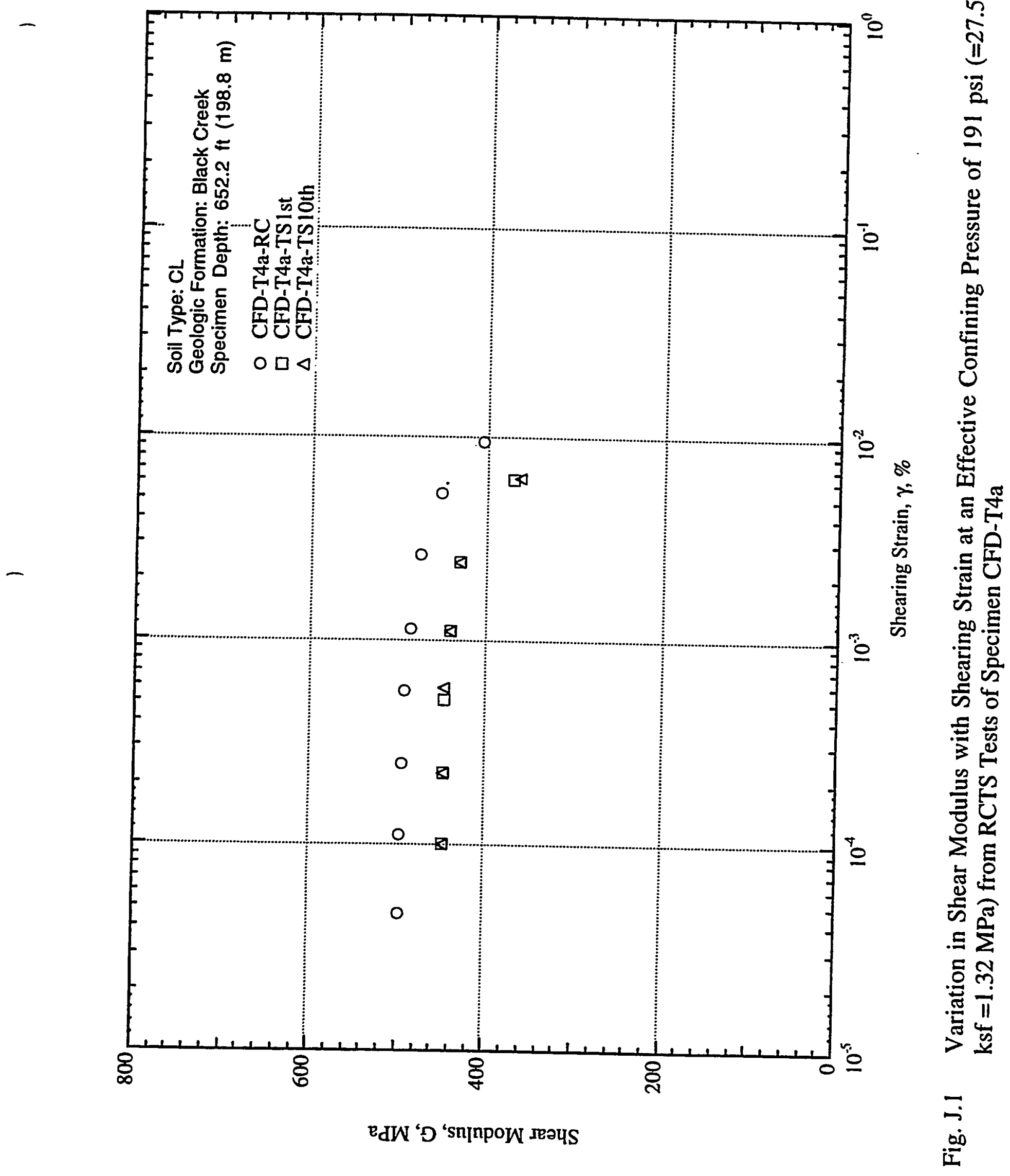




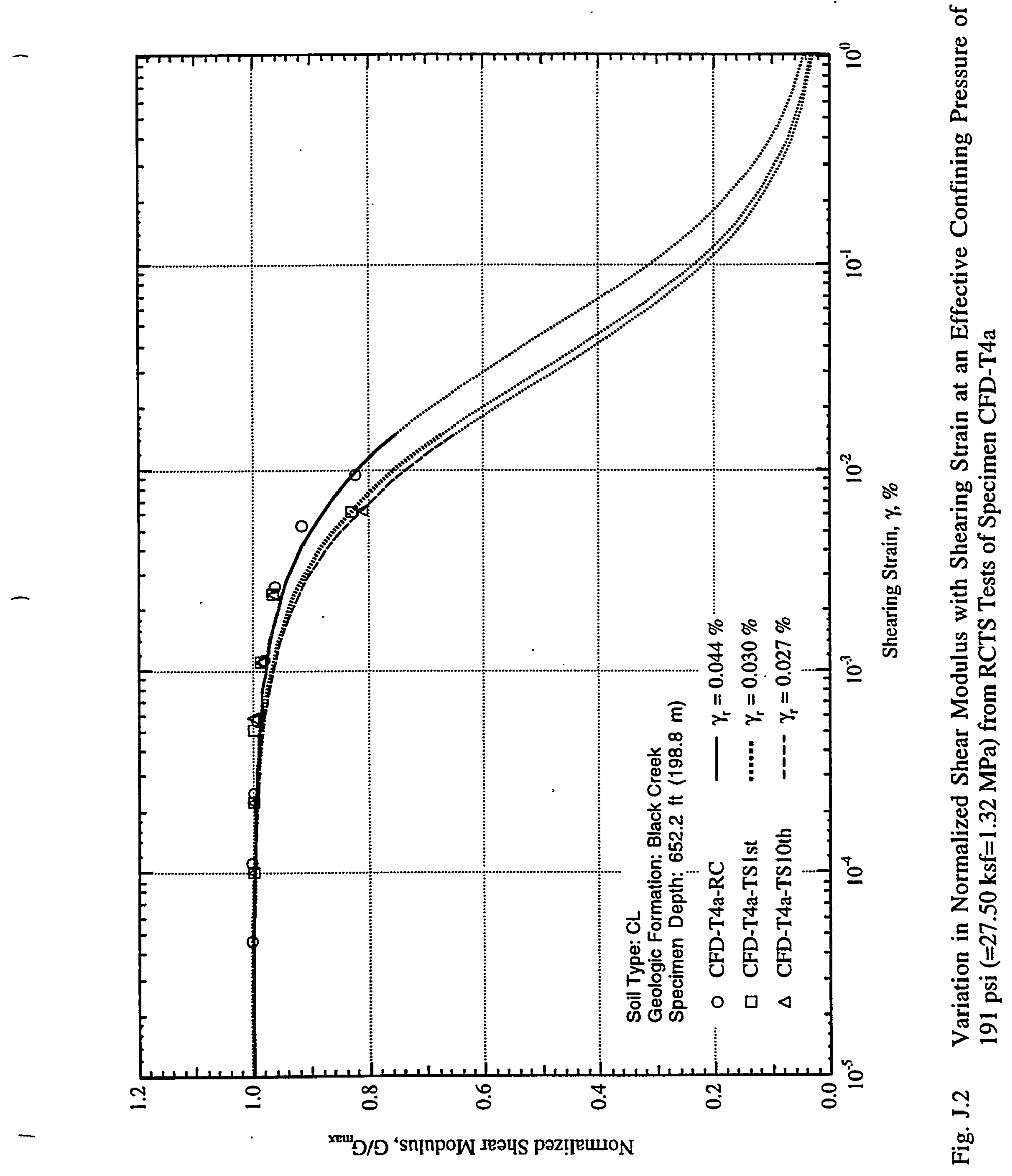




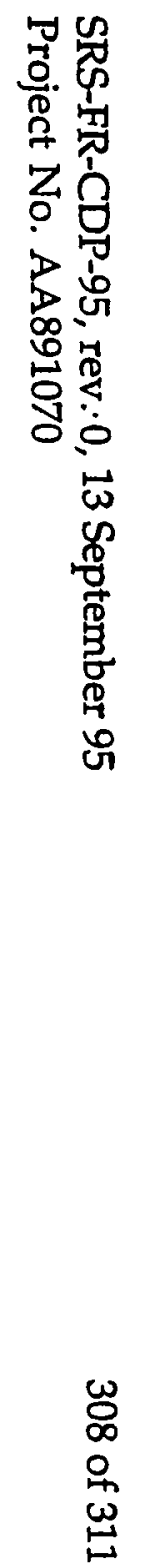

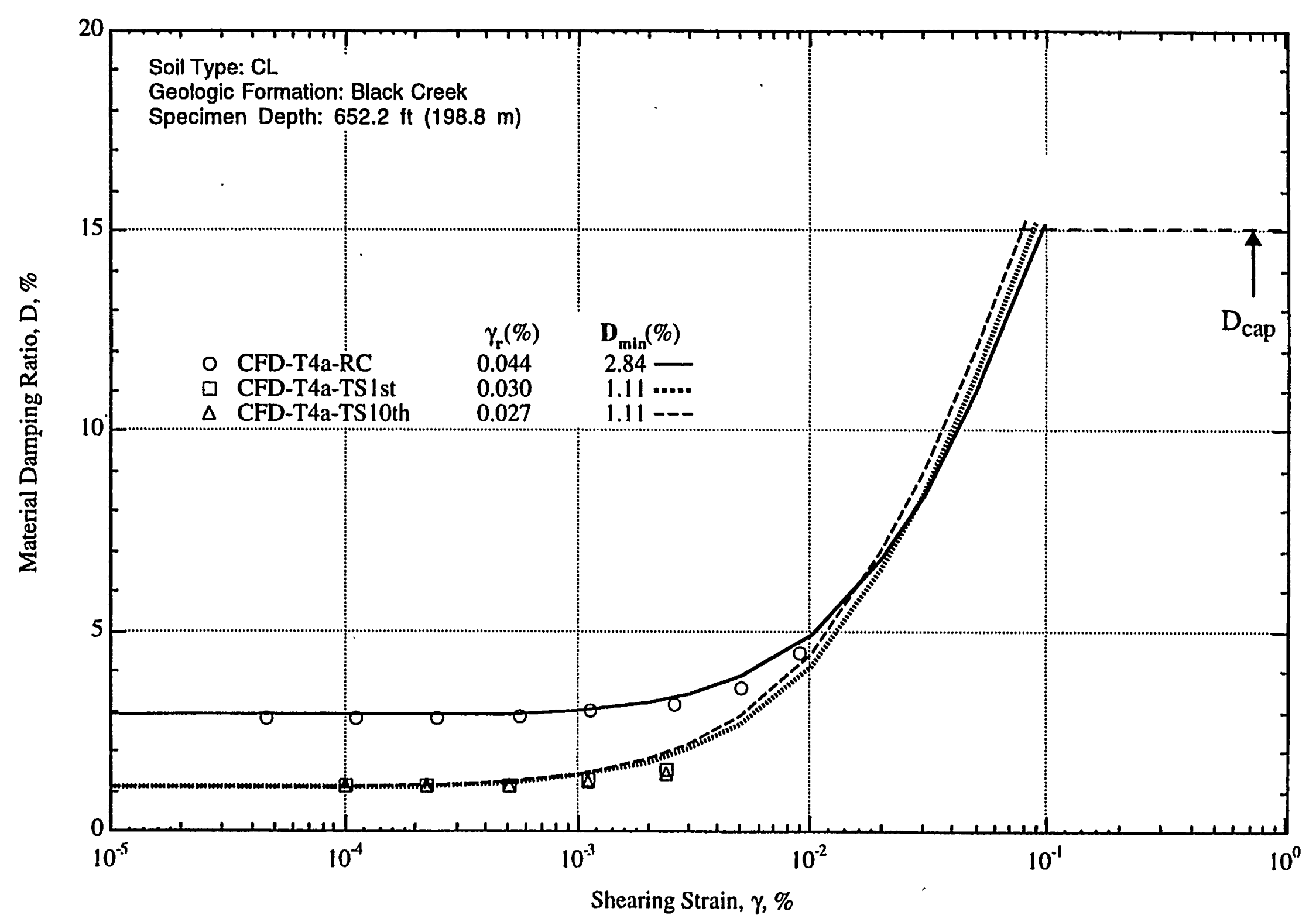

Fig. J.3 Variation in Material Damping Ratio with Shearing Strain at an Effective Confining Pressure of 191 psi (=27.50 ksf=1.32 MPa) from RCTS Tests of Specimen CFD-T4a 


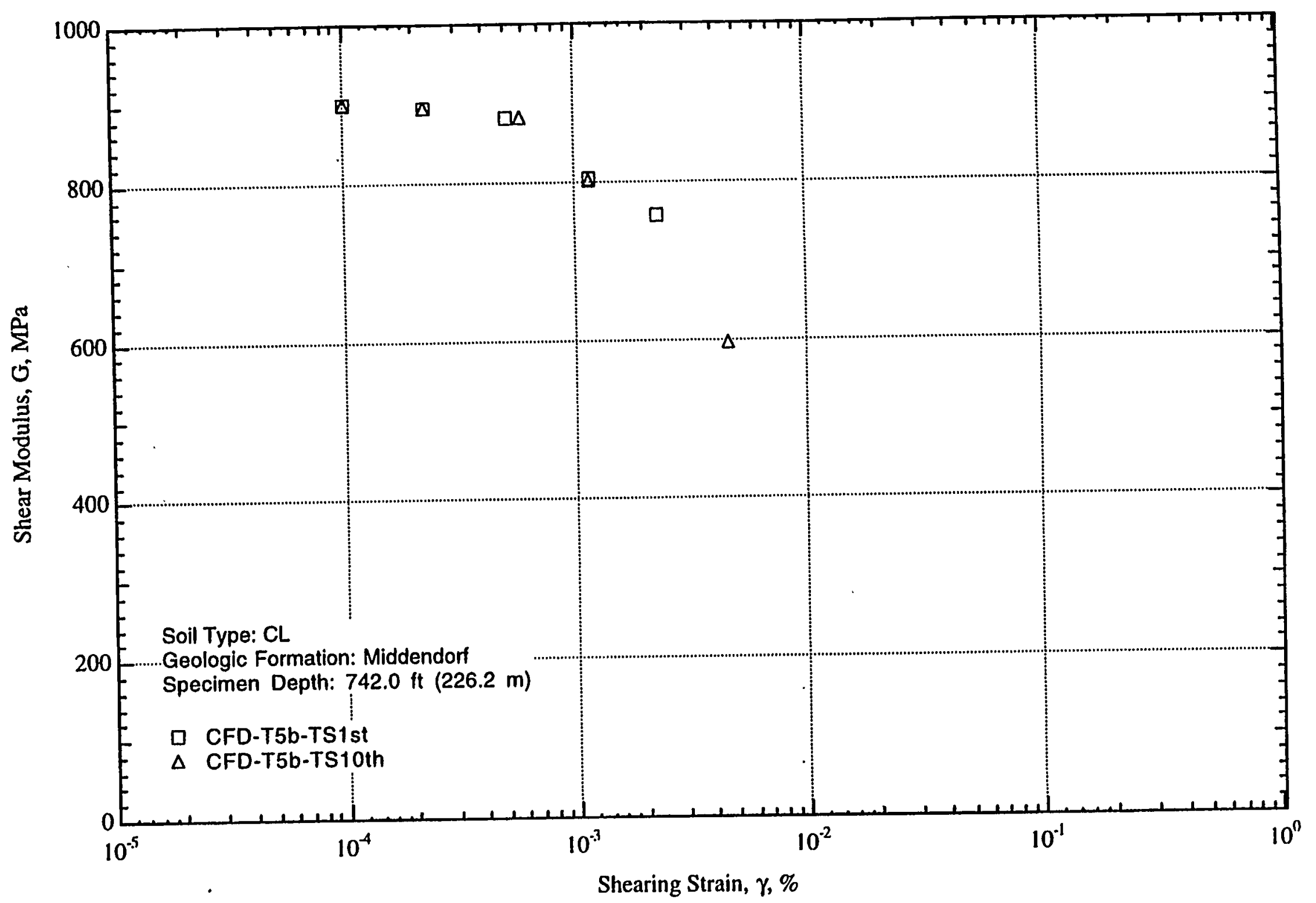

Fig. J.4 Variation in Shear Modulus with Shearing Strain at an Effective Confining Pressure of 215 psi $(=30.95 \mathrm{ksf}=1.48 \mathrm{MPa})$ from RCTS Tests of Specimen CFD-T5b 


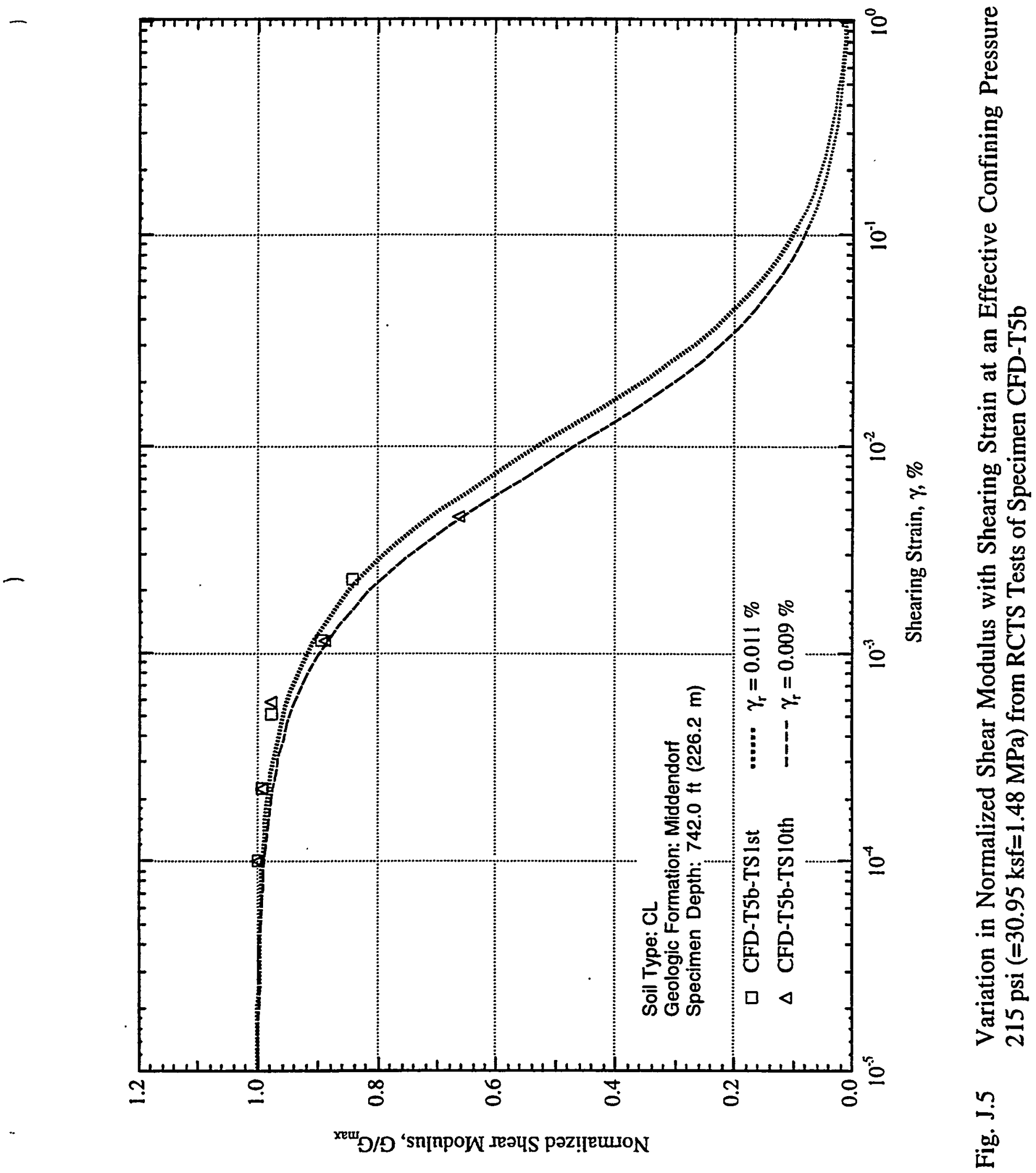




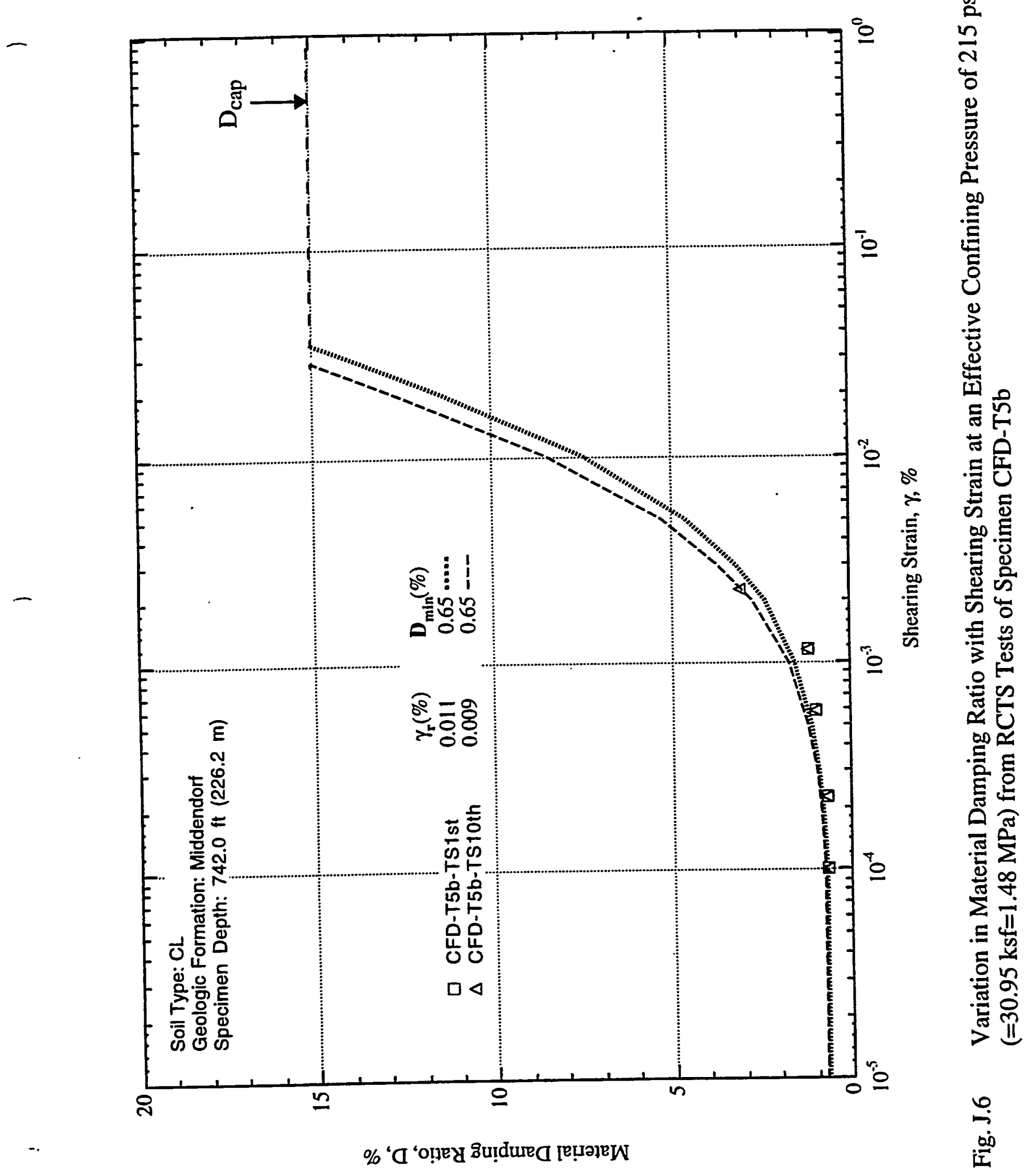

SRS-FR-CDP-95, rev. 0, 13 September 95 